

\title{
RUPTURAS Y ANÁLISIS DE LA EVOLUCIÓN TEMPORAL DE LA HOMOGENEIDAD DE LAS SERIES DE PRECIPITACIÓN DE VIZCAYA Y DE LA VERTIENTE CANTÁBRICA DE ÁLAVA
}

Nota técnica $\mathrm{N}^{\circ} 18$ de AEMET

Iñigo Javier Caballero López

Jefe Unidad de Estudios y Desarrollos

Delegación Territorial de AEMET en el País Vasco

San Sebastián, a 03 de diciembre de 2015.

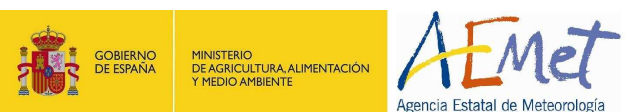


Fotografía de Zenarruza: Íñigo Javier Caballero López

Maquetación: Î̃nigo Javier Caballero López

Aviso Legal: los contenidos de esta publicación podrán ser reutilizados, citando la fuente y la fecha, en su caso, de la última actualización

\section{Edita:}

(C) Ministerio de Agricultura, Alimentación y Medio Ambiente Agencia Estatal de Meteorología Madrid, 2015

Catálogo de Publicaciones de la Administración General del Estado: https://cpage.mpr.gob.es

NIPO: $281-15-026-7$

https://doi.org/10.31978/281-15-026-7

Agencia Estatal de Meteorología (AEMET)

C/ Leonardo Prieto Castro, 8

28040 Madrid

http://www.aemet.es/

@Aemet_Esp 


\section{$\underline{\text { Índice }}$}

1.- Introducción

2.- Series analizadas: Emplazamientos, número de series e histogramas.

3.- Método: Tests de las rachas de Thom y de tendencia de Mann-Kendall.

4.- Resultados

4.1.- Rupturas detectadas en las series de precipitación.

4.1.1.- Análisis pormenorizado de cada serie pluviométrica.

4.1.2.- Conclusiones de las rupturas detectadas en las series de precipitación

4.2.- Intervalos homogéneos en las series de precipitación

4.3.- Análisis de la evolución temporal de las inhomogeneidades.

4.3.1.- Evolución temporal de las inhomogeneidades del test de Thom......

4.3.1.1.- Evolución temporal de las inhomogeneidades del test de Thom aplicado a la precipitación media anual..................................

Compendio de la evolución temporal de las inhomogeneidades

del test de Thom en las medidas de precipitación media anual.

4.3.1.2.- Evolución temporal de las inhomogeneidades del test de Thom aplicado a la precipitación media en Marzo, Abril y Mayo

Compendio de la evolución temporal de las inhomogeneidades

del test de Thom en las medidas de precipitación en Marzo, Abril y Mayo.

4.3.1.3.- Evolución temporal de las inhomogeneidades del test de Thom aplicado a la precipitación media en Abril, Mayo y Junio....

Compendio de la evolución temporal de las inhomogeneidades del test de Thom en las medidas de precipitación en Abril, Mayo y Junio...

4.3.2.- Evolución temporal de las inhomogeneidades del test de Mann - Kendall

4.3.2.1.- Evolución temporal de las inhomogeneidades del test de

Mann - Kendall aplicado a la precipitación media anual. 
Epítome del escudriñamiento del test de Mann - Kendall

de la precipitación media anual.......................................

4.3.2.2.- Evolución temporal de las inhomogeneidades del test de

Mann - Kendall aplicado a la precipitación media en Marzo, Abril y Mayo......

Epítome del escudriñamiento del test de Mann - Kendall

de la precipitación media en Marzo, Abril y Mayo. ...

4.3.2.3.- Evolución temporal de las inhomogeneidades del test de

Mann - Kendall aplicado a la precipitación media en Abril, Mayo y Junio.

Epítome del escudriñamiento del test de Mann - Kendall de la precipitación media en Abril, Mayo y Junio.

5.- Conclusiones

6.- Agradecimientos.

7.- Referencias

8.- Anexo: Nomenclátor y distribución comarcal de las series 


\section{Introducción:}

Las series pluviométricas del Aeropuerto de Bilbao (1082) y primigenia de Bilbao (1077C) han sido objeto de estudios; no obstante casi no hay monografías sobre los restantes registros de pluviosidad de Vizcaya y de la vertiente cantábrica de Álava.

Las finalidades de esta Nota Técnica son la investigación objetiva de la calidad y de la homogeneidad de las series de precipitaciones actuales y antiguas de Vizcaya y de la vertiente cantábrica de Álava, el desvelo de las rupturas en las condiciones de medida, su refrenda con las evidencias documentales existentes, la distinción entre inhomogeneidades "climatológicas" y "no climatológicas" y la determinación y la divulgación de los intersticios homogéneos de cada serie de pluviosidad.

Conrad y Pollack (1962) refiere: "Una muestra es homogénea si sus variaciones responden exclusivamente a las variaciones de la atmósfera".

Martínez Molina explica acerca del test de las rachas: "Muchas alternancias indican oscilación y muchas permanencias indican una tendencia o cambio": Un abundante número de rachas advierte de fluctuaciones en torno a la mediana de la serie y un parvo cómputo de rachas denota una tendencia.

La homogeneidad se escudriña aplicando consecutivamente los tests de las rachas de Thom y de tendencia de Mann -Kendall a los registros contemporáneos y pretéritos en el vasto intervalo temporal de valores pluviométricos disponibles (de 1859 a 2013).

En los intervalos de 10, 20, 30, 40, 50, 60 y 80 años, se adoptan los umbrales especificados para el test de las rachas en la publicación "Homogeneidad y variabilidad de los registros históricos de precipitación de España".

La detección de una tendencia prolongada en el tiempo por el test de Mann-Kendall o el descubrimiento por el test de Thom de inhomogeneidades en periodos iguales o superiores a los 20 años revela una rotura de la serie.

Los propósitos de:

1.- La distinción de las homogeneidades de tipo "climatológico" debidas a variaciones de la atmósfera, de las homogeneidades "no climatológicas" detectadas en las anotaciones de la pluviosidad causadas por alteraciones de la observación: cambio de ubicación; del entorno circundante; de instrumentos medidores; de colaborador... (Martínez Molina), las cuáles ocasionan súbitas rupturas en las mediciones.

2.- El revelamiento de los lapsos homogéneos del acervo de datos de pluviosidad.

3.- La detección de las rupturas de las series pluviométricas.

Se realizan mediante el cotejo de los registros en los observatorios y colaboradores más próximos, lo cuál colige los requisitos de un análisis global de las características de las series antiguas de precipitación y de una red de observaciones de una idónea densidad espacial y temporal. 
La carencia de datos (1861 a 1864, 1874, 1880, 1930, 1934 y 1936 a 1940), la cuantía de las roturas descubiertas y el exiguo montante de testimonios acrecientan la dificultad y la arduidad del espulgo de las series de precipitación respecto a la investigación de Guipúzcoa.

La declinación de enclaves de mediciones pluviométricas de duración superior a la década, principiada en 1988, rebasa límites alarmantes en los albores del siglo XXI.

La parca resolución espacial y temporal de las series climatológicas escrutadas precisa de la confrontación con series pluviométricas coetáneas de Guipúzcoa y de Álava.

Se efectúa un trabajo de campo de verificación y contraste de las rupturas desveladas por ambos tests: entrevista in situ a colaboradores de AEMET, consulta bibliográfica y de los archivos de la Unidad de Sistemas Básicos de la Delegación Territorial de AEMET en el País Vasco.

Fruto del mismo, ignotos jardines pluviométrico afloran en la Orduña y en la Vergara del siglo XIX y acrece el cómputo de años completos de 1055 Lequeitio Faro, 1057C Machicaco Faro, 1059 Punta Galea Faro y 1077 Larrasquitu.

Una exposición pormenorizada y minuciosa recopila para cada retahíla de valores las reseñas archivadas de las mudanzas de lugar, instrumental, colaborador y/o entorno, ilustra sobre un mapa las diversas ubicaciones conocidas y muestra los hallazgos de la aplicación conjunta de los dos tests con una descripción de las variaciones de las medianas de la pluviosidad en cada intervalo entre rupturas.

La totalidad de las roturas documentadas es desvelada por este escudriñamiento. Una tabla compendia las causas específicas de las rupturas constatadas.

Las rupturas detalladas detectadas en cada lapso escrutado (anual, Marzo - Abril Mayo y Abril - Mayo - Junio) por los tests de Thom y de Mann - Kendall concuerdan en las 3 escalas temporales.

Se incluyen los resultados pormenorizados de los intervalos homogéneos entre las rupturas (series con roturas) o el intervalo homogéneo de la serie (series sin roturas) en los periodos anual, Marzo - Abril - Mayo y Abril - Mayo - Junio y se precisa el \% de datos homogéneos.

La concordancia de máximos y de mínimos pluviométricos coadyuva la identificación de cadencias en la precipitación de Vizcaya y de la vertiente cantábrica de Álava cercanas a los 10, 20 y 30 años.

Tendencias de tipo climatológico afloran tanto a nivel de toda Vizcaya y de la vertiente cantábrica de Álava (sequía de los años 40, precipitaciones intensas a fines de los $70 . .$. ) como a escala comarcal (disminución de las precipitaciones en la década de los 80 en primavera en las Encartaciones). 


\section{2.- Series analizadas: Emplazamientos, número de series e histogramas:}

Se estudia el comportamiento de las series pluviométricas de Vizcaya y de la vertiente cantábrica de Álava con un número de datos mayor o igual a 10 de precipitación media anual (anual en lo sucesivo), precipitación media en el periodo Marzo - Abril - Mayo (MAM en lo subsiguiente) o precipitación media en el periodo Abril - Mayo - Junio (AMJ en lo sucesivo), atendidas por personal de AEMET, por colaboradores y automáticas, en funcionamiento y antiguas.

El periodo de datos estudiado abarca desde 1859 a 2013.

Se excluyen la vizcaína 1049U Ermua y la alavesa 1044D Aramayona Echaguen, disertadas en la Nota Técnica No 13 AEMET.

La exigua densidad espacial y temporal de las series climatológicas investigadas requiere de la confrontación con las siguientes series contemporáneas de pluviosidad de Guipúzcoa: 1013 Irún (Viteri), 1016 Oyarzun (Arditurri), 1024B San Sebastián (Faro), 1024 D San Sebastián (Instituto), 1024F San Sebastián, 1037 Legazpia, 1041 Zumaya, 1046 Aránzazu, Real Seminario de Nobles de Vergara, 1049U Ermua, 1050 Eibar, 1052 Motrico y 9268 I y 9268 II Otzaurte y de Álava: 9076 Ullivarri Gamboa (presa) y 9080 Urrunaga (presa).

Se toma como criterio de cómputo de los años de duración de cada serie, el de descartar para el cálculo de años el primer año y el último si en éstos no comienzan las medidas en Enero ni concluyen en Diciembre.

Así una serie sin lagunas como 1053 (Echevarría) que comienza en Octubre de 1961 y acaba en Enero de 1997, se considera que su cómputo empieza en 1962 y termina en 1996 con un $100 \%$ de datos.

Se aplica el mismo criterio, cuando una serie se interrumpe y se retoma. Por ejemplo, 9077E (Ochandiano Iberduero) arranca en enero de 1947, se abandona en mayo de 1971, se restablece en agosto de 1973 y finaliza en diciembre de 1995.

Para el cómputo de años completos de 9077E se inicia el cálculo de años en 1947, se suspende en 1970, se reanuda en 1974 y se termina en 1995.

Por brevedad, en lo sucesivo se designa cada serie por su indicativo climatológico. Se adjunta un listado de lugares de observación pluviométrica con sus coordenadas geográficas e indicativos en las tablas 109 a 111 del anexo.

La presente Nota Técnica desarrolla la investigación de la homogeneidad de 27 series de precipitación anual, 32 series en el periodo MAM y 33 series en el periodo AMJ con un número de valores mayor o igual a 10 años.

La figura 1 muestra la ubicación de las series estudiadas. 
Figura 1: Emplazamiento de las series analizadas:

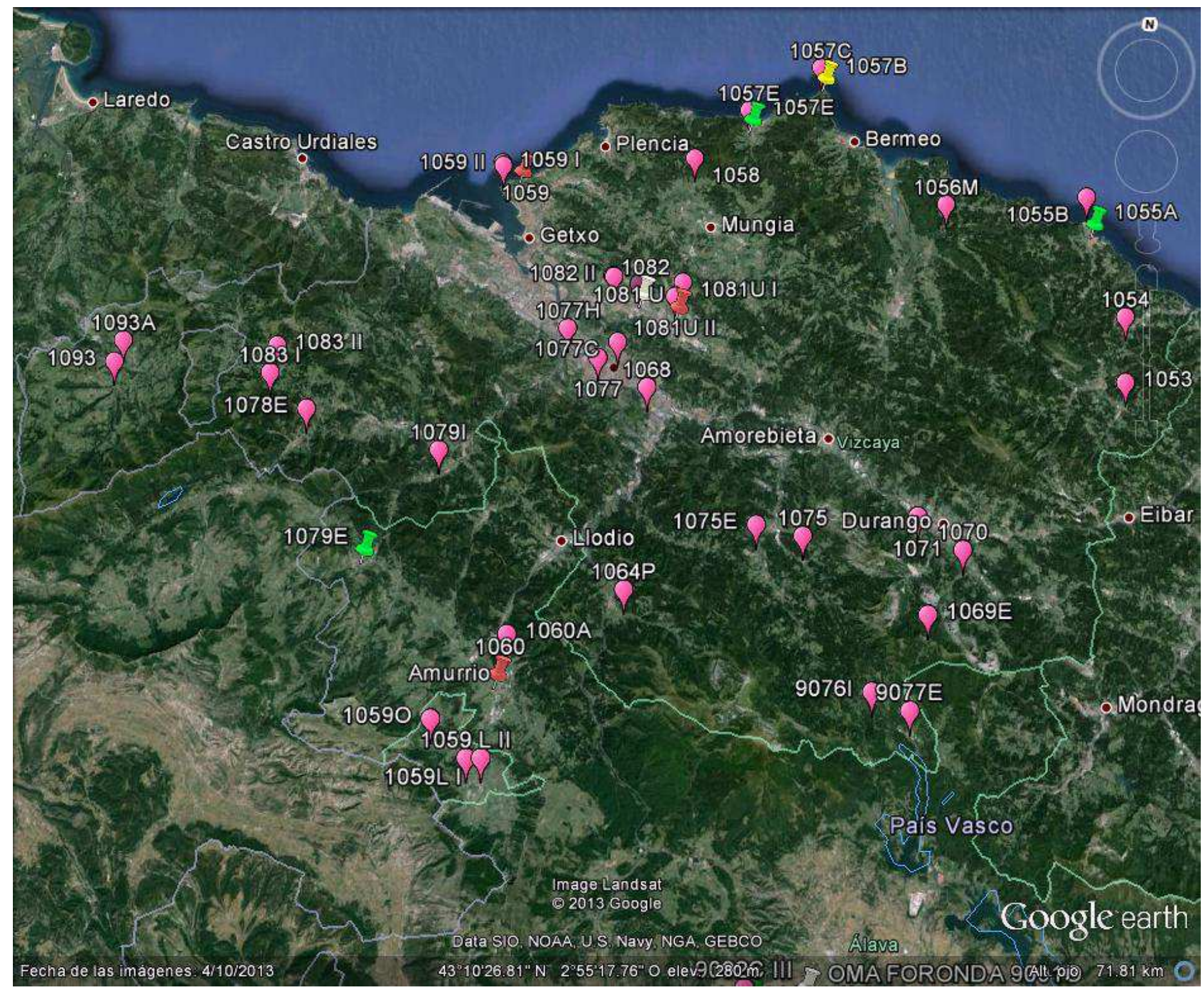

Leyenda:

$\S$ Colaboradores TP (Termo pluviométricos) actuales.

$\S$ Colaboradores P (Pluviométricos) actuales.

$\$$ Estaciones automáticas.

Colaboradores antiguos.

$\xi \quad$ Aeropuerto 
Esta leyenda será la empleada en las sucesivas figuras a excepción de la figura 10.

Se detallan los 4 emplazamientos del jardín meteorológico del aeropuerto de Bilbao 1082: 3 marcados con $\nabla$ señalan los emplazamientos pretéritos y uno en blanco corresponde a las medidas actuales del aeropuerto de Bilbao.

La gráfica 1 muestra la evolución temporal del número de series de precipitación anual escudriñadas.

Gráfica 1: Número de series de precipitación anual:

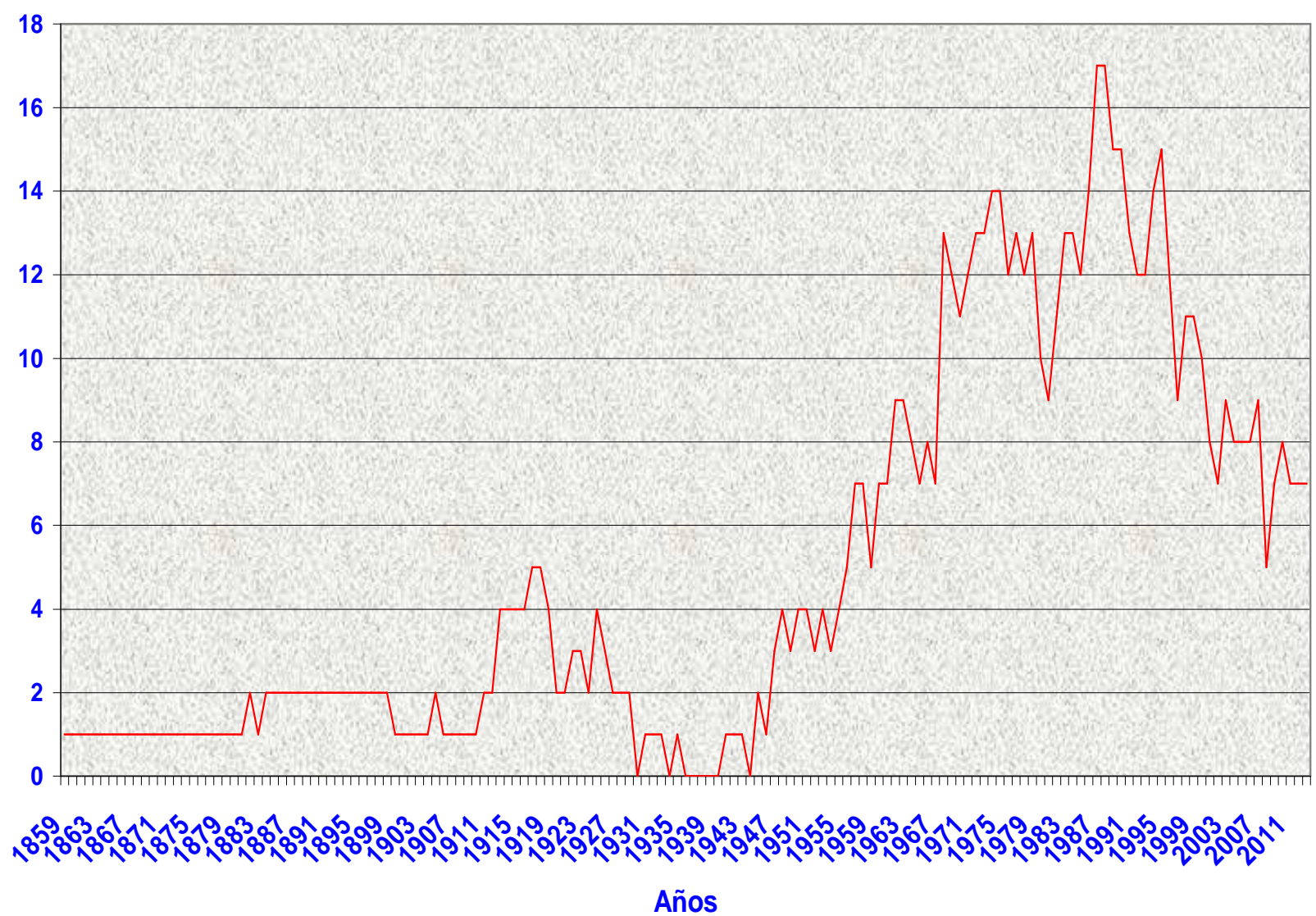

La carencia absoluta de registros pluviométricos acaece en 1934 y de 1936 a 1939. 
La gráfica 2 ostenta el histograma de duración temporal de las series de pluviosidad anual escrutadas.

Gráfica 2: Histograma de duración series de precipitación anual:

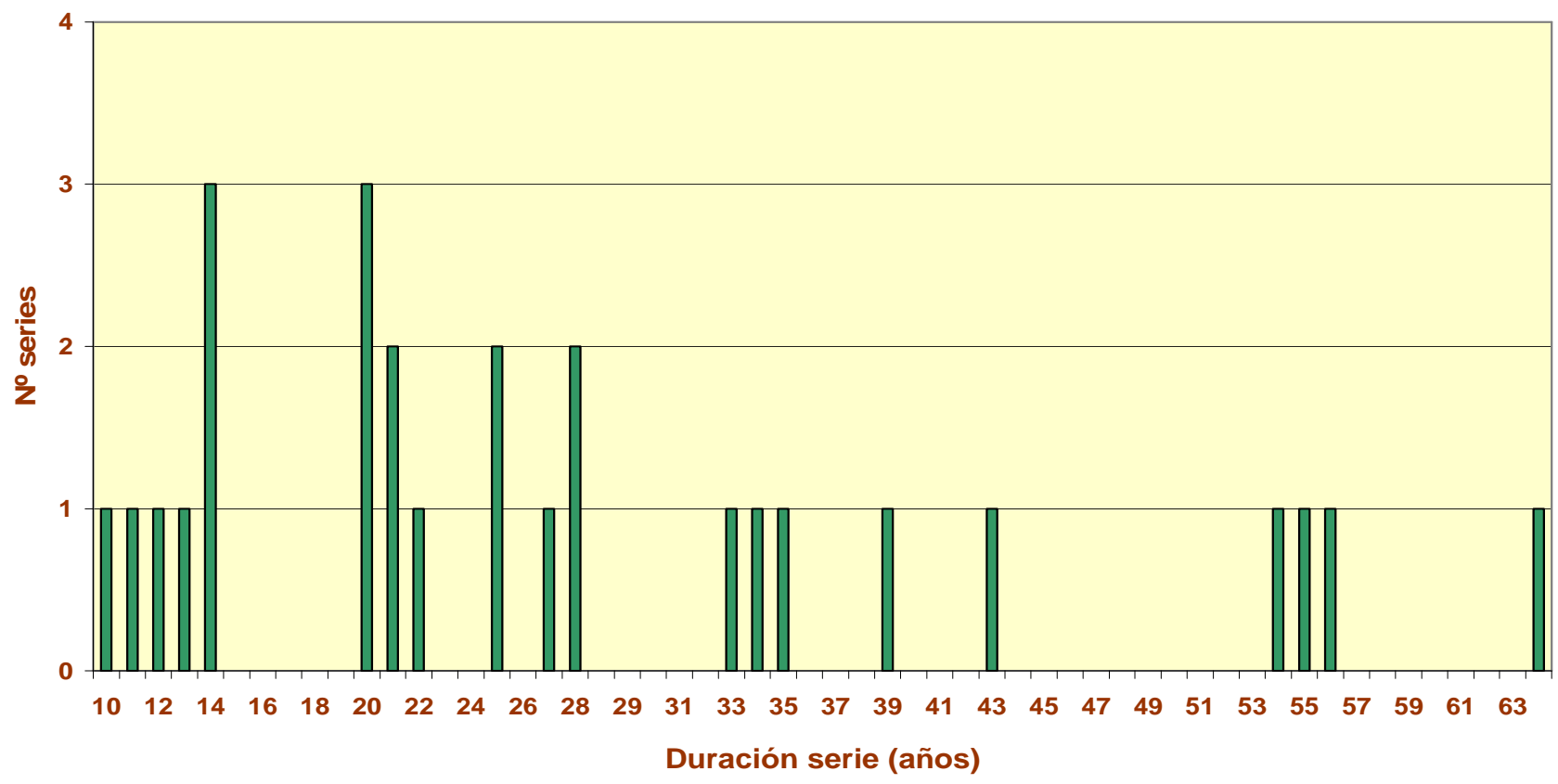

La gráfica 3 representa la evolución temporal del número de series pluviométricas MAM inspeccionadas.

Gráfica 3: $\mathrm{N}^{\mathrm{o}}$ series de precipitación Marzo-Abril-Mayo:

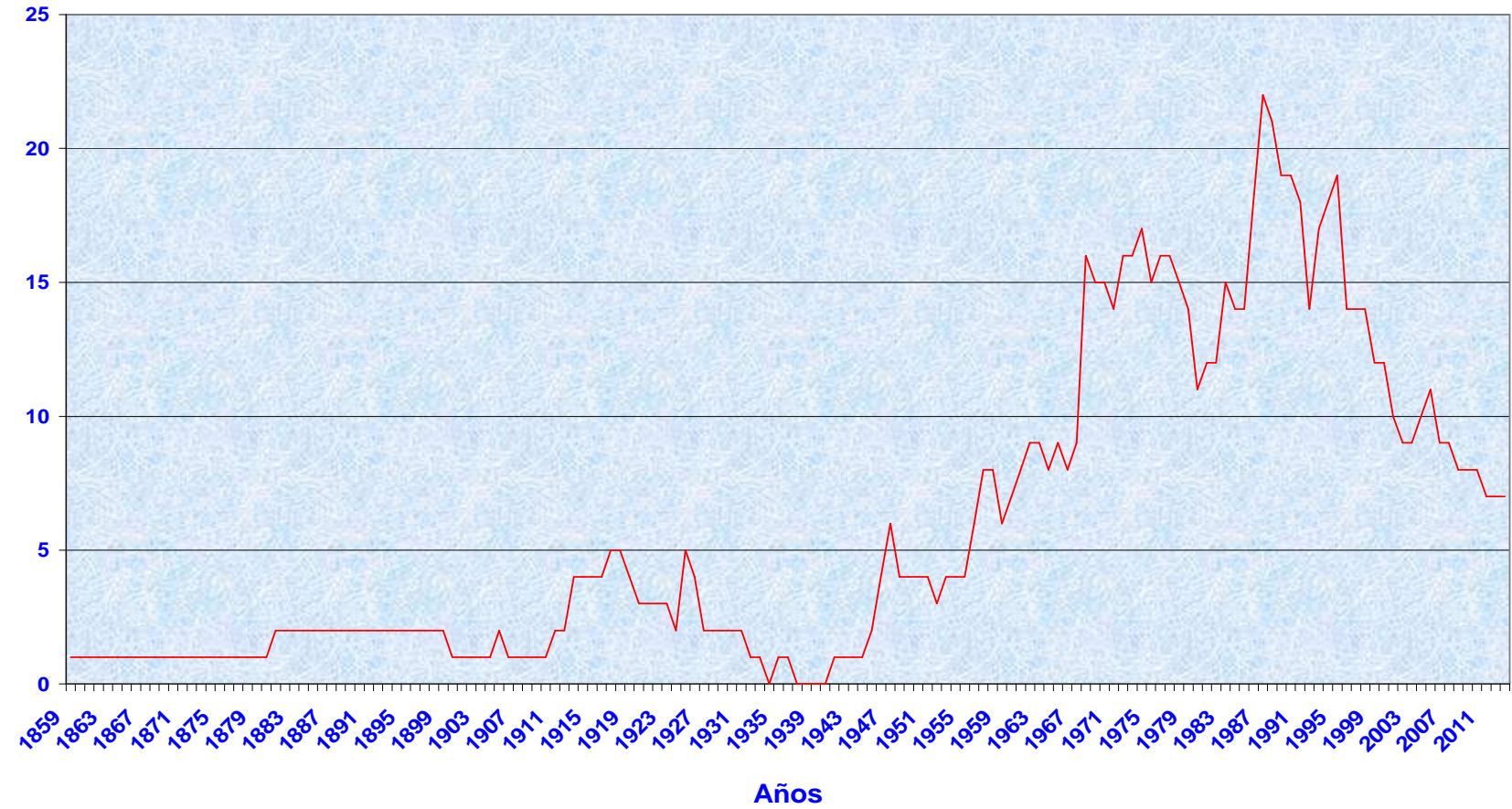


La gráfica 4 ilustra el histograma de permanencia temporal de las series de precipitación MAM investigadas.

Gráfica 4: Histograma de duración series de precipitación Marzo-Abril-Mayo:

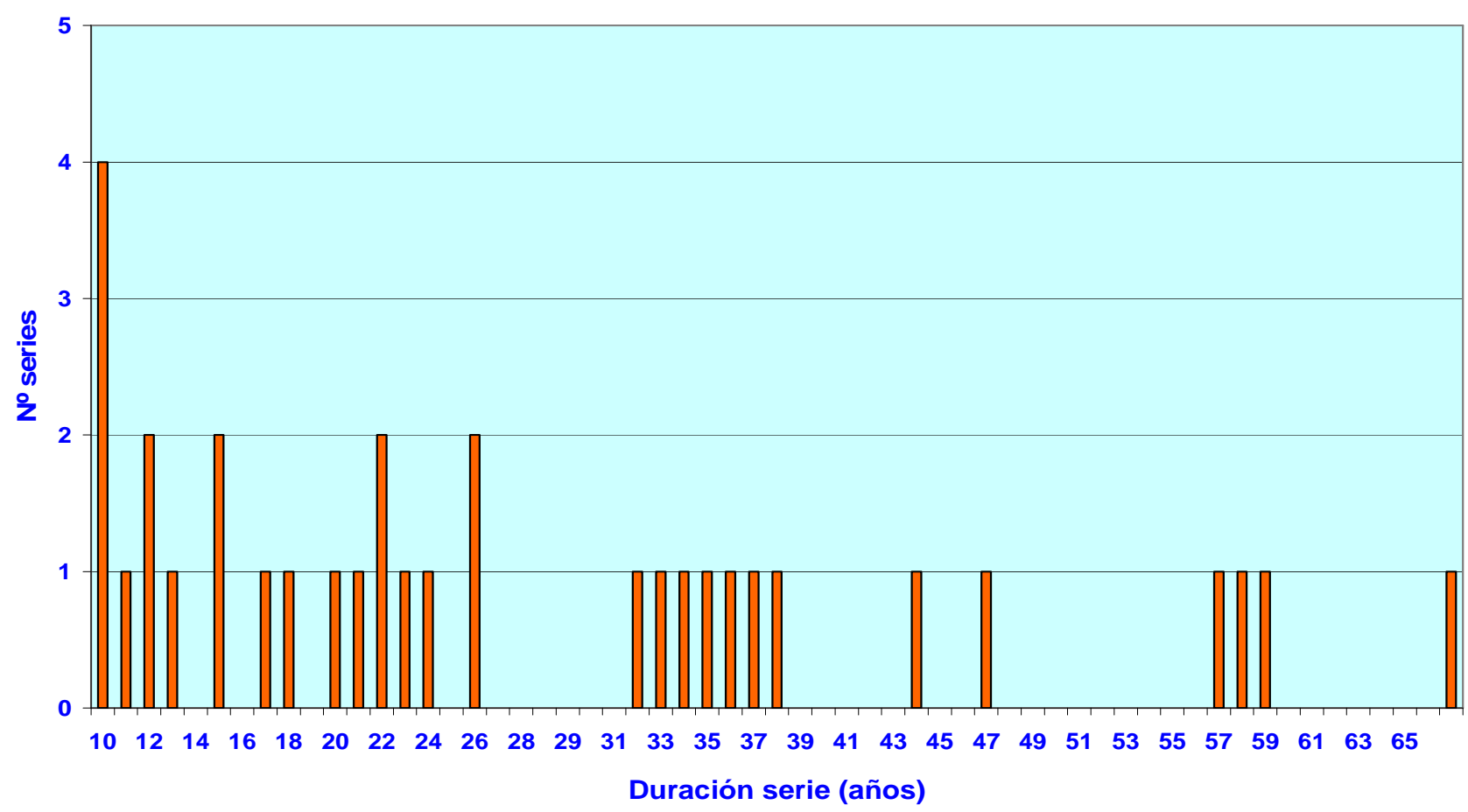

La gráfica 5 revela la evolución temporal del número de series analizadas en el intervalo AMJ espulgadas.

Gráfica 5: $\mathrm{N}^{\mathrm{o}}$ series de precipitación Abril-Mayo- Junio:

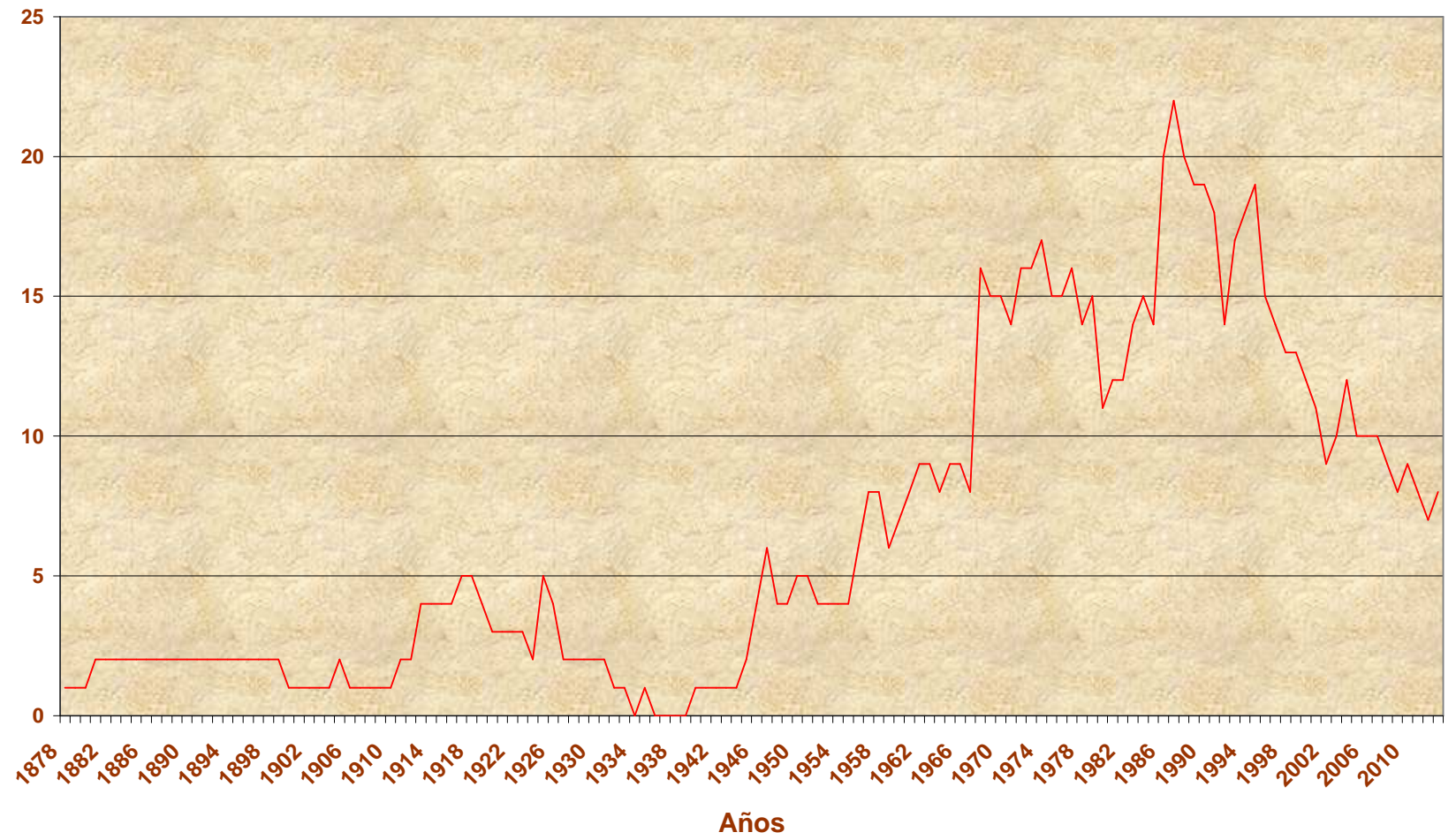


La gráfica 6 denota el histograma de la pluviosidad en el periodo AMJ:

Gráfica 6: Histograma de duración series de precipitación Abril-Mayo- Junio:

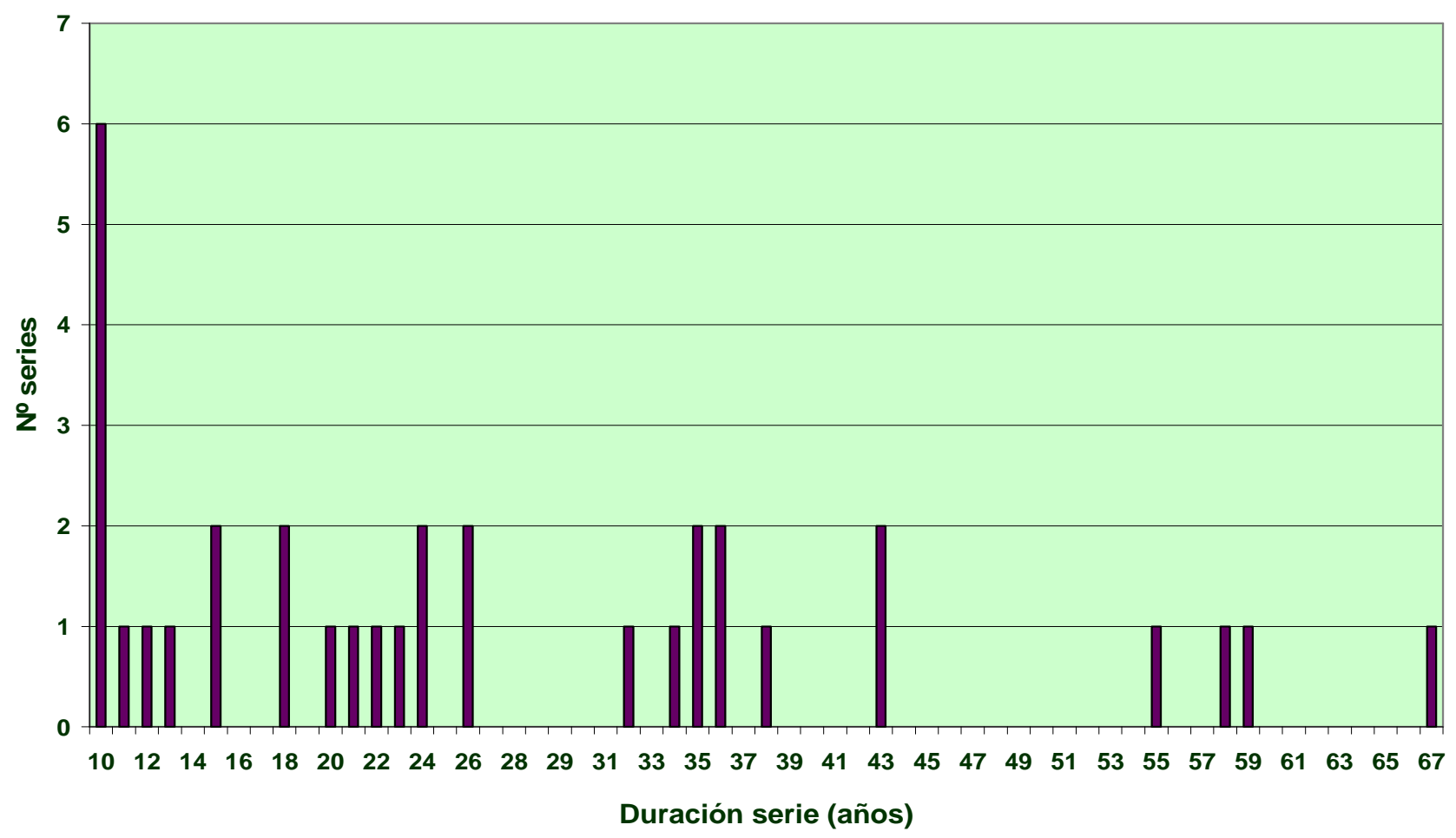

\section{3.- Método:}

Para su análisis, se emplean dos tests de homogeneidad absoluta: el test de las rachas de Thom y el test de Tendencia de Mann- Kendall.

Las series que cumplan la homogeneidad según los tests indican cierto factor de calidad, superior al de aquellas series no homogéneas de acuerdo a los dos tests.

En primer lugar se aplica el test de Thom a periodos de 10, 20, 30, 40, 50, 60 y 80 años y después, el test de Mann-Kendall.

Cuando se detecta ruptura en la serie de datos, se vuelven a analizar cada uno de los periodos con los tests de Thom y de Mann Kendall.

Siguiendo las obras "Homogeneidad y variabilidad de los registros históricos de precipitación de España." Monografía Técnica A-143 del INM y "Climatología de Extremadura".Publicación A-153 del INM, se describen a continuación los test de las rachas de Thom y de tendencia de Mann - Kendall. 


\section{1.- Test de las rachas de Thom:}

El estadístico del test es el número de secuencias o grupos de elementos consecutivos de la serie que están por encima o por debajo de la mediana.

En la tabla I se representan en función del número de datos de la serie los valores límite que determinan el dominio de aceptación del test.

Tabla I: Valores críticos test rachas.

\begin{tabular}{|c|c|c|c|c|c|c|c|}
\hline \multicolumn{7}{|c|}{ Test de las rachas de Thom } \\
\hline \multicolumn{7}{|c|}{ Valores críticos. Nivel de confianza del 95\% } \\
\hline $\mathrm{N}^{\text {o de datos }}$ & 10 & 20 & 30 & 40 & 50 & 60 & 80 \\
\hline $\mathrm{N}^{\mathbf{0}}$ mínimo de rachas & 2 & 6 & 10 & 14 & 18 & 22 & 31 \\
\hline $\begin{array}{c}\mathrm{N}^{\mathbf{0}} \text { máximo de } \\
\text { rachas }\end{array}$ & 6 & 15 & 21 & 27 & 33 & 39 & 50 \\
\hline
\end{tabular}

Los valores que aparecen en la tabla son los correspondientes a una serie aleatoria, en la que el número de rachas es menor que el umbral inferior con una probabilidad del 2,5\% y mayor que el umbral superior con una probabilidad del 2,5\%, por lo que si el valor del estadístico está comprendido entre los dos límites del test, se concluye que la serie es homogénea con un nivel de significación del $5 \%$.

En lo sucesivo y salvo que se especifique lo contrario, cuando se indique una inhomogeneidad según el test de Thom en un año, se refiere al análisis en el periodo de 10 años posteriores contados desde el año de inicio. Las inhomogeneidades a 20, 30, 40 y 50 años resultan muy útiles para detectar rupturas en la serie.

\section{2.- Test de tendencia de Mann - Kendall:}

Este test estudia la homogeneidad desde el punto de vista de la existencia de tendencia lineal, creciente o decreciente, en las series.

El estadístico del test se define por $\mathrm{t}=\sum_{i} n_{i}$

Donde $n_{i}$ es el número de elementos de las serie $X_{j}$ que preceden al elemento $X_{i}(i>j)$ de tal forma que $X_{i}>X_{j}$.

En una serie aleatoria simple la distribución del estadístico es t es asintóticamente normal. Una vez calculado el valor de t y éste estandarizado se calcula la probabilidad con ayuda de la ley normal. La hipótesis de aleatoriedad se conserva para un nivel del 5\% cuando el valor absoluto del estadístico es menor que 1,960. 


\section{4.- Resultados:}

\section{1.- Rupturas detectadas en las series de precipitación:}

Se detectan rupturas en las series debidas a cambios de ubicación, de observador, de pluviómetro, del entorno... Las tablas 1, 2 y 3 reflejan las roturas halladas aplicando los test de rachas de Thom y de tendencia de Mann-Kendall a la precipitación media anual, MAM y AMJ.

Cada tabla indica el nombre, indicativo, intervalo de años con registros, intervalo(s) de años entre la(s) ruptura(s) e identifica para cada serie los intervalos en que es homogénea aplicando los tests de Thom y de Mann-Kendall, denotando como n.d. (no detecta) cuando uno de los 2 tests no revela la ruptura de la serie. Se indica como n.d. con dudas, cuando un test no detecta la rotura, si bien arroja dudas.

El test de Thom se aplica a series de datos con una duración mínima de 10 años; la homogeneidad de aquellos intervalos de series con una duración inferior a 10 años no se analiza en las tablas 1,2 y 3 .

En el caso en que un test no descubra la ruptura, el periodo homogéneo se refiere al obtenido al examinar la serie completa de datos sin considerar ninguna rotura.

Tabla 1: Rupturas detectadas en la precipitación media anual:

\begin{tabular}{|c|c|c|c|c|c|}
\hline \multirow{2}{*}{ Nombre } & \multirow{2}{*}{ Indicativo } & \multirow{2}{*}{ Periodo años } & \multirow{2}{*}{$\begin{array}{l}\text { Periodos entre } \\
\text { rupturas }\end{array}$} & \multicolumn{2}{|c|}{ Periodos homogéneos } \\
\hline & & & & Thom & Mann Kendall \\
\hline Echevarría & 1053 & $1962-1996$ & $\begin{array}{l}1962-1975 \\
1976-1996 \\
\end{array}$ & $\begin{array}{l}1962-1975 \\
1976-1994 \\
\end{array}$ & $\begin{array}{l}1963-1975 \\
1980-1996 \\
\end{array}$ \\
\hline Marquina & 1054 & $1947-1974$ & $\begin{array}{l}1947-1951 \\
1957-1974\end{array}$ & $\begin{array}{c}1961-1974 \\
\text { (n. d., con dudas) }\end{array}$ & $\begin{array}{l}1947-1974 \\
\text { (n. d.) }\end{array}$ \\
\hline Lequeitio & $1055 \mathrm{~A}$ & $1987-2013$ & $\begin{array}{l}1987-2005 \\
2007-2013\end{array}$ & $1989-2003$ & $\begin{array}{c}1987-2013 \\
\text { (n. d.) }\end{array}$ \\
\hline $\begin{array}{l}\text { Machicaco } \\
\text { Faro Viejo } \\
\end{array}$ & $1057 \mathrm{C}$ & $1913-1933$ & $\begin{array}{l}1913-1920 \\
1922-1933 \\
\end{array}$ & $1922-1933$ & $\begin{array}{c}1913-1933 \\
\text { (n. d.) }\end{array}$ \\
\hline Baquio & $1057 \mathrm{E}$ & $1987-2013$ & $\begin{array}{l}1987-2007 \\
2010-2013 \\
\end{array}$ & $1987-2007$ & $\begin{array}{c}1988-2013 \\
\text { (n. d.) }\end{array}$ \\
\hline $\begin{array}{l}\text { Punta } \\
\text { Galea }\end{array}$ & 1059 & $\begin{array}{r}1911-1926 \\
1946-1968 \\
1995-2013 \\
\end{array}$ & $\begin{array}{l}1911-1926 \\
1946-1968 \\
1995-2013 \\
\end{array}$ & $\begin{array}{l}1914-1926 \\
1946-1968 \\
1995-2013 \\
\end{array}$ & $\begin{array}{c}1912-2013 \\
\text { (n. d.) }\end{array}$ \\
\hline Orduña & 1059L & $\begin{array}{c}1882-1899,1905 \\
1917-1918 \\
1986-1995 \\
\end{array}$ & $\begin{array}{c}1882-1899 y \\
1905 \\
1986-1995 \\
\end{array}$ & $\begin{array}{c}1882-1995 \\
\text { (n. d.) }\end{array}$ & $\begin{array}{c}1882-1899 y \\
1905\end{array}$ \\
\hline
\end{tabular}


Tabla 1 (continuación): Rupturas detectadas en la precipitación media anual:

\begin{tabular}{|c|c|c|c|c|c|}
\hline \multirow{2}{*}{ Nombre } & \multirow{2}{*}{ Indicativo } & \multirow{2}{*}{ Periodo años } & \multirow{2}{*}{$\begin{array}{l}\text { Periodos entre } \\
\text { rupturas }\end{array}$} & \multicolumn{2}{|c|}{ Periodos homogéneos } \\
\hline & & & & Thom & Mann Kendall \\
\hline $\begin{array}{l}\text { Amurrio } \\
\text { Instituto }\end{array}$ & 1060 & $1956-2013$ & $\begin{array}{l}1956-1966 \\
1968-1992 \\
1993-2013\end{array}$ & $\begin{array}{c}1956-2013 \\
\text { (n. d.) }\end{array}$ & $\begin{array}{l}1956-1962 \\
1968-1992 \\
1994-2013 \\
\end{array}$ \\
\hline Basauri & 1068 & $1945-1978$ & $\begin{array}{l}1945-1954 \\
1955-1978 \\
\end{array}$ & $1955-1977$ & $1955-1974$ \\
\hline Abadiano & 1070 & 1935 y $1968-2001$ & $\begin{array}{c}1935 y \\
1968-2001\end{array}$ & $1970-1996$ & $\begin{array}{c}1935 \mathrm{y} \\
1968-2001 \\
\text { (n. d.) } \\
\end{array}$ \\
\hline Dima & 1075 & 1925 y $1968-1977$ & $\begin{array}{c}1925 \\
1968-1977\end{array}$ & $1968-1977$ & $\begin{array}{c}1925 \text { y } \\
1968-1977 \\
\text { (n. d.) } \\
\end{array}$ \\
\hline Aránzazu & $1075 \mathrm{E}$ & $1968-2006$ & $\begin{array}{l}1968-1979 \\
1982-2006\end{array}$ & $1982-2006$ & $\begin{array}{c}1979-2006 \\
\text { (n. d.) }\end{array}$ \\
\hline Arceniega & $1079 \mathrm{E}$ & $1988-2013$ & $\begin{array}{l}1988-2003 \\
2005-2013\end{array}$ & $1988-2003$ & $\begin{array}{c}1988-2013 \\
\text { (n. d.) }\end{array}$ \\
\hline $\begin{array}{l}\text { Derio } \\
\text { Neiker }\end{array}$ & $1081 \mathrm{U}$ & $1987-2013$ & $\begin{array}{l}1987-1995 \\
1996-2008 \\
2009-2013 \\
\end{array}$ & $1996-2008$ & $\begin{array}{c}1987-2009 \\
\text { (n. d.) }\end{array}$ \\
\hline $\begin{array}{c}\text { Bilbao } \\
\text { Aeropuerto }\end{array}$ & 1082 & $1948-2013$ & $\begin{array}{l}1948-1984 \\
1985-1999 \\
2002-2013\end{array}$ & $\begin{array}{l}1948-1984 \\
1985-1999 \\
2002-2013\end{array}$ & $\begin{array}{l}1950-1984 \\
1985-1999 \\
2002-2013\end{array}$ \\
\hline Arcentales & 1083 & $1968-2006$ & $\begin{array}{l}1968-1979 \\
1982-1998 \\
1999-2006\end{array}$ & $\begin{array}{l}1968-1979 \\
1982-1998\end{array}$ & $\begin{array}{c}1984-2000 \\
\text { (n. d.) }\end{array}$ \\
\hline Carranza & 1093 & $1957-2000$ & $\begin{array}{l}1957-1983 \\
1984-1989 \\
1990-1993 \\
1994-1997 \\
1998-2000\end{array}$ & $1957-1983$ & $1966-1983$ \\
\hline Ochandiano & $9077 \mathrm{E}$ & $\begin{array}{l}1947-1969 \\
1976-1995\end{array}$ & $\begin{array}{l}1947-1969 \\
1976-1995\end{array}$ & $\begin{array}{l}1956-1969 \\
1976-1995\end{array}$ & $\begin{array}{c}1950-1990 \\
\text { (n. d.) }\end{array}$ \\
\hline
\end{tabular}

Comentarios a la tabla 1:

1.- La aplicación sucesiva de los tests de Thom y de Mann-Kendall a las 27 series de datos de precipitación anual situadas en cuencas que vierten al litoral de Vizcaya, detecta rupturas en 18 de ellas (el 67\%).

En Guipúzcoa, el escrutinio de los tests de Thom y de Mann-Kendall de las 50 series de datos de precipitación anual estudiadas refleja roturas en 10 series de las 50 estudiadas (el $20 \%$ ) (Nota Técnica N 13 AEMET). 
Tabla 2: Rupturas detectadas en la precipitación media MAM:

\begin{tabular}{|c|c|c|c|c|c|}
\hline \multirow{2}{*}{ Nombre } & \multirow{2}{*}{ Indicativo } & \multirow{2}{*}{ Periodo años } & \multirow{2}{*}{$\begin{array}{l}\text { Periodos entre } \\
\text { rupturas }\end{array}$} & \multicolumn{2}{|c|}{ Periodos homogéneos } \\
\hline & & & & Thom & Mann Kendall \\
\hline Marquina & 1054 & $1946-1976$ & $\begin{array}{l}1946-1952 \\
1957-1976\end{array}$ & $1958-1974$ & $\begin{array}{c}1964-1971 \\
\text { (n. d.) }\end{array}$ \\
\hline $\begin{array}{l}\text { Machicaco } \\
\text { Faro Viejo }\end{array}$ & $1057 \mathrm{C}$ & $1913-1933$ & $\begin{array}{l}1913-1921 \\
1922-1933\end{array}$ & $1922-1932$ & $\begin{array}{c}1913-1933 \\
\text { (n. d.) }\end{array}$ \\
\hline Maruri & 1058 & $1968-1988$ & $\begin{array}{l}1968-1979 \\
1982-1988\end{array}$ & & $\begin{array}{c}1968-1988 \\
\text { (n. d.) }\end{array}$ \\
\hline Punta Galea & 1059 & $\begin{array}{l}1911-1926 \\
1946-1969 \\
1994-2013 \\
\end{array}$ & $\begin{array}{l}1911-1926 \\
1946-1969 \\
1994-2013 \\
\end{array}$ & $\begin{array}{l}1911-1926 \\
1949-1969 \\
1994-2013 \\
\end{array}$ & $\begin{array}{l}1912-1926 \\
1946-1969 \\
1995-2013 \\
\end{array}$ \\
\hline Orduña & $1059 \mathrm{~L}$ & $\begin{array}{c}1881-1899,1905, \\
1917-1918, \\
1986-1995\end{array}$ & $\begin{array}{c}1881-1899 \text { y } 1905, \\
1917-1918 \\
1986-1995\end{array}$ & $\begin{array}{c}1881-1899 \mathrm{y} \\
1905\end{array}$ & $\begin{array}{c}1884-1899,1905, \\
1917-1918 \text { y } \\
1986-1995 \text { (n. d.) }\end{array}$ \\
\hline $\begin{array}{l}\text { Amurrio } \\
\text { Instituto }\end{array}$ & 1060 & $1956-2013$ & $\begin{array}{l}1956-1966 \\
1967-1992 \\
1993-2013 \\
\end{array}$ & $\begin{array}{l}1969-1992 \\
1993-2013 \\
\end{array}$ & \begin{tabular}{|l}
$1956-1966$ \\
$1967-1992$ \\
$1993-2013$ \\
\end{tabular} \\
\hline Abadiano & 1070 & $\begin{array}{l}1935,1936 y \\
1968-2002 \\
\end{array}$ & $\begin{array}{l}1935-1936 \\
1968-2002 \\
\end{array}$ & $1969-2002$ & $\begin{array}{c}1935,1936 \text { y } \\
1968-2002 \text { (n. d.) }\end{array}$ \\
\hline Dima & 1075 & $\begin{array}{c}1925 y \\
1968-1978 \\
\end{array}$ & $\begin{array}{c}1925 \\
1968-1978 \\
\end{array}$ & $1969-1978$ & $\begin{array}{c}1925 \mathrm{y} \\
1968-1977 \text { (n. d.) } \\
\end{array}$ \\
\hline Aránzazu & $1075 \mathrm{E}$ & $1968-2006$ & $\begin{array}{l}1968-1980 \\
1981-2006\end{array}$ & $\begin{array}{l}1968-1980 \\
1982-2004\end{array}$ & $\begin{array}{l}1969-1980 \\
1981-2006\end{array}$ \\
\hline Valmaseda & $1078 \mathrm{E}$ & $1972-2007$ & $\begin{array}{l}1972-1991 \\
1992-2007\end{array}$ & $\begin{array}{l}1972-1991 \\
1992-2007\end{array}$ & $\begin{array}{c}1973-2007 \\
\text { (n. d.) }\end{array}$ \\
\hline Arcentales & 1083 & $1968-2006$ & $\begin{array}{l}1968-1979 \\
1981-1999 \\
2000-2006\end{array}$ & $\begin{array}{c}1972-2005 \\
(\text { n. d. })\end{array}$ & $\begin{array}{l}1970-1979 \\
1982-1999\end{array}$ \\
\hline Carranza & 1093 & $1957-2000$ & $\begin{array}{l}1957-1983 \\
1984-1989 \\
1990-1993 \\
1994-1997 \\
1998-2000\end{array}$ & $1963-1983$ & $1964-1983$ \\
\hline
\end{tabular}

Comentarios a la tabla 2:

1.- 1058 Maruri: Se deja en blanco el periodo homogéneo de Maruri, al ser la ruptura en noviembre de 1977 y no disponerse de un periodo mínimo de 10 años en el intervalo MAM para emplear el test de Thom. 
2.- La investigación de los tests de Thom y de Mann-Kendall de las 33 series de datos de precipitación MAM localizadas en cuencas que vierten al litoral de Vizcaya descubre rupturas en 12 de ellas (el 36\%).

En Guipúzcoa, la aplicación de los 2 tests a la precipitación media de los meses MAM muestra roturas en 16 series de las 54 analizadas (el 30\%) (Nota Técnica No 13 AEMET).

3.- 1083 Arcentales: Intervalo sin datos de Marzo de 1980 a Enero de 1981 inclusive.

Tabla 3: Rupturas detectadas en la precipitación media AMJ:

\begin{tabular}{|c|c|c|c|c|c|}
\hline \multirow{2}{*}{ Nombre } & \multirow{2}{*}{ Indicativo } & \multirow{2}{*}{ Periodo años } & \multirow{2}{*}{$\begin{array}{l}\text { Periodos entre } \\
\text { rupturas }\end{array}$} & \multicolumn{2}{|c|}{ Periodos homogéneos } \\
\hline & & & & Thom & Mann Kendall \\
\hline Echevarría & 1053 & $1962-1996$ & $\begin{array}{l}1962-1975 \\
1976-1996 \\
\end{array}$ & $\begin{array}{l}1962-1974 \\
1976-1996 \\
\end{array}$ & $\begin{array}{c}1962-1996 \\
\text { (n. d.) }\end{array}$ \\
\hline Marquina & 1054 & $1946-1976$ & $\begin{array}{l}1946-1952 \\
1957-1976\end{array}$ & $1958-1976$ & $\begin{array}{c}1950-1976 \\
\text { (n. d.) }\end{array}$ \\
\hline Baquio & $1057 \mathrm{E}$ & $1986-2013$ & $\begin{array}{l}1986-2008 \\
2009-2013\end{array}$ & $\begin{array}{c}1986-2013 \\
\text { (n. d.) }\end{array}$ & $1986-2006$ \\
\hline Punta Galea & 1059 & $\begin{array}{l}1911-1926 \\
1946-1969 \\
1994-2013 \\
\end{array}$ & $\begin{array}{l}1911-1926 \\
1946-1969 \\
1994-2013 \\
\end{array}$ & $\begin{array}{l}1911-1924 \\
1948-1967 \\
1998-2008 \\
\end{array}$ & \begin{tabular}{|l|}
$1914-1926$ \\
$1946-1969$ \\
$1994-2013$ \\
\end{tabular} \\
\hline Orduña & $1059 \mathrm{~L}$ & $\begin{array}{c}1881-1899,1905, \\
1917-1918, \\
1986-1995\end{array}$ & $\begin{array}{c}1881-1899 \text { y } 1905, \\
1917-1918 \\
1986-1995\end{array}$ & $\begin{array}{c}1881-1899 \mathrm{y} \\
1905\end{array}$ & $\begin{array}{c}1881-1899,1905, \\
1917-1918 \text { y } \\
1986-1995 \text { (n. d.) }\end{array}$ \\
\hline $\begin{array}{l}\text { Amurrio } \\
\text { Instituto }\end{array}$ & 1060 & $1956-2013$ & $\begin{array}{r}1956-1966 \\
1968-1992 \\
1993-2013 \\
\end{array}$ & $\begin{array}{l}1956-1966 \\
1969-1989 \\
1993-2008 \\
\end{array}$ & $\begin{array}{c}1962-2013 \\
\text { (n. d.) }\end{array}$ \\
\hline Abadiano & 1070 & 1935 y $1968-2002$ & $\begin{array}{c}1935 \\
1968-2002\end{array}$ & $1975-2002$ & $1968-2002$ \\
\hline $\begin{array}{l}\text { Derio } \\
\text { Neiker }\end{array}$ & $1081 \mathrm{U}$ & $1987-2013$ & $\begin{array}{l}1987-1995 \\
1996-2009 \\
2010-2013 \\
\end{array}$ & $1996-2007$ & $\begin{array}{c}1987-2013 \\
\text { (n. d.) }\end{array}$ \\
\hline
\end{tabular}

$\underline{\text { Comentarios a la tabla 3: }}$

1.- El escudriñamiento de los tests de Thom y de Mann-Kendall de las 34 series de datos de precipitación AMJ, sitas en cuencas que vierten al litoral de Vizcaya aflora rupturas en 8 de ellas (el 24\%).

En Guipúzcoa, la aplicación de los 2 tests a la precipitación media de los meses AMJ revela roturas en 12 series de las 54 analizadas (el 22\%) (Nota Técnica $\mathrm{N}^{\circ} 13$ AEMET).

2.- 1060 Amurrio: Sin datos de Junio de 1967. 


\subsection{1.- Análisis pormenorizado de cada serie pluviométrica:}

Ulterior al escrutinio de los registros de precipitaciones mediante los test de Thom y de Mann - Kendall y a la realización de una labor de investigación de campo y bibliográfica, se aportan los resultados obtenidos en los comentarios siguientes:

\section{1.- 1053 Echevarría:}

1.1.- Las anotaciones las realiza exclusivamente el párroco de Echevarría en todo el lapso de la serie. En los archivos de SS.BB. ${ }^{1}$ de la Delegación Territorial de AEMET en el País Vasco figura que el 16 de Abril de 1994 le robaron la probeta al colaborador, recibiendo una nueva el 29 de Junio de 1994. El autor examinó el enclave, el jardín anejo a la casa parroquial de Echevarría.

1.2.- El test de rachas aplicado a la precipitación media anual y AMJ detecta una ruptura a finales de 1975.

1.3.- El test de Mann-Kendall empleado sobre la precipitación media anual de todo el intervalo de mediciones (1962 a 1996) indica una tendencia positiva de 1974 a 1984.

Esta tendencia positiva de 1974 a 1984 no es detectada en ninguna de las otras series analizadas en esta nota técnica (tabla 71, página 131) y tampoco se aprecia en las series de Guipúzcoa (Nota Técnica No 13 AEMET).

Es un ejemplo de la importancia de realizar un análisis conjunto con los registros de precipitación del entorno para dilucidar si una inhomogeneidad es climatológica o debida a otras causas.

\section{2.- 1054 Marquina:}

2.1.- Las mediciones principian en Enero de 1946 en el barrio de Plazakola de Marquina, con un único colaborador a lo largo de todo el intervalo de registros. En Julio de 1951 el pluviómetro estaba a $1 \mathrm{~m}$ sobre el suelo. Hay un intervalo sin datos de precipitación desde Febrero de 1952 a Abril de 1956, fecha en que el pluviómetro figura a 1,7 m sobre el terreno. En Marzo de 1977 finalizan las medidas en el mismo barrio de Plazakola de Marquina. El autor inspeccionó el lugar, una hondonada del río Artibai a una altitud de 33m.

2.2.- El análisis del test de rachas de la precipitación media en MAM y en AMJ revela una rotura de los datos previos a Febrero de 1952 (1054 I $\vee$ ) respecto a los posteriores a Abril de 1956 (1054 II $\vee$ ).

El test de rachas sobre la precipitación media anual no percibe una ruptura, si bien arroja dudas.

2.3.- El 04 de Noviembre de 2012 se retoman las observaciones pluviométricas en el barrio de Barroeta de Marquina con el indicativo 1054A $\$$, a una altitud de $94 \mathrm{~m}$ y a 3,1 Km. de distancia al S de 1054 I $\vee$ y 1054 II $\vee$.

\footnotetext{
${ }^{1}$ SS.BB.: Sistemas Básicos
} 
El autor colaboró activamente en la realización de gestiones para reanudar dichas observaciones en Marquina y en la apertura de 1054E Zenarruza.

1054A se halla en un prado a $15 \mathrm{~m}$ de la vivienda del colaborador y a $1 \mathrm{~m}$. sobre el suelo, alcanzando una altura pareja a la rasante del tejado de la vivienda.

Se trata de un emplazamiento muy abierto al S, W y N y con un pinar hacia el E a $90-$ $100 \mathrm{~m}$ de distancia y una altitud $30 \mathrm{~m}$ superior. Los vientos del $\mathrm{E}$ son los menos eficientes en cuanto a precipitaciones en Vizcaya.

La figura 2 presenta las localizaciones actual 1054A y antiguas (1054 I $\nabla$ y 1054 II $\vee$ ) de registro de precipitaciones en el término de Marquina.

\section{Figura 2: Ubicaciones actual 1054A \&y antiguas (1054 I \ y 1054 II $\vee$ ) del pluviómetro en Marquina:}

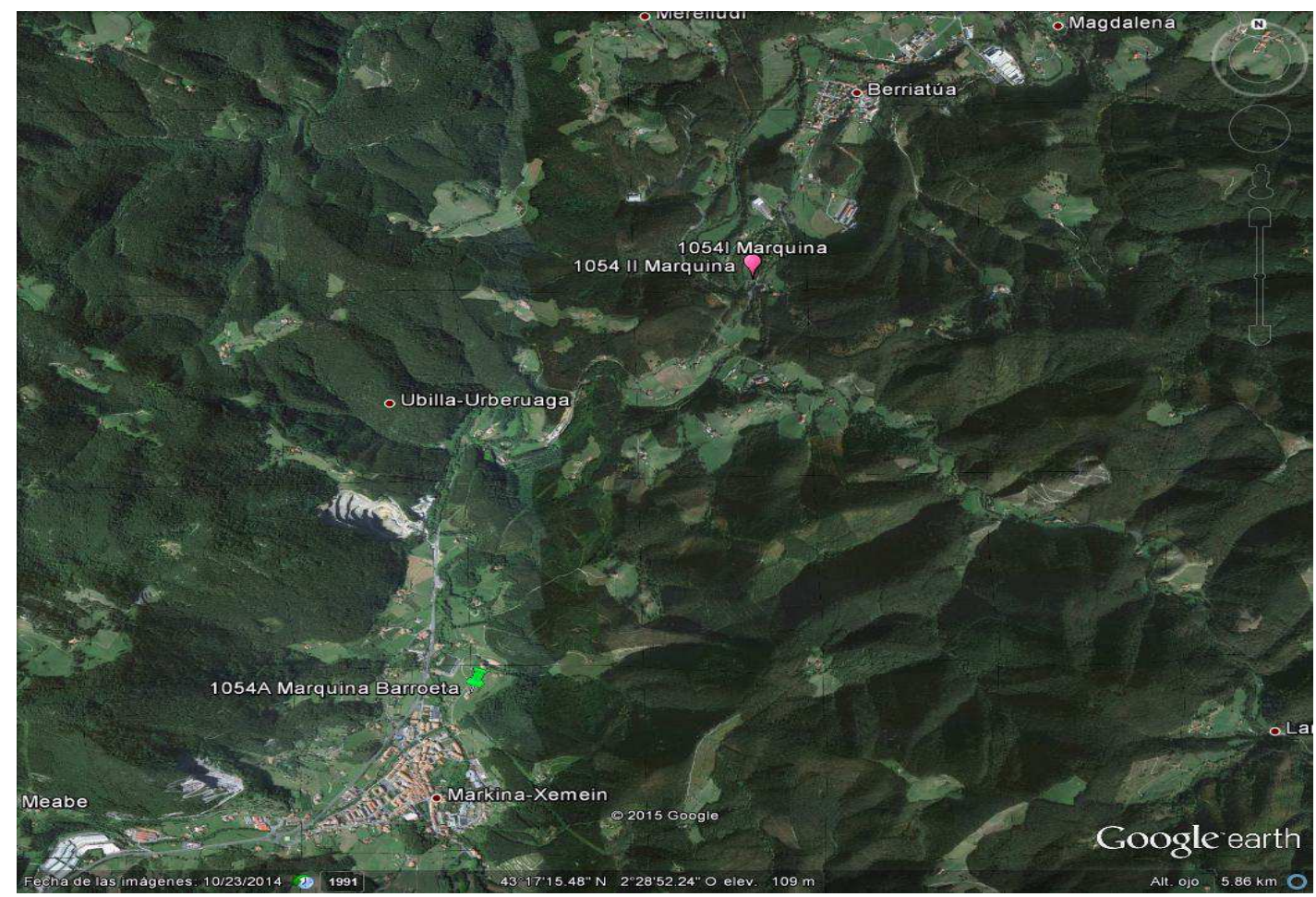

\section{3.- 1055A Lequeitio Agustinas:}

3.1.- El pluviómetro está situado en la huerta del convento de las Agustinas de Lequeitio. La colaboradora es la misma desde el comienzo de la serie de medidas en Abril de 1986.

3.2.- Hay una interrupción en las mediciones pluviométricas de Enero de 2006 a Mayo de 2006 inclusive. Las religiosas construyeron un nuevo convento en esas fechas produciéndose:

a) Un traslado del pluviómetro dentro del jardín del convento.

b) Una alteración del entorno (se reorganiza la huerta).

Asimismo, el aparato de registro cambió: El pluviómetro de Iberdrola se reemplaza por el modelo oficial del INM en Mayo de 2006. 
3.3.- En una llamada telefónica del Supervisor de SS.BB., la colaboradora confirma que en el antiguo convento no hubo, con anterioridad a las obras, cambio de emplazamiento ni del entorno del pluviómetro.

3.4.- El test de las rachas aplicado a la precipitación media anual es el único que manifiesta la inhomogeneidad.

\section{4.- 1057 C Machicaco Faro Viejo:}

4.1.- No hay valores de precipitación de Noviembre de 1921, única laguna desde Enero de 1913 a Diciembre de 1933. En las postrimerías de Diciembre de 1926 muda el primigenio colaborador (el torrero del faro), pasando a realizarlas con posterioridad al unísono 3 torreros, supervisados los 4 por el ingeniero del faro.

4.2.- El test de rachas anual y MAM detecta la rotura en Noviembre de 1921.

4.3.- La tabla siguiente refleja las medianas de la precipitación media anual y MAM de 1057C.

Tabla 4: Medianas de la precipitación media anual y MAM de 1057C $\nabla$ de la serie global y de cada lapso entre rupturas::

\begin{tabular}{|c|c|c|c|c|c|}
\hline & \multirow{2}{*}{ Intervalo años } & \multicolumn{2}{|c|}{ Mediana $\left(1 / \mathrm{m}^{2}\right)$} & \multicolumn{2}{|c|}{$\%$} \\
\hline & & Anual & MAM & Anual & MAM \\
\hline $1057 \mathrm{C} P$ & $1913-1933$ & 89,1 & 78,5 & 100 & 100 \\
\hline 1057C I $P$ & $1913-1920$ & 80,4 & & 90 & \\
\hline 1057C I $\vee$ & $1913-1921$ & & 79,5 & & 101 \\
\hline 1057C II $\vee$ & $1922-1933$ & 96,7 & 72,0 & 109 & 92 \\
\hline
\end{tabular}

La $2^{\mathrm{a}}$ fila se refiere a los datos de la serie completa de medidas (1913 a 1933); la $3^{\mathrm{a}}, 4^{\mathrm{a}}$ y $5^{\mathrm{a}}$ a las medianas de cada intervalo de rupturas de la serie: 1913 a 1920 (anual), 1913 a 1921 (MAM) y 1922 a 1933.

Las 2 últimas columnas exponen el \% de la mediana de cada intervalo respecto a la mediana de la serie global (1913 - 1933).

\section{5.- 1057E Baquio:}

5.1.- De los archivos de SS.BB., "se cambió el emplazamiento del pluviómetro el 21 de Mayo de 2009 a uno más expuesto". A su vez se reemplazó en dicha fecha el pluviómetro de plástico de Iberdrola por el estándar de AEMET.

5.2.- La primigenia localización del jardín meteorológico de Baquio 1057E I $\vee$ estaba resguardada en dirección $\mathrm{N}$ por la vivienda del colaborador $(8 \mathrm{~m}$. de altura, a menos de $30 \mathrm{~m}$.) y al $\mathrm{E}$ por un bosque a una distancia inferior a $30 \mathrm{~m}$.

El enclave actual 1057E II $\$$ está menos protegido (10 $\mathrm{m}$ al $\mathrm{E}$ hay un cobertizo de unos 3 m. de altura) y se encuentra a la misma altitud que la localización inicial. 
La figura 3 muestra los emplazamientos del pluviómetro en Baquio actual (1057E II ) y previo (1057E I $\nabla)$.

Figura 3: Enclaves actual 1057E II $\&$ y antiguo 1057E I $\vee$ del pluviómetro de 1057E Baquio:

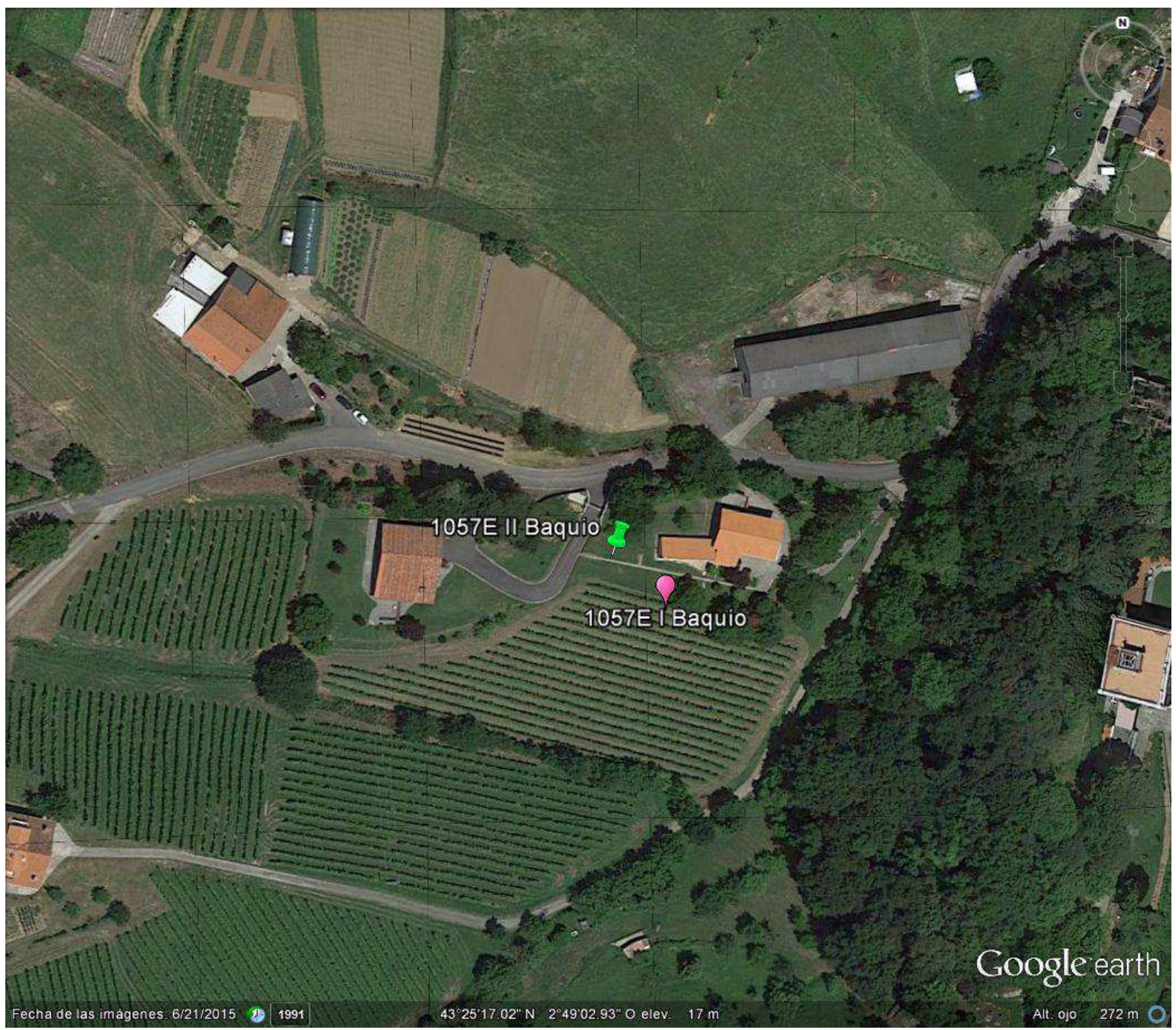

5.3.- El test de rachas aplicado a la precipitación media anual de toda la serie (1986 a 2013) indica 12 inhomogeneidades en 13 pruebas del test.

Aplicando el test de rachas a la precipitación media anual del intervalo de 1987 a 2007 (sin datos en Junio de 2008) resulta una serie homogénea al 100\%.

5.4.- El test de Mann-Kendall AMJ corrobora la ruptura de la primavera de 2009.

\section{6.- 1058 Maruri:}

6.1.- No hay registros de precipitación desde Noviembre de 1979 a Julio de 1982.

6.2.- El test de rachas MAM indica una ruptura de la homogeneidad de los datos previos a Noviembre de 1979 respecto a los ulteriores a Julio de 1982. 


\section{7.- 1059 Punta Galea Golf:}

7.1.- Las mediciones de Enero de 1911 a Diciembre de 1926 se efectuaron en el faro de Punta Galea (1059 I 8) "disponiendo de un pluviómetro modelo del Observatorio de San Fernando, con $0,0314 \mathrm{~m}^{2}$ de superficie receptora." "El pluviómetro, instalado en una terraza, tiene su boca a $10 \mathrm{~m}$. de altura sobre el terreno." ("Resumen de Observaciones Efectuadas durante el año 1914”).

En 1941, ante los riesgos de desprendimientos, se abandona el primigenio faro y se empieza a diseñar el faro definitivo (1059 II $\vee$ ), inaugurándose en 1950. 1059 II $\vee$ Punta Galea Faro está 180 m. al Sur de la prístina 1059 I $\nabla$ Punta Galea Faro.

Las mediciones en 1059 II $\nabla$ se realizaron desde Enero de 1946 hasta Septiembre de 1969 empleando un pluviómetro Hellmann.

En Marzo de 1994 se retoman los registros de precipitaciones con pluviómetro Hellmann en el Golf de Punta Galea (1059 III $\$$ ) a una distancia de 1200 metros de 1059 II $\nabla$ y una altitud de $80 \mathrm{~m}$ (30 m superior a 1059 II $\vee$ ), con un único esmerado colaborador desde Marzo de 1994 hasta la actualidad.

La figura 4 señala las ubicaciones del jardín meteorológico en Punta Galea actual (1059 III $\$$ ) y antiguas (1059 I $\nabla$ y 1059 II $\nabla)$.

Figura 4: Emplazamientos actual 1059 III $\$$ y antiguos (1059 I $\vee$ y 1059 II $\vee$ ) del jardín meteorológico de 1059:

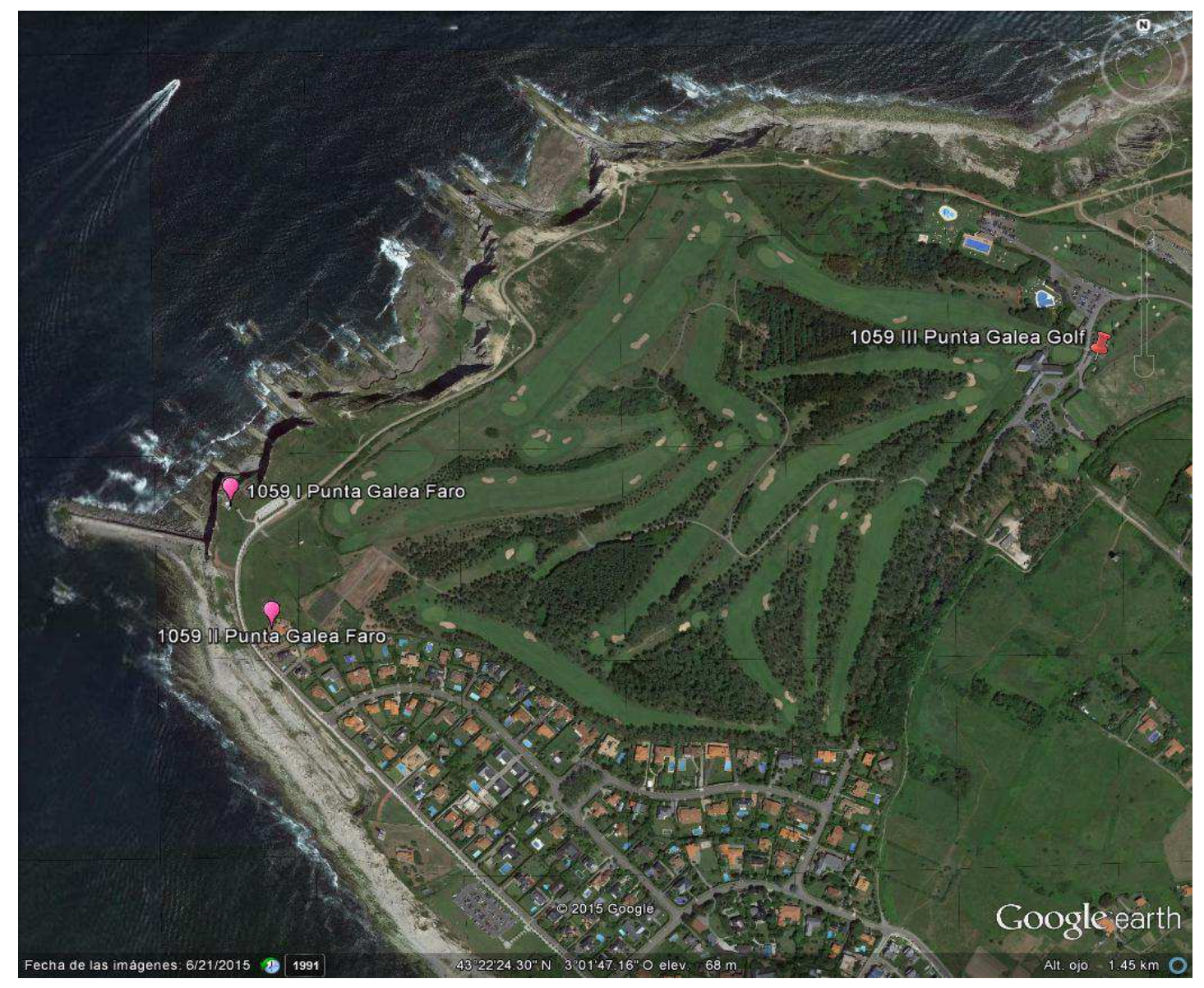


7.2.- El test de rachas aplicado a la precipitación media en MAM de la serie global (1911 a 1926, 1946 a 1969 y 1994 a 2013) descubre la ruptura de los datos de precipitación de 1059 I $\nabla$ respecto a los de 1059 II $\nabla$ (de 1946 a 1969) y de 1059 III (posteriores a 1994).

7.3.- El escrutinio del test de Mann-Kendall en MAM y en AMJ de la serie integral (1911 a 1926, 1946 a 1969 y 1994 a 2013), aflora una tendencia negativa "espuria" abarcando desde 1926 a 2013 en MAM y desde 1920 a 2013 en AMJ.

La consideración de una rotura de los datos anteriores a 1927 respecto a los posteriores a 1945 conlleva la eliminación de esta tendencia "ficticia" de la precipitación.

7.4.- El test de rachas empleado en la precipitación media anual de los registros de precipitaciones conjuntos de 1946 a 1968 y 1995 a 2013 revela la ruptura de los datos de precipitación de 1059 II $\nabla$ (previos a 1968) respecto a los de 1059 III $\$$ (ulteriores a 1995).

7.5.- La tabla siguiente expone las medianas de la precipitación media anual, MAM y AMJ de 1059 P.

Tabla 5: Medianas de la precipitación media anual, MAM y AMJ de 1059 de la serie global y de cada lapso entre rupturas (1059 I $\vee, 1059$ II $\vee$ y 1059 III $\$$ ):

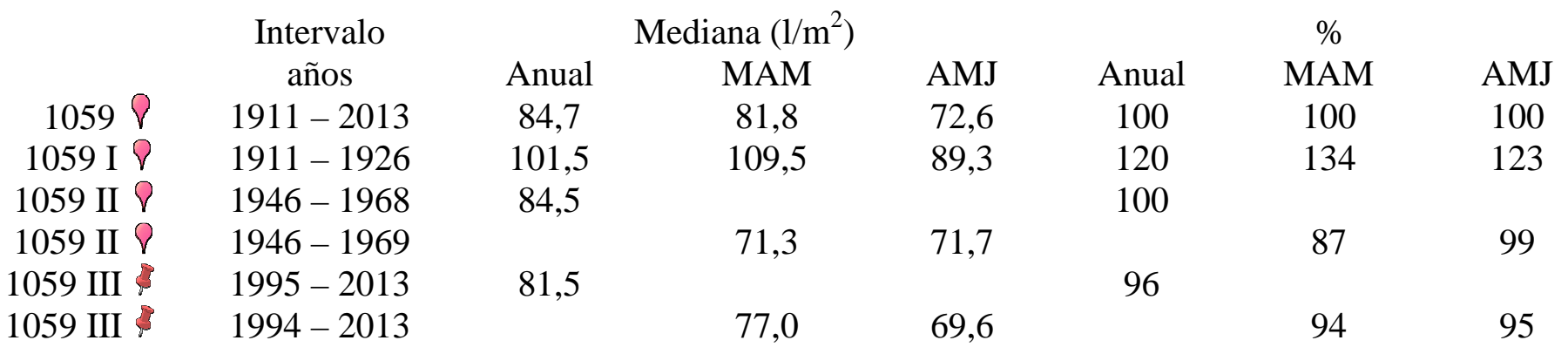

La $2^{\mathrm{a}}$ fila se refiere a los datos de la serie completa de medidas (1911 a 2013); las sucesivas filas a las medianas de cada intervalo de rupturas de la serie: 1911 a 1926 (anual, MAM y AMJ), 1946 a 1968 (anual), 1946 a 1969 (MAM y AMJ), 1995 a 2013 (anual) y 1994 a 2013 (MAM y AMJ).

La última columna indica el \% de la mediana de cada intervalo respecto a la mediana de la serie total de medidas $(1911-2013)$.

Es un paradigma de la trascendencia del conocimiento de la información de los diferentes lugares, instrumentos de medida y colaboradores como paso previo al análisis y examen de la serie de datos de precipitación para evitar conclusiones espurias de variación de la precipitación en una escala temporal de décadas, variación debida al cambio de emplazamiento y, en este caso en menor grado, a la modificación de instrumentación y de colaborador.

Se investiga más detalladamente en el apartado 3.2. Cadencias de las precipitaciones de la Nota Técnica AEMET Nº 19. 


\section{8.- 1059L Orduña:}

8.1.- De los "Resúmenes de Observaciones Meteorológicas":

a) 1059L I 8 Orduña se encontraba en el claustro de la Iglesia del antiguo Colegio de Jesuitas de Orduña. Hay datos de precipitación mensual de Febrero de 1881 a Diciembre de 1899 y registros completos de los años 1905, 1917 y 1918.

b) De 1881 a 1899 las anotaciones las efectúan sucesivamente 6 Padres Jesuitas. En 1905 figura un $7^{\circ}$ diferente.

c) En Agosto de 1916 se instaló un pluviómetro Hellmann en el jardín del claustro de los PP. Jesuitas, con la boca a 1,5m del suelo. Las mediciones de 1917 y 1918 las realiza un $8^{\circ}$ Jesuita.

d) De Enero de 1986 a Diciembre de 1995 las medidas las realizan las religiosas del pretérito convento de Carmelitas Descalzas de Orduña, anejo al Santuario de la Antigua de Orduña en 1059L II. $\vee$, a $1 \mathrm{Km}$. al Oeste y una altitud superior de $30 \mathrm{~m}$. de 1059L I $९$.

La figura 5 expone las localizaciones antiguas del jardín meteorológico en Orduña (1059L I $\vee$ y 1059L II $\vee$ ), ambos enclaves reconocidos por el autor.

Figura 5: Enclaves antiguos 1059L I $\vee$ y 1059L II $\vee$ del jardín meteorológico de 1059L:

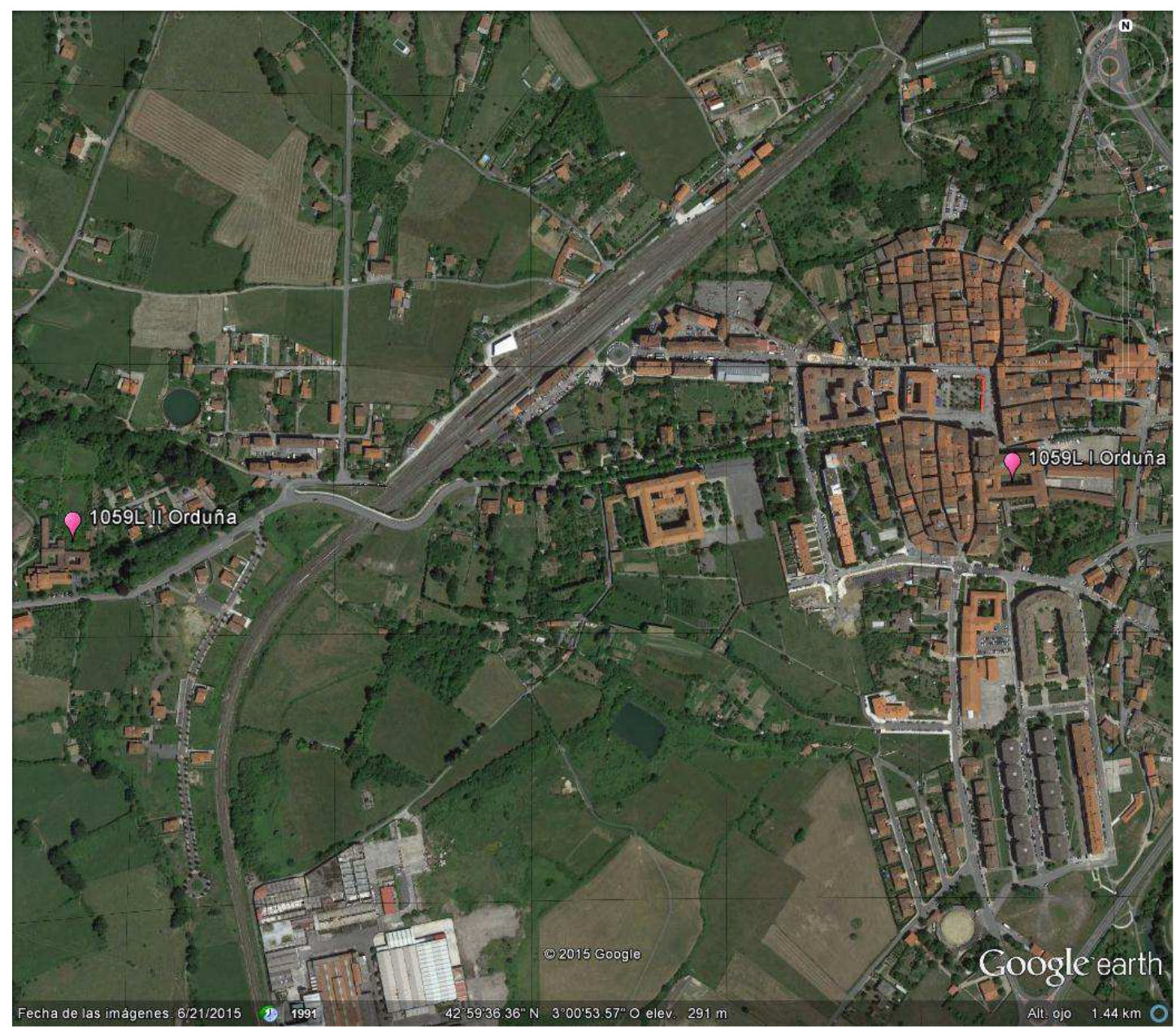


8.2.- Una ruptura de los datos de 1986 a 1995 (1059L II $\vee$ ) respecto al global de datos conocidos (1881 a 1995) es detectada por el test de rachas aplicado a las precipitaciones medias en MAM y en AMJ.

8.3.- El test de Mann-Kendall aplicado a la precipitación media anual percibe una rotura de los valores de 1986 a 1995 (1059L II $\vee$ ) respecto a la integridad de datos conocidos (1881 a 1995), indicando el test de Mann-Kendall una tendencia positiva de la precipitación en 1987, 1988 y de 1991 a 1995, no detectada en ninguna otra de las series de precipitación examinadas (tabla 71, página 131).

8.4.- El análisis del test de rachas de la precipitación en AMJ en el intervalo 1881 a 1918 aflora una $2^{\mathrm{a}}$ ruptura, debida al cambio de pluviómetro en 1916.

La tabla siguiente revela las medianas de la precipitación media anual, MAM y AMJ de 1059L \ Orduña.

Tabla 6: Medianas de la precipitación media anual, MAM y AMJ de 1059L $\varnothing$, de la serie global y de los lapsos entre rupturas (1059L I $\vee$ y 1059L II $\vee$ ):

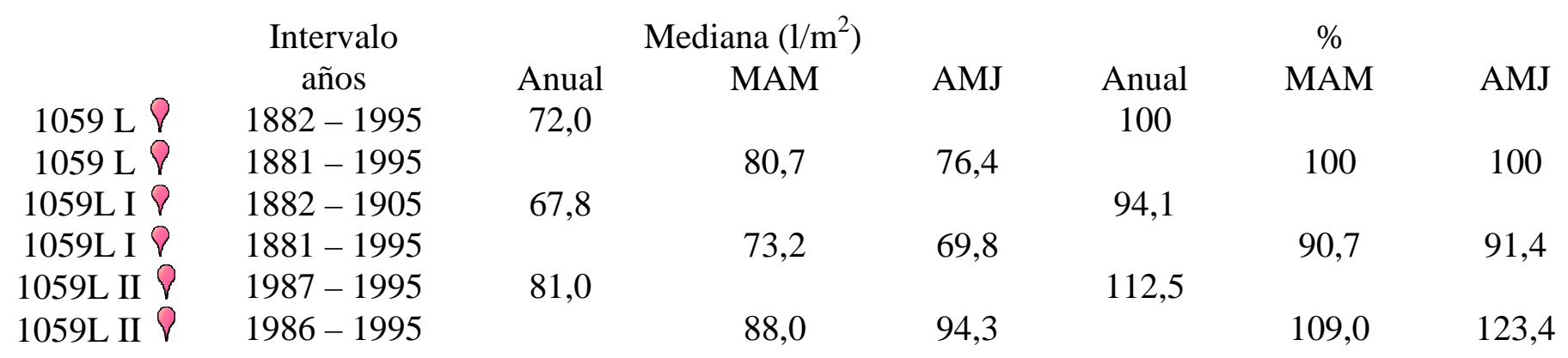

Las filas $3^{\mathrm{a}}$ y $4^{\mathrm{a}}$ se refieren a la mediana desde 1882 hasta 1995 (anual) y de 1881 a 1995 (MAM y AMJ) respectivamente; las filas $5^{\mathrm{a}}$ y $6^{\mathrm{a}}$ a la mediana de 1987 a 1995 (anual) y de 1986 a 1996 (MAM y AMJ).

\section{8.- 1060 Amurrio Instituto:}

8.1.- El entorno del jardín meteorológico y el colaborador responsable de las mediciones han variado desde Mayo de 1955, fecha de comienzo de las medidas, información confirmada por el actual colaborador en una visita del autor el 11 de Marzo de 2014.

8.2.- De la documentación de SS.BB. se entresaca la información siguiente referente a cambios de colaboradores y a alteraciones del entorno:

a) En 1955 figura como colaborador D. Pedro Albizua. El 05 de Octubre de 1959 se desplaza menos de 120 metros desde $43^{\circ} 03^{\prime} 04,3^{\prime \prime} \mathrm{N}$ y $03^{\circ} 00^{\prime} 17,2^{\prime \prime} \mathrm{N}$ e idéntica altitud, información suministrada al autor por la viuda de D. Pedro en una visita a Amurrio el 16 de Diciembre de 2015. Ninguno de los 2 tests en los 3 lapsos (anual, MAM y AMJ) detecta ruptura en esa fecha.

b) D. Fernando Arregui, eximio colaborador, figura como titular desde 1966 hasta la actualidad. 
c) En 1992 se amplía el Instituto y se construyen nuevas instalaciones próximas al jardín meteorológico, alterando su entorno. No cambia de ubicación el jardín meteorológico.

8.3.- El test de rachas aplicado a la pluviometría media en MAM detecta las rupturas a finales de 1992 y de 1966.

El test de rachas espulgando la precipitación media en AMJ percibe las roturas de fines de 1992 y de 1966, sin bien afloran dudas respecto a esta última.

8.4.- El escudriñamiento del test de Mann-Kendall de la pluviosidad media anual y en MAM detecta la discontinuidad a finales de 1966.

El examen del test de Mann-Kendall de la precipitación media anual de toda la serie (1956 a 2013) indica una tendencia positiva en 1963, 1965, 1966, 1969, 1971, 1972, 1974, 1975 y de 1977 a 1985.

El análisis del test de Mann-Kendall de la pluviometría media en MAM de la serie global (1956 a 2013) refleja una tendencia positiva de 1971 a 1985.

La apreciación de una ruptura en 1966 elimina estos dos incrementos "ficticios" de la precipitación, no detectados en ninguna otra de las series analizadas en esta Nota Técnica (tablas 71 y 83, páginas 131 y 173) ni en Guipúzcoa (Nota Técnica 13 AEMET).

El test de Mann Kendall anual y MAM de 1967 a 2013 indica tendencia negativa de 1999 a 2013 (anual) y de 2001 a 2007 y de 2010 a 2013 (MAM), no detectadas en ninguna otra serie de las estudiadas.

La estimación de una rotura en 1992 - conocida por el cambio del entorno del jardín meteorológico - elimina esta disminución "espuria" de la precipitación.

8.5.- La tabla siguiente expone las medianas de la precipitación media anual, MAM y AMJ de $1060 \bigcirc$ Amurrio Instituto.

Tabla 7: Medianas de la precipitación media anual, MAM y AMJ de 1060, de la serie global y de cada lapso entre rupturas (1060 I $\vee, 1060$ II $\vee$ y 1060 III $\&$ ):

\begin{tabular}{|c|c|c|c|c|c|c|c|}
\hline & Intervalo & \multicolumn{3}{|c|}{ Mediana $\left(1 / \mathrm{m}^{2}\right)$} & \multicolumn{3}{|c|}{$\%$} \\
\hline & años & Anual & MAM & AMJ & Anual & MAM & AMJ \\
\hline $1060 \curlyvee$ & $1956-2013$ & 89,7 & 90,4 & 88,5 & 100 & 100 & 100 \\
\hline $1060 \mathrm{I} \nabla$ & $1956-1966$ & 90,7 & 83,2 & 88,3 & 101,1 & 92,0 & 99,8 \\
\hline 1060 II $\nabla$ & $1967-1992$ & 95,7 & 110,2 & 93,9 & 106,7 & 121,9 & 106,1 \\
\hline 1060 III & $1993-2013$ & 77,9 & 75,7 & 79,6 & 86,8 & 83,7 & 89,9 \\
\hline
\end{tabular}

La fila $3^{\text {a }}$ se refiere a las medianas de 1956 a 2013.

La $4^{\mathrm{a}}$ fila corresponde a las medianas entre 1956 y 1966 (1060 I P).

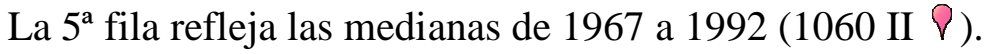

La $6^{\text {a }}$ fila describe las medianas desde 1993 hasta 2013 (1060 III $\%$ ). 


\section{9.- 1068 Basauri:}

9.1.- Las observaciones empiezan en el barrio de Finaga de Basauri el 1 de Noviembre de 1944 por el maestro del vecindario en la huerta de su propiedad. No hay datos de Diciembre de 1954.

9.2.- El test de rachas aplicado a la precipitación anual detecta una ruptura a fines de 1954.

9.3.- El test de Mann-Kendall sobre la precipitación media anual del intervalo total de la serie (1945 a 1979) muestra una tendencia negativa de 1967 a 1978.

Este resultado no es correcto, por la elevada duración elevada de la tendencia negativa de la precipitación y por no coincidir con los máximos de precipitación de 1978 registrados en 1078E I $\vee$ Valmaseda y 1093 I $\vee$ Carranza (tabla 27, página 65).

El empleo del test de Mann-Kendall en la precipitación media anual de 1955 a 1979 desvela que la precipitación es homogénea de 1955 a 1974 (tabla 14, página 41).

\section{0.- 1070 Abadiano (Mendiola):}

10.1.- La figura 6 ilustra las ubicaciones actual $\$$ y antigua $\nabla$ del pluviómetro de 1070:

Figura 6: Emplazamientos actual $\$$ y antiguo $\vee$ del pluviómetro de 1070:

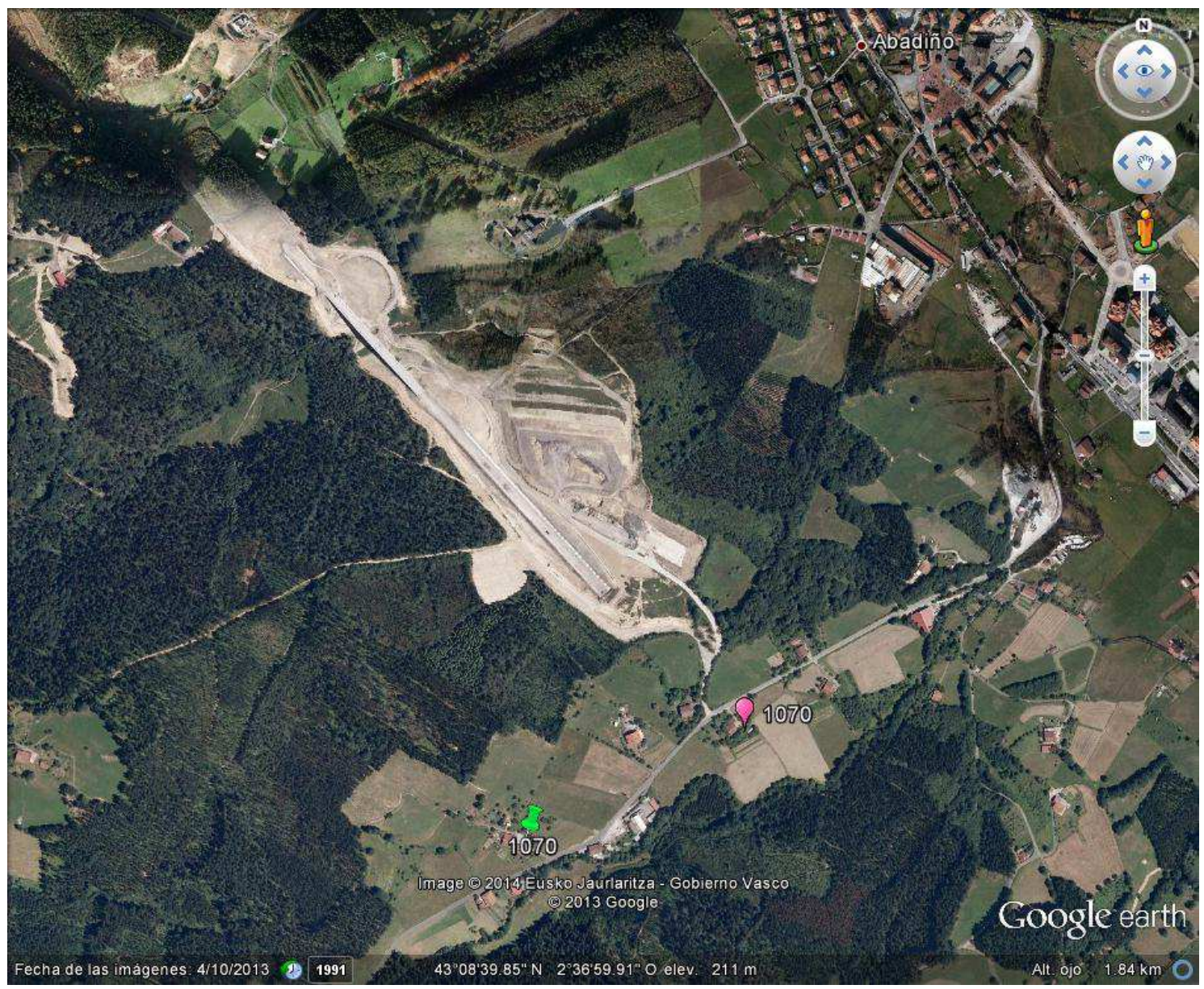


10.2.- Se conservan registros de Enero de 1935 a Mayo de 1936 (en una ubicación ignota) y de Enero de 1968 a Junio de 2002 (1070 \&, realizadas por un único diligente colaborador). El 01 de Octubre de 2013 se reanudan las medidas de precipitación en el mismo barrio de Muncharaz, en el sentido al vecindario de Mendiola de Abadiano (1070 ). El autor colaboró activamente en las gestiones para retomar las observaciones en Abadiano, reanudadas el $1 \mathrm{de}$ Octubre de 2013 e inspeccionó el enclave de las mediciones pretéritas de 1070 ४ y su entorno.

1070 está a menos de $400 \mathrm{~m}$ de $1070 \$$, con una diferencia de altitudes de $10 \mathrm{~m}$. Ambos lugares coinciden en: Una orientación del valle idéntica (SW a NE) y en distancias parejas a los pinares circundantes y a los respectivos caseríos (11 m 1070 \&, $15 \mathrm{~m} 1070 \$)$, los cuál se hallan al W de su pluviómetro.

10.3.- El espulgo del test de rachas de la pluviosidad media anual, MAM y AMJ detecta que los valores de 1935 y 1936 no son homogéneos respecto a los medidos entre 1968 y 2002.

\section{1.- 1075 Dima:}

11.1.- Hay valores completos del año 1925 (en Zamacola, barrio de Indusi de Dima). Las medidas se reanudan de Noviembre de 1967 a Mayo 1978 y en Julio y Agosto de 1982 en la Casa Forestal de "Lapur Erreka", rayana a la carretera de Dima a Ochandiano y próxima a la pista de aviación de Dima, a 3,2 Km. de Ochandiano. 1075 II 8 Dima ("Lapur Erreka"), visitada por el autor, está a 7,2 Km. al SE y a una altitud superior de 297 m. de 1075 I 8 Dima (Zamacola).

11.2.- El examen del test de rachas de la pluviometría media anual y MAM revela que los datos de 1925 no son homogéneos con los registrados entre 1968 y 1978.

\section{2.- 1075E Aránzazu:}

12.1.- Hay un intervalo sin datos de precipitación de Septiembre de 1980 a Enero de 1981.

12.2.- De los archivos de SS.BB., un único colaborador realiza las mediciones, el cuál comunica el 09 de Septiembre de 1981: "tenemos un pluviómetro y un termómetro no estando en buen estado".

12.3.- El test de rachas aplicado a la precipitación media anual y MAM detecta la ruptura de finales de 1981 .

12.4.- El test de Mann-Kendall en MAM corrobora la ruptura al final de 1981.

12.5.- La tabla siguiente muestra las medianas de la precipitación media anual y MAM de $1075 \mathrm{E} \vee$ para la serie completa de datos y para los 2 intervalos $1075 \mathrm{E}$ I $\nabla$ y $1075 \mathrm{E}$ II $\nabla$, considerando la rotura de fines de 1981.

Tabla 8: Medianas de la precipitación media anual y MAM de 1075E $P$ de la serie global y de cada lapsos entre rupturas (1075E I $\vee$ y 1075E II $\vee$ ):

\begin{tabular}{|c|c|c|c|c|c|}
\hline & \multirow{2}{*}{ Intervalo años } & \multicolumn{2}{|c|}{ Mediana $\left(1 / \mathrm{m}^{2}\right)$} & \multicolumn{2}{|c|}{$\%$} \\
\hline & & Anual & MAM & Anual & MAM \\
\hline $1075 \mathrm{E} P$ & $1968-2006$ & 111,2 & 121,5 & 100 & 100 \\
\hline $1075 \mathrm{E}$ I 8 & $1968-1980$ & 137,4 & 160,7 & 123,6 & 132,3 \\
\hline 1075E II $\varnothing$ & $1982-2006$ & 107,9 & 115,7 & 97,0 & 95,2 \\
\hline
\end{tabular}




\section{3.- 1078E Valmaseda:}

13.1.- El pluviómetro se sustituye el 27 de Diciembre de 1991 (archivos de SS.BB. de la Delegación Territorial), fecha en la que informa de escarcha. Las observaciones las efectúa el mismo colaborador sin mudanza de radicación de Enero de 1972 a Diciembre de 2007.

13.2.- El escrutinio del test de rachas de la precipitación en MAM arroja una ruptura de la serie de datos entre finales de 1991 y comienzos de 1992.

13.3.- La tabla siguiente refleja las medianas de la precipitación media MAM de 1078E $\bigcirc$ para la serie completa de datos y para los 2 intervalos 1078E I $\nabla$ y $1078 \mathrm{E}$ II $\vee$, considerando la rotura entre las postrimerías de 1991 y los albores de 1992.

Tabla 9: Medianas de la precipitación media MAM de 1078E $\nabla$ de la serie global y de cada lapsos entre rupturas (1078E I $\vee$ y $1078 \mathrm{E}$ II $\vee$ :

$\begin{array}{rccc} & \text { Intervalo años } & \text { Mediana }\left(1 / \mathrm{m}^{2}\right) & \% \\ 1078 \mathrm{E} \varnothing & 1972-2007 & 115,9 & 100 \\ 1078 \mathrm{E} \text { I } \varnothing & 1972-1991 & 127,2 & 109,7 \\ 1078 \mathrm{E} \text { II } \varnothing & 1992-2007 & 106,0 & 91,5\end{array}$

\section{4.- 1079E Arceniega:}

14.1.- El pluviómetro está en la huerta del convento de las Agustinas de Arceniega; cabe pensar que según el tipo de cultivo, se apantalle la precipitación en las épocas de maduración. Las medidas las realiza la hermana tornera, posición rotatoria en la comunidad de una duración mínima anual.

14.2.- Sin datos desde Mayo de 1996 a Marzo de 1997 inclusive, reanudándose la colaboración exactamente en el mismo emplazamiento, con el mismo entorno y con las mismas colaboradoras.

14.3- De los registros de SS.BB. de la Delegación Territorial, el 24 de Marzo de 2004 se sustituye el pluviómetro de Iberdrola por el reglamentario del INM y "se cambia a la altura adecuada".

14.4.- El test de rachas escrutando a la precipitación media anual en un intervalo de 10 años descubre inhomogeneidades de 1999 a 2010 y de 2002 a 2013, siendo la única serie de las investigadas en que se afloran inhomogeneidades en este intervalo temporal (tabla 17, página 50).

Es un ejemplo de la necesidad de un análisis conjunto con los registros de precipitación del entorno para detectar rupturas y discernir si una inhomogeneidad es climatológica o no.

14.5.- El 20 de Mayo de 2013 las religiosas construyen un invernadero, a la misma altura de la boca del pluviómetro y a unos $3 \mathrm{~m}$. de distancia. En una visita realizada por el autor el $11 \mathrm{de}$ Marzo de 2014, las religiosas le informaron que "el invernadero había sido destruido por los últimos temporales" y que "no tienen intención de reconstruirlo". 


\section{5.- $1081 \mathrm{U}$ Derio Neiker:}

15.1.- De los archivos de SS.BB. de la Delegación Territorial:

a) El 26 de Febrero de 1996 los colaboradores envían fax al Centro Meteorológico Territorial en San Sebastián comunicando "vamos a ver si bajamos la estación a la finca nueva en uno o 2 meses". El cambio se realizó a finales de Marzo de 1996.

El pluviómetro y la garita pasaron de estar a $43^{\circ} 18^{\prime} 03,1^{\prime \prime}$ N $2^{\circ} 52^{\prime} 01,7^{\prime \prime}$ ' $\mathrm{W}$ (figura 7 , 1081 U I P) y una altitud de $67 \mathrm{~m}$ a situarse a $43^{\circ} 17^{\prime} 28,11^{\prime}, \mathrm{N}, 2^{\circ} 52^{\prime} 24,24^{\prime}$ ' W (figura 7 , 1081 U II 8 ) y una altitud de $30 \mathrm{~m}$, siendo la distancia entre ambos lugares de $1180 \mathrm{~m}$.

b) El 22 de Junio de 2009, se cambió el emplazamiento del pluviómetro y de la garita a uno más abierto y más expuesto a las precipitaciones, dentro del recinto de los invernaderos, a una distancia de unos 63 m más al SSE siendo más una modificación del entorno que un cambio de emplazamiento.

La figura 7 indica el emplazamiento actual del jardín meteorológico en Derio (1081U y los 2 enclaves anteriores (1081U I Py 1081U II P).

Figura 7: Localización actual $\$$ y antiguas (1081U I $\vee$ y 1081U II $\vee$ ) de 1081U:

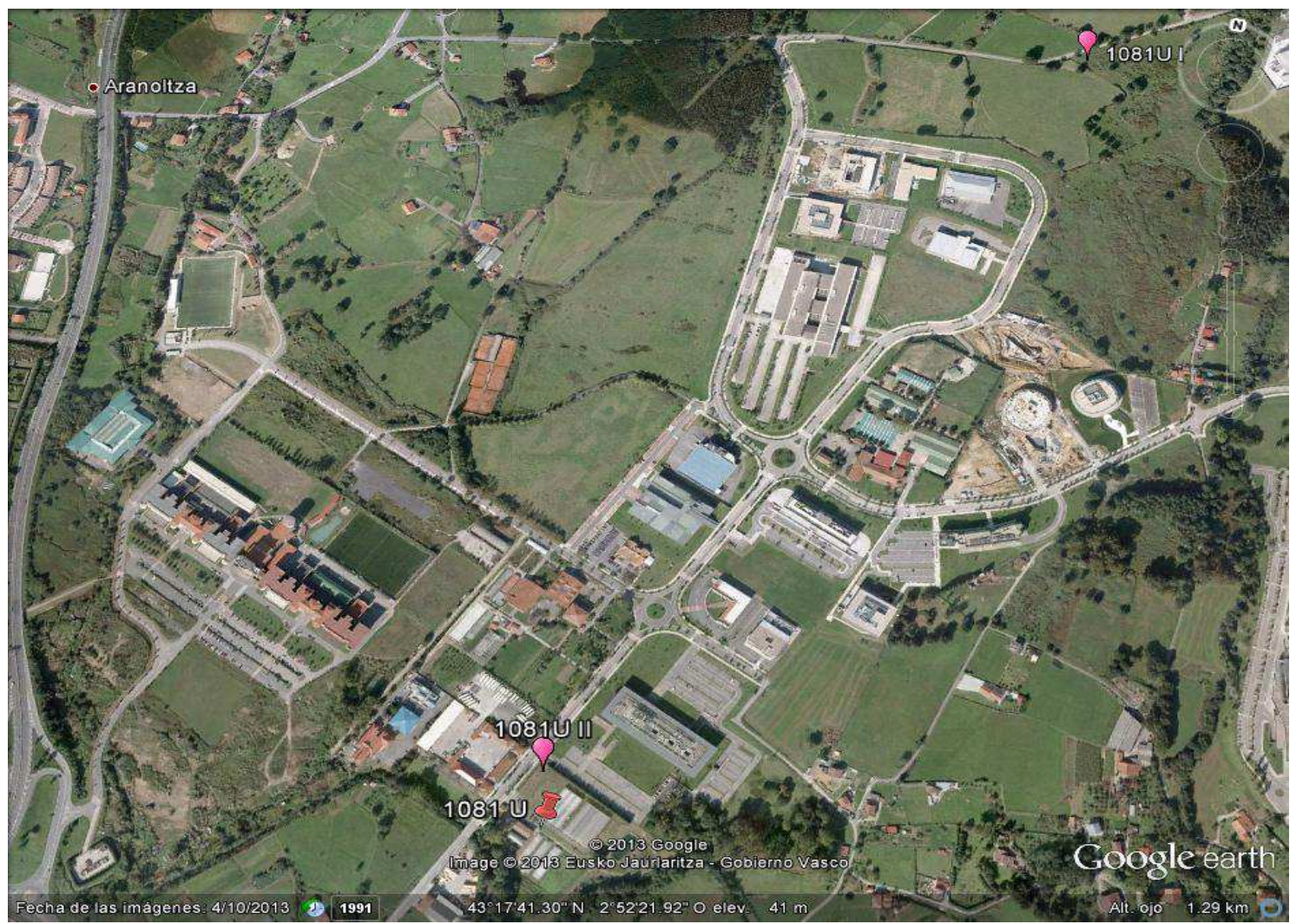

15.2.- La investigación del test de rachas de la precipitación media anual detecta el cambio de lugar de Marzo de 1996.

El test de rachas en el intervalo AMJ manifiesta el cambio de emplazamiento en la serie de medidas de $1081 \mathrm{U}$ de Junio de 2009. 
16.- 1082 Bilbao Aeropuerto:

16.1.- Desde el 01 de Marzo de 1947 se conservan registros de observaciones de precipitación (figura 8, 1082 I $\vee$ ) en el Banco de Datos Climatológico Nacional de AEMET.

16.2.- El 27 de Noviembre de 1984 se cambia la posición del jardín meteorológico a $43^{\circ} 18^{\prime} 05,87^{\prime \prime} \mathrm{N}$ y $2^{\circ} 55^{\prime} 42,57^{\prime \prime} \mathrm{W}$ (figura 8, 1082 II $\odot$ ).

16.3.- Debido a la construcción del nuevo aeropuerto de Bilbao, el día 16 de Noviembre de 2000 se traslada el jardín meteorológico a la cabecera 30 del nuevo aeropuerto, a una distancia de $1,9 \mathrm{Km}$., a la nueva ubicación $43^{\circ} 17^{\prime} 53,14^{\prime \prime} \mathrm{N}$ y $2^{\circ} 54^{\prime} 21,11^{\prime \prime} \mathrm{W}$ (figura 8, 1082 III $\nabla$ ).

No hay datos de Noviembre y Diciembre de 2000 ni de Enero de 2001. En estas fechas se cambia el instrumental de observación, pasando la medición de ser manual a automática.

16.4.- El 23 de Septiembre de 2013 se desplaza el jardín meteorológico $30 \mathrm{~m}$ hacia el SSW para cumplir los requerimientos de frangibilidad. Las nuevas coordenadas son $43^{\circ} 17^{\prime} 52,20^{\prime \prime} \mathrm{N}$ y $2^{\circ} 54^{\prime} 21,77^{\prime \prime} \mathrm{W}$ (figura 8,1082 ).

16.5.-La siguiente figura presenta la ubicación actual (1082 $\&$ ) y las anteriores (1082 I $\nabla$, 1082 II $\vee$ y 1082 III $\vee$ ) del jardín meteorológico del Aeropuerto de Bilbao.

Figura 8: Emplazamientos antiguos $\varnothing$ y localización actual \& del jardín meteorológico del aeropuerto de Bilbao:

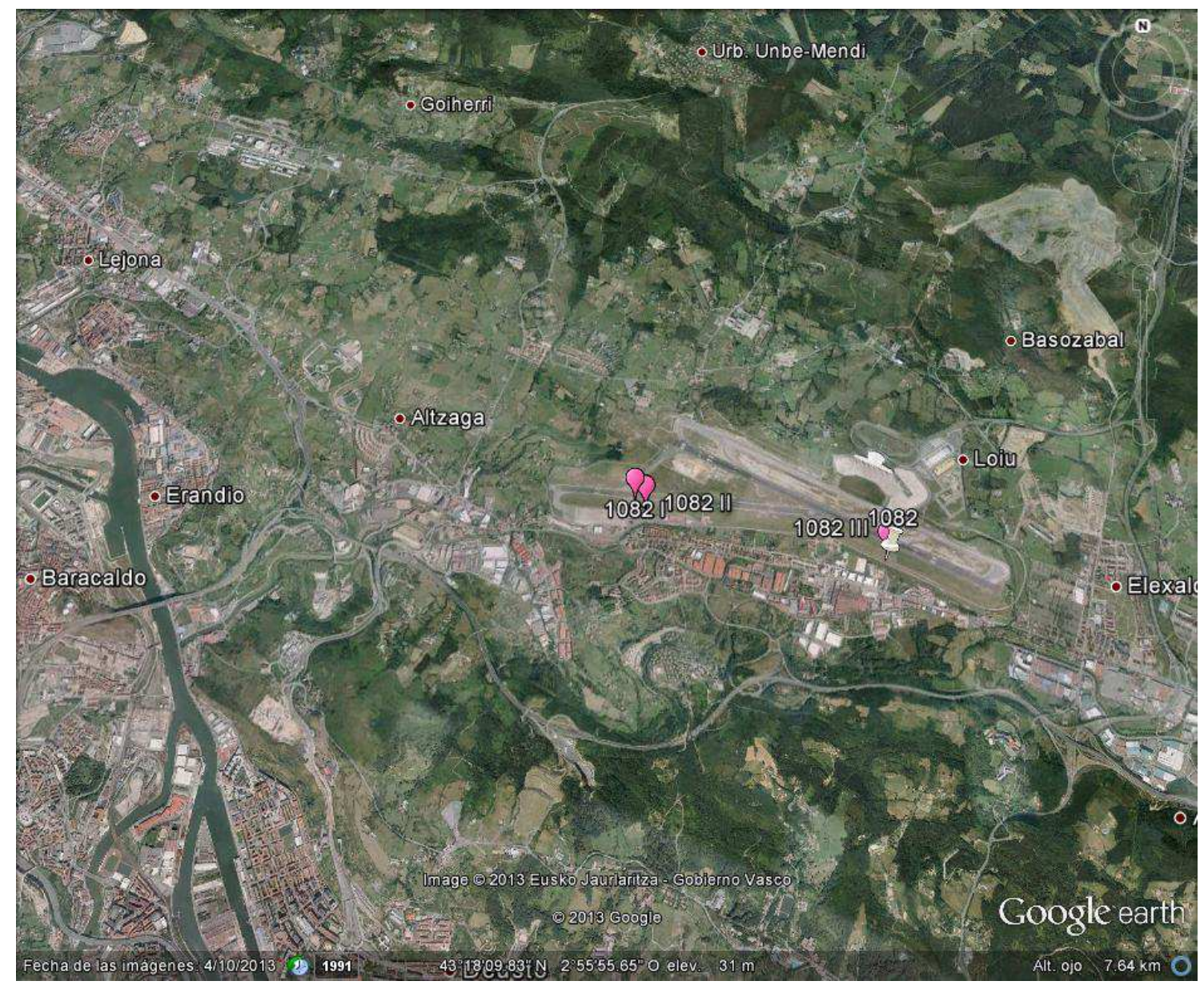


16.6.- El análisis del test de Mann Kendall de la pluviometría media anual de la serie global (de 1948 a 2013) aflora una tendencia negativa de 1997 a 2013. La consideración de la ruptura a finales del 2000 elimina esta tendencia espuria de la precipitación.

El test de rachas aplicado a la serie de precipitación media anual de 1948 a 1999 detecta una rotura a finales de 1984.

16.7.- La tabla siguiente expone las medianas de la pluviosidad media anual de $1082 \bigcirc$ de la serie integral de datos y de los 3 intervalos (1082 I $\nabla, 1082$ II $\nabla$ y 1082 III $\vee$ ), considerando las rupturas de Noviembre de 1984 y de Noviembre de 2000 a Enero de 2001.

Tabla 10: Medianas de la precipitación media anual de 1082:

$\begin{array}{rccc} & \text { Intervalo años } & \text { Mediana }\left(1 / \mathrm{m}^{2}\right) & \% \\ 1082 \text { } & 1948-2013 & 102,1 & 100 \\ 1082 \text { I } \varnothing & 1948-1984 & 108,6 & 106,4 \\ 1082 \text { II } \varnothing & 1985-1999 & 88,9 & 87,1 \\ 1082 \text { III } \varnothing & 2002-2013 & 92,8 & 90,9\end{array}$

De la tabla 10, se aprecia que la mediana de la precipitación media anual en el primer intervalo de datos (1948 a 1984) es el 122\% y el $117 \%$ respectivamente de las medianas en el segundo (1985 a 1999) y tercer intersticios (2002 a 2013).

\section{7.- 1083 Arcentales:}

17.1.- De los registros de SS.BB. de la Delegación Territorial de AEMET en el País Vasco, a primeros de Agosto de 1999 se jubila el colaborador y traslada el pluviómetro y la garita al jardín de su domicilio particular.

Allí continúa las observaciones hasta su defunción en 2002; su viuda prosigue las medidas hasta Mayo de 2006 en que cesa su colaboración.

17.2.- No se disponen de datos de precipitación de Marzo de 1980 a Enero de 1981.

17.3.- El primer emplazamiento estaba situado a $43^{\circ} 13^{\prime} 29^{\prime}$ ' $\mathrm{N}$ y $03^{\circ} 12^{\prime}$ '53' ' W y a 427 m. de altitud (figura 9, 1083 I $\vee$ y 1083 II $\vee$ ), en el recinto de la Casa Forestal "El Garmo". Los 3 sucesivos colaboradores de 1083 I $\vee$ y 1083 II $\nabla$ son guardas forestales, el último de los cuáles rellena las tarjetas pluviométricas desde el 01 de Octubre de 1972 hasta su deceso en 2002.

El segundo y último enclave estuvo a $43^{\circ} 14^{\prime} 24,41^{\prime}$ ' $\mathrm{N}$ y $03^{\circ} 13^{\prime} 05,74$ ' ' W y a $215 \mathrm{~m}$. de altitud, a menos de 1,8 Km. de distancia al $\mathrm{N}$ del primer enclave (figura 9, $1083 \mathrm{III} \vee$ ).

La siguiente figura revela las 2 localizaciones del pluviómetro y de la garita de Arcentales: La primera (1083 I $\vee$ y 1083 II $\vee$ ) y la última (1083 III $\nabla)$. 
Figura 9: Enclaves del jardín meteorológico de Arcentales:

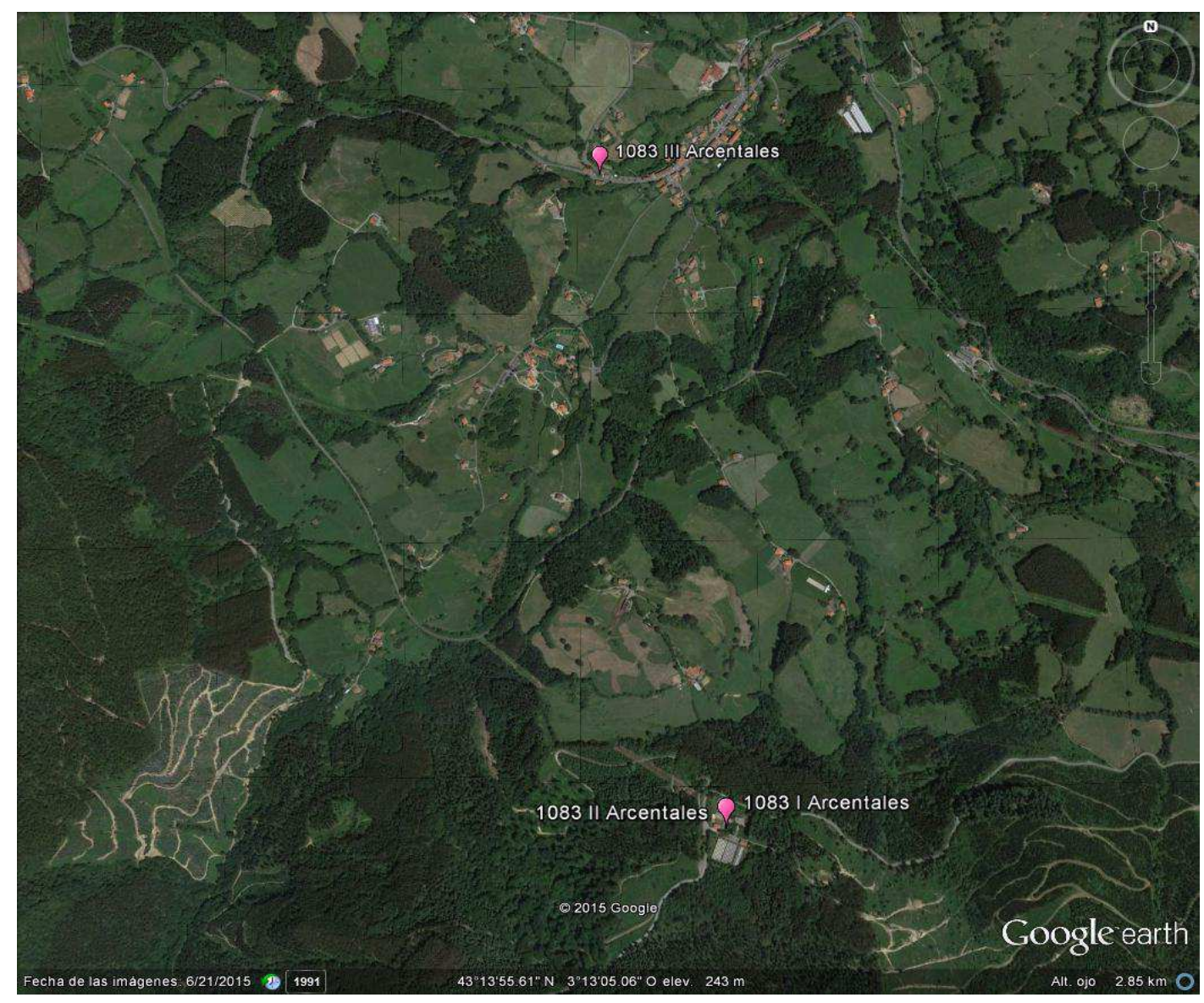

17.4.- El test de rachas empleado en la precipitación media anual señala 2 rupturas: En 1980 (coincidente con el intervalo descrito sin datos) y en Agosto de 1999 (concordante con el cambio de emplazamiento conocido).

17.5.- El escudriñamiento del test de Mann-Kendall de la pluviosidad media en MAM de la serie íntegra (1967 a 2006) detecta la rotura de 1980: Muestra una tendencia negativa de 1994 a 2005, siendo el único enclave de Vizcaya, de la vertiente atlántica de Álava (tabla 85, página 173) y de Guipúzcoa (Nota Técnica No 13 AEMET) en que aflora dicha tendencia.

17.6.- La tabla siguiente indica las medianas de la precipitación media anual y MAM de 1083 para la serie completa de datos (1967 a 2006) y para los 3 intervalos, teniendo en cuenta las roturas de 1980 y de Agosto de 1999.

Tabla 11: Medianas de la precipitación media anual y MAM de 1083 $\mathrm{P}$, de la serie global y de los lapsos entre rupturas (1083 I $\vee$ ), (1083 II $\vee$ ) y (1083 III $\vee$ ):

\begin{tabular}{|c|c|c|c|c|}
\hline \multirow{2}{*}{ Intervalo años } & \multicolumn{2}{|c|}{ Mediana $\left(1 / \mathrm{m}^{2}\right)$} & \multicolumn{2}{|c|}{$\%$} \\
\hline & Anual & MAM & Anual & MAM \\
\hline $1967-2006$ & 107,0 & 111,0 & 100,0 & 100,0 \\
\hline $1967-1979(1083$ I $\vee)$ & 124,7 & 147,9 & 116,5 & 133,2 \\
\hline $1981-1998$ (1083 II §) & 96,1 & 95,3 & 89,8 & 85,9 \\
\hline $1999-2006$ (1083 III Р) & & & & \\
\hline
\end{tabular}


n.a.: No analizado: Número de años disponibles inferior a 10.

De la tabla 11 se observa que las medianas de la pluviometría media anual y MAM en el segundo intersticio de valores (1083 II $\nabla$, de 1981 a 1998) son el $77 \%$ y el $64 \%$ respectivamente de las medianas en el primer periodo (1083 I $\vee$, de 1967 a 1979).

17.7.- El análisis de los datos de precipitación de 1083 revela la importancia de una aplicación conjunta de los 2 tests (Thom y Mann-Kendall) a los 3 intervalos temporales (anual, MAM y AMJ) para detectar inhomogeneidades producidas por cambio de emplazamiento, instrumental, entorno (sin cambio de emplazamiento) y/o de colaborador.

\section{8.- 1093 Carranza:}

18.1.- De los archivos de SS.BB. respecto a los cambio de emplazamiento y/o de colaborador:

18.1.1.- De Noviembre de 1956 a Febrero de 1989 las mediciones se realizan en el patio del Instituto Laboral de Carranza, hasta la jubilación del colaborador (1093 II $\vee$ y 1093 II $\vee$ ).

Informes de 1988 refieren que el pluviómetro estaba "muy mal situado (al alcance de cualquiera)" y "pluviómetro en lamentable estado." "No existía cerrado alrededor del pluviómetro." Asimismo "no anotan las precipitaciones comprendidas entre 0,1 y 0,9 mm.".

Si bien todas las medidas de precipitación se realizaron con el pluviómetro situado en el patio del Instituto, no hay garantía de que el pluviómetro no sufriera cambios bien de emplazamiento bien de entorno en el patio del citado Instituto de Carranza.

18.1.2.- El colaborador al jubilarse traslada el pluviómetro a la terraza del jardín de su casa a unos 500 m. de distancia, midiendo allí de Marzo de 1989 a Enero de 1990 (1093 III P).

18.1.3.- Tras su deceso en Enero de 1990, asume las observaciones un sobrino en el mismo lugar (1093 IV $\nabla$ ). Asimismo, se dota entonces al emplazamiento de una garita meteorológica. El autor ha visto una fotografía de 1990 del pluviómetro en la terraza del citado jardín.

18.1.4.- Entre Enero de 1990 y 1994 hubo un cambio de emplazamiento del pluviómetro, pasando a una ubicación muy protegida aneja a una pared, según muestra una fotografía de 1994 (1093 V P).

18.1.5.- Entre Febrero de 1998 y Julio de 2000 variaron el colaborador y la localización, trasladándose el pluviómetro y la garita al Centro de Iniciativas Turísticas de Carranza (1093 VI P).

18.1.6.- Esto es, hay una certeza de 4 emplazamientos diferentes y de 3 cambios de colaboradores.

18.2.- De los registros de SS.BB. de la Delegación Territorial, se evidencian los siguientes envíos de instrumentación: 
a) 30/10/1983: Pluviómetro, poste y probeta por rotura.

b) 09/1986: Pluviómetro y probeta por rotura.

c) 06/1998: Pluviómetro y termómetro.

d) 04/1999: Termómetro Six - Bellamy.

18.3.- El test de Thom aplicado a la pluviometría media anual y MAM detecta la ruptura de Marzo de 1989 (de (1093 II $\vee$ a 1093 III $\vee$ ). El escrutinio del test de Thom de la pluviosidad media anual aflora la rotura de Octubre de 1983.

De las tablas 1, 2, 14, 15 y 16, los períodos homogéneos en la precipitación anual en el intervalo de 1957 a 1982 (1966 a 1982), en el intervalo de 1957 a 1983 en MAM (1964 a 1983) y en AMJ (1962 a 1983), sugieren un cambio de emplazamiento del pluviómetro dentro del recinto del patio del Instituto, a mediados de la década de los 60.

18.4.- Los datos posteriores a 1983 (1093 II $\vee$ ) no alcanzan una duración mínima de 10 años para aplicar el test de Thom.

18.5.- El escudriñamiento del test de Mann-Kendall de la precipitación media anual revela el cambio de emplazamiento de finales de 1983.

\section{9.- 9077E Ochandiano:}

19.1.- Un paréntesis sin datos de precipitación abarca de Mayo de 1971 a Julio de 1973.

19.2.- En los archivos de SS.BB. figura un cambio de colaborador en Agosto de 1973, al cuál releva su hija en Septiembre de 1990. El autor visita a la última colaboradora el 16 de Diciembre de 2015 y, gracias al hijo de la colaboradora, puede inspeccionar el pluviómetro y su entorno, la huerta trasera de la casa paterna de la colaboradora, al W de la plaza y aneja por el N a la decimonónica bolera del pueblo. De 1973 a 1975 se ubica en la misma huerta, anexo al río.

19.3.- El empleo del test de rachas en la precipitación media anual revela una ruptura entre los registros previos a Mayo de 1971 y los posteriores a Julio de 1973.

19.4- La tabla siguiente refleja las medianas de la precipitación media anual de 9077E 8 para la serie global (1947 a 1965) y para 2 intervalos de datos (anteriores a Mayo de 1971, 9077E I $\vee$ y ulteriores a Julio de 1973, 9077E II \&).

Tabla 12: Medianas de la precipitación media anual de 9077E $\curlyvee$, de la serie global y de los lapsos entre rupturas $(9077 \mathrm{E}$ I $\vee$ y $9077 \mathrm{E}$ II $\vee$ ):

$\begin{array}{rccr} & \text { Intervalo años } & \text { Mediana }\left(1 / \mathrm{m}^{2}\right) & \% \\ 9077 \mathrm{E} \varnothing & 1947-1995 & 123,0 & 100 \\ 9077 \mathrm{E} \text { I } \varnothing & 1947-1969 & 127,1 & 103 \\ \text { 9077E II } \varnothing & 1976-1995 & 112,5 & 91\end{array}$




\subsection{2.- Conclusiones de las rupturas detectadas en las series de precipitación:}

1.- El examen de los registros de datos de precipitación media anual, MAM y AMJ detecta rupturas en 19 de las 33 series estudiadas (el 58\%) (tablas 1, 2 y 3).

En Guipúzcoa, la aplicación de los 2 tests en los intervalos temporales citados refleja roturas en 19 de las 54 series analizadas (el 35\%). (Nota Técnica Nº 13 AEMET, tablas 1, 2 y 3).

El número de rupturas de las series de datos respecto al total de series disponibles en Vizcaya y en la vertiente cantábrica de Álava es superior al de Guipúzcoa.

Estas roturas son debidas a cambios de emplazamiento, de entorno, de instrumental y/o de colaborador.

La figura 10 expone la ubicación de las series de precipitación analizadas, distinguiendo según sean actuales o antiguas, presenten o carezcan de rupturas y éstas sean corroboradas por evidencias.

Figura 10: Resultados de homogeneidad y de ruptura de series:

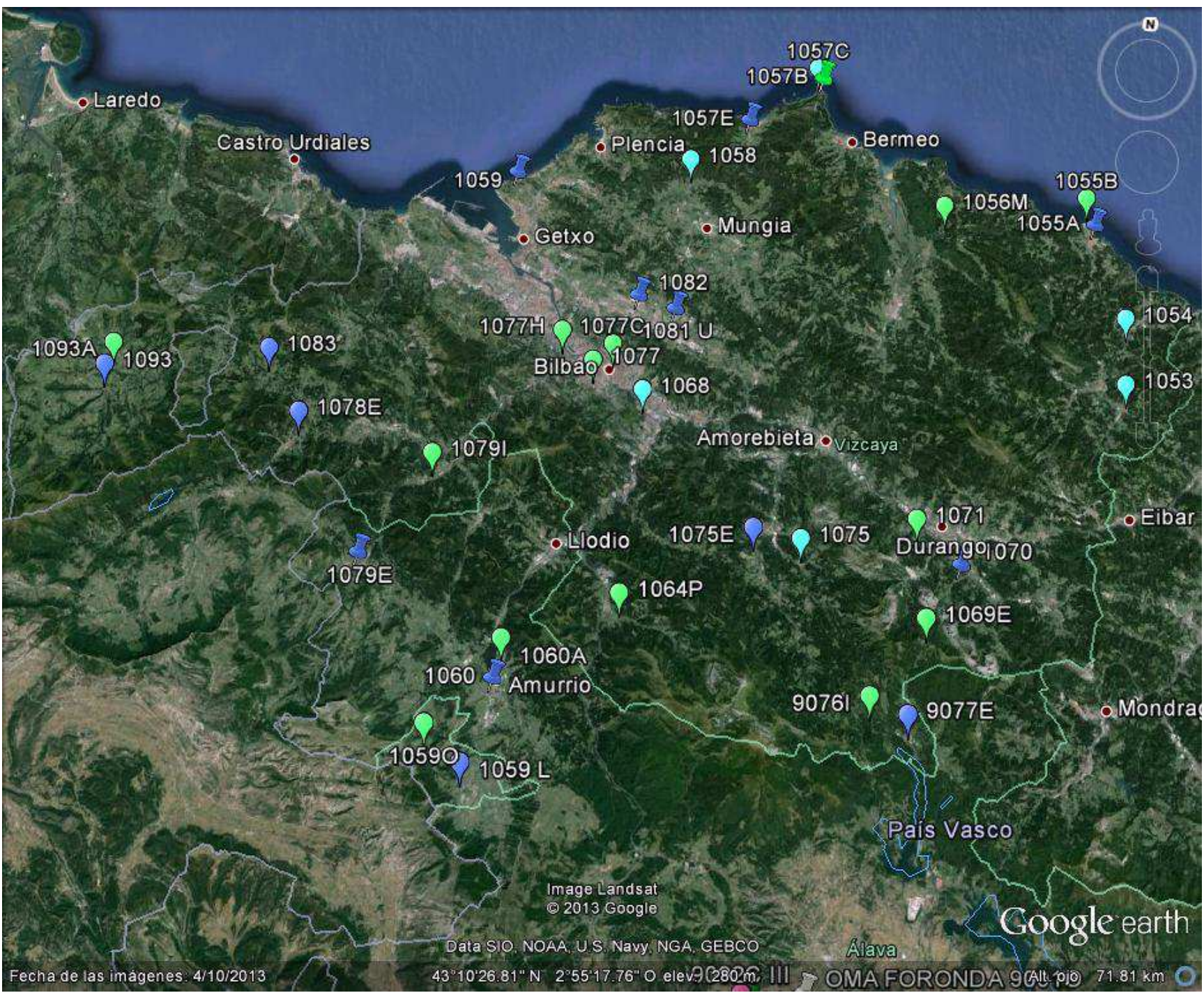




\section{Leyenda:}

Series actuales homogéneas sin indicios de rupturas.

Series antiguas homogéneas sin indicios de rupturas.

Series actuales con rupturas confirmadas por evidencias.

Series antiguas con rupturas confirmadas por evidencias.

Series actuales con rupturas sin evidencias confirmadoras.

Series antiguas con rupturas sin evidencias confirmadoras.

2.- La tabla siguiente compendia la información ya expuesta referida a las rupturas documentadas:

a) Indicativo de la serie de precipitación.

b) Fecha de rotura, precisando el día o el mes cuando hay evidencias de la fecha exacta. Si no, se anota el paréntesis sin datos entre los 2 intervalos de medidas.

c) Cambios de ubicación, separando variaciones inferiores y superiores a $50 \mathrm{~m}$.

d) Diferencias de altitud superiores a $50 \mathrm{~m}$.

e) Modificaciones del entorno.

f) Sustituciones del aparato de medida, indicando si el pluviómetro anterior era del modelo Hellmann.

g) Relevos de colaborador.

h) La antepenúltima fila refleja el número total de rupturas y las sumas parciales debidas a las diferentes causas. Por ejemplo, 10 cambios de ubicación superiores a $50 \mathrm{~m}$ en la horizontal.

i) La penúltima fila expone el \% de rupturas debida a cada causa documentada, diferenciando las mudanzas de ubicación inferiores y superiores a $50 \mathrm{~m} \mathrm{y}$ distinguiendo según el pluviómetro precedente fuera o no Hellman. Verbi gratia, en el $47 \%$ (9 de 19) de las roturas documentadas hay un cambio de colaborador, sin perjuicio de la coexistencia con otras causas de ruptura.

j) La última fila indica el \% de rupturas unificando todas las mudanzas de ubicación y aunando todos los reemplazos de registro de precipitaciones, sin precisar el tipo de pluviómetro antiguo. 
Tabla 13: Documentación de las rupturas de las series de precipitación:

\begin{tabular}{|c|c|c|c|c|c|c|c|c|}
\hline \multirow[t]{2}{*}{ Indicativo } & \multirow[t]{2}{*}{ Fecha Ruptura } & \multicolumn{2}{|c|}{ Ubicación } & \multirow[t]{2}{*}{ Altitud } & \multirow[t]{2}{*}{ Entorno } & \multicolumn{2}{|c|}{$\begin{array}{c}\text { Pluviómetro } \\
\text { antiguo }\end{array}$} & \multirow[t]{2}{*}{ Colaborador } \\
\hline & & $>50 \mathrm{~m}$ & $<50 \mathrm{~m}$ & & & No Hell. & Hell. & \\
\hline $1055 \mathrm{~A}$ & $\begin{array}{l}01-2006 \mathrm{a} \\
05-2006\end{array}$ & & Sí & & Sí & Sí & & \\
\hline $1057 \mathrm{E}$ & $21-05-2009$ & & Sí & & Sí & "Sí & & \\
\hline \multirow{2}{*}{1059} & $\begin{array}{c}01-1927 \mathrm{a} \\
12-1945\end{array}$ & Sí & & & Sí & Sí & & Sí \\
\hline & $\begin{array}{l}09-1969 \mathrm{a} \\
02-1994\end{array}$ & Sí & & & Sí & & Sí & Sí \\
\hline \multirow[t]{2}{*}{ 1059L } & $\begin{array}{l}01-1906 a \\
12-1916\end{array}$ & & & & & Sí & & Sí \\
\hline & $12-1985$ & 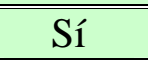 & & & 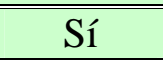 & & "Sí & Sí \\
\hline \multirow{2}{*}{1060} & $12-1966$ & & & & & & & Sí \\
\hline & Fines 1992 & & & & Sí & & & \\
\hline 1070 & $\begin{array}{l}07-2002 \mathrm{a} \\
09-2013\end{array}$ & Sí & & & Sí & & Sí & Sí \\
\hline 1075 & 1926 a 1967 & Sí & & Sí & Sí & & & Sí \\
\hline $1075 \mathrm{E}$ & Fines 1980 & & & & & & Sí & \\
\hline $1078 \mathrm{E}$ & $27-12-1991$ & & & & & & Sí & \\
\hline 1079E & $24-03-2004$ & & & & & Sí & & \\
\hline \multirow{2}{*}{$1081 \mathrm{U}$} & $03-1996$ & Sí & & & Sí & & & \\
\hline & $20 / 25-06-2009$ & Sí & & & Sí & & & \\
\hline \multirow{3}{*}{1082} & $27-11-1984$ & Sí & & & $\overline{\text { Sí }}$ & & & \\
\hline & $16-11-2000$ & Sí & & & Sí & & Sí & Sí \\
\hline & $23-09-2013$ & Sí & & & & & & \\
\hline 1083 & $08-1999$ & Sí & & Sí & Sí & & & \\
\hline 1093 & $30-10-1983$ & & & & & & S Sí & \\
\hline $9077 \mathrm{E}$ & $\begin{array}{c}05-1971 \mathrm{a} \\
07-1973 \\
\end{array}$ & Sí & & & Sí & & & Sí \\
\hline Total & 19 & 12 & 2 & 2 & 14 & 5 & 77 & 99 \\
\hline \% rupturas & & 63 & 11 & 11 & 74 & 26 & 37 & 47 \\
\hline$\%$ rupturas & & \multicolumn{2}{|c|}{74} & 11 & 74 & \multicolumn{2}{|c|}{63} & 47 \\
\hline
\end{tabular}

Notas a la tabla 13:

A) Se conservan evidencias en 14 de las 19 series con rupturas detectadas (74\%), con un total de 19 roturas documentadas debidas a cambios de emplazamiento, de entorno, de instrumental y/o de observador.

B) El cambio de 1060 Amurrio de finales de 1992 es el único en que varía el entorno del pluviómetro, sin traspaso del jardín meteorológico.

C) En el traslado de 1082 Bilbao Aeropuerto del 16 de Noviembre de 2000 se anota una mudanza de colaborador, al pasar las mediciones de manuales a automáticas. 
D) En las rupturas de 1075 Dima de enero de 1926 a Diciembre de 1967 y de 1083 Arcentales de Agosto de 1999 concurren variación de emplazamiento y de altitud.

E) Si bien hay sospechas de que en la ruptura de 9077E $\nabla$ Ochandiano se produjo un cambio de ubicación y de entorno, no se incluye en la tabla 13 al carecer de evidencias.

F) En una rotura coinciden uno o más orígenes: La suma de las rupturas debidas a cada causa diferenciada es superior al total de roturas (antepenúltima fila de la tabla 13).

G) Las principales fuentes evidenciadas de ruptura de series de pluviosidad son: Cambio de ubicación, de entorno y de instrumento de medida; en menor grado afecta el relevo de colaborador.

3.- Se resaltan la trascendencia de:

3.1.- La aplicación conjunta de los 2 tests (Thom y Mann-Kendall) en los 3 intervalos temporales (anual, MAM y AMJ) para descubrir rupturas e inhomogeneidades producidas por modificación del emplazamiento, del entorno (sin cambio de emplazamiento), de la instrumentación, del colaborador o por varios o todos estos factores simultáneamente.

3.2.- Un análisis conjunto de los valores de precipitación de cada serie estudiada con los registros pluviométricos del entorno para esclarecer si una inhomogeneidad es climatológica o no con el objetivo de desvelar las rupturas.

3.3. - Un conocimiento de la información relativa a los cambios (localización, entorno, instrumentación y/o observador) afectadores a la medición de las precipitaciones y la aplicación de dicha cognición antes del examen de las series globales de datos. La carencia del mismo puede concluir en conclusiones espurias de variación de la precipitación (por ejemplo, decremento en 1059 Punta Galea, incremento en 1059L Orduña).

4.- Se observa una concordancia de los resultados obtenidos al escrutar los tests de Thom y de Mann-Kendall la pluviosidad media anual, MAM y AMJ, según reflejan las tablas 1, 2 y 3.

5.- Todas las rupturas conocidas debidas a la variación del enclave, entorno, colaborador y/o instrumental son detectadas en este estudio, denotando la validez, potencia y calidad del método de investigación empleado para descubrir las roturas.

6.- Se destaca de un modo elogioso y encomiástico la excelente labor de documentación y registro de los colaboradores (variación de ubicación, de entorno, instrumentación y/o colaborador) realizada por el jubilado Supervisor de Sistemas Básicos en unión con el resto de la Unidad de Sistemas Básicos.

Todas las roturas de las series actuales reveladas por los tests de Thom y de Mann-Kendall están documentadas por SS.BB.

7.- Las medianas varían, en algunos casos considerablemente, en cada intervalo temporal de las series de precipitaciones con ruptura(s).

8.- El escudriñamiento de las rupturas de las series pluviométricas de Vizcaya y de la vertiente cantábrica de Álava es una primera indicación de su homogeneidad y calidad. 


\section{2.- Intervalos homogéneos en las series de precipitación:}

Las roturas halladas y los intervalos de años entre las rupturas se describen en el precedente apartado 4.1.- "Rupturas detectadas en las series de precipitación", según reflejan las tablas 1, 2 y 3 (páginas 14 a 17).

Las tablas 14, 15 y 16 detallan para cada serie de registros de precipitación media anual, MAM y AMJ:

a) Nombre.

b) Indicativo.

c) Periodo de datos entre rupturas, indicando sus años de comienzo y fin.

Cuando no se detectan rupturas en la serie, se exponen los años de inicio y término de la serie global; si no se alcanzan los 10 años de valores, se deja en blanco.

d) Intervalos de datos homogéneos obtenidos del análisis con el test de Thom.

e) El \% de datos homogéneos al emplear el test de Thom.

f) Lapsos de datos homogéneos derivados del examen del test de Mann-Kendall.

g) El \% de datos homogéneos al aplicar el test de Mann-Kendall.

Los intersticios de valores homogéneos se calculan en los intervalos entre las rupturas de las series. Cuando la serie carece de roturas, se computan respecto a la serie global.

El \% de datos homogéneos se elige el valor superior de:

1.- El \% de años homogéneos en relación al cómputo de años de cada intervalo de la serie (series con rupturas) o respecto al número de años global (sin roturas).

2.- El \% de análisis del test que indican una no homogeneidad referente al número de pruebas realizadas del test. Este criterio se escoge únicamente en los resultados del test de Thom en el estudio de la precipitación media:

2.1.- Anual de 1059 I $\vee$ de 1911 a 1926 y de $1077 \mathrm{C} \vee$ (tabla 14).

2.2.- MAM de 1077C $\vee$ y de 1082 I $\vee($ de 1947 a 1984) (tabla 15).

2.3.- AMJ de 1082 I $\vee($ de 1947 a 1984) (tabla 16).

En la cabecera de las tablas 14, 15 y 16 se denota Mann-Kendall por su abreviatura MK. 
Tabla 14: Resultados tests de homogeneidad de Thom y de Mann- Kendall de las series de datos de precipitación media anual:

\begin{tabular}{|c|c|c|c|c|c|c|}
\hline Nombre & Indicativo & $\begin{array}{l}\text { Periodos entre } \\
\text { rupturas }\end{array}$ & $\begin{array}{c}\text { Periodos } \\
\text { homogéneos } \\
\text { (Thom) }\end{array}$ & $\begin{array}{c}\% \\
\text { Homogéneos } \\
\text { (Thom) }\end{array}$ & $\begin{array}{c}\text { Periodos } \\
\text { homogéneos } \\
(\mathrm{MK})\end{array}$ & $\begin{array}{c}\% \\
\text { Homogéneos } \\
(\mathrm{MK})\end{array}$ \\
\hline Echevarría & 1053 & $\begin{array}{l}1962-1975 \\
1976-1996\end{array}$ & $\begin{array}{l}1962-1975 \\
1976-1994\end{array}$ & $\begin{array}{c}100 \\
90\end{array}$ & $\begin{array}{l}1963-1975 \\
1980-1996\end{array}$ & $\begin{array}{l}93 \\
81\end{array}$ \\
\hline Marquina & 1054 & $1957-1974$ & $1961-1974$ & 82 & $1957-1974$ & 100 \\
\hline Lequeitio & $1055 \mathrm{~A}$ & $1987-2005$ & $1989-2003$ & 73 & $1987-2005$ & 100 \\
\hline $\begin{array}{l}\text { Lequeitio } \\
\text { Faro }\end{array}$ & 1055 & $1913-1926$ & $1913-1926$ & 100 & $1915-1926$ & 82 \\
\hline $\begin{array}{l}\text { Machicaco } \\
\text { Faro Viejo }\end{array}$ & $1057 \mathrm{C}$ & $1922-1933$ & $1922-1933$ & 100 & $1922-1933$ & 100 \\
\hline Baquio & $1057 \mathrm{E}$ & $1987-2007$ & $1987-2007$ & 100 & $1988-2007$ & 94 \\
\hline $\begin{array}{l}\text { Punta } \\
\text { Galea }\end{array}$ & 1059 & $\begin{array}{l}1911-1926 \\
1946-1968 \\
1995-2013\end{array}$ & $\begin{array}{l}1914-1926 \\
1946-1968 \\
1995-2013\end{array}$ & $\begin{array}{r}80 \\
100 \\
100\end{array}$ & $\begin{array}{l}1911-1926 \\
1948-1968 \\
1995-2013\end{array}$ & $\begin{array}{c}100 \\
91 \\
100\end{array}$ \\
\hline Orduña & $1059 \mathrm{~L}$ & $\begin{array}{c}1882-1899 y \\
1905\end{array}$ & $1882-1897$ & 88 & $\begin{array}{c}1882-1899 y \\
1905\end{array}$ & 100 \\
\hline $\begin{array}{l}\text { Amurrio } \\
\text { Instituto }\end{array}$ & 1060 & $\begin{array}{l}1956-1966 \\
1968-1992 \\
1993-2013\end{array}$ & $\begin{array}{l}1956-1966 \\
1968-1992 \\
1993-2013\end{array}$ & $\begin{array}{l}100 \\
100 \\
100\end{array}$ & $\begin{array}{l}1956-1962 \\
1968-1992 \\
1994-2013\end{array}$ & $\begin{array}{c}70 \\
100 \\
95\end{array}$ \\
\hline $\begin{array}{l}\text { Amurrio } \\
\text { Colegio }\end{array}$ & $1060 \mathrm{~A}$ & $1962-1979$ & $1967-1979$ & 79 & $1962-1979$ & 100 \\
\hline Orozco & $1064 \mathrm{P}$ & $1983-1992$ & $1983-1992$ & 100 & $1983-1992$ & 100 \\
\hline Basauri & 1068 & $1955-1978$ & $1955-1977$ & 95 & $1955-1974$ & 83 \\
\hline Urquiola & $1069 \mathrm{E}$ & $1986-2008$ & $1986-2008$ & 100 & $1986-2008$ & 100 \\
\hline Abadiano & 1070 & $1968-2001$ & $1970-1996$ & 78 & $1968-2001$ & 100 \\
\hline Durango & 1071 & $1968-1993$ & $1968-1983$ & 64 & $1968-1993$ & 100 \\
\hline Dima & 1075 & $1968-1977$ & $1968-1977$ & 100 & $1968-1977$ & 100 \\
\hline Aránzazu & $1075 \mathrm{E}$ & $\begin{array}{l}1968-1979 \\
1982-2006\end{array}$ & $\begin{array}{l}1968-1979 \\
1982-2006\end{array}$ & 100 & $\begin{array}{l}1968-1979 \\
1982-2006\end{array}$ & 100 \\
\hline
\end{tabular}


Tabla 14 (continuación): Resultados tests de homogeneidad de Thom y de Mann - Kendall de las series de datos de precipitación media anual:

\begin{tabular}{|c|c|c|c|c|c|c|}
\hline Nombre & Indicativo & $\begin{array}{l}\text { Periodos entre } \\
\text { rupturas }\end{array}$ & $\begin{array}{c}\text { Periodos } \\
\text { homogéneos } \\
\text { (Thom) }\end{array}$ & $\begin{array}{c}\% \\
\text { Homogéneos } \\
\text { (Thom) }\end{array}$ & $\begin{array}{c}\text { Periodos } \\
\text { homogéneos } \\
(\mathrm{MK})\end{array}$ & $\begin{array}{c}\% \\
\text { Homogéneos } \\
(\mathrm{MK})\end{array}$ \\
\hline $\begin{array}{l}\text { Bilbao } \\
\text { Histórica }\end{array}$ & $1077 \mathrm{C}$ & $1859-1919$ & $1859-1914$ & 93 & $1859-1919$ & 100 \\
\hline Valmaseda & $1078 \mathrm{E}$ & $\begin{array}{l}1972-1991 \\
1992-2007\end{array}$ & $\begin{array}{l}1972-1987 \\
1992-2007\end{array}$ & $\begin{array}{r}79 \\
100\end{array}$ & $\begin{array}{l}1973-1991 \\
1993-2007\end{array}$ & $\begin{array}{l}95 \\
93\end{array}$ \\
\hline Arceniega & $1079 \mathrm{E}$ & $1987-2003$ & $1988-2003$ & 100 & $1988-2003$ & 100 \\
\hline Gordejuela & 1079I & $1973-1988$ & $1974-1988$ & 93 & $1973-1986$ & 86 \\
\hline $\begin{array}{l}\text { Derio } \\
\text { Neiker }\end{array}$ & $1081 \mathrm{U}$ & $1996-2008$ & $1996-2008$ & 100 & $1997-2008$ & 90 \\
\hline $\begin{array}{l}\text { Bilbao } \\
\text { Aeropuerto }\end{array}$ & 1082 & $\begin{array}{l}1948-1984 \\
1985-1999 \\
2002-2013\end{array}$ & $\begin{array}{l}1948-1984 \\
1985-1999 \\
2002-2013\end{array}$ & $\begin{array}{l}100 \\
100 \\
100\end{array}$ & $\begin{array}{l}1950-1984 \\
1985-1999 \\
2002-2013\end{array}$ & $\begin{array}{c}95 \\
100 \\
100\end{array}$ \\
\hline Arcentales & 1083 & $\begin{array}{l}1968-1979 \\
1982-1998\end{array}$ & $\begin{array}{l}1968-1979 \\
1982-1998\end{array}$ & $\begin{array}{l}100 \\
100\end{array}$ & $\begin{array}{l}1970-1977 \\
1984-1998\end{array}$ & $\begin{array}{l}64 \\
87\end{array}$ \\
\hline Carranza & 1093 & $1957-1983$ & $1957-1983$ & 100 & $1966-1983$ & 68 \\
\hline Carranza & $1093 \mathrm{~A}$ & $1975-1988$ & $1975-1988$ & 100 & $1977-1988$ & 92 \\
\hline Ochandiano & $9077 \mathrm{E}$ & $\begin{array}{l}1947-1969 \\
1976-1995\end{array}$ & $\begin{array}{l}1956-1969 \\
1976-1995\end{array}$ & $\begin{array}{r}64 \\
100\end{array}$ & $\begin{array}{l}1950-1969 \\
1976-1989\end{array}$ & $\begin{array}{l}91 \\
71\end{array}$ \\
\hline
\end{tabular}

Notas:

1.- 1075E I $\vee$ Aránzazu no alcanza un mínimo de 10 años de registros de precipitación media anual en el intervalo de 1968 a 1979.

2.- La homogeneidad de las series de precipitación media anual de Vizcaya y de la vertiente cantábrica de Álava es elevada, alcanzando valores óptimos en algunos casos.

3.- La inhomogeneidad descubierta en 1059 I $\nabla$ Punta Galea Faro (de 1911 a 1926) se examina en el apartado 4.3.- "Análisis evolución temporal de inhomogeneidades", donde se demuestra que es "climatológica”, página 56. 
Tabla 15: Resultados tests de homogeneidad de Thom y de Mann - Kendall de las series de datos de precipitación media MAM:

\begin{tabular}{|c|c|c|c|c|c|c|}
\hline Nombre & Indicativo & $\begin{array}{l}\text { Periodos entre } \\
\text { rupturas }\end{array}$ & $\begin{array}{c}\text { Periodos } \\
\text { homogéneos } \\
(\text { Thom })\end{array}$ & $\begin{array}{c}\% \\
\text { Homogéneos } \\
\text { (Thom) }\end{array}$ & $\begin{array}{c}\text { Periodos } \\
\text { homogéneos } \\
(\mathrm{MK})\end{array}$ & $\begin{array}{c}\% \\
\text { Homogéneos } \\
(\mathrm{MK})\end{array}$ \\
\hline Echevarría & 1053 & $\begin{array}{l}1962-1975 \\
1976-1996\end{array}$ & $\begin{array}{l}1962-1975 \\
1979-1996\end{array}$ & $\begin{array}{c}100 \\
86\end{array}$ & $\begin{array}{l}1962-1975 \\
1976-1995\end{array}$ & $\begin{array}{c}100 \\
95\end{array}$ \\
\hline Marquina & 1054 & $1957-1976$ & $1958-1974$ & 89 & $1958-1976$ & 94 \\
\hline Lequeitio & $1055 \mathrm{~A}$ & $1987-2005$ & $1987-2005$ & 100 & $1987-2005$ & 100 \\
\hline $\begin{array}{l}\text { Lequeitio } \\
\text { Faro }\end{array}$ & 1055 & $1913-1926$ & $1913-1926$ & 100 & $1917-1926$ & 67 \\
\hline Arteaga & $1056 \mathrm{M}$ & $1991-2000$ & $1991-2000$ & 100 & $1991-2000$ & 100 \\
\hline $\begin{array}{l}\text { Machicaco } \\
\text { Faro Viejo }\end{array}$ & $1057 \mathrm{C}$ & $1922-1933$ & $1922-1932$ & 91 & $1922-1933$ & 100 \\
\hline Baquio & $1057 \mathrm{E}$ & $1987-2009$ & $1987-2009$ & 100 & $1987-2009$ & 100 \\
\hline $\begin{array}{l}\text { Punta } \\
\text { Galea }\end{array}$ & 1059 & $\begin{array}{l}1911-1926 \\
1946-1969 \\
1994-2013\end{array}$ & $\begin{array}{l}1911-1926 \\
1949-1969 \\
1994-2013\end{array}$ & $\begin{array}{c}100 \\
88 \\
100\end{array}$ & $\begin{array}{l}1912-1926 \\
1946-1969 \\
1995-2013\end{array}$ & $\begin{array}{c}93 \\
100 \\
95\end{array}$ \\
\hline Orduña & $1059 \mathrm{~L}$ & $\begin{array}{c}1881-1899 y \\
1905\end{array}$ & $\begin{array}{c}1881-1899 y \\
1905\end{array}$ & 100 & $\begin{array}{c}1884-1899 y \\
1905\end{array}$ & 85 \\
\hline Lendoño & 10590 & $1986-1995$ & $1986-1995$ & 100 & $1986-1995$ & 100 \\
\hline $\begin{array}{l}\text { Amurrio } \\
\text { Instituto }\end{array}$ & 1060 & $\begin{array}{l}1956-1966 \\
1967-1992 \\
1993-2013\end{array}$ & $\begin{array}{l}1969-1992 \\
1993-2013\end{array}$ & $\begin{array}{r}0 \\
92 \\
100\end{array}$ & $\begin{array}{l}1956-1966 \\
1967-1992 \\
1993-2013\end{array}$ & $\begin{array}{l}100 \\
100 \\
100\end{array}$ \\
\hline $\begin{array}{l}\text { Amurrio } \\
\text { Colegio }\end{array}$ & $1060 \mathrm{~A}$ & $1962-1979$ & $1962-1976$ & 82 & $1965-1979$ & 82 \\
\hline Orozco & $1064 \mathrm{P}$ & $1983-1992$ & $1983-1992$ & 100 & $1983-1992$ & 100 \\
\hline Basauri & 1068 & $1955-1979$ & $1955-1979$ & 100 & $1955-1979$ & 100 \\
\hline Urquiola & $1069 \mathrm{E}$ & $1986-2008$ & $1988-2008$ & 85 & $1986-2008$ & 100 \\
\hline Abadiano & 1070 & $1968-2002$ & $1969-2002$ & 94 & $1968-2002$ & 100 \\
\hline Durango & 1071 & $1968-1993$ & $1968-1993$ & 100 & $1968-1993$ & 100 \\
\hline
\end{tabular}


Tabla 15 (continuación): Resultados tests de homogeneidad de Thom y de Mann - Kendall de las series de datos de precipitación media MAM:

\begin{tabular}{|c|c|c|c|c|c|c|}
\hline Nombre & Indicativo & $\begin{array}{l}\text { Periodos entre } \\
\text { rupturas }\end{array}$ & $\begin{array}{c}\text { Periodos } \\
\text { homogéneos } \\
\text { (Thom) }\end{array}$ & $\begin{array}{c}\% \\
\text { Homogéneo } \\
\text { s (Thom) }\end{array}$ & $\begin{array}{c}\text { Periodos } \\
\text { homogéneos } \\
(\mathrm{MK})\end{array}$ & $\begin{array}{c}\% \\
\text { Homogéneos } \\
(\mathrm{MK})\end{array}$ \\
\hline Dima & 1075 & $1968-1978$ & $1969-1978$ & 91 & $1968-1978$ & 100 \\
\hline Aránzazu & $1075 \mathrm{E}$ & $\begin{array}{l}1968-1980 \\
1981-2006\end{array}$ & $\begin{array}{l}1968-1980 \\
1982-2004\end{array}$ & $\begin{array}{c}100 \\
96\end{array}$ & $\begin{array}{l}1969-1980 \\
1981-2006\end{array}$ & $\begin{array}{c}92 \\
100\end{array}$ \\
\hline Larrasquitu & 1077 & $\begin{array}{c}1925-1931 \mathrm{y} \\
1941-1945\end{array}$ & $\begin{array}{c}1925-1931 y \\
1941-1945\end{array}$ & 100 & $\begin{array}{c}1925-1931 y \\
1941-1944\end{array}$ & 92 \\
\hline $\begin{array}{l}\text { Bilbao } \\
\text { Histórica }\end{array}$ & $1077 \mathrm{C}$ & $1859-1920$ & $1859-1920$ & 76 & $1859-1920$ & 100 \\
\hline $\begin{array}{l}\text { Bilbao } \\
\text { Labein }\end{array}$ & $1077 \mathrm{H}$ & $1987-1997$ & $1987-1997$ & 100 & $1987-1997$ & 100 \\
\hline Valmaseda & $1078 \mathrm{E}$ & $\begin{array}{l}1972-1991 \\
1992-2007\end{array}$ & $\begin{array}{l}1972-1991 \\
1992-2007\end{array}$ & $\begin{array}{l}100 \\
100\end{array}$ & $\begin{array}{l}1972-1991 \\
1993-2007\end{array}$ & $\begin{array}{c}100 \\
94\end{array}$ \\
\hline Arceniega & $1079 \mathrm{E}$ & $\begin{array}{l}1987-2003 \\
2004-2013\end{array}$ & $\begin{array}{l}1987-2003 \\
2004-2013\end{array}$ & $\begin{array}{l}100 \\
100\end{array}$ & $\begin{array}{l}1987-2003 \\
2004-2013\end{array}$ & $\begin{array}{l}100 \\
100\end{array}$ \\
\hline Gordejuela & $1079 \mathrm{I}$ & $1973-1988$ & $1973-1988$ & 100 & $1973-1986$ & 87 \\
\hline $\begin{array}{l}\text { Derio } \\
\text { Neiker }\end{array}$ & $1081 \mathrm{U}$ & $1996-2009$ & $1998-2009$ & 86 & $1997-2009$ & 93 \\
\hline $\begin{array}{l}\text { Bilbao } \\
\text { Aeropuerto }\end{array}$ & 1082 & $\begin{array}{l}1947-1984 \\
1985-2000 \\
2001-2013\end{array}$ & $\begin{array}{l}1947-1984 \\
1986-2000 \\
2001-2013\end{array}$ & $\begin{array}{r}79 \\
94 \\
100\end{array}$ & $\begin{array}{l}1948-1976 \\
1985-2000 \\
2004-2013\end{array}$ & $\begin{array}{c}76 \\
100 \\
77\end{array}$ \\
\hline Arcentales & 1083 & $\begin{array}{l}1968-1979 \\
1981-1999\end{array}$ & $\begin{array}{l}1968-1979 \\
1981-1999\end{array}$ & $\begin{array}{l}100 \\
100\end{array}$ & $\begin{array}{l}1970-1979 \\
1982-1999\end{array}$ & $\begin{array}{l}83 \\
94\end{array}$ \\
\hline Carranza & 1093 & $1957-1983$ & $1963-1983$ & 78 & $1964-1983$ & 74 \\
\hline Carranza & $1093 \mathrm{~A}$ & $1972-1989$ & $1972-1989$ & 100 & $1972-1989$ & 100 \\
\hline Ceanuri & $9076 \mathrm{I}$ & $\begin{array}{c}1947 \\
1968-1972 \text { y } \\
1983-1986\end{array}$ & $\begin{array}{c}1947, \\
1968-1972 \text { y } \\
1983-1986\end{array}$ & 100 & $\begin{array}{c}1968-1972 y \\
1983-1986\end{array}$ & 90 \\
\hline Ochandiano & $9077 \mathrm{E}$ & $\begin{array}{l}1947-1970 \\
1974-1995\end{array}$ & $\begin{array}{l}1956-1970 \\
1974-1995\end{array}$ & $\begin{array}{c}63 \\
100\end{array}$ & $\begin{array}{l}1947-1970 \\
1974-1995\end{array}$ & $\begin{array}{l}100 \\
100\end{array}$ \\
\hline
\end{tabular}

\section{Nota:}

Las inhomogeneidades detectadas en $1077 \mathrm{C}$ y en 1082 se analizan respectivamente en las páginas 82 a 86, 90 a 92 y 96 a 100, en donde se razona su índole "climatológica". 
Tabla 16: Resultados tests de homogeneidad de Thom y de Mann - Kendall de las series de datos de precipitación media AMJ:

\begin{tabular}{|c|c|c|c|c|c|c|}
\hline Nombre & Indicativo & $\begin{array}{l}\text { Periodos entre } \\
\text { rupturas }\end{array}$ & $\begin{array}{c}\text { Periodos } \\
\text { homogéneos } \\
\text { (Thom) }\end{array}$ & $\begin{array}{c}\% \\
\text { Homogéneo } \\
\text { s (Thom) }\end{array}$ & $\begin{array}{c}\text { Periodos } \\
\text { homogéneos } \\
(\mathrm{MK})\end{array}$ & $\begin{array}{c}\% \\
\text { Homogéneos } \\
(\mathrm{MK})\end{array}$ \\
\hline Echevarría & 1053 & $\begin{array}{l}1962-1975 \\
1976-1996\end{array}$ & $\begin{array}{l}1962-1974 \\
1976-1996\end{array}$ & $\begin{array}{c}93 \\
100\end{array}$ & $\begin{array}{l}1962-1975 \\
1976-1996\end{array}$ & $\begin{array}{l}100 \\
100\end{array}$ \\
\hline Marquina & 1054 & $1957-1976$ & $1958-1976$ & 94 & $1958-1976$ & 94 \\
\hline Lequeitio & $1055 \mathrm{~A}$ & $1986-2005$ & $1986-2005$ & 100 & $1986-2004$ & 94 \\
\hline $\begin{array}{l}\text { Lequeitio } \\
\text { Faro }\end{array}$ & 1055 & $1913-1926$ & $1914-1926$ & 92 & $1914-1926$ & 92 \\
\hline Arteaga & $1056 \mathrm{M}$ & $1991-2000$ & $1991-2000$ & 100 & $1991-2000$ & 100 \\
\hline $\begin{array}{c}\text { Machicaco } \\
\text { Faro }\end{array}$ & $1057 \mathrm{~B}$ & $1999-2013$ & $1999-2013$ & 100 & $1999-2013$ & 100 \\
\hline $\begin{array}{l}\text { Machicaco } \\
\text { Faro Viejo }\end{array}$ & $1057 \mathrm{C}$ & $1922-1933$ & $1922-1933$ & 100 & $1922-1933$ & 100 \\
\hline Baquio & $1057 \mathrm{E}$ & $1986-2007$ & $1986-2007$ & 100 & $1986-2006$ & 95 \\
\hline $\begin{array}{l}\text { Punta } \\
\text { Galea }\end{array}$ & 1059 & $\begin{array}{l}1911-1926 \\
1946-1969 \\
1994-2013\end{array}$ & $\begin{array}{l}1911-1924 \\
1948-1967 \\
1998-2008\end{array}$ & $\begin{array}{l}93 \\
83 \\
55\end{array}$ & $\begin{array}{l}1914-1926 \\
1946-1969 \\
1994-2013\end{array}$ & $\begin{array}{r}79 \\
100 \\
100\end{array}$ \\
\hline Orduña & $1059 \mathrm{~L}$ & $\begin{array}{c}1881-1899 \mathrm{y} \\
1905\end{array}$ & $\begin{array}{c}1881-1899 \mathrm{y} \\
1905\end{array}$ & 100 & $\begin{array}{c}1881-1899 \mathrm{y} \\
1905\end{array}$ & 100 \\
\hline Lendoño & 10590 & $1986-1995$ & $1986-1995$ & 100 & $1986-1995$ & 100 \\
\hline $\begin{array}{l}\text { Amurrio } \\
\text { Instituto }\end{array}$ & 1060 & $\begin{array}{l}1956-1966 \\
1968-1992 \\
1993-2013\end{array}$ & $\begin{array}{l}1956-1966 \\
1969-1989 \\
1993-2008\end{array}$ & $\begin{array}{r}100 \\
84 \\
76\end{array}$ & $\begin{array}{l}1956-1966 \\
1968-1992 \\
1993-2013\end{array}$ & $\begin{array}{l}100 \\
100 \\
100\end{array}$ \\
\hline $\begin{array}{l}\text { Amurrio } \\
\text { Colegio }\end{array}$ & $1060 \mathrm{~A}$ & $1962-1979$ & $1965-1979$ & 83 & $1965-1979$ & 83 \\
\hline Orozco & $1064 \mathrm{P}$ & $1983-1992$ & $1983-1992$ & 100 & $1983-1991$ & 90 \\
\hline Basauri & 1068 & $1955-1979$ & $1961-1979$ & 76 & $1955-1979$ & 100 \\
\hline Urquiola & $1069 \mathrm{E}$ & $1986-2008$ & $1986-2008$ & 100 & $1987-2008$ & 92 \\
\hline
\end{tabular}


Tabla 16 (continuación): Resultados tests de homogeneidad de Thom y de Mann - Kendall de las series de datos de precipitación media AMJ:

\begin{tabular}{|c|c|c|c|c|c|c|}
\hline Nombre & Indicativo & $\begin{array}{l}\text { Periodos entre } \\
\text { rupturas }\end{array}$ & $\begin{array}{c}\text { Periodos } \\
\text { homogéneos } \\
\text { (Thom) }\end{array}$ & $\begin{array}{c}\% \\
\text { Homogéneo } \\
\text { s (Thom) }\end{array}$ & $\begin{array}{c}\text { Periodos } \\
\text { homogéneos } \\
(\mathrm{MK})\end{array}$ & $\begin{array}{c}\% \\
\text { Homogéneos } \\
(\mathrm{MK})\end{array}$ \\
\hline Abadiano & 1070 & $1968-2002$ & $1975-2002$ & 80 & $1968-2002$ & 100 \\
\hline Durango & 1071 & $1968-1993$ & $1968-1993$ & 100 & $1968-1993$ & 100 \\
\hline Dima & 1075 & $1968-1977$ & $1968-1977$ & 100 & $1968-1977$ & 100 \\
\hline Aránzazu & $1075 \mathrm{E}$ & $\begin{array}{l}1968-1980 \\
1981-2006\end{array}$ & $\begin{array}{l}1968-1980 \\
1981-2006\end{array}$ & $\begin{array}{l}100 \\
100\end{array}$ & $\begin{array}{l}1968-1980 \\
1983-2004\end{array}$ & $\begin{array}{c}100 \\
88\end{array}$ \\
\hline Larrasquitu & 1077 & $\begin{array}{c}1925-1931 \mathrm{y} \\
1941-1945\end{array}$ & $\begin{array}{c}1925-1931 y \\
1941-1945\end{array}$ & 100 & $\begin{array}{c}1925-1931 \mathrm{y} \\
1941-1945\end{array}$ & 100 \\
\hline $\begin{array}{l}\text { Bilbao } \\
\text { Histórica }\end{array}$ & $1077 \mathrm{C}$ & $1859-1920$ & $1859-1920$ & 100 & $1867-1920$ & 97 \\
\hline $\begin{array}{l}\text { Bilbao } \\
\text { Labein }\end{array}$ & $1077 \mathrm{H}$ & $1987-1997$ & $1987-1997$ & 100 & $1987-1997$ & 100 \\
\hline Valmaseda & $1078 \mathrm{E}$ & $\begin{array}{l}1972-1991 \\
1992-2007\end{array}$ & $\begin{array}{l}1972-1991 \\
1992-2002\end{array}$ & $\begin{array}{c}100 \\
69\end{array}$ & $\begin{array}{l}1972-1991 \\
1992-2007\end{array}$ & $\begin{array}{l}100 \\
100\end{array}$ \\
\hline Arceniega & $1079 \mathrm{E}$ & $\begin{array}{l}1986-2003 \\
2004-2013\end{array}$ & $\begin{array}{l}1986-2003 \\
2004-2013\end{array}$ & $\begin{array}{l}100 \\
100\end{array}$ & $\begin{array}{l}1986-2003 \\
2004-2013\end{array}$ & $\begin{array}{l}100 \\
100\end{array}$ \\
\hline Gordejuela & 1079I & $1973-1988$ & $1973-1988$ & 100 & $1973-1986$ & 87 \\
\hline $\begin{array}{l}\text { Derio } \\
\text { Neiker }\end{array}$ & $1081 \mathrm{U}$ & $1996-2009$ & $1996-2007$ & 85 & $1996-2009$ & 100 \\
\hline $\begin{array}{c}\text { Bilbao } \\
\text { Aeropuerto }\end{array}$ & 1082 & $\begin{array}{l}1947-1984 \\
1985-2000 \\
2001-2013\end{array}$ & $\begin{array}{l}1947-1984 \\
1985-2000\end{array}$ & $\begin{array}{r}94 \\
100 \\
0\end{array}$ & $\begin{array}{l}1948-1984 \\
1986-2000 \\
2001-2013\end{array}$ & $\begin{array}{c}97 \\
94 \\
100\end{array}$ \\
\hline Arcentales & 1083 & $\begin{array}{l}1968-1979 \\
1981-1999\end{array}$ & $\begin{array}{l}1968-1979 \\
1981-1999\end{array}$ & $\begin{array}{l}100 \\
100\end{array}$ & $\begin{array}{l}1969-1979 \\
1981-1999\end{array}$ & $\begin{array}{c}92 \\
100\end{array}$ \\
\hline Carranza & 1093 & $1957-1983$ & $1965-1983$ & 73 & $1962-1983$ & 85 \\
\hline Carranza & $1093 \mathrm{~A}$ & $1972-1989$ & $1972-1989$ & 100 & $1972-1989$ & 100 \\
\hline Ceanuri & $9076 \mathrm{I}$ & $\begin{array}{c}1947,1968- \\
1972 \text { y } 1983- \\
1986\end{array}$ & $\begin{array}{c}1947, \\
1968-1972 \text { y } \\
1983-1986\end{array}$ & 100 & $\begin{array}{c}1968-1972 y \\
1983-1986\end{array}$ & 90 \\
\hline Ochandiano & $9077 \mathrm{E}$ & $\begin{array}{l}1947-1970 \\
1976-1995\end{array}$ & $\begin{array}{l}1947-1970 \\
1976-1995\end{array}$ & $\begin{array}{l}100 \\
100\end{array}$ & $\begin{array}{l}1948-1970 \\
1980-1995\end{array}$ & $\begin{array}{l}96 \\
79\end{array}$ \\
\hline
\end{tabular}




\section{$\underline{\text { Notas: }}$}

1.- La inhomogeneidad revelada en 1082 III (de 2001 a 2013) en AMJ (tabla 16) se estudia en el apartado 4.3.1.- "Análisis de la evolución temporal de las inhomogeneidades del test de Thom aplicado a la precipitación media en Abril, Mayo y Junio", en el cuál se prueba que es "climatológica” (páginas 122 y 123).

2.- De las tablas 14,15 y 16 se aprecia una excelente homogeneidad de las series de pluviosidad de Vizcaya y de la vertiente cantábrica de Álava.

3.- La tabla 16 bis expone meses sin datos pluviométricos de las series descritas en las tablas 14,15 y 16.

Tabla 16 bis: Ausencias de registros de precipitación:

$\begin{array}{cc}\text { Nombre } & \text { Indicativo } \\ \text { Lequeitio } & 1055 \mathrm{~A} \\ \text { Machicaco Faro Viejo } & 1057 \mathrm{C} \\ \text { Baquio } & 1057 \mathrm{E} \\ \text { Amurrio Instituto } & 1060 \\ \text { Aránzazu } & 1075 \mathrm{E} \\ \text { Arceniega } & 1079 \mathrm{E} \\ \text { Bilbao Aeropuerto } & 1082 \\ \text { Arcentales } & 1083 \\ & \\ \text { Ochandiano } & 9077 \mathrm{E}\end{array}$

\author{
Meses sin datos \\ Enero 2006 a Mayo 2006 \\ Noviembre 1921 \\ Junio 2008 \\ Mayo 1964, Junio 1967
}

Agosto 1969, Febrero 1970, Agosto 1976, Enero 1977,

Septiembre 1978, Septiembre 1980 a Enero 1981

Octubre 1987, Noviembre 2004

Noviembre 2000 a Enero 2001

Marzo 1980 a Enero 1981

Enero de 1970, Mayo 1971 a Julio de 1973, Junio y

Septiembre de 1974, Febrero a Junio 1975,

Septiembre a Diciembre 1975.

4.- En el siguiente apartado se escudriñan pormenorizadamente las inhomogeneidades afloradas por los tests de Thom y de Mann-Kendall en las series de precipitación media anual, MAM y AMJ. 


\section{3.- Análisis de la evolución temporal de las inhomogeneidades:}

El examen de la evolución temporal de las inhomogeneidades detectadas con los tests de Thom y de Mann-Kendall en las series de pluviosidad media anual, MAM y AMJ se realiza teniendo en cuenta los resultados del apartado 4.1. "Rupturas detectadas en las series de precipitación”.

El estudio pormenorizado de dicha evolución tiene como finalidad el análisis y la clasificación de las inhomogeneidades reveladas en los registros pluviométricos.

\subsection{1.- Evolución temporal de las inhomogeneidades del test de Thom:}

Las tablas 17, 33 y 50 (páginas 50, 79 y 108) ilustran para la precipitación media anual, MAM y AMJ:

a) Los intervalos de inhomogeneidades.

b) Los indicativos de las series.

c) El origen de la inhomogeneidad:

Climatológico (debida a variaciones atmosféricas) o no climatológico (cambios de emplazamiento, de entorno, de colaborador y/o de instrumentación, ausencia de datos...).

d) La última columna indica el \% de series en que la inhomogeneidad se revela respecto al total de series analizadas en cada intervalo de años.

Un intervalo describe los valores extremos del \% en dicho intersticio de años. Un número entre paréntesis indica el total de series estudiadas, cuando éste es escaso.

En las tablas 17, 33 y 50 se representan las inhomogeneidades en un lapso de 10 años. Así, una inhomogeneidad en 1906 abarca de 1906 a 1915.

Cuando aparecen lagunas en las series (como en 1054 Marquina) el periodo de la inhomogeneidad se amplía hasta alcanzar 10 años consecutivos de datos.

Por brevedad, las tablas 17, 33 y 50 agrupan en la columna de la izquierda los intervalos de solape de las inhomogeneidades y en la columna de la derecha se aúnan el \% de series. 


\subsubsection{1.- Evolución temporal de las inhomogeneidades del test de Thom aplicado a la precipitación media anual:}

Debido al extenso intervalo temporal escrutado (de 1859 a 2013) y al exiguo número de series anteriores a 1940 (inferior a 6 simultáneas), la evolución temporal de las inhomogeneidades se analiza en 2 tramos: de 1859 a 1940 y de 1941 a 2013.

Al aplicar el test de las rachas de Thom se considera un periodo de 10 años de datos consecutivos. Cuando aparecen lagunas en las series (como en 1078E Valmaseda) el periodo se amplía hasta alcanzar 10 años consecuentes de valores.

Las gráficas 7 y 8 revelan las inhomogeneidades descubiertas en un intersticio de 10 años sucesivos. Así, una inhomogeneidad manifestada en 1981 en una serie sin lagunas abarca de 1981 a 1990. Si hay una laguna en 1988, una inhomogeneidad en 1981 engloba de 1981 a 1991.

La gráfica 7 denota la evolución temporal de las inhomogeneidades afloradas por el test de las rachas en la precipitación media anual de 1859 a 1940.

Gráfica 7: Evolución temporal de las inhomogeneidades del análisis del test de Thom de las series de precipitación media anual de 1859 a 1940:

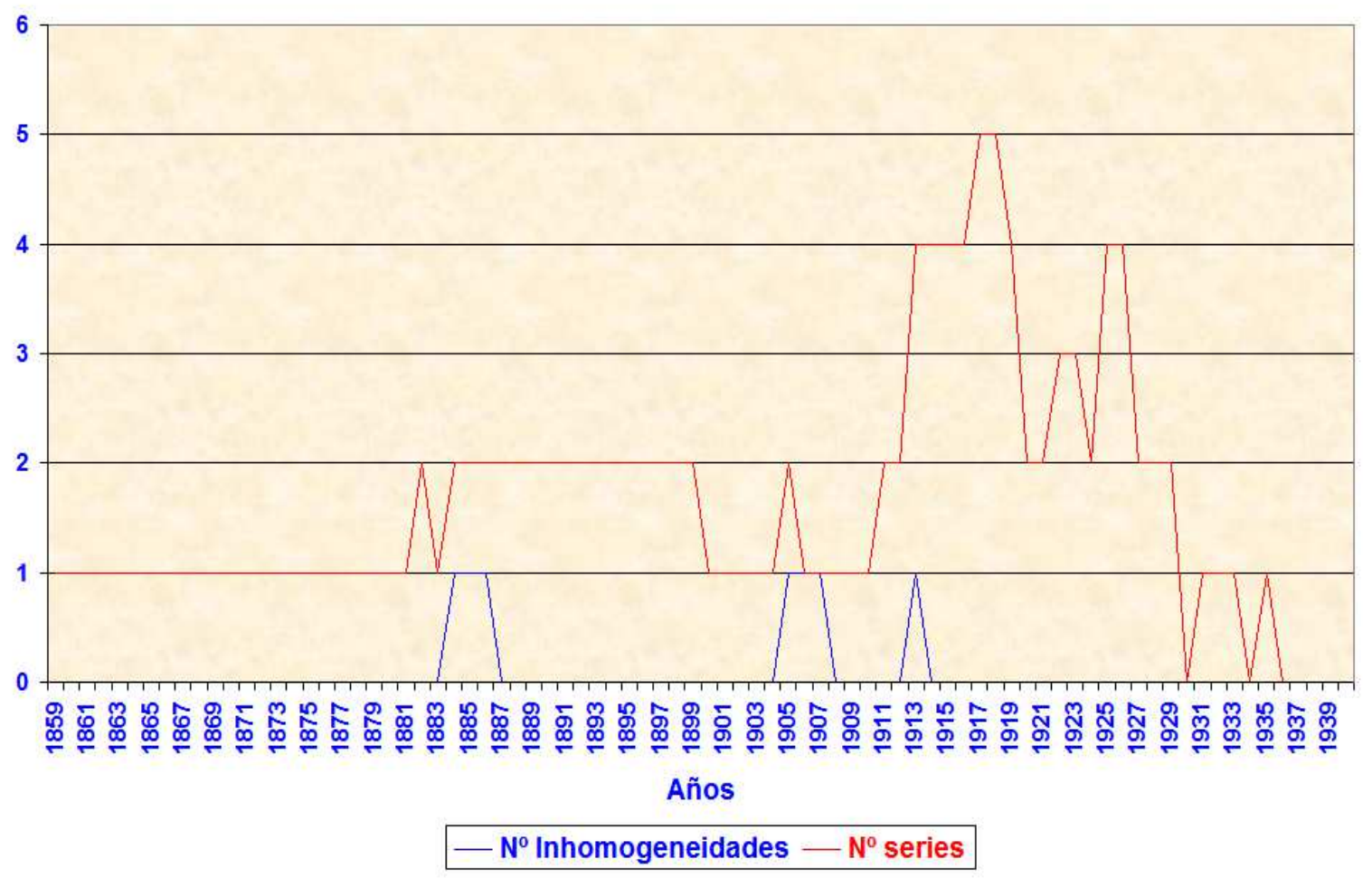

De la gráfica 7 se observa una homogeneidad muy buena de los datos pluviométricos existentes del siglo XIX.

La gráfica 8 muestra la evolución temporal de las inhomogeneidades detectadas por el test de las rachas en la precipitación media anual de 1941 a 2013. 
Gráfica 8: Evolución temporal de las inhomogeneidades del análisis del test de Thom de las series de precipitación media anual de 1941 a 2013:

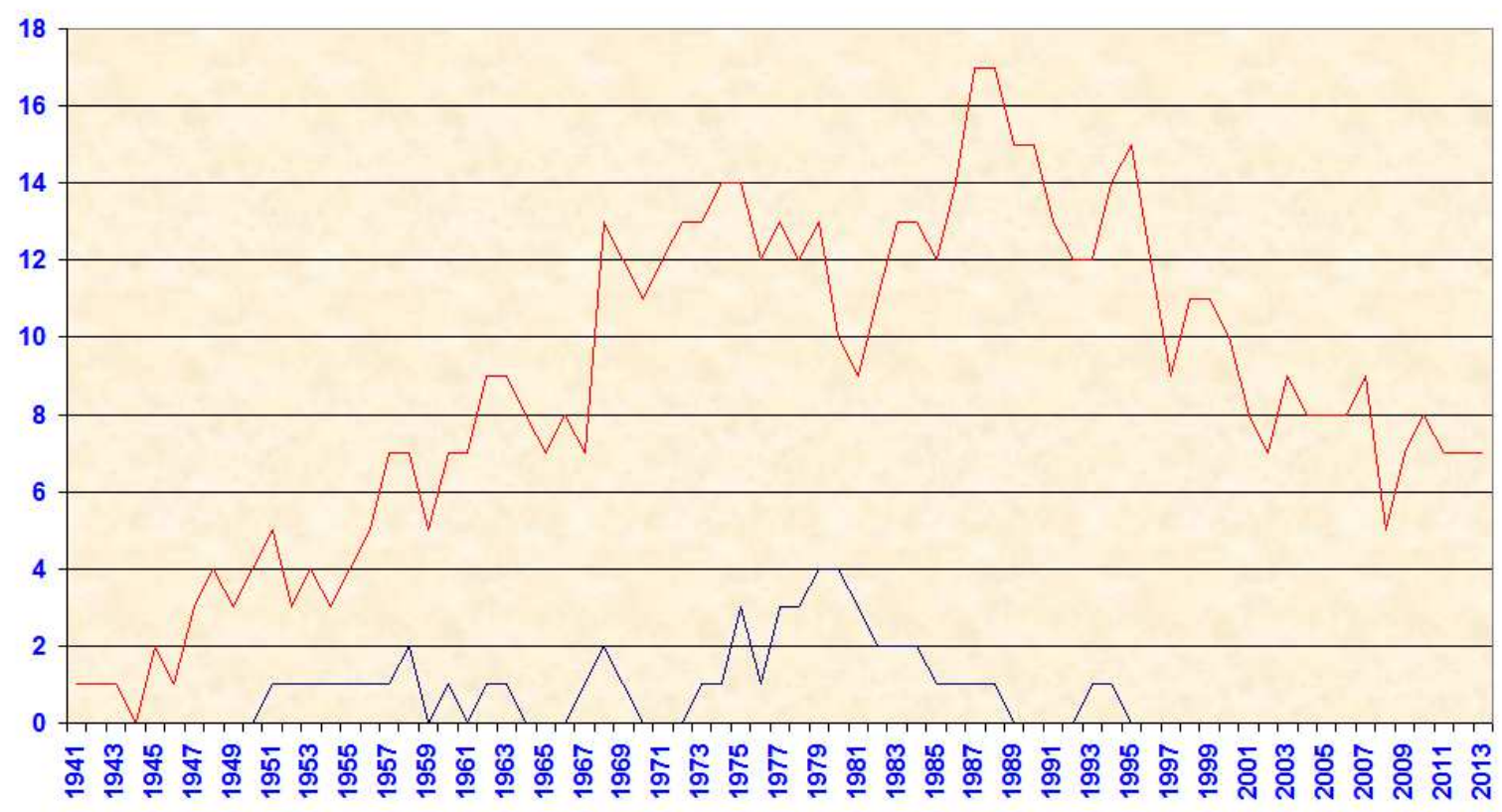

Años

\section{- $\mathbf{N}^{0}$ Inhomogeneidades $-\mathbf{N}^{0}$ series}

De la gráfica 8 se aprecia que el clímax de inhomogeneidades se da entre 1975 y 1990, con máximos secundarios entre 1958 y 1967 y entre 1968 y 1977.

La tabla 17 expone las inhomogeneidades descubiertas en un intervalo de 10 años.

Tabla 17: Inhomogeneidades detectadas aplicando el test de Thom a las medidas de precipitación media anual desde 1859 a 2013:

\begin{tabular}{|c|c|c||c||}
\hline $\begin{array}{c}\text { Periodo inhomogeneidad } \\
\text { (Años) }\end{array}$ & Indicativos & $\begin{array}{c}\text { Inhomogeneidad } \\
\text { "climatológica" }\end{array}$ & $\begin{array}{c}\text { \% series sobre } \\
\text { total }\end{array}$ \\
\hline \hline $1884-1895$ & $1059 \mathrm{~L}$ & Sí & $50(2)$ \\
\hline $1905-1916$ & $1077 \mathrm{C}$ & Sí & $50-100(1-2)$ \\
\hline $1913-1923$ & 1059 & Sí & $25(4)$ \\
\hline \hline $1951-1967$ & $9077 \mathrm{E}$ & Sí & $14-33(3-7)$ \\
\hline \hline $1958-1969$ & 1054 & Sí & $14(7)$ \\
\hline \hline $1962-1975$ & $1060 \mathrm{~A}$ & Sí & 11 \\
\hline \hline $1967-1979$ & $1060 \mathrm{~A}$ & Sí & $8-15$ \\
\hline \hline $1968-1977$ & 1070,1075 & Sí & $7-17$ \\
\hline \hline $1973-1988$ & $1079 \mathrm{I}$ & Sí & \\
\hline \hline $1975-1984$ & $1078 \mathrm{E}$ & Sí & $7-33$ \\
\hline \hline $1977-1990$ & $1078 \mathrm{E}$ & Sí & \\
\hline \hline $1975-1991$ & 1071 & Sí & 6 \\
\hline \hline $1979-1993$ & 1053 & Sí & $8-9$ \\
\hline \hline $1979-1997$ & 1070 & Sí & \\
\hline \hline $1987-2000$ & $1055 \mathrm{~A}$ & Sí & \\
\hline $1993-2005$ & $1055 \mathrm{~A}$ & Sí & \\
\hline \hline
\end{tabular}


Las inhomogeneidades de la tabla 17 se comparan con los resultados obtenidos del análisis del test de las rachas de las series de precipitación media anual de Guipúzcoa, debido a:

a) La exigua densidad espacial y temporal de las series de precipitación anual con una duración superior a 10 años disponibles en Vizcaya y en la vertiente cantábrica de Álava.

b) Las características climáticas similares de Vizcaya, la vertiente cantábrica de Álava y Guipúzcoa.

La tabla 18 reproduce los resultados correspondientes a las inhomogeneidades descubiertas por el test de las rachas en las medidas de la pluviosidad media anual, MAM y AMJ de 1878 a 1940 en Guipúzcoa.

Tabla 18: Inhomogeneidades detectadas aplicando el test de Thom a las medidas de precipitación media anual, MAM y AMJ desde 1878 a 1940 en Guipúzcoa:

\begin{tabular}{|c|c|c|c|c||}
\hline $\begin{array}{c}\text { Periodo } \\
\text { inhomogeneidad } \\
\text { (Años) }\end{array}$ & Indicativos & $\begin{array}{c}\text { Detectado en } \\
\text { periodo }\end{array}$ & $\begin{array}{c}\text { Inhomogeneidad } \\
\text { "climatológica" }\end{array}$ & $\begin{array}{c}\text { \% series } \\
\text { sobre total }\end{array}$ \\
\hline \hline $1885-1995$ & 1024D & AMJ & Sí & $100(1)$ \\
\hline \hline $1891-1900$ & $1024 \mathrm{D}$ & MAM & Sí & $100(1)$ \\
\hline \hline $1905-1917$ & $1024 \mathrm{~F}$ & Anual & Sí & $33(3)$ \\
\hline \hline $1916-1925$ & 1013 & Anual & Sí & $25(4)$ \\
\hline $1918-1927$ & 1013 & MAM & Sí & $33(3)$ \\
\hline $1919-1928$ & $1024 \mathrm{~F}$ & MAM & Sí & $50(4)$ \\
\hline $1920-1930$ & $1013,1024 \mathrm{~F}$ & MAM & Sí & $33(3)$ \\
\hline $1922-1932$ & $1024 \mathrm{~F}$ & MAM & Sí & $25(4)$ \\
\hline $1926-1935$ & 1032 & AMJ & No & $25(4)$ \\
\hline \hline $1928-1938$ & $1024 \mathrm{E}$ & Anual & & \\
\hline
\end{tabular}

La tabla 19 transcribe los resultados de la aplicación del test de las rachas a la pluviometría media anual de 1941 a 2012 en Guipúzcoa.

Las tablas 18 y 19 provienen de la Nota Técnica No 13 de AEMET “Análisis de la homogeneidad de las series de precipitación de Guipúzcoa". 
Tabla 19: Inhomogeneidades detectadas aplicando el test de Thom a las medidas de precipitación media anual desde 1941 a 2012 en Guipúzcoa:

\begin{tabular}{|c|c|c|c|}
\hline $\begin{array}{l}\text { Periodo inhomogeneidad } \\
\text { (Años) }\end{array}$ & Indicativos & $\begin{array}{l}\text { Inhomogeneidad } \\
\text { "climatológica" }\end{array}$ & $\begin{array}{c}\% \text { series sobre } \\
\text { total }\end{array}$ \\
\hline $1950-1959$ & 1016 & Sí & $9-10$ \\
\hline $1951-1961$ & $1016,1024 \mathrm{E}$ & Sí & $13-18$ \\
\hline $1962-1975$ & 1017 & No & 5 \\
\hline $1966-1975$ & 1022 & "Sí & 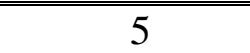 \\
\hline $1967-1978$ & 1016,1022 & Sí & $9-11$ \\
\hline $1967-1984$ & 1026 & Sí & 5 \\
\hline $1970-1980$ & $1016,1022,1036$ & Sí & $12-16$ \\
\hline $1972-1981$ & 1016 & Sí & 5 \\
\hline $1973-1983$ & 1022 & Sí & 5 \\
\hline $1974-1985$ & $1022,1035,1036$ & Sí & $12-15$ \\
\hline $1976-1986$ & 1036 & Sí & 6 \\
\hline $1977-1986$ & 1021E, 1035 & Sí & 13 \\
\hline $1978-1989$ & 1036 & Sí & $5-6$ \\
\hline $1981-1994$ & $1014,1024 \mathrm{E}$ & Sí & $10-11$ \\
\hline $1983-1992$ & $1049 \mathrm{U}$ & Sí & 5 \\
\hline $1986-1997$ & $1014,1024 \mathrm{E}, 1033 \mathrm{U}, 1037 \mathrm{Q}$ & Sí & \multirow{2}{*}{$20-22$} \\
\hline $1987-1998$ & $1037 \mathrm{O}, 1037 \mathrm{Q}$ & Sí & \\
\hline $1987-2008$ & $1050 \mathrm{~L}$ & No & $4-6$ \\
\hline $1988-1997$ & 1013I, 1019A & \multirow{2}{*}{ Sí } & \multirow{2}{*}{$21-22$} \\
\hline $1989-1999$ & 1013I, 1014, 1019A, 1024E & & \\
\hline $1988-2001$ & 1041 & Sí & 4 \\
\hline $1989-1998$ & 1031 & Sí & 4 \\
\hline $1990-1999$ & 1026B, 1031 & Sí & \multirow{2}{*}{16} \\
\hline $1990-2001$ & $1037 \mathrm{O}$ & Sí & \\
\hline $1991-2001$ & $1014,1026 \mathrm{~B}, 1031$ & Sí & 17 \\
\hline $1992-2003$ & $1035 \mathrm{U}$ & Sí & 4 \\
\hline $1993-2002$ & 1031,10360 & Sí & \multirow[b]{2}{*}{30} \\
\hline $1993-2003$ & $\begin{array}{c}1014,1026 \mathrm{~B}, 1037,1041, \\
1049\end{array}$ & Sí & \\
\hline $1994-2006$ & 1041 & Sí & 4 \\
\hline $1995-2004$ & $1036 \mathrm{O}, 1037,1049$ & Sí & 19 \\
\hline $1996-2006$ & 10360,1049 & Sí & $18-20$ \\
\hline $1996-2011$ & $1025 \mathrm{~N}$ & Sí & $4-5$ \\
\hline $1998-2011$ & $1033 \mathrm{U}$ & ¿No? & $5-6$ \\
\hline
\end{tabular}


Las tablas 20 a 30 exponen para cada serie de medidas de precipitación:

a) El indicativo y el nombre del emplazamiento.

b) La duración precisando los años sin datos (sd).

c) Los años con máximos pluviométricos en el intervalo en que aflora la inhomogeneidad, con el ordinal entre paréntesis referido al lapso global de medidas de la serie.

d) La precipitación media mensual anual de los años en que acaecen máximos pluviométricos.

e) Los años con mínimos de la pluviosidad en el intersticio temporal de la inhomogeneidad; se señala entre paréntesis el ordinal respecto al intervalo anual global de registros.

f) La precipitación media mensual anual de los años de mínimos pluviométricos.

A causa de la exigua densidad espacial y temporal de los enclaves de medición de Vizcaya y de la vertiente cantábrica de Álava, las precipitaciones en los años de inhomogeneidades se cotejan con las cuantías de:

A) 1024D $\nabla$ (San Sebastián Instituto) de 1884 a 1895: 1059L I $\nabla$ Orduña, 1077C $\vee$ Bilbao Histórica y 1024D $\vee$ son los únicos lugares con datos coetáneos en Vizcaya, en la vertiente cantábrica de Álava y en Guipúzcoa en ese intervalo temporal.

B) 1024F I 8 (San Sebastián) entre 1905 y 1916, ya que sólo 1024F I $\vee$ y 1077C $\vee$ abarcan este intersticio.

C) 1013 I $\vee$ (Irún Fitosanitaria) de 1915 a 1923. 1013 I $\vee$ es la exclusiva serie de Guipúzcoa que cubre este lapso sin rupturas: 1024F $\vee$ cambió de altitud en 1918 (Doporto, 55 años de Observaciones pluviométricas).

D) 9076 I $\vee$ (Ullivarri Gamboa) y 9080 I $\vee$ (Urrunaga), las localizaciones con observaciones pluviométricas de 1951 a 1967 más próximas a 9077E I $\vee$ (Ochandiano).

E) $1052 \mathrm{P}$ (Motrico) al ser un enclave de calidad con registros de precipitación de 1958 a 1968 (Nota Técnica No 13 AEMET) cercano a 1054 II 8 (Marquina).

F) $1049 \mathrm{U} \vee$ (Ermua), emplazamiento de notable calidad (Nota Técnica 13 de AEMET) con anotaciones de pluviosidad coetáneas de 1983 a 1997, allegado a $1071 \varnothing$ (Durango), 1053 II $\vee$ (Echevarría) y 1070 P (Abadiano).

G) 1041 (Zumaya) es la localidad con mediciones simultáneas de precipitación de 1987 a 2005 más propincua a 1055A I $\nabla$ Lequeitio, habiéndose realizado las medidas en ambos lugares en condiciones similares. 
1.- Inhomogeneidad de 1884 a 1895 en 1059L:

Tabla 20: Años con precipitaciones medias máximas y mínimas:

\begin{tabular}{|c|c|c|c|c|c|}
\hline $\begin{array}{c}\text { Indicativo y } \\
\text { nombre }\end{array}$ & Duración serie & Año Máximo & $\begin{array}{c}\text { Precipitación } \\
\left(1 / \mathrm{m}^{2}\right)\end{array}$ & Año Mínimo & $\begin{array}{c}\text { Precipitación } \\
\left(1 / \mathrm{m}^{2}\right)\end{array}$ \\
\hline \multirow{4}{*}{$\begin{array}{l}\text { 1059L I } \vee \\
\text { Orduña }\end{array}$} & \multirow{4}{*}{$\begin{array}{c}1882-1899 \text { y } \\
1905 \text { (sd 1883, } \\
1899)\end{array}$} & $1889\left(1^{\circ}\right)$ & 90,4 & $1887\left(1^{\circ}\right)$ & 51,7 \\
\hline & & $1893\left(3^{\circ}\right)$ & 79,3 & $1884\left(2^{\circ}\right)$ & 52,3 \\
\hline & & $1888\left(4^{\circ}\right)$ & 74,6 & $1891\left(3^{\circ}\right)$ & 54,4 \\
\hline & & & & $1894\left(4^{\circ}\right)$ & 58,1 \\
\hline \multirow{4}{*}{$\begin{array}{c}1077 \mathrm{C} P \\
\text { Bilbao Histórica }\end{array}$} & \multirow{4}{*}{$\begin{array}{c}1859-1919 \\
(\mathrm{sd} 1862 \mathrm{a} \\
1864 \text { y } 1874)\end{array}$} & $1885\left(1^{\circ}\right)$ & 134,3 & $1891\left(4^{\circ}\right)$ & 78,7 \\
\hline & & $1889\left(2^{\circ}\right)$ & 128,4 & $1894\left(5^{\circ}\right)$ & 80,1 \\
\hline & & $1886\left(3^{\circ}\right)$ & 123,0 & $1895\left(15^{\circ}\right)$ & 90,0 \\
\hline & & $1888\left(6^{\circ}\right)$ & 115,7 & & \\
\hline \multirow{3}{*}{$\begin{array}{c}\text { 1024D } 8 \\
\text { San Sebastián }\end{array}$} & \multirow{3}{*}{$1878-1900$} & $1889\left(1^{\circ}\right)$ & 150,1 & $1891\left(2^{\circ}\right)$ & 88,8 \\
\hline & & $1886\left(5^{\circ}\right)$ & 131,8 & $1894\left(4^{\circ}\right)$ & 93,9 \\
\hline & & $1885\left(9^{\circ}\right)$ & 123,8 & $1884\left(6^{\circ}\right)$ & 101,3 \\
\hline
\end{tabular}

1.- Las únicas ubicaciones con datos de pluviosidad de 1884 a 1895 en Vizcaya, en la vertiente cantábrica de Álava y en Guipúzcoa son 1059L I \ Orduña, 1077C \& Bilbao Histórica y 1024D \& San Sebastián Instituto.

2.- A modo de comparativa, se incluyen en la tabla 20 los valores de precipitación de 1077C $\vee$ y de 1024D $P$.

3.- Se observa de la tabla 20 una simultaneidad de los años con máximos $(1885,1889$ y 1888) y mínimos pluviométricos (1891, 1894 y 1884).

Asimismo, se percibe que la concordancia de máximos y mínimos entre 1077C $\nabla$ y 1024D $\odot$ (ambas situadas a la orilla del mar) es mejor que la correspondencia con 1059L I 8 .

4.- Las precipitaciones registradas en 1077C $\nabla$ superan las de 1059L I $\nabla$ un 35 a $42 \%$ los años lluviosos y en torno al 33\% los años secos; en 1024D $\vee$ se recogen un 40\% más de precipitaciones respecto a 1059L I $\vee$ los años con máximos pluviométricos y entre un 38 y un $48 \%$ los años de sequías.

Se aprecia que la razón de las precipitaciones medidas es aproximadamente constante.

5.- De 1884 a 1895 se suceden 4 años de sequías y 3 muy lluviosos, oscilando las pluviosidades recogidas en torno a la mediana de valores de la pluviometría media anual de 1059L I $\vee$ Orduña de 1882 a 1899 y 1905.

Por tanto, se la clasifica como inhomogeneidad "climatológica". 


\section{2.- Inhomogeneidad de 1905 a 1916 en 1077C:}

Tabla 21: Años con precipitaciones medias máximas y mínimas:

\begin{tabular}{|c|c|c|c|c|c|}
\hline $\begin{array}{c}\text { Indicativo y } \\
\text { nombre }\end{array}$ & Duración serie & Año Máximo & $\begin{array}{c}\text { Precipitación } \\
\left(1 / \mathrm{m}^{2}\right)\end{array}$ & Año Mínimo & $\begin{array}{c}\text { Precipitación } \\
\left(1 / \mathrm{m}^{2}\right)\end{array}$ \\
\hline \multirow{3}{*}{$\begin{array}{c}1077 \mathrm{C} \vee \\
\text { Bilbao Histórica }\end{array}$} & \multirow{3}{*}{$\begin{array}{c}1859-1919 \\
(\mathrm{sd} 1862 \mathrm{a} \\
1864 \text { y } 1874)\end{array}$} & $1906\left(7^{\circ}\right)$ & 115,5 & $1912\left(2^{\circ}\right)$ & 71,6 \\
\hline & & $1908\left(9^{\circ}\right)$ & 114,5 & $1916\left(7^{\circ}\right)$ & 82,5 \\
\hline & & $1910\left(10^{\circ}\right)$ & 114,3 & $1911\left(9^{\circ}\right)$ & 82,8 \\
\hline \multirow{3}{*}{$\begin{array}{c}\text { 1024F I } \supsetneq \\
\text { San Sebastián }\end{array}$} & \multirow{3}{*}{$1901-1917$} & $1910\left(1^{\circ}\right)$ & 132,5 & $1916\left(1^{\circ}\right)$ & 55,8 \\
\hline & & $1908\left(4^{\circ}\right)$ & 105,4 & $1912\left(2^{\circ}\right)$ & 74,5 \\
\hline & & $1907\left(5^{\circ}\right)$ & 104,9 & $1911\left(4^{\circ}\right)$ & 82,8 \\
\hline
\end{tabular}

1.- $1077 \mathrm{C} \vee$ Bilbao Histórica, con comienzo en Enero de 1859 y fin en Octubre de 1920, es la única serie con registros de precipitación anual continuos en Vizcaya desde 1905 a 1916.

2.- La tabla 21 refleja los datos correspondientes a 1024F I $\vee$ de 1905 a 1916 como cotejo.

3.- Se percibe de la tabla 21 una concordancia entre los máximos $(1910,1908)$ y mínimos $(1911,1912,1916)$ pluviométricos recogidos en ambos lugares.

4.- De la tabla 18 (página 51), se observa que 1024F I \ San Sebastián exterioriza una inhomogeneidad de tipo climatológico entre 1905 y 1917.

5.- $1077 \mathrm{C} \&$ presenta una excelente homogeneidad: el test de Thom aflora 3 inhomogeneidades en 46 pruebas de un periodo de 10 años, no descubriéndose ninguna inhomogeneidad en periodos de 20, 30, 40 y 50 años.

6.- La aplicación de los test de Thom y de Mann-Kendall a las precipitaciones medias anual, MAM y AMJ no detecta ninguna ruptura en 1077C $\vee$, según se refleja en el apartado 4.1.- "Rupturas detectadas en las series de precipitación". simultáneas.

7.- Las inhomogeneidades de $1077 \mathrm{C} \nabla$ y de $1024 \mathrm{~F} \mathrm{I} \nabla$ son prácticamente

8.- Se detecta de la tabla 21 una alternancia entre años muy pluviosos con años muy secos de 1905 a 1917 en 1024F I $\nabla$ y en 1077C $\vee$. En este lapso de tiempo, las medidas oscilan en torno a la mediana la pluviometría anual de 1077C $\vee$ de 1859 a 1919.

Por consiguiente, la inhomogeneidad de 1077C $\odot$ se considera de tipo "climatológica". 
3.- Inhomogeneidad de 1913 a 1923 en 1059 :

Tabla 22: Años con precipitaciones máximas y mínimas:

\begin{tabular}{|c|c|c|c|c|c|}
\hline $\begin{array}{l}\text { Indicativo } \\
\text { y nombre }\end{array}$ & Duración serie & Año Máximo & $\begin{array}{c}\text { Precipitación } \\
\left(1 / \mathrm{m}^{2}\right)\end{array}$ & Año Mínimo & $\begin{array}{c}\text { Precipitación } \\
\left(1 / \mathrm{m}^{2}\right)\end{array}$ \\
\hline \multirow{3}{*}{$\begin{array}{c}1059 \text { I } 8 \\
\text { Punta } \\
\text { Galea }\end{array}$} & \multirow{3}{*}{$\begin{array}{c}1911-1926 \\
(\text { sd 1925) }\end{array}$} & $1923\left(2^{\circ}\right)$ & 114,8 & $1920\left(1^{\circ}\right)$ & 57,0 \\
\hline & & $1917\left(3^{\circ}\right)$ & 114,4 & $1916\left(2^{\circ}\right)$ & 68,0 \\
\hline & & $1913\left(4^{\circ}\right)$ & 109,3 & $1914\left(5^{\circ}\right)$ & 82,2 \\
\hline \multirow{3}{*}{$\begin{array}{l}\text { 1057C I } \$ \\
\text { Machicaco }\end{array}$} & \multirow{3}{*}{$1913-1920$} & $1917\left(1^{\circ}\right)$ & 108,7 & $1920\left(1^{\circ}\right)$ & 61,4 \\
\hline & & $1919\left(2^{\circ}\right)$ & 101,1 & $1916\left(2^{\circ}\right)$ & 71,2 \\
\hline & & & & $1914\left(3^{\circ}\right)$ & 73,4 \\
\hline \multirow{2}{*}{$\begin{array}{l}\text { 1057C II P } \\
\text { Machicaco }\end{array}$} & \multirow{2}{*}{$\begin{array}{c}1922-1933 \\
(\mathrm{sd} 1930)\end{array}$} & $1923\left(1^{\circ}\right)$ & 108,8 & & \\
\hline & & $1922\left(3^{\circ}\right)$ & 98,6 & & \\
\hline \multirow{3}{*}{$\begin{array}{c}1013 \text { I } 8 \\
\text { Irún }\end{array}$} & \multirow{3}{*}{$\begin{array}{c}1915-1930 \\
(\text { sd 1926) }\end{array}$} & $1923\left(1^{\circ}\right)$ & 213,4 & $1921\left(1^{\circ}\right)$ & 110,8 \\
\hline & & $1917\left(2^{\circ}\right)$ & 201,4 & $1920\left(3^{\circ}\right)$ & 123,8 \\
\hline & & $1919\left(4^{\circ}\right)$ & 183,5 & $1916\left(4^{\circ}\right)$ & 128,1 \\
\hline
\end{tabular}

1.- Las medidas de 1057C I $\vee$, 1057C II $\vee$ Machicaco Faro y de 1013 I $\vee$ Irún se agregan como contraste en la tabla 22.

2.- Una inhomogeneidad de tipo "climatológico" se manifiesta en 1013 I $\nabla$ Irún en la precipitación media anual de 1916 a 1925 (tabla 18, página 51).

3.- Los años con máximos (1923, 1917 y 1919) y mínimos (1920, 1916 y 1914) de la pluviosidad concuerdan en los 3 enclaves.

4.- De las tablas 31 y 31 bis (página 74), 1917 y 1923 son máximos pluviométricos en Guipúzcoa y 1920 un mínimo.

5.- Hay una coherencia espacial de las precipitaciones registradas en los 3 lugares. De la tabla 22 se observa:

a) Las precipitaciones recogidas en $1059 \mathrm{I} \nabla$ son del orden del $5 \%$ superiores a las de 1057C I $\vee$ y 1057C II $\nabla$ los años lluviosos y oscilan entre un $10 \%$ inferiores y un $7 \%$ superiores los años secos.

b) Las cantidades registradas en 1013 I $\nabla$ rebasan las de 1059 I $\nabla$ entre un 76 y un $86 \%$ los años pluviosos y entre el 88 y el $117 \%$ los años áridos. constante.

Se percibe que el cociente de las precipitaciones recogidas es aproximadamente

6.- En el intervalo de 1913 a 1923 analizado en la tabla 22, acontecen los años más lluviosos y los años más áridos en los 3 emplazamientos, fluctuando las precipitaciones apuntadas en torno a las respectivas medianas.

Por tanto, se la cataloga como inhomogeneidad "climatológica". 
4.- Inhomogeneidad de 1951 a 1967 en 9077E:

Tabla 23: Años con precipitaciones máximas y mínimas:

\begin{tabular}{|c|c|c|c|c|c|}
\hline $\begin{array}{c}\text { Indicativo y } \\
\text { nombre }\end{array}$ & Duración serie & Año Máximo & $\begin{array}{c}\text { Precipitación } \\
\left(1 / \mathrm{m}^{2}\right)\end{array}$ & Año Mínimo & $\begin{array}{c}\text { Precipitación } \\
\left(1 / \mathrm{m}^{2}\right)\end{array}$ \\
\hline \multirow{4}{*}{$\begin{array}{l}\text { 9077E I } \vee \\
\text { Ochandiano }\end{array}$} & \multirow{4}{*}{$\begin{array}{c}1947-1970 \\
(\mathrm{sd} 1949,1970)\end{array}$} & $1954\left(1^{\circ}\right)$ & 166,3 & $1957\left(1^{\circ}\right)$ & 88,4 \\
\hline & & $1952\left(2^{\circ}\right)$ & 152,8 & $1955\left(3^{\circ}\right)$ & 97,4 \\
\hline & & $1966\left(3^{\circ}\right)$ & 148,9 & $1964\left(4^{\circ}\right)$ & 107,5 \\
\hline & & $1960\left(4^{\circ}\right)$ & 145,5 & $1967\left(5^{\circ}\right)$ & 112,5 \\
\hline \multirow{4}{*}{$\begin{array}{l}9076 \text { I } ~ \\
\text { Ullivarri } \\
\text { Gamboa }\end{array}$} & \multirow{4}{*}{$\begin{array}{c}1945-1995 \\
(\text { sd 1963) }\end{array}$} & $1952\left(1^{\circ}\right)$ & 124,4 & $1957\left(2^{\circ}\right)$ & 50,2 \\
\hline & & $1954\left(4^{\circ}\right)$ & 101,4 & $1955\left(10^{\circ}\right)$ & 65,2 \\
\hline & & $1960\left(6^{\circ}\right)$ & 95,7 & $1961\left(13^{\circ}\right)$ & 67,7 \\
\hline & & $1951\left(7^{\circ}\right)$ & 94,6 & $1964\left(14^{\circ}\right)$ & 68,5 \\
\hline \multirow{3}{*}{$\begin{array}{l}9080 \text { I } P \\
\text { Urrunaga }\end{array}$} & \multirow{3}{*}{$\begin{array}{c}1943-1985 \\
(\text { sd 1949, 1962) }\end{array}$} & $1956\left(3^{\circ}\right)$ & 110,7 & $1967\left(7^{\circ}\right)$ & 69,2 \\
\hline & & $1952\left(4^{\circ}\right)$ & 108,7 & $1957\left(10^{\circ}\right)$ & 73,7 \\
\hline & & $1958\left(5^{\circ}\right)$ & 107,4 & $1965\left(11^{\circ}\right)$ & 75,1 \\
\hline
\end{tabular}

1.- La tabla 23 incorpora las medidas de pluviosidad de 9076 I $\vee$ Ullivarri Gamboa y 9080 I 8 Urrunaga.

2.- La figura 11 describe la situación de 9077E I $\vee$ Ochandiano y de los enclaves más próximos: 9076I $\vee$ Ceanuri (5 años completos de precipitación anual), 9076 I $\vee$ Ullivarri Gamboa, 9080 I $\vee$ Urrunaga y 9080 II $\vee$ Urrunaga.

Figura 11: Emplazamientos de 9076I $\vee, 9077$ E I $\vee, 9076$ I $\nabla, 9080$ I $\vee$ y 9080 II $\vee:$

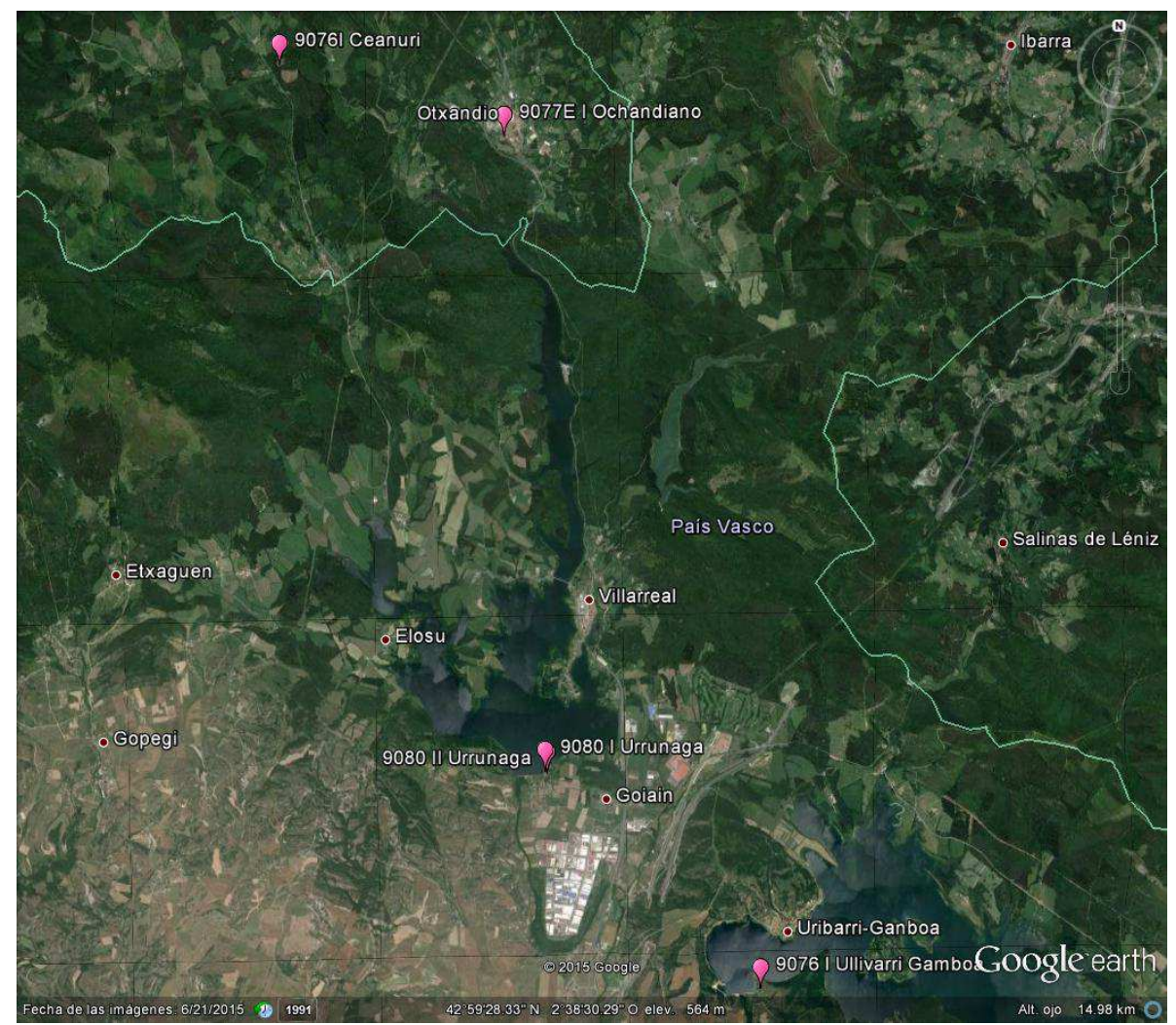


9080 I $\vee$ y 9080 II $\vee$ representan las dos ubicaciones del jardín meteorológico de la presa de Urrunaga y distan entre sí menos de $50 \mathrm{~m}$, con una diferencia de altitud inferior a $5 \mathrm{~m}$., confirmado por la viuda del colaborador en una visita del autor.

La tabla 23 bis indica las altitudes de 9076 I $\nabla$, 9077E I $\nabla, 9080$ I $\nabla$ y la distancia a 9077E I $\vee$ de 9076 I $\vee$ y de 9080 I $\vee$.

Tabla 23 bis: Características geográficas de 9076 I $\vee$, 9077E I $\vee$ y 9080 I $\vee$ :

$\begin{array}{rccc}\text { Indicativo } & \text { Nombre } & \text { Altitud }(\mathrm{m}) & \text { Distancia a 9077E I } \nabla(\mathrm{Km} .) \\ 9076 \text { I } ~ & \text { Ullivarri Gamboa } & 545 & 12,8 \\ 9077 \mathrm{E} \text { I } 8 & \text { Ochandiano } & 559 & \\ 9080 \text { I } \nabla & \text { Urrunaga (presa) } & 547 & 9,2\end{array}$

Los datos de Urrunaga en la tabla 23 bis son los de 9080 I $\vee$, situación del jardín meteorológico de $9080 \vee$ en el intervalo de inhomogeneidades de 9077E I $\vee$.

Los pluviómetros de 9077E I $\vee, 9076$ I $\nabla$ y 9080 \ estaban a menos de $13 \mathrm{Km}$. entre sí con una diferencia de altitudes inferior a 15 metros.

No hay obstáculos orográficos significativos entre ambos enclaves ni en el entorno de cada uno de los emplazamientos; la campiña desciende suavemente desde Ochandiano a Ullivarri Gamboa y a Urrunaga, tal y cómo se aprecia en la figura 11.

3.- 9076 I $\nabla$ y 9080 I $\nabla$ son los emplazamientos con medidas pluviométricas coetáneas de 1951 a 1967 más próximos a 9077E I $\vee$ de toda Álava, Guipúzcoa y Vizcaya.

4.- Para dilucidar si la inhomogeneidad de 9077E I $\nabla$ es climatológica o no, se comparan sus datos con los registros de precipitación de 9076 I $\vee$ y 9080 I $\vee$ (tabla 23).

5.- 9076 I $\vee$ tiene una ruptura en 1995, debida a un relevo del colaborador. Se ignora si hubo en esa época un cambio de lugar del pluviómetro de 9076 I 8.

El test de rachas escrutando la precipitación media anual detecta una inhomogeneidad de 1952 a 1967 en 9076 I P.

Los tests señalan una rotura en $9080 \nabla$ a finales de 1985, causada por el traslado del jardín meteorológico de Urrunaga de 9080 I $\nabla$ a 9080 II $\vee$.

6.- Coinciden los años con máximos $(1952,1954$ y 1960) y mínimos $(1955,1957$ y 1967), siendo las precipitaciones anotadas en 9076 I $\nabla$ entre el 55 y el $80 \%$ de las recogidas en 9077E I $\nabla$ y las medidas de 9080 I $\vee$ entre el 60 y el $85 \%$ de los valores de 9077E I $\nabla$.

7.- 1960 es un año de máximo pluviométrico en 1054 II $\vee$ y en 1052 (tabla 24).

8.- Guipúzcoa registra máximos en 1954 y en 1960 y un mínimo en 1957 (tablas 31 y 31 bis, página 74).

Por consiguiente, se trata de una inhomogeneidad "climatológica". 
5.- Inhomogeneidad de 1958 a 1969 en 1054:

Tabla 24: Años con precipitaciones máximas y mínimas:

\begin{tabular}{|c|c|c|c|c|c|}
\hline $\begin{array}{l}\text { Indicativo } \\
\text { y nombre }\end{array}$ & Duración serie & Año Máximo & $\begin{array}{c}\text { Precipitación } \\
\left(1 / \mathrm{m}^{2}\right)\end{array}$ & Año Mínimo & $\begin{array}{c}\text { Precipitación } \\
\left(1 / \mathrm{m}^{2}\right)\end{array}$ \\
\hline \multirow{3}{*}{$\begin{array}{l}1054 \text { II } P \\
\text { Marquina }\end{array}$} & \multirow{3}{*}{$\begin{array}{c}1957-1974 \\
(\text { sd 1959) }\end{array}$} & $1960\left(2^{\circ}\right)$ & 151,3 & $1962\left(3^{\circ}\right)$ & 118,1 \\
\hline & & $1966\left(3^{\circ}\right)$ & 142,1 & $1968\left(4^{\circ}\right)$ & 119,6 \\
\hline & & $1967\left(4^{\circ}\right)$ & 134,6 & $1964\left(5^{\circ}\right)$ & 121,4 \\
\hline \multirow{3}{*}{$\begin{array}{c}1053 \text { I } 8 \\
\text { Echevarría }\end{array}$} & \multirow{3}{*}{$1962-1975$} & $1966\left(3^{\circ}\right)$ & 144,8 & $1962\left(1^{\circ}\right)$ & 109,7 \\
\hline & & $1965\left(4^{\circ}\right)$ & 143,2 & $1964\left(2^{\circ}\right)$ & 115,2 \\
\hline & & $1967\left(5^{\circ}\right)$ & 135,2 & $1963\left(3^{\circ}\right)$ & 116,1 \\
\hline \multirow{3}{*}{$\begin{array}{l}1052 \curlyvee \\
\text { Motrico }\end{array}$} & \multirow{3}{*}{$\begin{array}{c}1956-1974 \\
(\text { sd 1969) }\end{array}$} & $1965\left(3^{\circ}\right)$ & 127,5 & $1968\left(1^{\circ}\right)$ & 78,9 \\
\hline & & $1960\left(3^{\circ}\right)$ & 125,9 & $1964\left(2^{\circ}\right)$ & 102,4 \\
\hline & & $1966\left(4^{\circ}\right)$ & 125,9 & $1962\left(3^{\circ}\right)$ & 103,2 \\
\hline
\end{tabular}

1.- Las estaciones de medida pluviométrica con registros de 1958 a 1969 más cercanas a 1054 II $\vee$ Marquina son 1052 \& Motrico y 1053 I $\vee$ Echevarría.

No se consideran los datos de $1050 \bigcirc$ Eibar (a 12,7 Km. de distancia) por presentar una ruptura a finales de 1964 (Nota Técnica No 13 AEMET).

2.- Al ser escaso el número de series disponibles (7) en este intervalo en Vizcaya y en la vertiente cantábrica de Álava, se incluyen en la tabla 24 los datos de 1958 a 1969 correspondientes a 1052 \& Motrico.

La tabla 24 bis acopia la altitud y la distancia a 1054 II $\nabla$ de 1052 \& y 1053 I $\nabla$.

Tabla 24 bis: Características geográficas de 1052, 1053 I Py 1054 II $\vee$ :

$\begin{array}{rccc}\text { Indicativo } & \text { Nombre } & \text { Altitud }(\mathrm{m}) & \text { Distancia a } 1054(\mathrm{Km} .) \\ 1052 \nabla & \text { Motrico } & 49 & 7,2 \\ 1053 \text { I } \varnothing & \text { Echevarría } & 107 & 4,8 \\ 1054 \text { II } \varnothing & \text { Marquina } & 33 & \end{array}$

3.- El test de rachas aplicado a la precipitación media anual de 1054 II $\vee$ en el intervalo de 1957 a 1974 revela inhomogeneidades en 2 de las 8 ocasiones en que se prueba el test.

4.- La tabla 24 arroja una simultaneidad de años de máximos (1960, 1965, 1966, 1967) y mínimos $(1962,1964,1968)$ pluviométricos.

5.- En la figura 12 se dibujan los emplazamientos de $1052 \nabla, 1053$ I $\nabla$ y 1054 II $\nabla$. 


\section{Figura 12: Localización de 1052 ४, 1053 I \& 1054 II $\vee:$}

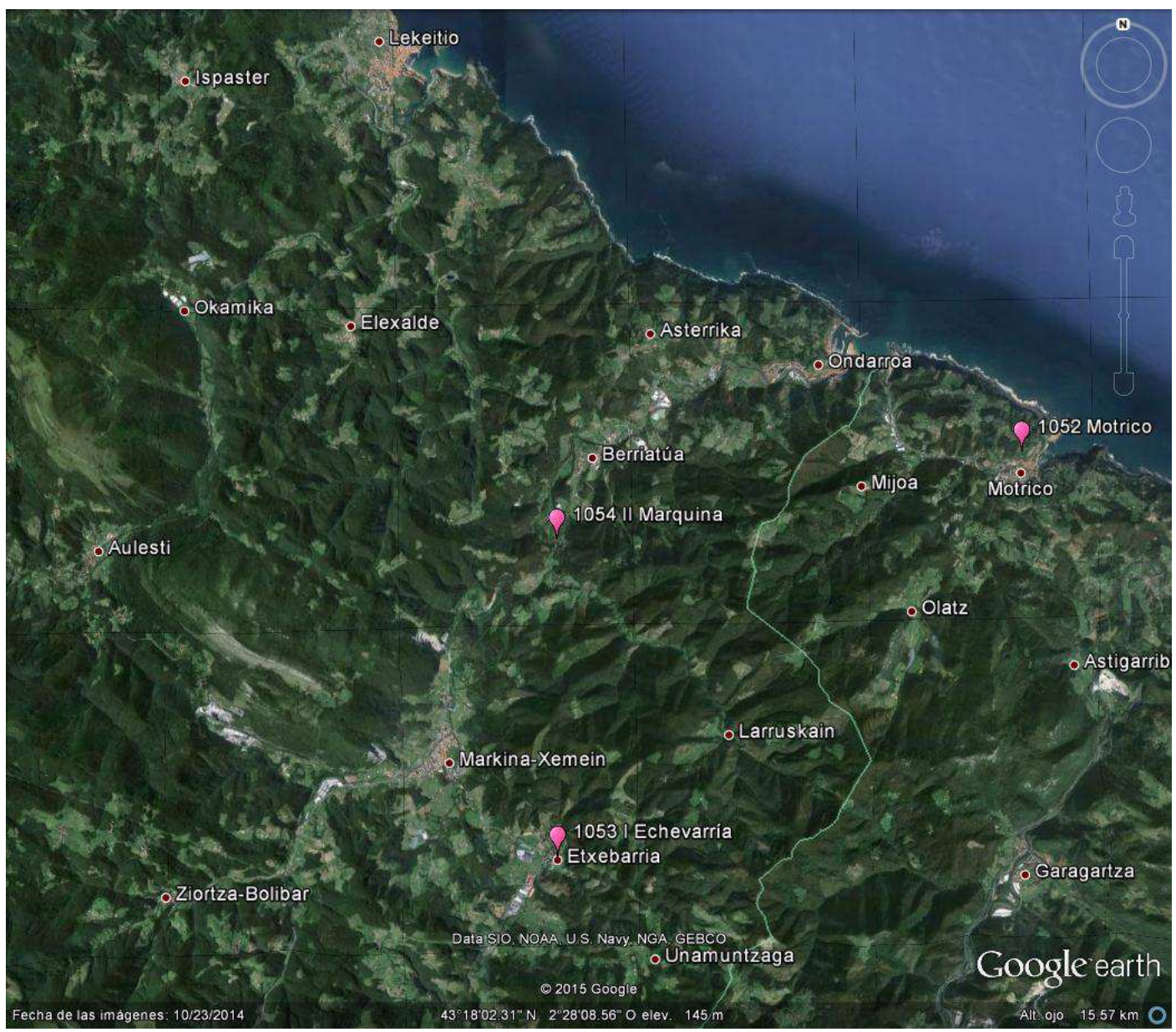

5.- La tabla 24 muestra que la pluviosidad media anual en $1052 \checkmark$ fue la menor de los 3 enclaves, coherente con un aumento de la pluviometría desde la costa hacia el interior.

Asimismo, las precipitaciones medias recogidas en 1053 I $\nabla$ y en 1054 II $\nabla$ son de cuantía muy similar, siendo ligeramente superiores en 1053 I $\nabla$ respecto a 1054 II $\nabla$ los años muy lluviosos y ligeramente inferiores en 1053 I $\nabla$ los años muy secos.

Por tanto, hay una coherencia espacial de las precipitaciones recogidas.

6.- 1960, 1965 y 1966 registran años de máximos pluviométricos simultáneos en 1060; 1964 y 1968 son mínimos de la pluviosidad en 1060A $\vee$, en 1060 I $\vee$ y en 1060 II $\nabla$ respectivamente (tabla 25 ).

7.- 1960, 1965 y 1966 son máximos pluviométricos y 1962 un mínimo en Guipúzcoa (tablas 31 y 31 bis, página 74).

8.- De 1958 a 1969 se suceden en 1054 II $\vee 3$ años de máximos y 3 de mínimos de precipitación, con una oscilación de los valores recogidos en torno a la mediana de la serie de valores de 1054 II $\nabla$ de 1957 a 1974. Esto máximos y mínimos concuerdan con los registrados en los enclaves cercanos.

Por tanto, se la considera como inhomogeneidad "climatológica". 
6.- Inhomogeneidad de 1962 a 1975 en 1060A:

Tabla 25: Años con precipitaciones máximas y mínimas:

\begin{tabular}{|c|c|c|c|c|c|}
\hline $\begin{array}{l}\text { Indicativo } \\
\text { y nombre }\end{array}$ & Duración serie & Año Máximo & $\begin{array}{c}\text { Precipitación } \\
\left(1 / \mathrm{m}^{2}\right)\end{array}$ & Año Mínimo & $\begin{array}{c}\text { Precipitación } \\
\left(1 / \mathrm{m}^{2}\right)\end{array}$ \\
\hline \multirow{4}{*}{$\begin{array}{l}\text { 1060A } \curlyvee \\
\text { Amurrio } \\
\text { Colegio }\end{array}$} & \multirow{4}{*}{$\begin{array}{c}1962-1979 \\
(\mathrm{sd} 1965,1966 \\
1968,1978)\end{array}$} & $1971\left(2^{\circ}\right)$ & 106,2 & $1964\left(1^{\circ}\right)$ & 65,4 \\
\hline & & $1975\left(3^{\circ}\right)$ & 101,1 & $1967\left(3^{\circ}\right)$ & 78,9 \\
\hline & & $1972\left(4^{\circ}\right)$ & 94,4 & $1970\left(4^{\circ}\right)$ & 79,4 \\
\hline & & $1974\left(4^{\circ}\right)$ & 94,4 & $1973\left(5^{\circ}\right)$ & 83,4 \\
\hline \multirow{2}{*}{$\begin{array}{l}1060 \text { I } 8 \\
\text { Amurrio }\end{array}$} & \multirow{2}{*}{$\begin{array}{c}1956-1966 \\
(\mathrm{sd} 1964)\end{array}$} & $1965\left(1^{\circ}\right)$ & 101,6 & & \\
\hline & & $1966\left(1^{\circ}\right)$ & 101,6 & & \\
\hline \multirow{3}{*}{$\begin{array}{l}1060 \text { II } P \\
\text { Amurrio }\end{array}$} & \multirow{3}{*}{$\begin{array}{c}1967-1992 \\
(\text { sd 1967) }\end{array}$} & $1971\left(2^{\circ}\right)$ & 124,0 & $1968\left(6^{\circ}\right)$ & 85,1 \\
\hline & & $1975\left(3^{\circ}\right)$ & 112,2 & $1973\left(9^{\circ}\right)$ & 88,6 \\
\hline & & $1974\left(10^{\circ}\right)$ & 99,0 & $1970\left(10^{\circ}\right)$ & 90,8 \\
\hline
\end{tabular}

1.-Los valores de 1060A $\nabla$ Amurrio Colegio se comparan con los registros de 1060 Amurrio Instituto de 1962 a 1975. 1060 tiene rupturas a finales de 1966 y de 1992, analizadas en el apartado 4.1 "Rupturas detectadas en las series de precipitación" (páginas 25 y 26$)$.

Por ello, se presentan en la tabla 25 los máximos y mínimos de 1060 en los intervalos de 1956 a 1966 (1060 I $\vee$ ) y de 1967 a 1992 (1060 II $\vee$ ).

2.- No hay datos coetáneos de precipitación media anual de 1060 I $\vee, 1060$ II $\nabla$ y 1060A $\vee$ en 1964, 1965, 1966, 1967 y 1968.

3.-La tabla 25 bis recoge las altitudes de 1060 y 1060A $\nabla$ y la distancia entre ambas.

Tabla 25 bis: Características geográficas de 1060 y 1060A:

$\begin{array}{cccc}\text { Indicativo } & \text { Nombre } & \text { Altitud }(\mathrm{m}) & \text { Distancia entre sí } \\ 1060 & \text { Amurrio Instituto } & 219 & 2,2 \mathrm{Km} \\ 1060 \mathrm{~A} \nabla & \text { Amurrio Colegio } & 190 & \end{array}$

1060A P se situó en el "Colegio de los alemanes" de Amurrio, en un edificio cuyo uso anterior fue de secadero de tabaco.

El jardín meteorológico de 1060 I $\vee, 1060$ II $\vee$ y 1060 III $\$$ se halla cerca del linde $\mathrm{NE}$ del recinto del Instituto Zaraobe, en su primigenia ubicación.

1060 y 1060A $\vee$ son enclaves situados extramuros de Amurrio. 1060A $P$.

3.- La figura 13 revela las ubicaciones de 1060 I $\nabla, 1060$ II $\nabla$ y 1060 III $\&$ y 
Figura 13: Emplazamientos de 1060 I $\vee, 1060$ II $\vee$ y 1060 III $\%$ y $1060 \mathrm{~A} \vee:$

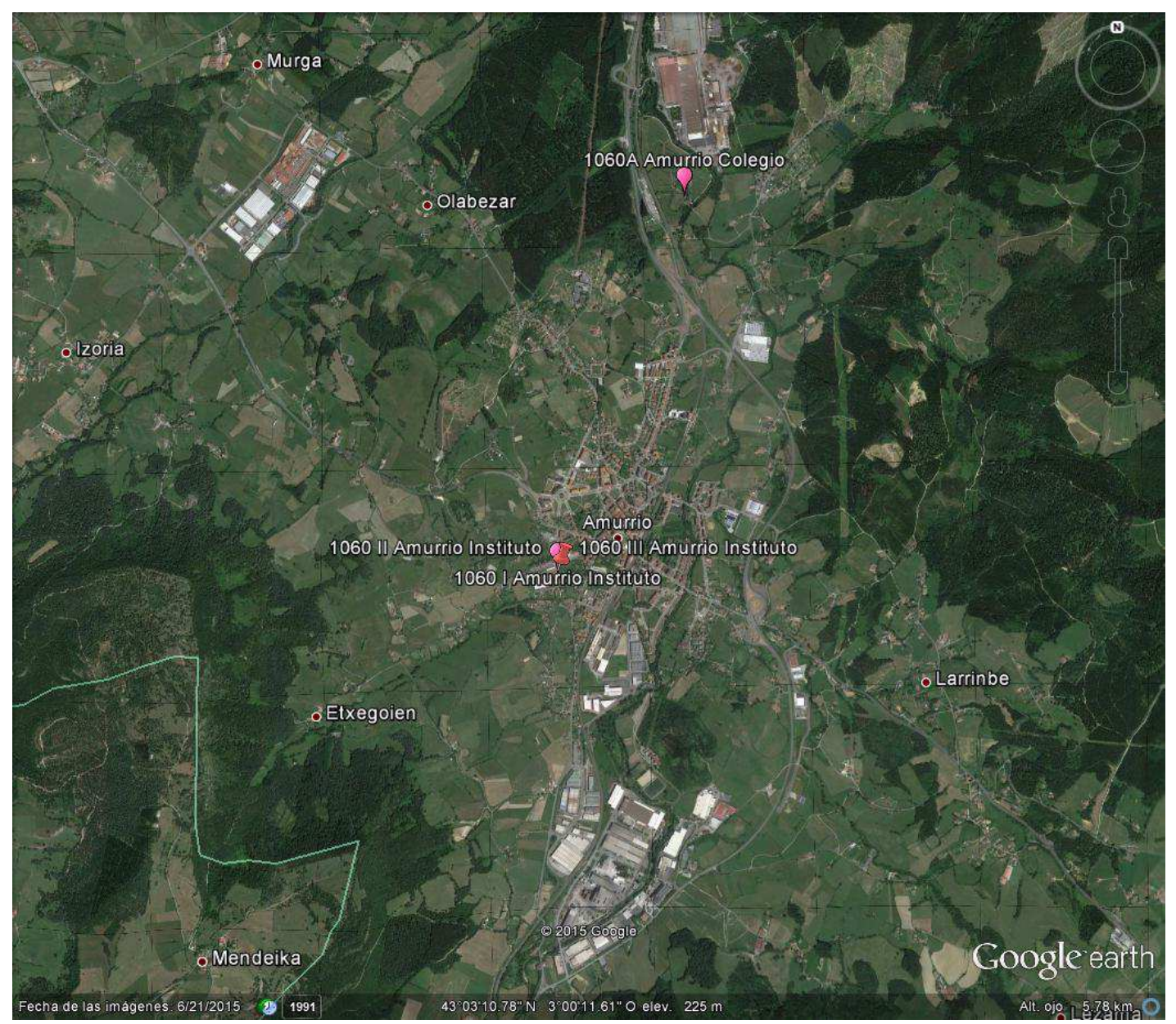

5.- Concurren los años con máximos pluviométricos de 1060A $\nabla$ y de 1060 II $\nabla$ : 1971, 1974 y 1975, los cuáles son a su vez lluviosos en 1070 \& Abadiano (1971, 1974 y 1975) y en 1075 II $\vee$ Dima (1974 y 1975), según refleja la tabla 26 (página 63).

6.- 1964 es un año de mínimo pluviométrico en 1060A $\nabla$, acaeciendo también en 1052 Potrico, 1053 I $\vee$ Echevarría y en 1054 II $\$$ Marquina (tabla 24, página 59).

7.- 1970 y 1973 son mínimos de precipitación sincrónicos en 1060 II $\$$ y en 1060A $\$$ y mínimos coetáneos de precipitación en 1070 ४ y en 1075 II $\$$ (tabla 26).

8.- Las cantidades de precipitación registradas en 1060 II $\nabla$ rebasan del orden del $10 \%$ las recogidas en $1060 \mathrm{~A} P$.

9.- En Guipúzcoa 1974 es un máximo de pluviosidad y 1970 un mínimo (tablas 31 y 31 bis, página 74).

10.- Los años más lluviosos y secos en 1060A $\$$ acontecen entre 1962 y 1975 , con una oscilación de la precipitación observada alrededor de la mediana de 1060A $\nabla$.

Por tanto, se la clasifica como inhomogeneidad "climatológica" a escala comarcal. 
7.- Inhomogeneidades de 1967 a 1979 en 1060 A y de 1968 a 1977 en 1070 y en 1075 :

Tabla 26: Años con precipitaciones máximas y mínimas:

\begin{tabular}{|c|c|c|c|c|c|}
\hline $\begin{array}{l}\text { Indicativo } \\
\text { y nombre }\end{array}$ & Duración serie & Año Máximo & $\begin{array}{c}\text { Precipitación } \\
\left(1 / \mathrm{m}^{2}\right)\end{array}$ & Año Mínimo & $\begin{array}{c}\text { Precipitación } \\
\left(1 / \mathrm{m}^{2}\right)\end{array}$ \\
\hline \multirow{4}{*}{$\begin{array}{c}1070 \vee \\
\text { Abadiano }\end{array}$} & \multirow{4}{*}{$\begin{array}{c}1968-2001 \\
(\mathrm{sd} 1989,1990)\end{array}$} & $1974\left(3^{\circ}\right)$ & 141,2 & $1970\left(4^{\circ}\right)$ & 104,2 \\
\hline & & $1975\left(7^{\circ}\right)$ & 134,8 & $1976\left(6^{\circ}\right)$ & 107,8 \\
\hline & & $1971\left(9^{\circ}\right)$ & 129,6 & $1973\left(7^{\circ}\right)$ & 108,2 \\
\hline & & $1972\left(12^{\circ}\right)$ & 127,4 & $1968\left(10^{\circ}\right)$ & 113,4 \\
\hline \multirow{3}{*}{$\begin{array}{c}1075 \text { II } \vee \\
\text { Dima }\end{array}$} & \multirow{3}{*}{$1968-1977$} & $1975\left(1^{\circ}\right)$ & 160,1 & $1970\left(1^{\circ}\right)$ & 106,4 \\
\hline & & $1974\left(2^{\circ}\right)$ & 158,4 & $1968\left(2^{\circ}\right)$ & 112,4 \\
\hline & & $1977\left(3^{\circ}\right)$ & 131,8 & $1973\left(3^{\circ}\right)$ & 122,4 \\
\hline \multirow{4}{*}{$\begin{array}{l}\text { 1060A } \supsetneq \\
\text { Amurrio } \\
\text { Colegio }\end{array}$} & \multirow{4}{*}{$\begin{array}{c}1962-1979 \\
\text { (sd 1965, 1966, } \\
1968,1978)\end{array}$} & $1979\left(1^{\circ}\right)$ & 116,7 & $1976\left(2^{\circ}\right)$ & 70,4 \\
\hline & & $1971\left(2^{\circ}\right)$ & 106,2 & $1967\left(3^{\circ}\right)$ & 78,9 \\
\hline & & $1975\left(3^{\circ}\right)$ & 101,1 & $1970\left(4^{\circ}\right)$ & 79,4 \\
\hline & & $1972\left(4^{\circ}\right)$ & 92,4 & $1973\left(5^{\circ}\right)$ & 83,4 \\
\hline \multirow{4}{*}{$\begin{array}{c}1060 \text { II } \nabla \\
\text { Amurrio }\end{array}$} & \multirow{4}{*}{$\begin{array}{c}1967-1992 \\
(\text { sd 1967) }\end{array}$} & $1979\left(1^{\circ}\right)$ & 124,0 & $1968\left(6^{\circ}\right)$ & 85,1 \\
\hline & & $1971\left(2^{\circ}\right)$ & 124,0 & $1976\left(7^{\circ}\right)$ & 85,6 \\
\hline & & $1975\left(3^{\circ}\right)$ & 112,2 & $1973\left(9^{\circ}\right)$ & 88,6 \\
\hline & & $1977\left(7^{\circ}\right)$ & 101,8 & $1970\left(10^{\circ}\right)$ & 90,8 \\
\hline
\end{tabular}

Los datos de 1060 II $P$ Amurrio de 1967 a 1979 se añaden como cotejo, dada la gran calidad de las medidas y la excelsa homogeneidad de 1060 I $\nabla, 1060$ II $\nabla$ y 1060 III $\$$.

La tabla 26 bis muestra la altitud, la distancia a la divisoria de aguas y la orientación del valle de cada uno de los 4 enclaves.

Tabla 26 bis: Características geográficas de 1070 २, 1075 II $\vee, 1060 \mathrm{~A} \vee$ y 1060 II $\vee$ :

\begin{tabular}{|c|c|c|c|c|}
\hline Indicativo & Nombre & Altitud (m) & $\begin{array}{c}\text { Distancia a divisoria } \\
\text { aguas }(\mathrm{Km} .)\end{array}$ & $\begin{array}{l}\text { Orientación } \\
\text { valle }\end{array}$ \\
\hline $1070 \vee$ & Abadiano & 177 & 5,2 & SW a NE \\
\hline $1075 \mathrm{II} \vee$ & Dima & 574 & 1,4 & $\mathrm{~S}$ a N \\
\hline 1060A 8 & Amurrio Colegio & 190 & 9,8 & $\mathrm{~S}$ a N \\
\hline 1060 II $\vee$ & Amurrio & 219 & 8,2 & $\mathrm{~S}$ a N \\
\hline
\end{tabular}

De la tabla 26 bis, los 4 emplazamientos tienen altitudes muy próximas y se encuentran en el extremo sur de las series analizadas, a una distancia entre 1,4 y 9,8 Km. de la divisoria de aguas entre la vertiente atlántica y la mediterránea

La orientación de los valles en que se sitúan es similar, correspondiendo el valle más abierto a Amurrio, ubicado en la vertiente cantábrica de Álava. 1060 II 8 .

La figura 14 muestra las localizaciones de $1070 \vee, 1075$ II $\vee, 1060 \mathrm{~A} \vee$ y 


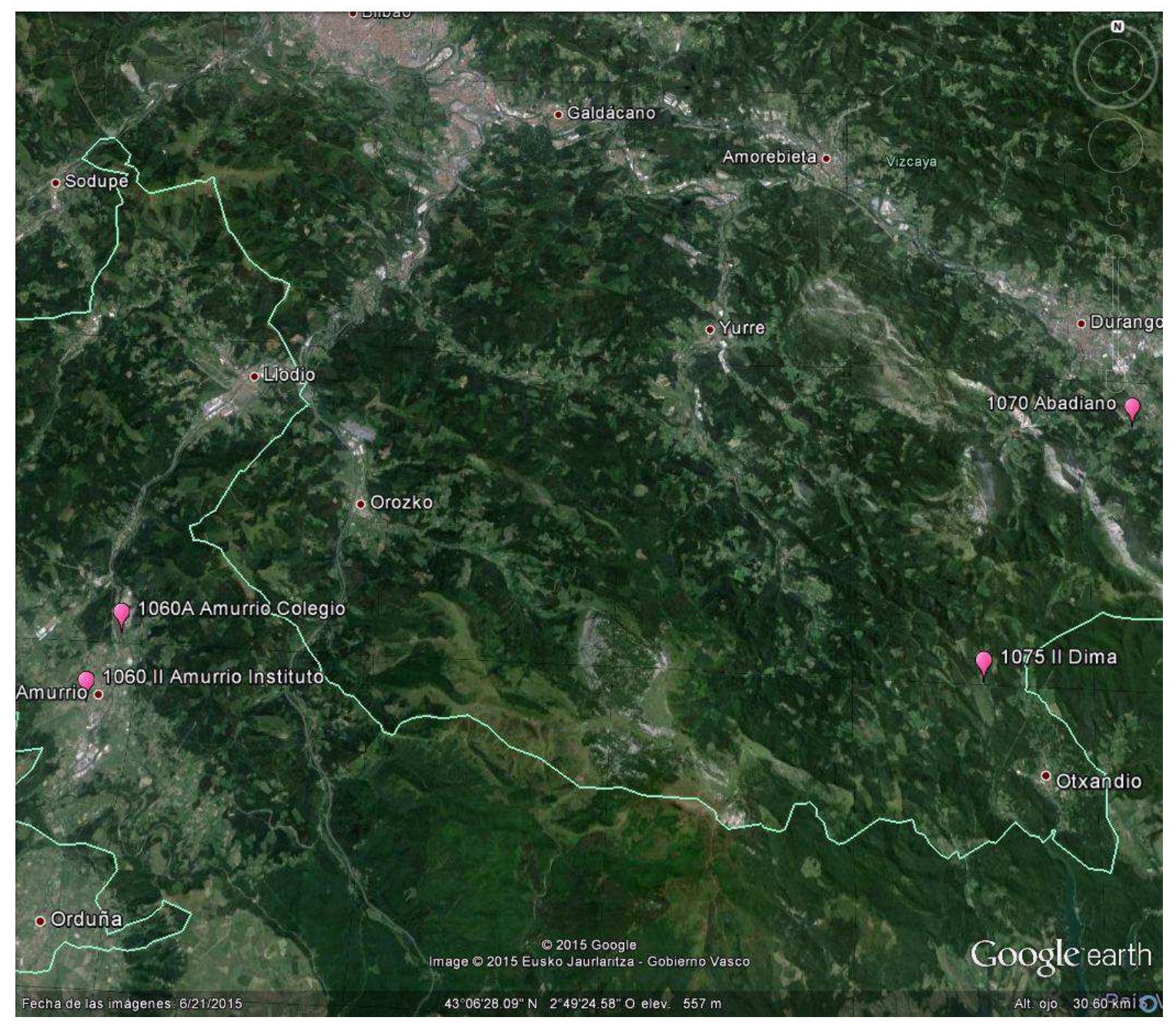

1.- Concuerdan los años con máximos (1971, 1974, 1975 y 1979) y mínimos de precipitación (1968, 1970, 1973 y 1976).

2.- 1974, 1975 y 1979 son máximos pluviométricos concurrentes en 1079I 8 Gordejuela, en 1078E I $\vee$ Valmaseda y en 1093 I $\vee$ Carranza y 1976 mínimo en 1078E I $\vee$ y en 1093 I $\vee$ (tabla 27, página 65).

3.- La tabla 28 (página 68) refiere como 1979 es asimismo un máximo de pluviosidad en $1071 \vee$ Durango, en 1053 II $\vee$ y en $1070 \vee$ y 1976 un mínimo en 1071 P.

4.- En Guipúzcoa acontecen máximos pluviométricos en 1974 y 1979 y un mínimo en 1970 (tablas 31 y 31 bis, página 74).

5.- Hay una concomitancia espacial de las precipitaciones medidas en los 4 lugares. Así, de la tabla 26 se observa:

a) Las precipitaciones recogidas en 1075 II $\nabla$ superan en un 10 al $15 \%$ a las de $1070 \vee$ los años lluviosos y del 2 al $12 \%$ los años secos. 
b) Las precipitaciones registradas en $1070 \nabla$ son en torno del 5 al $13 \%$ superiores a las de 1060 II $\vee$ los años pluviosos y de un 10 al $20 \%$ los años áridos.

c) Las precipitaciones medidas en 1060 II $\nabla$ sobrepasan las de $1060 \mathrm{~A} \nabla$ un 5 al $15 \%$ los años lluviosos y del 5 al $18 \%$ los años de sequía.

Amurrio (1060 II $\nabla$ y 1060A $\vee$ ), situado en la vertiente atlántica de Álava, es la localidad con una pluviometría inferior de las 3 poblaciones en el intervalo de años analizados.

Esto es, el cociente entre las precipitaciones registradas es aproximadamente constante.

6.- En el intersticio de años estudiado en la tabla 26, transcurren años muy lluviosos y años secos o muy secos en los 4 enclaves, fluctuando las precipitaciones recogidas en torno a las respectivas medianas. comarcal.

Por todo lo expuesto, se trata de una inhomogeneidad "climatológica" a escala

8.- Inhomogeneidades de 1973 a 1988 en 1079I, de 1975 a 1984 en 1078 E y de 1977 a 1990 en 1078E:

Tabla 27: Años con precipitaciones máximas y mínimas:

\begin{tabular}{|c|c|c|c|c|c|}
\hline $\begin{array}{l}\text { Indicativo } \\
\text { y nombre }\end{array}$ & Duración serie & Año Máximo & $\begin{array}{c}\text { Precipitación } \\
\left(1 / \mathrm{m}^{2}\right)\end{array}$ & Año Mínimo & $\begin{array}{c}\text { Precipitación } \\
\left(1 / \mathrm{m}^{2}\right)\end{array}$ \\
\hline \multirow{3}{*}{$\begin{array}{c}\text { 1079I } \vee \\
\text { Gordejuela }\end{array}$} & \multirow{3}{*}{$\begin{array}{c}1973-1988 \\
(\text { sd 1976, 1981) }\end{array}$} & $1975\left(1^{\circ}\right)$ & 131,5 & $1985\left(1^{\circ}\right)$ & 64,1 \\
\hline & & $1979\left(2^{\circ}\right)$ & 124,8 & $1980\left(2^{\circ}\right)$ & 80,8 \\
\hline & & $1974\left(3^{\circ}\right)$ & 115,9 & $1987\left(3^{\circ}\right)$ & 82,8 \\
\hline \multirow{4}{*}{$\begin{array}{l}\text { 1078E I } \supsetneq \\
\text { Valmaseda }\end{array}$} & \multirow{4}{*}{$\begin{array}{c}1972-1991 \\
(\operatorname{sd} 1986)\end{array}$} & $1979\left(1^{\circ}\right)$ & 137,6 & $1981\left(3^{\circ}\right)$ & 94,3 \\
\hline & & $1975\left(2^{\circ}\right)$ & 128,6 & $1983\left(4^{\circ}\right)$ & 95,9 \\
\hline & & $1978\left(3^{\circ}\right)$ & 124,6 & $1976\left(7^{\circ}\right)$ & 99,2 \\
\hline & & $1974\left(5^{\circ}\right)$ & 120,9 & & \\
\hline \multirow{4}{*}{$\begin{array}{l}\text { 1078E I } P \\
\text { Valmaseda }\end{array}$} & \multirow{4}{*}{$\begin{array}{c}1972-1991 \\
(\mathrm{sd} 1986)\end{array}$} & $1979\left(1^{\circ}\right)$ & 137,6 & $1989\left(1^{\circ}\right)$ & 72,5 \\
\hline & & $1978\left(3^{\circ}\right)$ & 124,6 & $1990\left(2^{\circ}\right)$ & 92,3 \\
\hline & & $1984\left(4^{\circ}\right)$ & 124,2 & $1981\left(3^{\circ}\right)$ & 94,3 \\
\hline & & $1982\left(6^{\circ}\right)$ & 118,0 & $1983\left(4^{\circ}\right)$ & 95,9 \\
\hline \multirow{4}{*}{$\begin{array}{l}1093 \text { I } \curlyvee \\
\text { Carranza }\end{array}$} & \multirow{4}{*}{$\begin{array}{c}1957-1983 \\
(\text { sd 1959, 1967) }\end{array}$} & $1978\left(1^{\circ}\right)$ & 183,4 & $1981\left(2^{\circ}\right)$ & 90,2 \\
\hline & & $1979\left(2^{\circ}\right)$ & 156,0 & $1982\left(8^{\circ}\right)$ & 110,5 \\
\hline & & $1975\left(3^{\circ}\right)$ & 152,8 & $1976\left(11^{\circ}\right)$ & 115,2 \\
\hline & & $1974\left(5^{\circ}\right)$ & 141,4 & & \\
\hline
\end{tabular}

1.- Las inhomogeneidades se detectan en 1079I $\nabla$ y en 1078E I $\nabla$, sitas ambas en la comarca de las Encartaciones. 
1.- Las filas $4^{\mathrm{a}}$ a $7^{\mathrm{a}}$ reflejan los años con máximos y mínimos pluviométricos de 1078E I \& Valmaseda de 1975 a 1984; las filas $8^{\mathrm{a}}$ a $11^{\mathrm{a}}$ los años extremos de 1977 a 1990 de 1078E I 8 .

Los valores de 1093 I $\vee$ Carranza de 1973 a 1983 se incluyen como confrontación en la tabla 27.

2.- La tabla 27 bis describe las altitudes de 1079I $\nabla$, 1078E I $\nabla$ y 1093 I $\nabla$ y el espacio de 1079I $\nabla$ y 1093 I $\vee$ a 1078 E I $\nabla$.

Tabla 27 bis: Características geográficas de 1079I $\vee, 1078$ E I $\vee$ y 1093 I $\vee$ :

\begin{tabular}{|c|c|c|c|}
\hline Indicativo & Nombre & Altitud (m) & Distancia a 1078E I $\vee(\mathrm{Km})$. \\
\hline 1079I $P$ & Gordejuela & 80 & 9,9 \\
\hline 1078E I $\vee$ & Valmaseda & 140 & \\
\hline 1093 I P & Carranza & 220 & 14,3 \\
\hline
\end{tabular}

2.- La figura 15 refleja las ubicaciones de $1079 \mathrm{I} \vee$, 1078E I $\nabla$ y 1093 I $\vee$ :

Figura 15: Emplazamientos de 1079I $\vee, 1078$ E I $\vee$ y 1093 I $\vee:$

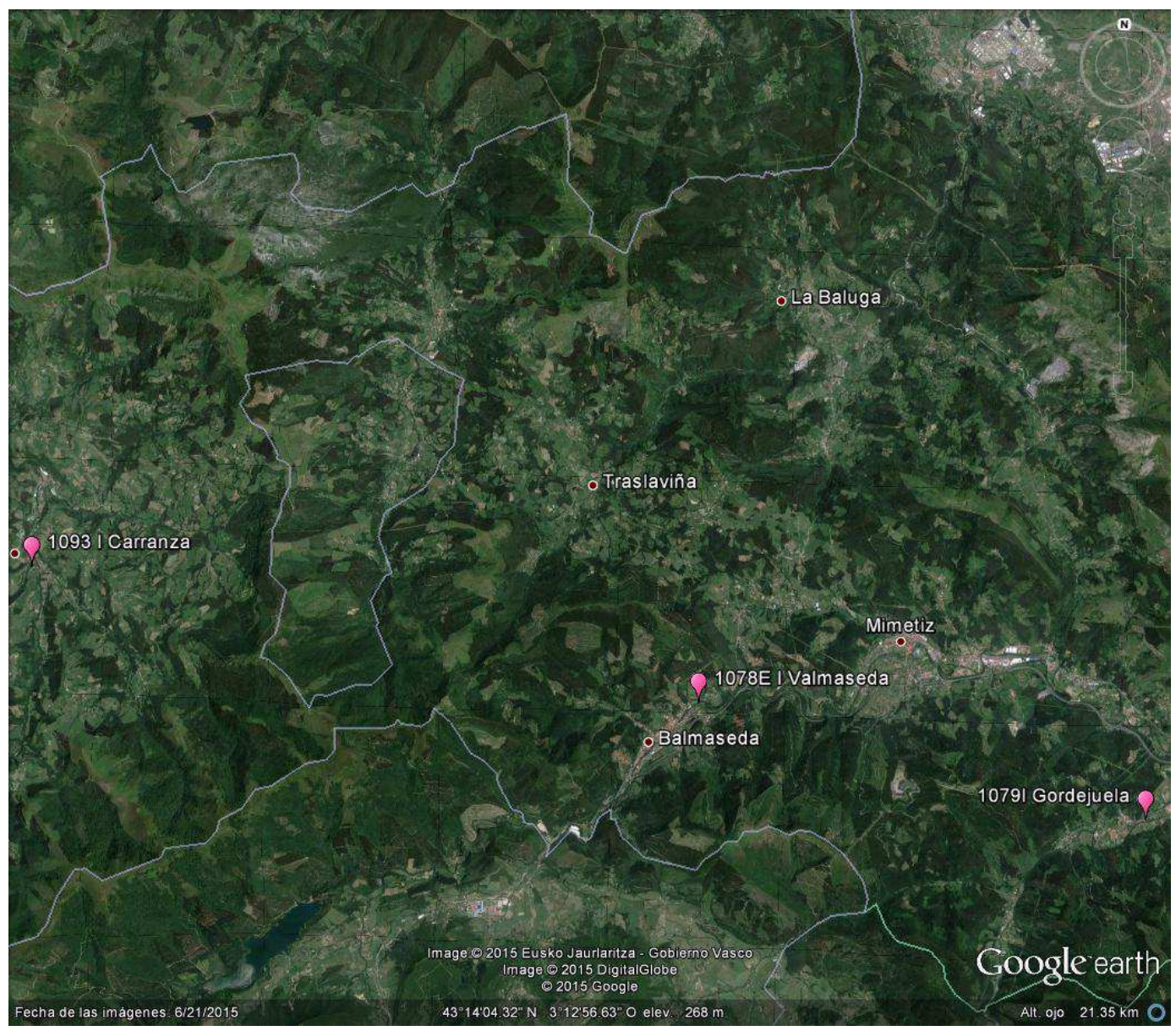


3.- Los pluviómetros de 1079I $\vee$ y 1093 I $\vee$ estuvieron localizados en los valles más occidentales de Vizcaya (cuyos ríos fluyen hacia el $\mathrm{N}-\mathrm{NE}$ ), a menos de $15 \mathrm{Km}$. de distancia de 1078E I $\nabla$ y con una diferencia de altitudes inferior a $150 \mathrm{~m}$.

4.- Los máximos de precipitación de 1974, 1975, 1978 y 1979 coinciden en los 3 lugares de la tabla 27.

5.- Los máximos expuestos en la tabla 27 corresponden con los de otras ubicaciones:

a) 1974 y 1975 son máximos coetáneos en 1060 II $\nabla$ Amurrio Instituto, 1060A $P$ Amurrio Colegio, $1070 \vee$ Abadiano, 1075 II $\vee$ Dima, 1078E I $\nabla$ y 1079I $\nabla$ (tablas 25, 26 y 27, páginas 61,63 y 65).

b) Un máximo pluviométrico acaece en 1979 en 1060 II $\nabla, 1060 \mathrm{~A} \vee, 1071 \nabla$ Durango y 1053 II $\vee$ Echevarría (tablas 26 y 28).

d) 1984 es un año lluvioso en 1071 \ y 1049 U $\vee$ Ermua (tabla 28, página 68).

6.- Los mínimos de pluviosidad de 1989, 1981, 1985, 1976, 1987 (tabla 27) son concurrentes a los de otros lugares:

a) 1976 es un mínimo secundario de precipitación sincrónico en 1070 \&, 1060 II $\vee$ y $1060 \mathrm{~A} \vee$ (tabla 26) y en $1071 \nabla$ (tabla 28).

b) En 1985 concurre un año seco simultáneo en $1071 \nabla, 1053$ II $\vee, 1070 \vee$ y 1049 U $\vee$ (tabla 28).

c) 1987 marca un mínimo secundario de precipitación en 1053 II $\nabla, 1070$, 1049 U $\vee$ y 1055A I $\vee$ Lequeitio (tablas 28 y 29, páginas 68 y 70).

d) 1989 es el año más seco en 1071 P, 1053 II $\vee, 1049$ U $\vee$ (tabla 28), 1055A I $\vee$ y en $1041 \vee$ (tabla 29) y 1990 es un año seco en 1053 II $\vee$ (tabla 28).

7.- En Guipúzcoa se suceden máximos pluviométricos en 1974, 1979 y 1984 y mínimos en 1983 y 1989 (tablas 31 y 31 bis, página 74).

8.- Hay una congruencia de las precipitaciones medidas en 1079I $\nabla$ y en 1078E I $\nabla$.

De la tabla 27, se aprecia que en los años lluviosos las precipitaciones son de una magnitud similar, fluctuando las de 1079I $P$ entre el $90 \%$ y el 102\% de las de 1078E I $P$, reflejo de la altitud ligeramente superior de 1078E I $\nabla$ (60 m. más elevada); 1093 I $\nabla$ rebasa entre un 15 y un $33 \%$ la cuantía de las precipitaciones de 1078E I $\nabla$.

Las cantidades fluctúan en los años secos entre el 85 y el 105\% (tabla 27).

9.- Los años más lluviosos y los más secos en 1079I $\nabla$ y 1078E I $\nabla$ ocurren en el intervalo de años escrutado en la tabla 27, oscilando las precipitaciones recogidas en torno a las respectivas medianas.

Por tanto, se la cataloga como inhomogeneidad "climatológica". 
9.- Inhomogeneidades de 1975 a 1991 en 1071 , de 1979 a 1993 en 1053 y de 1979 a 1997 en 1070:

Tabla 28: Años con precipitaciones máximas y mínimas:

\begin{tabular}{|c|c|c|c|c|c|}
\hline $\begin{array}{l}\text { Indicativo } \\
\text { y nombre }\end{array}$ & Duración serie & Año Máximo & $\begin{array}{c}\text { Precipitación } \\
\left(1 / \mathrm{m}^{2}\right)\end{array}$ & Año Mínimo & $\begin{array}{c}\text { Precipitación } \\
\left(1 / \mathrm{m}^{2}\right)\end{array}$ \\
\hline \multirow{4}{*}{$\begin{array}{c}1071 \vee \\
\text { Durango }\end{array}$} & \multirow{4}{*}{$\begin{array}{c}1968-1993 \\
(\text { sd 1988) }\end{array}$} & $1979\left(2^{\circ}\right)$ & 148,4 & $1989\left(1^{\circ}\right)$ & 92,5 \\
\hline & & $1986\left(3^{\circ}\right)$ & 138,7 & $1985\left(3^{\circ}\right)$ & 100,2 \\
\hline & & $1984\left(6^{\circ}\right)$ & 133,3 & $1983\left(5^{\circ}\right)$ & 106,9 \\
\hline & & $1991\left(7^{\circ}\right)$ & 130,8 & $1976\left(6^{\circ}\right)$ & 108,9 \\
\hline \multirow{4}{*}{$\begin{array}{l}1053 \text { II } \supsetneq \\
\text { Echevarría }\end{array}$} & \multirow{4}{*}{$1976-1996$} & $1979\left(1^{\circ}\right)$ & 193,1 & $1989\left(1^{\circ}\right)$ & 83,2 \\
\hline & & $1981\left(3^{\circ}\right)$ & 145,3 & $1985\left(3^{\circ}\right)$ & 98,9 \\
\hline & & $1992\left(4^{\circ}\right)$ & 144,4 & $1990\left(5^{\circ}\right)$ & 108,2 \\
\hline & & $1986\left(5^{\circ}\right)$ & 143,3 & $1987\left(6^{\circ}\right)$ & 110,1 \\
\hline \multirow{4}{*}{$\begin{array}{c}1070 \varnothing \\
\text { Abadiano }\end{array}$} & \multirow{4}{*}{$\begin{array}{c}1968-2001 \\
(\operatorname{sd} 1989,1990)\end{array}$} & $1996\left(1^{\circ}\right)$ & 151,0 & $1985\left(2^{\circ}\right)$ & 98,0 \\
\hline & & $1992\left(2^{\circ}\right)$ & 147,2 & $1995\left(3^{\circ}\right)$ & 102,7 \\
\hline & & $1982\left(4^{\circ}\right)$ & 138,9 & $1987\left(5^{\circ}\right)$ & 106,6 \\
\hline & & $1979\left(5^{\circ}\right)$ & 137,5 & $1983\left(8^{\circ}\right)$ & 109,0 \\
\hline \multirow{4}{*}{$\begin{array}{c}1049 \mathrm{U} P \\
\text { Ermua }\end{array}$} & \multirow{4}{*}{$1983-2005$} & $1992\left(1^{\circ}\right)$ & 160,0 & $1989\left(1^{\circ}\right)$ & 81,3 \\
\hline & & $1984\left(2^{\circ}\right)$ & 159,3 & $1985\left(3^{\circ}\right)$ & 97,8 \\
\hline & & $1986\left(5^{\circ}\right)$ & 137,0 & $1987\left(6^{\circ}\right)$ & 110,3 \\
\hline & & $1988\left(7^{\circ}\right)$ & 132,0 & $1983\left(7^{\circ}\right)$ & 110,8 \\
\hline
\end{tabular}

1.- Los datos de 1053 II $\vee, 1070 \vee$ y $1071 \vee$ se contrastan con los de $1049 \mathrm{U} \vee$ Ermua de 1983 a 1992.

2.- La tabla 19 (página 52) refleja una inhomogeneidad de tipo "climatológico" en 1049 U $\vee$ en la precipitación media anual de 1983 a 1992.

3.- En la Nota Técnica No 13 de AEMET “Análisis de la homogeneidad de las series de precipitación de Guipúzcoa” se propone a 1049U $\vee$ Ermua como una serie de referencia para la comarca del Medio Deba por su elevada homogeneidad. 1053 II $P$.

4.- La tabla 28 bis recoge la altitud y la distancia a $1049 \mathrm{U} \vee$ de $1071 \vee, 1070 \vee$ y

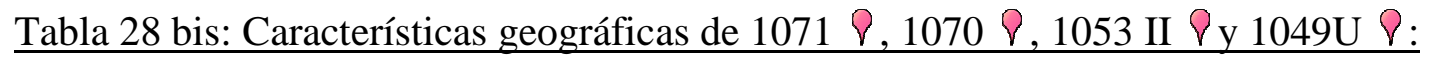

$\begin{array}{rccc}\text { Indicativo } & \text { Nombre } & \text { Altitud }(\mathrm{m}) & \text { Distancia a } 1049 \mathrm{U} \vee(\mathrm{Km} .) \\ 1071 \varnothing & \text { Durango } & 280 & 12,4 \\ 1070 \varnothing & \text { Abadiano } & 177 & 10,4 \\ 1053 \mathrm{II} \varnothing & \text { Echevarría } & 107 & 7,5 \\ 1049 \mathrm{U} \odot & \text { Ermua } & 226 & \end{array}$


La figura 16 se representan los enclaves de $1071 \nabla, 1053$ II $\vee, 1070 \vee$ y 1049 U $\vee$ : Figura 16: Emplazamientos de 1071 २, 1070 २, 1053 II $\vee y$ 1049U $\vee:$

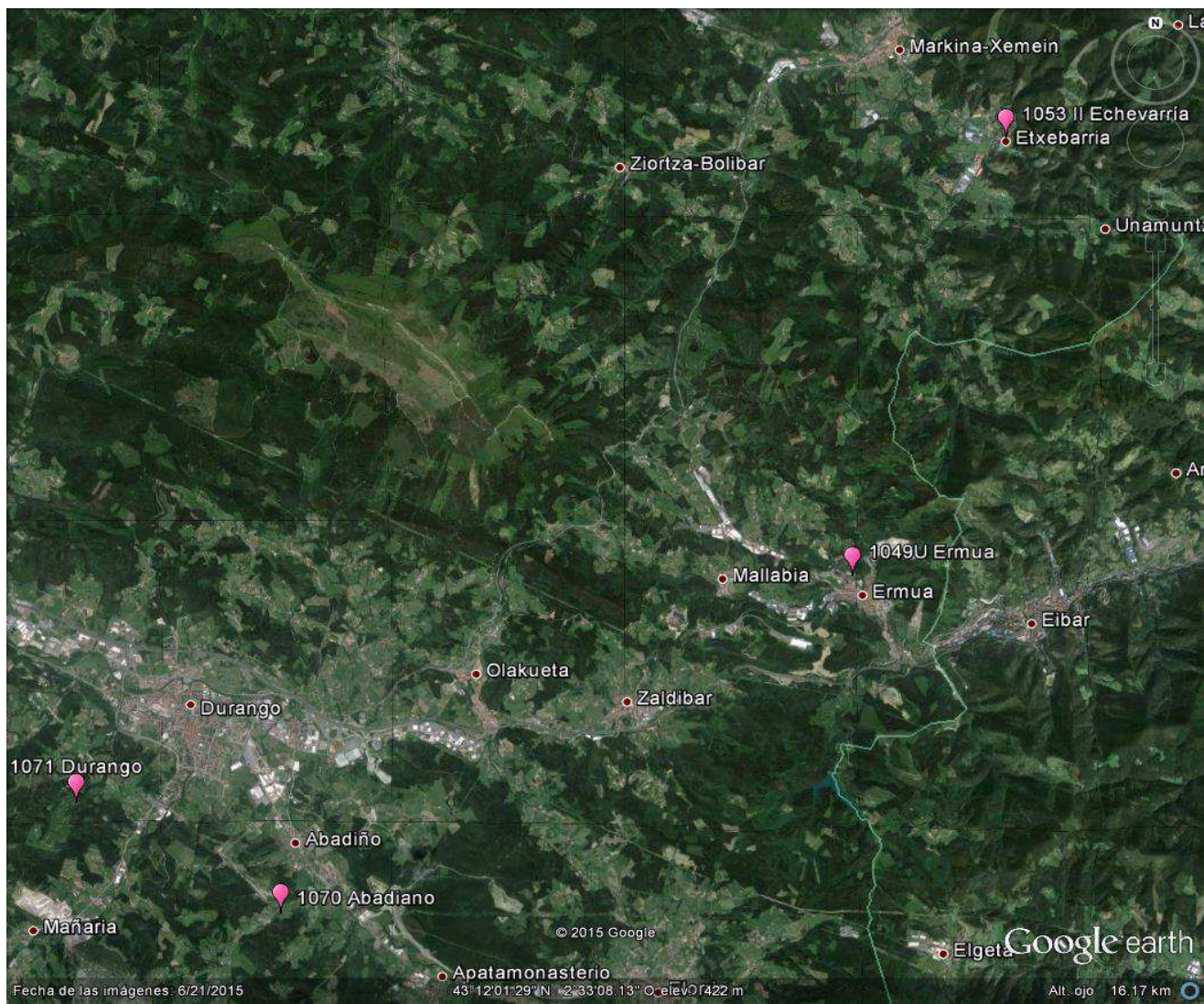
entre sí.

4.1.- 1053 II $\vee$ y 1049U $\vee$ están en valles orientados de W a Este y distan 7,5 Km.

4.2.- $1071 \vee$ y $1070 \bigcirc$ se encuentran al $\mathrm{W}$ de $1049 \mathrm{U} \vee$ y a 3,8 Km. de distancia.

5.- Los máximos (1979, 1984, 1986 y 1992) y mínimos (1983, 1985, 1987 y 1989) concuerdan en las 4 localizaciones.

6.- 1996 es un año con un máximo relativo de precipitación en 1055A I 8 Lequeitio y en $1041 \vee$ Zumaya, siendo 1987 y 1989 mínimos en 1055A I $\vee$ (tabla 29).

7.- En Guipúzcoa acaecen máximos pluviométricos en 1979, 1984, 1986 y 1992 y mínimos en 1983 y 1989 (tablas 31 y 31 bis, página 74).

En Guipúzcoa los máximos de la pluviosidad anual se focalizan de 1978 a 1980; sin embargo en 1071 ○ el año más lluvioso acontece en 1992, seguido de 1979; en 1070 los máximos de precipitación anual son 1996 y 1992 y en 1075E II $\vee$ Aránzazu transcurren en 1996, 1984 y 1992.

8.- Hay una coherencia espacial de las precipitaciones. Las cantidades de precipitación recogidas en los 4 lugares son bastante similares, siendo ligeramente más lluviosos 1049U $\nabla$ y 1071 (tabla 28), congruente con el hecho de estar ligeramente más elevados (tabla 28 bis). 
9.- $1071 \vee, 1070 \vee$ y 1053 II $\nabla$ son las únicas series de Vizcaya y la vertiente cantábrica de Álava en que se detecta esta inhomogeneidad. De la tabla 19 (página 52), se aprecia una inhomogeneidad "climatológica" común a 1049U P, 1014 II \& Aeropuerto Fuenterrabía, 1021E I $\vee$ Añarbe, 1024 I $\vee$ Ategorrieta, 1024 E Igueldo, 1035 Lasarte y 1036 \& Zarauz.

Esta inhomogeneidad "climatológica" se detecta en este intervalo temporal solamente en la comarca de San Sebastián y en la zona limítrofe interior entre Vizcaya y Guipúzcoa en las series investigadas, situadas en cuencas que vierten al litoral de Vizcaya y de Guipúzcoa.

10.- Los años más pluviosos y más áridos en los 4 emplazamientos se suceden en el intersticio anual examinado en la tabla 28, fluctuando las medidas de precipitación en torno a las respectivas medianas.

11.- Por tanto, se la califica como inhomogeneidad "climatológica.

10.- Inhomogeneidades de 1987 a 2000 en $1055 \mathrm{~A}:$

Tabla 29: Años con precipitaciones máximas y mínimas:

\begin{tabular}{|c|c|c|c|c|c|}
\hline $\begin{array}{c}\text { Indicativo y } \\
\text { nombre }\end{array}$ & Duración serie & Año Máximo & $\begin{array}{c}\text { Precipitación } \\
\left(1 / \mathrm{m}^{2}\right)\end{array}$ & Año Mínimo & $\begin{array}{c}\text { Precipitación } \\
\left(1 / \mathrm{m}^{2}\right)\end{array}$ \\
\hline \multirow{4}{*}{$\begin{array}{l}\text { 1055A I } 8 \\
\text { Lequeitio }\end{array}$} & \multirow{4}{*}{$\begin{array}{c}1987-2005 \\
(\mathrm{sd} 1991,1992, \\
1997)\end{array}$} & $1996\left(1^{\circ}\right)$ & 116,0 & $1989\left(1^{\circ}\right)$ & 74,2 \\
\hline & & $2000\left(2^{\circ}\right)$ & 103,6 & $1995\left(2^{\circ}\right)$ & 78,4 \\
\hline & & $1994\left(3^{\circ}\right)$ & 103,2 & $1987\left(4^{\circ}\right)$ & 83,4 \\
\hline & & $1988\left(4^{\circ}\right)$ & 99,9 & $1998\left(7^{\circ}\right)$ & 90,4 \\
\hline \multirow{4}{*}{$\begin{array}{l}10418 \\
\text { Zumaya }\end{array}$} & \multirow{4}{*}{$\begin{array}{c}1987-2007 \\
(\mathrm{sd} 1987,1990 \\
1991,1992,1997)\end{array}$} & $1993\left(1^{\circ}\right)$ & 113,4 & $1989\left(1^{\circ}\right)$ & 68,5 \\
\hline & & $1996\left(2^{\circ}\right)$ & 110,2 & $1995\left(3^{\circ}\right)$ & 89,6 \\
\hline & & $1994\left(3^{\circ}\right)$ & 109,2 & $2000\left(7^{\circ}\right)$ & 99,5 \\
\hline & & $1988\left(5^{\circ}\right)$ & 105,8 & $1998\left(9^{\circ}\right)$ & 103,3 \\
\hline
\end{tabular}

1.- Los valores de 1055A I 8 Lequeitio se confrontan con los registros de 10418 Zumaya al ser el enclave costero más cercano con datos de precipitación de 1987 a 2000.

2.- De la tabla 19 (página 52) se observa una inhomogeneidad de tipo “climatológico" en 1041 Zumaya en la precipitación media anual de 1988 a 2001, simultánea a la inhomogeneidad de 1055 A I $\nabla$.

Los valores de $1041 \bigcirc$ incluidos en la tabla 29 se refieren al intervalo de 1988 a 2000, por su carencia de mediciones de Agosto de 1987.

3.- Las medidas pluviométricas de 1055A I $\nabla$ y 1041 \& se efectúan en el huerto de dos conventos de clausura en el margen NW de las afueras del núcleo urbano de dos poblaciones costeras.

Al NW de Zumaya y de Lequeitio se elevan sendas colinas no muy elevadas. 1041 Z Zumaya y 1055A I $\nabla$ Lequeitio distan $21 \mathrm{Km}$. entre sí, siendo sus altitudes $12 \mathrm{~m}$. y $31 \mathrm{~m}$., respectivamente. 
Esto es, 1055A I $\nabla$ y $1041 \vee$ presentan unas características muy similares (tipo colaboradoras, entorno circundante al pluviómetro, radicadas a las afueras del núcleo urbano de sendas localidades costeras).

En la figura 17 se muestran los emplazamientos de 1055A I $\nabla$ y de $1041 \nabla$ :

\section{Figura 17: Emplazamientos de 1055A I $\vee$ y 1041 ○:}

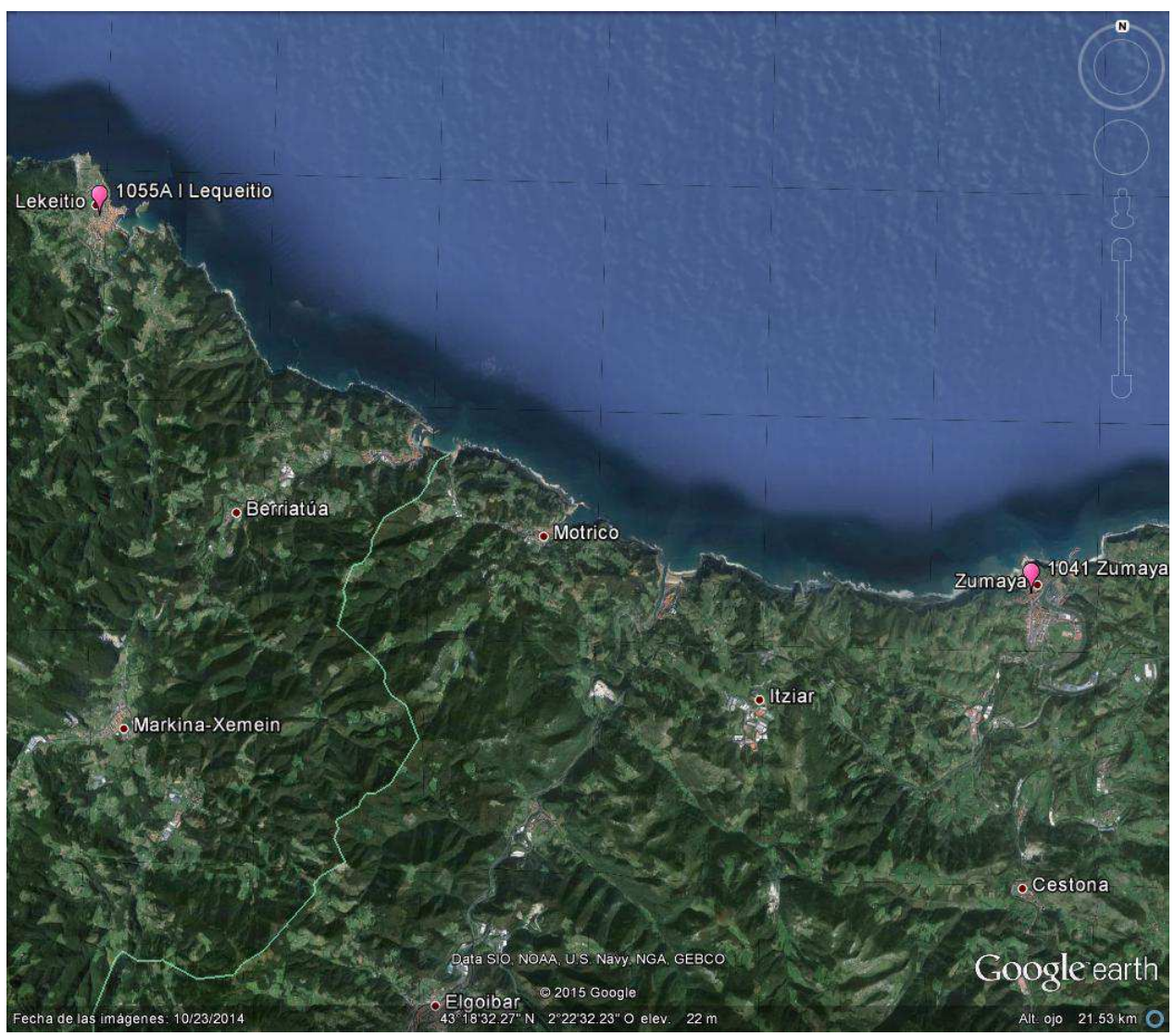

4.- Los máximos $(1996,1994,1988)$ y mínimos $(1989,1995,1998)$ pluviométricos de $1055 \mathrm{~A}$ I $\vee$ y $1041 \nabla$ coinciden (tabla 29$)$.

5.- Se percibe una concomitancia de las precipitaciones recogidas en los 2 enclaves.

De la tabla 29, los años lluviosos la diferencia entre 1055A I $\nabla$ y 1041 P es inferior al 6\%, no superando el $12 \%$ los años secos: El cociente de las precipitaciones registradas es aproximadamente constante.

6.-, Los años más lluviosos y más secos en los 2 emplazamientos investigados sobrevienen en el lapso de años analizado en la tabla 29, fluctuando las medidas de precipitación en torno a las respectivas medianas.

7.- Esta inhomogeneidad no aflora en ninguna más de las series analizadas situadas en valles que vierten al litoral de Vizcaya. comarcal.

Por todo lo expuesto, se la considera como inhomogeneidad "climatológica" a escala 


\section{1.- Inhomogeneidades de 1993 a 2005 en 1055A:}

Tabla 30: Años con precipitaciones máximas y mínimas:

\begin{tabular}{|c|c|c|c|c|c|}
\hline $\begin{array}{c}\text { Indicativo y } \\
\text { nombre }\end{array}$ & Duración serie & Año Máximo & $\begin{array}{c}\text { Precipitación } \\
\left(1 / \mathrm{m}^{2}\right)\end{array}$ & Año Mínimo & $\begin{array}{c}\text { Precipitación } \\
\left(1 / \mathrm{m}^{2}\right)\end{array}$ \\
\hline \multirow{3}{*}{$\begin{array}{c}\text { 1055A I } \nabla \\
\text { Lequeitio }\end{array}$} & \multirow{3}{*}{$\begin{array}{c}1987-2005 \\
(\mathrm{sd} 1997,2002)\end{array}$} & $1996\left(1^{\circ}\right)$ & 116,0 & $1995\left(2^{\circ}\right)$ & 78,4 \\
\hline & & $2000\left(2^{\circ}\right)$ & 103,6 & $2001\left(3^{\circ}\right)$ & 83,3 \\
\hline & & $1994\left(3^{\circ}\right)$ & 103,2 & $2005\left(5^{\circ}\right)$ & 89,9 \\
\hline \multirow{4}{*}{$\begin{array}{l}1041 \text { } \\
\text { Zumaya }\end{array}$} & \multirow{4}{*}{$\begin{array}{c}1987-2007 \\
(\mathrm{sd} \mathrm{1987,1990}, \\
1991,1992,1997)\end{array}$} & $1993\left(1^{\circ}\right)$ & 113,4 & $2001\left(2^{\circ}\right)$ & 76,3 \\
\hline & & $1996\left(2^{\circ}\right)$ & 110,2 & $1995\left(3^{\circ}\right)$ & 89,6 \\
\hline & & $1994\left(3^{\circ}\right)$ & 109,2 & $2006\left(4^{\circ}\right)$ & 90,8 \\
\hline & & $2002\left(4^{\circ}\right)$ & 107,1 & $2005\left(5^{\circ}\right)$ & 94,7 \\
\hline
\end{tabular}

1.- $1055 \mathrm{~A}$ I $\vee$ y $1041 \vee$ poseen características geográficas muy similares, escudriñadas en el punto precedente.

2.- El emplazamiento costero más cercano con datos pluviométricos de 1993 a 2005 es 1041 Zumaya. Se incluyen sus datos a modo de comparativa.

3.- De la tabla 19 (página 52), 1041 Z Zumaya presenta una inhomogeneidad de tipo "climatológico" en la pluviosidad anual de 1993 a 2006, simultánea a la inhomogeneidad de 1055A I P.

4.- Los máximos $(1994,1996)$ y mínimos $(1995,2001,2005)$ pluviométricos anuales coinciden en ambas localizaciones.

5.- Hay una congruencia espacial de las precipitaciones medidas en los 2 lugares, siendo las precipitaciones medias anuales recogidas en ambos semejantes, con una diferencia inferior al 5\% los años pluviosos y al $13 \%$ los años secos.

Así, el cociente de las pluviosidades registradas es aproximadamente constante.

6.- En el intervalo anual analizado en la tabla 30, se registran los años más lluviosos y más secos en los 2 emplazamientos, fluctuando las medidas pluviométricas en torno a las respectivas medianas.

7.- Esta inhomogeneidad no emerge en ninguna más de las series analizadas situadas en valles que vierten al litoral de Vizcaya.

Por todo lo expuesto, se la considera como inhomogeneidad "climatológica" a escala comarcal. 
Como conclusiones del estudio de la evolución temporal de las inhomogeneidades detectadas por el test de las rachas en las medidas de la precipitación anual:

Una vez reveladas las roturas de las series de precipitación, el test de las rachas se aplica a cada intervalo de la serie delimitado por rupturas y superior a 10 años (caso de roturas) o a la serie completa (caso sin rupturas) con los siguientes resultados:

1.- Todas las inhomogeneidades descubiertas (tabla 17, página 50) son "climatológicas".

2.- El culmen de inhomogeneidades se registra de 1977 a 1991.

3.- La trascendencia de la inclusión en el análisis de las series de datos antiguas, para poder clasificar las inhomogeneidades entre "climatológicas" y no "climatológicas", cotejando el comportamiento de la pluviosidad en emplazamientos cercanos.

Esto es, el conocimiento de la evolución temporal de la homogeneidad de una serie larga precisa de un examen minucioso y global abarcando las series de precipitaciones actuales y antiguas próximas.

4.- La tabla 30 bis compendia el número de series, de inhomogeneidades y la inhomogeneidad media (cociente del número de inhomogeneidades entre el número de series) por comarca.

Tabla 30 bis: Distribución comarcal de las inhomogeneidades "climatológicas" del test de rachas de la precipitación media anual:

Comarca

Arratia - Nervión
Duranguesado
Encartaciones
Gran Bilbao

Guernica - Bermeo

Marquina - Ondarroa

Plencia - Munguía

Cantábrica Alavesa
$\mathrm{N}^{\mathrm{o}}$ series analizadas

$\mathrm{N}^{\mathrm{o}}$ inhomogeneidades

4
4
5
5
1
4
1
3

4

4

5

5

1

4

1

3
Inhomogeneidad media

4
24
10
4
0
12
0
4

1

6

2

0,8

0

3

0

1,3

Las inhomogeneidades se concentran en el Duranguesado y en Marquina - Ondarroa, comarcas limítrofes con Guipúzcoa y, en menor cuantía, en las Encartaciones, lo cuál resalta la importancia de un examen a una escala comarcal, dada la quebrada orografía de Vizcaya y de la vertiente cantábrica de Álava.

5.- Una gran similitud de las características de las series de precipitación anual próximas (tablas 23 a 30), pudiendo hablar no sólo de inhomogeneidades "climatológicas" a nivel provincial, sino de inhomogeneidades "climatológicas" en una misma comarca o en comarcas colindantes. 
Esta semejanza se manifiesta:

A) Temporalmente: Simultaneidad de máximos y de mínimos pluviométricos.

B) Espacialmente: La razón de las pluviosidades es aproximadamente constante, con una dispersión mayor de los cocientes de las precipitaciones los años secos o muy secos frente a los lluviosos a muy lluviosos (analizado en los comentarios de las tablas 20 a 30).

6.- El allegamiento de los datos de las tablas 20 a 30 insinúa dobles ciclos en la precipitación anual allegados a los 10 años y 30 años y triples ciclos rayanos los 20 años.

6.1.- Las tablas 31 y 31 bis reproducen, a modo de cotejo, los años de máximos y mínimos pluviométricos de la precipitación anual de Guipúzcoa de 1878 a 2012 (Nota Técnica $\mathrm{N}^{\circ} 13$ AEMET).

En las tablas 31 y 31 bis se señalan en negrita los años con valores extremos de la serie de datos. Se dejan en blanco los años en que no parece cumplirse la cadencia del ciclo.

Tabla 31: Años con máximos pluviométricos:

\begin{tabular}{|l|c|c|c|c|c|c|c|}
\hline Máximos & 1879 & 1889 & 1900 & 1910 & $\mathbf{1 9 1 7}$ & $\mathbf{1 9 2 3}$ & 1930,33 \\
\hline \hline Máximos & 1940,42 & $\mathbf{1 9 5 0}$ & $\mathbf{1 9 5 4}$ & 1960 & $1965-66$ & 1969 & 1974 \\
\hline \hline Máximos & $\mathbf{1 9 7 8 - 8 4}$ & 1986 & 1990,2 & 2002 & 2013 & & \\
\hline \hline
\end{tabular}

Tabla 31 bis: Años con mínimos de precipitación:

\begin{tabular}{|l|c|c|c|c|c|c|c|}
\hline Mínimos & 1880 & 1891 & 1899 & $\mathbf{1 9 1 2 , 1 6}$ & $1920-21$ & 1934 & $\mathbf{1 9 4 5}$ \\
\hline \hline Mínimos & $\mathbf{1 9 4 8}$ & $1956-57$ & 1962 & & $\mathbf{1 9 7 0 , 7 2}$ & & 1983 \\
\hline \hline Mínimos & 1989 & 1995 & $\mathbf{2 0 0 1 , 0 3}$ & $2005-06$ & & & \\
\hline \hline
\end{tabular}

6.2.- De los valores de las tablas 20 a 30 se observan una serie de años con máximos y mínimos sincrónicos en las pluviosidades anuales de Vizcaya y de la vertiente cantábrica de Álava de 1859 a 2013.

Las tablas 32 y 32 bis, obtenidas de la recopilación de los datos de las tablas 20 a 30, recogen los años con máximos y mínimos pluviométricos desde 1859 a 2013 de Vizcaya y de la vertiente cantábrica de Álava. 
La siguiente notación se emplea en las tablas 32 y 32 bis:

a) En azul oscuro, máximos y mínimos de precipitación concordantes en Vizcaya y en la vertiente cantábrica de Álava con los de Guipúzcoa.

b) En rojo, extremos pluviométricos no registrados en las tablas de Guipúzcoa, congruentes con un doble ciclo de 10 años.

c) Se dejan en blanco los años sin máximos o mínimos pluviométricos significativos (tablas 20 a 31), sea por la carencia de series de datos (1933 a 1944), sea por concurrir con un intervalo carente de inhomogeneidades (de 1923 a 1933, tabla 17) o por coincidir con un intervalo lluvioso (finales $1^{\text {a }}$ década siglo XX) o muy seco (de 1944 a 1948).

d) En negrita, los años con máximos y mínimos pluviométricos notorios, por el número de ubicaciones y por su carácter de extremos. 1979.

e) Un guión - indica años de la tabla englobados: Por ejemplo 1978-79: De 1978 a

f) Una coma , denota años no consecutivos: Por ejemplo 1917, 19: 1917 y 1919.

Tabla 32: Años con máximos pluviométricos:

\begin{tabular}{|l|c|c|c|c|c|c|c|}
\hline Máximos & $\mathbf{1 8 8 5 - 8 6}$ & $1888-89$ & & & 1906 & 1910 & \\
\hline \hline Máximos & $\mathbf{1 9 1 7 , 1 9}$ & $\mathbf{1 9 2 3}$ & & & & & \\
\hline \hline Máximos & $\mathbf{1 9 5 2}$ & $\mathbf{1 9 5 4}$ & $\mathbf{1 9 6 0}$ & $1965-66$ & $\mathbf{1 9 7 1}$ & $1974-75$ & $1978-79$ \\
\hline \hline Máximos & $\mathbf{1 9 8 4 , 8 6}$ & $\mathbf{1 9 9 2}$ & $\mathbf{1 9 9 6}$ & 2000 & & & \\
\hline \hline
\end{tabular}

Tabla 32 bis: Años con mínimos de precipitación:

\begin{tabular}{|l|c|c||c|c|c|c|c|}
\hline Mínimos & $\mathbf{1 8 8 4}$ & $\mathbf{1 8 9 1}$ & $\mathbf{1 8 9 4}$ & & & & $1911-\mathbf{1 2}$ \\
\hline \hline Mínimos & $\mathbf{1 9 1 6}$ & $\mathbf{1 9 2 0}$ & & & & & \\
\hline \hline Mínimos & & $\mathbf{1 9 5 5}$ & $\mathbf{1 9 5 7}$ & 1964 & 1968 & $\mathbf{1 9 7 0}$ & 1976 \\
\hline \hline Mínimos & $\mathbf{1 9 8 1}$ & $\mathbf{1 9 8 5}$ & $\mathbf{1 9 8 9}$ & $\mathbf{1 9 9 5}$ & $\mathbf{2 0 0 1}$ & & \\
\hline \hline
\end{tabular}

6.3.- Dos ciclos de aproximadamente 10 años en los máximos de precipitación anual se aprecian de la tabla 32:

a) $1885-1886 \Rightarrow \ldots \Rightarrow 1906 \Rightarrow>\ldots=>1923 \Rightarrow \ldots \Rightarrow 1952 \Rightarrow>1960 \Rightarrow 1971 \Rightarrow$ $1978-1979 \Rightarrow 1992 \Rightarrow 2000 \ldots$

b) $1888-1889 \Rightarrow \ldots \Rightarrow 1910 \Rightarrow>1919 \Rightarrow>\ldots$. $1954 \Rightarrow 1965-1966 \Rightarrow 1974-$ $1975 \Rightarrow 1984$ y $1986=>1996 \ldots$ 
Análogamente, se percibe de la tabla 32 bis dos ciclos de periodo cercano a los 10 años en los años secos con mínimos en:

a) $1884 \Rightarrow>1894 \Rightarrow>\ldots=>1911-1912 \Rightarrow>1920 \Rightarrow \ldots=>1957 \Rightarrow>1968 \Rightarrow>1976$ $\Rightarrow 1985=>1995 \ldots$

b) $1891 \Rightarrow \ldots=>1916 \Rightarrow>\ldots 1955 \Rightarrow>1964 \Rightarrow>1970 \Rightarrow>1981 \Rightarrow>1989 \Rightarrow>2001$

Los ... advierten de huecos en la euritmia del ciclo, bien por ausencia de datos (de 1933 a 1944), bien por concurrir con un intersticio muy lluvioso (fines $1^{\text {a }}$ década siglo XX) o seco (2 $2^{\text {a }}$ mitad años 40).

6.4.- Se vislumbran ciclos superiores, de 20 y 30 años, con los siguientes valores:

\subsection{1.- Ciclos 20 años:}

Tres ciclos de unos 20 años se insinúan en los máximos de precipitación:
A) $1885-1886=>\ldots=>1923 \Rightarrow>\ldots=>1960=>1979 \ldots$
B) 1917 y $1919 \Rightarrow \ldots \Rightarrow>1954 \Rightarrow>1975 \Rightarrow 1996 \ldots$
C) $1952 \Rightarrow 1971 \Rightarrow>1992 \Rightarrow 2008 \ldots$

Y tres ciclos cercanos a los 20 años en los años de mínimos de precipitación:
A) $1884 \Rightarrow \ldots \Rightarrow 1920 \Rightarrow \ldots \Rightarrow 1957 \Rightarrow>\ldots=>1995 \ldots$
B) $1894 \Rightarrow 1912 \Rightarrow \ldots \Rightarrow 1985 \ldots$
C) $1916=>\ldots \Rightarrow 1970 \Rightarrow 1989 \ldots$

\subsection{2.- Ciclos 30 años:}

Dos ciclos de aproximadamente 30 años afloran en los años lluviosos:

I) $1885-86,1889=>1917,1919 \Rightarrow>1952,1954 \Rightarrow>1979,1984 \ldots$

II) Se insinúa en $1960=>1992,1996 \ldots$

Y en los años secos:

I) $1884,1891 \Rightarrow>1916,1920 \Rightarrow>\ldots=>1981 \Rightarrow>2011 \ldots$

II) $1894=>\ldots=>1955,1957 \Rightarrow>1985,1989 \ldots$

Estos ciclos propincuos a los 10, 20 y 30 años de la precipitación anual se analizan más detalladamente en el apartado 3.2.3 Cadencias de la precipitación anual de la Nota Técnica No 19 AEMET. 


\subsubsection{2.- Evolución temporal de las inhomogeneidades del test de Thom aplicado a la precipitación media MAM:}

Debido al vasto intervalo temporal analizado (de 1859 a 2013) y al escaso número de series precedentes a 1940 (inferior a 6 coetáneas), se representa el periodo en 2 tramos: de 1859 a 1940 y de 1941 a 2013.

Las gráficas 9 y 10 exponen las inhomogeneidades detectadas en un periodo de 10 años. Así, una inhomogeneidad descubierta en 1968 abarca desde 1968 a 1977.

Al aplicar el test de las rachas de Thom se considera un periodo de 10 años de datos consecutivos. Cuando aparecen lagunas en las series (como en 1054 Marquina) el periodo se amplía hasta alcanzar 10 años consecutivos de datos.

La gráfica 9 muestra la evolución temporal de las inhomogeneidades descubiertas aplicando el test de las rachas a la precipitación media MAM de 1859 a 1940.

Gráfica 9: Evolución temporal de las inhomogeneidades del análisis del test de Thom de las series de precipitación media MAM de 1859 a 1940:

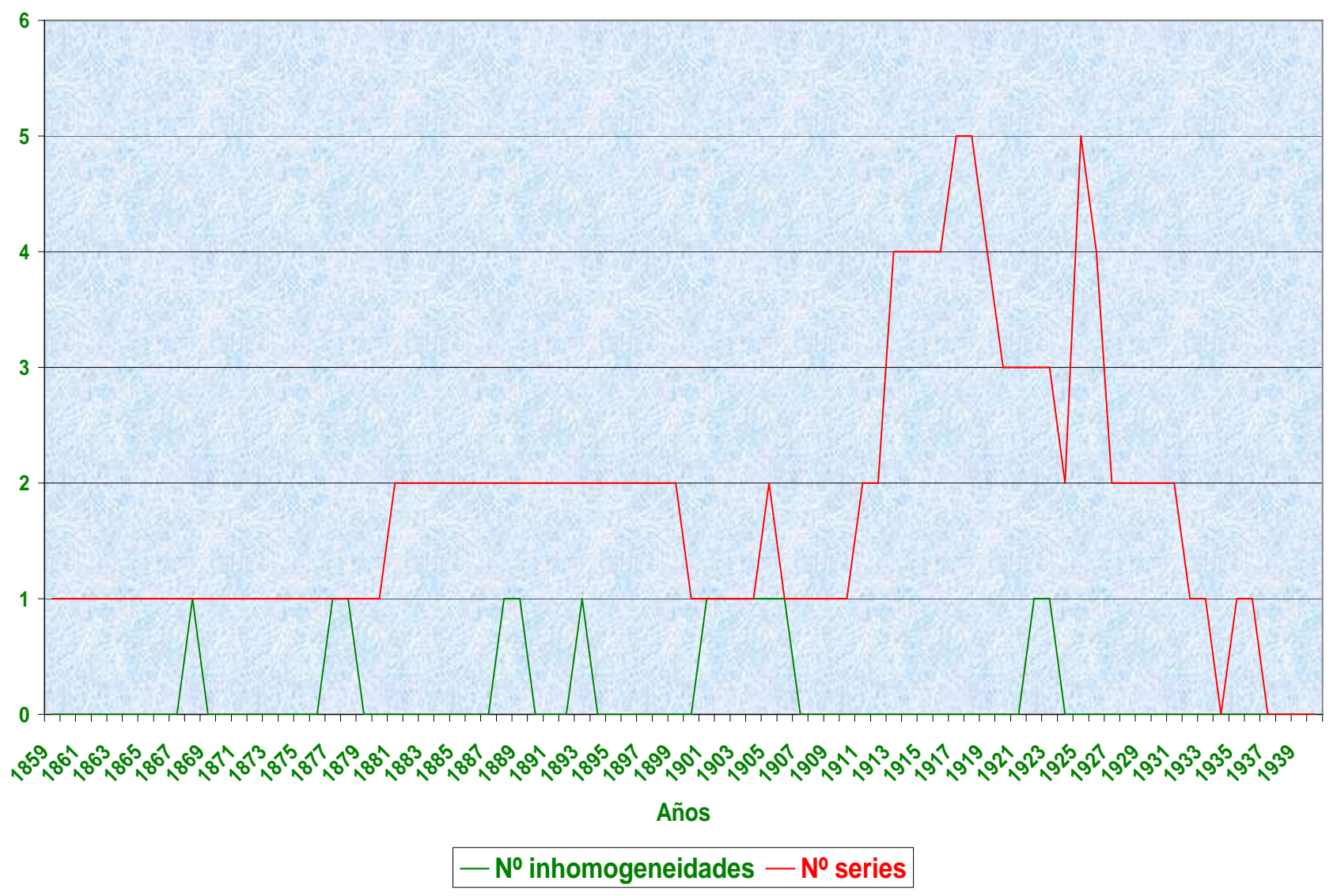


La gráfica 10 ilustra la evolución temporal de las inhomogeneidades desveladas por el test de las rachas de Thom en la precipitación media MAM de 1941 a 2013.

Gráfica 10: Evolución temporal de las inhomogeneidades del análisis del test de Thom de las series de precipitación media MAM de 1941 a 2013:

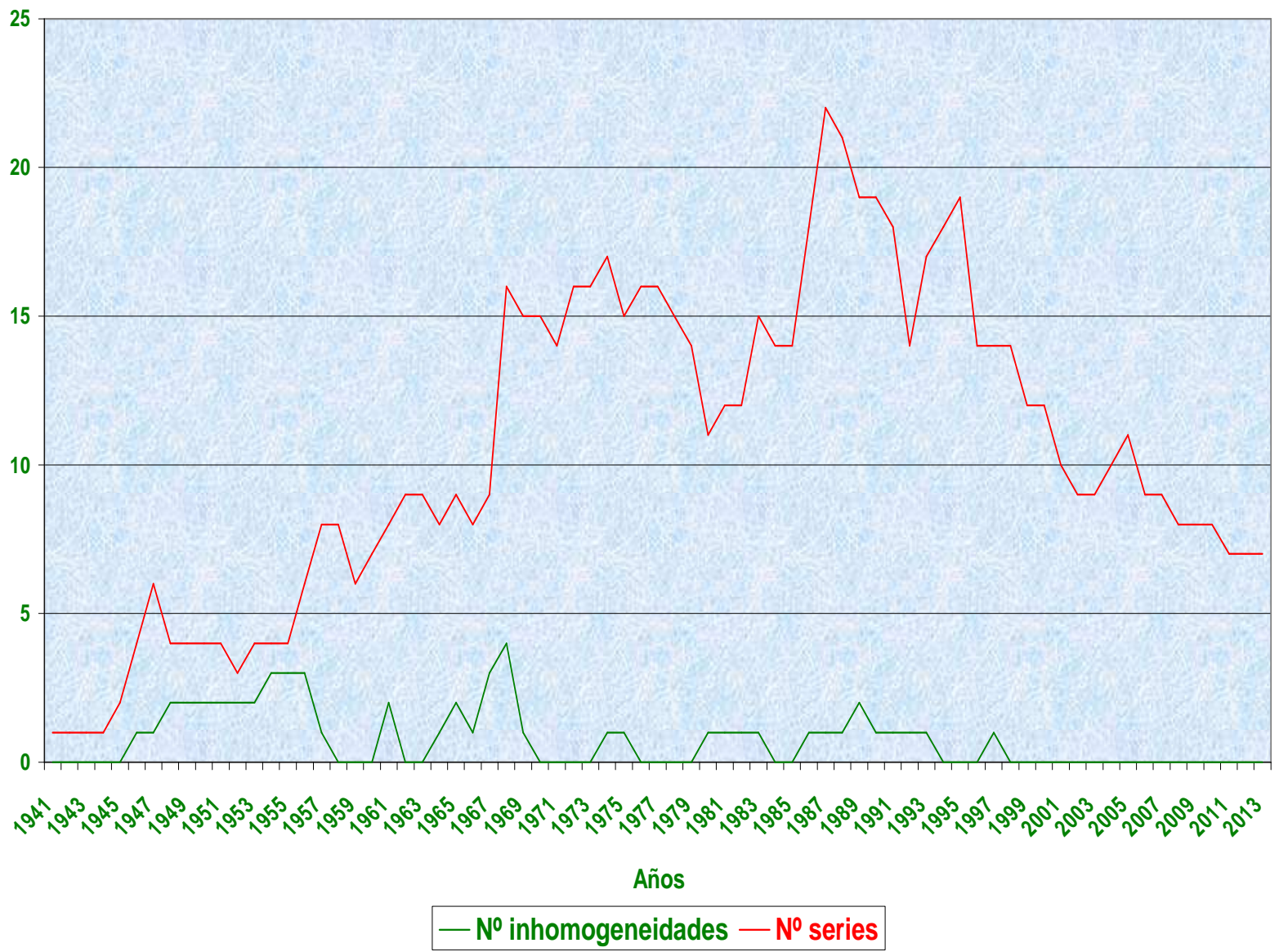

De la gráfica 10 se aprecia que el máximo de inhomogeneidades acaece entre 1954 y 1965 y entre 1967 y 1977.

Las inhomogeneidades afloradas en un periodo de 10 años se revelan en la tabla 33. Así, una inhomogeneidad detectada en 1906 abarca de 1906 a 1915.

Cuando aparecen lagunas en las series (como en 1055A Lequeitio) el periodo anotado se amplía hasta alcanzar 10 años consecutivos de datos.

Por brevedad, en la tabla 33 se agrupan en la columna de la izquierda periodos de solape de las inhomogeneidades.

En la columna de la derecha se indica el \% de series en que se encuentra la inhomogeneidad. Cuando las series son escasas, se añade el cómputo total de las mismas entre paréntesis. 
Tabla 33: Inhomogeneidades detectadas aplicando el test de Thom a las medidas de precipitación media MAM desde 1859 a 2013:

\begin{tabular}{|c|c|c|c|}
\hline $\begin{array}{l}\text { Periodo inhomogeneidad } \\
\text { (Años) }\end{array}$ & Indicativos & $\begin{array}{l}\text { Inhomogeneidad } \\
\text { "climatológica" }\end{array}$ & $\begin{array}{c}\% \text { series sobre } \\
\text { total }\end{array}$ \\
\hline $1868-1878$ & $1077 \mathrm{C}$ & Sí & $100(1)$ \\
\hline $1877-1887$ & $1077 \mathrm{C}$ & 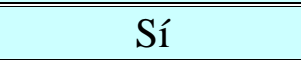 & $100(1)$ \\
\hline $1888-1898$ & $1077 \mathrm{C}$ & Sí & $50(2)$ \\
\hline $1893-1902$ & $1077 \mathrm{C}$ & 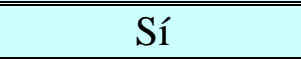 & $50-100(1-2)$ \\
\hline $1901-1915$ & $1077 \mathrm{C}$ & 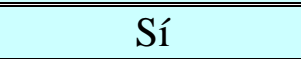 & $50-100(1-2)$ \\
\hline $1922-1932$ & $1057 \mathrm{C}$ & $\overline{\text { Sí }}$ & $33(3)$ \\
\hline $1946-1962$ & 1059 & Sí & \multirow{2}{*}{$50-67(3-4)$} \\
\hline $1948-1962$ & $9077 \mathrm{E}$ & 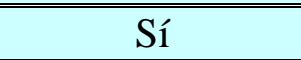 & \\
\hline $191954-1964$ & 9077E, 1059, 1082 & Sí & \multirow{4}{*}{$13-75(4-8)$} \\
\hline $1956-1965$ & 1059,1082 & 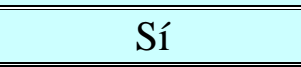 & \\
\hline $1956-1966$ & 1060 & Sí & \\
\hline $1957-1967$ & 1054 & SSí & \\
\hline $1961-1970$ & 1054,1082 & 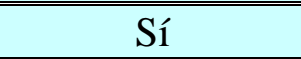 & $25(8)$ \\
\hline $1964-1975$ & $1060 \mathrm{~A}$ & 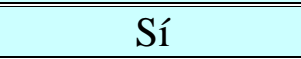 & \multirow{5}{*}{$7-33$} \\
\hline $1965-1976$ & 1054 & Sí & \\
\hline $1967-1976$ & $1060,1060 \mathrm{~A}, 1093$ & Sí & \\
\hline $1968-1977$ & $1060,1060 \mathrm{~A}, 1070,1075$ & 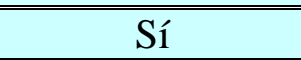 & \\
\hline $1969-1978$ & 1075 & Sí & \\
\hline $191974-1984$ & 1082 & 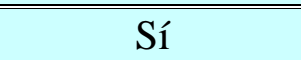 & $6-7$ \\
\hline $1980-1992$ & 1053 & 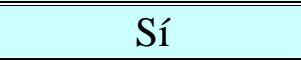 & \multirow{2}{*}{$6-9$} \\
\hline $1986-1995$ & 1082 & Sí & \\
\hline $1987-2006$ & $1069 \mathrm{E}$ & Sí & \multirow{4}{*}{$5-11$} \\
\hline $1988-2002$ & 1070 & Sí & \\
\hline $1989-1998$ & 1082 & Sí & \\
\hline $1997-2006$ & $1081 \mathrm{U}$ & Sí & \\
\hline
\end{tabular}

Las inhomogeneidades de la tabla 33 se comparan con los resultados del análisis del test de las rachas de las series de precipitación media MAM de Guipúzcoa, debido a:

a) La exigua densidad espacial y temporal de las series de pluviosidad MAM con una extensión superior a 10 años disponibles en Vizcaya y en la vertiente cantábrica de Álava.

b) Las características climáticas similares de Vizcaya, la vertiente cantábrica de Álava y Guipúzcoa.

La tabla 34, procedente de la Nota Técnica No 13 de AEMET, transcribe los resultados de la aplicación del test de las rachas a la pluviometría media MAM de 1941 a 2012 en Guipúzcoa. 
Tabla 34: Inhomogeneidades detectadas aplicando el test de Thom a las medidas de precipitación MAM en Guipúzcoa desde 1937 a 2012:

\begin{tabular}{|c|c|c|c|}
\hline $\begin{array}{l}\text { Periodo inhomogeneidad } \\
\text { (Años) }\end{array}$ & Indicativos & $\begin{array}{l}\text { Inhomogeneidad } \\
\text { "climatológica" }\end{array}$ & $\begin{array}{c}\% \text { series sobre } \\
\text { total }\end{array}$ \\
\hline $1937-1946$ & $1024 \mathrm{E}$ & Sí & $100(1)$ \\
\hline $1946-1983$ & 1045 & No & $4-7$ \\
\hline $1946-1959,1948-1961$ & 1050 & Sí & 7 \\
\hline $1947-1961$ & 1016 & Sí & $6-7$ \\
\hline $1948-1957$ & 1031 & Sí & 7 \\
\hline $1953-1962$ & 1016,1032 & Sí & 13 \\
\hline $1954-1963$ & $1016,1018,1032,1035$ & Sí & 22 \\
\hline $1955-1965$ & $\begin{array}{c}1016,1018,1032,1035, \\
1052\end{array}$ & Sí & $25-28$ \\
\hline $1957-1966$ & $1014,1018,1046$ & Sí & 14 \\
\hline $1958-1967$ & 1014,1018 & Sí & 9 \\
\hline $1959-1968$ & $1014,1018,1046,1052$ & Sí & 20 \\
\hline $1961-1970$ & 1016 & Sí & 5 \\
\hline $1962-1972$ & 1017 & Sí & 4 \\
\hline $1963-1973$ & 9268 & Sí & 5 \\
\hline $1964-1973$ & 1017,1023 & Sí & 10 \\
\hline $1965-1975$ & 1017 & Sí & 4 \\
\hline $1967-1976$ & 1036 & Sí & \multirow{3}{*}{$9-14$} \\
\hline $1967-1977$ & 1037,1050 & Sí & \\
\hline $1968-1977$ & 1023 & Sí & \\
\hline $1979-1988$ & $1025 \mathrm{E}, 1046$ & Sí & 9 \\
\hline $1979-1992$ & $1022 \mathrm{~A}$ & Sí & 4 \\
\hline $1979-1989$ & 1046 & Sí & \multirow{2}{*}{9} \\
\hline $1980-1989$ & 1050 & Sí & \\
\hline $1981-1991$ & 1025E, 1037O, 1046, 1050 & Sí & 18 \\
\hline $1983-1992$ & $1037 \mathrm{O}, 1046,1050$ & Sí & 12 \\
\hline $1984-1994$ & 10370 & Sí & 4 \\
\hline $1985-1995$ & $1049 U$ & Sí & 4 \\
\hline $1987-1997$ & 10370 & Sí & 4 \\
\hline $1988-1998$ & 1037Q & Sí & 4 \\
\hline $1989-1998$ & $1049 \mathrm{U}$ & Sí & 4 \\
\hline $1989-1999$ & 1037O, 1037Q & Sí & 7 \\
\hline $1990-2000$ & $1026 \mathrm{~B}$ & Sí & $4-5$ \\
\hline $2001-2011$ & 1026B & No & 5 \\
\hline $1992-2001$ & $1021 \mathrm{E}$ & Sí & 7 \\
\hline $2000-2012$ & 1044D & ¿Sí? & 4 \\
\hline
\end{tabular}


Las tablas 35 a 47 detallan para cada serie de registros de precipitación:

a) El indicativo y el nombre del enclave.

b) La subsistencia en años pormenorizando los años sin datos (sd).

c) Los años de máximos pluviométricos en el intersticio en que se detecta la inhomogeneidad, con el ordinal entre paréntesis referido al intervalo anual total de mediciones de la serie. pluviosidad.

d) La precipitación media mensual en el periodo MAM de los años de máximos de la

e) Los años de mínimos de la precipitación en el lapso temporal de la inhomogeneidad; se indica entre paréntesis el ordinal referido al lapso anual global de observaciones.

f) La pluviosidad media mensual MAM de los años de mínimos pluviométricos.

Debido a la baja densidad espacial y temporal de los emplazamientos de medida de Vizcaya y de la vertiente cantábrica de Álava, las precipitaciones en los años de inhomogeneidades se contraponen con las mediciones de:

A) El Real Seminario de Nobles de Vergara de 1867 a 1873.

B) 1024D $P$ (San Sebastián Instituto) entre 1878 y 1900.

C) 1024F I $\vee$ (San Sebastián) entre 1901 y 1915.

D) 1013 I $\vee$ (Irún Fitosanitaria) y 1024F II $\vee$ (San Sebastián) de 1922 a 1932. 1024F $\vee$ mudó de altitud en 1918 (Doporto, 55 años de Observaciones pluviométricas).

E) 9076 I 8 (Ullivarri Gamboa) y 9080 I $\vee$ Urrunaga de 1948 a 1962, las localizaciones más cercanas a 9077E I $\vee$ Ochandiano. (Marquina).

F) 1052 (Motrico) de 1954 a 1967, una serie de calidad próxima a 1054 II $\nabla$

G) 1050 II $\vee$ (Eibar) de 1967 a 1977 y de 1980 a 1995, colindante con Vizcaya y con una rotura en 1964 (Nota Técnica 13 AEMET).

H) 1049U $\vee$ (Ermua) de 1988 a 2005, ubicación de notables calidad y homogeneidad - según se analiza en la Nota Técnica No 13 AEMET - próxima a $1071 \nabla$ (Durango), 1053 II $\nabla$ (Echevarría) y $1070 \bigcirc$ (Abadiano). 
1.- Inhomogeneidades de 1868 a 1878 en $1077 \mathrm{C}:$

Tabla 35: Años con precipitaciones máximas y mínimas:

\begin{tabular}{|c|c|c|c|c|c|}
\hline $\begin{array}{c}\text { Indicativo y } \\
\text { nombre }\end{array}$ & Duración serie & Año Máximo & $\begin{array}{c}\text { Precipitación } \\
\left(1 / \mathrm{m}^{2}\right)\end{array}$ & Año Mínimo & $\begin{array}{c}\text { Precipitación } \\
\left(1 / \mathrm{m}^{2}\right)\end{array}$ \\
\hline \multirow{4}{*}{$\begin{array}{c}\text { 1077C } \vee \\
\text { Bilbao Histórica }\end{array}$} & \multirow{4}{*}{$\begin{array}{c}1859-1920 \\
(\mathrm{sd} 1862 \mathrm{a} \\
1864 \text { y } 1874)\end{array}$} & $1869\left(1^{\circ}\right)$ & 208,1 & $1871\left(1^{\circ}\right)$ & 47,6 \\
\hline & & $1873\left(8^{\circ}\right)$ & 132,4 & $1870\left(4^{\circ}\right)$ & 60,7 \\
\hline & & $1877\left(9^{\circ}\right)$ & 132,0 & $1878\left(8^{\circ}\right)$ & 73,3 \\
\hline & & & & $1875\left(18^{\circ}\right)$ & 83,4 \\
\hline \multirow{3}{*}{$\begin{array}{c}\text { Real Seminario } \\
\text { de Vergara } \varnothing\end{array}$} & \multirow{3}{*}{$1867-1873$} & $1869\left(1^{\circ}\right)$ & 278,4 & $1870\left(1^{\circ}\right)$ & 61,7 \\
\hline & & $1873\left(2^{\circ}\right)$ & 126,9 & $1871\left(2^{\circ}\right)$ & 68,7 \\
\hline & & $1872\left(3^{\circ}\right)$ & 104,9 & $1868\left(3^{\circ}\right)$ & 79,4 \\
\hline $\begin{array}{c}\text { 1024D } \vee \\
\text { San Sebastián }\end{array}$ & $1878-1900$ & & & $1878\left(11^{\circ}\right)$ & 107,8 \\
\hline
\end{tabular}

1.- $1077 \mathrm{C} \vee$ Bilbao Histórica, con comienzo en Enero de 1859 y fin en Octubre de 1920, es la única serie con registros de precipitación en Vizcaya en MAM desde 1859 a 1920.

2.- La tabla 30 incluye como cotejo los datos correspondientes al Real Seminario de Nobles de Vergara de 1868 a 1873 y el registro de 1878 de 1024D $\vee$ San Sebastián Instituto. (Datos de Vergara obtenidos de los Resúmenes de las Observaciones Meteorológicas efectuadas en la Península desde el $1^{\circ}$ de diciembre de 1867 al 30 de noviembre de 1874).

D. Paulino Caballero fue catedrático de Física del Real Seminario de Vergara y realizó las primeras mediciones meteorológicas de Guipúzcoa en Vergara hasta Noviembre de 1873.

En Enero de 1878, ya como catedrático de Física del Instituto de San Sebastián, anota las precipitaciones en 1024D $\nabla$ hasta 1891.

3.- La tabla 35 revela una concordancia de los años lluviosos (1869 y 1873) y secos $(1870,1871,1878)$.

4.- Se aprecia una coherencia espacial de las precipitaciones, siendo las cantidades recogidas en Vergara y en San Sebastián (1024D \&) superiores a las de Bilbao (1077C P).

En Bilbao se registran entre un 69 y un $104 \%$ de las cuantías de Vergara.

5.- Se percibe en la tabla 35 una sucesión de MAM muy lluviosos y muy secos de 1868 a 1878 en $1077 \mathrm{C} \nabla$, oscilando los registros en torno a la mediana de la serie.

Por tanto, se considera esta inhomogeneidad de 1077C $\vee$ como "climatológica". 
2.- Inhomogeneidades de 1877 a 1887 en $1077 \mathrm{C}:$

Tabla 36: Años con precipitaciones máximas y mínimas:

\begin{tabular}{|c|c|c|c|c|c|}
\hline $\begin{array}{c}\text { Indicativo y } \\
\text { nombre }\end{array}$ & Duración serie & Año Máximo & $\begin{array}{c}\text { Precipitación } \\
\left(1 / \mathrm{m}^{2}\right)\end{array}$ & Año Mínimo & $\begin{array}{c}\text { Precipitación } \\
\left(1 / \mathrm{m}^{2}\right)\end{array}$ \\
\hline \multirow{4}{*}{$\begin{array}{l}\text { 1077C } \supsetneq \\
\text { Bilbao } \\
\text { Histórica }\end{array}$} & \multirow{4}{*}{$\begin{array}{c}1859-1920 \\
(\mathrm{sd} 1862 \text { a } 1864 \\
\text { y } 1874)\end{array}$} & $1879\left(3^{\circ}\right)$ & 157,8 & $1882\left(7^{\circ}\right)$ & 64,0 \\
\hline & & $1884\left(6^{\circ}\right)$ & 141,3 & $1878\left(8^{\circ}\right)$ & 73,3 \\
\hline & & $1877\left(9^{\circ}\right)$ & 132,0 & $1887\left(11^{\circ}\right)$ & 75,7 \\
\hline & & $1880\left(18^{\circ}\right)$ & 110,2 & $1881\left(21^{\circ}\right)$ & 87,7 \\
\hline \multirow{4}{*}{$\begin{array}{c}\text { 1024D P } \\
\text { San Sebastián }\end{array}$} & \multirow{4}{*}{$1878-1900$} & $1879\left(1^{\circ}\right)$ & 182,9 & $1887\left(2^{\circ}\right)$ & 69,0 \\
\hline & & $1884\left(6^{\circ}\right)$ & 132,3 & $1882\left(5^{\circ}\right)$ & 94,7 \\
\hline & & $1880\left(9^{\circ}\right)$ & 121,8 & $1883\left(9^{\circ}\right)$ & 102,0 \\
\hline & & & & $1878\left(11^{\circ}\right)$ & 107,8 \\
\hline \multirow{2}{*}{$\begin{array}{c}\text { 1059L I } P \\
\text { Orduña }\end{array}$} & \multirow{2}{*}{$\begin{array}{c}1881-1899 \mathrm{y} \\
1905\end{array}$} & $1886\left(6^{\circ}\right)$ & 93,3 & $1887\left(2^{\circ}\right)$ & 50,3 \\
\hline & & $1884\left(7^{\circ}\right)$ & 88,7 & $1881\left(4^{\circ}\right)$ & 56,7 \\
\hline
\end{tabular}

1.- Los únicos lugares con medidas pluviométricas en 1878 en Vizcaya, en Álava y en Guipúzcoa son 1077C \ Bilbao Histórica y 1024D P San Sebastián Instituto. En 1881 se les aúna 1059L I $\vee$ Orduña. (Datos de Orduña procedentes de los Resúmenes de las Observaciones Meteorológicas efectuadas en la Península y algunas de sus islas adyacentes).

2.- A modo de comparativa, se agregan en la tabla 36 los datos de 1059L I $\nabla$ Orduña de 1881 a 1887 y los registros correspondientes a 1024D $\vee$ de 1878 a 1887, serie de excelsa calidad según se escudriña en la Nota Técnica No 13 AEMET.

3.- Se aprecia de la tabla 36 una simultaneidad de los máximos de precipitación: 1884 sincrónico en $1077 \mathrm{C} \nabla$, en 1024D $\nabla$ y en 1059L I $\nabla ; 1879$ y 1880 coetáneos en 1077C $\vee$ y en 1024D $\nabla$.

Los mínimos pluviométricos concuerdan: 1887 concurrente en los 3 enclaves, 1882 y 1878 coetáneos en 1024D $\vee$ y en 1077C $\vee, 1881$ común a 1077C $\vee$ y 1059L I $\vee$ (tabla 36).

4.- Hay una concomitancia espacial de las precipitaciones. Se observa de la tabla 36:

a) Las precipitaciones en $1077 \mathrm{C} \vee$ oscilan entre un 86 y un $107 \%$ respecto a las de $1024 \mathrm{D} \vee \operatorname{los}$ años lluviosos y entre el 68 y el $110 \%$ los años de sequías.

b) Los valores de 1059L I $\bigcirc$ fluctúan entre el 63 y el 66\% en relación a los registros de 1077C P.

Se advierte que el cociente de las precipitaciones es aproximadamente constante.

5.- De 1877 a 1887 alternan años de MAM lluviosos y sequías en 1077C $\nabla$, 1024D $\vee$ y 1059L I $\vee$ : En este lapso temporal, las medidas alternan en torno a las medianas de las series.

Por todo lo expuesto, se trata de una inhomogeneidad "climatológica". 
3.- Inhomogeneidades de 1888 a 1898 en $1077 \mathrm{C}:$

Tabla 37: Años con precipitaciones máximas y mínimas:

\begin{tabular}{|c|c|c|c|c|c|}
\hline $\begin{array}{c}\text { Indicativo y } \\
\text { nombre }\end{array}$ & Duración serie & Año Máximo & $\begin{array}{c}\text { Precipitación } \\
\left(1 / \mathrm{m}^{2}\right)\end{array}$ & Año Mínimo & $\begin{array}{c}\text { Precipitación } \\
\left(1 / \mathrm{m}^{2}\right)\end{array}$ \\
\hline \multirow{3}{*}{$\begin{array}{c}\text { 1077C } \\
\text { Bilbao } \\
\text { Histórica } \\
\end{array}$} & \multirow{3}{*}{$\begin{array}{c}1859-1920 \\
\text { (sd } 1862 \text { a } 1864 \\
\text { y } 1874)\end{array}$} & $1891\left(7^{\circ}\right)$ & 137,7 & $1893\left(2^{\circ}\right)$ & 54,7 \\
\hline & & $1888\left(11^{\circ}\right)$ & 129,0 & $1896\left(12^{\circ}\right)$ & 76,0 \\
\hline & & $1889\left(13^{\circ}\right)$ & 121,3 & $1897\left(13^{\circ}\right)$ & 77,0 \\
\hline \multirow{4}{*}{$\begin{array}{c}\text { 1024D } \vee \\
\text { San Sebastián }\end{array}$} & \multirow{4}{*}{$1878-1900$} & $1889\left(2^{\circ}\right)$ & 165,3 & $1893\left(1^{\circ}\right)$ & 58,0 \\
\hline & & $1895\left(3^{\circ}\right)$ & 148,7 & $1892\left(4^{\circ}\right)$ & 84,3 \\
\hline & & $1894\left(4^{\circ}\right)$ & 135,0 & $1898\left(6^{\circ}\right)$ & 95,7 \\
\hline & & $1890\left(5^{\circ}\right)$ & 133,0 & $1896\left(7^{\circ}\right)$ & 99,3 \\
\hline \multirow{4}{*}{$\begin{array}{l}\text { 1059L I } \vee \\
\text { Orduña }\end{array}$} & \multirow{4}{*}{$\begin{array}{c}1881-1899 \mathrm{y} \\
1905\end{array}$} & $1890\left(1^{\circ}\right)$ & 112,3 & $1893\left(1^{\circ}\right)$ & 43,0 \\
\hline & & $1892\left(2^{\circ}\right)$ & 102,0 & $1896\left(7^{\circ}\right)$ & 60,3 \\
\hline & & $1888\left(3^{\circ}\right)$ & 97,3 & $1897\left(9^{\circ}\right)$ & 70,3 \\
\hline & & $1889\left(4^{\circ}\right)$ & 95,0 & $1898\left(11^{\circ}\right)$ & 75,0 \\
\hline
\end{tabular}

1.- Los datos de 1888 a 1898 de 1024D $\vee$ San Sebastián Instituto y de 1059L I P Orduña se incluyen como contraste en la tabla 37.

2.- La tabla 18 muestra una inhomogeneidad "climatológica" en 1024D $\nabla$ San Sebastián de 1891 a 1900 en MAM.

3.- Se observa de la tabla 37 una concordancia de los máximos $(1888,1889,1890)$ y de los mínimos $(1893,1896,1897,1898)$ pluviométricos en los tres lugares.

4.- De la tabla 37 aflora una similitud entre las pluviosidades de $1077 \mathrm{C} \vee$, 1024D $\vee$ y 1059L I $\vee:$

a) Las precipitaciones medias anuales en 1077C $\nabla$ son inferiores a las de 1024D 8 , superando las cantidades recogidas en 1024D $P$ entre un 6 y un 37\% a las de 1077C $\vee$.

b) Las precipitaciones medias anuales en 1077C $\nabla$ sobrepasan del orden del 9 al $22 \%$ las de 1059L I $P$.

Esto es, la razón de las precipitaciones es prácticamente constante.

5.- De 1888 a 1898 transcurren MAM pluviosos y áridos en 1024D $\nabla$ y en 1077C $\vee$ : Las medidas fluctúan en torno a las respectivas medianas de las series en este intersticio temporal.

Por consiguiente, se la clasifica como una inhomogeneidad "climatológica". 
Tabla 38: Años con precipitaciones máximas y mínimas:

\begin{tabular}{|c|c|c|c|c|c|}
\hline Indicativo y nombre & Duración serie & Año Máximo & $\begin{array}{l}\text { Precipitación } \\
\left(1 / \mathrm{m}^{2}\right)\end{array}$ & $\begin{array}{c}\text { Año } \\
\text { Mínimo }\end{array}$ & $\begin{array}{c}\text { Precipitación } \\
\left(1 / \mathrm{m}^{2}\right)\end{array}$ \\
\hline \multirow{3}{*}{$\begin{array}{c}\text { 1077C \& Bilbao } \\
\text { Histórica }\end{array}$} & \multirow{3}{*}{$\begin{array}{c}1859-1920 \\
\text { (sd } 1862 \text { a } 1864 \\
\text { y } 1874)\end{array}$} & $1900\left(16^{\circ}\right)$ & 118,0 & $1893\left(2^{\circ}\right)$ & 54,7 \\
\hline & & $1901\left(21^{\circ}\right)$ & 106,7 & $1899\left(5^{\circ}\right)$ & 62,7 \\
\hline & & & & $1896\left(12^{\circ}\right)$ & 76,0 \\
\hline \multirow{2}{*}{ 1059L I $\$ Orduña } & \multirow{2}{*}{$\begin{array}{c}1881-1899 \mathrm{y} \\
1905\end{array}$} & $1894\left(8^{\circ}\right)$ & 80,7 & $1893\left(1^{\circ}\right)$ & 43,0 \\
\hline & & $1895\left(9^{\circ}\right)$ & 80,7 & $1899\left(3^{\circ}\right)$ & 52,3 \\
\hline \multirow{4}{*}{$\begin{array}{c}\text { 1024D } ~ \\
\text { San Sebastián }\end{array}$} & \multirow{4}{*}{$1878-1900$} & $1895\left(3^{\circ}\right)$ & 148,7 & $1893\left(1^{\circ}\right)$ & 58,0 \\
\hline & & $1894\left(4^{\circ}\right)$ & 135,0 & $1899\left(3^{\circ}\right)$ & 75,3 \\
\hline & & $1897\left(7^{\circ}\right)$ & 130,0 & $1898\left(6^{\circ}\right)$ & 95,7 \\
\hline & & $1900\left(9^{\circ}\right)$ & 128,3 & $1896\left(7^{\circ}\right)$ & 99,3 \\
\hline 1024F I \& S. Sebastián & $1901-1917$ & $1901\left(4^{\circ}\right)$ & 113,7 & & \\
\hline
\end{tabular}

1.- Las únicas series coetáneas de $1077 \mathrm{C} \vee$ de 1893 a 1902 en Vizcaya, Álava y Guipúzcoa son 1059L I $\$$ Orduña, 1024D \& San Sebastián Instituto y 1024F I $\vee$ San Sebastián.

2.- Las precipitaciones de $1077 \mathrm{C} \vee$ Bilbao Histórica se contraponen en la tabla 38 con las cuantías recogidas en 1059L I $\vee$ de 1881 a 1899 , en 1024D $P$ de 1893 a 1900 y en 1024F I \& de 1901 a 1902.

3.- 1024D \ San Sebastián exterioriza una inhomogeneidad "climatológica" de 1891 a 1900 en MAM (tabla 18, página 51).

4.- Los máximos de la pluviosidad $(1900,1901)$ en $1077 \mathrm{C} \vee$ y los mínimos pluviométricos $(1893,1899,1896)$ de 1077C $\nabla$ concurren con las anotaciones de 1024D $\nabla$, $1024 \mathrm{~F}$ I $\vee$ y $1059 \mathrm{~L}$ I $\vee$, según expone la tabla 38. 1024D P.

Asimismo, se registran máximos simultáneos en 1894 y en 1895 en 1059L I $\nabla$ y en

5.- Las precipitaciones anuales en $1077 \mathrm{C} P$ son inferiores a las de 1024D $P$, rebasando las cantidades recogidas en 1024D $\$$ entre un 6 y un $37 \%$ a las de $1077 \mathrm{C} \vee$.

6.- De 1893 a 1898 se suceden años de MAM lluviosos y años secos en 1077C 8 , en 1024D $\$$ y en 1059L I $\$$ (tabla 38): Las anotaciones oscilan en torno a las medianas de las series en este lapso de tiempo.

Por todo lo expuesto, se la cataloga de inhomogeneidad "climatológica". 


\section{5.- Inhomogeneidades de 1901 a 1915 en 1077C:}

Tabla 39: Años con precipitaciones máximas y mínimas:

\begin{tabular}{|c|c|c|c|c|c|}
\hline $\begin{array}{c}\text { Indicativo y } \\
\text { nombre }\end{array}$ & Duración serie & $\begin{array}{c}\text { Año } \\
\text { Máximo }\end{array}$ & $\begin{array}{c}\text { Precipitación } \\
\left(1 / \mathrm{m}^{2}\right)\end{array}$ & $\begin{array}{c}\text { Año } \\
\text { Mínimo }\end{array}$ & $\begin{array}{c}\text { Precipitación } \\
\left(1 / \mathrm{m}^{2}\right)\end{array}$ \\
\hline \multirow{2}{*}{$\begin{array}{c}1077 \mathrm{C} \mathrm{P} \\
\text { Bilbao Histórica }\end{array}$} & \multirow{2}{*}{$\begin{array}{c}1859-1920 \\
(\text { sd } 1862-64 \text { y } 1874)\end{array}$} & $1913\left(4^{\circ}\right)$ & 145,1 & $1909\left(3^{\circ}\right)$ & 60,3 \\
\hline & & $1908\left(10^{\circ}\right)$ & 130,0 & $1912\left(6^{\circ}\right)$ & 63,4 \\
\hline \multirow{3}{*}{$\begin{array}{l}\text { 1024F I P San } \\
\text { Sebastián }\end{array}$} & \multirow{3}{*}{$1901-1917$} & $1910\left(1^{\circ}\right)$ & 123,3 & $1909\left(1^{\circ}\right)$ & 75,3 \\
\hline & & $1913\left(2^{\circ}\right)$ & 122,4 & $1904\left(2^{\circ}\right)$ & 75,6 \\
\hline & & $1901\left(4^{\circ}\right)$ & 113,7 & $1912\left(3^{\circ}\right)$ & 76,0 \\
\hline \multirow{2}{*}{$\begin{array}{c}1059 \text { I } P \\
\text { Punta Galea }\end{array}$} & \multirow{2}{*}{$\begin{array}{l}1911-1926 \\
(\text { sd 1925) }\end{array}$} & $1913\left(1^{\circ}\right)$ & 199,3 & $1914\left(4^{\circ}\right)$ & 88,9 \\
\hline & & $1911\left(2^{\circ}\right)$ & 198,0 & $1915\left(6^{\circ}\right)$ & 106,4 \\
\hline \multirow{2}{*}{$\begin{array}{c}1057 \mathrm{C} \mathrm{I} \\
\text { Machicaco Faro }\end{array}$} & \multirow{2}{*}{$1913-1921$} & $1913\left(3^{\circ}\right)$ & 86,2 & $1914\left(2^{\circ}\right)$ & 73,9 \\
\hline & & & & $1915\left(3^{\circ}\right)$ & 74,9 \\
\hline
\end{tabular}

1.- Los registros de precipitación de 1077C $\vee$ Bilbao Histórica se confrontan en la tabla 39 con los datos correspondientes de 1024F I \ San Sebastián de 1901 a 1915, de 1059 I $\vee$ Punta Galea Faro de 1911 a 1915 y de 1057C I $\vee$ Machicaco Faro de 1913 a 1915.

La ruptura de Noviembre de 1921 en $1057 \mathrm{C} P$, la ubicación de 1059 I $\nabla$ de 1911 a 1926 en el primigenio faro de Punta Galea (ambas descritas en el apartado 4.1.) y la rotura de Febrero a Marzo de 1918 de 1024F I $\vee$ (Nota Técnica No 13 AEMET) se tienen en cuenta en los intervalos de duración de las series recogidos en la tabla 39.

2.- Se percibe de la tabla 39 que 1913 es un máximo pluviométrico simultáneo en 1077C $\vee, 1024$ F I $\vee, 1059$ I $\vee$ y 1057C I $\vee$.

1909 y 1912 marcan mínimos pluviométricos sincrónicos en 1077C $\nabla$ y 1024F I $\nabla$. 1914 y 1915 son años de sequías coetáneas en 1059 I $\nabla$ y en 1057C I $\nabla$.

3.- Coherencia espacial de las precipitaciones:

a) En los años analizados, 1024F I $\nabla$ mide entre un 17 y un $25 \%$ más referido a 1077C $P$ los años secos. 1059 I $P$.

b) $1057 \mathrm{C}$ I $\vee$ registra entre un 70 y un $83 \%$ de las cantidades de precipitación de

4.- De la tabla 33, se observa que de 1901 a 1915 acaecen años de MAM lluviosos y secos, fluctuando las precipitaciones medidas en torno a las respectivas medianas.

Por tanto, se la califica como inhomogeneidad "climatológica". 
6.- Inhomogeneidades de 1922 a 1932 en 1057C:

Tabla 40: Años con precipitaciones máximas y mínimas:

\begin{tabular}{|c|c|c|c|c|c|}
\hline $\begin{array}{c}\text { Indicativo y } \\
\text { nombre }\end{array}$ & Duración serie & Año Máximo & $\begin{array}{c}\text { Precipitación } \\
\left(1 / \mathrm{m}^{2}\right)\end{array}$ & Año Mínimo & $\begin{array}{c}\text { Precipitación } \\
\left(1 / \mathrm{m}^{2}\right)\end{array}$ \\
\hline \multirow{3}{*}{$\begin{array}{c}\text { 1057C II } 8 \\
\text { Machicaco Faro }\end{array}$} & \multirow{3}{*}{$1922-1933$} & $1925\left(1^{\circ}\right)$ & 103,3 & $1926\left(1^{\circ}\right)$ & 57,6 \\
\hline & & $1922\left(2^{\circ}\right)$ & 101,7 & $1924\left(2^{\circ}\right)$ & 59,2 \\
\hline & & $1927\left(3^{\circ}\right)$ & 95,1 & $1929\left(3^{\circ}\right)$ & 60,1 \\
\hline \multirow{2}{*}{$\begin{array}{c}1059 \text { I } ९ \\
\text { Punta Galea }\end{array}$} & \multirow{2}{*}{$\begin{array}{l}1911-1926 \\
\text { (sd 1925) }\end{array}$} & $1922\left(6^{\circ}\right)$ & 114,3 & $1924\left(1^{\circ}\right)$ & 73,7 \\
\hline & & $1923\left(8^{\circ}\right)$ & 107,0 & $1926\left(2^{\circ}\right)$ & 82,0 \\
\hline \multirow{4}{*}{$\begin{array}{c}1077 \text { ९ } \\
\text { Larrasquitu }\end{array}$} & \multirow{4}{*}{$\begin{array}{c}1925-1931 y \\
1940-1945\end{array}$} & $1925\left(1^{\circ}\right)$ & 161,2 & $1929\left(3^{\circ}\right)$ & 80,7 \\
\hline & & $1930\left(2^{\circ}\right)$ & 143,3 & $1926\left(6^{\circ}\right)$ & 88,3 \\
\hline & & $1931\left(3^{\circ}\right)$ & 124,5 & & \\
\hline & & $1927\left(4^{\circ}\right)$ & 117,6 & & \\
\hline \multirow{4}{*}{1013 I \& Irún } & \multirow{4}{*}{$1914-1930$} & $1925\left(1^{\circ}\right)$ & 205,9 & $1924\left(2^{\circ}\right)$ & 103,7 \\
\hline & & $1927\left(3^{\circ}\right)$ & 198,4 & $1929\left(3^{\circ}\right)$ & 103,9 \\
\hline & & $1923\left(5^{\circ}\right)$ & 190,4 & $1926\left(5^{\circ}\right)$ & 130,5 \\
\hline & & $1922\left(6^{\circ}\right)$ & 185,4 & $1928\left(6^{\circ}\right)$ & 135,1 \\
\hline \multirow{4}{*}{$\begin{array}{l}1024 \mathrm{~F} \text { I } \\
\text { San Sebastián }\end{array}$} & \multirow{4}{*}{$1918-1936$} & $1923\left(1^{\circ}\right)$ & 225,3 & $1929\left(3^{\circ}\right)$ & 88,6 \\
\hline & & $1922\left(2^{\circ}\right)$ & 215,1 & $1924\left(4^{\circ}\right)$ & 101,6 \\
\hline & & $1927\left(4^{\circ}\right)$ & 161,1 & $1932\left(5^{\circ}\right)$ & 103,4 \\
\hline & & $1925\left(5^{\circ}\right)$ & 155,6 & $1926\left(6^{\circ}\right)$ & 103,6 \\
\hline
\end{tabular}

1.- Los valores de 1013 I $\vee$ de 1922 a 1930, de $1024 \mathrm{~F}$ I $\nabla$ de 1922 a 1932, de 1059 I $\nabla$ de 1922 a 1926 y de $1077 \vee$ de 1925 a 1931 se añaden a modo de comparativa en la tabla 40.

2.- La tabla 18 (página 51) expone dos inhomogeneidades "climatológicas" en 1013 I $\nabla$ de 1918 a 1927 y de 1920 a 1930 y una inhomogeneidad "climatológica" en 1024F I $\nabla$ de 1919 a 1932.

3.- Los años pluviosos $(1925,1922,1927)$ y secos $(1926,1924,1929)$ de 1057C II $\$$ concuerdan plenamente con los registrados en los demás emplazamientos recogidos en la tabla 40. 1923 es un máximo pluviométrico sincrónico en 1059 I $\nabla, 1013$ I $\nabla$ y 1024F I $\nabla$.

4.- 1925, 1922, 1930 y 1931 son máximos y 1929 y 1924 mínimos de precipitación simultáneos en Guipúzcoa (tablas 48 y 48 bis, página 103).

5.- Las precipitaciones recogidas en los 6 enclaves son concurrentes, registrando $1057 \mathrm{C}$ II $\$$ entre el 64 y el $81 \%$ de 1077 \&; entre el 70 y el $90 \%$ de 1059 I $\$$; del 44 al $58 \%$ de 1013 I $\vee$ entre el 47 y el 60\% de 1024F I $\vee$.

6.- De 1918 a 1932 se presentan MAM lluviosos o muy lluviosos y secos o muy secos en los 5 lugares, oscilando las precipitaciones recogidas en torno a la mediana.

Por consiguiente, se la considera una inhomogeneidad "climatológica". 
7.- Inhomogeneidades de 1946 a 1962 en 1059 y de 1948 a 1962 en 9077E:

Tabla 41: Años con precipitaciones máximas y mínimas:

\begin{tabular}{|c|c|c|c|c|c|}
\hline $\begin{array}{c}\text { Indicativo y } \\
\text { nombre }\end{array}$ & Duración serie & Año Máximo & $\begin{array}{c}\text { Precipitación } \\
\left(1 / \mathrm{m}^{2}\right)\end{array}$ & Año Mínimo & $\begin{array}{c}\text { Precipitación } \\
\left(1 / \mathrm{m}^{2}\right)\end{array}$ \\
\hline \multirow{4}{*}{$\begin{array}{c}1059 \text { II } \bigcirc \\
\text { Punta Galea }\end{array}$} & \multirow{4}{*}{$1946-1969$} & $1958\left(2^{\circ}\right)$ & 108,3 & $1955\left(1^{\circ}\right)$ & 34,6 \\
\hline & & $1949\left(4^{\circ}\right)$ & 98,9 & $1953\left(2^{\circ}\right)$ & 45,9 \\
\hline & & $1962\left(7^{\circ}\right)$ & 88,0 & $1961\left(3^{\circ}\right)$ & 46,8 \\
\hline & & $1956\left(8^{\circ}\right)$ & 84,0 & $1947\left(4^{\circ}\right)$ & 56,2 \\
\hline \multirow{4}{*}{$\begin{array}{c}1082 \text { I } P \\
\text { Bilbao } \\
\text { Aeropuerto }\end{array}$} & \multirow{4}{*}{$1947-1984$} & $1949\left(6^{\circ}\right)$ & 131,0 & $1955\left(1^{\circ}\right)$ & 53,1 \\
\hline & & $1958\left(9^{\circ}\right)$ & 128,1 & $1953\left(2^{\circ}\right)$ & 55,5 \\
\hline & & $1962\left(14^{\circ}\right)$ & 106,2 & $1957\left(4^{\circ}\right)$ & 62,0 \\
\hline & & $1951\left(15^{\circ}\right)$ & 103,3 & $1947\left(5^{\circ}\right)$ & 63,5 \\
\hline \multirow{4}{*}{$\begin{array}{c}\text { 9077E I } \vee \\
\text { Ochandiano }\end{array}$} & \multirow{4}{*}{$1947-1970$} & $1958\left(1^{\circ}\right)$ & 194,7 & $1955\left(1^{\circ}\right)$ & 62,0 \\
\hline & & $1949\left(2^{\circ}\right)$ & 178,4 & $1953\left(3^{\circ}\right)$ & 83,7 \\
\hline & & $1950\left(4^{\circ}\right)$ & 170,4 & $1960\left(4^{\circ}\right)$ & 84,9 \\
\hline & & $1954\left(5^{\circ}\right)$ & 159,0 & $1948\left(5^{\circ}\right)$ & 85,6 \\
\hline \multirow{4}{*}{$\begin{array}{l}9076 \text { I } \\
\text { Ullivarri } \\
\text { Gamboa }\end{array}$} & \multirow{4}{*}{$\begin{array}{c}1943-1995 \\
(\operatorname{sd~1948,~1963)~}\end{array}$} & $1949\left(2^{\circ}\right)$ & 152,5 & $1955\left(1^{\circ}\right)$ & 37,1 \\
\hline & & $1951\left(4^{\circ}\right)$ & 129,6 & $1960\left(2^{\circ}\right)$ & 42,6 \\
\hline & & $1954\left(6^{\circ}\right)$ & 116,6 & $1947\left(3^{\circ}\right)$ & 43,3 \\
\hline & & $1950\left(8^{\circ}\right)$ & 114,0 & $1961\left(5^{\circ}\right)$ & 47,0 \\
\hline \multirow{4}{*}{$\begin{array}{l}9080 \text { I } \varnothing \\
\text { Urrunaga }\end{array}$} & \multirow{4}{*}{$1943-1985$} & $1958\left(3^{\circ}\right)$ & 125,7 & $1960\left(2^{\circ}\right)$ & 50,3 \\
\hline & & $1951\left(6^{\circ}\right)$ & 124,0 & $1955\left(3^{\circ}\right)$ & 51,1 \\
\hline & & $1949\left(7^{\circ}\right)$ & 122,6 & $1947\left(7^{\circ}\right)$ & 53,7 \\
\hline & & $1954\left(11^{\circ}\right)$ & 116,1 & $1953\left(10^{\circ}\right)$ & 64,2 \\
\hline
\end{tabular}

1.- Los registros de 1946 a 1962 de 1082 I $\vee$ Bilbao Aeropuerto y de las presas de Ullivarri - Gamboa 9076 I $\nabla$ y Urrunaga 9080 I $\nabla$ se incluyen en la tabla 41 por sus respectivas proximidades a 1059 II $\nabla$ Punta Galea Faro y a 9077E I $\vee$ Ochandiano.

2.- Se detectan en 1082 I $\vee, 9076$ I $\nabla$ y 9080 I $\nabla$ las siguientes roturas, corroboradas por la evidencia documental de los registros de SS.BB. de la Delegación Territorial:

2.1.- 1082 Bilbao Aeropuerto $\bigcirc$ tiene una ruptura el 27 de noviembre de 1984, analizada en las páginas 31 y 32 del apartado 4.1.- "Rupturas detectadas en las series de precipitación".

2.2.- El test de rachas aplicado a la precipitación media anual descubre una rotura en 9076 I $\vee$ en 1995, ocasionada por la jubilación del colaborador.

El test de rachas en MAM revela en 9076 I $\nabla$ inhomogeneidades de 1945 a 1956 y de 1950 a 1966, sincrónicas con las de 1059 II $\vee$ y 9077E I $\nabla$ (tabla 33, página 79).

2.3.- 9080 I $\nabla$ Urrunaga Presa: Se conservan evidencias fotográficas de un traslado del jardín meteorológico de 40 metros. 
El escrutinio del test de rachas de la precipitación media anual, MAM y AMJ y el espulgo del test de Mann-Kendall de la precipitación media anual coinciden en la localización de la rotura de $9080 \vee$ en 1985.

El test de rachas en MAM aflora en 9080 I $\nabla$ una inhomogeneidad de 1948 a 1957 y otra de 1950 a 1963, coetáneas con las examinadas en 1059 II $\vee$ y en 9077E I $\vee$ en la tabla 41.

3.- Las características geográficas de 9077E I $\vee, 9076$ I $\nabla$ y 9080 I $\nabla$ se analizan someramente en el punto 4 del apartado 4.3.1.- "Evolución temporal de las inhomogeneidades del test de Thom aplicado a la precipitación media anual" (páginas 57 y $58)$.

4.- Las precipitaciones son congruentes a lo largo del tiempo:

a) Los máximos pluviométricos coinciden en los años 1958, 1949, 1950, 1954 y 1962 (tabla 41).

1951 es un máximo secundario común en 1082 I $\vee, 9076$ I $\vee$ y 9080 I $\vee$.

1958 y 1962 son máximos concurrentes en 1060 I $\nabla$, en 1054 II $\nabla$ y en 1052 ; 1962 en 9076 I $\vee$ y en 9077E I $\vee ; 1954$ en 9076 I $\vee$ y 9080 I $\vee$ (tabla 42, página 90). (tabla 41).

b) Los mínimos de precipitación concuerdan en 1955, 1947, 1953, 1957, 1960 y 1961

1960 y 1961 son mínimos coetáneos en 1054 II $\vee, 1060$ I $\vee, 1082$ I $\vee$ y 9076 I $\vee$; 1961 en 1052 ४ y en 9077E I $\vee ; 1955$ mínimo en 1052 ४; 1957 mínimo en 1052 , 1054 II $\vee, 1059$ II $\vee, 1060$ I $\vee 1082$ I $\vee$ y 9077E I $\vee$ (tabla 42).

\section{5.- Las precipitaciones son acordes en su distribución:}

En los años estudiados, 1059 II $\vee$ recaba entre el 75 y el $85 \%$ de 1082 I $\vee$ los años pluviosos y del 65 al 89\% los áridos, del 55 al 56\% de 9077E I $\vee$, del 65 al 130\% de 9076 I $\vee$ y entre el 81 y el $86 \%$ de 9080 I $\vee$ los años lluviosos, con una horquilla del 68 al $105 \%$ los secos.

1947 es la única ocasión en el intersticio de 1948 a 1962 en que las precipitaciones de 1059 II $\nabla$ superan las de 9076 I $\nabla$ y las de 9080 I $\vee$. La pluviosidad de 9077E I $\nabla$ rebasa en un $80 \%$ la de 1059 II $\nabla$ y sobrepasa la de 9076 I $\nabla$ entre un 15 y un $33 \%$ los años lluviosos y entre el 40 y el $49 \%$ los secos.

6.- 1951, 1954 y 1958 son máximos simultáneos en Guipúzcoa; 1947, 1953 y 1957 son años de mínimos pluviométricos sincrónicos en Guipúzcoa (tablas 48 y 48 bis, página 103).

7.- De 1946 a 1962 alternan MAM secos y lluviosos en los 3 lugares y en las ubicaciones más próximas, oscilando las precipitaciones en torno a las respectivas medianas.

Por todo lo expuesto, se la clasifica como inhomogeneidad "climatológica". 
8.- Inhomogeneidades de 1954 a 1964 en $9077 \mathrm{E}$, de 1954 a 1965 en 1059 y en 1082 , de 1956 a 1966 en 1060 y de 1957 a 1967 en $1054:$

Tabla 42: Años con precipitaciones máximas y mínimas:

\begin{tabular}{|c|c|c|c|c|c|}
\hline $\begin{array}{c}\text { Indicativo y } \\
\text { nombre }\end{array}$ & Duración serie & Año Máximo & $\begin{array}{c}\text { Precipitación } \\
\left(1 / \mathrm{m}^{2}\right)\end{array}$ & Año Mínimo & $\begin{array}{c}\text { Precipitación } \\
\left(1 / \mathrm{m}^{2}\right)\end{array}$ \\
\hline \multirow{4}{*}{$\begin{array}{c}\text { 9077E I } \vee \\
\text { Ochandiano }\end{array}$} & \multirow{4}{*}{$1947-1970$} & $1958\left(1^{\circ}\right)$ & 194,7 & $1955\left(1^{\circ}\right)$ & 62,0 \\
\hline & & $1954\left(5^{\circ}\right)$ & 159,0 & $1960\left(4^{\circ}\right)$ & 84,9 \\
\hline & & $1962\left(7^{\circ}\right)$ & 149,5 & $1957\left(6^{\circ}\right)$ & 90,1 \\
\hline & & $1956\left(8^{\circ}\right)$ & 145,5 & $1961\left(7^{\circ}\right)$ & 102,0 \\
\hline \multirow{4}{*}{$\begin{array}{c}1059 \text { II } \varnothing \\
\text { Punta Galea }\end{array}$} & \multirow{4}{*}{$1946-1969$} & $1964\left(1^{\circ}\right)$ & 109,7 & $1955\left(1^{\circ}\right)$ & 34,6 \\
\hline & & $1958\left(2^{\circ}\right)$ & 108,3 & $1961\left(3^{\circ}\right)$ & 46,8 \\
\hline & & $1965\left(5^{\circ}\right)$ & 96,1 & $1957\left(5^{\circ}\right)$ & 56,3 \\
\hline & & $1962\left(7^{\circ}\right)$ & 88,0 & $1963\left(6^{\circ}\right)$ & 58,7 \\
\hline \multirow{4}{*}{$\begin{array}{c}1082 \text { I } \bigcirc \\
\text { Bilbao } \\
\text { Aeropuerto }\end{array}$} & \multirow{4}{*}{$1947-1984$} & $1964\left(3^{\circ}\right)$ & 141,2 & $1955\left(1^{\circ}\right)$ & 53,1 \\
\hline & & $1965\left(4^{\circ}\right)$ & 139,4 & $1957\left(4^{\circ}\right)$ & 62,0 \\
\hline & & $1958\left(9^{\circ}\right)$ & 128,1 & $1960\left(6^{\circ}\right)$ & 68,1 \\
\hline & & $1962\left(14^{\circ}\right)$ & 106,2 & $1961\left(7^{\circ}\right)$ & 68,3 \\
\hline \multirow{3}{*}{$\begin{array}{l}1060 \text { I } \bigcirc \\
\text { Amurrio }\end{array}$} & \multirow{3}{*}{$\begin{array}{c}1956-1966 \\
(\text { sd 1964) }\end{array}$} & $1965\left(1^{\circ}\right)$ & 112,6 & $1960\left(1^{\circ}\right)$ & 50,7 \\
\hline & & $1962\left(2^{\circ}\right)$ & 107,5 & $1957\left(2^{\circ}\right)$ & 62,7 \\
\hline & & $1958\left(3^{\circ}\right)$ & 98,4 & $1961\left(3^{\circ}\right)$ & 73,9 \\
\hline \multirow{4}{*}{$\begin{array}{l}1054 \text { II } \bigcirc \\
\text { Marquina }\end{array}$} & \multirow{4}{*}{$\begin{array}{c}1957-1976 \\
(\text { sd 1959, 1975) }\end{array}$} & $1958\left(2^{\circ}\right)$ & 166,1 & $1957\left(1^{\circ}\right)$ & 66,3 \\
\hline & & $1964\left(6^{\circ}\right)$ & 145,4 & $1961\left(2^{\circ}\right)$ & 84,4 \\
\hline & & $1965\left(7^{\circ}\right)$ & 139,4 & $1960\left(3^{\circ}\right)$ & 87,9 \\
\hline & & $1962\left(9^{\circ}\right)$ & 135,0 & $1966\left(4^{\circ}\right)$ & 89,6 \\
\hline \multirow{3}{*}{$\begin{array}{c}9076 \mathrm{I} \\
\text { Ullivarri } \\
\text { Gamboa }\end{array}$} & \multirow{3}{*}{$\begin{array}{c}1943-1995 \\
(\text { sd 1948, 1963) }\end{array}$} & $1954\left(6^{\circ}\right)$ & 116,6 & $1955\left(1^{\circ}\right)$ & 37,1 \\
\hline & & $1962\left(10^{\circ}\right)$ & 111,4 & $1960\left(2^{\circ}\right)$ & 42,6 \\
\hline & & $1956\left(20^{\circ}\right)$ & 97,8 & $1961\left(5^{\circ}\right)$ & 47,0 \\
\hline \multirow{3}{*}{$\begin{array}{l}9080 \text { I } 8 \\
\text { Urrunaga }\end{array}$} & \multirow{3}{*}{$1943-1985$} & $1958\left(3^{\circ}\right)$ & 125,7 & $1960\left(2^{\circ}\right)$ & 50,3 \\
\hline & & $1954\left(11^{\circ}\right)$ & 116,1 & $1955\left(3^{\circ}\right)$ & 51,1 \\
\hline & & $1959\left(15^{\circ}\right)$ & 100,0 & $1967\left(6^{\circ}\right)$ & 53,0 \\
\hline \multirow{4}{*}{$\begin{array}{l}1052 \varnothing \\
\text { Motrico }\end{array}$} & \multirow{4}{*}{$\begin{array}{c}1955-1974 \\
(\text { sd 1972) }\end{array}$} & $1958\left(1^{\circ}\right)$ & 157,7 & $1955\left(1^{\circ}\right)$ & 43,0 \\
\hline & & $1965\left(2^{\circ}\right)$ & 136,3 & $1957\left(3^{\circ}\right)$ & 66,6 \\
\hline & & $1964\left(3^{\circ}\right)$ & 125,7 & $1966\left(4^{\circ}\right)$ & 73,8 \\
\hline & & $1962\left(4^{\circ}\right)$ & 120,7 & $1961\left(6^{\circ}\right)$ & 75,5 \\
\hline
\end{tabular}

1.- La tabla 42 agrega los datos de 1954 a 1967 de 1052 Motrico, la población más occidental del litoral de Guipúzcoa. Se incorporan los valores de 1954 a 1967 de 9076 I $\vee$ Ullivarri y de 9080 I $\vee$ Urrunaga, por su cercanía a 9077E I 8 . La tabla 34 (página 80) refleja una inhomogeneidad "climatológica" de 1955 a 1965 en 1052 P.

2.- Las inhomogeneidades se detectan en todas las series analizadas, salvo en 1068 II $P$ Basauri, con una rotura a finales de 1954 (examinada en la página 27).

3.- La tabla 42 aflora una simultaneidad de los años de máximos $(1958,1964,1965$, 1962 y 1954) y mínimos de precipitación $(1955,1957,1961,1960$ y 1966) en el intervalo temporal estudiado. 
1965 y 1964 son máximos y 1963, 1966 mínimos sincrónicos con 1053 I $\vee$ (tabla 43). 1967 es un mínimo coetáneo en 9080 I $\vee, 1054$ II $\vee, 1082$ I $\vee, 1059$ II $\vee$ y 1053 I $\vee$.

4.- 1954, 1958, 1964 y 1965 son máximos pluviométricos coetáneos en Guipúzcoa (tabla 48), con 1954 un máximo secundario de precipitación. 1957, 1963, 1966 y 1967 marcan mínimos concurrentes con Guipúzcoa (tabla 48 bis) y 1963 un mínimo secundario.

5.- La distribución espacial de las precipitaciones es congruente. Las tablas 42 bis y 42 tris exponen para los años pluviosos y áridos en los lapsos de la tabla 42 el \% de la pluviometría de las series en ordenadas respecto de la pluviosidad de las series en abscisas.

Se omiten la diagonal principal (comparativa de la serie consigo misma) y los resultados superiores a la diagonal, simétricos respecto a los inferiores a la diagonal.

Tabla 42 bis: Cociente de la precipitación media de los años lluviosos:

\begin{tabular}{|c|c|c|c|c|c|c|c|c|}
\hline & $9077 \mathrm{E} \mathrm{I} \nabla$ & 1059 II $\vee$ & $1082 \mathrm{I} P$ & $1060 \mathrm{I} P$ & 1054 II 8 & $9076 \mathrm{I} \nabla$ & $9080 \mathrm{I} P$ & 10528 \\
\hline \multicolumn{9}{|l|}{ 9077E I $P$} \\
\hline 1059 II $P$ & $56-59$ & & & & & & & \\
\hline $1082 \mathrm{I} P$ & $66-71$ & $118-145$ & & & & & & \\
\hline $1060 \mathrm{I} P$ & $51-72$ & $91-117$ & $77-101$ & & & & & \\
\hline 1054 II $\vee$ & $85-90$ & $122-153$ & $100-130$ & $124-169$ & & & & \\
\hline 9076 I 8 & $67-75$ & 127 & 105 & 104 & 83 & & & \\
\hline $9080 \mathrm{I} \vee$ & $65-73$ & 153 & 98 & 128 & 76 & 100 & & \\
\hline 10528 & 81 & $115-146$ & $89-123$ & $112-160$ & $86-98$ & 108 & 125 & \\
\hline
\end{tabular}

$\underline{\text { Tabla } 42 \text { tris: Cociente de la precipitación media de los años secos: }}$

\begin{tabular}{|c|c|c|c|c|c|c|c|c|}
\hline & 9077E I 8 & 1059 II $\nabla$ & $1082 \mathrm{I} P$ & $1060 \mathrm{I} P$ & 1054 II 8 & 9076 I $\nabla$ & 9080 I 8 & 10528 \\
\hline \multicolumn{9}{|l|}{ 9077E I $\vee$} \\
\hline 1059 II $\vee$ & $46-62$ & & & & & & & \\
\hline $1082 \mathrm{I} \&$ & $67-86$ & $110-153$ & & & & & & \\
\hline $1060 \mathrm{I} P$ & $60-72$ & $111-158$ & $74-108$ & & & & & \\
\hline 1054 II $P$ & $74-104$ & $118-180$ & $107-129$ & $106-173$ & & & & \\
\hline 9076 I 8 & $46-60$ & $94-107$ & $63-70$ & $64-84$ & $48-56$ & & & \\
\hline $9080 \mathrm{I} \nabla$ & $59-82$ & 148 & $74-96$ & 99 & 57 & $118-138$ & & \\
\hline 10528 & $69-74$ & $119-161$ & $81-110$ & $102-106$ & $82-100$ & $116-161$ & 84 & \\
\hline
\end{tabular}

De las tablas 42 bis y 42 tris se infiere una correlación muy buena entre las precipitaciones, siendo su razón bastante constante y con unos intervalos reducidos de variación, algo mayores los años de sequías.

6.- Se suceden años de MAM lluviosos o muy lluviosos con años de MAM secos o muy secos, alternando las precipitaciones en torno a sus respectivas medianas.

Por tanto, y dado el elevado porcentaje de series en que la inhomogeneidad aflora y su coetáneo afloramiento en 1052 \& Motrico, en 9076 I $\nabla$ Ullivarri y en 9080 I $\nabla$ Urrunaga, se la considera inhomogeneidad "climatológica". 


\section{9.- Inhomogeneidades de 1961 a 1970 en 1054 y en 1082:}

Tabla 43: Años con precipitaciones máximas y mínimas:

\begin{tabular}{|c|c|c|c|c|c|}
\hline $\begin{array}{c}\text { Indicativo y } \\
\text { nombre }\end{array}$ & Duración serie & Año Máximo & $\begin{array}{c}\text { Precipitación } \\
\left(1 / \mathrm{m}^{2}\right)\end{array}$ & Año Mínimo & $\begin{array}{c}\text { Precipitación } \\
\left(1 / \mathrm{m}^{2}\right)\end{array}$ \\
\hline \multirow{4}{*}{$\begin{array}{l}1054 \text { II } \varnothing \\
\text { Marquina }\end{array}$} & \multirow{4}{*}{$\begin{array}{c}1957-1976 \\
(\text { sd } 1959,1975)\end{array}$} & $1969\left(5^{\circ}\right)$ & 145,5 & $1961\left(2^{\circ}\right)$ & 84,4 \\
\hline & & $1964\left(6^{\circ}\right)$ & 145,4 & $1966\left(4^{\circ}\right)$ & 89,6 \\
\hline & & $1965\left(7^{\circ}\right)$ & 139,4 & $1967\left(5^{\circ}\right)$ & 92,2 \\
\hline & & $1968\left(8^{\circ}\right)$ & 135,6 & $1963\left(7^{\circ}\right)$ & 118,8 \\
\hline \multirow{4}{*}{$\begin{array}{c}1082 \text { I } ९ \\
\text { Bilbao } \\
\text { Aeropuerto }\end{array}$} & \multirow{4}{*}{$1947-1984$} & $1964\left(3^{\circ}\right)$ & 141,2 & $1961\left(7^{\circ}\right)$ & 68,3 \\
\hline & & $1965\left(4^{\circ}\right)$ & 139,4 & $1967\left(11^{\circ}\right)$ & 81,4 \\
\hline & & $1968\left(12^{\circ}\right)$ & 115,7 & $1966\left(12^{\circ}\right)$ & 81,7 \\
\hline & & $1969\left(13^{\circ}\right)$ & 110,8 & $1963\left(13^{\circ}\right)$ & 85,8 \\
\hline \multirow{4}{*}{$\begin{array}{c}1059 \text { II } \\
\text { Punta Galea }\end{array}$} & \multirow{4}{*}{$1946-1969$} & $1964\left(1^{\circ}\right)$ & 109,7 & $1961\left(3^{\circ}\right)$ & 46,8 \\
\hline & & $1969\left(3^{\circ}\right)$ & 102,2 & $1963\left(6^{\circ}\right)$ & 58,7 \\
\hline & & $1965\left(5^{\circ}\right)$ & 96,1 & $1966\left(8^{\circ}\right)$ & 59,8 \\
\hline & & $1968\left(6^{\circ}\right)$ & 95,5 & $1967\left(10^{\circ}\right)$ & 64,7 \\
\hline \multirow{3}{*}{$\begin{array}{c}1053 \text { I } 8 \\
\text { Echevarría }\end{array}$} & \multirow{3}{*}{$1962-1975$} & $1969\left(4^{\circ}\right)$ & 156,5 & $1967\left(2^{\circ}\right)$ & 98,6 \\
\hline & & $1965\left(5^{\circ}\right)$ & 150,2 & $1963\left(3^{\circ}\right)$ & 100,8 \\
\hline & & $1964\left(7^{\circ}\right)$ & 140,3 & $1966\left(4^{\circ}\right)$ & 104,8 \\
\hline
\end{tabular}

1.- Las medidas de 1961 a 1969 de 1059 II $\vee$ Punta Galea Faro y de 1962 a 1970 de 1053 I $\nabla$ Echevarría se añaden en la tabla 43 para cotejo, al ser los enclaves más cercanos respectivamente a 1082 I $\nabla$ y a 1059 II $\vee$.

2.- 1053 I $\vee$ presenta una ruptura a finales de 1975 , examinada en la página 18 del apartado 4.1.- "Rupturas detectadas en las series de precipitación".

3.- Los máximos $(1964,1965,1969)$ y los mínimos $(1961,1966,1967,1963)$ pluviométricos concuerdan en MAM.

4.- 1969 es un máximo coetáneo en 1060 II $\nabla$ (tabla 44); 1967 es un mínimo simultáneo en 1060A $\vee, 1093$ I $\vee, 1060$ II $\vee$ y 1050 II $\vee$ (tabla 44).

5.- 1964, 1965 y 1969 son máximos y 1966 y 1967 mínimos de la pluviosidad sincrónicos en Guipúzcoa (tablas 48 y 48 bis, página 103).

6.- Hay una concomitancia espacial de las precipitaciones en las 4 ubicaciones en el intersticio temporal escrutado: Las precipitaciones de 1082 I $\nabla$ son del 72 al $100 \%$ respecto a 1054 II $\vee ; 1059$ II $\nabla$ registra del 69 al $75 \%$ de 1054 II $\vee$ los años lluviosos y del 49 al $70 \%$ los secos; en 1053 I $\nabla$ se recogen del 96 al 108\% de 1054 II $\nabla$ los años lluviosos y del 85 al $117 \%$ los secos.

7.- Los máximos y mínimos secundarios pluviométricos se suceden de 1961 a 1970.

Por consiguiente, se la cataloga como inhomogeneidad "climatológica". 
10.- Inhomogeneidades de 1964 a 1977 en 1060A, de 1965 a 1976 en 1054,1967 a 1976 en 1093, 1967 a 1977 en 1060, 1968 a 1977 en 1070 y 1968 a 1978 en $1075:$

Tabla 44: Años con precipitaciones máximas y mínimas:

\begin{tabular}{|c|c|c|c|c|c|}
\hline $\begin{array}{c}\text { Indicativo y } \\
\text { nombre }\end{array}$ & Duración serie & Año Máximo & $\begin{array}{c}\text { Precipitación } \\
\left(1 / \mathrm{m}^{2}\right)\end{array}$ & Año Mínimo & $\begin{array}{c}\text { Precipitación } \\
\left(1 / \mathrm{m}^{2}\right)\end{array}$ \\
\hline \multirow{4}{*}{$\begin{array}{c}\text { 1060A } \bigcirc \\
\text { Amurrio } \\
\text { Colegio }\end{array}$} & \multirow{4}{*}{$\begin{array}{c}1962-1979 \\
(\text { sd 1966) }\end{array}$} & $1975\left(1^{\circ}\right)$ & 158,0 & $1967\left(2^{\circ}\right)$ & 68,7 \\
\hline & & $1977\left(2^{\circ}\right)$ & 141,5 & $1964\left(3^{\circ}\right)$ & 69,9 \\
\hline & & $1971\left(4^{\circ}\right)$ & 129,8 & $1976\left(4^{\circ}\right)$ & 77,7 \\
\hline & & $1972\left(6^{\circ}\right)$ & 114,7 & $1970\left(5^{\circ}\right)$ & 77,8 \\
\hline \multirow{4}{*}{$\begin{array}{l}1054 \text { II } \bigcirc \\
\text { Marquina }\end{array}$} & \multirow{4}{*}{ 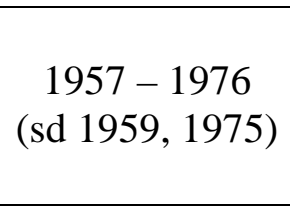 } & $1972\left(1^{\circ}\right)$ & 177,7 & $1966\left(4^{\circ}\right)$ & 89,6 \\
\hline & & $1971\left(3^{\circ}\right)$ & 163,2 & $1967\left(5^{\circ}\right)$ & 92,2 \\
\hline & & $1974\left(4^{\circ}\right)$ & 146,3 & $1973\left(6^{\circ}\right)$ & 96,3 \\
\hline & & $1969\left(5^{\circ}\right)$ & 145,5 & $1976\left(8^{\circ}\right)$ & 120,2 \\
\hline \multirow{4}{*}{$\begin{array}{l}1093 \text { I } \\
\text { Carranza }\end{array}$} & \multirow{4}{*}{$1957-1983$} & $1975\left(2^{\circ}\right)$ & 249,8 & $1967\left(5^{\circ}\right)$ & 76,0 \\
\hline & & $1971\left(3^{\circ}\right)$ & 198,0 & $1973\left(7^{\circ}\right)$ & 87,7 \\
\hline & & $1972\left(4^{\circ}\right)$ & 173,2 & $1970\left(12^{\circ}\right)$ & 114,4 \\
\hline & & $1974\left(7^{\circ}\right)$ & 144,8 & $1976\left(14^{\circ}\right)$ & 121,3 \\
\hline \multirow{4}{*}{$\begin{array}{c}1060 \text { II } \nabla \\
\text { Amurrio }\end{array}$} & \multirow{4}{*}{$1967-1992$} & $1975\left(2^{\circ}\right)$ & 168,1 & $1967\left(3^{\circ}\right)$ & 74,7 \\
\hline & & $1977\left(3^{\circ}\right)$ & 159,4 & $1973\left(5^{\circ}\right)$ & 83,4 \\
\hline & & $1971\left(4^{\circ}\right)$ & 155,1 & $1968\left(6^{\circ}\right)$ & 86,6 \\
\hline & & $1969\left(8^{\circ}\right)$ & 125,8 & $1970\left(8^{\circ}\right)$ & 96,2 \\
\hline \multirow{3}{*}{$\begin{array}{c}1070 \bigcirc \\
\text { Abadiano }\end{array}$} & \multirow{3}{*}{$1968-2002$} & $1975\left(1^{\circ}\right)$ & 211,6 & $1973\left(5^{\circ}\right)$ & 96,4 \\
\hline & & $1972\left(5^{\circ}\right)$ & 165,4 & $1970\left(9^{\circ}\right)$ & 113,6 \\
\hline & & $1971\left(8^{\circ}\right)$ & 162,6 & $1976\left(11^{\circ}\right)$ & 115,1 \\
\hline \multirow{2}{*}{1075 II $\&$ Dima } & \multirow{2}{*}{$1968-1978$} & $1978\left(1^{\circ}\right)$ & 291,3 & $1973\left(1^{\circ}\right)$ & 114,8 \\
\hline & & $1975\left(2^{\circ}\right)$ & 244,4 & $1968\left(2^{\circ}\right)$ & 120,9 \\
\hline \multirow{4}{*}{1050 II $\vee$ Eibar } & \multirow{4}{*}{$1965-1997$} & $1975\left(1^{\circ}\right)$ & 226,0 & $1973\left(2^{\circ}\right)$ & 75,8 \\
\hline & & $1972\left(2^{\circ}\right)$ & 216,5 & $1967\left(4^{\circ}\right)$ & 86,3 \\
\hline & & $1971\left(6^{\circ}\right)$ & 179,3 & $1976\left(11^{\circ}\right)$ & 120,0 \\
\hline & & $1977\left(9^{\circ}\right)$ & 165,0 & $1970\left(14^{\circ}\right)$ & 127,6 \\
\hline \multirow{4}{*}{$\begin{array}{c}1053 \text { I } \bigcirc \\
\text { Echevarría }\end{array}$} & \multirow{4}{*}{$1962-1975$} & $1975\left(1^{\circ}\right)$ & 206,6 & $1973\left(1^{\circ}\right)$ & 86,3 \\
\hline & & $1971\left(2^{\circ}\right)$ & 179,7 & $1967\left(2^{\circ}\right)$ & 98,6 \\
\hline & & $1972\left(3^{\circ}\right)$ & 172,2 & $1966\left(4^{\circ}\right)$ & 104,8 \\
\hline & & $1969\left(4^{\circ}\right)$ & 156,5 & $1970\left(6^{\circ}\right)$ & 123,2 \\
\hline
\end{tabular}

1.- Las mediciones de 1053 I $\bigcirc$ Echevarría de 1964 a 1975 y de 1050 II $\bigcirc$ Eibar de 1967 a 1977 se agregan para contraste en la tabla 44. 1050 II $\vee$, situada a 1,5 Km. de Vizcaya, manifiesta una inhomogeneidad "climatológica" de 1967 a 1977 (tabla 34, página $80)$.

1050 II $\bigcirc$ Eibar presenta una ruptura a fines de 1964 y una notable homogeneidad de 1965 a 1997 (Nota Técnica No 13 AEMET).

2.- La figura 18 muestra las ubicaciones de 1050 II $\nabla, 1053$ I $\varnothing, 1054$ II $\varnothing, 1070 \varnothing$, 1075 II $\odot, 1060$ II $\vee, 1060 \mathrm{~A} \vee$ y 1093 I $\vee$. 
Figura 18: Emplazamientos de 1050 II $\vee, 1053$ I $\vee, 1054$ II $\nabla, 1070$, 1075 II $\vee$, 1060 II $\vee, 1060 \mathrm{~A} \vee$ y 1093 I $\vee$ :

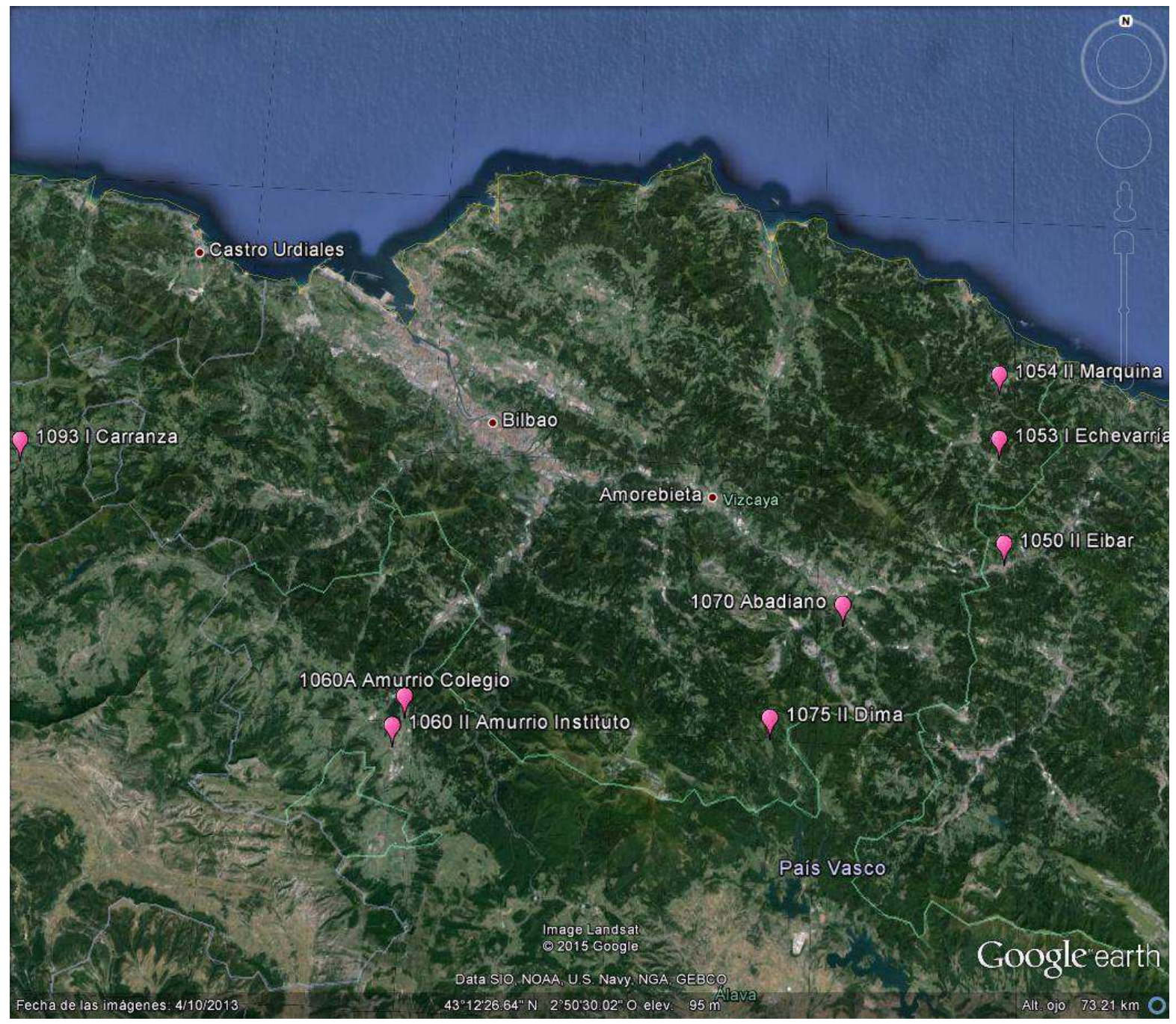

1060 II $\vee$ y 1060A $\vee$ son las series más meridionales examinadas;

1093 I $\vee$ la más occidental; 1075 II $\vee$ y 1070 se localizan en el SE de Vizcaya; 1053 I $\vee$ y 1054 II $\vee$ se hallan en el valle más oriental de Vizcaya.

3.- Los años de máximos (1975, 1971, 1972, 1977 y 1969) y mínimos $(1973,1967$, 1970 y 1976) pluviométricos coinciden.

Un máximo secundario de precipitación acontece en 1977; en 1970 y 1976 acaecen mínimos secundarios de precipitación.

4.- 1975,1977 son máximos sincrónicos en 1082 I $\vee$ y 1078E I $\vee ; 1976$ mínimo en 1078E I $\vee$ y en 1060 II $\vee$ (tabla 45).

5.- 1972 y 1969 son máximos y 1967 y 1973 mínimos simultáneos en Guipúzcoa (tablas 48 y 48 bis, página 103).

6.- Se percibe una congruencia espacial de las precipitaciones anotadas en el intervalo de años escrutado. 
Las tablas 44 bis y 44 tris detallan para los años lluviosos y secos de la tabla 44 el \% pluviometría de las series en ordenadas respecto de la pluviosidad de las series en abscisas.

Por claridad, se omiten la diagonal principal (comparativa de la serie consigo misma) y los resultados superiores a la diagonal, simétricos respecto a los inferiores.

Tabla 44 bis: Cociente de la precipitación media de los años lluviosos

\begin{tabular}{|c|c|c|c|c|c|c|c|c|}
\hline & 1060A $P$ & 1054 II $P$ & 1093 I P & 1060 II $P$ & 10708 & 1075 II 8 & 1050 II $P$ & $1053 \mathrm{I} P$ \\
\hline 1060A $P$ & & & & & & & & \\
\hline $1054 \mathrm{II} \vee$ & 126 & & & & & & & \\
\hline $1093 \mathrm{I} P$ & $151-158$ & $97-121$ & & & & & & \\
\hline 1060 II $P$ & $106-119$ & $86-95$ & $67-78$ & & & & & \\
\hline $1070 \vee$ & $125-144$ & $93-100$ & $82-95$ & $105-126$ & & & & \\
\hline 1075 II $P$ & 154 & & 98 & 145 & 116 & & & \\
\hline $1050 \mathrm{II} P$ & $117-189$ & $110-122$ & $90-125$ & $104-134$ & $107-131$ & 92 & & \\
\hline $1053 \mathrm{I} \nabla$ & $131-150$ & $97-110$ & $83-99$ & $116-124$ & $98-110$ & 85 & $80-100$ & \\
\hline
\end{tabular}

Tabla 44 tris: Cociente de la precipitación media de los años secos

\begin{tabular}{|c|c|c|c|c|c|c|c|c|}
\hline \multirow{2}{*}{ 1060A 8} & 1060A $P$ & 1054 II $\bigcirc$ & 1093 I $P$ & 1060 II $\vee$ & $1070 \curlyvee$ & 1075 II 8 & 1050 II $P$ & $1053 \mathrm{I} P$ \\
\hline & & & & & & & & \\
\hline 1054 II $P$ & $134-155$ & & & & & & & \\
\hline $1093 \mathrm{I} \vee$ & $111-156$ & $82-101$ & & & & & & \\
\hline 1060 II $P$ & $109-124$ & $81-87$ & $84-98$ & & & & & \\
\hline $1070 \vee$ & $146-148$ & $96-100$ & $95-110$ & $116-118$ & & & & \\
\hline 1075 II $P$ & & 119 & 131 & $138-140$ & 119 & & & \\
\hline $1050 \mathrm{II} \vee$ & $126-164$ & $79-100$ & $86-114$ & $91-133$ & $79-112$ & 66 & & \\
\hline $1053 \mathrm{I} P$ & $143-158$ & $90-117$ & $98-130$ & $103-132$ & $90-108$ & 75 & $97-114$ & \\
\hline
\end{tabular}

Se dejan en blanco las contraposiciones de 1075 II $\nabla$ con 1060A $\nabla$ los años áridos y de 1075 II $\vee$ con 1054 II $\vee$ los años pluviosos al carecer de extremos pluviométricos concurrentes en el lapso temporal escrutado.

Los intervalos del cociente de precipitaciones aumentan al ser mayores las distancias entre los enclaves, desde las muy cercanas 1060 II $\nabla$ y 1060A $\nabla, 1070 \vee$ y 1050 II $\nabla$ o 1053 I $\nabla$ y 1054 II $\nabla$ hasta las más alejadas 1050 II $\nabla$ y $1060 \mathrm{~A} \vee$ o 1093 I $\varnothing$ y 1050 II $\nabla$.

La elevada correlación y los estrechos intervalos de 1060 II $\nabla$ respecto a las series de pluviosidad más próximas contrastan con los amplios intervalos de los cocientes de precipitación de 1050 II $\vee$.

Las amplitudes de las razones de precipitación son, en general, más amplias los años secos que los húmedos (tablas 44 bis y 44 tris).

7.- Los años de MAM más lluviosos y años de MAM secos y muy secos transcurren en el intervalo de años detallado en la tabla 44 en los enclaves analizados.

Por tanto, se la cataloga como “inhomogeneidad climatológica”, 
11.- Inhomogeneidades de 1974 a 1984 en 1082:

Tabla 45: Años con precipitaciones máximas y mínimas:

\begin{tabular}{|c|c|c|c|c|c|}
\hline $\begin{array}{c}\text { Indicativo y } \\
\text { nombre }\end{array}$ & Duración serie & Año Máximo & $\begin{array}{c}\text { Precipitación } \\
\left(1 / \mathrm{m}^{2}\right)\end{array}$ & Año Mínimo & $\begin{array}{c}\text { Precipitación } \\
\left(1 / m^{2}\right)\end{array}$ \\
\hline \multirow{4}{*}{$\begin{array}{c}1082 \text { I } 8 \\
\text { Bilbao } \\
\text { Aeropuerto }\end{array}$} & \multirow{4}{*}{$1947-1984$} & $1975\left(1^{\circ}\right)$ & 162,8 & $1982\left(3^{\circ}\right)$ & 58,6 \\
\hline & & $1978\left(2^{\circ}\right)$ & 151,6 & $1984\left(15^{\circ}\right)$ & 86,0 \\
\hline & & $1977\left(8^{\circ}\right)$ & 129,0 & $1981\left(17^{\circ}\right)$ & 90,1 \\
\hline & & $1979\left(10^{\circ}\right)$ & 125,8 & $1983\left(18^{\circ}\right)$ & 93,3 \\
\hline \multirow{4}{*}{$\begin{array}{l}\text { 1078E I } ९ \\
\text { Valmaseda }\end{array}$} & \multirow{4}{*}{$1972-1991$} & $1975\left(1^{\circ}\right)$ & 198,4 & $1982\left(1^{\circ}\right)$ & 59,0 \\
\hline & & $1978\left(4^{\circ}\right)$ & 152,4 & $1981\left(3^{\circ}\right)$ & 92,2 \\
\hline & & $1977\left(7^{\circ}\right)$ & 137,8 & $1976\left(5^{\circ}\right)$ & 96,3 \\
\hline & & $1979\left(8^{\circ}\right)$ & 135,9 & $1984\left(7^{\circ}\right)$ & 113,0 \\
\hline \multirow{3}{*}{$\begin{array}{c}1070 \bigcirc \\
\text { Abadiano }\end{array}$} & \multirow{3}{*}{$1968-2002$} & $1975\left(1^{\circ}\right)$ & 211,6 & $1982\left(4^{\circ}\right)$ & 89,8 \\
\hline & & $1978\left(3^{\circ}\right)$ & 180,6 & $1981\left(10^{\circ}\right)$ & 113,6 \\
\hline & & $1980\left(9^{\circ}\right)$ & 160,8 & $1976\left(11^{\circ}\right)$ & 115,1 \\
\hline \multirow{4}{*}{$\begin{array}{l}1093 \text { I } 8 \\
\text { Carranza }\end{array}$} & \multirow{4}{*}{$1957-1983$} & $1978\left(1^{\circ}\right)$ & 254,7 & $1982\left(3^{\circ}\right)$ & 61,4 \\
\hline & & $1975\left(2^{\circ}\right)$ & 249,8 & $1984\left(10^{\circ}\right)$ & 93,8 \\
\hline & & $1979\left(5^{\circ}\right)$ & 151,9 & $1981\left(12^{\circ}\right)$ & 103,5 \\
\hline & & $1980\left(6^{\circ}\right)$ & 145,8 & $1983\left(17^{\circ}\right)$ & 116,2 \\
\hline \multirow{4}{*}{$\begin{array}{c}1060 \mathrm{II} P \\
\text { Amurrio }\end{array}$} & \multirow{4}{*}{$1967-1992$} & $1975\left(2^{\circ}\right)$ & 168,1 & $1982\left(2^{\circ}\right)$ & 57,7 \\
\hline & & $1977\left(3^{\circ}\right)$ & 159,4 & $1981\left(7^{\circ}\right)$ & 90,1 \\
\hline & & $1978\left(6^{\circ}\right)$ & 150,4 & $1976\left(9^{\circ}\right)$ & 96,3 \\
\hline & & $1980\left(7^{\circ}\right)$ & 126,1 & $1984\left(11^{\circ}\right)$ & 100,6 \\
\hline
\end{tabular}

1.- Los valores de 1082 I $\$$ se contrastan en la tabla 45 con los datos de 1093 I $P$ Carranza ,1078E I $\vee$ Valmaseda, 1060 II $\vee$ Amurrio y 1070 \ Abadiano, situados al W, SW, S y SE de 1082 I $\nabla$ y próximos a 1082 I $\$$.

2.- Los años con máximos $(1975,1978,1979,1980$ y 1977) pluviométricos concuerdan en los 4 lugares, coincidiendo en su importancia relativa los máximos en 1082 I $\nabla$ y en 1078E I $\nabla$. 1984.

Los años de mínimos $(1982,1981,1976,1984)$ de precipitación concurren de 1974 a

3.- 1980 es un máximo secundario de precipitación y 1982 es un mínimo sincrónico en 1053 II $\$$ y en 1050 II $\$$ (tabla 46, página 98).

4.- 1978,1979 y 1980 son máximos de precipitación y 1984 un mínimo pluviométrico secundario coincidentes con Guipúzcoa (tablas 48 y 48 bis, página 103). 1060 II 8 .

5.- La figura 19 revela las situaciones de 1082 I $\vee, 1078$ E I $\vee, 1070 \vee$, 1093 I $\vee$ y 
Figura 19: Ubicaciones de 1082 I $\nabla, 1078$ E I $\nabla, 1070 \vee, 1093$ I $\vee$ y 1060 II $\vee$ :

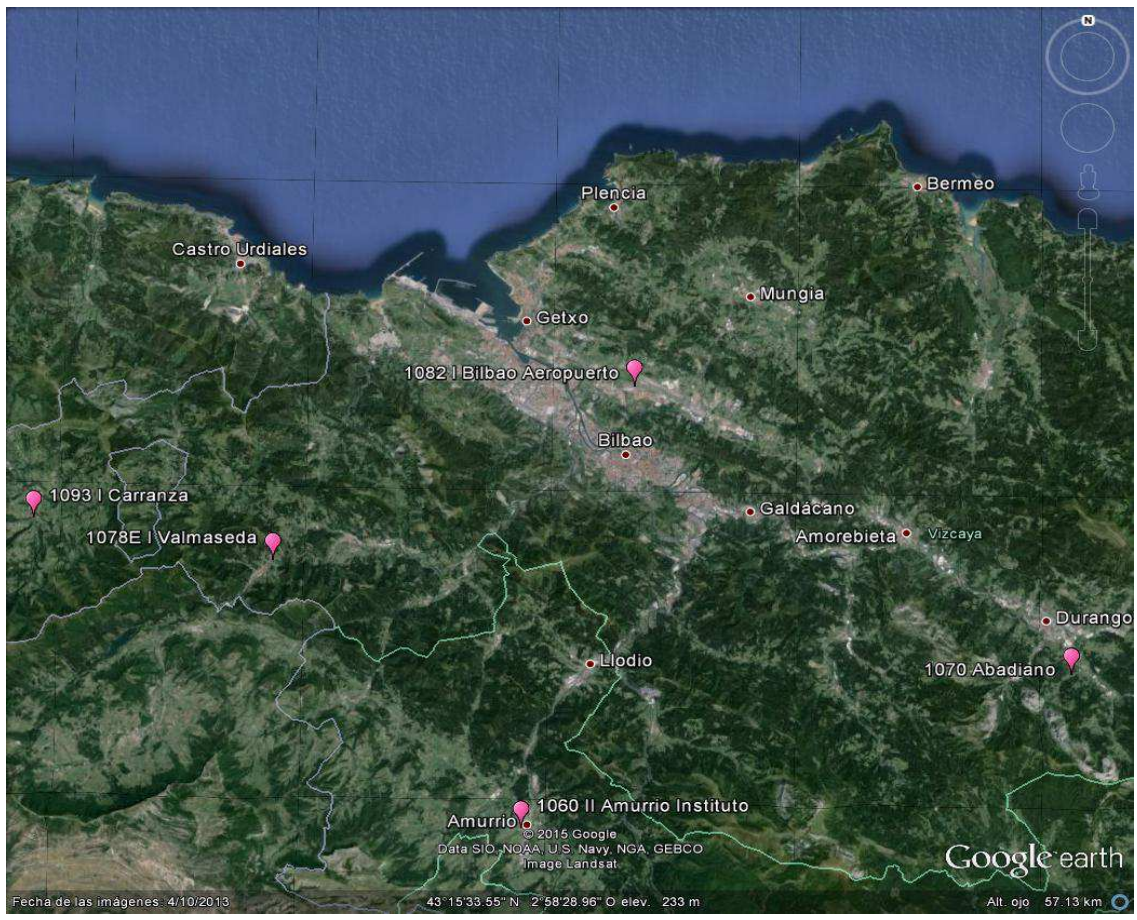

6.- Coherencia espacial: Las tablas 45 bis y 45 tris exponen el \% de la pluviosidad de las series en la primera columna respecto de la pluviometría de las series en la primera fila.

$\underline{\text { Tabla } 45 \text { bis: Cociente de la precipitación media en años lluviosos }}$

\begin{tabular}{|c|c|c|c|c|c|}
\hline & 1082 I $P$ & 1078E I $P$ & 10708 & 1093 I 8 & $1060 \mathrm{II} P$ \\
\hline $1082 \mathrm{I} P$ & & & & & \\
\hline 1078E I 8 & $101-122$ & & & & \\
\hline $1070 \mathrm{P}$ & $119-130$ & $107-119$ & & & \\
\hline 1093 I 8 & $121-168$ & $118-167$ & $118-141$ & & \\
\hline 1060 II $\$$ & $99-124$ & $85-116$ & $78-83$ & $59-86$ & \\
\hline
\end{tabular}

Tabla 45 tris: Cociente de la precipitación media en años secos

\begin{tabular}{|c|c|c|c|c|c|}
\hline & 1082 I 8 & 1078E I 8 & 10708 & 1093 I P & 1060 II 8 \\
\hline 1082 I P & & & & & \\
\hline 1078E I $\$$ & $101-131$ & & & & \\
\hline $1070 \bigcirc$ & $126-153$ & $120-152$ & & & \\
\hline 1093 I 8 & $105-125$ & $83-112$ & $68-91$ & & \\
\hline 1060 II $\vee$ & $98-117$ & $89-100$ & $64-84$ & $87-107$ & \\
\hline
\end{tabular}

Se infiere que el cociente de precipitaciones es aproximadamente constante.

6.- En el intersticio temporal analizado, se suceden años de MAM muy lluviosos y secos en los 5 enclaves.

Por todo lo expuesto, se la cataloga de "inhomogeneidad climatológica". 
12.- Inhomogeneidades de 1980 a 1992 en 1053 y de 1986 a 1995 en 1082 :

Tabla 46: Años con precipitaciones máximas y mínimas:

\begin{tabular}{|c|c|c|c|c|c|}
\hline $\begin{array}{c}\text { Indicativo y } \\
\text { nombre }\end{array}$ & Duración serie & Año Máximo & $\begin{array}{c}\text { Precipitación } \\
\left(1 / \mathrm{m}^{2}\right)\end{array}$ & Año Mínimo & $\begin{array}{c}\text { Precipitación } \\
\left(1 / \mathrm{m}^{2}\right)\end{array}$ \\
\hline \multirow{4}{*}{$\begin{array}{l}1053 \text { II } 8 \\
\text { Echevarría }\end{array}$} & \multirow{4}{*}{$1976-1996$} & $1991\left(3^{\circ}\right)$ & 186,7 & $1987\left(2^{\circ}\right)$ & 74,0 \\
\hline & & $1985\left(4^{\circ}\right)$ & 175,4 & $1982\left(3^{\circ}\right)$ & 81,9 \\
\hline & & $1988\left(5^{\circ}\right)$ & 167,0 & $1990\left(5^{\circ}\right)$ & 116,9 \\
\hline & & $1980\left(7^{\circ}\right)$ & 155,8 & $1992\left(6^{\circ}\right)$ & 117,1 \\
\hline \multirow{4}{*}{$\begin{array}{c}1082 \text { II } ~ \\
\text { Bilbao } \\
\text { Aeropuerto }\end{array}$} & \multirow{4}{*}{$1985-2000$} & $1991\left(1^{\circ}\right)$ & 137,3 & $1987\left(2^{\circ}\right)$ & 52,7 \\
\hline & & $1988\left(3^{\circ}\right)$ & 119,0 & $1992\left(4^{\circ}\right)$ & 71,5 \\
\hline & & $1994\left(4^{\circ}\right)$ & 118,7 & $1993\left(7^{\circ}\right)$ & 98,0 \\
\hline & & $1989\left(5^{\circ}\right)$ & 103,7 & $1990\left(8^{\circ}\right)$ & 98,5 \\
\hline \multirow{3}{*}{$\begin{array}{l}\text { 1078E I } ९ \\
\text { Valmaseda }\end{array}$} & \multirow{3}{*}{$1972-1991$} & $1991\left(2^{\circ}\right)$ & 198,2 & $1982\left(1^{\circ}\right)$ & 59,0 \\
\hline & & $1985\left(3^{\circ}\right)$ & 163,6 & $1987\left(2^{\circ}\right)$ & 68,2 \\
\hline & & $1988\left(5^{\circ}\right)$ & 146,9 & $1981\left(3^{\circ}\right)$ & 92,2 \\
\hline \multirow{4}{*}{$\begin{array}{c}1050 \text { II } P \\
\text { Eibar }\end{array}$} & \multirow{4}{*}{$1965-1997$} & $1991\left(5^{\circ}\right)$ & 180,2 & $1987\left(3^{\circ}\right)$ & 81,8 \\
\hline & & $1985\left(7^{\circ}\right)$ & 174,2 & $1982\left(5^{\circ}\right)$ & 92,8 \\
\hline & & $1988\left(8^{\circ}\right)$ & 171,0 & $1995\left(7^{\circ}\right)$ & 100,5 \\
\hline & & $1980\left(10^{\circ}\right)$ & 158,6 & $1993\left(9^{\circ}\right)$ & 110,7 \\
\hline
\end{tabular}

1.- Los valores de 1053 II $\nabla$ Echevarría y de 1082 II $\vee$ Bilbao Aeropuerto se cotejan con las medidas de 1078E I $\vee$ Valmaseda y 1050 II $\nabla$ Eibar en la tabla 46, las series respectivamente más próximas en el intervalo estudiado.

Los datos de $1078 \mathrm{E}$ I $\nabla$ y 1050 II $\nabla$ son de 1980 a $1995 ;$ los de 1053 II $\nabla$ y 1082 II $\vee$ corresponden al intervalo de sus inhomogeneidades.

2.- Los máximos $(1991,1985,1988,1980)$ y mínimos $(1987,1982,1992)$ pluviométricos son simultáneos.

3.- Los extremos de precipitación concurren en otras localizaciones: 1988 máximo en 1069E $\nabla, 1070 \vee$ Abadiano y 1049U $\vee ; 1989$ máximo en $1070 \vee ; 1991$ máximo en

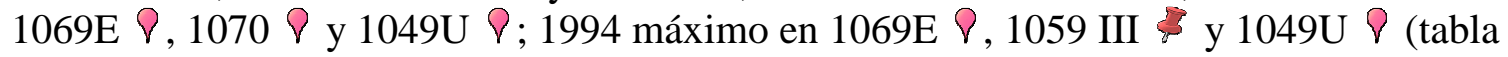
47).

Un MAM seco acontece en 1987 en 1069E $\$$ Urquiola y 1049U $\vee$ Ermua (tabla 47).

4.- 1980, 1985, 1991 y 1994 son máximos y 1987, 1992 son mínimos pluviométricos coetáneos en Guipúzcoa (tablas 48 y 48 bis, página 103).

5.- Concomitancia espacial: Las precipitaciones de 1082 II $\bigcirc$ abarcan del 71 al $74 \%$ los años lluviosos y del 61 al 84\% los secos de 1053 II $\nabla$; del 69 al $81 \%$ de los registros de 1078E I $\vee$ y del 70 al $76 \%$ los años pluviosos y del 64 al $89 \%$ de 1050 II $\vee$ los años áridos. estudiado.

6.- MAM lluviosos y secos coetáneos acaecen en los 4 lugares en el intervalo

Por tanto, se la clasifica como "inhomogeneidad climatológica". 
13.- Inhomogeneidades de 1987 a 2006 en 1069E, de 1988 a 2002 en 1070 , de 1989 a 1998 en 1082 y de 1997 a 2006 en 1081 U:

Tabla 47: Años con precipitaciones máximas y mínimas:

\begin{tabular}{|c|c|c|c|c|c|}
\hline $\begin{array}{c}\text { Indicativo y } \\
\text { nombre }\end{array}$ & Duración serie & Año Máximo & $\begin{array}{c}\text { Precipitación } \\
\left(1 / \mathrm{m}^{2}\right)\end{array}$ & Año Mínimo & $\begin{array}{c}\text { Precipitación } \\
\left(1 / \mathrm{m}^{2}\right)\end{array}$ \\
\hline \multirow{3}{*}{$\begin{array}{l}\text { 1069E } P \\
\text { Urquiola }\end{array}$} & \multirow{3}{*}{$\begin{array}{c}1986-2008 \\
(\text { sd } 1992 \text { y } 1996 \\
\text { a 2004) }\end{array}$} & $1991\left(2^{\circ}\right)$ & 252,0 & $1987\left(1^{\circ}\right)$ & 100,1 \\
\hline & & $1988\left(4^{\circ}\right)$ & 206,2 & $2006\left(2^{\circ}\right)$ & 128,7 \\
\hline & & $1994\left(5^{\circ}\right)$ & 185,9 & $1995\left(3^{\circ}\right)$ & 140,8 \\
\hline \multirow{4}{*}{$\begin{array}{c}1070 \varnothing \\
\text { Abadiano }\end{array}$} & \multirow{4}{*}{$1968-2002$} & $1991\left(2^{\circ}\right)$ & 200,5 & $1997\left(2^{\circ}\right)$ & 85,7 \\
\hline & & $1993\left(6^{\circ}\right)$ & 165,0 & $1996\left(3^{\circ}\right)$ & 87,7 \\
\hline & & $1988\left(7^{\circ}\right)$ & 163,7 & $2002\left(6^{\circ}\right)$ & 105,7 \\
\hline & & $1989\left(11^{\circ}\right)$ & 155,1 & $2001\left(7^{\circ}\right)$ & 106,0 \\
\hline \multirow{4}{*}{$\begin{array}{c}1082 \text { II } \nabla \\
\text { Bilbao } \\
\text { Aeropuerto }\end{array}$} & \multirow{4}{*}{$1985-2000$} & $1991\left(1^{\circ}\right)$ & 137,3 & $1997\left(1^{\circ}\right)$ & 42,1 \\
\hline & & $1994\left(4^{\circ}\right)$ & 118,7 & $1996\left(3^{\circ}\right)$ & 53,6 \\
\hline & & $1989\left(5^{\circ}\right)$ & 118,7 & $1992\left(4^{\circ}\right)$ & 71,5 \\
\hline & & $1998\left(6^{\circ}\right)$ & 103,7 & $1993\left(7^{\circ}\right)$ & 98,0 \\
\hline \multirow{3}{*}{$\begin{array}{c}\text { 1081U II } \vee \\
\text { Derio }\end{array}$} & \multirow{3}{*}{$1996-2009$} & $2005\left(3^{\circ}\right)$ & 132,4 & $1997\left(1^{\circ}\right)$ & 51,0 \\
\hline & & $1998\left(4^{\circ}\right)$ & 107,5 & $1996\left(2^{\circ}\right)$ & 69,2 \\
\hline & & $2001\left(5^{\circ}\right)$ & 105,9 & $2003\left(3^{\circ}\right)$ & 78,9 \\
\hline \multirow{4}{*}{$\begin{array}{l}1059 \text { III } \\
\text { Punta Galea }\end{array}$} & \multirow{4}{*}{$1994-2013$} & $1998\left(5^{\circ}\right)$ & 94,4 & $1997\left(2^{\circ}\right)$ & 39,6 \\
\hline & & $2004\left(6^{\circ}\right)$ & 92,8 & $1996\left(4^{\circ}\right)$ & 54,4 \\
\hline & & $1994\left(7^{\circ}\right)$ & 90,9 & $2003\left(5^{\circ}\right)$ & 54,7 \\
\hline & & $2005\left(8^{\circ}\right)$ & 84,2 & $2001\left(6^{\circ}\right)$ & 64,1 \\
\hline \multirow{4}{*}{$\begin{array}{c}\text { 1049U } \bigcirc \\
\text { Ermua }\end{array}$} & \multirow{4}{*}{$1983-2005$} & $1994\left(1^{\circ}\right)$ & 198,7 & $1996\left(1^{\circ}\right)$ & 64,9 \\
\hline & & $1991\left(2^{\circ}\right)$ & 188,7 & $1987\left(2^{\circ}\right)$ & 74,9 \\
\hline & & $2005\left(3^{\circ}\right)$ & 165,2 & $1997\left(3^{\circ}\right)$ & 85,5 \\
\hline & & $1988\left(4^{\circ}\right)$ & 162,1 & $2003\left(4^{\circ}\right)$ & 97,1 \\
\hline
\end{tabular}

1.- Estas inhomogeneidades afloran exclusivamente en el Duranguesado y en el Gran Bilbao, no surgiendo en ninguna otra comarca de Vizcaya ni de la vertiente cantábrica de Álava.

Los registros de 1059 III Punta Galea Golf de 1994 a 2013 y de 1049U P Ermua de 1988 a 2005 se agregan como contraste a la tabla 47, por su respectiva cercanía a 1082 II $>$ Bilbao Aeropuerto, a 1069E $>$ Urquiola y a 1070 P Abadiano.

La tabla 34 (página 80) refleja dos inhomogeneidades "climatológicas" en 1049U P en la precipitación media en MAM de 1989 a 1998 y de 1985 a 1995.

2.- Los máximos (1991, 1988, 1994, 1998, 2005) y mínimos pluviométricos (1997, 1996, 1987, 2001, 2003) coinciden en los 6 enclaves.

3.- 1991 y 1994 son máximos simultáneos en Guipúzcoa (tabla 48). 1987, 1992, 1996, 1997, 2001 y 2003 son mínimos sincrónicos en Guipúzcoa (tabla 48 bis).

La figura 20 refleja a la izquierda las ubicaciones de 1059 III, 1082 II $\nabla$ y 1081U II $\vee$; a la derecha, las localizaciones de 1049U $\vee, 1069 \mathrm{E} \vee$ y 1070 . 
Figura 20: A la izquierda, emplazamientos de 1059 III $\$, 1082$ II $\vee$ y 1081 U II $\nabla$; a la derecha, enclaves de 1049U $\nabla, 1069 \mathrm{E} \vee$ y $1070 \vee$ :
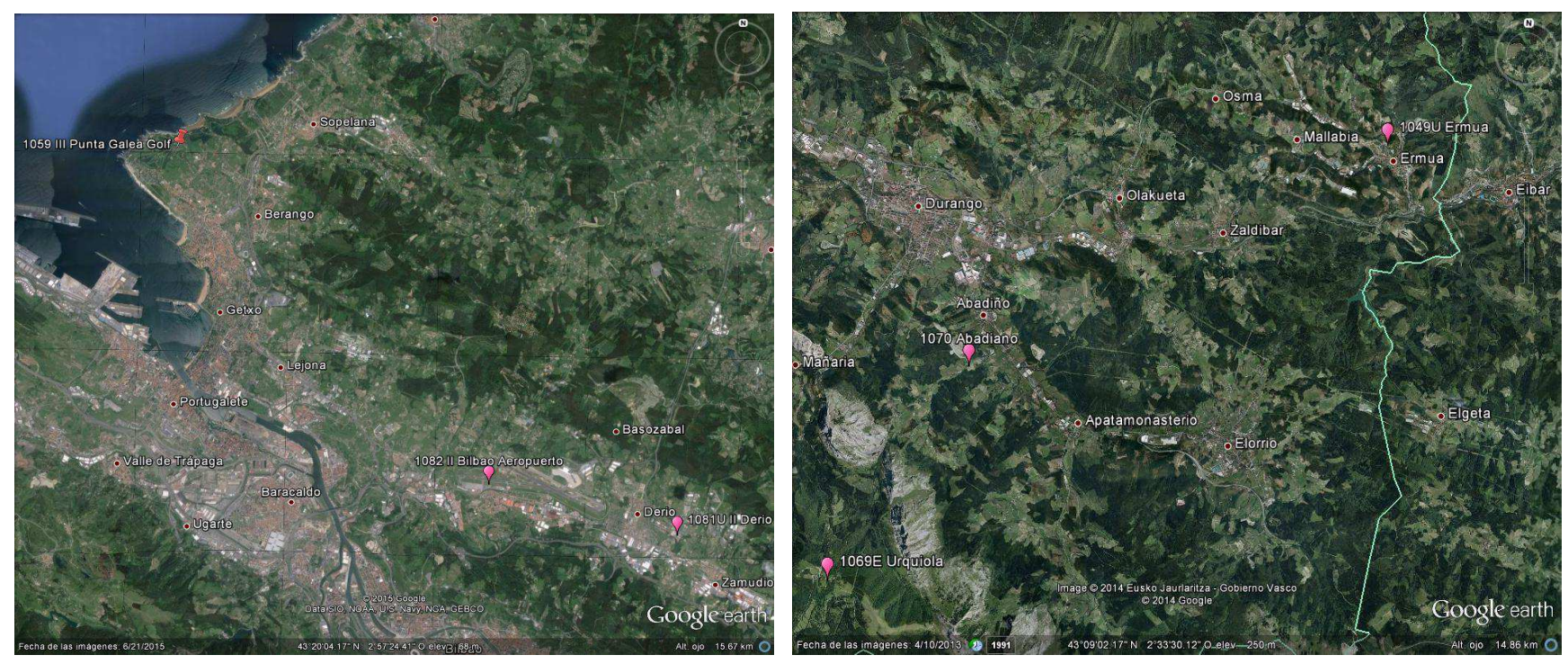

La tabla 47 segunda describe las altitudes de las localizaciones analizadas y su distancia a 1082 II $\nabla$ (series del Gran Bilbao) y a $1070 \vee$ (series del Duranguesado).

\section{Tabla 47 segunda: Características geográficas de 1059 III \& 1082 II $\vee$ y 1081 U II $\nabla$ (Gran Bilbao) y de $1049 \mathrm{U} \vee, 1069 \mathrm{E} \vee$ y $1070 \bigcirc$ (Duranguesado):}

\begin{tabular}{|c|c|c|c|c|}
\hline Indicativo & Nombre & Altitud (m) & Distancia a 1082 II $\vee(\mathrm{Km})$ & Distancia a $1070 \vee(\mathrm{Km})$ \\
\hline 1059 III & Punta Galea & 80 & 11,1 & \\
\hline 1082 II $\vee$ & Bilbao Aeropuerto & 32 & & \\
\hline 1081 U II $P$ & Derio Neiker & 30 & 4,6 & \\
\hline $1049 U \nabla$ & Ermua & 226 & & 10,4 \\
\hline $1069 \mathrm{E} P$ & Urquiola & 733 & & 5,3 \\
\hline 10708 & Abadiano & 177 & & \\
\hline
\end{tabular}

4.-Hay una coherencia espacial en las precipitaciones: Urquiola, el de mayor elevación, registra las precipitaciones superiores. Las cuantías del Duranguesado descuellan tocantes a las del Gran Bilbao.

En el intersticio temporal escrutado, las precipitaciones de $1069 \mathrm{E} P$ son del 126 al $184 \%$ respecto a 1082 II $\vee$; en $1070 \nabla$ se registra del 125 al $127 \%$ de 1082 II $\vee$ los años lluviosos y del 164 al $204 \%$ de 1082 II $\vee$ los años secos; en 1081U II $\vee$ se recogen del orden del 104\% los años pluviosos y del $121 \%$ los años áridos referido a 1082 II $\vee$; 1059 III $₹$ mide del 77 al $91 \%$ de 1082 II $\vee$ los años lluviosos y del 94 al 99\% los años secos; 1049 U $\nabla$ anota del 137 al $167 \%$ de 1082 II $P$ los años lluviosos y del 100 al $121 \%$ los años secos.

5.- Años de MAM lluviosos y secos o muy secos transcurren simultáneamente en el intersticio temporal descrito por la tabla 47 en los 6 emplazamientos.

Por todo lo expuesto, se la considera una "inhomogeneidad climatológica". 
Como compendio del análisis de la evolución temporal de las inhomogeneidades detectadas por el test de las rachas en las medidas de la precipitación MAM:

Una vez descubiertas las roturas de las series pluviométricas, el test de las rachas escruta cada intervalo (caso de rupturas) y la serie completa (caso sin rupturas) encontrándose:

1.- La totalidad de las inhomogeneidades (tabla 33, página 79) es “climatológica".

2.- Los clímax de inhomogeneidades se registran de 1954 a 1965 (coetáneo con el máximo de Guipúzcoa, de 1954 a 1968) y de 1967 a 1977.

Una regularidad en la cadencia de las inhomogeneidades "climatológicas" de 1077C $\vee$ Bilbao Histórica (tabla 33), con un periodo cercano a 10 años.

3.- La importancia de realizar un estudio conjunto de las series de datos actuales y antiguas, para poder discernir las inhomogeneidades entre "climatológicas" y no "climatológicas", confrontando el comportamiento de la precipitación entre enclaves cercanos.

La comprensión de la evolución temporal de la homogeneidad de una serie pluviométrica larga constriñe a un examen minucioso y global abarcando las series de precipitaciones actuales y antiguas próximas.

4.- La necesidad de una resolución superior a la provincia para realizar un espulgo de las inhomogeneidades:

4.1.- Las inhomogeneidades de 1980 a 1995 se circunscriben al Gran Bilbao y a Marquina - Ondarroa y las inhomogeneidades de 1987 a 2006 al Gran Bilbao y al Duranguesado, no aflorando en ninguna otra comarca.

4.2.- La tabla 47 bis condensa el número de series, de inhomogeneidades y la inhomogeneidad media (razón del número de inhomogeneidades entre el número de series) para cada comarca.

Tabla 47 bis: Distribución comarcal de las inhomogeneidades "climatológicas" del test de rachas de la precipitación media MAM:

$\begin{array}{cccc}\text { Comarca } & \mathrm{N}^{\mathrm{o}} \text { series analizadas } & \mathrm{N}^{\mathbf{o}} \text { inhomogeneidades } & \begin{array}{c}\text { Inhomogeneidad } \\ \text { media }\end{array} \\ \text { Arratia - Nervión } & 5 & 2 & 0,4 \\ \text { Duranguesado } & 5 & 16 & 3,2 \\ \text { Encartaciones } & 5 & 1 & 0,2 \\ \text { Gran Bilbao } & 7 & 32 & 4,6 \\ \text { Guernica - Bermeo } & 2 & 2 & 1 \\ \text { Marquina - Ondarroa } & 4 & 8 & 2 \\ \text { Plencia - Munguía } & 1 & 0 & 0 \\ \text { Cantábrica Alavesa } & 3 & 7 & 2,3\end{array}$


Además del máximo del Gran Bilbao, la mayoría de las inhomogeneidades se ubican en el Duranguesado y en Marquina - Ondarroa, comarcas colindantes con Guipúzcoa, lo cuál destaca la trascendencia de un examen a una escala comarcal, debido al desigual relieve de Vizcaya.

La cuantía de las precipitaciones recogidas en MAM presenta una gran variabilidad interanual, pudiendo un año lluvioso rebasar en un 300 a $500 \%$ las cantidades registradas en los años secos (tablas 35 a 47).

No se puede determinar el comportamiento pluviométrico de una zona extensa sin el conocimiento detallado de la climatología a escala comarcal.

5.- Una gran semejanza en el devenir de las series pluviométricas MAM próximas (tablas 40 a 47), pudiendo disertar no sólo de inhomogeneidades "climatológicas" a nivel provincial, sino de inhomogeneidades "climatológicas" en una misma comarca o en comarcas limítrofes.

Esta similitud se exterioriza:

A) Temporalmente: Los máximos y mínimos pluviométricos son sincrónicos.

B) Espacialmente: Una elevada correlación entre las pluviosidades de las diversas ubicaciones.

La razón de las precipitaciones es aproximadamente constante, con unos intervalos reducidos de variación de los cocientes de precipitaciones y con una dispersión mayor de los cocientes los años secos o muy secos frente a los lluviosos o muy pluviosos (descrito en las tablas 42 bis y 42 tris, 44 bis y 44 tris, 45 bis y 45 tris y analizado en los comentarios de las tablas 35 a 47).

6.- El acopio de los valores de las tablas 35 a 47 insinúa un doble ciclo en la precipitación MAM rayano a los 10 años, un triple ciclo allegado a los 20 años y un doble ciclo propincuo a los 30 años.

6.1.- Las tablas 48 y 48 bis transcriben los años lluviosos y secos en MAM en Guipúzcoa (Nota Técnica No 13 AEMET) para su contraste con los resultados de Vizcaya y de la vertiente cantábrica de Álava, recogidos en las tablas 49 y 49 bis.

La siguiente nomenclatura se utiliza en las tablas 48, 48 bis, 49 y 49 bis:

a) En azul oscuro, los máximos y mínimos pluviométricos simultáneos en Vizcaya, en la vertiente cantábrica de Álava y en Guipúzcoa.

b) En azul aguamarina, los máximos y mínimos de precipitación secundarios coetáneos en Vizcaya, en la vertiente cantábrica de Álava y en Guipúzcoa.

c) En rojo, los extremos pluviométricos de Vizcaya y de la vertiente cantábrica de Álava no sincrónicos con los registrados en Guipúzcoa y congruentes con el doble ciclo de 10 años de MAM lluviosos y de MAM secos. 
d) En rojo oscuro, los máximos y mínimos de precipitación secundarios de Vizcaya y de la vertiente cantábrica de Álava no concurrentes en Guipúzcoa y coherentes con el doble ciclo decenal de MAM pluviosos y de MAM áridos.

e) Se dejan en blanco los años sin máximos o mínimos pluviométricos MAM recopilados de las tablas 35 a 47, sea por la carencia de series de datos (1934 a 1943) o por concurrir con un intervalo carente de inhomogeneidades (de 1916 a 1921, tabla 33).

f) En negrita, los años con máximos y mínimos pluviométricos MAM notorios, por el número de localizaciones y por su naturaleza de extremos. 1961.

g) Un guión - denota años de la tabla englobados: Por ejemplo 1960-61: 1960 y

h) Una coma , indica años no consecutivos. Verbi gratia 1911,13: 1911 y 1913.

Tabla 48: Años con máximos pluviométricos en precipitación MAM:

\begin{tabular}{|c|c|c|c|c|c|c|c|}
\hline Máximos & 1879 & 1884 & $1889-90$ & $1894-95$ & $1900-01$ & & 1908 \\
\hline \hline Máximos & 1917 & 1922,23 & 1925 & $1930-31$ & 1933 & $1939-40$ & 1942 \\
\hline \hline Máximos & 1951 & 1954 & 1958 & $1964-65$ & 1969 & $1972-74$ & $\mathbf{1 9 7 8 , 7 9 , 8 0}$ \\
\hline \hline Máximos & $1985-86$ & 1991 & 1994 & 2000 & & $2007-08$ & $\mathbf{2 0 1 3}$ \\
\hline \hline
\end{tabular}

Tabla 48 bis: Años con mínimos pluviométricos en precipitación MAM:

\begin{tabular}{|l||c|c|c|c|c||c||c|}
\hline \hline Mínimos & & 1882 & 1888 & $1892-93$ & $1898-99$ & 1904 & 1909 \\
\hline \hline Mínimos & 1915 & 1921 & 1924 & 1929 & 1934 & 1938 & $\mathbf{1 9 4 3 - 4 4}$ \\
\hline \hline Mínimos & $1947-48$ & 1953 & 1957 & 1963 & $1966-67$ & $\mathbf{1 9 7 3}$ & \\
\hline Mínimos & 1984 & 1987 & $1992-93$ & $1996-97$ & 2001 & $\mathbf{2 0 0 3}$ & $2010-11$ \\
\hline
\end{tabular}

Una iteración de máximos y mínimos pluviométricos se aprecia de las tablas 35 a 47, los cuáles quedan compilados en las tablas 49 (máximos) y 49 bis (mínimos).

Tabla 49: Años con máximos pluviométricos en precipitación MAM:

\begin{tabular}{|l|c|c||c|c||c|c|c||}
\hline Máximos & $\mathbf{1 8 6 9}$ & 1873 & $1877, \mathbf{7 9}$ & $\mathbf{1 8 8 4}$ & $1888-9, \mathbf{1}$ & 1894 & $1900-01$ \\
\hline \hline Máximos & & 1908 & $\mathbf{1 9 1 1 , 1 3}$ & & $\mathbf{1 9 2 2}$ & $\mathbf{1 9 2 5}$ & $\mathbf{1 9 3 0}$ \\
\hline Máximos & & & & $\mathbf{1 9 4 9 , 5 1}$ & & $\mathbf{1 9 5 8}$ & $1964-\mathbf{6 5}$ \\
\hline \hline Máximos & 1969,71 & $1972, \mathbf{5}$ & $\mathbf{1 9 7 7 - 8 - 9}$ & 1985 & $1988, \mathbf{9 1}$ & 1994 & 1998 \\
\hline \hline Máximos & 2005 & & & & & & \\
\hline \hline
\end{tabular}


1888-9,1: 1889 y 1891 máximos relevantes por la cuantía de las precipitaciones. 1889 máximo simultáneo en Guipúzcoa, Vizcaya y la vertiente cantábrica de Álava.

1971-2,5: 1975 máximo notorio por la abundancia de las precipitaciones. $1971 \mathrm{y}$ 1975 máximos no sincrónicos en Guipúzcoa. 1972 año lluvioso en Guipúzcoa, Vizcaya y la vertiente cantábrica de Álava.

1977-8-9: 1978 máximo prominente en Vizcaya y en la vertiente cantábrica de Álava por la cuantía de la pluviosidad. 1978 y 1979 máximos simultáneos en Guipúzcoa, Vizcaya y la vertiente cantábrica de Álava. 1977 máximo no coetáneo en Guipúzcoa.

1954 y 1964 son máximos secundarios coetáneos en Guipúzcoa (tabla 48).

Tabla 49 bis: Años con mínimos pluviométricos en precipitación MAM:

\begin{tabular}{||l||c||c||c||c||c||c|c||}
\hline \hline Mínimos & 1868 & $\mathbf{1 8 7 0 - 7 1}$ & 1878 & $1881-82$ & 1887 & $\mathbf{1 8 9 3}$ & $\mathbf{1 8 9 9}$ \\
\hline Mínimos & & & $\mathbf{1 9 0 9 , 1 2}$ & 1914 & & 1924 & 1929 \\
\hline Mínimos & & & & $\mathbf{1 9 4 7 - 4 8}$ & $\mathbf{1 9 5 3 , 5 5}$ & $\mathbf{1 9 5 7}$ & $\mathbf{1 9 6 0 - 6 1}$ \\
\hline \hline Mínimos & $1966-\mathbf{6 7}$ & $\mathbf{1 9 7 3}$ & 1976 & $\mathbf{1 9 8 2}$ & $\mathbf{1 9 8 7}$ & 1992 & $\mathbf{1 9 9 6 - 9 7}$ \\
\hline \hline Mínimos & $2001, \mathbf{0 3}$ & 2006 & & & & & \\
\hline \hline
\end{tabular}

6.2.- Dos ciclos próximos a los 10 años en los máximos de precipitación media MAM emergen de la tabla 49:

a) $1873 \Rightarrow>1884 \Rightarrow>1894 \Rightarrow>\ldots \Rightarrow 1911$ y $1913 \Rightarrow>1922 \Rightarrow>1930 \Rightarrow>\ldots=>1949$ y $1951 \Rightarrow>1958 \Rightarrow>1969$ y $1971 \Rightarrow>1977-1978-1979 \Rightarrow 1988$ y $1991 \Rightarrow>1998$ $\Rightarrow$...

b) $1869 \Rightarrow>1877$ y $1879 \Rightarrow>1888-1889$ y $1891 \Rightarrow>1900-1901 \Rightarrow>1908 \Rightarrow \ldots=>$ $1925 \Rightarrow \ldots \Rightarrow 1964-1965 \Rightarrow 1972$ y $1975 \Rightarrow 1985 \Rightarrow>1994 \Rightarrow 2005=>\ldots$

Los años duplicados del ciclo van asociados a años lluviosos o muy lluviosos en MAM; los triplicados a efemérides de precipitación (tabla 49). 49 bis:

Dos ciclos en los mínimos pluviométricos cercanos a los 10 años afloran de la tabla

a) $1868 \Rightarrow>1878 \Rightarrow>1887 \Rightarrow>1899 \Rightarrow>\ldots=>1914 \Rightarrow>1924 \Rightarrow>\ldots=>1953$ y 1955 $=>1960-1961 \Rightarrow>1973 \Rightarrow 1982 \Rightarrow>1992 \Rightarrow 2001$ y $2003 \Rightarrow \ldots$

b) $1870-1871 \Rightarrow>1881-1882 \Rightarrow>1893 \Rightarrow>\ldots=>1909$ y $1912 \Rightarrow>\ldots=>1929 \Rightarrow>$ $\ldots=>1947-1948 \Rightarrow>1957 \Rightarrow>1966-1967 \Rightarrow 1976 \Rightarrow>1987 \Rightarrow>1996-1997$ $=>2006=>\ldots$

Los años del ciclo duplicados van relacionados a años de sequías en MAM.

Los ... denotan saltos en la cadencia del ciclo, bien por ausencia de datos (de 1934 a 1940), bien por concurrir con un intersticio muy seco ( $2^{\mathrm{a}}$ mitad años 40$)$. 
Se aprecia una muy buena regularidad de los ciclos de 10 años de máximos y mínimos en Vizcaya y en la vertiente cantábrica de Álava, especialmente en 1077C $\bigcirc$ Bilbao Histórica durante el s. XIX, reflejada en las tablas 35, 36, 37, 38, 39, 49 y 49 bis.

6.3.- De la tabla 49 se insinúan tres ciclos allegados a 20 años, con máximos:
A) $1884 \Rightarrow>\ldots \Rightarrow 1922 \Rightarrow>\ldots=>1958 \Rightarrow>1977-1978 \Rightarrow>\ldots=>i 2017 ?$ o $¿ 2018 ?$ $=i 2038$ ?...
B) $1869 \Rightarrow>1891 \Rightarrow>\ldots=>1925 \Rightarrow>\ldots=>1965 \Rightarrow>\ldots=>i 2025 ? \ldots$
C) $1913 \Rightarrow>1930 \Rightarrow>1949 \Rightarrow \ldots \Rightarrow 1991 \Rightarrow$

Y tres ciclos de aproximadamente 20 años de años secos (tabla 49 bis):
A) $1870-1871 \Rightarrow>1893 \Rightarrow>1909$ y $1912 \Rightarrow>\ldots 1947 \Rightarrow>1967 \Rightarrow>1987 \Rightarrow$
B) $1899=>\ldots=>1953$ y $1955 \Rightarrow>1973=>\ldots$
C) $\ldots=>1960-1961 \Rightarrow 1982 \Rightarrow 2003=>\ldots$

Se vislumbran dos ciclos de aproximadamente 30 años de años muy lluviosos, de efemérides (tabla 49):

I) 1884 y $1891 \Rightarrow>1913 \Rightarrow>1949 \Rightarrow 1975,1977$ y $1978=>\ldots$

II) $1869 \Rightarrow \ldots=>1925$ y $1930 \Rightarrow>1958 \Rightarrow>1991 \Rightarrow \ldots$

Y se intuyen dos ciclos de sequías severas cercanos a 30 años (tabla 49 bis):

I) $1870-1871 \Rightarrow 1899 \Rightarrow>\ldots=>1953,1955$ y $1957 \Rightarrow>1982$ y $1987=>\ldots$

II) $1882 \Rightarrow>1912 \Rightarrow>1947 \Rightarrow 1973 \Rightarrow 2003 \Rightarrow$

Los máximos y mínimos del ciclo propincuo a los 30 años en MAM se registran en 2 y en 3 años, en especial las sequías.

Los años lluviosos y secos no se distribuyen de un modo aleatorio, sino según la euritmia descrita, apareciendo correlativos años secos y lluviosos en MAM.

Los años de precipitaciones muy elevadas y de sequías severas se suceden consecutivos, contiguos en el tiempo.

Estos ciclos en la precipitación a escalas rayanas a los 10, 20 y 30 años de la pluviosidad MAM se investigan más prolijamente en el apartado 3.2.4.- Cadencias de la precipitación MAM de la Nota Técnica No 19 AEMET. 


\subsubsection{3.- Evolución temporal de las inhomogeneidades del test de Thom aplicado a la precipitación media AMJ:}

El extenso intersticio analizado (de 1859 a 2013) y el escaso número de series previas a 1940 (inferior a 6 sincrónicas), hacen menester representar la evolución temporal en 2 tramos: de 1859 a 1940 y de 1941 a 2013.

El test de las rachas de Thom se aplica en un intervalo de 10 años consecutivos. Cuando aparecen lagunas en las series (caso de 1081U II P), el lapso se extiende hasta abarcar 10 años consecutivos de datos.

Las gráficas 11 y 12 ilustran las inhomogeneidades detectadas en un periodo de 10 años. Así, una inhomogeneidad en 1954 en una serie sin lagunas abarca de 1954 a 1963. Si hay una laguna en 1960, una inhomogeneidad en 1954 engloba de 1954 a 1964.

La gráfica 11 describe la evolución temporal de las inhomogeneidades descubiertas por el test de las rachas en la precipitación media AMJ de 1859 a 1940.

Gráfica 11: Evolución temporal de las inhomogeneidades del análisis del test de Thom de las series de precipitación media AMJ de 1859 a 1940:

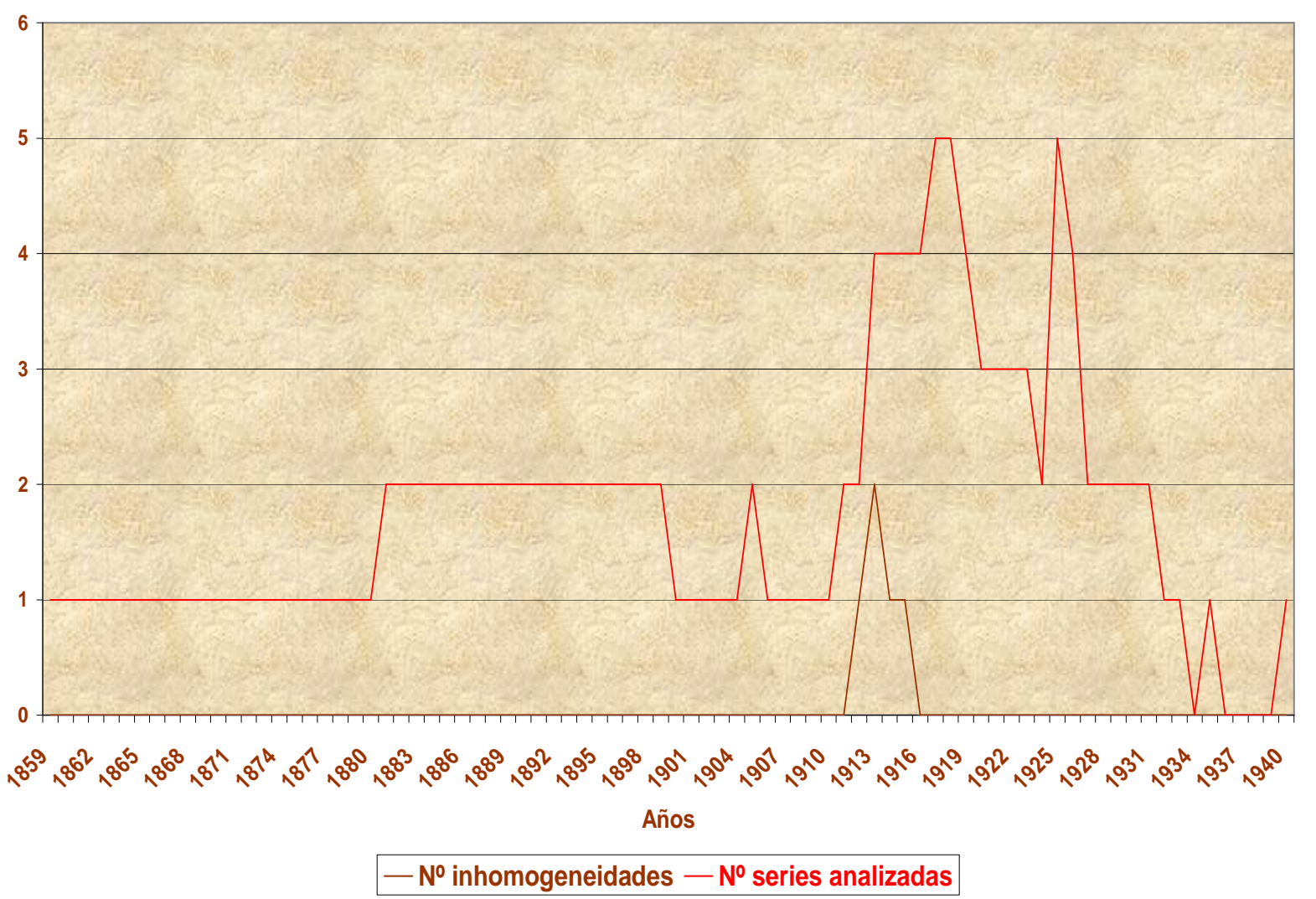

De la gráfica 11, no se aprecia ninguna inhomogeneidad en los registros pluviométricos conservados del siglo XIX. 
La gráfica 12 expone la evolución temporal de las inhomogeneidades detectadas por el test de las rachas en la precipitación media AMJ de 1941 a 2013.

Gráfica 12: Evolución temporal de las inhomogeneidades del análisis del test de Thom de las series de precipitación media AMJ de 1941 a 2013:

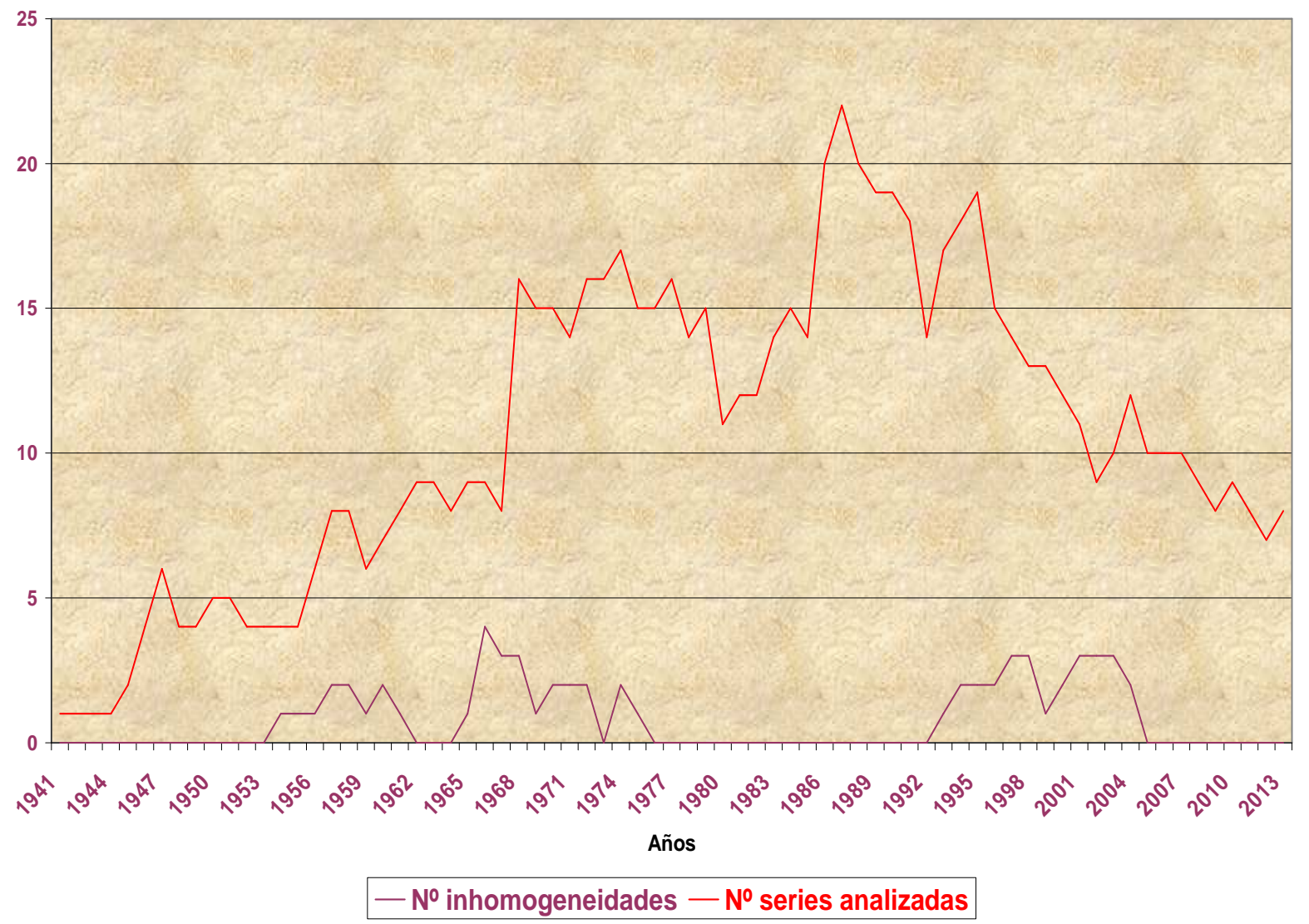

De la gráfica 12 se observan dos máximos de inhomogeneidades: De 1966 a 1977 (concordante con el máximo de inhomogeneidades en MAM entre 1967 y 1977) y de 1998 a 2013.

Las inhomogeneidades afloradas en un periodo de 10 años se revelan en la tabla 50. Así, una inhomogeneidad detectada en 1967 abarca de 1967 a 1976.

Por brevedad, en la tabla 50 se agrupan en la columna de la izquierda periodos en que las inhomogeneidades se solapan.

En la columna de la derecha se muestra el \% de series en que se detecta la inhomogeneidad. Cuando las series son exiguas, se indica el número total de las mismas entre paréntesis. 
Tabla 50 Inhomogeneidades detectadas aplicando el test de Thom a las medidas de precipitación media AMJ desde 1859 a 2013:

\begin{tabular}{|c|c|c|c|}
\hline $\begin{array}{c}\text { Periodo } \\
\text { inhomogeneidad (Años) }\end{array}$ & Indicativos & $\begin{array}{l}\text { Inhomogeneidad } \\
\text { "climatológica" }\end{array}$ & $\begin{array}{c}\% \text { series sobre } \\
\text { total }\end{array}$ \\
\hline $1912-1923$ & 1059 & Sí & \multirow{2}{*}{$25-50(2-4)$} \\
\hline $1913-1926$ & 1055 & Sí & \\
\hline $1954-1965$ & 1059 & Sí & \multirow{3}{*}{$13-29(4-8)$} \\
\hline $1957-1969$ & 1054,1068 & Sí & \\
\hline $1961-1970$ & 1093 & Sí & \\
\hline $1965-1974$ & $1060 \mathrm{~A}$ & Sí & \multirow{5}{*}{$7-44$} \\
\hline $1966-1975$ & $1053,1060 \mathrm{~A}, 1082,1093$ & Sí & \\
\hline $1967-1976$ & $1060 \mathrm{~A}, 1082,1093$ & Sí & \\
\hline $1968-1977$ & 1060A, 1093, 1070 & Sí & \\
\hline $1969-1978$ & 1070 & Sí & \\
\hline $1970-1981$ & 1060,1070 & Sí & \multirow{3}{*}{$7-14$} \\
\hline $1974-1983$ & 1060,1070 & Sí & \\
\hline $1975-1984$ & 1060 & Sí & \\
\hline $1993-2002$ & $1078 \mathrm{E}$ & Sí́ & \multirow{4}{*}{$6-21$} \\
\hline $1994-2005$ & $1078 \mathrm{E}, 1059$ & Sí & \\
\hline $1997-2006$ & $1078 \mathrm{E}, 1059,1060$ & Sí & \\
\hline $1998-2007$ & $1078 \mathrm{E}$ & Sí & \\
\hline $1998-2008$ & $101059,1081 \mathrm{U}$ & Sí & \multirow{3}{*}{$8-33$} \\
\hline $2000-2009$ & 1059,1060 & Sí & \\
\hline $2001-2013$ & $1059,1060,1082$ & Sí & \\
\hline
\end{tabular}

Las tablas 51, 52, 55, 58, 62 y 65 detallan para cada serie de registros de pluviosidad:

a) El indicativo y el nombre del emplazamiento.

b) La duración en años puntualizando los años sin datos (sd).

c) Los años de máximos pluviométricos en el intersticio en que se detecta la inhomogeneidad, con el ordinal entre paréntesis referido al lapso anual total.

d) La pluviosidad media mensual AMJ de los años de máximos de precipitación.

e) Los años de mínimos pluviométricos en el intersticio temporal de la inhomogeneidad; se señala entre paréntesis el ordinal respecto al intervalo anual global.

f) La precipitación media mensual AMJ de los años de mínimos de pluviosidad.

Debido a la escasa densidad espacial y temporal de los emplazamientos de medida de Vizcaya y de la vertiente cantábrica de Álava, las precipitaciones en los años de inhomogeneidades se comparan con los datos de Guipúzcoa de 1013 I $\vee$ (Irún Fitosanitaria) de 1915 a 1926 y de 1024B P (Igueldo Faro) de 1913 a 1926. 


\section{1.- Inhomogeneidades de 1912 a 1923 en 1059 y de 1913 a 1926 en 1055 :}

Tabla 51: Años con precipitaciones máximas y mínimas:

\begin{tabular}{|c|c|c|c|c|c|}
\hline $\begin{array}{c}\text { Indicativo y } \\
\text { nombre }\end{array}$ & Duración serie & Año Máximo & $\begin{array}{l}\text { Precipitación } \\
\left(1 / \mathrm{m}^{2}\right)\end{array}$ & Año Mínimo & $\begin{array}{l}\text { Precipitación } \\
\left(1 / \mathrm{m}^{2}\right)\end{array}$ \\
\hline \multirow{3}{*}{$\begin{array}{c}1059 \text { I } P \\
\text { Punta Galea Faro }\end{array}$} & \multirow{3}{*}{$\begin{array}{c}1911-1926 \\
(\mathrm{sd} 1921,1925)\end{array}$} & $1913\left(1^{\circ}\right)$ & 184,0 & $1920\left(1^{\circ}\right)$ & 60,3 \\
\hline & & $1915\left(3^{\circ}\right)$ & 118,0 & $1923\left(3^{\circ}\right)$ & 67,3 \\
\hline & & $1918\left(4^{\circ}\right)$ & 111,3 & $1919\left(4^{\circ}\right)$ & 68,3 \\
\hline \multirow{4}{*}{$\begin{array}{c}1055 \varnothing \\
\text { Lequeitio Faro }\end{array}$} & \multirow{4}{*}{ 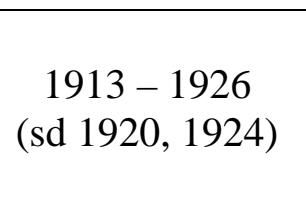 } & $1925\left(1^{\circ}\right)$ & 127,9 & $1916\left(1^{\circ}\right)$ & 39,6 \\
\hline & & $1919\left(2^{\circ}\right)$ & 108,3 & $1914\left(2^{\circ}\right)$ & 55,7 \\
\hline & & $1922\left(3^{\circ}\right)$ & 99,2 & $1913\left(3^{\circ}\right)$ & 67,3 \\
\hline & & $1918\left(4^{\circ}\right)$ & 90,3 & $1921\left(4^{\circ}\right)$ & 68,1 \\
\hline \multirow{4}{*}{$\begin{array}{c}\text { 1057C I } \bigcirc \\
\text { Machicaco Faro }\end{array}$} & \multirow{4}{*}{$1913-1921$} & $1913\left(1^{\circ}\right)$ & 96,0 & $1919\left(1^{\circ}\right)$ & 43,8 \\
\hline & & $1917\left(2^{\circ}\right)$ & 93,8 & $1920\left(2^{\circ}\right)$ & 58,1 \\
\hline & & $1915\left(3^{\circ}\right)$ & 87,4 & $1921\left(3^{\circ}\right)$ & 58,2 \\
\hline & & $1918\left(4^{\circ}\right)$ & 80,4 & $1916\left(4^{\circ}\right)$ & 63,3 \\
\hline \multirow{2}{*}{$\begin{array}{c}\text { 1057C II P } \\
\text { Machicaco Faro }\end{array}$} & \multirow{2}{*}{$1922-1933$} & $1925\left(1^{\circ}\right)$ & 100,4 & $1926\left(1^{\circ}\right)$ & 47,0 \\
\hline & & $1922\left(3^{\circ}\right)$ & 100,0 & $1924\left(4^{\circ}\right)$ & 57,3 \\
\hline \multirow{3}{*}{$\begin{array}{c}\text { 1077C } \varnothing \\
\text { Bilbao Histórica }\end{array}$} & \multirow{3}{*}{$1859-1920$} & $1913\left(1^{\circ}\right)$ & 155,7 & $1912\left(2^{\circ}\right)$ & 48,4 \\
\hline & & $1918\left(6^{\circ}\right)$ & 130,0 & $1920\left(4^{\circ}\right)$ & 50,3 \\
\hline & & $1915\left(9^{\circ}\right)$ & 120,6 & $1919\left(12^{\circ}\right)$ & 68,5 \\
\hline \multirow{4}{*}{1013 I $\vee$ Irún } & \multirow{4}{*}{$1915-1931$} & $1917\left(1^{\circ}\right)$ & 177,9 & $1915\left(2^{\circ}\right)$ & 97,2 \\
\hline & & $1925\left(3^{\circ}\right)$ & 162,6 & $1921\left(3^{\circ}\right)$ & 97,4 \\
\hline & & $1923\left(4^{\circ}\right)$ & 157,8 & $1924\left(5^{\circ}\right)$ & 98,0 \\
\hline & & $1918\left(6^{\circ}\right)$ & 143,4 & $1919\left(6^{\circ}\right)$ & 103,1 \\
\hline \multirow{4}{*}{$\begin{array}{c}\text { 1024B } \vee \\
\text { Igueldo Faro }\end{array}$} & \multirow{4}{*}{$\begin{array}{c}1913-1927 \\
\text { y } 1934(\text { sd } 1924)\end{array}$} & $1913\left(1^{\circ}\right)$ & 158,9 & $1914\left(1^{\circ}\right)$ & 56,0 \\
\hline & & $1915\left(2^{\circ}\right)$ & 145,7 & $1921\left(2^{\circ}\right)$ & 61,6 \\
\hline & & $1917\left(3^{\circ}\right)$ & 143,5 & $1919\left(3^{\circ}\right)$ & 63,4 \\
\hline & & $1918\left(4^{\circ}\right)$ & 117,4 & $1916\left(4^{\circ}\right)$ & 69,6 \\
\hline
\end{tabular}

1.- Las precipitaciones de 1059 I $\nabla$ Punta Galea Faro y de $1055 \nabla$ Lequeitio Faro se cotejan con los registros de 1057C I $\vee$ y 1057C II $\vee$ Machicaco Faro Viejo de 1913 a 1921 y de 1922 a 1926, de 1077C $\nabla$ Bilbao Histórica de 1912 a 1920, de 1013 I $\nabla$ Irún Fitosanitaria de 1915 a 1926 y de 1024B P Igueldo Faro de 1913 a 1926.

(Datos de 1059 I $>$ Punta Galea y de 1055 P Lequeitio obtenidos de los Resúmenes de las Observaciones Meteorológicas efectuadas durante los años 1913 a 1926).

La ruptura de Noviembre de 1921 en el Faro Viejo de Machicaco 1057C $\nabla$ y la ubicación de 1059 I $\vee$ de 1911 a 1926 en el primigenio faro de Punta Galea (ambas descritas en las páginas 20, 22 y 23 del apartado 4.1. "Rupturas detectadas en las series de precipitación") se tienen en cuenta en los intervalos de duración de las series de la tabla 51.

2.- En este lapso temporal, todos los emplazamientos con una duración superior a 10 años existentes en Vizcaya y en Guipúzcoa son costeros o muy próximos a la costa (Bilbao, Irún), careciendo de datos la vertiente cantábrica de Álava. 1057C I $\nabla$ y 1057C II $\nabla$ Machicaco Faro dista 23 Km. de 1059 I $\&$ Punta Galea y 22 Km. de 1055 \& Lequeitio Faro. 
3.- Las precipitaciones son congruentes a lo largo del tiempo: y 1918 .

a) Los máximos de precipitación coinciden en los años 1925, 1913, 1915, 1922, 1917

b) Los mínimos pluviométricos concuerdan en 1920, 1919, 1916 y 1921.

c) $1925,1922,1917$ y 1918 son máximos simultáneos en Guipúzcoa (tabla 69, página 127).

d) 1916 y 1921 son mínimos concurrentes en Guipúzcoa (tabla 69 bis, página 127).

1919 es un mínimo sincrónico en 1059 I $\vee$, en 1057C I $\vee$, en 1077C $\vee$, en 1013 I $\vee$ y 1024B $\vee ; 1914$ mínimo en 1055 จ y 1024B $\vee ; 1924$ mínimo coetáneo en 1057C II $\vee$ y 1013 I $P$.

e) Discrepancias de los extremos de 1055 P:

En 1913 acaecen un mínimo en $1055 \nabla$ y un máximo concomitante en 1059 I $\nabla$, 1057C I $\nabla, 1077 \mathrm{C} \vee$ y 1024B $\vee($ tabla 51).

1919 es un máximo en 1055 y un mínimo coetáneo en 1059 I $\vee, 1057$ C I $\vee$, 1077C $\nabla, 1013$ I $\vee$ y 1024B $\nabla$ (tabla 51).

El opuesto carácter en AMJ de 1059 I $\vee$, de 1077C $\vee$ y de 1057C I $\nabla$ frente al de $1055 \nabla$ en 1913 y en 1919 advierte de una cautela respecto a la calidad de los valores de $1055 \bigcirc$ en AMJ en 1913 y en 1919.

Los restantes máximos y mínimos pluviométricos de $1055 \nabla$ en AMJ son congruentes con los observados en el resto de enclaves analizados en la tabla 51.

El intervalo homogéneo de 1055 \& en AMJ abarca de 1914 a 1926 (tabla 16, página 45), lo cuál incrementa la suma reserva ante los valores de 1913 de $1055 \bigcirc$ en AMJ.

La comparación de las mediciones simultáneas en localizaciones próximas de características climáticas similares y el análisis con el test de rachas revelan un criterio para detectar errores puntuales en los registros de una serie de datos.

Estas disonancias en las cuantías de las precipitaciones (tabla 51) previenen de la necesidad de un análisis a escala comarcal

4.- De 1912 a 1926 transcurren los años de AMJ más pluviosos y más áridos en las ubicaciones detalladas en la tabla 51. En este lapso de tiempo, las medidas oscilan en torno a las medianas de las series de precipitaciones.

5.- La inhomogeneidad se la cataloga como "climatológica" por su sincronía en 1059 I $\vee$ y en 1055 y por la concurrencia de los años de AMJ máximos y mínimos pluviométricos en los 6 enclaves analizados (con las salvedades ya indicadas). 
2.- Inhomogeneidades de 1954 a 1965 en 1059 , de 1957 a 1969 en 1054 y en 1068 y de 1961 a 1970 en 1093:

Tabla 52: Años con precipitaciones máximas y mínimas:

\begin{tabular}{|c|c|c|c|c|c|}
\hline $\begin{array}{c}\text { Indicativo y } \\
\text { nombre }\end{array}$ & Duración serie & Año Máximo & $\begin{array}{c}\text { Precipitación } \\
\left(1 / \mathrm{m}^{2}\right)\end{array}$ & Año Mínimo & $\begin{array}{c}\text { Precipitación } \\
\left(1 / \mathrm{m}^{2}\right)\end{array}$ \\
\hline \multirow{3}{*}{$\begin{array}{l}1054 \text { II } \nabla \\
\text { Marquina }\end{array}$} & \multirow{3}{*}{$\begin{array}{c}1957-1976 \\
(\text { sd 1959) }\end{array}$} & $1958\left(3^{\circ}\right)$ & 120,7 & $1967\left(2^{\circ}\right)$ & 80,9 \\
\hline & & $1969\left(5^{\circ}\right)$ & 119,8 & $1960\left(4^{\circ}\right)$ & 84,2 \\
\hline & & $1964\left(6^{\circ}\right)$ & 117,8 & $1963\left(5^{\circ}\right)$ & 94,2 \\
\hline \multirow{4}{*}{$\begin{array}{c}1059 \text { II } \nabla \\
\text { Punta Galea }\end{array}$} & \multirow{4}{*}{$1946-1969$} & $1964\left(2^{\circ}\right)$ & 88,4 & $1955\left(1^{\circ}\right)$ & 28,1 \\
\hline & & $1956\left(4^{\circ}\right)$ & 87,2 & $1960\left(2^{\circ}\right)$ & 49,6 \\
\hline & & $1957\left(8^{\circ}\right)$ & 80,5 & $1963\left(3^{\circ}\right)$ & 52,6 \\
\hline & & $1961\left(9^{\circ}\right)$ & 76,9 & $1959\left(6^{\circ}\right)$ & 60,5 \\
\hline \multirow{3}{*}{$\begin{array}{c}1068 \text { II P } \\
\text { Basauri }\end{array}$} & \multirow{3}{*}{$1955-1979$} & $1961\left(4^{\circ}\right)$ & 97,4 & $1960\left(4^{\circ}\right)$ & 55,3 \\
\hline & & $1969\left(5^{\circ}\right)$ & 96,9 & $1963\left(5^{\circ}\right)$ & 63,3 \\
\hline & & $1957\left(6^{\circ}\right)$ & 94,9 & $1968\left(7^{\circ}\right)$ & 66,7 \\
\hline \multirow{3}{*}{$\begin{array}{l}1093 \text { I } 8 \\
\text { Carranza }\end{array}$} & \multirow{3}{*}{$\begin{array}{c}1957-1983 \\
(\text { sd 1959) }\end{array}$} & $1966\left(7^{\circ}\right)$ & 112,4 & $1963\left(3^{\circ}\right)$ & 56,4 \\
\hline & & $1965\left(8^{\circ}\right)$ & 98,0 & $1967\left(4^{\circ}\right)$ & 64,9 \\
\hline & & $1969\left(10^{\circ}\right)$ & 97,8 & $1961\left(7^{\circ}\right)$ & 77,6 \\
\hline \multirow{4}{*}{$\begin{array}{c}1082 \text { I } 8 \\
\text { Bilbao } \\
\text { Aeropuerto }\end{array}$} & \multirow{4}{*}{$1947-1984$} & $1965\left(6^{\circ}\right)$ & 112,8 & $1955\left(1^{\circ}\right)$ & 41,2 \\
\hline & & $1956\left(7^{\circ}\right)$ & 109,9 & $1959\left(6^{\circ}\right)$ & 67,9 \\
\hline & & $1964\left(8^{\circ}\right)$ & 108,4 & $1960\left(7^{\circ}\right)$ & 68,0 \\
\hline & & $1957\left(11^{\circ}\right)$ & 100,7 & $1963\left(8^{\circ}\right)$ & 68,2 \\
\hline \multirow{3}{*}{$\begin{array}{l}1060 \mathrm{I} \vee \\
\text { Amurrio }\end{array}$} & \multirow{3}{*}{$\begin{array}{c}1956-1966 \\
(\text { sd 1964) }\end{array}$} & $1966\left(1^{\circ}\right)$ & 108,0 & $1960\left(1^{\circ}\right)$ & 46,0 \\
\hline & & $1957\left(2^{\circ}\right)$ & 99,0 & $1963\left(2^{\circ}\right)$ & 62,2 \\
\hline & & $1961\left(3^{\circ}\right)$ & 92,3 & $1959\left(3^{\circ}\right)$ & 64,3 \\
\hline
\end{tabular}

1.- La tabla 52 recoge como contraste los resultados de 1954 a 1970 de 1082 I $\nabla$ Bilbao Aeropuerto y de 1956 a 1966 de 1060 I $\vee$ Amurrio Instituto.

La rotura de finales de 1966 en $1060 \curvearrowright$ Amurrio Instituto (página 26 del apartado 4.1.1) fija el lapso de 1060 I $\vee$ recabado en la tabla 52.

2.- Los años lluviosos concurren en 1956 (máximo pluviométrico), 1961 y 1969 (máximos pluviométricos secundarios). óptima.

3.- Los años secos concuerdan en 1955, 1960, 1963, 1959 y 1967, una concordancia

4.- 1966 es un máximo secundario de precipitación coetáneo en 1053 I 8 y 1082 I 8 (tabla 55, página 113).

5.- 1967 registra un mínimo pluviométrico sincrónico en 1060A $\vee, 1053$ I $\vee$ y 1082 I $\vee ; 1968$ un mínimo secundario concurrente en 1053 I $\vee$ y 1075E I $\vee ; 1970$ un mínimo secundario simultáneo de precipitación en 1060A $\nabla, 1082$ I $\vee, 1093$ I $\vee, 1070 \varnothing$, $1071 \vee$ y 1075E I $\vee$ (tabla 55). 
6.- 1956, 1961, 1964 y 1969 son máximos coetáneos en Guipúzcoa (tabla 69, página 127). 1955, 1959, 1960, 1963 y 1967 son mínimos simultáneos concomitantes en Guipúzcoa (tabla 69 bis, página 127).

El año 1961 es un mínimo pluviométrico en 1093 I $\nabla$ y un máximo en 1059 II $\nabla$, 1060 I $\vee$ y 1068 II $\$ .1093$ I $\vee$ Carranza es la más occidental de las series estudiadas y se sitúa en una cuenca que vierte en el litoral de Cantabria. Esto realza la necesidad de un análisis a una escala comarcal.

7.- Las precipitaciones son acordes en su distribución: Las tablas 53 y 54 refieren para los años lluviosos y secos de la tabla 52 el \% de la precipitación de las series en la primera columna respecto de la pluviosidad de las series en la prima fila.

Por claridad, se omiten la diagonal principal (comparativa de la serie consigo misma) y los resultados superiores a la diagonal, simétricos respecto a los inferiores.

Tabla 53: Cociente de la precipitación media en años lluviosos

\begin{tabular}{|c|c|c|c|c|c|}
\hline 1054 II $P$ & 1054 II $\vee$ & 1059 II $\nabla$ & $1068 \mathrm{II} \vee$ & 1093 I $\nabla$ & $1082 \mathrm{I} \nabla$ \\
\hline 1059 II $\nabla$ & 75 & & & & \\
\hline 1068 II $P$ & 81 & $118-127$ & & & \\
\hline $1093 \mathrm{I} P$ & 82 & & 101 & & \\
\hline $1082 \mathrm{I} P$ & 92 & $123-126$ & 106 & 115 & \\
\hline $1060 \mathrm{I} \vee$ & 78 & $120-123$ & $95-104$ & 96 & 98 \\
\hline
\end{tabular}

Tabla 54: Cociente de la precipitación media en años secos

\begin{tabular}{|c|c|c|c|c|}
\hline 1059 II $\vee$ & $56-59$ & & & \\
\hline 1068 II P & $66-68$ & $111-120$ & & \\
\hline 1093 I 8 & $60-80$ & 107 & 89 & \\
\hline $1082 \mathrm{I} P$ & $72-81$ & $112-147$ & $108-123$ & 121 \\
\hline $1060 \mathrm{I} \nabla$ & $55-66$ & $93-118$ & $83-99$ & 110 \\
\hline
\end{tabular}

La correlación de las precipitaciones registradas en los diferentes enclaves es muy buena, siendo su razón prácticamente constante, con unos intervalos muy reducidos de variación, algo mayores los años de sequías.

La comparativa de 1093 I $\vee$ con 1059 II $\vee$ los años pluviosos se deja en blanco por la carencia de años lluviosos concurrentes en el intersticio temporal espulgado.

8.- En el intervalo temporal escrutado de 1954 a 1970 (tabla 52) acaecen años de AMJ pluviosos y secos, alternando las precipitaciones recogidas en torno a las respectivas medianas.

Por todo lo expuesto y dado el considerable porcentaje de series en que la inhomogeneidad aflora, se la considera "climatológica". 
3.- Inhomogeneidades de 1965 a 1977 en 1060 A, 1966 a 1975 en 1053,1966 a 1976 en 1082, de 1966 a 1977 en 1093 y de 1968 a 1978 en 1070:

Tabla 55: Años con precipitaciones máximas y mínimas:

\begin{tabular}{|c|c|c|c|c|c|}
\hline $\begin{array}{c}\text { Indicativo y } \\
\text { nombre }\end{array}$ & Duración serie & Año Máximo & $\begin{array}{c}\text { Precipitación } \\
\left(1 / \mathrm{m}^{2}\right)\end{array}$ & Año Mínimo & $\begin{array}{c}\text { Precipitación } \\
\left(1 / \mathrm{m}^{2}\right)\end{array}$ \\
\hline \multirow{4}{*}{$\begin{array}{l}\text { 1060A } \bigcirc \\
\text { Amurrio }\end{array}$} & \multirow{4}{*}{$1962-1979$} & $1977\left(1^{\circ}\right)$ & 155,3 & $1974\left(2^{\circ}\right)$ & 48,5 \\
\hline & & $1972\left(3^{\circ}\right)$ & 127,2 & $1976\left(3^{\circ}\right)$ & 54,2 \\
\hline & & $1975\left(4^{\circ}\right)$ & 123,2 & $1967\left(5^{\circ}\right)$ & 60,5 \\
\hline & & $1971\left(5^{\circ}\right)$ & 112,7 & $1970\left(6^{\circ}\right)$ & 69,0 \\
\hline \multirow{4}{*}{$\begin{array}{c}1053 \text { I } 8 \\
\text { Echevarría }\end{array}$} & \multirow{4}{*}{$1962-1975$} & $1972\left(1^{\circ}\right)$ & 177,0 & $1974\left(1^{\circ}\right)$ & 78,2 \\
\hline & & $1971\left(2^{\circ}\right)$ & 154,0 & $1967\left(2^{\circ}\right)$ & 83,1 \\
\hline & & $1966\left(3^{\circ}\right)$ & 124,4 & $1968\left(4^{\circ}\right)$ & 91,3 \\
\hline & & $1975\left(4^{\circ}\right)$ & 120,6 & $1973\left(5^{\circ}\right)$ & 97,3 \\
\hline \multirow{4}{*}{$\begin{array}{c}1082 \text { I } 8 \\
\text { Bilbao } \\
\text { Aeropuerto }\end{array}$} & \multirow{4}{*}{$1947-1984$} & $1971\left(3^{\circ}\right)$ & 133,5 & $1976\left(10^{\circ}\right)$ & 70,8 \\
\hline & & $1972\left(4^{\circ}\right)$ & 130,8 & $1974\left(11^{\circ}\right)$ & 70,9 \\
\hline & & $1975\left(9^{\circ}\right)$ & 106,9 & $1970\left(12^{\circ}\right)$ & 72,1 \\
\hline & & $1966\left(13^{\circ}\right)$ & 99,0 & $1967\left(15^{\circ}\right)$ & 82,9 \\
\hline \multirow{4}{*}{$\begin{array}{l}1093 \text { I } \nabla \\
\text { Carranza }\end{array}$} & \multirow{4}{*}{$\begin{array}{c}1957-1983 \\
(\text { sd 1959) }\end{array}$} & $1977\left(2^{\circ}\right)$ & 189,0 & $1967\left(4^{\circ}\right)$ & 64,9 \\
\hline & & $1972\left(3^{\circ}\right)$ & 178,6 & $1976\left(8^{\circ}\right)$ & 80,4 \\
\hline & & $1971\left(4^{\circ}\right)$ & 152,4 & $1974\left(9^{\circ}\right)$ & 81,2 \\
\hline & & $1975\left(5^{\circ}\right)$ & 144,5 & $1970\left(11^{\circ}\right)$ & 89,4 \\
\hline \multirow{4}{*}{$\begin{array}{c}1070 \varnothing \\
\text { Abadiano }\end{array}$} & \multirow{4}{*}{$1968-2002$} & $1977\left(1^{\circ}\right)$ & 189,4 & $1974\left(3^{\circ}\right)$ & 68,8 \\
\hline & & $1972\left(3^{\circ}\right)$ & 164,2 & $1976\left(6^{\circ}\right)$ & 80,7 \\
\hline & & $1978\left(6^{\circ}\right)$ & 157,7 & $1973\left(11^{\circ}\right)$ & 100,9 \\
\hline & & $1975\left(7^{\circ}\right)$ & 151,2 & $1970\left(13^{\circ}\right)$ & 108,2 \\
\hline \multirow{4}{*}{$\begin{array}{c}1071 \curlyvee \\
\text { Durango }\end{array}$} & \multirow{4}{*}{$1968-1993$} & $1977\left(1^{\circ}\right)$ & 187,0 & $1974\left(2^{\circ}\right)$ & 80,4 \\
\hline & & $1972\left(3^{\circ}\right)$ & 166,1 & $1976\left(4^{\circ}\right)$ & 84,9 \\
\hline & & $1978\left(7^{\circ}\right)$ & 152,0 & $1973\left(7^{\circ}\right)$ & 100,4 \\
\hline & & $1971\left(10^{\circ}\right)$ & 146,6 & $1970\left(8^{\circ}\right)$ & 102,7 \\
\hline \multirow{4}{*}{$\begin{array}{l}\text { 1075E I P } \\
\text { Aránzazu }\end{array}$} & \multirow{4}{*}{$1968-1981$} & $1977\left(1^{\circ}\right)$ & 217,5 & $1974\left(1^{\circ}\right)$ & 71,7 \\
\hline & & $1972\left(2^{\circ}\right)$ & 191,3 & $1976\left(3^{\circ}\right)$ & 82,5 \\
\hline & & $1975\left(3^{\circ}\right)$ & 163,9 & $1970\left(4^{\circ}\right)$ & 95,2 \\
\hline & & $1978\left(4^{\circ}\right)$ & 161,1 & $1968\left(5^{\circ}\right)$ & 95,3 \\
\hline
\end{tabular}

1.- La tabla 55 incorpora las precipitaciones de 1965 a 1978 de $1071 \bigcirc$ Durango, próximo a 1053 I $\vee$ Echevarría y a 1070 Abadiano y de 1075E I $\vee$ Aránzazu, a 19 Km. de $1060 \mathrm{~A} \vee$ Amurrio y a $20 \mathrm{Km}$. de 1082 I $\nabla$ Bilbao Aeropuerto.

1053 I $\nabla$ presenta una ruptura a fines de 1975 y 1075 E I $\nabla$ a finales de 1981 , descritas respectivamente en las páginas 18 y 28 del apartado 4.1.- "Rupturas detectadas en las series de precipitación". 
2.- La figura 21 refleja a la izquierda las ubicaciones de 1053 I $\vee, 1070 \varnothing, 1071 \varnothing$ y 1075E I $\nabla$; a la derecha las de $1060 \mathrm{~A} \vee, 1082$ I $\nabla$ y 1093 I $\nabla$.

Figura 21: A la izquierda, emplazamientos de 1053 I $\nabla, 1070 \varnothing, 1071 \nabla$ y 1075E I $\nabla$; a la derecha, enclaves de 1060A $\vee, 1082$ I $P$ y 1093 I $\vee$ :
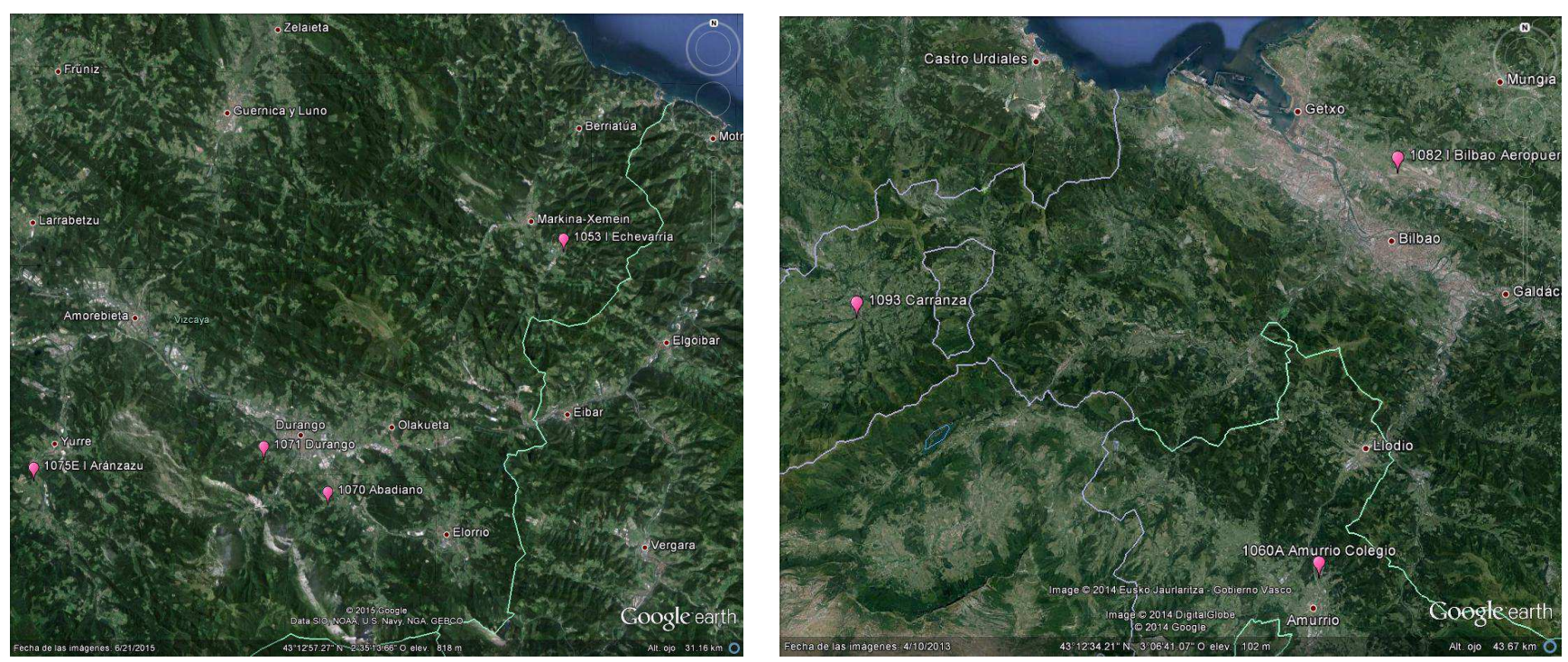

2.- Las precipitaciones son concomitantes temporalmente:

a) Los máximos significativos de precipitación concuerdan en 1977, 1972, 1971, 1975 y 1978. 1966 es un máximo simultáneo de precipitación.

b) Los mínimos pluviométricos concurren en 1974, 1976 y 1967.

Mínimos pluviométricos secundarios acontecen en 1968, 1970 y 1973.

c) Los siguientes años son extremos coetáneos en otros enclaves:

1972 y 1975 máximos sincrónicos en 1060 II $\vee, 1977$ y 1978 concordantes en 1060 II $\vee$ y en 9077E II $\vee$ (tabla 58, página 116). $58)$.

1974 mínimo simultáneo en 1060 II $\vee ; 1976$ en 1060 II $\vee$ y en 9077E II $\vee$ (tabla

d) Máximos y mínimos sincrónicos con los acaecidos en Guipúzcoa: Máximos: 1971, 1972 y 1978 (tabla 69, página 127); mínimos: 1967, 1974, 1976 (tabla 69 bis, página 127).

\section{3.- Las precipitaciones son coherentes en su distribución espacial:}

Las tablas 56 y 57 exponen para los años lluviosos y secos de la tabla 55 el \% de la pluviosidad de las series en ordenadas respecto de la precipitación de las series en abscisas.

Por claridad, se omiten la diagonal principal (comparativa de la serie consigo misma) y los resultados superiores a la diagonal, simétricos respecto a los inferiores. 
Tabla 56: Cociente de la precipitación media en años lluviosos

\begin{tabular}{|c|c|c|c|c|c|c|}
\hline & $1060 \mathrm{~A} P$ & 1053 I P & 1082 I $\nabla$ & 1093 I 8 & 10708 & 10718 \\
\hline 1060A P & & & & & & \\
\hline 1053 I P & $98-139$ & & & & & \\
\hline 1082 I P & $87-118$ & $74-87$ & & & & \\
\hline 1093 I P & $117-140$ & $99-120$ & $114-137$ & & & \\
\hline 1070 P & $123-129$ & $93-125$ & $126-141$ & $92-104$ & & \\
\hline 10718 & $120-131$ & $94-95$ & $110-127$ & $93-99$ & $96-101$ & \\
\hline 1075E I $\$$ & $133-150$ & $108-136$ & $146-153$ & $107-115$ & $102-117$ & $106-116$ \\
\hline
\end{tabular}

Tabla 57: Cociente de la precipitación media en años secos

\begin{tabular}{|c|c|c|c|c|c|c|}
\hline & 1060A 8 & 1053 I P & 1082 I $\nabla$ & 1093 I P & $1070 \nabla$ & 10718 \\
\hline $\begin{array}{l}1060 \mathrm{~A} P \\
1053 \text { I } 8\end{array}$ & $137-161$ & & & & & \\
\hline 1082 I $P$ & $104-146$ & $91-100$ & & & & \\
\hline 1093 I P & $107-167$ & $78-104$ & $78-124$ & & & \\
\hline 1070 P & $142-157$ & $88-104$ & $97-150$ & $85-121$ & & \\
\hline 1071 P & $148-166$ & 103 & $113-142$ & $99-115$ & $95-117$ & \\
\hline 1075 E I $\varnothing$ & $138-152$ & $92-104$ & $101-132$ & $88-106$ & $88-104$ & $89-97$ \\
\hline
\end{tabular}

La elevada pluviometría de 1060A $\odot$ en 1975 incrementa la amplitud de los intervalos de las razones de la pluviosidad respecto a 1060A $\nabla$. Estos intervalos del cociente, excluido 1975, se ciñen a 137 - 139 (1053 I $\nabla / 1060 \mathrm{~A} \vee), 103$ - 118 $(1082$ I $\nabla / 1060 \mathrm{~A} \vee)$ y $120-131(1071 \nabla / 1060 \mathrm{~A} \vee)$.

La correlación entre $1070 \varnothing, 1071 \nabla$ y 1060A $\nabla$ es muy buena en el intervalo temporal escrutado, especialmente los años lluviosos. La correspondencia entre $1071 \nabla$ y 1053 I $\vee$ resulta excelente. En 1075E I $\vee$ llueve más que en 1053 I $\$$ los años pluviosos y las precipitaciones son similares en cuantía los años de sequías. La correspondencia de $1075 \mathrm{E}$ I $\$$ con el resto de registros de precipitación es muy buena.

La correlación de $1071 \curlyvee$ con $1070 \curlyvee$ es superior a la correspondencia de $1071 \varnothing$

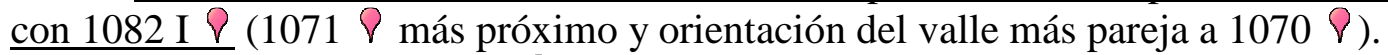
La reciprocidad entre 1075E I $\vee$ y 1082 I $\vee$ es óptima los años pluviosos. La correlación de $1093 \mathrm{~A} \vee$ y de 1075E I $\nabla$ con el Duranguesado es muy buena los años lluviosos y permanece óptima respecto a $1071 \vee$ los áridos.

Las amplitudes de los intervalos de los cocientes de las pluviosidades resultan, en general, más amplias los años secos (respecto a los lluviosos), indicio de una mayor variabilidad en la distribución espacial de las precipitaciones los años de sequías.

4.- En el intersticio temporal espulgado en la tabla 55, se suceden AMJ lluviosos (muy lluviosos en Duranguesado y en Marquina-Ondarroa) con AMJ secos; las precipitaciones fluctúan en torno a sus respectivas medianas.

Por tanto, se la califica de inhomogeneidad "climatológica". 
4.- Inhomogeneidades de 1970 a 1981 en 1060 y en 1070, de 1974 a 1983 en 1070 y de 1974 a 1984 en 1060:

Tabla 58: Años con precipitaciones máximas y mínimas:

\begin{tabular}{|c|c|c|c|c|c|}
\hline $\begin{array}{c}\text { Indicativo y } \\
\text { nombre }\end{array}$ & Duración serie & Año Máximo & $\begin{array}{c}\text { Precipitación } \\
\left(1 / \mathrm{m}^{2}\right)\end{array}$ & Año Mínimo & $\begin{array}{c}\text { Precipitación } \\
\left(1 / \mathrm{m}^{2}\right)\end{array}$ \\
\hline \multirow{4}{*}{$\begin{array}{c}1060 \text { II } \nabla \\
\text { Amurrio }\end{array}$} & \multirow{4}{*}{$\begin{array}{c}1967-1992 \\
(\text { sd 1967) }\end{array}$} & $1977\left(1^{\circ}\right)$ & 208,1 & $1982\left(1^{\circ}\right)$ & 40,2 \\
\hline & & $1972\left(3^{\circ}\right)$ & 132,4 & $1974\left(3^{\circ}\right)$ & 58,7 \\
\hline & & $1978\left(4^{\circ}\right)$ & 130,9 & $1983\left(4^{\circ}\right)$ & 63,9 \\
\hline & & $1975\left(6^{\circ}\right)$ & 123,0 & $1976\left(6^{\circ}\right)$ & 67,6 \\
\hline \multirow{4}{*}{$\begin{array}{c}1070 \varnothing \\
\text { Abadiano }\end{array}$} & \multirow{4}{*}{$1968-2002$} & $1977\left(1^{\circ}\right)$ & 189,4 & $1982\left(1^{\circ}\right)$ & 51,7 \\
\hline & & $1972\left(3^{\circ}\right)$ & 164,2 & $1974\left(3^{\circ}\right)$ & 68,8 \\
\hline & & $1978\left(6^{\circ}\right)$ & 157,7 & $1976\left(6^{\circ}\right)$ & 80,7 \\
\hline & & $1975\left(7^{\circ}\right)$ & 151,2 & $1983\left(7^{\circ}\right)$ & 82,7 \\
\hline \multirow{3}{*}{$\begin{array}{l}\text { 1060A } 8 \\
\text { Amurrio }\end{array}$} & \multirow{3}{*}{$1962-1979$} & $1977\left(1^{\circ}\right)$ & 155,3 & $1974\left(2^{\circ}\right)$ & 48,5 \\
\hline & & $1978\left(2^{\circ}\right)$ & 127,5 & $1976\left(3^{\circ}\right)$ & 54,2 \\
\hline & & $1972\left(3^{\circ}\right)$ & 127,2 & $1970\left(6^{\circ}\right)$ & 69,0 \\
\hline \multirow{4}{*}{$\begin{array}{c}1071 \bigcirc \\
\text { Durango }\end{array}$} & \multirow{4}{*}{$1968-1993$} & $1977\left(1^{\circ}\right)$ & 187,0 & $1982\left(1^{\circ}\right)$ & 49,2 \\
\hline & & $1972\left(3^{\circ}\right)$ & 166,1 & $1974\left(2^{\circ}\right)$ & 80,4 \\
\hline & & $1978\left(7^{\circ}\right)$ & 152,0 & $1981\left(3^{\circ}\right)$ & 81,0 \\
\hline & & $1971\left(10^{\circ}\right)$ & 146,6 & $1976\left(4^{\circ}\right)$ & 84,9 \\
\hline \multirow{4}{*}{$\begin{array}{c}\text { 1075E I } 8 \\
\text { Aránzazu }\end{array}$} & \multirow{4}{*}{$1968-1981$} & $1977\left(1^{\circ}\right)$ & 217,5 & $1974\left(1^{\circ}\right)$ & 71,7 \\
\hline & & $1972\left(2^{\circ}\right)$ & 191,3 & $1981\left(2^{\circ}\right)$ & 78,3 \\
\hline & & $1975\left(3^{\circ}\right)$ & 163,9 & $1976\left(3^{\circ}\right)$ & 82,5 \\
\hline & & $1978\left(4^{\circ}\right)$ & 161,1 & $1970\left(4^{\circ}\right)$ & 95,2 \\
\hline \multirow{4}{*}{$\begin{array}{l}\text { 9077E II } \vee \\
\text { Ochandiano }\end{array}$} & \multirow{4}{*}{$\begin{array}{c}1974-1995 \\
(\mathrm{sd} 1974,1975, \\
1992)\end{array}$} & $1977\left(1^{\circ}\right)$ & 189,3 & $1982\left(1^{\circ}\right)$ & 47,7 \\
\hline & & $1978\left(2^{\circ}\right)$ & 169,1 & $1983\left(5^{\circ}\right)$ & 84,0 \\
\hline & & $1979\left(4^{\circ}\right)$ & 159,6 & $1976\left(6^{\circ}\right)$ & 93,9 \\
\hline & & $1980\left(5^{\circ}\right)$ & 146,9 & $1981\left(7^{\circ}\right)$ & 100,8 \\
\hline
\end{tabular}

1.- La tabla 58 agrega los valores de 1970 a 1984 de 1060A $\vee$ Amurrio Colegio y de $1071 \vee$ Durango, por su proximidad e idénticas características geográficas a 1060 II $\nabla$ y a $1070 \vee$, respectivamente. Se incorporan los datos de 1075E I $\nabla$ Aránzazu de 1970 a 1981 y de 9077E II P Ochandiano de 1976 a 1984.

2.- La ruptura de $1075 \mathrm{E} \vee$ Aránzazu a finales de 1981 y la rotura de $9077 \mathrm{E} \vee$ Ochandiano entre los registros anteriores a Mayo de 1971 y los posteriores a Julio de 1973, ambas escudriñadas en las páginas 28 y 35 del apartado 4.1.- "Rupturas detectadas en las series de precipitación", precisan sus intersticios temporales en la tabla 58.

3.- La orientación de los valles donde se ubican 1060 II $\nabla, 1060 \mathrm{~A} P, 1070 \varnothing$, $1071 \vee, 1075 \mathrm{E}$ I $\vee$ y 9077E II $\vee$ es muy similar, según muestran la tabla 59 y la figura 22. 
Tabla 59: Características geográficas de 1060 II $\nabla, 1060 \mathrm{~A} \vee, 1070 \varnothing, 1071 \varnothing, 1075 \mathrm{E}$ I $\varnothing$ y $9077 \mathrm{E}$ II $\odot$ :

\begin{tabular}{|c|c|c|c|c|}
\hline Indicativo & Nombre & Altitud (m) & $\begin{array}{c}\text { Distancia a } \\
\text { 1075E I } \vee(\mathrm{Km} .)\end{array}$ & $\begin{array}{l}\text { Orientación } \\
\text { valle }\end{array}$ \\
\hline 1060 II P & Amurrio & 219 & 20,5 & $\mathrm{~S}$ a N \\
\hline $1060 \mathrm{~A} P$ & Amurrio Colegio & 190 & 18,8 & $\mathrm{~S}$ a N \\
\hline 1070 尺 & Abadiano & 177 & 14,4 & SW a NE \\
\hline 10718 & Durango & 280 & 11,3 & SE a NW \\
\hline 1075E I $\varnothing$ & Aránzazu & 112 & & $\mathrm{~S}$ a N \\
\hline 9077E II $\varnothing$ & Ochandiano & 559 & 16,1 & $\mathrm{~S}$ a N \\
\hline
\end{tabular}

La figura 22 expone la localización de 1060 II $\nabla, 1060 \mathrm{~A} \vee, 1070 \vee, 1071 \nabla$, 1075E I $\vee$ y 9077 E II $\vee$.

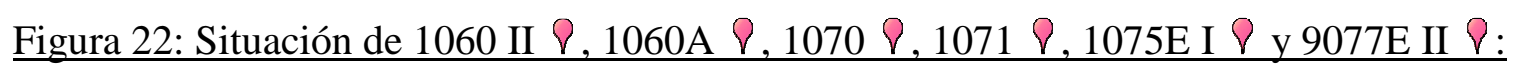

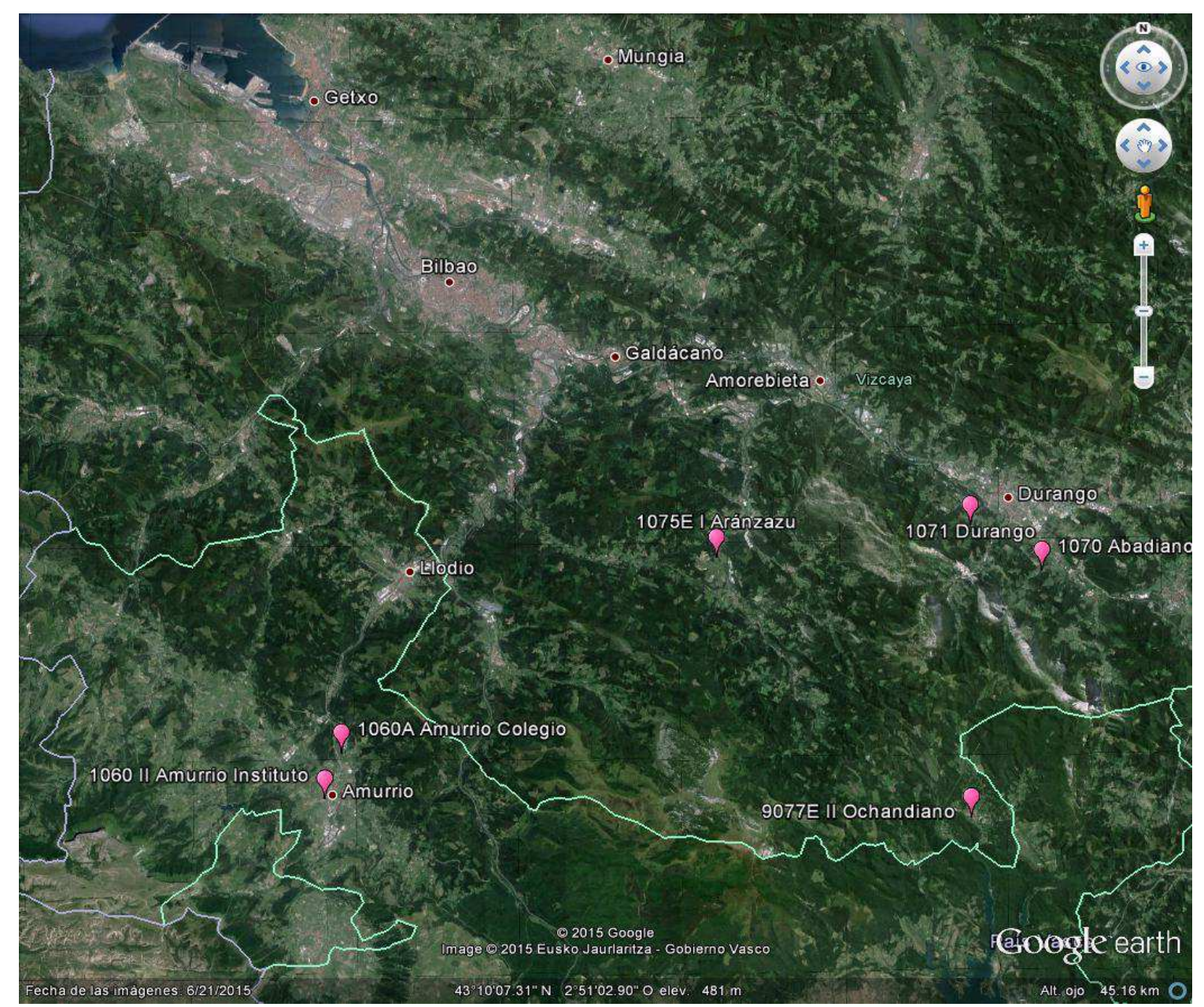

4.- Los máximos (1977, 1972, 1978 y 1975) y mínimos (1982, 1974, 1981, 1976 y 1983) de precipitación coinciden con una idéntica importancia relativa de los máximos pluviométricos en 1060 II $\nabla$ y en $1070 \varnothing$. 
5.- 1972 y 1978 son máximos y 1974, 1976 y 1982 mínimos coetáneos en Guipúzcoa (tablas 69 y 69 bis, página 127).

6.- Hay una coherencia espacial de las precipitaciones: Las tablas 60 y 61 describen para los años pluviosos y secos de la tabla 58 el \% de la precipitación de las series en ordenadas respecto de la pluviometría de de las series en abscisas.

Se omiten la diagonal principal (comparativa de la serie consigo misma) y los resultados superiores a la diagonal, simétricos respecto a los inferiores.

Tabla 60: Cociente de la precipitación media en años lluviosos

\begin{tabular}{|c|c|c|c|c|c|c|}
\hline & $1060 \mathrm{II} \nabla$ & 1060A 8 & $1070 \nabla$ & 10718 & $1075 \mathrm{E} \mathrm{I} \varnothing$ & 9077E II $\vee$ \\
\hline 1060 II $\vee$ & & & & & & \\
\hline 1060A $P$ & $75-97$ & & & & & \\
\hline 1070 P & $91-124$ & $122-129$ & & & & \\
\hline 10718 & $90-125$ & $119-131$ & $96-101$ & & & \\
\hline $1075 \mathrm{E} I$ & $105-145$ & $126-150$ & $102-117$ & $106-116$ & & \\
\hline 9077E II $\vee$ & $91-129$ & $122-132$ & $100-107$ & $101-111$ & $87-105$ & \\
\hline
\end{tabular}

Tabla 61: Cociente de la precipitación media en años secos

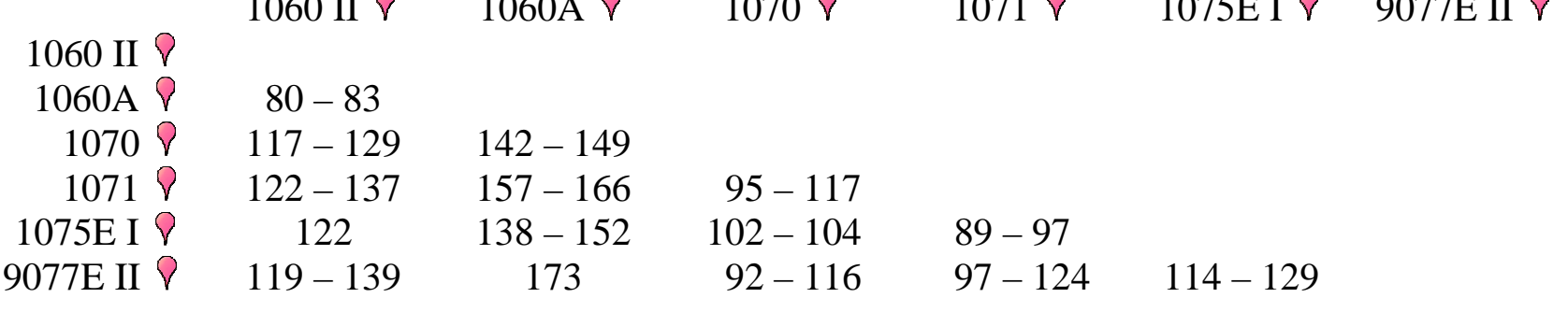

La correlación entre las pluviosidades de los AMJ lluviosos es muy buena, alcanzando la excelencia entre 1071 P, 1070 \& y 9077E II $\vee$ los años lluviosos, fluctuando las precipitaciones en torno a una misma cuantía.

La incertidumbre en el cociente de las precipitaciones aumenta en los años secos, salvo entre 1071 \& y 1075E I $\vee$ con una óptima correspondencia en años lluviosos y secos. Las precipitaciones disminuyen los AMJ secos en Amurrio respecto al resto de lugares, según recogen las tablas 60 y 61.

Un comportamiento bipolar se aprecia entre 1075E I $\nabla$ y 9077E II $\nabla$ y, en menor medida, de $1070 \varnothing$ y $1071 \varnothing$ con 9077E II $\vee:$ En las vertientes opuestas de los puertos de Dima y de Urquiola, los años lluviosos se recogen precitaciones semejantes o superiores en 1075E I $\vee, 1070 \varnothing$ y $1071 \curlyvee$ respecto a 9077E II $\vee$ y los secos, llueve más en 9077E II $\varnothing$.

7.- De 1970 a 1984 acontecen años de AMJ muy lluviosos, con efemérides de precipitación (tabla 59) y años de AMJ secos o muy secos, fluctuando las precipitaciones observadas en torno a las respectivas medianas.

Por consiguiente, se trata de una inhomogeneidad "climatológica". 
5.- Inhomogeneidades de 1993 a 2007 en 1078E, de 1994 a 2006 en 1059 y de 1997 a 2006 en 1060:

Tabla 62: Años con precipitaciones máximas y mínimas:

\begin{tabular}{|c|c|c|c|c|c|}
\hline $\begin{array}{c}\text { Indicativo y } \\
\text { nombre }\end{array}$ & Duración serie & Año Máximo & $\begin{array}{c}\text { Precipitación } \\
\left(1 / \mathrm{m}^{2}\right)\end{array}$ & Año Mínimo & $\begin{array}{l}\text { Precipitación } \\
\left(1 / \mathrm{m}^{2}\right)\end{array}$ \\
\hline \multirow{4}{*}{$\begin{array}{l}1078 \text { E II } \curlyvee \\
\text { Valmaseda }\end{array}$} & \multirow{4}{*}{$1992-2007$} & $1998\left(1^{\circ}\right)$ & 148,1 & $1995\left(1^{\circ}\right)$ & 51,0 \\
\hline & & $1992\left(2^{\circ}\right)$ & 119,0 & $1996\left(2^{\circ}\right)$ & 55,8 \\
\hline & & $1994\left(3^{\circ}\right)$ & 116,9 & $2006\left(3^{\circ}\right)$ & 62,2 \\
\hline & & $1993\left(4^{\circ}\right)$ & 113,4 & $2001\left(4^{\circ}\right)$ & 67,3 \\
\hline \multirow{4}{*}{$\begin{array}{l}1059 \text { III } 8 \\
\text { Punta Galea }\end{array}$} & \multirow{4}{*}{$1994-2013$} & $1994\left(4^{\circ}\right)$ & 102,0 & $1995\left(2^{\circ}\right)$ & 39,0 \\
\hline & & $1998\left(5^{\circ}\right)$ & 96,6 & $2001\left(3^{\circ}\right)$ & 45,1 \\
\hline & & $2005\left(7^{\circ}\right)$ & 73,6 & $2006\left(4^{\circ}\right)$ & 48,3 \\
\hline & & $2002\left(8^{\circ}\right)$ & 73,6 & $1999\left(5^{\circ}\right)$ & 52,5 \\
\hline \multirow{4}{*}{$\begin{array}{c}1060 \text { III } \\
\text { Amurrio }\end{array}$} & \multirow{4}{*}{$1993-2013$} & $2005\left(3^{\circ}\right)$ & 108,9 & $2001\left(1^{\circ}\right)$ & 39,9 \\
\hline & & $2003\left(8^{\circ}\right)$ & 87,8 & $2004\left(5^{\circ}\right)$ & 49,7 \\
\hline & & $2002\left(9^{\circ}\right)$ & 81,9 & $1999\left(6^{\circ}\right)$ & 50,9 \\
\hline & & $1998\left(10^{\circ}\right)$ & 81,8 & $2006\left(7^{\circ}\right)$ & 60,0 \\
\hline \multirow{4}{*}{$\begin{array}{c}\text { 1057E I } P \\
\text { Baquio }\end{array}$} & \multirow{4}{*}{$\begin{array}{c}1986-2007 \\
(\text { sd 1992) }\end{array}$} & $1998\left(3^{\circ}\right)$ & 126,4 & $1995\left(1^{\circ}\right)$ & 52,5 \\
\hline & & $1993\left(4^{\circ}\right)$ & 116,5 & $2006\left(2^{\circ}\right)$ & 54,8 \\
\hline & & $1994\left(5^{\circ}\right)$ & 115,4 & $2001\left(3^{\circ}\right)$ & 65,6 \\
\hline & & $2002\left(8^{\circ}\right)$ & 106,3 & $1996\left(4^{\circ}\right)$ & 67,7 \\
\hline \multirow{3}{*}{$\begin{array}{l}1082 \text { III } \nabla \\
\text { Bilbao } \\
\text { Aeropuerto }\end{array}$} & \multirow{3}{*}{$1985-2000$} & $1994\left(1^{\circ}\right)$ & 123,6 & $1999\left(1^{\circ}\right)$ & 58,4 \\
\hline & & $1993\left(5^{\circ}\right)$ & 102,2 & $1995\left(2^{\circ}\right)$ & 58,8 \\
\hline & & $1998\left(6^{\circ}\right)$ & 102,0 & $1996\left(3^{\circ}\right)$ & 61,2 \\
\hline \multirow{4}{*}{$\begin{array}{l}\text { 1079E I } 8 \\
\text { Arceniega }\end{array}$} & \multirow{4}{*}{$\begin{array}{c}1986-2003 \\
(\mathrm{sd} 1992,1993, \\
1996,2000)\end{array}$} & $1998\left(2^{\circ}\right)$ & 114,7 & $1995\left(1^{\circ}\right)$ & 39,1 \\
\hline & & $2003\left(6^{\circ}\right)$ & 92,2 & $2001\left(3^{\circ}\right)$ & 47,2 \\
\hline & & $1994\left(7^{\circ}\right)$ & 91,4 & $1999\left(5^{\circ}\right)$ & 61,6 \\
\hline & & $2002\left(8^{\circ}\right)$ & 74,2 & $1997\left(6^{\circ}\right)$ & 66,5 \\
\hline \multirow{3}{*}{$\begin{array}{c}1083 \text { II } \\
\text { Arcentales }\end{array}$} & \multirow{3}{*}{$\begin{array}{c}1981-1999 \\
(\text { sd 1988, 1990) }\end{array}$} & $1998\left(1^{\circ}\right)$ & 122,2 & $1995\left(1^{\circ}\right)$ & 57,9 \\
\hline & & $1993\left(4^{\circ}\right)$ & 108,5 & $1999\left(2^{\circ}\right)$ & 58,0 \\
\hline & & $1994\left(7^{\circ}\right)$ & 103,2 & $1996\left(3^{\circ}\right)$ & 60,0 \\
\hline
\end{tabular}

1.- La tabla 62 embebe las mediciones de 1082 III $\nabla$ Bilbao Aeropuerto de 1993 a 2000, por su cercanía a 1059 III $\$$ Punta Galea Golf; de 1057E I $\vee$ Baquio, el enclave costero más próximo a 1059 III \& con medidas sin rupturas de 1993 a 2007; de 1083 II $\nabla$ Arcentales, la más cercana a 1078E II $\vee$ Valmaseda y de 1079E I $\nabla$ Arceniega, única serie coetánea a 1060 III $\$$ Amurrio en la vertiente cantábrica alavesa.

2.- La figura 23 presenta la ubicación de 1057E I $\nabla, 1059$ III $\$, 1060$ III $\$$, 1078 E II $\vee, 1079$ E I $\vee, 1082$ III $\vee$ y 1083 II $\vee$.

La tabla 62 bis indica las altitudes de las localizaciones de la tabla 62 y su distancia a 1059 III $\&$ y a 1079 E I $\vee$. 
Figura 23.- Enclaves de 1057E I $\vee, 1059$ III $\%, 1060$ III $\$, 1078 \mathrm{E}$ II $\nabla, 1079 \mathrm{E}$ I $\vee$, 1082 III $\vee$ y 1083 II $\vee$ :

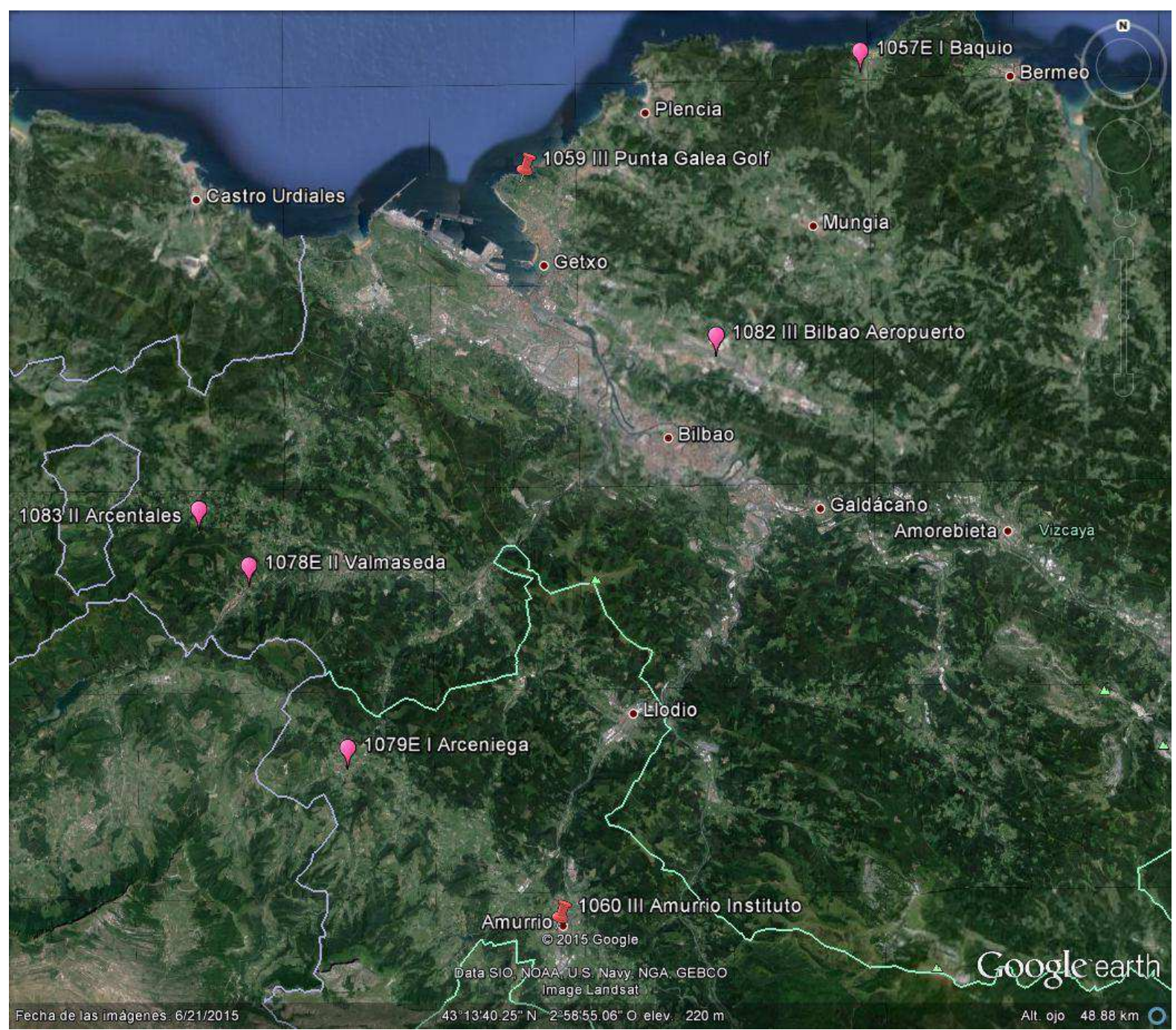

Tabla 62 bis: Características geográficas de 1059 III $\&, 1082$ III $\vee$ y $1057 \mathrm{E}$ I $\vee$ (Gran Bilbao y Plencia - Munguía) y de 1078E II $\vee, 1083$ II $P, 1060$ III $\$$ y 1079E I $P$ (Encartaciones y Cantábrica Alavesa):

\begin{tabular}{|c|c|c|c|c|}
\hline Indicativo & Nombre & Altitud (m) & Km. a 1059 III & Km. a 1079E I $\vee$ \\
\hline 1059 III & Punta Galea & 80 & & \\
\hline 1082 III $\vee$ & Bilbao Aeropuerto & 32 & 12,6 & \\
\hline 1057E I 8 & Baquio & 16 & 17,3 & \\
\hline 1078E II $\vee$ & Valmaseda & 140 & & 10,0 \\
\hline 1083 II $\vee$ & Arcentales & 300 & & 13,5 \\
\hline 1060 III & Amurrio & 219 & & 12,7 \\
\hline 1079E I $\vee$ & Arceniega & 207 & & \\
\hline
\end{tabular}

3.- Las precipitaciones concuerdan en los 7 lugares a lo largo del tiempo: Los máximos de precipitación coinciden en 1998, 1994, 1993 y en 2005. Los mínimos pluviométricas concurren en 1995, 2001, 2006, 1999 y en 1996. 
Máximos secundarios de precipitación acaecen en 2002 y 2003 en la comarca de la Cantábrica Alavesa (1060 III \& y 1079E I \&).

4.- 2002 es un máximo sincrónico en Guipúzcoa (tabla 69, página 127). 1995, 1996 y 2001 son mínimos simultáneos en Guipúzcoa (tabla 69 bis, página 127).

5.- Las precipitaciones son acordes en su distribución: Las tablas 63 y 64 detallan para los años lluviosos y secos de la tabla 62 el \% de la pluviosidad de las series en la prima columna respecto de la precipitación de las series en la primera fila.

Por claridad, se omiten la diagonal principal (comparativa de la serie consigo misma) y los resultados superiores a la diagonal, simétricos respecto a los inferiores.

Tabla 63: Cociente de la precipitación media en años lluviosos

\begin{tabular}{|c|c|c|c|c|c|c|}
\hline 1078E II $\varnothing$ & 1078E II $\varnothing$ & 1059 III & $1060 \mathrm{III}$ & 1057E I $\vee$ & 1082 III $\nabla$ & 1079E I 8 \\
\hline 1059 III & $65-87$ & & & & & \\
\hline 1060 III & 65 & $85-148$ & & & & \\
\hline 1057E I $\nabla$ & $85-103$ & $113-144$ & $130-155$ & & & \\
\hline 1082 III $\nabla$ & $69-106$ & $106-121$ & 125 & $81-107$ & & \\
\hline 1079E I $\varnothing$ & $77-78$ & $90-119$ & $91-140$ & $70-91$ & $74-112$ & \\
\hline 1083 II $P$ & $83-96$ & $101-127$ & 149 & $89-97$ & $83-120$ & $107-113$ \\
\hline
\end{tabular}

Las abundantes precipitaciones de 1078E II $\vee$ en AMJ en 1998 (las mayores cuantías de las 7 series de la tabla 62) incrementan el límite superior del intervalo del cociente de pluviosidades. Este método de comparativa por cociente interesa para detectar registros de precipitaciones de dudosa calidad.

Tabla 64: Cociente de la precipitación media en años secos:

$1078 \mathrm{E}$ II $\bigcirc$

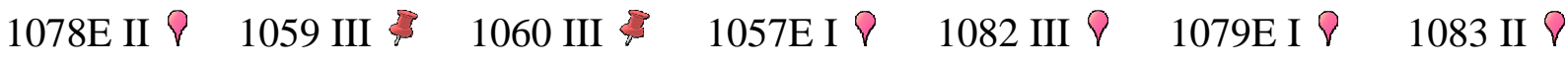

1059 III $67-78$

1060 III $59-96 \quad 88-124$

1057E I $\bigcirc \quad 88-121 \quad 113-145 \quad 91-164$

1082 III $P \quad 110-115 \quad 111-151 \quad 115 \quad 90-112$

$\begin{array}{llllll}1079 \mathrm{E} I \mathrm{P} & 70-77 & 100-117 & 118-121 & 72-74 & 66-105\end{array}$

$\begin{array}{lllllll}1083 \text { II } \vee & 107-114 & 110-148 & 114 & 89-110 & 98-99 & 94-148\end{array}$

La correspondencia es notable entre las siguientes series: 1078E II $\nabla-1079 \mathrm{E} \mathrm{I} \nabla$,

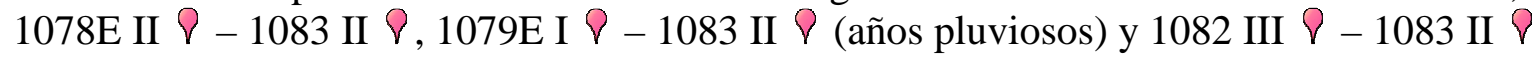
(años áridos).

De 1993 a 2007, alternan años de AMJ lluviosos con años de AMJ secos y muy secos, oscilando las precipitaciones en torno a las respectivas medianas de las series.

Por todo lo expuesto, se la califica como inhomogeneidad "climatológica". 
6.- Inhomogeneidades de 1998 a 2008 en 1081 U, de 1998 a 2013 en 1059 , de 2000 a 2013 en 1060 y de 2001 a 2013 en 1082 :

Tabla 65: Años con precipitaciones máximas y mínimas:

\begin{tabular}{|c|c|c|c|c|c|}
\hline $\begin{array}{c}\text { Indicativo y } \\
\text { nombre }\end{array}$ & Duración serie & Año Máximo & $\begin{array}{c}\text { Precipitación } \\
\left(1 / \mathrm{m}^{2}\right)\end{array}$ & Año Mínimo & $\begin{array}{c}\text { Precipitación } \\
\left(1 / \mathrm{m}^{2}\right)\end{array}$ \\
\hline \multirow{4}{*}{$\begin{array}{l}1059 \text { III } \\
\text { Punta Galea }\end{array}$} & \multirow{4}{*}{$1994-2013$} & $2013\left(1^{\circ}\right)$ & 131,3 & $2011\left(1^{\circ}\right)$ & 37,5 \\
\hline & & $2008\left(2^{\circ}\right)$ & 128,4 & $2001\left(3^{\circ}\right)$ & 45,1 \\
\hline & & $2012\left(3^{\circ}\right)$ & 103,2 & $2006\left(4^{\circ}\right)$ & 48,3 \\
\hline & & $1998\left(5^{\circ}\right)$ & 96,6 & $1999\left(5^{\circ}\right)$ & 52,5 \\
\hline \multirow{4}{*}{$\begin{array}{c}\text { 1081U II } \vee \\
\text { Derio Neiker }\end{array}$} & \multirow{4}{*}{$\begin{array}{c}1996-2009 \\
(\text { sd 2001) }\end{array}$} & $2008\left(1^{\circ}\right)$ & 137,8 & $2006\left(1^{\circ}\right)$ & 58,3 \\
\hline & & $2005\left(2^{\circ}\right)$ & 115,1 & $1999\left(2^{\circ}\right)$ & 59,3 \\
\hline & & $1998\left(3^{\circ}\right)$ & 107,1 & $2004\left(3^{\circ}\right)$ & 62,2 \\
\hline & & $2002\left(4^{\circ}\right)$ & 94,0 & $2009\left(5^{\circ}\right)$ & 73,8 \\
\hline \multirow{4}{*}{$\begin{array}{c}1060 \text { III } \\
\text { Amurrio }\end{array}$} & \multirow{4}{*}{$1993-2013$} & $2008\left(1^{\circ}\right)$ & 127,5 & $2001\left(1^{\circ}\right)$ & 39,9 \\
\hline & & $2005\left(3^{\circ}\right)$ & 108,9 & $2011\left(2^{\circ}\right)$ & 41,4 \\
\hline & & $2013\left(5^{\circ}\right)$ & 102,4 & $2009\left(3^{\circ}\right)$ & 46,4 \\
\hline & & $2010\left(6^{\circ}\right)$ & 99,8 & $2004\left(5^{\circ}\right)$ & 49,7 \\
\hline \multirow{4}{*}{$\begin{array}{l}1082 \text { III } \vee \\
\text { Bilbao } \\
\text { Aeropuerto }\end{array}$} & \multirow{4}{*}{$2001-2013$} & $2010\left(1^{\circ}\right)$ & 126,8 & $2011\left(1^{\circ}\right)$ & 33,2 \\
\hline & & $2013\left(2^{\circ}\right)$ & 125,5 & $2006\left(2^{\circ}\right)$ & 51,4 \\
\hline & & $2008\left(3^{\circ}\right)$ & 121,6 & $2001\left(3^{\circ}\right)$ & 52,4 \\
\hline & & $2012\left(4^{\circ}\right)$ & 107,3 & $2004\left(4^{\circ}\right)$ & 55,9 \\
\hline \multirow{3}{*}{$\begin{array}{l}\text { 1079E II } \\
\text { Arceniega }\end{array}$} & \multirow{3}{*}{$2004-2013$} & $2008\left(1^{\circ}\right)$ & 124,4 & $2011\left(1^{\circ}\right)$ & 36,3 \\
\hline & & $2012\left(2^{\circ}\right)$ & 98,7 & $2004\left(2^{\circ}\right)$ & 48,8 \\
\hline & & $2013\left(3^{\circ}\right)$ & 98,6 & $2009\left(3^{\circ}\right)$ & 50,1 \\
\hline
\end{tabular}

1.- Las precipitaciones de 1079E II $\$$ Arceniega, a 12,7 Km. al NW de 1060 III $\&$, se añaden como confrontación en la tabla 65. Las series en que afloran las inhomogeneidades se circunscriben al Gran Bilbao y a la Cantábrica Alavesa.

2.- Los máximos (2013, 2008, 2012, 1998) y mínimos (2011, 2001, 2006) pluviométricos concurren en los enclaves de la tabla 65, con 2004 un mínimo secundario de precipitación.

3.- La evolución temporal de las precipitaciones es coherente:

2008, 2012 y 2013 son máximos coetáneos en Guipúzcoa (tabla 69, página 127).

2001 y 2011 son mínimos simultáneos en Guipúzcoa (tabla 69 bis, página 127).

4.- Congruencia espacial de las precipitaciones medidas: Las tablas 66 y 67 refieren para los AMJ lluviosos y secos de la tabla 65 el \% de la pluviosidad de las series en ordenadas respecto de la pluviometría de las series en abscisas.

Por claridad, se omiten la diagonal principal (comparativa de la serie consigo misma) y los resultados superiores a la diagonal, simétricos respecto a los inferiores. 
Tabla 66: Cociente de la precipitación media en años lluviosos:

1059 III

1059 III $\$ 1081 \mathrm{UII} \vee \quad 1060 \mathrm{III} \& \quad 1082 \mathrm{III} \vee \quad 1079 \mathrm{E}$ II

1081U II $\bigcirc \quad 99-111$

1060 III $78-99$

1082 III $>\quad 95-104$

1079E II $\quad 75-97$

$93-95$
88
90

$95-127$
$96-98$

$79-102$

Tabla 67: Cociente de la precipitación media en años secos:

1059 III

1059 III $\quad 1081 \mathrm{UII} \& 1060 \mathrm{III} \& 1082 \mathrm{III} \& \quad 1079 \mathrm{E}$ II

1081U II $\bigcirc \quad 113-121$

1060 III

$88-110$

80

1082 III $P$

1079E II

$89-116$

$88-90$

$80-131$

97

$68-78$

$88-108$

$87-110$

Excelsa es la correlación entre: 1081U II $\nabla-1060$ III $₹, 1081$ U II $\nabla-1082$ III $\nabla$ y 1060 III $\$-1079 \mathrm{E} \mathrm{II} \$$.

La tabla 67 bis allega los cocientes de la precipitación media en AMJ de 1082 III $\nabla$ Bilbao Aeropuerto respecto a 1059 III $\uparrow$ Punta Galea Golf (tablas 53, 54, 63, 64, 66 y 67, páginas 112, 121 y 123):

Tabla 67 bis: Comparativa de la razón de la precipitación media AMJ en 1082 Bilbao Aeropuerto y en 1059 Punta Galea, en sus diversos enclaves:

$\begin{array}{cccc}\text { Razón precipitación media } & \text { Años lluviosos } & \text { Años secos } & \text { Intervalo temporal } \\ 1082 \text { I } \vee / 1059 \text { II } \$ & 123-126 & 112-147 & 1954-1969 \\ 1082 \text { II } \vee / 1059 \text { III } \$ & 106-121 & 111-151 & 1994-2000 \\ 1082 \text { III } \nabla / 1059 \text { III } \$ & 95-104 & 89-116 & 2001-2013\end{array}$

La contraposición de los datos de precipitaciones de 1082 II $\nabla$ y 1082 III $\nabla$ con las cuantías de 1059 III $\$$ (1059 III $\$$ sin cambios de ubicación, entorno, colaborador o instrumentación) corrobora la rotura de 1082 III $\vee$ de Noviembre de 2000 a Enero de 2001.

La tabla 67 bis evidencia una disminución en las precipitaciones recogidas en 1082 III $\vee$ respecto a 1082 II $\vee$, ratificada por el cotejo de 1082 III $\vee$ con 1081 U II $\nabla$, a 2,7 Km al Este: Las medidas de $1082 \mathrm{III} \$$ son del 88 al $90 \%$ de las cantidades de precipitación medidas en 1081 U II 8 .

En modo alguno se debe inferir de la tabla 67 bis la existencia de un mínimo pluviométrico, de una zona seca en 1082, ni mucho menos, un descenso de las precipitaciones registradas en el Aeropuerto de Bilbao posteriores a Noviembre de 2000.

5.- En el lapso temporal escudriñado se suceden los AMJ más lluviosos y secos de las series de la tabla 65 , fluctuando las precipitaciones en torno a las respectivas medianas.

Por tanto, se la cataloga como inhomogeneidad "climatológica". 
Como enumeración del análisis de la evolución temporal de las inhomogeneidades descubiertas por el test de las rachas en las medidas de la precipitación AMJ:

1.- La plenitud de las inhomogeneidades afloradas (tabla 50, página 108) es climatológica.

2.- Los máximos de inhomogeneidades se exteriorizan de 1966 a 1977 (concordante con el máximo de inhomogeneidades en MAM entre 1967 y 1977 y parcialmente solapado con el máximo de Guipúzcoa en AMJ de 1957 a 1977) y de 1998 a 2013.

3.- La trascendencia de un análisis global de las series de datos contemporáneas y pretéritas con el fin de:

3.1.- La clasificación de las inhomogeneidades en "climatológicas" y no "climatológicas", contraponiendo las mediciones de la precipitación en ubicaciones allegadas.

3.2.- El cotejo de las mediciones coetáneas en localizaciones próximas de características climáticas similares y el análisis con el test de las rachas revelan un criterio para detectar puntuales aminoraciones de la calidad en las mediciones en AMJ de una serie de datos, verbi gratia:

1) $1055 \nabla$ Lequeitio Faro en 1913 y en 1919.

2) Las sospechosas precitaciones de 1078E II $\bigcirc$ Valmaseda en 1998.

Estas disonancias en las cuantías de las precipitaciones (tablas 51 y 62, páginas 109 y 119) advierten del menester de un análisis a escala comarcal.

3.3.- El cotejo del cociente de precipitaciones máximas (tablas $53,56,60$ y 63 ) y mínimas (tablas 54, 57, 61 y 64) resulta provechoso para un relleno de lagunas, con la salvedad de que los cocientes varían los AMJ pluviosos respecto a los áridos y la amplitud de la razón de precipitaciones aumenta en los AMJ secos respecto a los lluviosos.

3.4. - El conocimiento de la evolución temporal de la homogeneidad de una serie pluviométrica larga precisa de un examen minucioso y global englobando las series de precipitaciones actuales y antiguas cercanas.

4.- La necesidad de una resolución espacial superior a la provincia para escudriñar las inhomogeneidades:

4.1.- Las inhomogeneidades de 1970 a 1984 se focalizan en 2 comarcas: Duranguesado y Cantábrica Alavesa. Las inhomogeneidades de 1998 a 2013 se ciñen al Gran Bilbao y a la Cantábrica Alavesa.

4.2.- La tabla 68 recapitula el número de series, de inhomogeneidades y la inhomogeneidad media (cociente del número de inhomogeneidades entre el número de series) para cada comarca. 
Tabla 68: Distribución comarcal de las inhomogeneidades "climatológicas" del test de rachas de la precipitación media AMJ:

Comarca $\quad \mathrm{N}^{\circ}$ series analizadas $\quad \mathrm{N}^{\circ}$ inhomogeneidades

Inhomogeneidad media

$\begin{array}{cc}\text { Arratia - Nervión } & 5 \\ \text { Duranguesado } & 5 \\ \text { Encartaciones } & 5 \\ \text { Gran Bilbao } & 7 \\ \text { Guernica - Bermeo } & 3 \\ \text { Marquina - Ondarroa } & 4 \\ \text { Plencia - Munguía } & 1 \\ \text { Cantábrica Alavesa } & 3\end{array}$

5
5
5
7
3
4
1
3

0

0

6

1,2

$5210 \quad 2$

$\begin{array}{lll}7 & 27 & 3,9\end{array}$

300

$\begin{array}{lll}3 & 7 & 1,8\end{array}$

00

$\begin{array}{lll}1 & 15 & 5\end{array}$

El máximo de inhomogeneidades se centra en el Gran Bilbao (al igual que en MAM), en la Cantábrica Alavesa y en las Encartaciones.

En Arratia - Nervión, Guernica y Plencia, el número de inhomogeneidades es bajo, quizá atribuible al escaso número de series y a la brevedad de las mismas.

De la comparativa de las tablas 68, 47 bis (página 101) y 30 bis (página 73):

1) En el Gran Bilbao la precipitación en primavera es menos homogénea que la precipitación anual.

2) En el Marquinesado y en el Duranguesado, la precipitación primaveral es más homogénea que en el resto del año.

3) Las comarcas de Arratia - Nervión, Guernica y Plencia exteriorizan un número parejo de inhomogeneidades en la precipitación anual y primaveral.

Las precipitaciones registradas en AMJ muestran una elevada disparidad interanual: En un año de AMJ lluvioso sobrepasan en un 300 a un $500 \%$ a las precipitaciones recogidas en los años secos (tablas 51, 52, 55, 58 y 62).

4.3.- El comportamiento bipolar de la pluviosidad entre 1075E I $\nabla$ Aránzazu, 1070 \& Abadiano y 1071 \& Durango respecto a 9077E II $>$ Ochandiano: En las vertientes opuestas de los puertos de Dima y de Urquiola, los años lluviosos se miden precitaciones semejantes o superiores en 1075E I $\nabla, 1070 \vee$ y $1071 \nabla$ respecto a 9077E II $\nabla$ y los secos, llueve más en 9077E II $P$.

No se puede precisar el comportamiento pluviométrico de una zona extensa sin el conocimiento detallado de la climatología a escala comarcal.

5.- La gran afinidad en el transcurrir de las series de precipitación AMJ próximas (tablas 51 a 67), permite la disertación no sólo de inhomogeneidades "climatológicas" a escala provincial, sino de inhomogeneidades "climatológicas" en una misma comarca o en comarcas contiguas. 
Esta semejanza se patentiza:

A) Temporalmente: Los máximos y mínimos pluviométricos son simultáneos.

B) Espacialmente: Una sublime correspondencia entre las pluviosidades de las diversas localizaciones.

El cociente de las precipitaciones es prácticamente constante, con unos estrechos intersticios de las razones pluviométricas y con una variación de los cocientes algo mayor los años secos o muy secos frente a los lluviosos o muy lluviosos (expuesto en las tablas 53, $54,56,57,60,61,63,64,66$ y 67 y examinado en los comentarios de las tablas 51 a 67 bis).

6.- La recogida de los datos de las tablas $51,52,55,58,62$ y 65 (páginas 109,111 , $113,116,119$ y 122) sugiere un doble ciclo en la precipitación AMJ propincuo a los 10 años, un triple ciclo allegado a los 20 años y un doble ciclo rayano a los 30 años.

6.1.- Las tablas 69 y 69 bis reproducen los años pluviosos y áridos en AMJ en Guipúzcoa (Nota Técnica No 13 AEMET) para su cotejo con los resultados de Vizcaya y de la vertiente cantábrica de Álava, recopilados en las tablas 70 y 70 bis.

La siguiente nomenclatura se emplea en las tablas 69, 69 bis, 70 y 70 bis:

a) En azul oscuro, los máximos y mínimos pluviométricos sincrónicos en Vizcaya, en la vertiente cantábrica de Álava y en Guipúzcoa.

b) En azul aguamarina, los máximos y mínimos de precipitación secundarios simultáneos en Vizcaya, en la vertiente cantábrica de Álava y en Guipúzcoa.

c) En rojo, los extremos de la pluviosidad de Vizcaya y de la vertiente cantábrica de Álava no concurrentes en Guipúzcoa y congruentes con el duplo ciclo decenal de AMJ lluviosos y de AMJ secos.

d) Se dejan en blanco los años sin máximos o mínimos pluviométricos AMJ recogidos de las tablas 51 a 65, sea por la exigüidad de series de datos (1934 a 1943) o por coincidir con un lapso sin inhomogeneidades: No hay inhomogeneidades anteriores a 1911, ni de 1927 a 1953 ni de 1985 a 1992 (tabla 50, página 108).

e) En negrita, los años con máximos y mínimos pluviométricos $\mathrm{AMJ}$ relevantes, por el número de emplazamientos y por la relevancia de sus extremos.

f) Un guión - señala años de la tabla conjuntos: Por ejemplo 1977-78: 1977 y 1978.

g) Una coma , denota años no consecutivos. Verbi gratia 1915, 18: 1915 y 1918. 
Tabla 69: Años con máximos pluviométricos en precipitación AMJ:

\begin{tabular}{|l||c|c|c|c|c||c|c|}
\hline Máximos & $1879-80$ & $\mathbf{1 8 8 4 - 8 5}$ & $\mathbf{1 8 8 8 - 8 9}$ & & 1900 & & $\mathbf{1 9 1 0}$ \\
\hline \hline Máximos & $1917-18$ & $1922-23$ & 1925,27 & $1930-31$ & $\mathbf{1 9 3 3}$ & $\mathbf{1 9 4 0}$ & 1942 \\
\hline \hline Máximos & 1951 & 1956 & 1961 & 1964 & 1969 & $1971-72$ & $\mathbf{1 9 7 8 , 7 9 , 8 0}$ \\
\hline \hline Máximos & 1986 & 1990 & $\mathbf{1 9 9 7}$ & 2002 & 2008 & 2012 & \\
\hline \hline
\end{tabular}

Tabla 69 bis: Años con mínimos pluviométricos en precipitación AMJ:

\begin{tabular}{|l|c|c|c||c|c|c|c||}
\hline Mínimos & & 1882 & 1887 & $1892-93$ & $\mathbf{1 8 9 6 - 9 8}$ & $1903-04$ & 1909 \\
\hline Mínimos & $1915-16$ & 1921 & 1924 & 1928 & 1934 & 1938 & $\mathbf{1 9 4 3 - 4 4}$ \\
\hline \hline Mínimos & $\mathbf{1 9 4 7 - 4 8}$ & 1952,55 & $1959-60$ & 1963 & 1967 & 1974 & 1976 \\
\hline \hline Mínimos & $\mathbf{1 9 8 2}$ & 1987 & $\mathbf{1 9 9 5}-96$ & 2001 & $\mathbf{2 0 0 3 - 0 4}$ & 2011 & \\
\hline
\end{tabular}

La sincronía de los máximos y mínimos pluviométricos, advertida de las tablas 51 , $52,55,58,62$ y 65 , se compendia en las tablas 70 (máximos) y 70 bis (mínimos).

Tabla 70: Años con máximos pluviométricos en precipitación AMJ:

\begin{tabular}{|l|c|c|c|c|c|c|c||}
\hline Máximos & $\mathbf{1 9 1 3}$ & $\mathbf{1 9 1 5 , 7 - 8}$ & $\mathbf{1 9 2 2}$ & $\mathbf{1 9 2 5}$ & & & \\
\hline \hline Máximos & & & $\mathbf{1 9 5 6}$ & 1961 & 1966 & $1969, \mathbf{7 1}$ & $\mathbf{1 9 7 2 , 7 5}$ \\
\hline \hline Máximos & $\mathbf{1 9 7 7 - 7 8}$ & & & $1993-\mathbf{9 4}$ & $\mathbf{1 9 9 8}$ & $\mathbf{2 0 0 5}$ & $\mathbf{2 0 0 8}$ \\
\hline \hline Máximos & $\mathbf{2 0 1 2 - 1 3}$ & & & & & & \\
\hline
\end{tabular}

Tabla 70 bis: Años con mínimos pluviométricos en precipitación AMJ:

\begin{tabular}{||c|c|c|c|c|c||c|c||}
\hline Mínimos & 1916 & $\mathbf{1 9 1 9 - 2 0}$ & 1924 & & & & \\
\hline \hline Mínimos & & $\mathbf{1 9 5 5}$ & $1959, \mathbf{6 0}$ & 1963 & 1967 & $\mathbf{1 9 7 4}$ & 1976 \\
\hline \hline Mínimo & $\mathbf{1 9 8 1 - 2 - 3}$ & & & $\mathbf{1 9 9 5 - 9 6}$ & $1999, \mathbf{0 1}$ & $\mathbf{2 0 0 6}$ & $\mathbf{2 0 1 1}$ \\
\hline
\end{tabular}

6.2.- Dos ciclos allegados a los 10 años en los máximos de precipitación media AMJ afloran de la tabla 70:

a) 1915,1917 y $1918 \Rightarrow>1925 \Rightarrow>\ldots=>1956 \Rightarrow 1966 \Rightarrow>1972$ y $1975 \Rightarrow>$. $\Rightarrow$ $1993-1994=>2005=>2012-2013=>\ldots$ $2008=>$...

b) $1913 \Rightarrow>1922 \Rightarrow>\ldots \Rightarrow 1961 \Rightarrow 1969$ y $1971 \Rightarrow 1977-1978 \Rightarrow \ldots \Rightarrow 1998 \Rightarrow>$ 
Los años duplicados del ciclo van relacionados a años muy lluviosos en AMJ.

Dos ciclos cercanos a los 10 años en los mínimos de precipitación media AMJ surgen de la tabla 70 bis:

a) $1919-1920=>\ldots=>1959-1960 \Rightarrow>1967 \Rightarrow>1976=>\ldots \Rightarrow>1995-1996 \Rightarrow>$ $2006=>$...

b) $1916 \Rightarrow>1924 \Rightarrow>\ldots=>1955 \Rightarrow>1963 \Rightarrow>1974 \Rightarrow>1981-1983 \Rightarrow>\ldots=>1999 y$ $2001 \Rightarrow 2011=>\ldots$

Los años del ciclo duplicados van asociados a años de sequías en AMJ.

6.3.- Tres ciclos próximos a los 20 años de máximos emergen de la tabla 70:
A) $1915,1917-1918=>\ldots=>1956 \Rightarrow>1972$ y $1975 \Rightarrow>1994 \Rightarrow 2013=>\ldots$
B) $1922=>\ldots=>1977-1978 \Rightarrow>1998=>\ldots$
C) $1913 \Rightarrow>\ldots=>1971 \Rightarrow$. $=>2008=>\ldots$

Y tres ciclos cercanos a los 20 años de años secos (tabla 70 bis):
A) $1919-1920 \Rightarrow>\ldots=>1960 \Rightarrow>\ldots=>1995-1996=>\ldots$
B) $1955=>1974=>\ldots=>2011=>\ldots$
C) $1981-1982 \Rightarrow 2001 \Rightarrow$

Se intuyen 2 ciclos rayanos a los 30 años de años lluviosos en extremo (tabla 70):

I) $1918 \Rightarrow \ldots=>1977-1978 \Rightarrow 2008$ y $2013=>\ldots$

II) $1913 \Rightarrow>\ldots=>1971-1972$ y $1975=>2005 \Rightarrow>\ldots$

Y se bosquejan dos ciclos de severas sequías propincuos a los 30 años (tabla 70 bis):

I) $1955=>1981-1982 \Rightarrow 2011=>\ldots$

II) $1974=>2001$ y $2006=>\ldots$

Los años lluviosos y secos no se distribuyen al azar, sino según la cadencia expuesta, sucediéndose años secos y lluviosos en AMJ.

Los años de precipitaciones muy elevadas y de sequías severas se originan de la superposición de los ciclos de 10 años y sobrevienen consecutivos, allegados en el tiempo.

Estos ciclos en la pluviometría allegados a los 10, 20 y 30 años de la pluviosidad AMJ se escrutan más minuciosamente en el apartado 3.2.5.- Cadencias de la precipitación AMJ de la Nota Técnica No 19 AEMET. 
Las tablas ulteriores 71, 83 y 92 (páginas 131, 173 y 207) revelan para la precipitación anual, MAM y AMJ:

a) Los años con tendencias detectadas.

b) Los indicativos de las series.

c) El tipo de tendencia: Positiva (+) o negativa (-).

d) La índole de la tendencia:

Climatológica: Causada por variaciones atmosféricas.

No climatológica: Originada por cambios de ubicación, entorno, colaborador y/o instrumentación o por carencia de datos.

e) La última columna expone el \% de series en que la tendencia aflora respecto al total de series analizadas en cada intervalo de años.

Un intervalo describe los valores extremos del \% de series en dicho lapso temporal. Un intersticio entre paréntesis indica el total de series estudiadas, cuando éste es escaso.

A las series con rupturas se les pospone el ordinal en números latinos, para especificar el orden que ocupa en las sucesivas roturas. Aeropuerto.

Por ejemplo, 1082 II $\nabla$ se refiere al segundo intervalo de medidas de 1082 Bilbao

\subsubsection{1.- Evolución temporal de las inhomogeneidades del test de Mann - Kendall aplicado a la precipitación anual:}

El vasto lapso temporáneo estudiado (de 1859 a 2013) y el parco número de series anteriores a 1940 (inferior a 6 sincrónicas) requieren la representación gráfica en 2 intersticios: De 1859 a 1940 y de 1941 a 2013.

La gráfica 13 ilustra la evolución temporal de las tendencias descubiertas por el test de Mann - Kendall en la precipitación anual de 1859 a 1940 de Vizcaya y de la vertiente cantábrica de Álava. 
Gráfica 13: Evolución temporal de las tendencias del análisis del test de Mann - Kendall de las series de precipitación de 1859 a 1940:

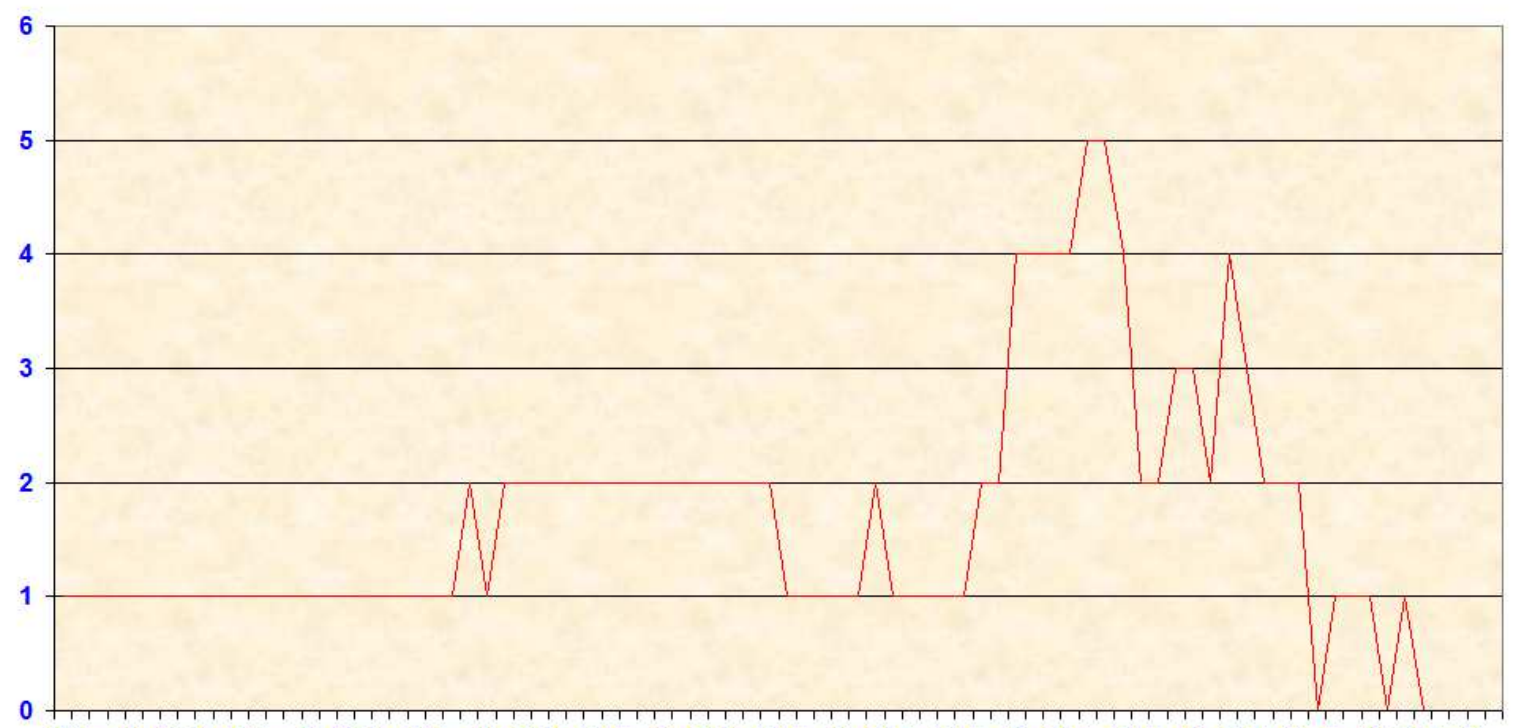

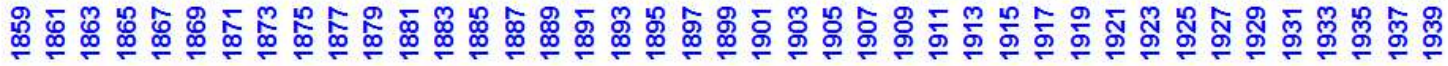
Años

\section{- $\mathrm{N}^{\circ}$ Series - Suma Tendencias}

La gráfica 14 expone la evolución temporal de las tendencias detectadas por el test de Mann - Kendall en la precipitación anual de 1941 a 2013 de Vizcaya y de la vertiente cantábrica de Álava.

Gráfica 14: Evolución temporal de las tendencias del análisis del test de Mann - Kendall de las series de precipitación de 1941 a 2013:

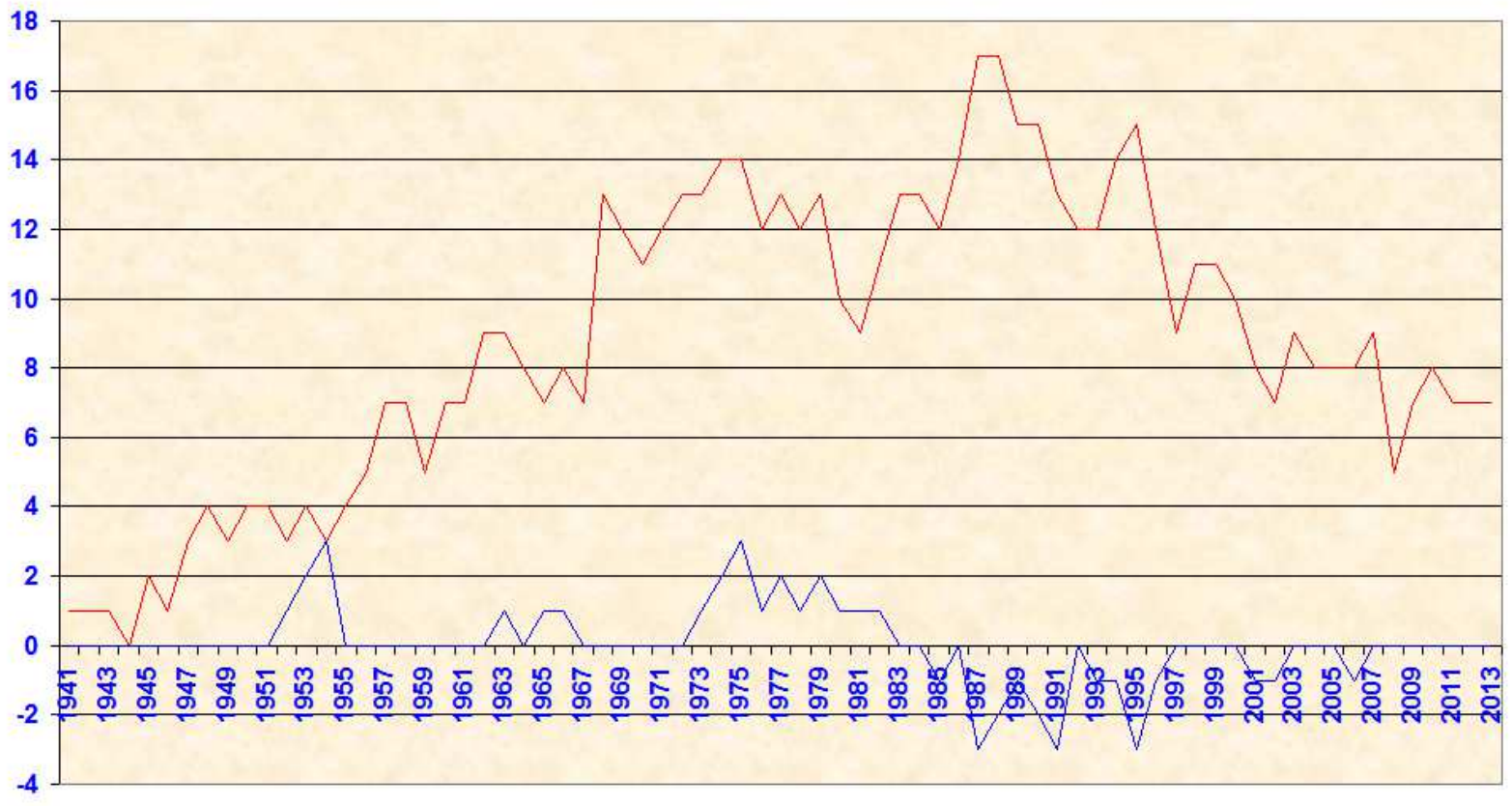

Años

$\mathrm{N}^{\circ}$ Series - Suma Tendencias 
De la gráfica 13 se aprecia un nulo número de tendencias precedentes a 1923, indicio de una excelente homogeneidad de los datos de precipitación anual existentes del siglo XIX y de los albores del siglo XX.

De la gráfica 14 se observa que:

1) Los extremos de tendencias positivas acaecen de 1952 a 1953 y de 1975 a 1979, más significativo el primer extremo, al ser menor el número de series disponibles.

2) Los máximos de tendencias negativas acontecen en 1988, 1990 y en 1995.

Tabla 71: Inhomogeneidades y tendencias detectadas aplicando el test de Mann - Kendall a la precipitación anual de 1859 a 2013:

\begin{tabular}{|c|c|c|c|c|}
\hline Años inhomogeneidad & Indicativos & Tendencia & $\begin{array}{l}\text { Inhomogeneidad } \\
\text { "climatológica" }\end{array}$ & $\begin{array}{c}\% \text { series } \\
\text { sobre total }\end{array}$ \\
\hline $1923,1925,1926$ & 1055 & + & No & $25-33(3-4)$ \\
\hline 1952 & 1059 & + & Sí & $33(3)$ \\
\hline 1953 & 1059,1082 & + & 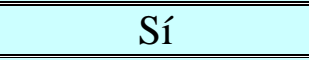 & $50(4)$ \\
\hline 1954 & $1059,1082,9077 \mathrm{E}$ & + & Sí & $100(3)$ \\
\hline $1963,1965,1966$ & 1060 & + & 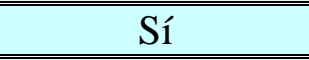 & $11-14$ \\
\hline 1973 & 1093 & + & Sí & 8 \\
\hline 1974 & 1053,1093 & + & Sí & 14 \\
\hline \multirow{2}{*}{1975} & $1053,1078 \mathrm{E}, 1093$ & + & Sí & \multirow{2}{*}{29} \\
\hline & 1083 & + & $\mathrm{No}$ & \\
\hline $1975-1976$ & 1068 & - & No & $7-8$ \\
\hline \multirow{2}{*}{$1976-1978$} & 1093 & + & Sí & \multirow{5}{*}{$15-23$} \\
\hline & 1083 & + & No & \\
\hline 1977 & 1075 & + & Sí & \\
\hline \multirow{2}{*}{1979} & 1053,1093 & + & Sí & \\
\hline & 1083 & + & No & \\
\hline $1980-1982$ & 1093 & + & S Sí & $9-11$ \\
\hline 1985 & 1083 & - & Sí & \multirow{4}{*}{$7-18$} \\
\hline 1987 & 1079I, 1083, 1093A & - & Sí & \\
\hline 1988 & 1079I, 1093A & 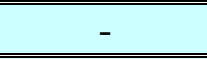 & Sí & \\
\hline 1989 & 1083 & 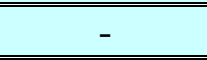 & Sí & \\
\hline 1990 & $1053,9077 \mathrm{E}$ & 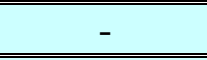 & Sí & 13 \\
\hline 1991 & $1053,1083,9077 \mathrm{E}$ & 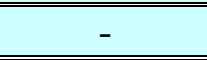 & Sí & 23 \\
\hline $1993-1994$ & $9077 \mathrm{E}$ & 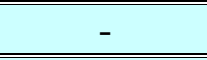 & Sí & $7-8$ \\
\hline $\begin{array}{l}1995 \\
\end{array}$ & $1053,1078 \mathrm{E}, 9077 \mathrm{E}$ & $\begin{array}{c} \\
\end{array}$ & Sí & 20 \\
\hline 1996 & 1053 & - & Sí & 8 \\
\hline 1996 & $1057 \mathrm{E}$ & + & No & 8 \\
\hline $2001-2002$ & 1060 & 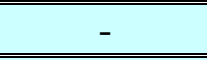 & Sí & $13-14(7-8)$ \\
\hline 2006 & $1081 \mathrm{U}$ & $\begin{array}{l}- \\
\end{array}$ & Sí & $13(8)$ \\
\hline
\end{tabular}


Los hallazgos de la tabla 71 se cotejan con los obtenidos del examen del test de Mann - Kendall de las series de precipitación anual de Guipúzcoa debido a:

a) La escasa densidad espacial y temporal de las series de pluviosidad anual abarcando al menos 10 años en Vizcaya y en la vertiente cantábrica de Álava.

b) Las parejas propiedades climáticas de Vizcaya, la vertiente cantábrica de Álava y Guipúzcoa.

Los registros de Vizcaya y de la vertiente cantábrica de Álava se contrastan con las observaciones de 1013 I $\vee$ Irún Viteri, 1016 ○ Oyarzun Arditurri, 1024B \ Igueldo Faro, 1046 III $\vee$ y 1046 IV $>$ Aránzazu y 1049U $\vee$ Ermua.

La tabla 72, procedente de la Nota Técnica № 13 de AEMET, transcribe los resultados del escrutinio de las series de precipitación anual de Guipúzcoa de 1941 a 2012 con el test de Mann - Kendall.

Tabla 72: Inhomogeneidades y tendencias detectadas aplicando el test de Mann - Kendall a la precipitación anual en Guipúzcoa de 1941 a 2012:

\begin{tabular}{|c|c|c|c|c|}
\hline Años inhomogeneidad & Indicativos & Tendencia & $\begin{array}{l}\text { Inhomogeneidad } \\
\text { "climatológica" }\end{array}$ & $\begin{array}{c}\% \text { series } \\
\text { sobre total }\end{array}$ \\
\hline 1948 & $1024 \mathrm{E}$ & - & $\begin{array}{c}\text { Sí } \\
\end{array}$ & 10 \\
\hline 1951 & $1015,1022 \mathrm{~A}, 1037$ & + & 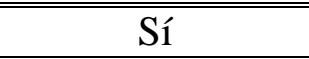 & 19 \\
\hline 1952 & $1015,1016,1035,1037$ & + & Sí & 36 \\
\hline 1954 & 1016,1031 & + & Sí & 14 \\
\hline 1957 & 1032 & - & Sí & 6 \\
\hline 1958 & 1031 & + & Sí & 5 \\
\hline 1960 & 1014 & + & Sí & 5 \\
\hline $1966-1972$ & 1026 & + & 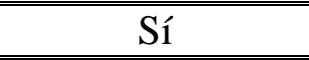 & 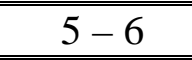 \\
\hline 1975,1976 & $1018 \mathrm{~A}$ & + & Sí & 6 \\
\hline $1977,1978,1979$ & 1017 & - & No & $5-6$ \\
\hline 1978 & 1022,1023 & + & Sí & 11 \\
\hline 1979 & $1014,1022,1023,1026$ & + & Sí & 25 \\
\hline 1980 & $1014,1022,1023,1024$ & + & Sí & 17 \\
\hline 1981 & 1014,1026 & + & Sí & 11 \\
\hline 1982 & $1014,1022,1023,1024$ & + & Sí & 21 \\
\hline 1983 & $1022,1023,1026$ & + & Sí & 25 \\
\hline 1984 & 1024,1026 & + & Sí & 10 \\
\hline $\begin{array}{c}1983,1985,1987, \\
1990,1991 \\
\end{array}$ & $1025 \mathrm{E}$ & - & ¿Sí? & $4-5$ \\
\hline 1989 & 1024 & - & Sí & 4 \\
\hline 1992 & 1021E, 1031 & + & Sí & 8 \\
\hline 1995 & 1038 & - & Sí & 5 \\
\hline
\end{tabular}




\section{1.- Tendencia positiva en 1923,1925 y 1926 en 1055 :}

1.- La escasez de series en Vizcaya y en la vertiente cantábrica de Álava (3 en 1923, 4 en 1925 y 3 en 1926) precisa de la inclusión para contraposición, de las mediciones de las series coetáneas en Guipúzcoa de 1024B $\$$ Igueldo Faro y 1013 I $\$$ Irún Viteri.

Los valores de Lequeitio Faro 1055 , Punta Galea Faro 1059 I $\$$ y Machicaco Faro 1057C I $९$ provienen de los Resúmenes de las Observaciones Meteorológicas efectuadas durante los años 1911 a 1926. A finales de Abril de 1924 cambia el colaborador de 1055 \& (de los archivos de la Delegación Territorial).

Las observaciones de Igueldo Faro 1024B $\vee$ de 1913 a 1915 proceden de los Resúmenes de las Observaciones Meteorológicas efectuadas durante los años 1913, 1914 y 1915.

La tabla 73 recoge la fecha de inicio y los años incompletos de los lapsos sin roturas

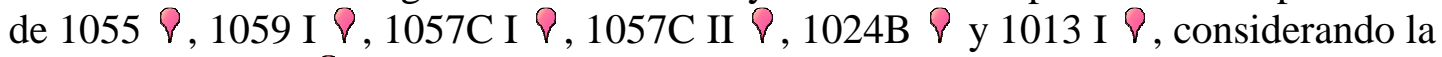
ruptura de 1057C $\$$ Machicaco Faro en Noviembre del año 1921, descrita en la página 20.

Tabla 73: Fecha inicio y años incompletos de 1055 P, 1059 I $\nabla, 1057 \mathrm{C}$ I $\nabla, 1057 \mathrm{C}$ II $\nabla$, 1024B $\nabla$ y 1013 I $\vee:$

\begin{tabular}{|c|c|c|c|}
\hline Indicativo & Nombre & Comienzo & Años incompletos \\
\hline 1055 P & Lequeitio Faro & $01-05-1911$ & $1912,1919,1920,1924$ \\
\hline 1059 I $\nabla$ & Punta Galea Faro & $01-01-1911$ & 1925 \\
\hline 1057C I $\bigcirc$ & Machicaco Faro & $01-01-1913$ & \\
\hline $1057 \mathrm{C}$ II $\nabla$ & Machicaco Faro & $01-12-1921$ & 1930 \\
\hline 1024B 8 & Igueldo Faro & $01-01-1913$ & 1915,1924 \\
\hline $1013 \mathrm{I} \nabla$ & Irún Fitosanitaria & $01-02-1914$ & 1926 \\
\hline
\end{tabular}

Las 5 series principian entre 1911 y 1914, con una ubicación costera (faros) o próxima a la costa (Irún).

2.- Esta tendencia positiva únicamente aflora en $1055 \mathrm{P}$ de todos los registros de precipitación superiores a 10 años de duración de Vizcaya, de la vertiente cantábrica de Álava y de Guipúzcoa (tablas 71 y 72).

3.- La gráfica 15 expone la precipitación total anual y la mediana de la precipitación global anual de $1055 \vee, 1057 \mathrm{C}$ I $\vee, 1057 \mathrm{C}$ II $\vee, 1059$ I $\vee, 1024 \mathrm{~B} \vee$ y 1013 I $\vee$ de 1913 a 1926.

En la gráfica 15 se representa la precipitación total anual con líneas continuas y con líneas discontinuas la mediana de la precipitación total anual en el intersticio temporal entre rupturas de cada serie. 
Gráfica 15: Precipitación total anual y mediana de la precipitación total anual $\left(1 / \mathrm{m}^{2}\right) \mathrm{de}$

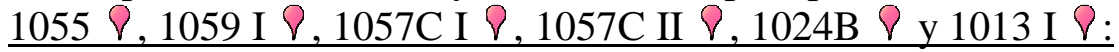

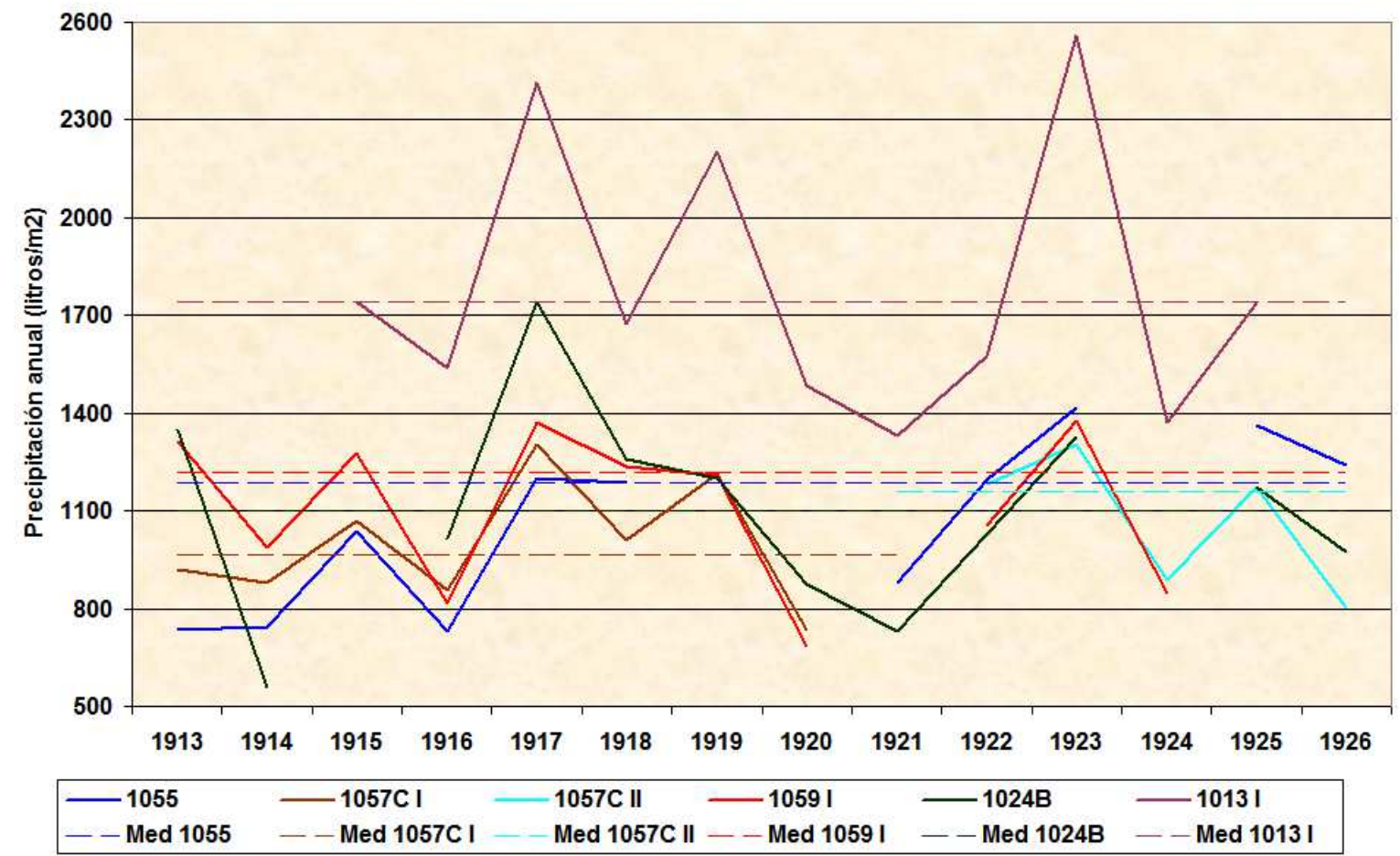

3.1.- Irún es el lugar más pluvioso de los 5 enclaves escrutados, con una mediana de $1742,4 \mathrm{l} / \mathrm{m}^{2}$.

3.2.- $1055 \bigcirc$ es el emplazamiento con los menores registros de precipitación anual de 1913 a 1918 (con la salvedad de 1024B $\nabla$ en 1914 y de 1057C I $\nabla$ en 1918).

Transcurrido 1920, sus registros ascienden a la $2^{\mathrm{a}}$ posición, sólo rebasados por $1013 \mathrm{I} \vee$ : 1055 ○ muda de ser el más seco de los 5 , al $2^{\circ}$ más lluvioso.

3.3.- Los incrementos y decrementos de los valores pluviométricos de $1055 \bigcirc$ son congruentes con los observados en el resto de emplazamientos:

a) 1923, 1917 y 1919 son los años más pluviosos en la plenitud de jardines meteorológicos, acorde con los hallazgos de la tabla 32 (página 75).

b) Los mínimos coetáneos de 1916 y 1920 son coherentes con los resultados de la tabla 32 bis (página 75). 1921, 1924 y 1926 son años áridos coetáneos en todos los lugares.

3.4.- La medida de la pluviosidad anual de 1024B $P$ en 1914 es sospechosa: $558 \mathrm{l} / \mathrm{m}^{2}$, frente a una mediana de 1024B $P$ de $1099,21 / \mathrm{m}^{2}$ : Es la menor medición de 1913 a 1926 de las 5 localizaciones.

4.- La gráfica 16 muestra el cociente de la precipitación total anual de 1055 จ Lequeitio Faro respecto a la precipitación global anual en cada sucesivo año de 1059 I $\varnothing$, 1057C I $\vee, 1057$ C II $\vee, 1024$ B $\vee$ y 1013 I $\vee$ de 1913 a 1926. 
Gráfica 16: Razón de las precipitaciones de 1055 Prespecto a 1057C I $\vee, 1057 \mathrm{C}$ II $\vee$, 1059 I $P, 1024 \mathrm{~B} P$ y 1013 I $\vee:$

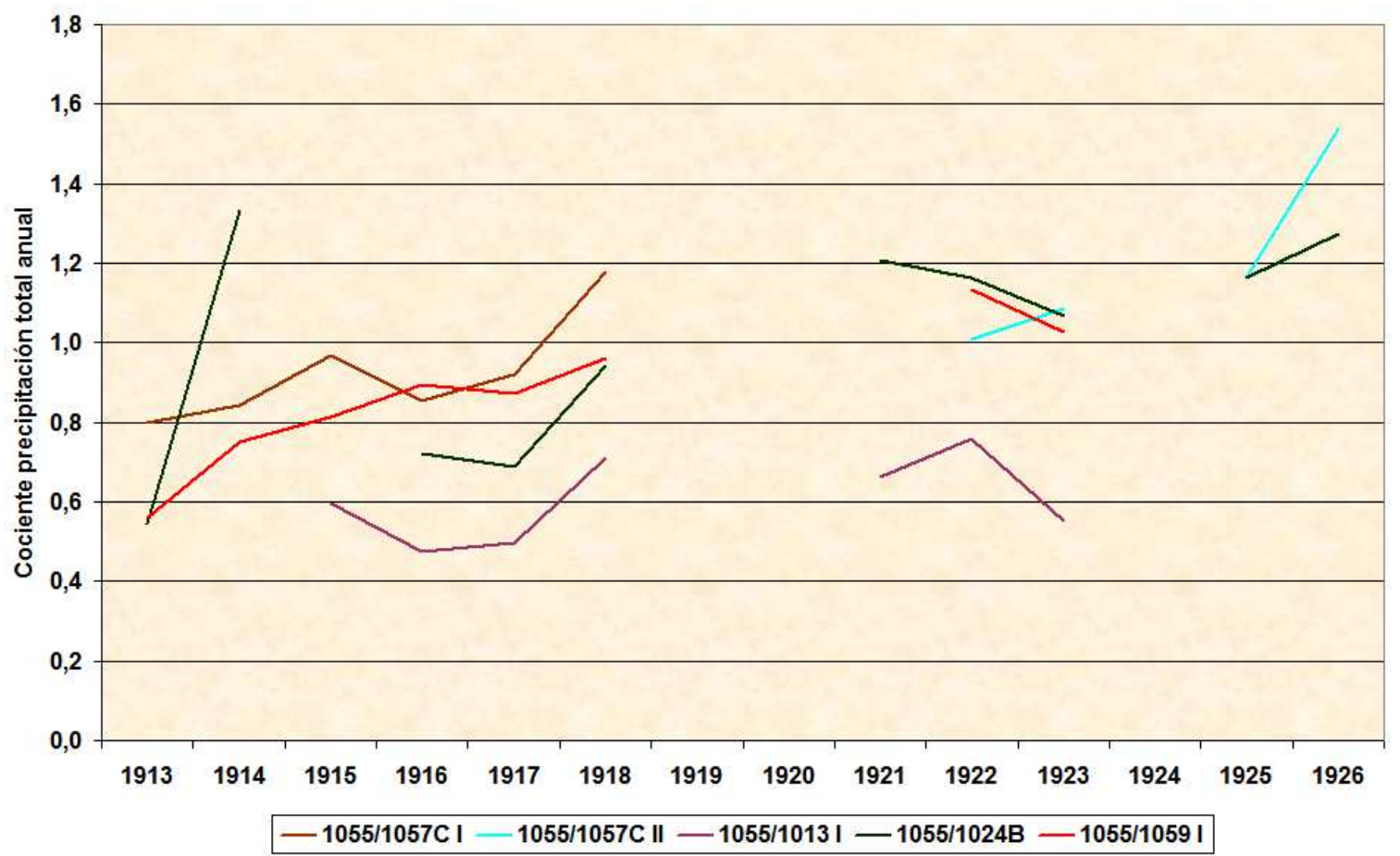

4.1.- La carencia de datos de 1055 fuerza la omisión de los cocientes en 1919, 1920 y 1924.

4.2.- El cociente de las precipitaciones $1055 \mathrm{P} / 1057 \mathrm{C} \vee$ corrobora la ruptura de 1057C $\vee$ en Noviembre de 1921: El valor de 1918 es inferior al de 1922, síntoma de la rotura de $1057 \mathrm{C} P$.

4.3.- De la gráfica 16 se infiere un aumento de la razón de la precipitación recogida en $1055 \nabla$ respecto a la medida en cada uno de los restantes lugares, debido al incremento de las cuantías de las precipitaciones anotadas en $1055 \bigcirc$.

Este acrecentamiento espurio es aún más notable cuando se comparan las razones previas a 1919 con las posteriores a 1920: Los cocientes ulteriores a 1920 rebasan a los previos a 1919.

Asimismo se aprecia una acrecencia de 1913 a 1918 de los cocientes de la precipitación medida en 1055 respecto a las cantidades recabadas en los restantes lugares, signo de un acrecimiento "ficticio" de la precipitación en $1055 \nabla$.

4.4.- La compilación de estas conclusiones arroja ciertas dudas sobre la calidad de las cuantías apuntadas en 10558 .

Por todo lo expuesto, se la cataloga como tendencia "no climatológica". 
1.- La exigüidad de observaciones pluviométricas en Vizcaya y en la vertiente cantábrica de Álava (3 en 1952 y 1954, 4 en 1953) requiere de su incremento para un cotejo; se opta por agregar 1016 ○ Oyarzun Arditurri, el enclave con registros más elevados de precipitación en toda Vizcaya, Guipúzcoa y Álava.

La tabla 74 detalla la fecha de comienzo y los años sin la plenitud de los valores de la pluviosidad anual de 1059 II $\vee$ Punta Galea Faro, 1082 I $\vee$ Bilbao Aeropuerto, 9077E I $\vee$ Ochandiano y de $1016 \vee$ Oyarzun Arditurri, acordes a las roturas descritas y analizadas en las páginas 22, 23, 31, 32 y 35 del apartado 4.1. "Rupturas detectadas en las series de precipitación".

Tabla 74: Fecha inicio y años incompletos de 1059 II $\nabla, 1082$ I $\nabla, 9077$ E I $\nabla$ y de 1016 \&:

$\begin{array}{rccc}\text { Indicativo } & \text { Nombre } & \text { Comienzo } & \text { Años incompletos } \\ \text { 1059 II } \varnothing & \text { Punta Galea Faro } & 01-01-1946 & 1965 \\ \text { 1082 I } \varnothing & \text { Bilbao Aeropuerto } & 01-03-1947 & \\ \text { 9077E I } \varnothing & \text { Ochandiano } & 01-01-1947 & 1949 \text { y } 1970 \\ 1016 \varnothing & \text { Oyarzun Arditurri } & 01-06-1946 & 1955\end{array}$

Las 4 series comienzan entre Enero de 1946 y Marzo de 1947.

2.- Esta tendencia se alcanza a detectar en el $100 \%$ de las 3 series disponibles en 1954 con una duración superior a 10 años en Vizcaya y la vertiente cantábrica de Álava.

3.- El test de Mann - Kendall aprecia una tendencia positiva de la precipitación coetánea en Guipúzcoa en 1952 en 1015 \ Fuenterrabía Guadalupe, 1016 \ Oyarzun Arditurri, 1035 Lasarte Michelín y 1037 I $\bigcirc$ Legazpia; en 1954 en 1016 \ y 1031 I $\vee$ Elduayen (tabla 72, página 132).

4.- El test de las rachas aplicado a la precipitación anual desvela una inhomogeneidad “climatológica” en 9077E I $\nabla$ de 1951 a 1967 (tabla 17, página 50), en 1016 \& de 1950 a 1961 y en 1024 E \& Igueldo de 1951 a 1961 (tabla 19, página 52).

5.- En Guipúzcoa "hubo una sequía de 1945 a 1948, seguida de 1950 a 1954 por unos años de precipitaciones elevadas" (Nota Técnica No 13 AEMET).

6.- La tabla 23 (página 57) señala a 1954 y 1952 como los 2 años más lluviosos en 9077E I $\vee$, siendo máximos sincrónicos en 9076 I $\vee$ Ullivarri Gamboa. 
7.- La gráfica 17 revela la precipitación total anual y la mediana de 1059 II $P$, 1082 I $\vee, 9077$ E I $\vee$ y 1016 \& de 1947 a 1958.

Gráfica 17: Precipitación total anual y mediana de la precipitación total anual $\left(1 / \mathrm{m}^{2}\right) \mathrm{de}$ 1059 II $\vee, 1082$ I $\vee, 9077$ E I $\vee$ y 1016 \&:

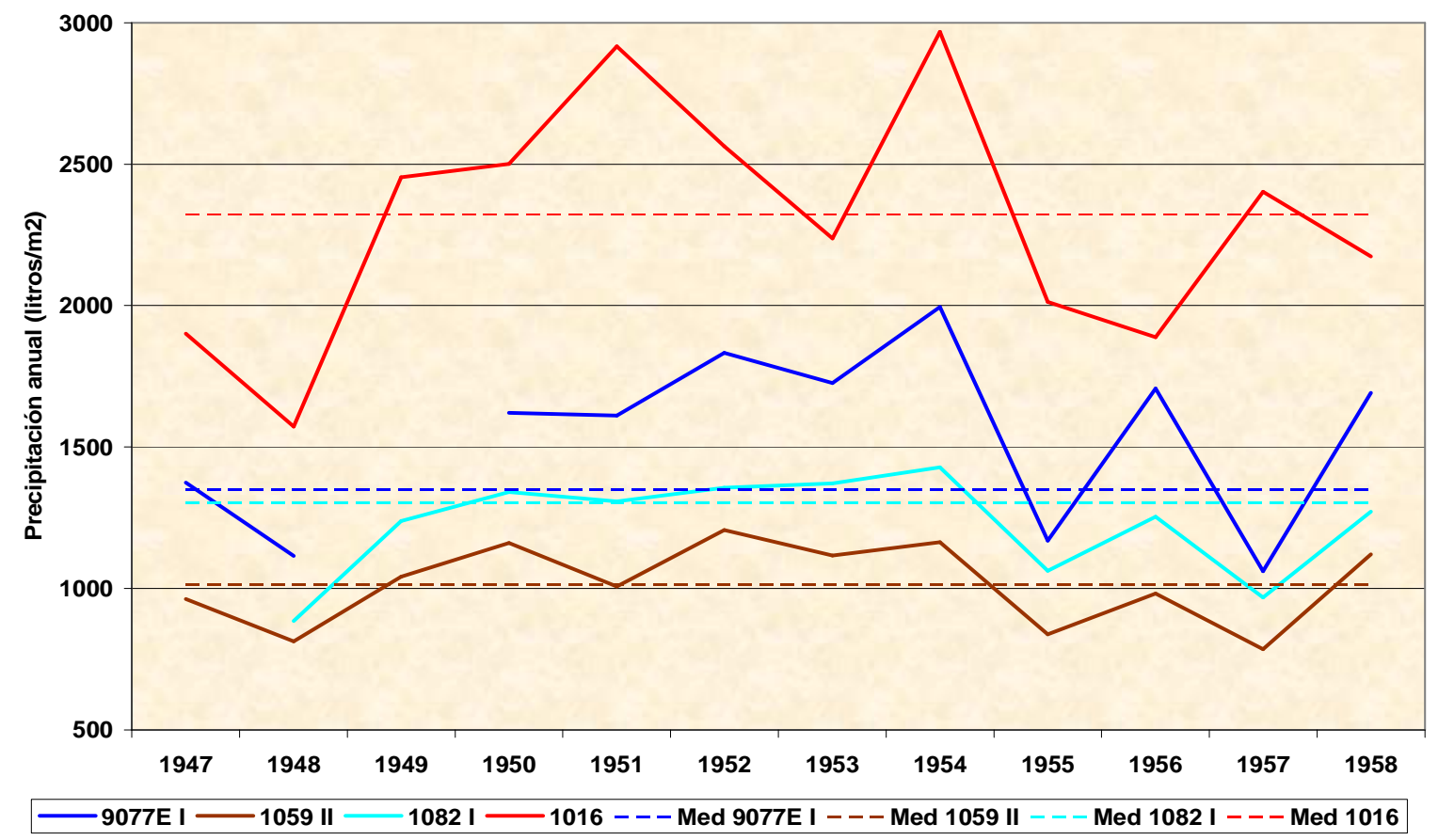

Un trazo continuo denota la precipitación total anual; uno discontinuo, la mediana en el intervalo entre roturas de cada serie.

De la gráfica 17 se advierte:

7.1.- Las precipitaciones acrecen de Oeste a Este, permaneciendo invariante la gradación pluviométrica de los enclaves.

7.2.- A las sequías de 1947 y de 1948 le siguen de 1950 a 1954 unos años de una pluviometría superior a la mediana; transcurrido 1954 las precipitaciones disminuyen en 1955 y 1957 siguiendo una cadencia próxima al decenio. La tendencia positiva escrutada es congruente con la abundante pluviosidad de 1950 a 1954.

7.3.- 1952 y 1954 son máximos de pluviosidad relevantes sincrónicos en las 3 series de Vizcaya y de la vertiente cantábrica de Álava y concuerdan con los años lluviosos referidos en la tabla 32.

7.4.- 1955 y 1957 son mínimos pluviométricos simultáneos en las 3 series de Vizcaya, conformes con los años secos de la tabla 32 bis (página 75). 1948 es un año árido coetáneo en Guipúzcoa (tabla 31 bis, página 74). 
7.5.- La pluviosidad de 1953 respecto a 1952 asciende únicamente en 1082 I $\nabla$, precursor del incremento generalizado de precipitaciones en 1954.

8.- La tendencia positiva de 1952 a 1954 es una recuperación a los valores normales de precipitación, tras la severa sequía de los años 40, siendo 1954 cuando la restitución es más acusada.

9.- Esta reversión se detecta en las 3 series analizadas.

10.- La gráfica 18 expone el cociente de la pluviosidad total anual de 1059 II $\vee$ Punta Galea Faro respecto a la precipitación total en cada sucesivo año de 1082 I 8 , 9077E I P y 1016 P de 1947 a 1958.

\section{Gráfica 18: Razón de las precipitaciones de 1059 II $\nabla$ respecto a 9077E I $\nabla, 1082$ I $\vee$ y} 1016 P:

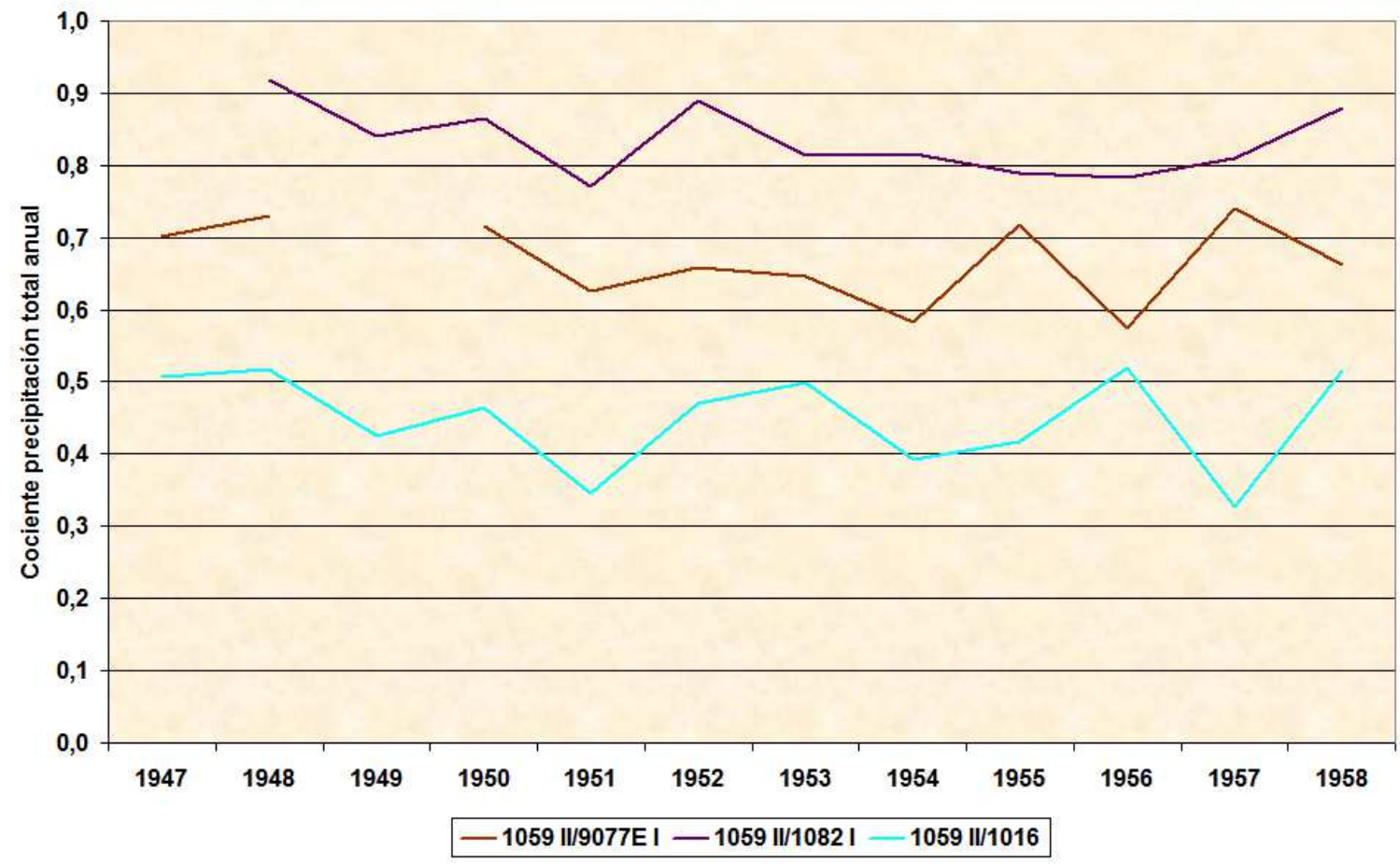

Se deja un hueco en el cociente 1059 II $\vee / 9077$ E I $\vee$ de 1949, un año incompleto de precipitación en 9077E I $P$.

El cociente de las precipitaciones en los 4 lugares es aproximadamente constante y fluctúa entre unos valores máximos y mínimos invariables, con una periodicidad en los máximos y en los mínimos cercana a los 10 años (gráfica 18).

Por tanto, se la clasifica como tendencia "climatológica". 


\section{3.- Tendencia positiva en 1963,1965 y 1966 en 1060 :}

1.- Los registros de 1060 I $P$ Amurrio se confrontan con los datos de 1082 I $P$ Bilbao Aeropuerto, 1059 II $\vee$ Punta Galea Faro, 1054 II $\vee$ Marquina y 1093 I $\vee$ Carranza, las restantes series coetáneas de la Vizcaya y Álava cantábricas. Las medidas de 1068 II $P$ Basauri no se incluyen (motivado en las gráficas 24 y 26 y en los comentarios a las gráficas 24 y 26, páginas 146 a 148).

La tabla 75 describe la fecha de empiece y los años no íntegros de precipitación de los intervalos sin roturas de 1060 I $\nabla, 1082$ I $\nabla, 1059$ II $\nabla, 1054$ II $\nabla$ y 1093 I $\nabla$, tratados en el apartado 4.1. "Rupturas detectadas en las series de precipitación" (páginas 25, 26, 31, $32,22,23,18,19,34$ y 35$)$.

Tabla 75: Fecha inicio y años incompletos de 1060 I $\vee, 1082$ I $\vee, 1059$ II $\vee, 1054$ II $\vee$ y 1093 I P:

$\begin{array}{cccc}\text { Indicativo } & \text { Nombre } & \text { Comienzo } & \text { Años incompletos } \\ 1060 \text { I } P & \text { Amurrio } & 01-05-1955 & 1964 \\ 1082 \text { I } ~ & \text { Bilbao Aeropuerto } & 01-03-1947 & \\ 1059 \text { II } 8 & \text { Punta Galea Faro } & 01-01-1946 & 1965 \\ 1054 \text { II } 8 & \text { Marquina } & 01-05-1956 & 1959,1975,1976 \\ 1093 \text { I } \varnothing & \text { Carranza } & 01-11-1956 & 1959,1967\end{array}$

Las 5 series empiezan en 1946, 1947, 1955 y 1956. 1955 es un año con un mínimo pluviométrico relevante (tabla 32 bis, página 75).

2.- Esta tendencia solamente aflora en la Cantábrica Alavesa; la única tendencia simultánea en Guipúzcoa es 1026 \& Beasain en 1966.

3.- El análisis del test de las rachas de la precipitación anual señala una inhomogeneidad "climatológica" en 1060A \ Amurrio Instituto de 1962 a 1975 (tabla 17, página 50).

4.- 1965 y 1966 son los años más lluviosos en 1060 I $\vee$ (tabla 25, página 61). Asimismo, 1965 y 1966 son años de elevadas precipitaciones en 1052 P Motrico y en 1053 I $\nabla$ Echevarría (tabla 24) y en 1966 concurre un máximo pluviométrico en 9077E I $\nabla$ Ochandiano y en 1054 II $\vee$ (tablas 23 y 24, páginas 57 y 59).

5.- La gráfica 19 refiere la precipitación total anual y la mediana de la precipitación total anual de 1060 I $\nabla, 1082$ I $\vee, 1059$ II $\nabla, 1054$ II $\vee$ y 1093 I $\vee$ de 1956 a 1966.

La gráfica 19 indica con líneas de trazo continuo la precipitación total anual y con líneas discontinuas, la mediana en el lapso temporal entre rupturas de cada serie. 
Gráfica 19: Precipitación total anual y mediana de la precipitación total anual $\left(1 / \mathrm{m}^{2}\right)$ de 1060I $\vee, 1082$ I $\vee, 1059$ II $\vee, 1093$ I $\vee$ y 1054 II $\vee:$

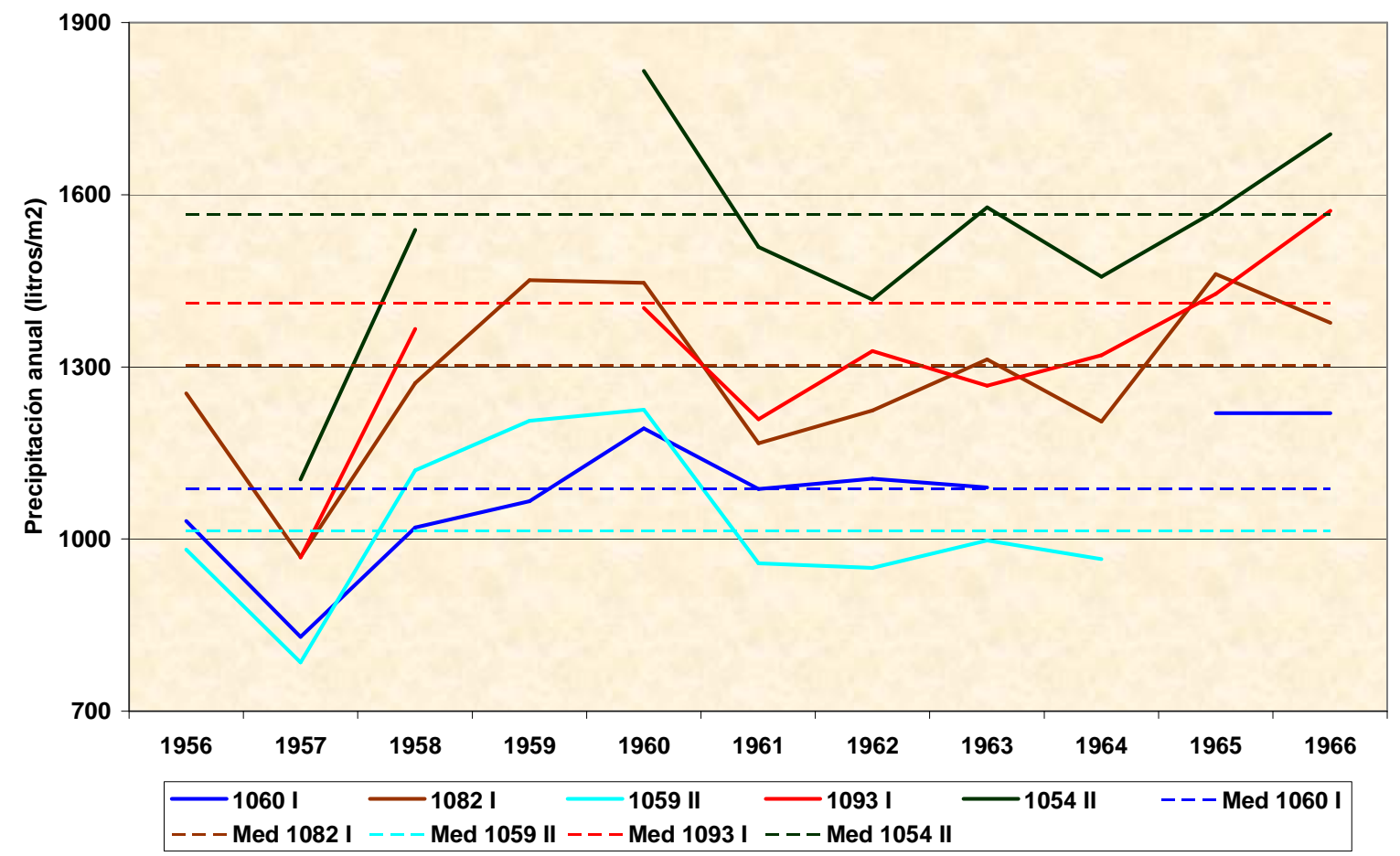

De la gráfica 19 se colige:

5.1.- Las localizaciones más secas son 1059 II $\vee$ y 1060 I $\vee$. En un rango intermedio se ubican 1082 I $\vee$ y 1093 I $\vee$. 1054 II $\vee$ es la más lluviosa.

5.2.- Al muy significativamente seco 1957 le suceden los muy lluviosos 1959 y 1960. Al normal 1963 y al seco 1964 en precipitaciones le sobreviene un acrecimiento de la pluviosidad en los 5 lugares en 1965 y en 1966, salvo en 1966 en el Gran Bilbao. La tendencia positiva de 1060 I $\vee$ concuerda con este incremento pluviométrico.

La disminución de la pluviosidad en 1966 en el Gran Bilbao, en contraposición al resto de enclaves, refuerza la necesidad de un análisis a una escala comarcal.

5.3.- 1960, 1965 y 1966 son máximos sincrónicos en las 5 series (gráfica 19) y son congruentes con los compilados en la tabla 32 (página 75). Los 3 años son máximos coetáneos en Guipúzcoa (tabla 31, página 74). La máxima precipitación en 1060 I $\nabla$ se registra en 1966 ex aqueo con 1965 (tabla 25, página 61).

5.4.- 1958 y 1963 son años de una precipitación total anual pareja, muy cercana a la mediana de cada serie.

5.5.- 1957 es un mínimo notorio de pluviosidad en las 5 ubicaciones y un mínimo simultáneo en Guipúzcoa (tabla 31 bis, página 74). En 1964 acaece un mínimo pluviométrico secundario en la totalidad de los lugares de la tabla 75. 
5.6.- El aumento y el decremento de la precipitación concuerda en todos los enclaves: La evolución temporal de las precipitaciones es similar en los 5 lugares.

5.7.- De 1959 a 1960 la pluviosidad solamente decrece en 1082 I $\nabla$, preludio del descenso generalizado de 1961.

6.- La gráfica 20 representa el cociente de la precipitación total anual de 1060 I $\nabla$ Amurrio Instituto respecto a la precipitación total en cada sucesivo año de 1082 I $\nabla$, 1059 II $\nabla, 1054$ II $\vee$ y 1093 I $\nabla$ de 1956 a 1966.

Gráfica 20: Razón de las precipitaciones de 1060 I $\vee$ respecto a 1082 I $\vee, 1059$ II $\vee$, 1093 I $P$ y 1054 II $\vee:$

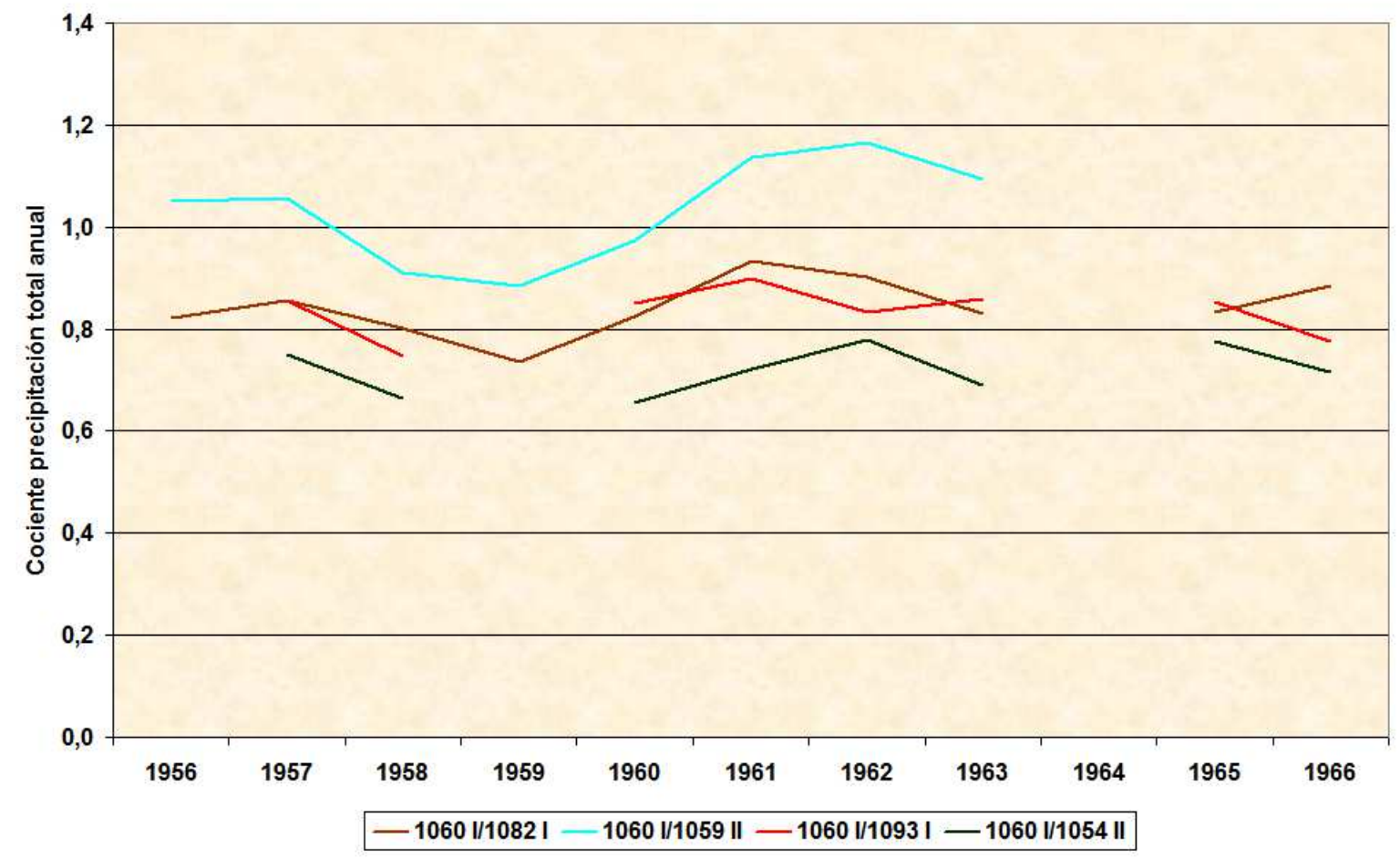

Se omite el cociente en 1964, año sin plenitud de datos de precipitación en 1060 I $\nabla$.

7.- El cociente de precipitaciones oscila entre unos valores máximos y mínimos constantes: El devenir de la razón de precipitaciones de 1060 I $\nabla$ versus 1059 II $\nabla$, 1082 I $\vee, 1093$ I $\vee$ y 1054 II $\vee$ (con la salvedad de 1966 en el Gran Bilbao) es idéntico.

Las precipitaciones en 1059 II $\vee$ y en 1060 I $\vee$ son de una cuantía pareja.

8.- La tendencia positiva de 1963, 1965 y 1966 es un restablecimiento a los valores normales de precipitación, tras la intensa sequía de 1957.

Por consiguiente, se la considera una tendencia "climatológica". 
4.- Tendencia positiva de 1973 a 1975 en 1093 , de 1974 a 1975 en 1053 y en 1975 en $1078 \mathrm{E}$ y en 1083:

1.- Los datos pluviométricos de 1093 I $\vee$ Carranza, 1053 I $\vee$ Echevarría, 1078E I $\nabla$ Valmaseda y 1083 I $\vee$ Arcentales son contrapuestos a las medidas de 1053 II $\vee$ Echevarría, 1060 I $\vee$ y 1060 II $\vee$ Amurrio y 1082 I $\vee$ Bilbao Aeropuerto, los enclaves coetáneos más próximos.

La tabla 76 allega la fecha de iniciación y los años con valores parciales de los intervalos sin rupturas de 1053 I $\nabla, 1078 \mathrm{E}$ I $\nabla, 1083$ I $\nabla, 1093$ I $\nabla, 1053$ II $\nabla, 1060$ I $\nabla$, 1060 II $\nabla$ y 1082 I $\vee$ teniendo en cuenta la rotura de $1053 \nabla$ Echevarría a finales de 1975 y la ruptura de $1060 \vee$ Amurrio de fines de 1960.

Tabla 76: Fecha inicio y años incompletos de 1053 I $\vee, 1078 \mathrm{E}$ I $\vee, 1083$ I $\vee, 1093$ I $\vee$, 1053 II $\vee, 1060$ I $\vee, 1060$ II $\vee$ y 1082 I $\vee$ :

\begin{tabular}{|c|c|c|c|}
\hline Indicativo & Nombre & Comienzo & Años incompletos \\
\hline $1053 \mathrm{I} P$ & Echevarría & $01-10-1961$ & \\
\hline $1078 \mathrm{E} \mathrm{I} 8$ & Valmaseda & $01-01-1972$ & 1986 \\
\hline $1083 \mathrm{I} \gamma$ & Arcentales & $01-08-1967$ & 1973 \\
\hline $1093 \mathrm{I} P$ & Carranza & $01-11-1956$ & 1959,1967 \\
\hline $1053 \mathrm{II} P$ & Echevarría & Final 1975 & \\
\hline $1060 \mathrm{I} P$ & Amurrio & $01-05-1955$ & 1964 \\
\hline 1060 II $P$ & Amurrio & Final 1966 & 1967 \\
\hline $1082 \mathrm{I} P$ & Bilbao Aeropuerto & $01-03-1947$ & \\
\hline
\end{tabular}

2.- Esta tendencia se exterioriza en dos comarcas de Vizcaya y de la vertiente cantábrica de Álava: Encartaciones (1093 I \&, 1078E I \ y 1083 I $\vee$ ) y Marquina Ondarroa (1053 I ₹).

3.- En Guipúzcoa hay una tendencia positiva de la precipitación anual en 1972 en 1026 Peasain y en 1975 en 1018A $\vee$ Rentería (tabla 72, página 132).

4.- El test de las rachas aplicado a la precipitación anual aflora una inhomogeneidad “climatológica” en 1078E I $\vee$ de 1975 a 1984 (tabla 17, página 50).

5.- La figura 24 presenta las ubicaciones de 1060 II $\vee, 1078 \mathrm{E}$ I $\vee, 1082$ I $\vee$, 1083 I $\odot$ y 1093 I $\vee$.

La gráfica 21 ilustra la precipitación total anual y la mediana de la precipitación total anual de 1053 I $\nabla, 1053$ II $\nabla, 1060$ II $\nabla, 1078$ E I $\nabla, 1082$ I $\nabla, 1083$ I $\nabla$ y 1093 I $\nabla$ de 1968 a 1977.

La gráfica 22 refleja el cociente de 1957 a 1977 de la precipitación total anual de 1093 I $\nabla$ respecto a la precipitación total anual de 1053 I $\nabla, 1060$ I $\nabla, 1060$ II $\nabla$, 1078E I $\vee, 1082$ I $\vee, 1083$ I $\vee$ y el cociente de 1083 I $\vee$ referido a 1082 I $\vee$. 
Figura 24.- Emplazamientos de 1060 II $\nabla, 1078$ E I $\vee, 1082$ I $\vee, 1083$ I $\vee$ y 1093 I $\vee$ :

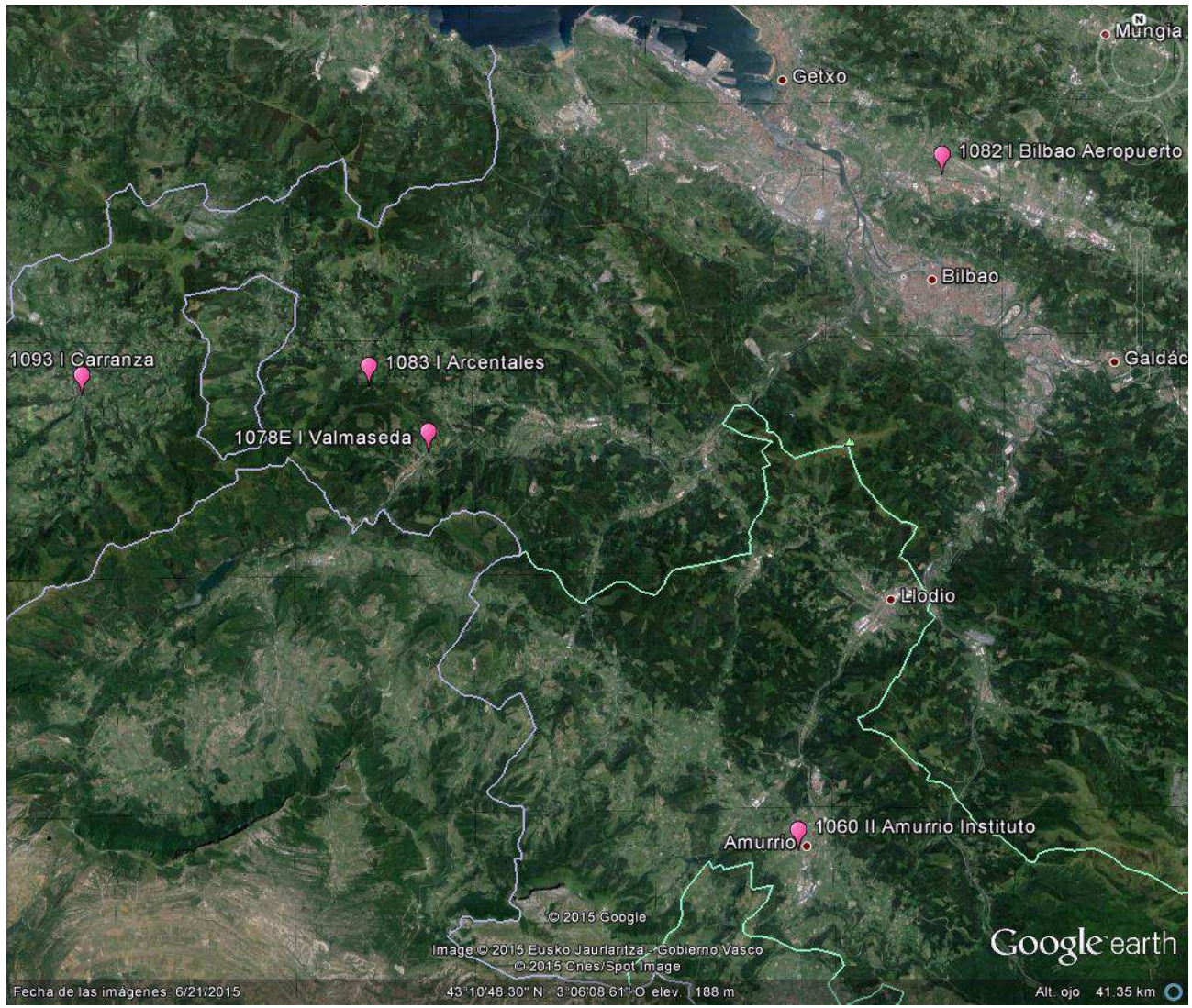

Gráfica 21: Precipitación total anual y mediana de la precipitación total anual $\left(1 / \mathrm{m}^{2}\right)$ de

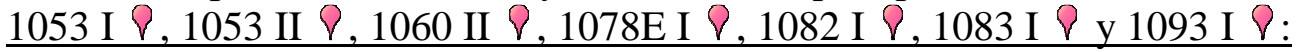

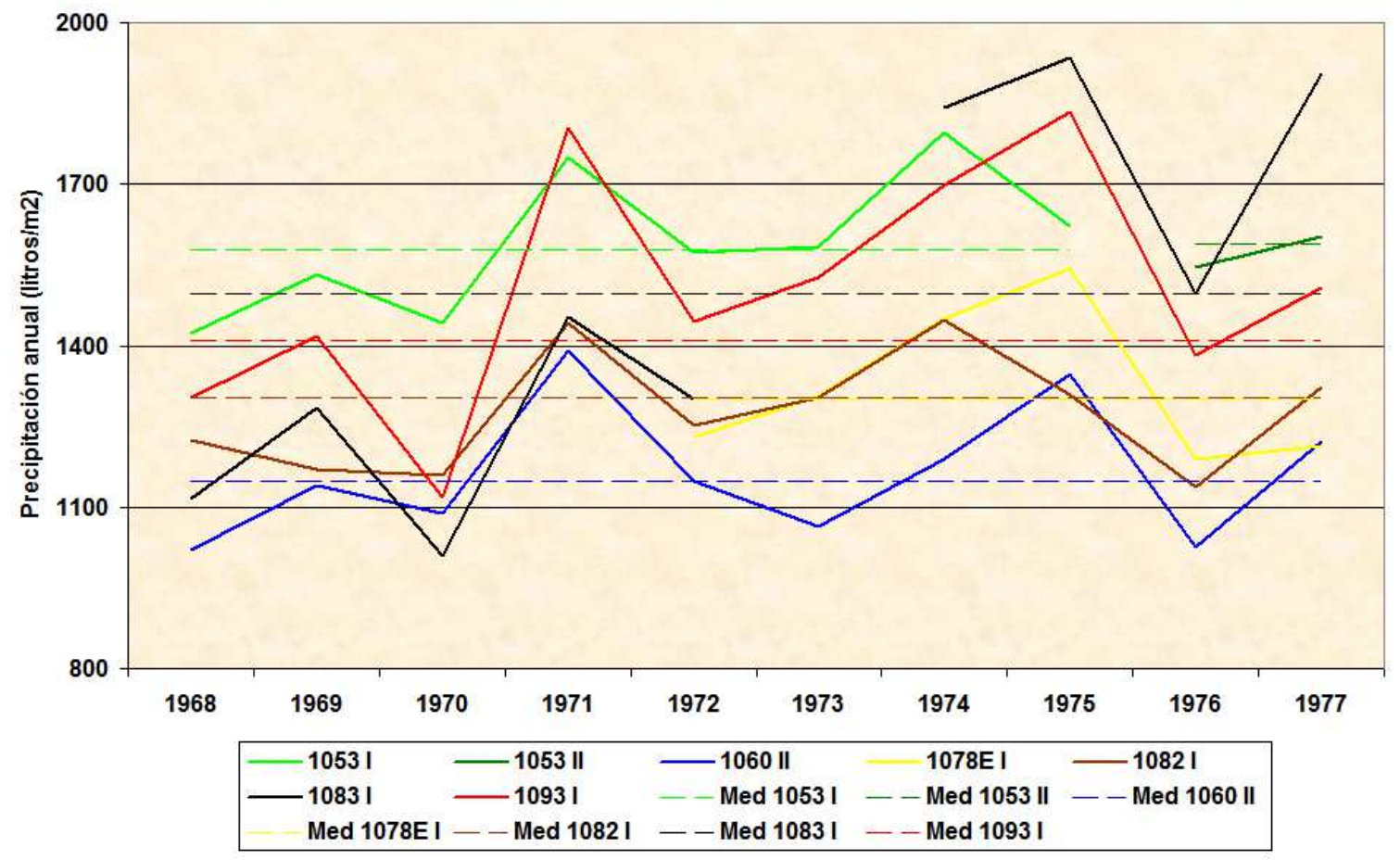


5.1.- La sincronía de los máximos y mínimos pluviométricos es excelente.

5.2.- La evolución de la pluviosidad de 1082 I $\vee$ en 1968 - 1969 y 1974 - 1975 discuerda de la del resto de enclaves: 1082 I 8 antecede al devenir de las demás series.

5.3.- Las precipitaciones apuntadas por el colaborador de $1083 \mathrm{I} \vee$ Arcentales ( $s i n$ datos en Octubre de 1973) acrecen notablemente: De 1968 a 1972, 1083 I $\bigcirc$ es uno de los enclaves con menor cuantía de precipitaciones registradas. De 1974 a 1977, 1083 I muta a ser de los más lluviosos e incluso el más pluvioso en 1975 y en 1977.

Gráfica 22: Razón de las precipitaciones de 1093 I $\nabla$ respecto a 1053 I $\nabla, 1060$ I $\nabla, 1060$ II

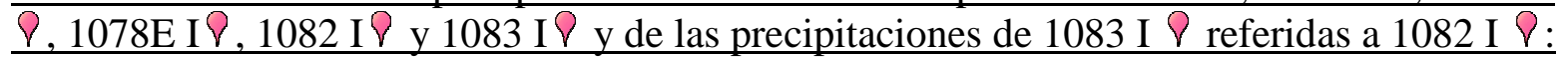

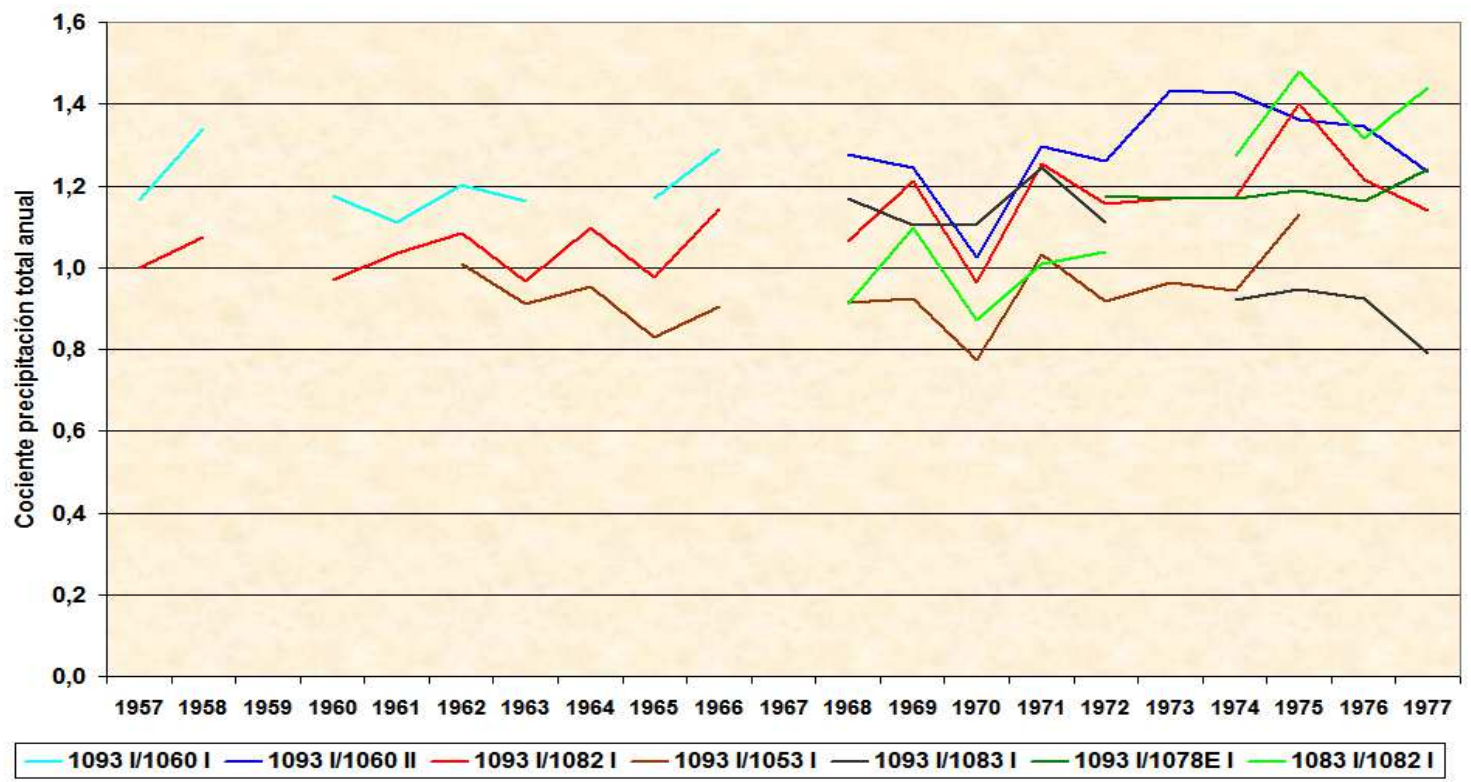

6.1.- El cociente de la precipitación de 1093 I $\vee$ Carranza permanece casi constante (con la excepción de 1975) y disminuye en relación a 1083 I $\vee$, con una euritmia en sus máximos $(1966,1975)$ y mínimos $(1960,1970)$.

6.2.- La razón de las pluviosidades 1083 I $\vee / 1082$ I $\vee$ aumenta tras el incompleto 1973, síntoma de una acrecencia de la precipitación recogida en 1083 I $\vee$, cotejada con la serie de referencia 1082 I $\vee$, sin cambios registrados.

El cociente 1093 I $\nabla / 1083$ I $\vee$ muestra un acrecentamiento de la pluviosidad posterior a 1973 medida en 1083 I 8 comparada con los datos de 1093 I $\nabla$.

6.3.- El cociente de precipitaciones permite detectar rupturas inadvertidas por el análisis con los tests de rachas y de Mann - Kendall y corrobora los resultados de roturas de $\underline{\text { los tests de rachas y de Mann - Kendall. }}$

6.4.- La ruptura de 1083 I $\vee$ en Octubre de 1973 es de un complejo apercibimiento, embebida en el transcurso de la precipitación de 1083 I ₹: Al seco 1968 (tabla 32 bis, página 75), primer año completo de 1083 I $\$$, le sobrevienen los muy pluviosos 1974, 1975, 1978 y 1979 (tabla 32, página 75). 
7.- La gráfica 23 presenta el cociente de la precipitación total anual de 1053 I $\nabla$ y 1053 II $\vee$ Echevarría referido a la precipitación total anual de 1060 II $\vee, 1082$ I $\vee, 1070 \vee$ Abadiano, 1071 P Durango y 1046 IV \& Aránzazu de 1968 a 1983.

Gráfica 23: Razón de las precipitaciones de 1053 I $\vee$ y 1053 II $\nabla$ respecto a 1060 II $\nabla$,

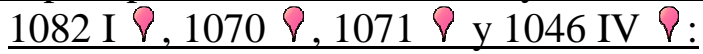

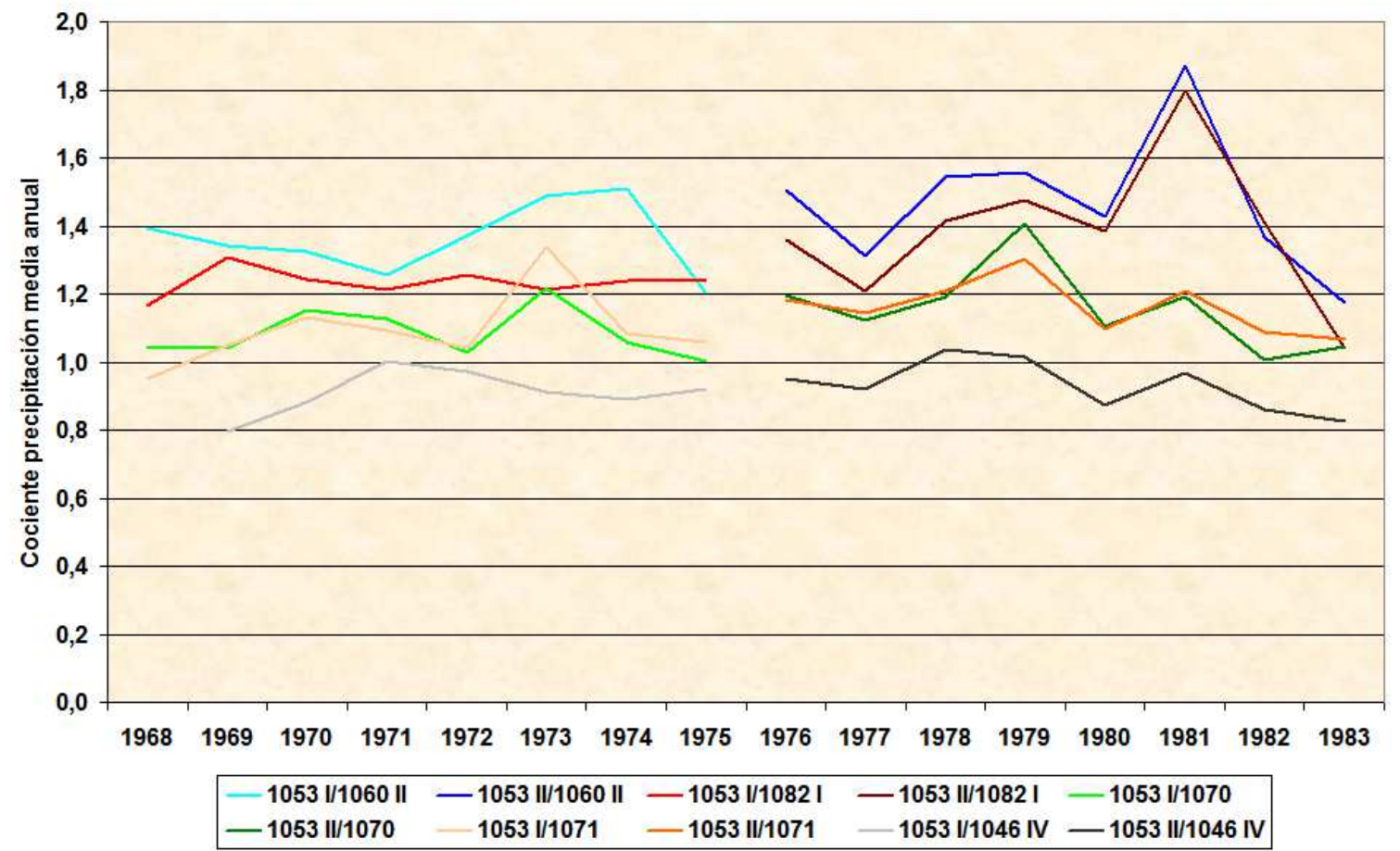

7.1.- La razón de las precipitaciones de 1053 \& Echevarria previa a 1976 (1053 I $\vee$ ) y posterior a 1975 (1053 II $\nabla$ ) con las precipitaciones de las restantes localizaciones es aproximadamente constante.

7.2.- La rotura de $1053 \bigcirc$ es corroborada gráficamente: Las precipitaciones recabadas en $1053 \bigcirc$ ulteriores a 1975 acrecen respecto a las mediciones del resto de lugares.

7.3.- En 1981 las precipitaciones de 1053 II $\nabla$ se "disparan" en comparación con

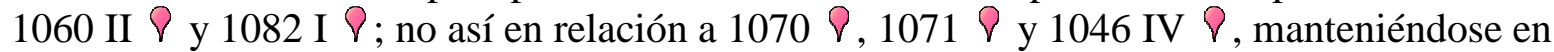
torno a su banda central de fluctuación.

La única comparativa de 1053 II $\vee$ con 1060 II $\vee$ y 1082 I $\nabla$, ignorando a $1070 \nabla$, 1071 y 1046 IV $\vee$, hubiera concluido en calificar de "dudosa" la precipitación anual de 1053 II $\vee$ en 1981. Este hecho vigoriza la importancia de un análisis a una resolución superior a la provincial y es un indicio de características climáticas más parejas entre el Duranguesado, Echevarría 1053 II $\vee$ y Aránzazu 1046 IV $P$.

Por todo lo expuesto, la tendencia de 1973 a 1975 en 1093 I $\vee$, de 1974 a 1975 en 1053 I $\vee$ y en 1975 en 1078E I $\nabla$ se trata de una tendencia "climatológica" y la tendencia de 1083 I $\vee$ de 1975 se califica de "no climatológica". 
1.- La tabla 77 detalla el inicio y los años incompletos de los intersticios sin rupturas de 1068 II $\vee, 1053$ I $\vee, 1053$ II $\vee, 1060$ I $\vee, 1060$ II $\nabla, 1082$ I $\vee, 1093$ I $\vee, 1046$ III $\vee$ y 1046 IV $\vee$.

Tabla 77: Fecha inicio y años incompletos de 1068 II $\nabla, 1053$ I $\nabla, 1053$ II $\nabla, 1060$ I $\nabla$, 1060 II $\vee, 1082$ I $\vee, 1093$ I $\vee, 1046$ III $\vee$ y 1046 IV $\vee$ :

\begin{tabular}{|c|c|c|c|}
\hline Indicativo & Nombre & Comienzo & Años incompletos \\
\hline 1068 II $\nabla$ & Basauri & Final 1954 & 1956 \\
\hline $1053 \mathrm{I} \vee$ & Echevarría & $01-10-1961$ & \\
\hline 1053 II P & Echevarría & Final 1975 & \\
\hline $1060 \mathrm{I} P$ & Amurrio & $01-05-1955$ & 1964 \\
\hline 1060 II $\vee$ & Amurrio & Final 1966 & 1967 \\
\hline $1082 \mathrm{I} \vee$ & Bilbao Aeropuerto & $01-03-1947$ & \\
\hline $1093 \mathrm{I} \vee$ & Carranza & $01-11-1956$ & 1959, 1967 \\
\hline 1046 III 8 & Aránzazu & $01-12-1945$ & $1947,1948,1952$ \\
\hline 1046 IV $P$ & Aránzazu & Final 1968 & \\
\hline
\end{tabular}

2.- La gráfica 24 representa la precipitación total anual y la mediana de la precipitación de las series de la tabla 77 de 1957 a 1978.

Gráfica 24: Precipitación total anual y mediana de la precipitación total anual $\left(1 / \mathrm{m}^{2}\right)$ de 1068 II $\vee, 1053$ I $\vee, 1053$ II $\vee, 1060$ I $\vee, 1060$ II $\vee, 1082$ I $\vee, 1093$ I $\vee, 1046$ III $\vee y$ 1046 IV $P$ :

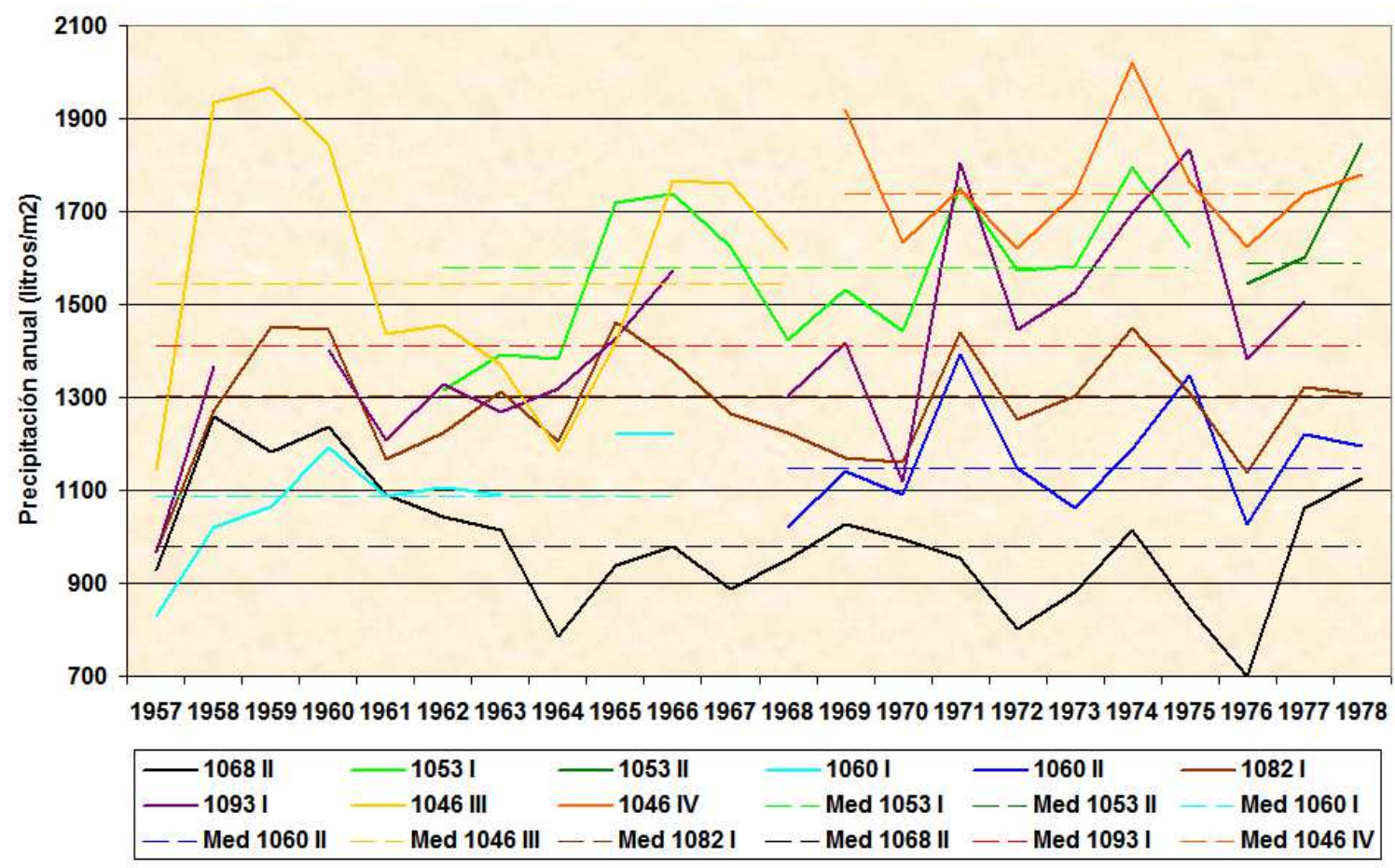


2.1.- La precipitación anotada en 1068 II $\nabla$, de unos valores similares en 1957 y en 1958 a los de 1082 I $\vee$ y de 1093 I $\vee$, decrece con el acontecer del tiempo: A partir de 1962, 1068 II $\nabla$ es el enclave con las menores cuantías de precipitación medidas, alcanzando en 19771093 I $\vee$ un $197 \%$ de las mediciones de 1068 II $\vee$ y 1082 I $\vee$ un $163 \%$.

2.2.- A lo largo del devenir de 1068 II $\vee$, se observa que si bien la cuantía de las precipitaciones disminuye cuando se compara con las series concurrentes más cercanas, los máximos y mínimos pluviométricos 1068 II $\bigcirc$ concuerdan con los extremos de las precipitaciones de las restantes localizaciones.

Tras el significativo mínimo de pluviosidad de 1957 (tabla 32 bis, página 75), las precipitaciones se recuperan en 1958.

En el lapso de 1958 a 1978, las precipitaciones (consideradas las roturas) de la totalidad de ubicaciones fluctúan entre los valores máximos (1959, 1960, 1965 - 1966, 1971, 1974 - 1975 y 1978) y los mínimos $(1957,1968,1970$ y 1976) con la excepción del paulatino y constante decremento de 1068 II $\vee$.

\section{3.- Los máximos y mínimos son congruentes con los resultados de las tablas 32 y} 32 bis (página 75 ).

3.1.- La gráfica 25 expone la razón de la precipitación total anual de 1068 II $P$ Basauri en relación a la precipitación total anual de 1060 II $\vee, 1082$ I 8,1093 I $\vee, 1053$ I P y 1046 IV $\vee$ de 1968 a 1978:

Gráfica 25: Razón de las precipitaciones de 1068 II $\nabla$ de 1968 a 1978 respecto a 1060 II $\vee$, 1082 I $\vee, 1093$ I $\vee, 1053$ I $\odot$ y 1046 IV $\vee:$

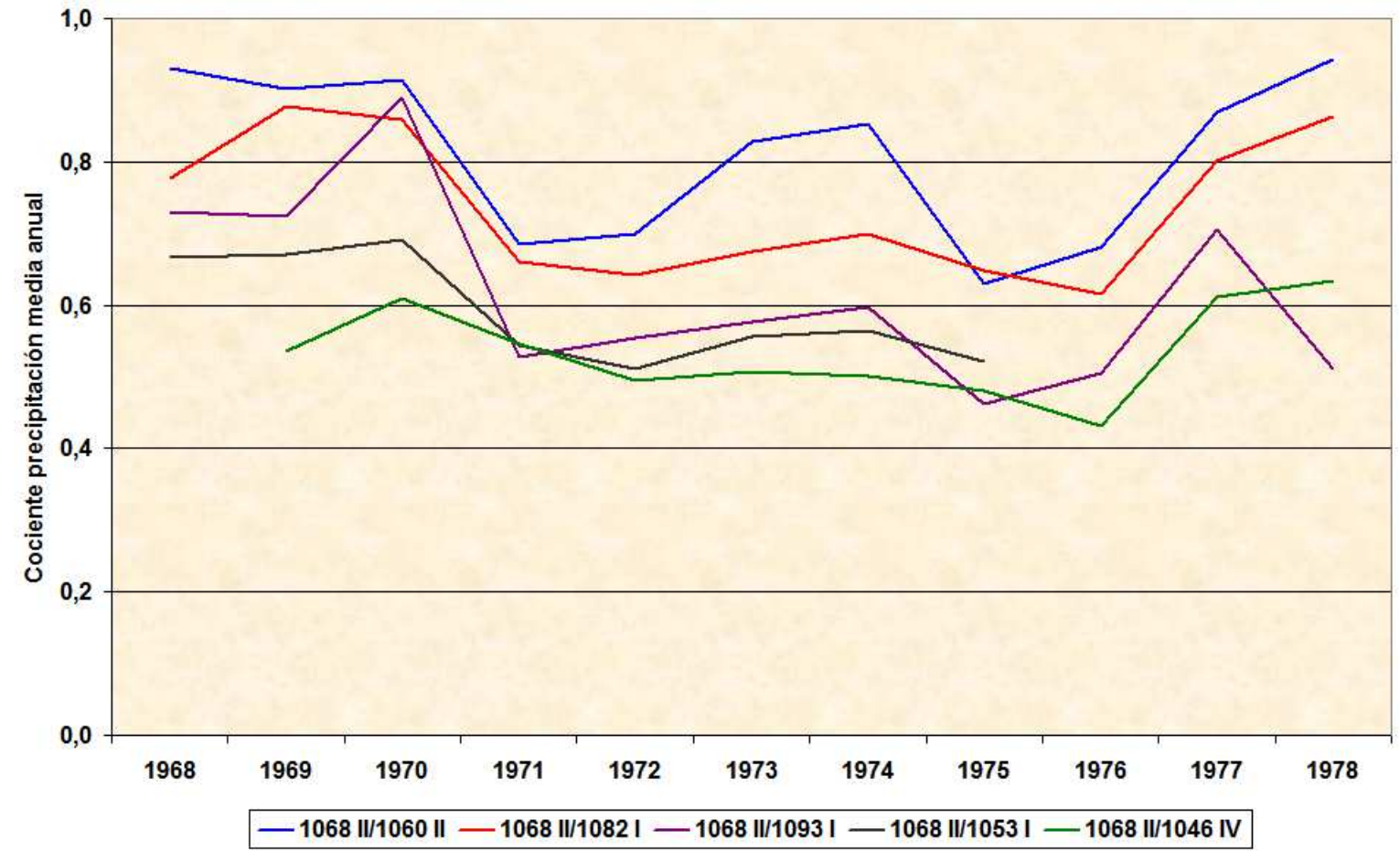


La gráfica 25 no permite un nítido discernimiento de la disminución o constancia del cociente de precipitaciones de 1068 II $\vee$ respecto al resto de series.

4.- La gráfica 26 recoge la razón de la precipitación total anual de 1068 II $\nabla$, incrementando el intervalo temporal de comparación de 1957 a 1978.

Gráfica 26: Razón de las precipitaciones de 1068 II $\nabla$ de 1957 a 1978 respecto a 1060 I $\nabla$, 1060 II $\vee, 1082$ I $\vee, 1093$ I $\vee, 1053$ I $\vee, 1046$ III $\vee$ y 1046 IV $\vee:$

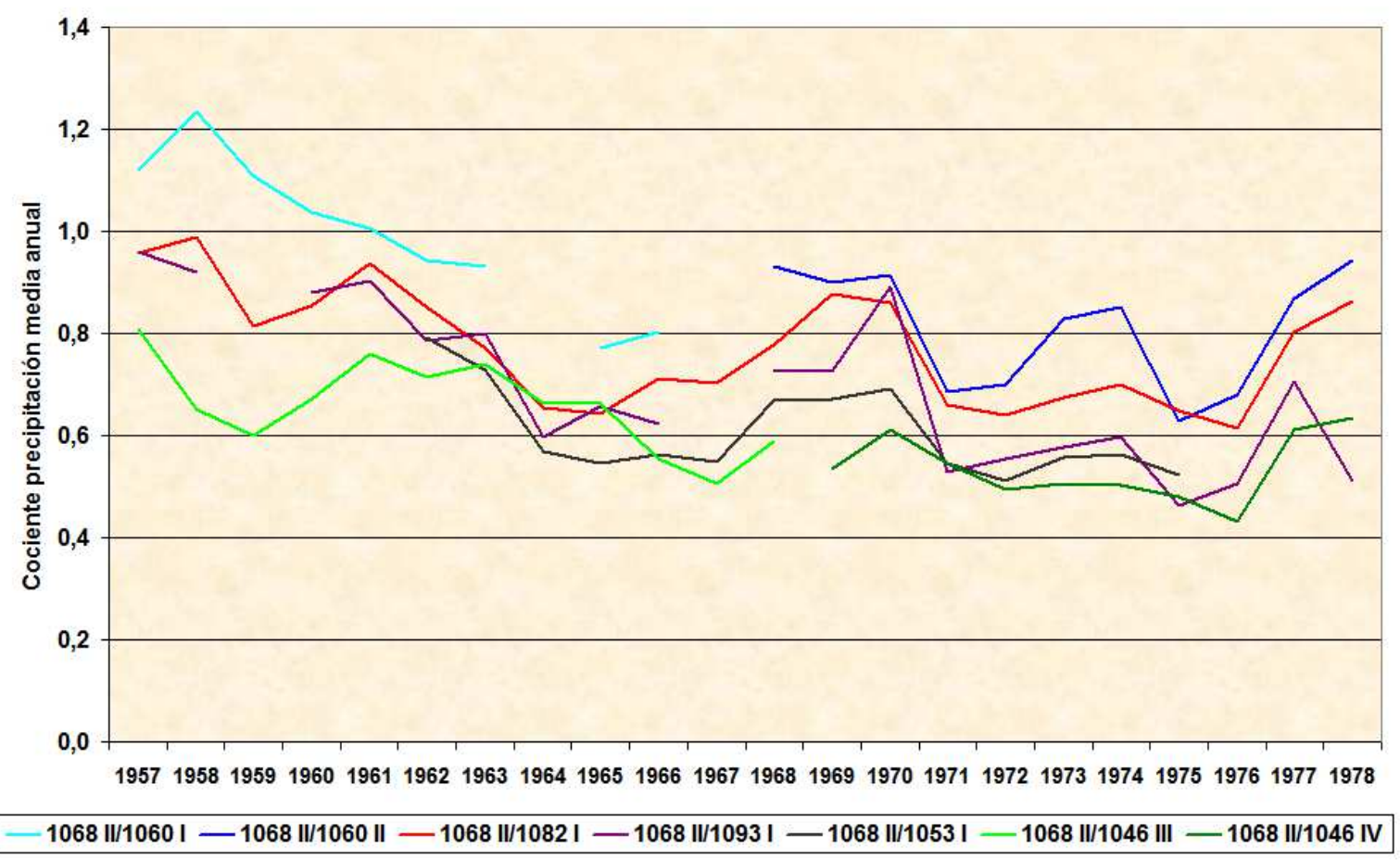

De la gráfica 26, se infiere:

4.1.- El cociente de la precipitación total anual medida en 1068 II $\vee$, respecto a las observaciones de la totalidad de las series coetáneas seleccionadas como referentes, desciende con el transcurrir de los años en las series sin rupturas en este lapso $(1082$ I $\vee, 1093$ I $\vee$ ) y en cada intersticio de las series con roturas $(1060$ I $\vee, 1060$ II $\vee$, 1053 I $\vee, 1046$ III $\vee$ y 1046 IV $\vee$ ).

4.2.- La merma del cociente no es lineal, sino con una cadencia de máximos y mínimos en el cociente cercana a los 9 años. Para un relleno de lagunas, es importante determinar la posición del año a estimar en la euritmia del ciclo.

4.3.- Una suma cautela respecto a la calidad de los datos de precipitación anual de 1068 II $P$.

4.4.- La repercusión de la resolución temporal en el deslinde de cada tendencia en climatológica o no climatológica.

Por tanto, se la cataloga de tendencia "no climatológica.". 
6.- Tendencia positiva de 1976 a 1978 en 1083 y en 1093 , en 1977 en 1075 , en 1979 en 1053,1083 y en 1093 y de 1980 a 1982 en $1093:$

1.- Los valores de 1083 I $\vee$ Arcentales, 1093 I $\vee$ Carranza, 1075 II $\vee$ Dima y 1053 II $\vee$ Echevarría se comparan con los registros de 1053 I $\vee$ Echevarría, 1060 II $\nabla$ Amurrio, $1070 \vee$ Abadiano, 1078E I $\vee$ Valmaseda, 1082 I $\vee$ Bilbao Aeropuerto y 1093A $\vee$ Carranza, las series simultáneas próximas.

La tabla 78 muestra el empiece y los años incompletos de los periodos sin roturas de

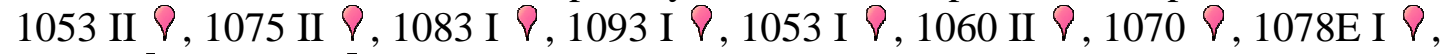
1082 I $\odot$ y $1093 \mathrm{~A} \vee$.

Tabla 78: Fecha inicio y años incompletos de 1053 II $\nabla, 1075$ II $\nabla, 1083$ I $\vee, 1093$ I $\nabla$, 1053 I $\vee, 1060$ II $\vee, 1070 \varnothing, 1078$ E I $\vee, 1082$ I $\vee$ y 1093A $\vee:$

\begin{tabular}{|c|c|c|c|}
\hline Indicativo & Nombre & Comienzo & Años incompletos \\
\hline 1053 II $\nabla$ & Echevarría & Final 1975 & \\
\hline $1075 \mathrm{II} \vee$ & Dima & $01-11-1967$ & \\
\hline $1083 \mathrm{I} 8$ & Arcentales & $01-08-1967$ & 1973 \\
\hline 1093 I 8 & Carranza & $01-11-1956$ & 1959,1967 \\
\hline 1053 I 8 & Echevarría & $01-10-1961$ & \\
\hline 1060 II $P$ & Amurrio & Final 1966 & 1967 \\
\hline $1070 \vee$ & Abadiano & $01-12-1967$ & 1989,1990 \\
\hline 1078E I P & Valmaseda & $01-01-1972$ & 1986 \\
\hline $1082 \mathrm{I} P$ & Bilbao Aeropuerto & $01-03-1947$ & \\
\hline $1093 \mathrm{~A} P$ & Carranza & $01-01-1972$ & $1972-1974,1976,198$ \\
\hline
\end{tabular}

1083 I $\nabla, 1075$ II $\vee, 1060$ II $\vee$ y $1070 \vee$ arrancan en datas cercanas; 1078 E I $\vee$ y 1093A $\vee$ el mismo día.

2.- Una tendencia positiva sincrónica de la precipitación se observa en Guipúzcoa de 1978 a 1983 (tabla 72, página 132).

3.- El examen de la precipitación anual con el test de las rachas (tabla 17, página 50) aflora una inhomogeneidad "climatológica" en 1070 \& y en 1075 II $\vee$ de 1968 a 1977 , en 1079I $\vee$ Gordejuela de 1973 a 1988, en 1078E I $\vee$ de 1975 a 1984 y en 1071 \& Durango de 1975 a 1991.

4.- 1978 y 1979 son años considerablemente lluviosos en $1078 \mathrm{E}$ I $\vee$ y en 1093 I $\nabla$, 1979 en 1079I $\vee, 1060$ II $\vee$ y 1053 II $\vee$ (tablas 26, 27 y 28, páginas 63, 65 y 68).

5.- La gráfica 27 refiere la precipitación total anual y la mediana de $1053 \mathrm{I} \nabla$,

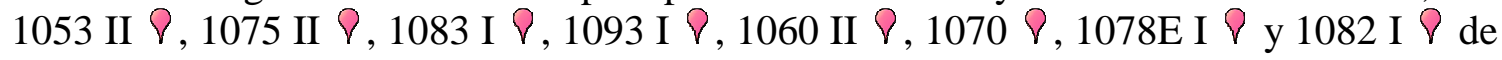
1968 a 1983. 
Gráfica 27: Precipitación total anual y mediana de la precipitación total anual $\left(1 / \mathrm{m}^{2}\right)$ de 1053

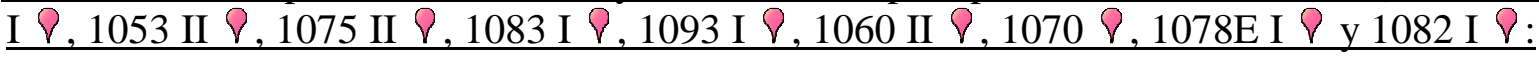

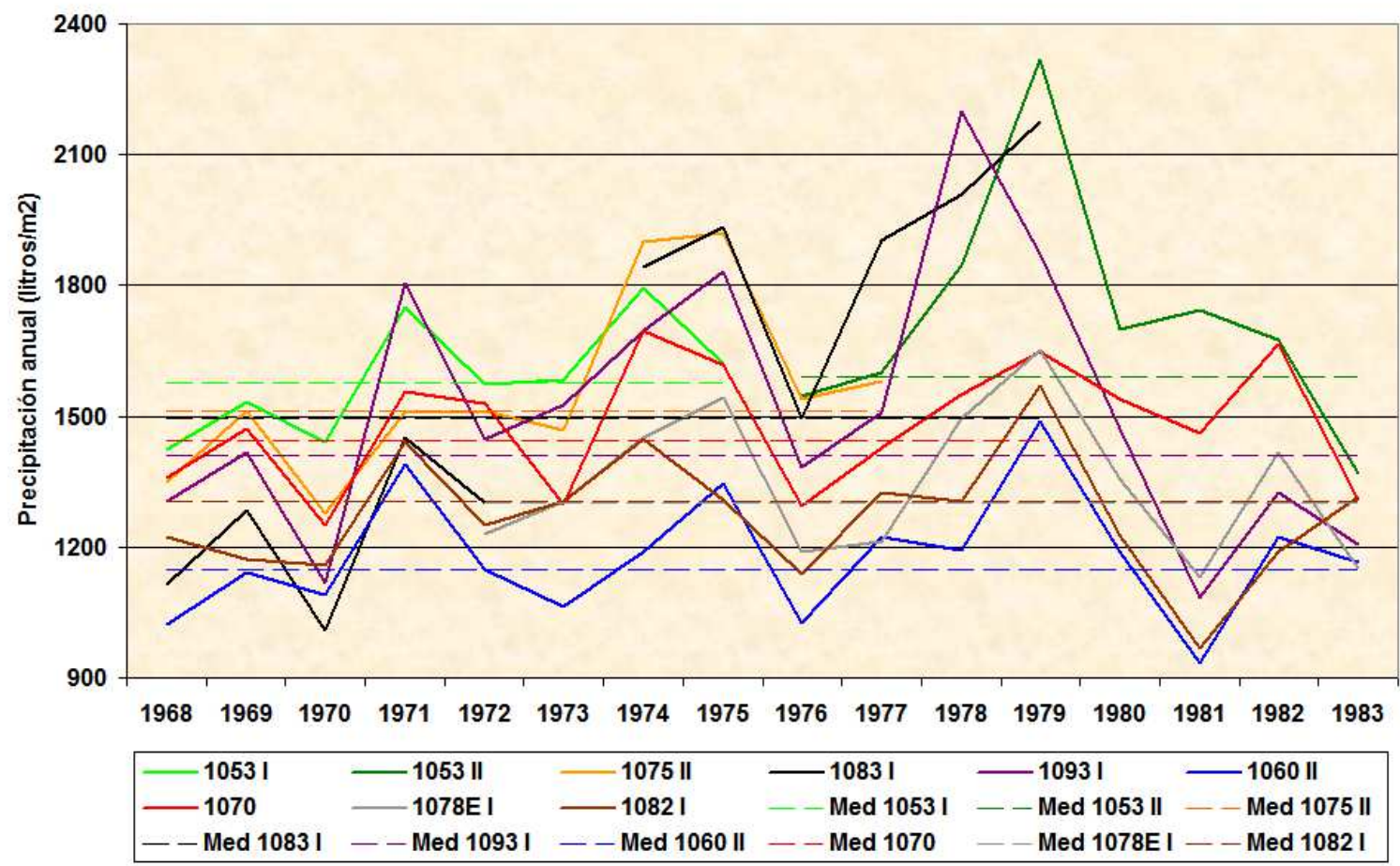

La gráfica 27 denota la precipitación total anual con segmentos continuos; con segmentos discontinuos, la mediana en los intervalos entre las rupturas de cada serie.

De la gráfica 27 se colige:

\section{1.- Las precipitaciones aumentan de Oeste a Este.}

5.2.- Los máximos pluviométricos coincidentes de 1971, 1974 - 1975, 1978 - 1979 concuerdan con los expuestos en la tabla 32 (página 75). La tendencia positiva espulgada es coherente con dichos años de elevada pluviometría.

5.3.- Los años de sequías concurren en 1968, 1970, 1976 y 1981, corroborando los resultados de la tabla 32 bis (página 75).

5.4.- La precipitación anual de 1983 respecto a la de 1982 acrece en 1082 I $\nabla$ y mengua en el resto de enclaves, anticipando el carácter muy lluvioso de 1984.

5.5.- El acrecentamiento "no climatológico" de la pluviosidad de 1083 I $\bigcirc$ ulterior a 1973, incremento descrito en los comentarios de las gráficas 21 y 22 (páginas 143 y 144).

5.6.- La década de los años 70 es muy pluviosa: Las precipitaciones rebasan las medianas de las series de datos, exceptuando los 2 años secos de 1973 y 1976. 
6.- La gráfica 28 ilustra el cociente de la precipitación total anual de 1093 I $\vee$ Carranza respecto a la precipitación total anual de 1053 II $\vee, 1060$ II $\vee, 1075$ II $\vee$, 1078E I $\vee, 1082$ I $\vee, 1083$ I $\vee$ y 1093A $\vee$ de 1968 a 1983.

Gráfica 28: Razón de las precipitaciones de 1093 I $\nabla$ de 1968 a 1983 respecto a 1060 II $\nabla$, 1078E I $\vee, 1082$ I $\vee, 1083$ I $\vee, 1075$ II $\vee, 1053$ II $\vee$ y 1093A $\vee:$

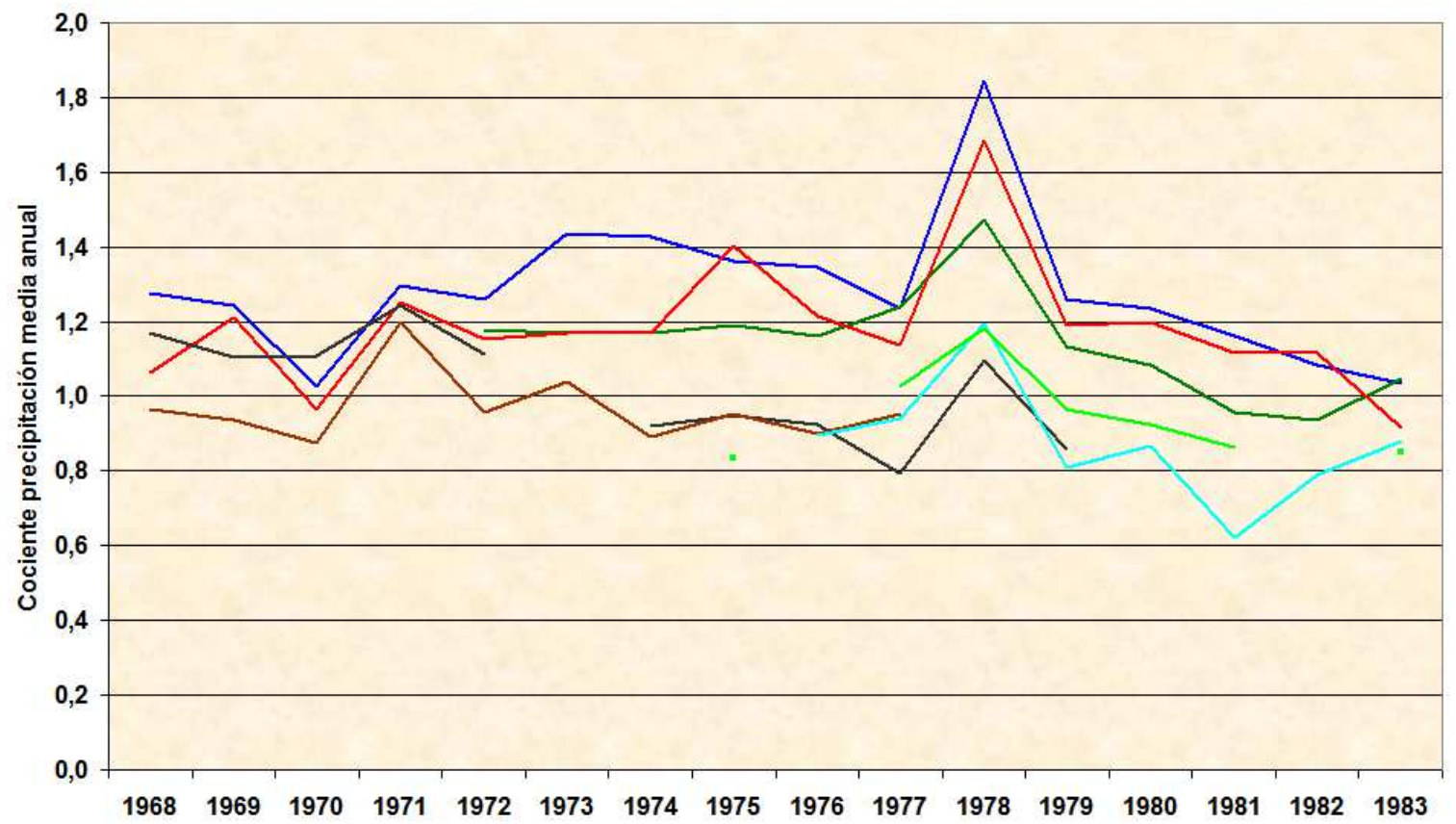

$-1093 \mathrm{I} / 1060 \mathrm{II}-1093 \mathrm{I} / 1078 \mathrm{E} \mathrm{I}-1093 \mathrm{I} / 1082 \mathrm{I}-1093 \mathrm{I} / 1083 \mathrm{I}-1093 \mathrm{I} / 1075 \mathrm{II}-1093 \mathrm{I} / 1053 \mathrm{II}-1093 \mathrm{I} / 1093 \mathrm{~A}$

De la gráfica 28, se aprecia:

6.1.- El cociente de las precipitaciones de 1093 I $\nabla$ es constante, con unos valores semejantes en 1968 y 1979 y una periodicidad en los mínimos del cociente ligeramente superior a 10 años (1970 y 1981 - 1982), excepto en 1978 debido a las intensas precipitaciones apuntadas por el colaborador de 1093 I $\nabla$ en Enero de 1978.

La evolución de las medidas de 1093 I $\nabla$ referida a las recabadas en el resto de enclaves es pareja, con la salvedad de 1978.

6.2.- Cuán importante es la resolución espacial: El cotejo de 1093 I $\vee$ únicamente con 1082 I $\vee$ y 1060 II $\nabla$ colegiría la espuria conclusión de calificar de dudosas las precipitaciones de 1093 I $\vee$ ulteriores a 1978.

La inclusión de 1078E I $\vee, 1053$ II $\nabla$ y, en especial, de 1093A $\nabla$ valida la calidad de los datos de 1093 I $P$.

6.3.- La correlación de 1093 I $\vee$ es mejor con 1078E I $\vee$ y $1093 \mathrm{~A} \vee$, ubicadas en la misma comarca de las Encartaciones. 
7.- La gráfica 29 refleja la razón de la precipitación total anual de 1968 a 1979 de 1083 I $\nabla$ Arcentales respecto a la precipitación total anual de 1060 II $\vee, 1070 \varnothing, 1075$ II $\vee$, 1078 E I $\nabla$ y 1082 I $\vee$ y el cociente de 1075 II $\nabla$ Dima con 1060 II $\vee, 1070 \vee$ y 1082 I $\nabla$.

Gráfica 29: Razón de las precipitaciones de 1083 I $\vee$ y 1075 II $\vee$ respecto a 1060 II $\vee, 1070$ P, 1078E I $\vee$ y 1082 I $\vee$ y de las precipitaciones de 1083 I $\varnothing$ en relación a 1075 II $\vee$ :

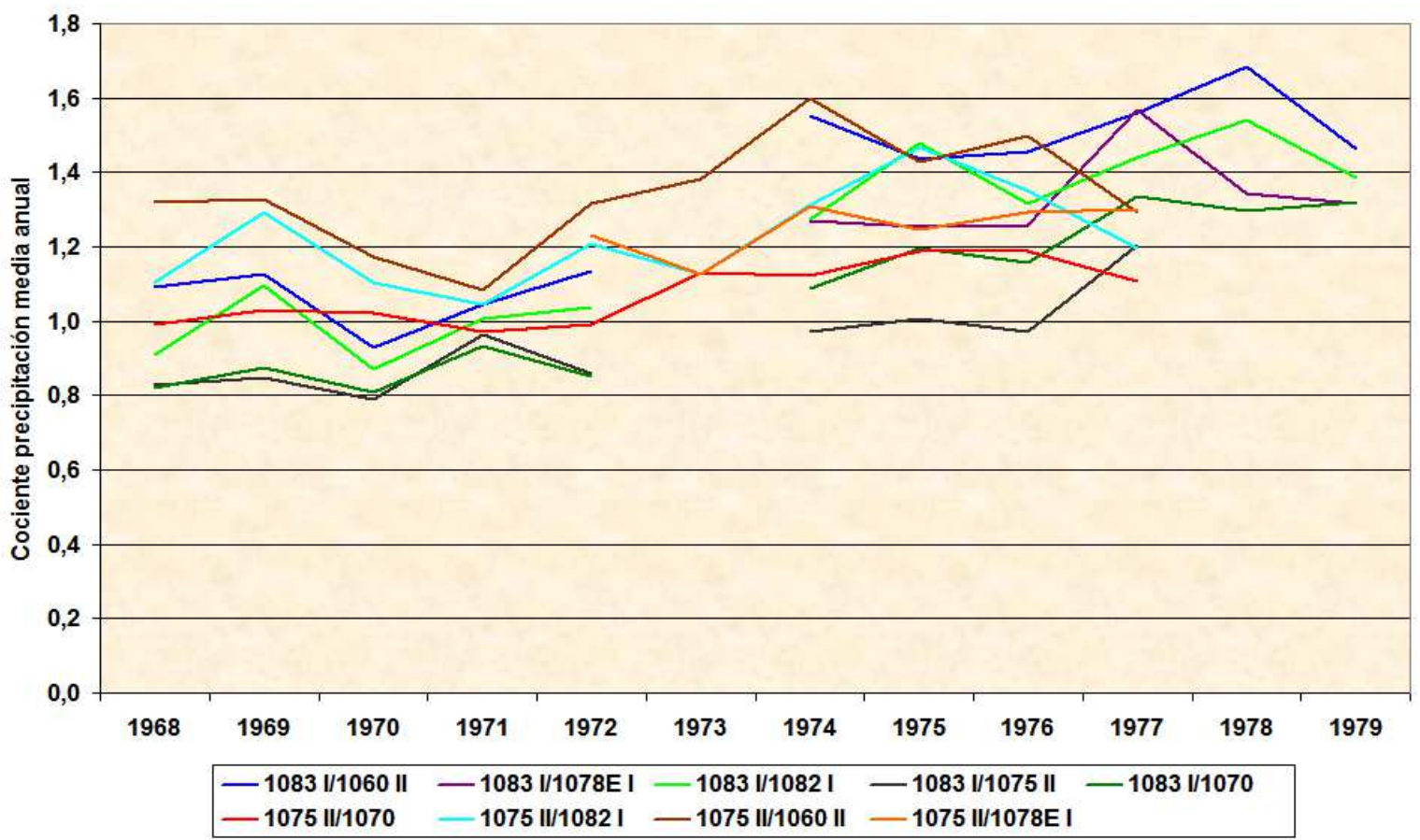

7.1.- El cociente de 1083 I $\vee$ en 1973 se omite por su carencia de datos en Octubre de 1973.

7.2.- El cociente de las precipitaciones medidas en 1083 I $\vee$ en contraposición a las cuantías en las restantes ubicaciones aumenta, en clara oposición a los resultados de 1093 I $\nabla$ expuestos en la gráfica 28.

7.3.- La razón de las precipitaciones de 1075 II $\nabla$ respecto a las cuantías de $1070 \nabla$, 1082 I $\nabla$ y 1060 II $\nabla$ no acrece en el intervalo de 1968 a 1977.

7.4.- La tendencia positiva "no climatológica" de 1083 I $\vee$ es de difícil detección en un somero análisis sin una representación gráfica ni una comparativa de los cocientes de precipitación, encubierta en el incremento de precipitación de 1978 y 1979, los años más lluviosos de las series en sus lapsos entre rupturas.

Por consiguiente, la tendencia de 1976 a 1978 en 1093 I $\nabla$, en 1977 en 1075 II $\nabla$, en 1979 en 1053 II $\nabla$ y en 1093 I $\nabla$ y de 1980 a 1982 en 1093 I $\vee$ es una tendencia "climatológica" y la tendencia de 1083 I $\vee$ de 1978 y 1979 se cataloga de tendencia "no climatológica.". 
7.- Tendencia negativa en 1985 , en 1987 y en 1989 en 1083 y negativa de 1987 a 1988 en 1079I y en 1093A:

1.- Las anotaciones pluviométricas de 1083 II $\vee$ Arcentales, 1079I $\vee$ Gordejuela y 1093A $\nabla$ Carranza se contrastan con las mediciones de 1053 II $\vee$ Echevarría, 1060 II $\vee$ Amurrio, 1075E II $\vee$ Aránzazu, 1078E I $\vee$ Valmaseda, 1082 I $\vee$ y 1082 II $\vee$ Bilbao Aeropuerto.

La tabla 79 recoge la fecha de inicio y los años sin plenitud de datos de los intersticios sin rupturas de 1083 II $\nabla, 1079$ I $\nabla, 1093 \mathrm{~A} P, 1053$ II $\nabla, 1060$ II $\nabla$, 1075E II $\vee, 1078$ E I $\vee, 1082$ I $\vee$ y 1082 II $\vee$ y tiene presente la rotura de $1082 \bigcirc$ Bilbao Aeropuerto del 27 de Noviembre de 1984 (páginas 31 y 32).

Tabla 79: Fecha inicio y años incompletos de 1083 II $\vee, 1079 \mathrm{I} \vee, 1093 \mathrm{~A} \vee, 1053$ II $\vee$, 1060 II $\vee, 1075$ E II $\vee, 1082$ I $\vee, 1082$ II $\vee$ y 1078 E I $\vee:$

\begin{tabular}{|c|c|c|c|}
\hline Indicativo & Nombre & Comienzo & Años incompletos \\
\hline 1083 II $\nabla$ & Arcentales & $01-02-1981$ & 1988,1990 \\
\hline 1079I $\varnothing$ & Gordejuela & $01-06-1972$ & 1976,1981 \\
\hline $1093 \mathrm{~A} \nabla$ & Carranza & $01-01-1972$ & $1972-1974,1976,1982$ \\
\hline $1053 \mathrm{II} P$ & Echevarría & Final 1975 & \\
\hline $1060 \mathrm{II} P$ & Amurrio & Final 1966 & 1967 \\
\hline 1075E II $P$ & Aránzazu & Final 1981 & 1991, 1993, 1997, 2005 \\
\hline $1078 \mathrm{E} \mathrm{I} 8$ & Valmaseda & $01-01-1972$ & 1986 \\
\hline $1082 \mathrm{I} P$ & Bilbao Aeropuerto & $01-03-1947$ & \\
\hline 1082 II $P$ & Bilbao Aeropuerto & $27-11-1984$ & 2000 \\
\hline
\end{tabular}

2.- Esta tendencia emerge únicamente en las Encartaciones.

3.- Una tendencia negativa coetánea aflora en Guipúzcoa en 1985 y en 1987 en 1025E $\vee$ Mutiloa y en 1989 en 1024 II $\vee$ Ategorrieta (tabla 72, página 132).

4.- El análisis de la precipitación anual con el test de las rachas (tabla 17, página 50) revela una inhomogeneidad "climatológica" en 1079I $\vee$ de 1973 a 1988, en 1078E I $\vee$ de 1975 a 1984 y de 1977 a 1990, en 1071 P Durango de 1975 a 1991, en 1053 II $\vee$ de 1979 a 1993 y en 1070 P Abadiano de 1979 a 1997.

5.- La gráfica 30 exterioriza la precipitación total anual y la mediana de $1060 \mathrm{II} \nabla$, 1075E II $\vee, 1078$ E I $\nabla, 1079$ I $\vee, 1082$ I $\vee, 1082$ II $\vee, 1083$ II $\nabla$ y 1093A $\vee$ de 1980 a 1993 .

La gráfica 30 expone la precipitación total anual con líneas continuas; con líneas discontinuas, la mediana en los intervalos entre roturas de cada serie. 
Gráfica 30: Precipitación total anual y mediana de la precipitación total anual $\left(1 / \mathrm{m}^{2}\right) \mathrm{de}$

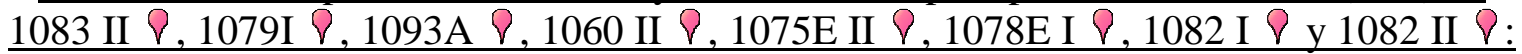

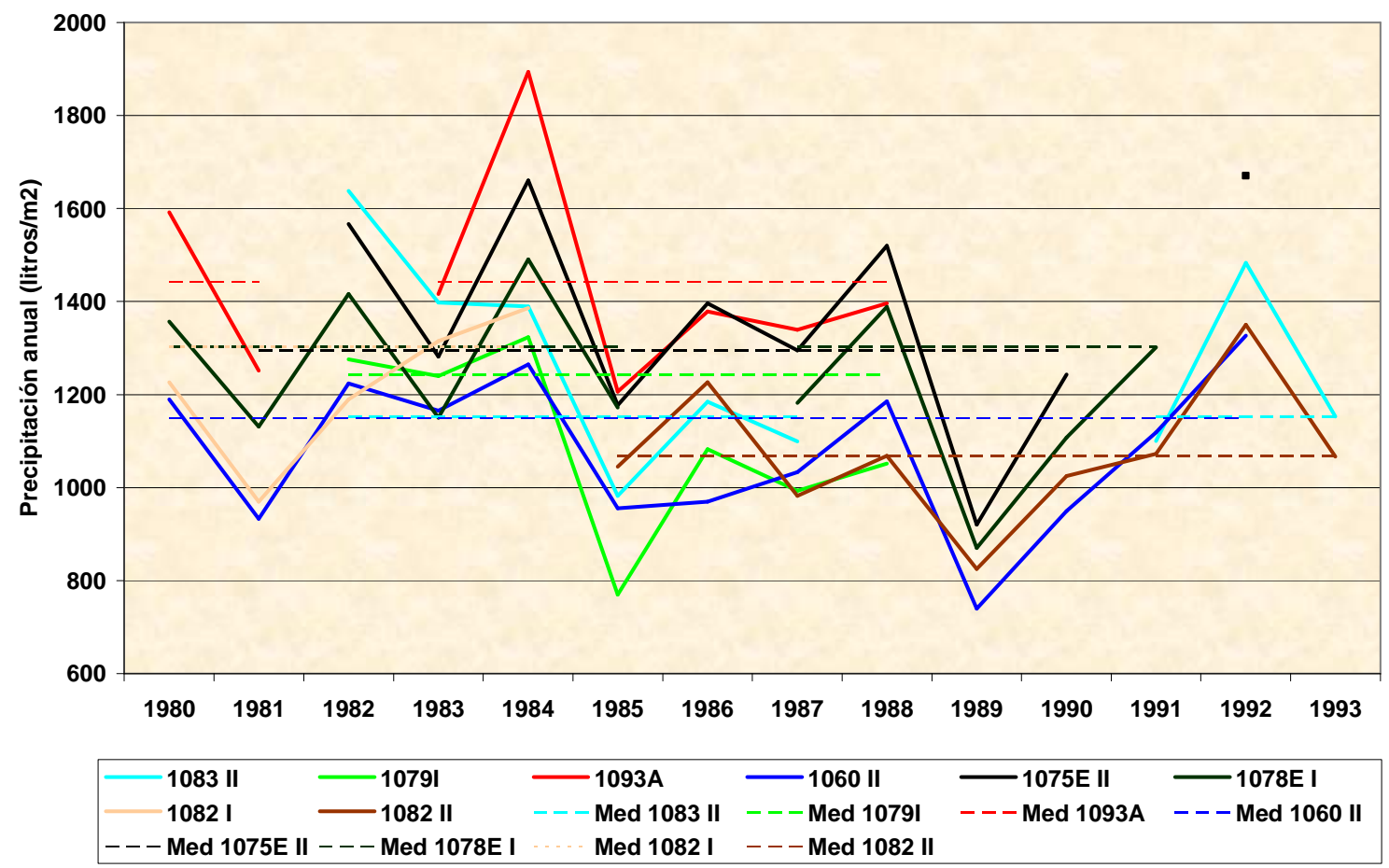

La gráfica 30 representa con un trazo continuo la precipitación total anual y mediante trazo discontinuo la mediana en el intersticio temporal entre rupturas de cada serie.

De la gráfica 30, se advierte:

5.1.- Al muy pluvioso 1984 le suceden los secos 1985 a 1991 con precipitaciones inferiores a las respectivas medianas y un descenso pluviométrico acusado en 1985 y 1989, decrecimiento con las excepciones de 1986 y 1988.

5.2.- Los máximos de precipitación se corresponden en 1984, 1986 y 1992 , consonantes con los recogidos en la tabla 32 (página 75).

5.3.- Los mínimos pluviométricos de 1981, 1985 y 1989 son acordes con los resultados de la tabla 32 bis (página 75) y concordes con la tendencia negativa analizada.

5.4.- Se aprecia un decremento de la precipitación en 1082 II $\nabla$ respecto a 1082 I $\nabla$, coincidente con la rotura documentada del 27 de Noviembre de 1984.

5.5.- Transcurrido 1982, 1083 II $\nabla$ retorna a situarse en una posición intermedia en el ranking de precipitación anual. 
6.- La gráfica 31 ostenta el cociente de la precipitación total anual de 1083 II $\nabla$ Arcentales de 1982 a 1993 referido a la precipitación total anual de 1060 II $\nabla, 1075 \mathrm{E}$ II $\nabla$, 1079I $\vee, 1082$ I $\vee, 1082$ II $\vee$ y 1093A $\vee$ de 1982 a 1993.

\section{Gráfica 31: Razón de las precipitaciones de 1083 II $\nabla$ respecto a 1060 II $\nabla, 1075 E$ II $\nabla$,} 1079I $P, 1082$ I $\vee, 1082$ II $\vee$ y 1093A $\vee$ :

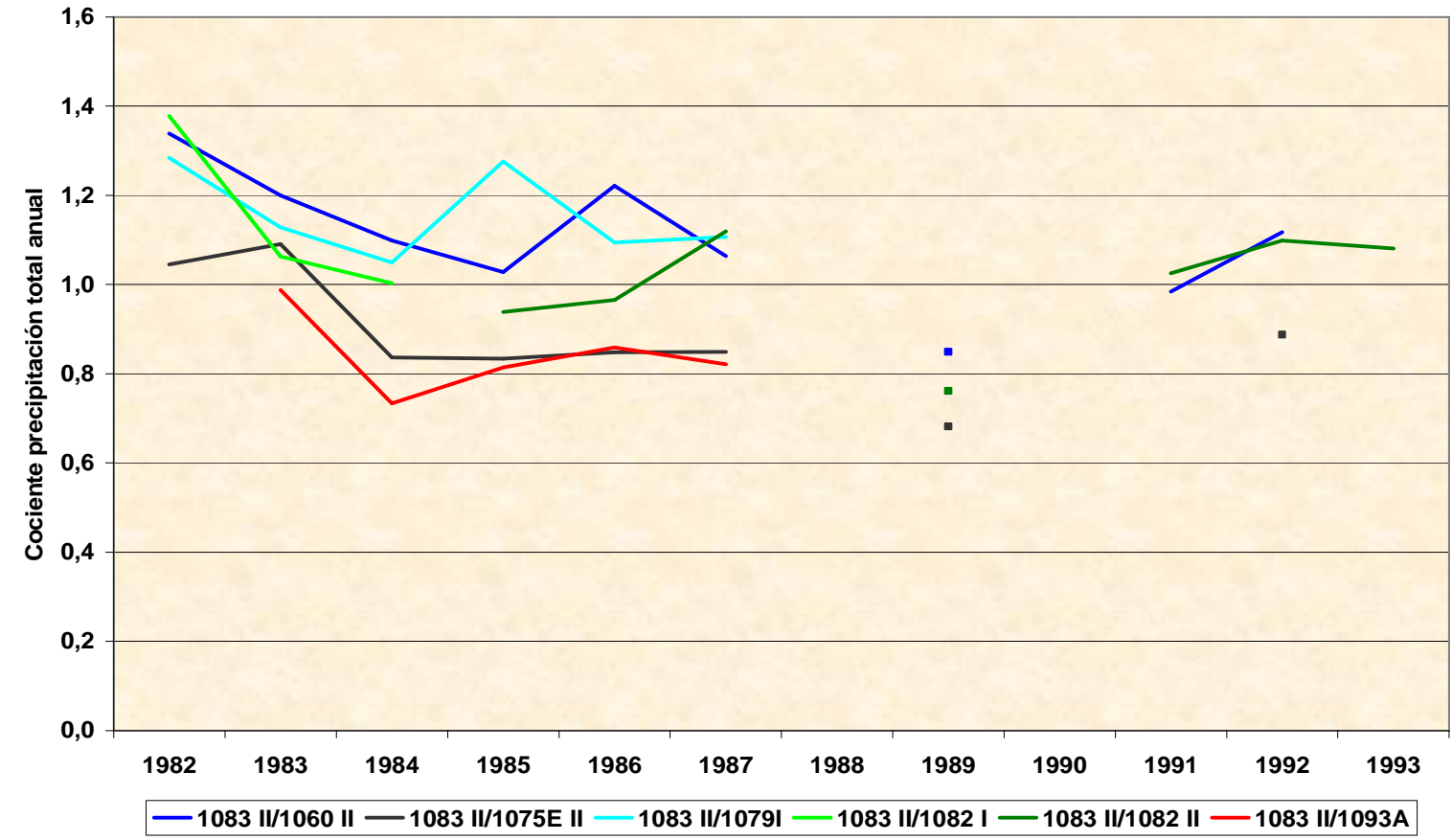

Los cocientes de 1988 y de 1990 son excluidos, por la carencia de datos completos de precipitación anual en 1083 II $P$.

De la gráfica 31 se concluye: de enclaves.

6.1.- La precipitación de 1083 II $\vee$ es de una cuantía pareja a la recabada en el resto

6.2.- El cociente de las precipitaciones de 1083 II $\nabla$ alcanza en este intersticio sus valores mínimos en los años secos $(1985,1989)$ (gráfica 30 y tabla 32 bis) y los máximos en los años lluviosos $(1992,1986)$.

7.- La gráfica 32 expone el cociente de la precipitación total anual de 1973 a 1988 de 1079I $\vee$ Gordejuela y 1093A $\vee$ Carranza ligada a la precipitación total anual de 1060 II $\vee$, 1078E I $\nabla, 1053$ II $\vee$ y 1093A $\nabla$ y la razón de 1093A $\nabla$ en relación a 1060 II $\vee$, 1078E I $\vee$ y 1053 II $\vee$ de 1973 a 1998. 
Gráfica 32: Razón de las precipitaciones de 1079I $\vee$ y 1093A $\vee$ respecto a 1060 II $\nabla$, 1078E I $\vee$ y 1053 II $\vee$ :

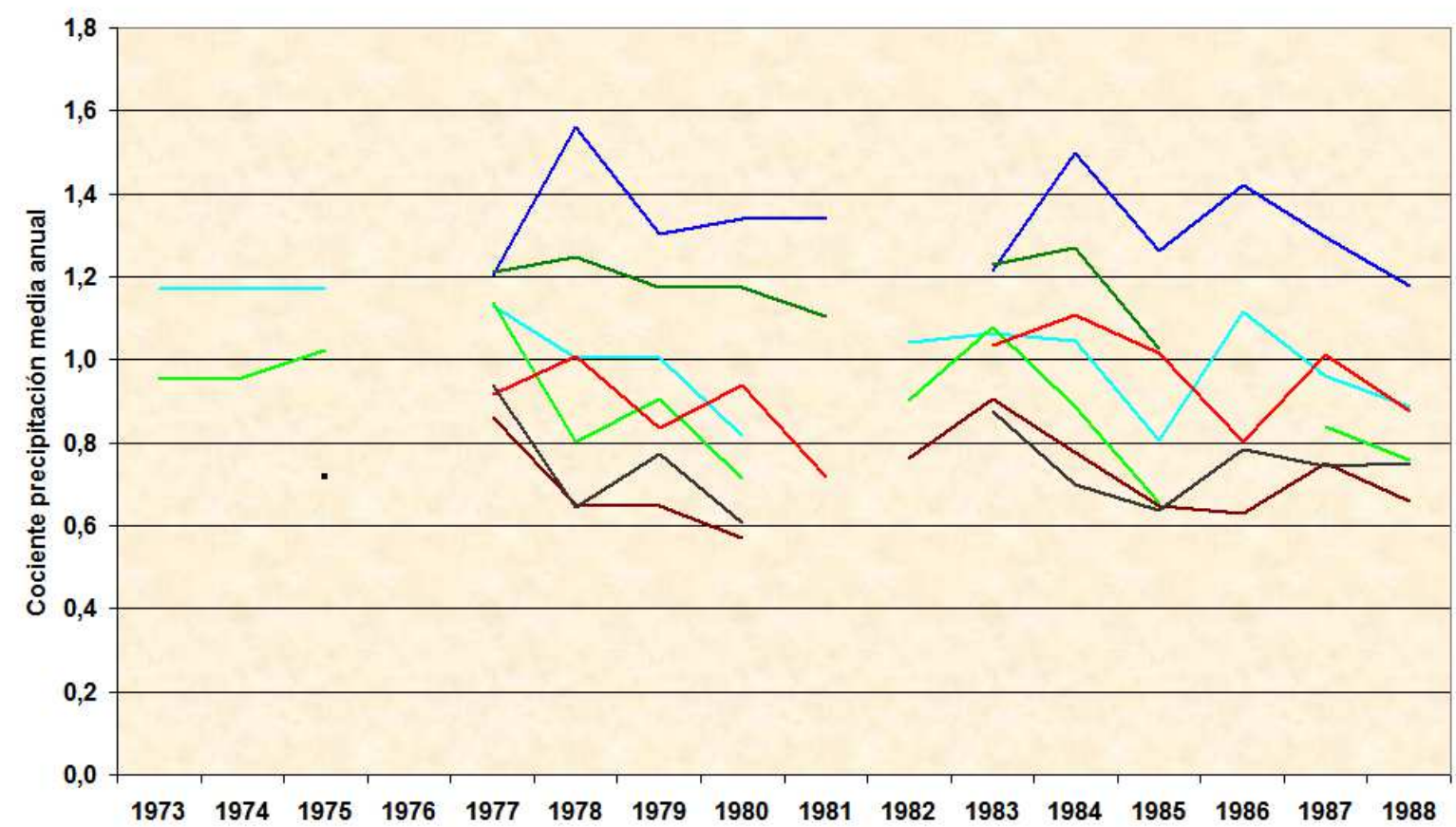

1079I /1060 || -1093A/1060 II -1079I/1078E I -1093A/1078E I - 1079I/1053 || -1093A/1053 || - 1079I/1093A

7.1.- 1976 es un año sin la integridad de los datos pluviométricos en 1079I $\nabla$ y 1093A $\vee$, por lo cuál se soslaya su cociente en la gráfica 32.

7.2.- La comparativa de $1079 \mathrm{I} \vee$ y de $1093 \mathrm{~A} \vee$ con 1060 II $\nabla$ y $1078 \mathrm{E}$ I $\nabla$, las series coetáneas más próximas sin rupturas de 1972 a 1988, muestra una fluctuación de la razón de las precipitaciones en torno a un valor constante.

7.3.- El cotejo de las pluviosidades de 1079I $\nabla$ y de 1093A $\nabla$ con las cuantías de 1053 II 8 , la serie sincrónica de Vizcaya y de la vertiente cantábrica de Álava más alejada a la comarca de las Encartaciones, revela una estabilidad del cociente de precipitaciones.

7.4.- La confrontación de 1079I P con 1093A P, ambas en las Encartaciones, arroja un transcurrir constante de la razón de su precipitación a lo largo del tiempo.

7.5.- El cociente de 1093A $\curlyvee$, la más pluviosa de las series escrutadas en las gráficas 30 y 32, alcanza máximos en 1978 y en 1984 y mínimos en 1981 y en 1985 correspondientes con los máximos y mínimos de precipitación de las tablas 32 y 32 bis, amago de una euritmia refleja de la cadencia propincua al decenio en la precipitación.

$\underline{\text { Los años lluviosos llueve más en la pluviosa ubicación de 1093A. }}$

Por tanto, se trata de una tendencia "climatológica". 
8.- Tendencia negativa de 1990 a 1991 en 1053 y en 9077E, negativa en 1991 en 1083 , negativa de 1993 a 1995 en 9077E, negativa en 1995 en $1078 \mathrm{E}$ y en 1053 , negativa en 1996 en 1053 y positiva en 1996 en $1057 \mathrm{E}$ :

1.- Las mediciones de 1053 II $\nabla$ Echevarría, 9077E II $\nabla$ Ochandiano, 1083 II $\nabla$ Arcentales, 1078E II $\vee$ Valmaseda y 1057E I $\vee$ Baquio se contraponen con los registros de 1049U $\vee$ Ermua, 1055A I $\nabla$ Lequeitio Agustinas, 1060 II $\vee$ y 1060 III $\$$ Amurrio Instituto y 1082 II $\vee$ Bilbao Aeropuerto.

La tabla 80 expone la fecha de arranque y los años no íntegros de precipitación de los lapsos sin rupturas de 1049U $\nabla, 1053$ II $\nabla, 1055$ A I $\vee, 1057 \mathrm{E} \vee, 1060$ II $\varnothing$, 1060 III $\&, 1078$ E II $\nabla, 1082$ II $\vee, 1083$ II $\vee$ y 9077E II $\vee$.

Tabla 80: Fecha inicio y años incompletos de 1049U $\nabla, 1053$ II $\nabla, 1055$ A I $\vee, 1057 E$ I $\varnothing$, 1060 II $\vee, 1060$ III $\$, 1078$ E II $\vee, 1082$ II $\vee, 1083$ II $\vee$ y 9077E II $\vee$ :

\begin{tabular}{|c|c|c|c|}
\hline Indicativo & Nombre & Comienzo & Años incompletos \\
\hline $1053 \mathrm{II} \vee$ & Echevarría & Final 1975 & \\
\hline 9077E II $\varnothing$ & Ochandiano & $01-08-1973$ & $1974,1975,1977,1985,1992$ \\
\hline 1083 II P & Arcentales & $01-02-1981$ & 1988,1990 \\
\hline $1078 \mathrm{E} \mathrm{II} 8$ & Valmaseda & $28-12-1991$ & 2006 \\
\hline 1057E I $\varnothing$ & Baquio & $01-04-1986$ & 1991, 1992, 1993, 1995 \\
\hline $1049 U$ P & Ermua & $01-10-1982$ & \\
\hline $1055 \mathrm{~A} \mathrm{I} P$ & Lequeitio Agustinas & $01-04-1986$ & 1991, 1992, 1996, 2002 \\
\hline 1060 II 8 & Amurrio & Final 1966 & 1967 \\
\hline 1060 III 8 & Amurrio & Final 1992 & \\
\hline 1082 II $\vee$ & Bilbao Aeropuerto & $27-11-1984$ & 2000 \\
\hline
\end{tabular}

2.- Una tendencia negativa concurrente es detectada en Guipúzcoa en 1995 en 1038 Beizama (tabla 72, página 132).

3.- El examen del test de las rachas de la precipitación anual señala una inhomogeneidad "climatológica" en 1053 II $\nabla$ de 1979 a 1993, en 1070 \& Abadiano de 1979 a 1997 y en 1055A I $\nabla$ de 1987 a 2000 y de 1993 a 2005 (tabla 17, página 50).

4.- La gráfica 33 ilustra la precipitación total anual y la mediana de $1049 \mathrm{U} \nabla$, 1053 II $\nabla, 1055 \mathrm{~A}$ I $\nabla, 1057 \mathrm{E} \nabla, 1060$ II $\nabla, 1060$ III $₹, 1078 \mathrm{E}$ II $\nabla, 1082$ II $\vee, 1083$ II $\nabla$ y $9077 \mathrm{E}$ II $\vee$ de 1980 a 1998.

La gráfica 33 describe la precipitación total anual en segmentos continuos; en segmentos discontinuos, la mediana en los intersticios entre roturas de cada serie. 
Gráfica 33: Precipitación total anual y mediana de la precipitación total anual $\left(1 / \mathrm{m}^{2}\right)$ de

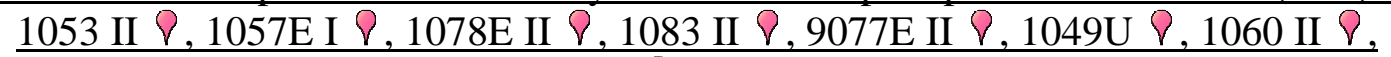
1060 III $y 1082$ II $P$ :

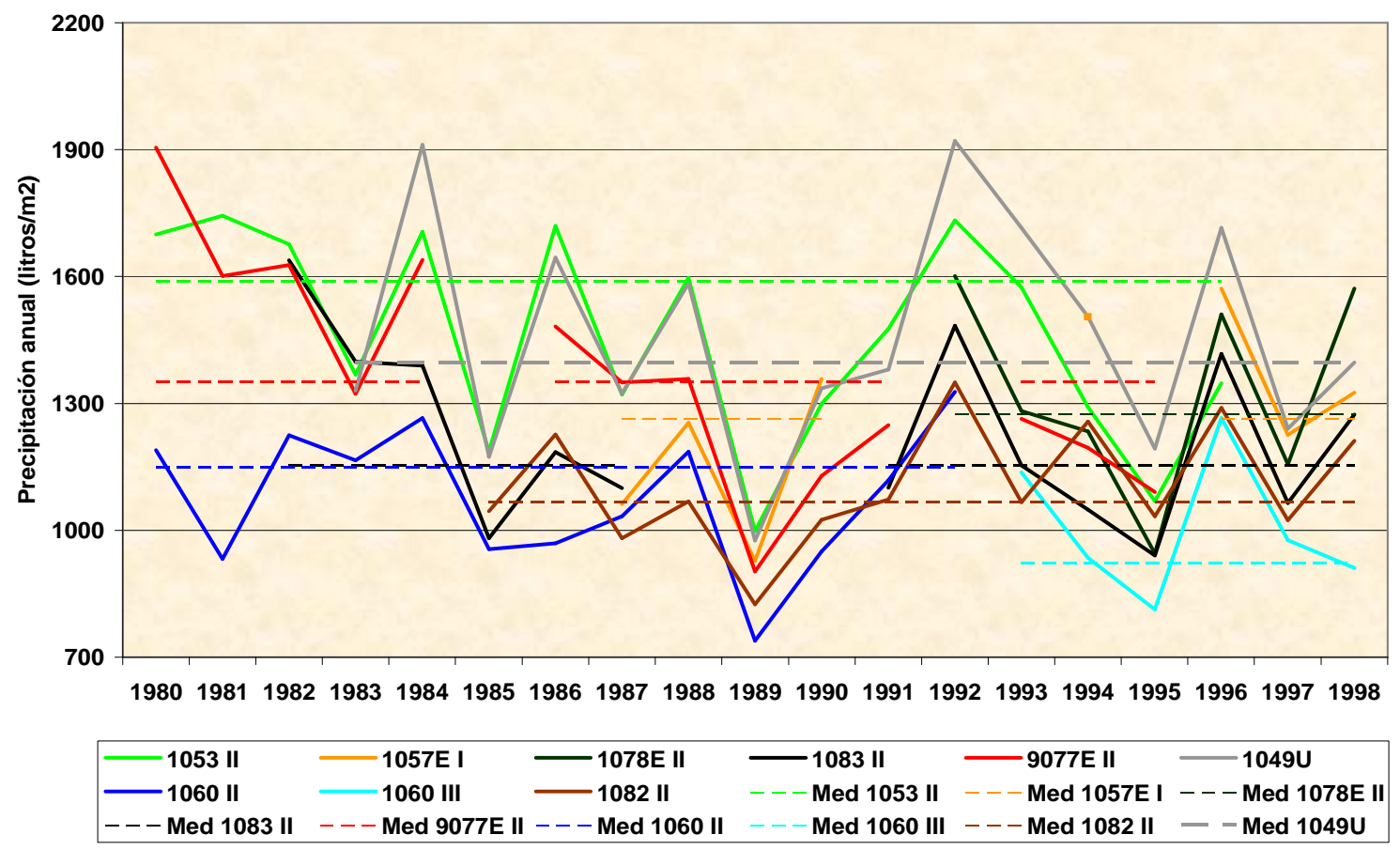

Se colige de la gráfica 33:

4.1.- De 1980 a 1990 las precipitaciones disminuyen gradualmente en la totalidad de las ubicaciones escrutadas con picos de sierra de sucesivos máximos y mínimos pluviométricos decrecientes.

Al extremadamente seco 1989 le sobreviene una abrupta recuperación en 1992, con un continuado descenso de la pluviosidad anual hasta 1995, sucedido por el fugaz lluvioso 1996, que en 1053 II $\vee$ no llega a alcanzar la mediana de precipitación.

La tendencia negativa de la precipitación de los años 90 es congruente con el decremento generalizado de la precipitación en Vizcaya y en la vertiente cantábrica de Álava a lo largo de la década de los años 80 y es acorde con los años de sequías de la tabla 32 bis.

4.2.- Los máximos pluviométricos simultáneos de 1984, 1986, 1992 y 1996, concuerdan con los valores de la tabla 32 (página 75).

4.3.- Los mínimos de pluviosidad (1981, 1985, 1989, 1995) son sincrónicos con los compilados en la tabla 32 bis (página 75).

4.4.- La precipitación aumenta de Oeste a Este, con una gradación pluviométrica de $\underline{\text { las series similar a lo largo del tiempo. }}$ 
5.- La gráfica 34 presenta la razón de la precipitación de 1083 II $\nabla$ Arcentales en relación a la precipitación total anual de 1060 II $\nabla, 1060$ III $\$, 1078 \mathrm{E}$ II $\nabla, 1082$ I $\nabla$, 1082 II $\nabla$, 9077E II $\nabla$ y 1053 II $\nabla$ y el cociente de 1078E II $\nabla$ Valmaseda referido a 1060 III y 1082 II $\vee$ de 1982 a 1997.

Gráfica 34: Razón de las precipitaciones de 1083 II $\nabla$ respecto a 1060 II $\nabla, 1060$ III $\nabla$, 1078E II $\vee, 1082$ I $\vee, 1082$ II $\vee, 1053$ II $\vee$ y 9077E II $\vee$ y razón de las precipitaciones de 1078 E II $\bigcirc$ respecto a 1060 III $\vee$ y 1082 II $\vee$ :

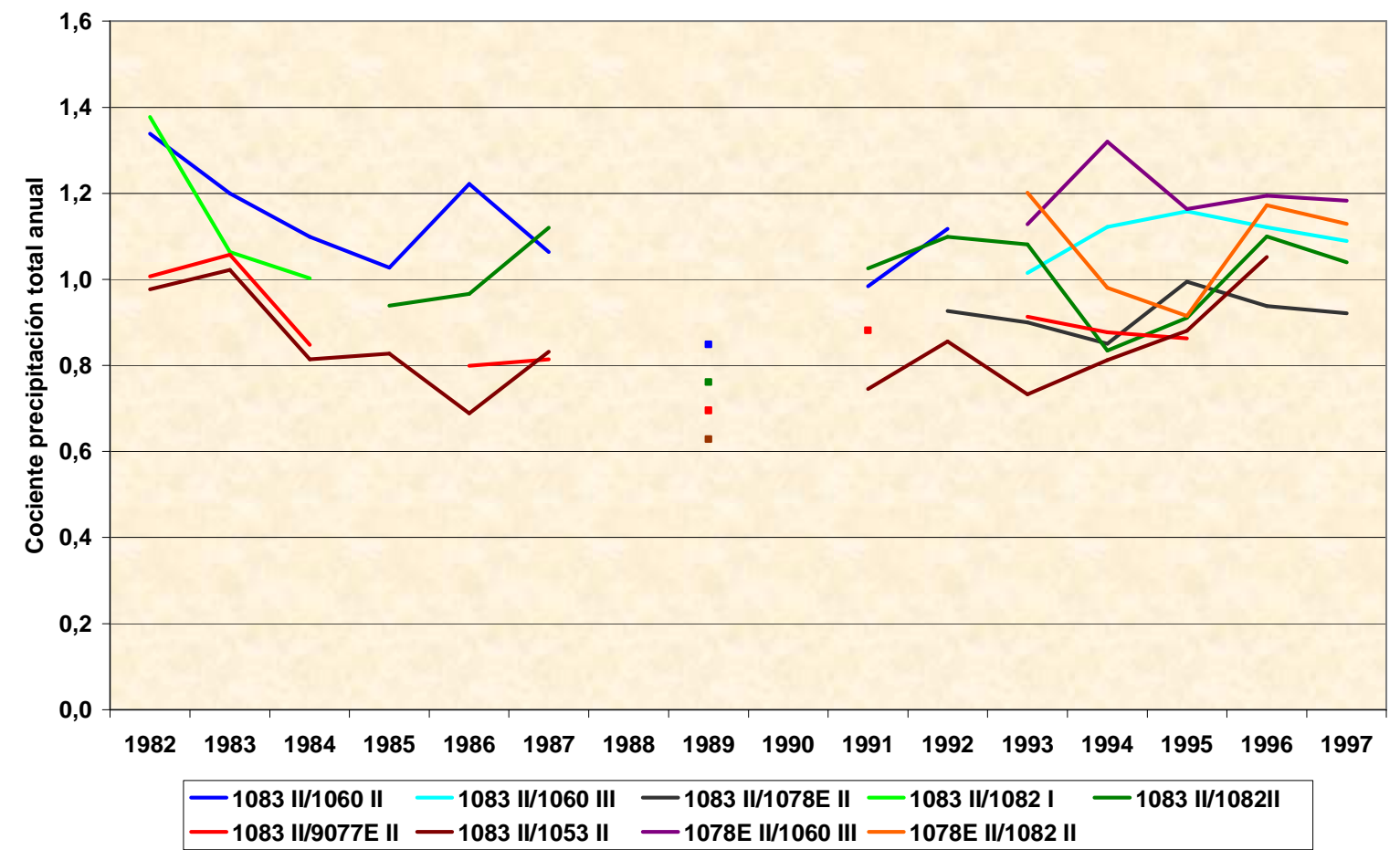

La gráfica 34 advierte de:

5.1.- La trascendencia de un acervo de series climatológicas sin lagunas:

La gráfica 34 adolece de la carencia de resultados recopilada en la tabla 80.

5.2.- La evolución del cociente de la precipitación anual de 1083 II $\$ comparada con las precipitaciones de las ubicaciones de referencia de Vizcaya y de la vertiente cantábrica de Álava fluctúa en una banda constante.

5.3.- La razón de las precipitaciones de 1083 II $\vee$ es mínima en los años secos (1985, 1989), resultado análogo al inferido de la gráfica 31 (página 155).

6.- La gráfica 35 refleja la razón de la precipitación de 1985 a 1998 de 1053 II $\vee$ Echevarría, 9077E II $\nabla$ Ochandiano y de 1057E I $\nabla$ Baquio referida a 1082 II 8 y a 1055A I $\nabla$ y el cociente 1057E I P/ 1053 II $P$. 
Gráfica 35: Razón de las precipitaciones de 1053 II $\nabla, 9077 \mathrm{E}$ II $\nabla$ y de 1057E I $\nabla$ respecto a 1082 II $\vee$ y 1055A I $\vee$ y razón de las precipitaciones de 1057 E I $\vee$ respecto a 1053 II $\vee$ :

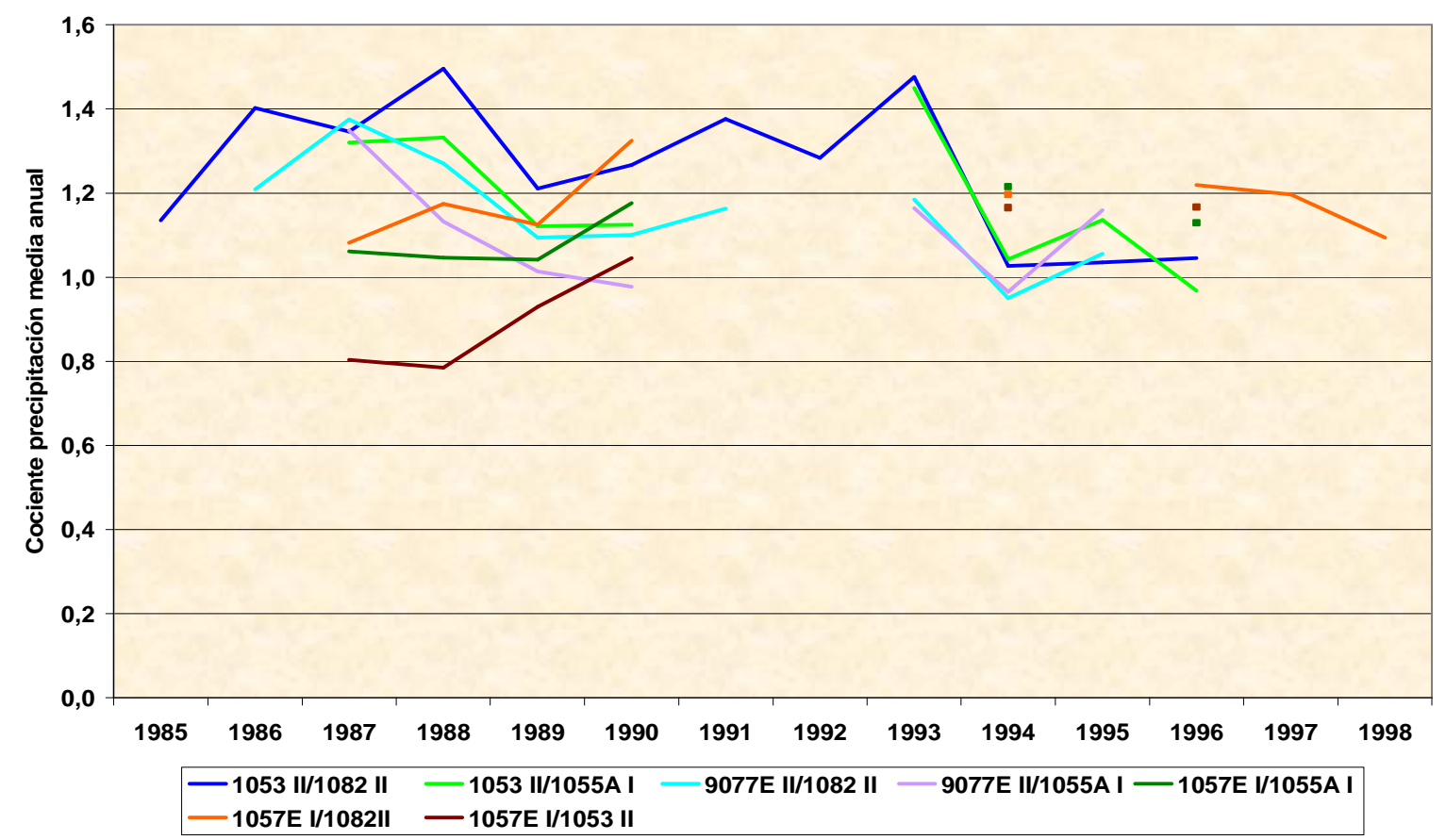

La gráfica 36 incluye el cociente de 1053 II $\vee$, 9077E II $\nabla$ y de 1057E I $\nabla$ en contraposición a 1049U $\nabla$ y el cociente de 1053 II $\nabla$ a 9077E II $\nabla$, respecto a la gráfica 35 .

Gráfica 36: Razón de las precipitaciones de 1053 II $\vee$, 9077E II $\bigcirc$ y de las precipitaciones

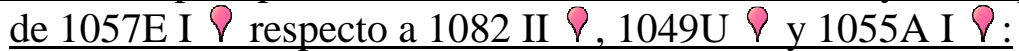

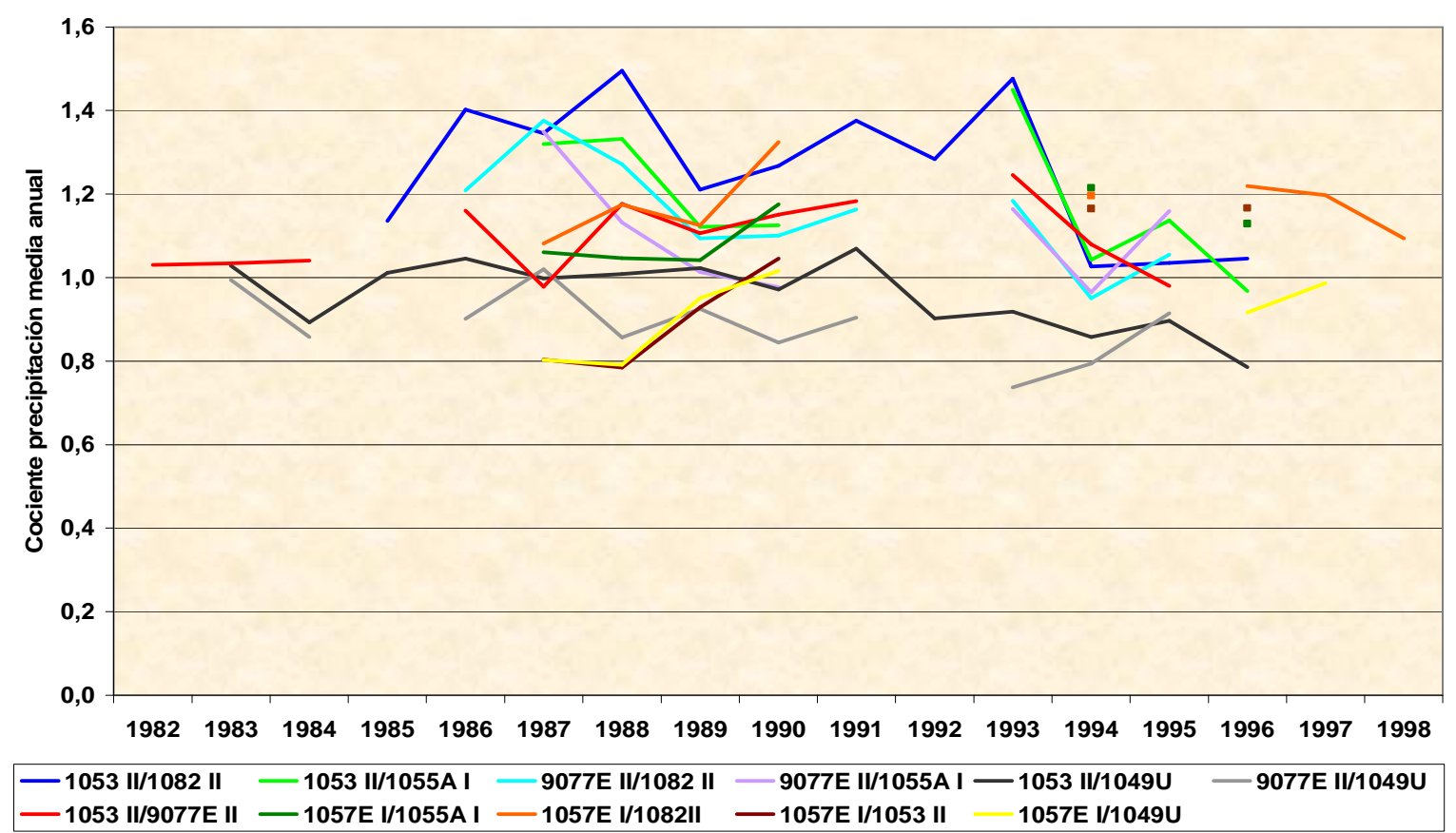


De las gráficas 33,35 y 36 se colige:

6.1.- La correlación de la pluviosidades de 1053 II $\vee$ Echevarría y 9077E II $\bigcirc$ Ochandiano es óptima.

6.2.- Un análisis de 1053 II $\nabla$ y 9077E II $\nabla$ circunscrito a 1082 II $\vee$ y a $1055 \mathrm{~A}$ I $P$ (gráfica 35) concluye en una disminución de la precipitación en 1053 II $\vee$ y en 9077E II $\nabla$.

6.3.- La inclusión de $1049 \mathrm{U}$ (gráfica 36) revela que la variación de las precipitaciones es similar en 1049U 8,1053 II $\nabla$ y 9077E II $\nabla$.

La carencia, la ausencia de datos de 9077E II $>$ podría inferir la espuria conclusión de la consideración de las tendencias negativas de 1053 II $\vee$ de 1995 y 1996 y, en menor medida, de 9077E II $P$ de 1993 a 1995, como "no climatológicas", por contraste con la serie de referencia 1082 II $\vee$ y con la serie de $1055 \mathrm{~A} \mathrm{I} \vee$ (a $12,7 \mathrm{Km}$. al NW de 1053 II $\vee$ ).

No, el clima de Vizcaya, con una escabrosa orografía, precisa de una red de medidas de una densidad espacial elevada.

6.4.- 1987 y 1989 son años de pluviosidad inferior a la mediana y 1988 de pluviometría normal en 1057E I $\vee$ y en las restantes localizaciones.

La distribución por quintiles de la precipitación de 1057E I $\nabla$ es: 1994 y 1996 en el $1^{\circ}, 1990$ en el $2^{\circ}, 1988$ y 1998 en el central, 1997 en el $4^{\circ}$ y 1987 y 1989 en el $5^{\circ}$.

6.5.- El cociente de 1057E I $\nabla$ Baquio respecto a:

a) $1055 \mathrm{~A}$ I $\vee$ y 1082 II $\vee$ es constante, a excepción de 1990 en 1082 II $\vee$.

b) 1049U $\nabla$ y 1053 II $\nabla$ : Tras una relación conforme en 1987 y en 1988, aumenta su cociente en 1989 y de ahí transcurre sin cambios.

6.6.- La importancia y la necesidad de una amplia, luenga y densa red de estaciones de medida, de una resolución a escala comarcal e incluso superior con un énfasis en la disponibilidad de series pluviométricas largas.

6.7.- La tendencia de 1057E I $\vee$ es "no climatológica", originada por la ausencia de datos de precipitación en los normales 1991 y 1993, en el lluvioso 1992 y en el muy seco 1995.

Sin embargo, el cotejo de las mediciones de 1057E I $\vee$ con las series pluviométricas cercanas (gráfica de precipitaciones 33 y gráficas de los cocientes 34 y 35) revela una muy buena calidad de las mediciones de 1057E I $\nabla$.

Por consiguiente, la tendencia de 1990 a 1991 en 1053 II $\nabla$ y en 9077E II $\nabla$, en 1991 en 1083 II $\nabla$, de 1993 a 1995 en 9077E II $\nabla$, en 1995 en 1053 II $\nabla$ y en 1078E II $\nabla$ y en 1996 en 1053 II $\nabla$ se cataloga de tendencia "climatológica" y la tendencia de 1057E I $\nabla$ se califica como tendencia "no climatológica.". 


\section{9.- Tendencia negativa de 2001 a 2002 en 1060 y en 2006 en $1081 \mathrm{U}$ :}

1.- Los datos de 1060 III Amurrio y de 1081 II $\$$ Derio Neiker se confrontan con las cuantías de precipitación medidas en los pluviómetros de 1059 III Punta Galea Golf, 1075E II $\vee$ Aránzazu, 1078E II $\$$ Valmaseda, 1082 II $\$$ y 1082 III $\$ Bilbao Aeropuerto.

La tabla 81 recopila la fecha de arranque y los años incompletos de los intervalos sin roturas de 1060 III $\$, 1081 \mathrm{U}$ II $\vee, 1059$ III $\$, 1075 \mathrm{E}$ II $\vee, 1078 \mathrm{E}$ II $\vee, 1082$ II $\vee$ y de 1082 III $P$.

Tabla 81: Fecha inicio y años incompletos de 1060 III $\$, 1081$ U II $\vee, 1059$ III $\$$, 1075E II $\vee, 1078$ E II $\vee, 1082$ II $\vee$ y 1082 III $\vee$ :

\begin{tabular}{|c|c|c|c|}
\hline Indicativo & Nombre & Comienzo & Años incompletos \\
\hline 1060 III $\$$ & Amurrio & Final 1992 & \\
\hline 1081U II $\vee$ & Derio Neiker & Final Marzo 1996 & $2001,2002,2005$ \\
\hline 1059 III & Punta Galea Golf & $01-03-1994$ & \\
\hline $1075 \mathrm{E}$ II 8 & Aránzazu & Final 1981 & 1991, 1993, 1997, 2005 \\
\hline 1078E II $\nabla$ & Valmaseda & $28-12-1991$ & 2006 \\
\hline 1082 II $P$ & Bilbao Aeropuerto & $27-11-1984$ & 2000 \\
\hline 1082 III $P$ & Bilbao Aeropuerto & $01-02-2001$ & \\
\hline
\end{tabular}

2.- La tendencia negativa únicamente aflora en la Cantábrica Alavesa y en el Gran Bilbao.

3.- El estudio de la precipitación anual con el test de las rachas exterioriza una inhomogeneidad "climatológica" en 1055A I \& Lequeitio de 1993 a 2005 (tabla 17, página 50).

4.- El test de Mann - Kendall no detecta tendencias coetáneas de la precipitación anual en Guipúzcoa (tabla 72, página 132).

5.- 2001 es el tercer año más seco en 1055A I $\vee$ (tabla 30, página 72).

6.- La gráfica 37 expone la precipitación total anual y la mediana de $1060 \mathrm{III}$, 1081U II $\vee, 1059$ III $\$, 1075$ E II $\vee, 1078$ E II $\vee, 1082$ II $\vee$ y 1082 III $\nabla$ de 1993 a 2008.

La precipitación total anual se dibuja mediante segmentos continuos en la gráfica 37 y con segmentos discontinuos la mediana en el lapso temporal entre rupturas de cada serie pluviométrica. 
Gráfica 37: Precipitación total anual y mediana de la precipitación total anual $\left(1 / \mathrm{m}^{2}\right) \mathrm{de}$

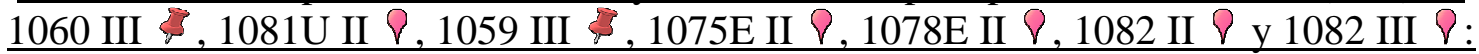

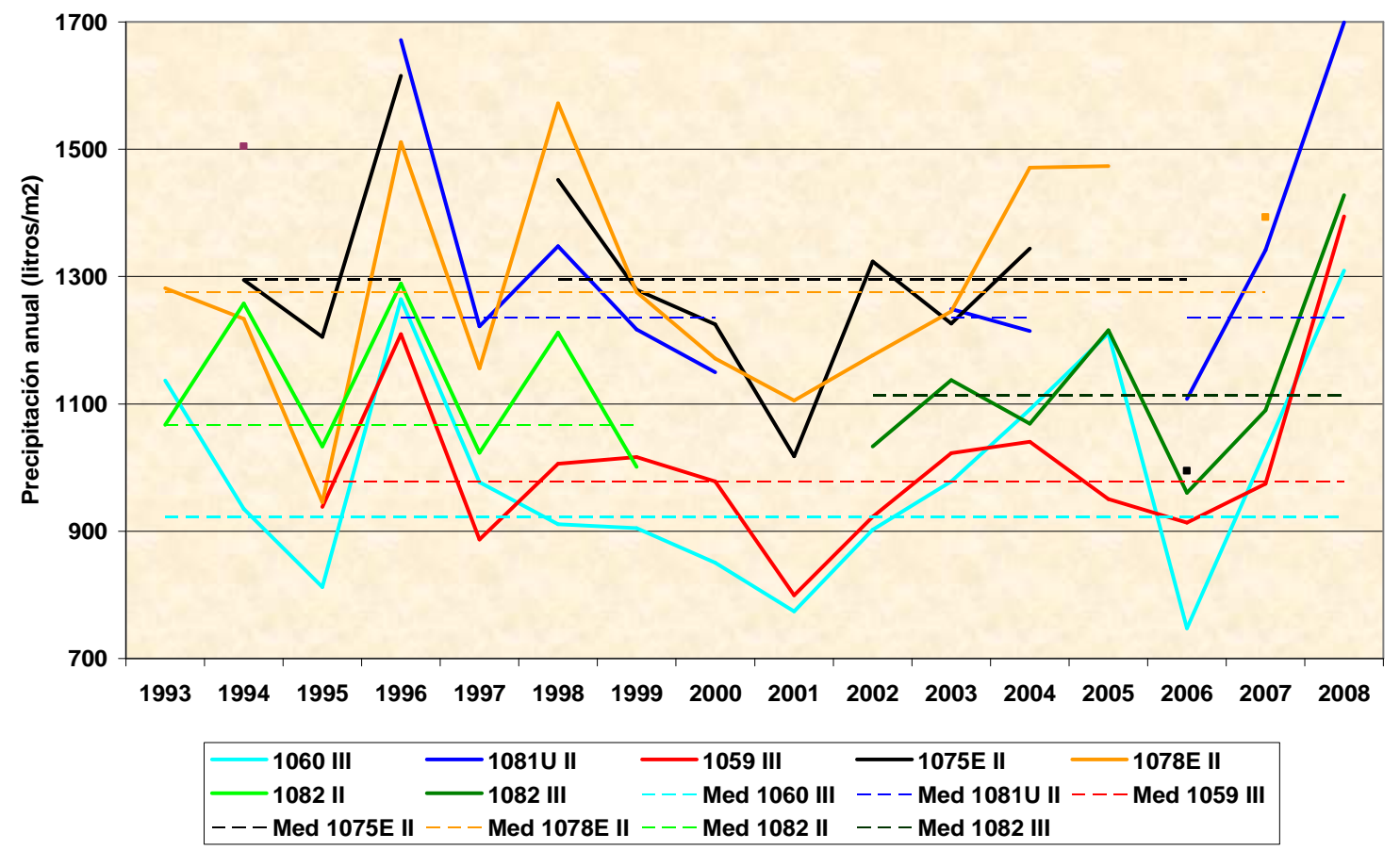

De la gráfica 37:

6.1.- Al seco 1995 le sucede el muy lluvioso 1996, tras el cuál acontece una disminución de las precipitaciones con valores inferiores a las respectivas medianas e interrumpida por el lluvioso 1998, alcanzando un mínimo en el muy seco 2001, seguida por el seco 2002.

2003 y 2004 transcurren con precipitaciones cercanas a la normal. Al lluvioso 2005 le sigue el excepcionalmente seco 2006.

La tendencia negativa de 2001 y de 2002 en 1060 III $\$$ y la tendencia negativa de

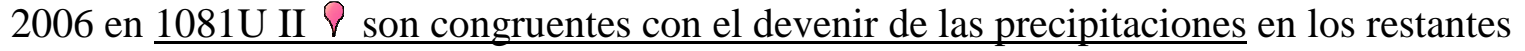
lugares.

6.2.- Los años de máximos pluviométricos coinciden en 1996, 2005 y 2008.

6.3.- Los años de pluviosidades mínimas sincronizan en 1995, 2001 y 2006, acordes con los resultados de la tabla 32 bis (página 75).

6.4.- La evolución temporal de la prelación de la cuantía de las precipitaciones recogidas en los diversos enclaves es constante: Las ubicaciones más lluviosas son 1075E II $\vee$, 1078E II $\nabla$ y 1081U II $\vee$; en rango medio pluviométrico, 1082 II $\nabla$ y 1082 III $\vee$ y los más secos, 1060 III $\$$ y 1059 III $\$$ 
6.5.- El carácter precursor de $1082 \bigcirc$ Bilbao Aeropuerto, precedente a su cambio de ubicación y de instrumentación de 1082 II $\vee$ a 1082 III $\vee$, lo asume 1059 III $\$$ en el tránsito de 2004 a 2005.

7.- La gráfica 38 ilustra la razón de $1081 \mathrm{U}$ II $\vee$ Derio Neiker en relación a 1059 III $\$, 1060$ III $\$, 1075$ E II $\vee, 1078$ E II $\vee, 1082$ II $\vee$ y 1082 III $\vee$ de 1996 a 2008.

Gráfica 38: Razón de las precipitaciones de 1081U II $\nabla$ respecto a 1059 III $\$, 1060$ III 1075E II $\vee, 1078$ E II $\vee, 1082$ II $\vee$ y 1082 III $\vee$ :

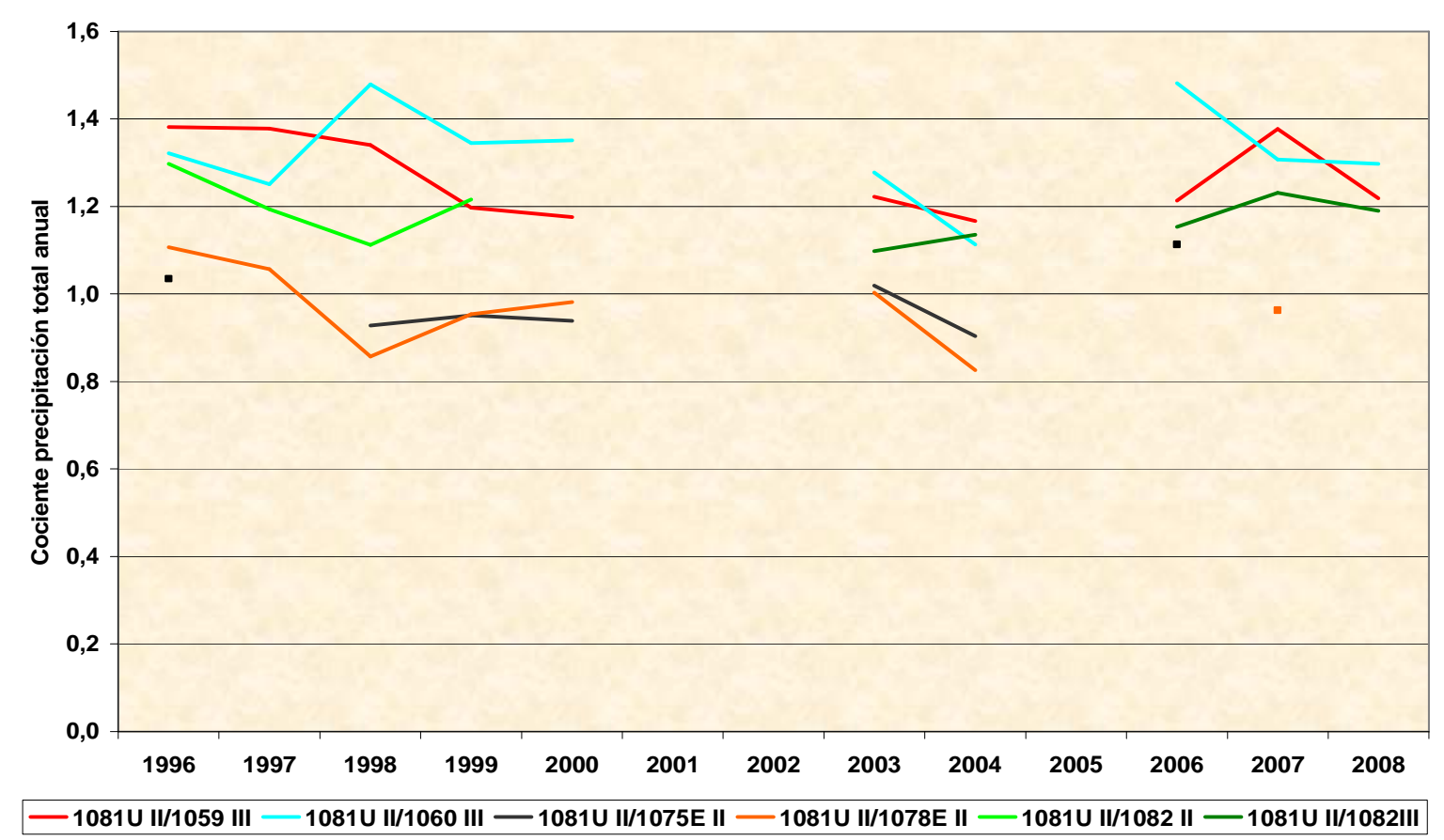

De la gráfica 38 se colige:

7.1.- La importancia de la ausencia de lagunas en las series de datos, reflejada en las ausencias de 1081U II $\vee$ de 2001, 2002 y 2005.

7.2.- El cociente de las precipitaciones recabadas en 1081U II $\nabla$ referidas a las series disponibles más próximas fluctúa entre unos valores máximos y mínimos constantes de 1996 a 2008.

7.3.- Las precipitaciones medidas en $1081 \mathrm{U}$ II $\nabla$ superan a las de 1082 II $\nabla$ y 1082 III $\vee$. Las características geográficas de 1081 U II $\nabla$ y 1082 II $\vee$ son esbozadas en la tabla 47 segunda (página 101).

7.4.- Los registros pluviométricos de 1081U II $\nabla$, 1075E II $\vee$ y 1078E II $\vee$ son de una magnitud semejante. 
8.- La gráfica 39 muestra el cociente de las precipitaciones de 1060 III $\$$ Amurrio Instituto referido a 1059 III $\$, 1075 \mathrm{E}$ II $\nabla, 1078 \mathrm{E}$ II $\nabla, 1082$ II $\vee$ y 1082 III $\vee$ de 1993 a 2008.

Gráfica 39: Razón de las precipitaciones de 1060 III $\$$ respecto a 1059 III $\$, 1075 E$ II $\nabla$, 1078E II $\vee, 1082$ II $\vee$ y 1082 III $\vee$ :

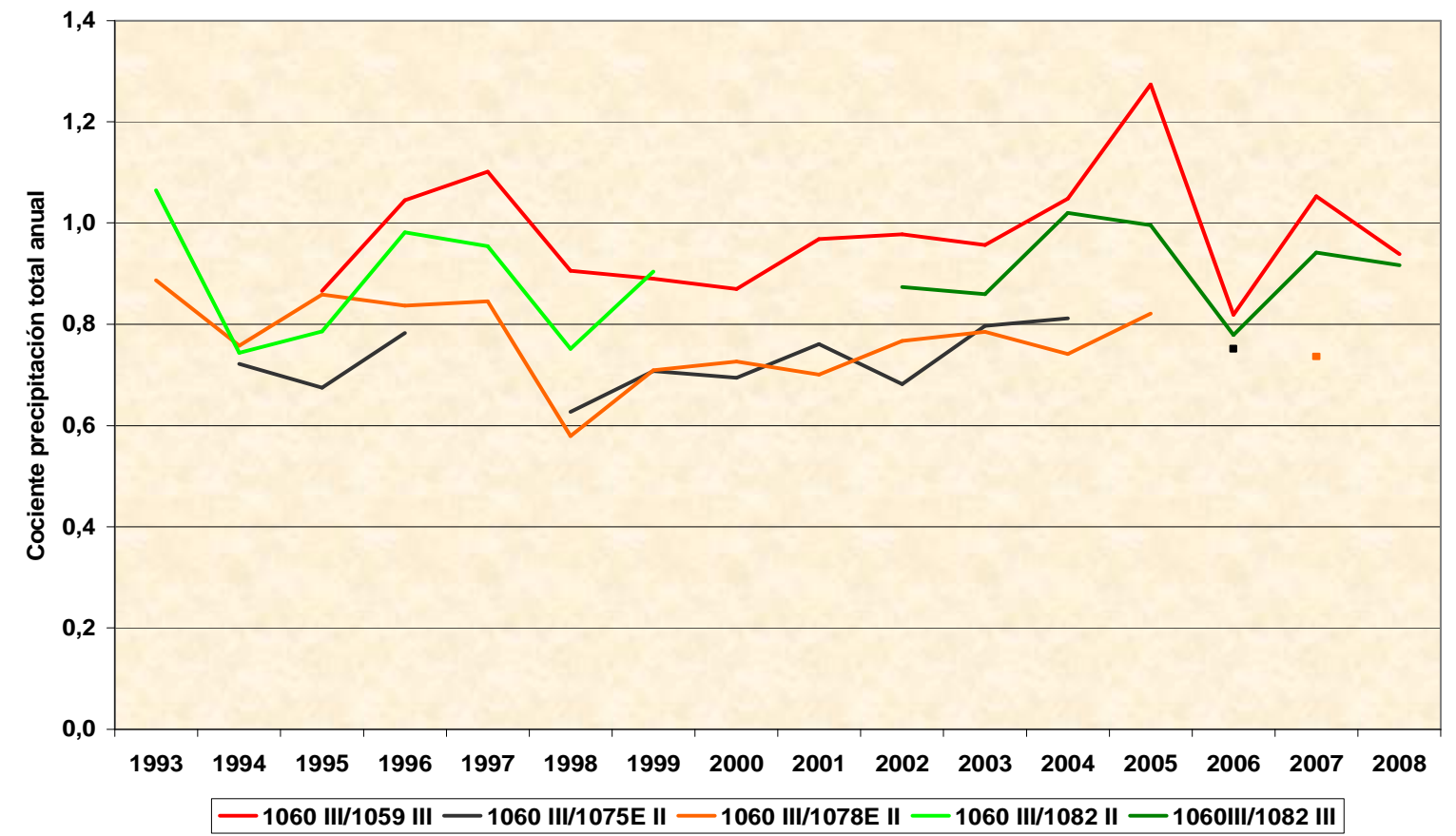

De la gráfica 39 se infiere:

9.1.- El cociente de la precipitación de 1060 III fluctúa entre unos máximos $(1996,1997,2005)$ y mínimos $(1995,1998,2006)$ constantes, con valores parejos al inicio y al final del intervalo de contraste con cada serie.

La evolución de las registros de 1060 III $\varangle$ en relación a los datos del resto de enclaves es similar.

Una regularidad se insinúa en la cadencia de máximos y mínimos del cociente de precipitaciones.

9.2.- La pluviosidad de 1060 III $\$$ y de 1059 III $\$$ es cercana.

10.- La tendencia negativa de 2001, 2002 y 2006 es un reflejo de la sequía de comienzos del siglo XXI, precedente a los muy lluviosos 2008 y 2013.

Por todo lo expuesto, se la cataloga como tendencia "climatológica". 
El epítome del escrutinio con el test de Mann - Kendall de la precipitación total anual de Vizcaya y de la vertiente cantábrica de Álava:

1.- Las tendencias se disciernen en "climatológicas" y "no climatológicas".

Las tendencias "no climatológicas" se detectan por:

1.1.- El anómalo comportamiento de la precipitación respecto a las series circundantes: 1055 P Lequeitio Faro, 1068 II $P$ Basauri y 1083 I 8 (1975 a 1979) Arcentales.

\section{2.- La carencia de datos: 1057E I $\nabla$ Baquio.}

La tendencia "no climatológica" de 1057E I $\nabla$ es la única en la cuál la pluviosidad transcurre pareja a la de los restantes enclaves.

2.- El incremento y el decremento de la precipitación concuerda en todos los emplazamientos, salvo en las tendencias "no climatológicas" de 1055 P, 1068 II $\vee$ y de 1975 a 1979 en 1083 I 8.

La evolución temporal de las precipitaciones es similar en los lugares escrutados, con una excelente sincronía de los máximos y mínimos pluviométricos.

3.- Las tendencias "climatológicas" de Vizcaya y de la vertiente cantábrica de Álava son congruentes con:

3.1.- El transcurso de las precipitaciones en los emplazamientos coetáneos allegados (gráficas 15 a 39).

3.2- La sucesión de años pluviosos y secos de los emplazamientos (gráficas de precipitación total anual 15, 17, 19, 21, 24, 27, 30, 33 y 37), con las sequías severas precediendo a los años muy lluviosos.

3.3.- Las tablas 83 y 83 , obtenidas de la recapitulación de los comentarios a las gráficas $15,17,19,21,24,27,30,33$ y 37, las cuáles epitoman los años con máximos y mínimos pluviométricos desvelados por el análisis de Mann - Kendall de la precipitación anual de Vizcaya y de la vertiente cantábrica de Álava.

La siguiente notación se emplea en las tablas 82 y 83:

a) En azul oscuro, máximos y mínimos de precipitación coincidentes en Vizcaya y en la vertiente cantábrica de Álava con los de Guipúzcoa.

b) En rojo, extremos de la pluviosidad no registrados en las tablas de Guipúzcoa, coherentes con un doble ciclo de 10 años.

c) Se dejan en blanco los años sin máximos o mínimos pluviométricos, sea por la carencia de series de datos (1933 a 1944), sea por su concurrencia con un intervalo carente de inhomogeneidades (de 1859 a 1922, tabla 71, página 131) o por su coincidencia con un intersticio muy seco (albor de la primera década del siglo XXI). 
d) En negrita, los años con máximos y mínimos pluviométricos significativos, por el número de ubicaciones y por su carácter de extremos. 1979.

e) Un guión - denota años de la tabla englobados: Por ejemplo 1978-79: De 1978 a

f) Una coma , indica años no consecutivos: Verbi gratia, 1984, 86: 1984 y 1986.

Tabla 82: Años con máximos pluviométricos:

\begin{tabular}{|l|c|c|c|c|c|c|c|}
\hline Máximos & $\mathbf{1 9 1 7 , 1 9}$ & $\mathbf{1 9 2 3}$ & & & & & \\
\hline \hline Máximos & $\mathbf{1 9 5 2}$ & $\mathbf{1 9 5 4}$ & $\mathbf{1 9 6 0}$ & $1965-66$ & $\mathbf{1 9 7 1}$ & $1974-75$ & $1978-79$ \\
\hline \hline Máximos & $\mathbf{1 9 8 4 , 8 6}$ & $\mathbf{1 9 9 2}$ & $\mathbf{1 9 9 6}$ & & 2005 & $\mathbf{2 0 0 8}$ & \\
\hline
\end{tabular}

Tabla 83: Años con mínimos de precipitación:

\begin{tabular}{||l||c|c|c||c|c|c|c||}
\hline Mínimos & $\mathbf{1 9 1 6}$ & $\mathbf{1 9 2 0}$ & $\mathbf{1 9 2 4 , 1 9 2 6}$ & & & & \\
\hline \hline Mínimos & $\mathbf{1 9 4 8}$ & $\mathbf{1 9 5 5}$ & $\mathbf{1 9 5 7}$ & 1964 & $\mathbf{1 9 6 8}$ & $\mathbf{1 9 7 0}$ & 1976 \\
\hline \hline Mínimos & $\mathbf{1 9 8 1}$ & $\mathbf{1 9 8 5}$ & $\mathbf{1 9 8 9}$ & $\mathbf{1 9 9 5}$ & $\mathbf{2 0 0 1}$ & $\mathbf{2 0 0 6}$ & \\
\hline
\end{tabular}

3.4.- Los máximos y mínimos de pluviosidad revelados por el análisis de las inhomogeneidades del test de Thom de la precipitación anual (tablas 32 y 32 bis, página 75), los cuáles coinciden con los resultados expuestos en las tablas 82 y 83 .

3.5.- Las tendencias "climatológicas" de la pluviometría anual de Guipúzcoa descritas en la tabla 72 de la página 132 (analizadas en la Nota Técnica № 13 AEMET).

4.- Se resalta la importancia y potencia de un examen conjunto de la precipitación mediante los tests de Thom y de Mann-Kendall.

5.- Los cúlmenes de tendencias positivas acaecen de 1952 a 1953 y de 1975 a 1979 (posterior a la sequía finalizada en 1948 y ulterior a los muy secos 1968 y 1970), coherentes con los clímax de Guipúzcoa: 1951 - 1952 y 1978 - 1984 (Nota Técnica Nº 13 AEMET).

El número de tendencias "climatológicas positivas" (24) excede al de negativas (21), descrito en las gráficas 13 y 14 (página 130) y en la tabla 71 (página 131).

Ambos hechos indician:

a) La transición de un período de sequía a uno de precipitaciones copiosas es más rauda que la mudanza de un intersticio de una cuantiosa pluviometría a uno seco.

Este breve tránsito de años de sequía a años lluviosos o muy lluviosos acontece acorde a los hallazgos de Guipúzcoa (Nota Técnica No 13 AEMET). 
b) El número de series de inicio en años de sequía (17) rebasa al cómputo de series de comienzo en años pluviosos (3).

El primigenio año completo de las siguientes series sin tendencias "no climatológicas" es:

A) Años secos: 1059 I $\vee(1911) ; 1077$ P (1926); 1059 II $\vee$ (1946); 9077E I $\vee$ (1947); 1082 I $\vee$ (1948); 1060 I $\nabla$ (1956); 1054 II $\vee$ y 1093 I $\vee(1957) ; 1060$ II $\vee$, $1070 \vee, 1071 \nabla, 1075$ II $\vee, 1075$ E I $\vee$ y 1083 I $\vee(1968) ; 1053$ II $\vee$ y 9077E II $\vee(1976)$ y 1059 III (1995) (tabla 32 bis, página 75).

32, página 75$)$.

B) Años lluviosos: 1093A $\vee$ (1975); 1078E II $\vee$ (1992); 1081U II $\vee$ (1996) (tabla

La serie de tendencia "no climatológica" 1068 II $\vee$ empieza en el seco 1955.

El primer año de cada serie es crucial en el devenir de un posterior aumento o disminución de la precipitación: El estudio de una serie (por ejemplo 1082 I $\vee$ Bilbao Aeropuerto), según arrancara en un año seco (1955) o lluvioso (1954), inferiría una acrecencia o una descrecencia de la pluviosidad.

La cognición de las características pluviométricas del año inicial de las observaciones y el conocimiento de los factores exógenos (cambios de emplazamiento, de entorno, instrumentación y/o observador) es crítico antes del escrutinio de la evolución de la pluviosidad anual, de los incrementos, decrementos y ciclos de las cuantías de precipitación registradas en cada ubicación.

La carencia del mismo colige conclusiones espurias referentes a acrecimientos o decrecimientos ulteriores de la precipitación, ajenos a variaciones climáticas y de causa, bien la influencia del prístino año de medidas, bien alteraciones en las condiciones de medición.

Es menester agregar las características climáticas del año de inicio a las influencias externas citadas en un paso previo al estudio de la evolución de las precipitaciones acopiadas en un lugar.

6.- El cociente de las precipitaciones totales anuales en los casos de tendencia "climatológica" fluctúa entre unos máximos y mínimos invariables, con una cadencia en los máximos y en los mínimos cercana a los 10 años (gráficas 16, 18, 20, 22, 23, 25, 26, 28, 29, $31,32,34,35,36,38$ y 39) y los años de máximos y mínimos del cociente concuerdan con los años recogidos en las tablas 32 y 32 bis.

$\underline{\text { Para un relleno de lagunas, es importante determinar la posición del año sin la }}$ plenitud de datos en la euritmia del ciclo.

7.- La razón de precipitaciones posibilita:

7.1.- La detección de rupturas desapercibidas por el análisis con los tests de Thom y de Mann - Kendall (verbi gratia, 1083 I $\vee$ Arcentales en Octubre de 1973). 
7.2.- La corroboración de los resultados de roturas de los tests de Thom y de Mann Kendall (por ejemplo, 1057 C P Machicaco Faro en Noviembre de 1921, 1053 P Echevarría a finales de 1975, 1082 \& Bilbao Aeropuerto el 27 de Noviembre de 1984).

\section{8.- La trascendencia de:}

8.1.- La resolución temporal para discernir si una tendencia es climatológica o no (por ejemplo, tener en cuenta 11 ó 22 años en 1068 II $\vee$ Basauri, gráficas 25 y 26).

8.2.- La resolución espacial para distinguir las tendencias "climatológicas" de las "no climatológicas" (verbi gratia: 1053 II $\nabla$ Echevarría en 1981).

Un único contraste de 1053 II $\vee$ con 1060 II $\nabla$ y 1082 I $\nabla$, sin un cotejo con $1070 \varnothing$, $1071 \vee$ y 1046 IV $\vee$, hubiera conducido a catalogar de "sospechosa" la pluviometría anual de 1053 II $\vee$ en 1981. La penuria de datos puede concluir en calificar de dudosos datos correctos.

8.3.- La repercusión y la necesidad de una luenga y densa red de estaciones de medida, de una densidad a escala comarcal e incluso mayor con un énfasis en la disponibilidad de series pluviométricas largas.

Se destaca la importancia de realizar una comparativa de las tendencias detectadas con el comportamiento de la precipitación en los enclaves cercanos, actuales y antiguos.

\section{4.- Una resolución de escala superior a la provincia:}

A) La tabla 84 expone la distribución comarcal de las tendencias "climatológicas" del test de Mann - Kendall de la precipitación total anual:

Tabla 84: Distribución comarcal de las tendencias "climatológicas" del test de Mann - Kendall de la precipitación total anual:

Comarca

Arratia - Nervión

Duranguesado

Encartaciones

Gran Bilbao

Guernica - Bermeo

Marquina - Ondarroa

Plencia - Munguía

Cantábrica Alavesa

$$
\mathrm{N}^{\mathrm{o}} \text { series analizadas }
$$

$\mathrm{N}^{\mathrm{o}}$ inhomogeneidades

4
4
5
5
1
4
1
3

Inhomogeneidad media

0,25

1,5

4

1,2

0

1,75

0

1,67

Las tendencias "no climatológicas" de 1055 \, 1068 II $\vee, 1083$ I $\vee$ de 1975 a 1979 y $1057 \mathrm{E}$ I $\nabla$ en 1996 son excluidas en la tabla 84.

El clímax de inhomogeneidades se registra en las Encartaciones, seguido por Marquina - Ondarroa. 
$\underline{\text { La distribución de inhomogeneidades no es homogénea y discrepa conforme a cada }}$ comarca.

B) Similitud de las tendencias detectadas en emplazamientos próximos:

B1) Las tendencias "climatológicas" de 1973 a 1975 sólo afloran en Marquina Ondarroa y en las Encartaciones (tabla 71, página 131).

B2) Las tendencias "climatológicas" de 1980 a 1989 se manifiestan exclusivamente en las Encartaciones (tabla 71).

B3) Las tendencias "climatológicas" de 2001 a 2006 únicamente emergen en la Cantábrica Alavesa y en el Gran Bilbao (tabla 71).

B4) De 1952 a 1954 y de 1987 a 1996 las tendencias "climatológicas" principian cerca de la costa (1059 II $\vee$ y 1082 I $\vee ; 1083$ II $\vee, 1079$ I $\nabla$ y 1093A $\vee$ ) y se trasladan al interior (9077E I P; 9077E II $\vee$ ), revelado por la tabla 71.

Estas características refuerzan y vigorizan la necesidad de un análisis a una resolución mayor que la provincial.

9.- El carácter precursor de la precipitación total anual de 1082 I $\vee$ Bilbao Aeropuerto de:

9.1.- 1952 a 1953 las precipitaciones aumentan excepcionalmente en 1082 I $\nabla$, heraldo del incremento generalizado de precipitaciones en 1954.

9.2.- 1959 a 1960 la pluviometría solamente disminuye en 1082 I $\vee$, preludio del descenso generalizado de 1961.

9.3.- 1968 a 1969 y 1974 a 1975 discuerda con la del resto de ubicaciones: 1082 I $\nabla$ antecede al devenir de las demás series.

9.4.- 1982 a 1983, la pluviosidad acrece en 1082 I $\nabla$ y mengua en el resto de emplazamientos, anticipando el carácter muy lluvioso del subsiguiente 1984.

9.5.- El carácter precursor de 1082 I $\vee$, precedente a su cambio de ubicación y de instrumentación de 1082 II $\vee$ a 1082 III $\vee$, lo asume 1059 III $\$$ de 2004 a 2005.

10.- La ausencia de tendencia en las luengas 1077C $\vee$ Bilbao Histórica (55 años) y $1070 \vee$ Abadiano (33 años).

11.- La criticidad de una adecuada densidad espacial y temporal de series de datos pluviométricos sin lagunas con la finalidad del logro de un idóneo conocimiento del clima en Vizcaya y en la vertiente cantábrica de Álava, de un quebrado relieve. 


\subsubsection{2.- Evolución temporal de las inhomogeneidades del test de Mann - Kendall aplicado a la precipitación media MAM:}

El luengo intervalo temporal escrutado (de 1859 a 2013) y la exigua cuantía de series previas a 1940 (menor de 6 simultáneas) precisan la exposición gráfica en 2 intersticios: De 1859 a 1940 y de 1941 a 2013.

La gráfica 40 recoge la evolución temporal de las tendencias descubiertas por el test de Mann - Kendall en la precipitación media MAM de 1859 a 1940 de Vizcaya y de la vertiente cantábrica de Álava.

Gráfica 40: Evolución temporal de las tendencias del análisis del test de Mann - Kendall de las series de precipitación media MAM de 1859 a 1940:

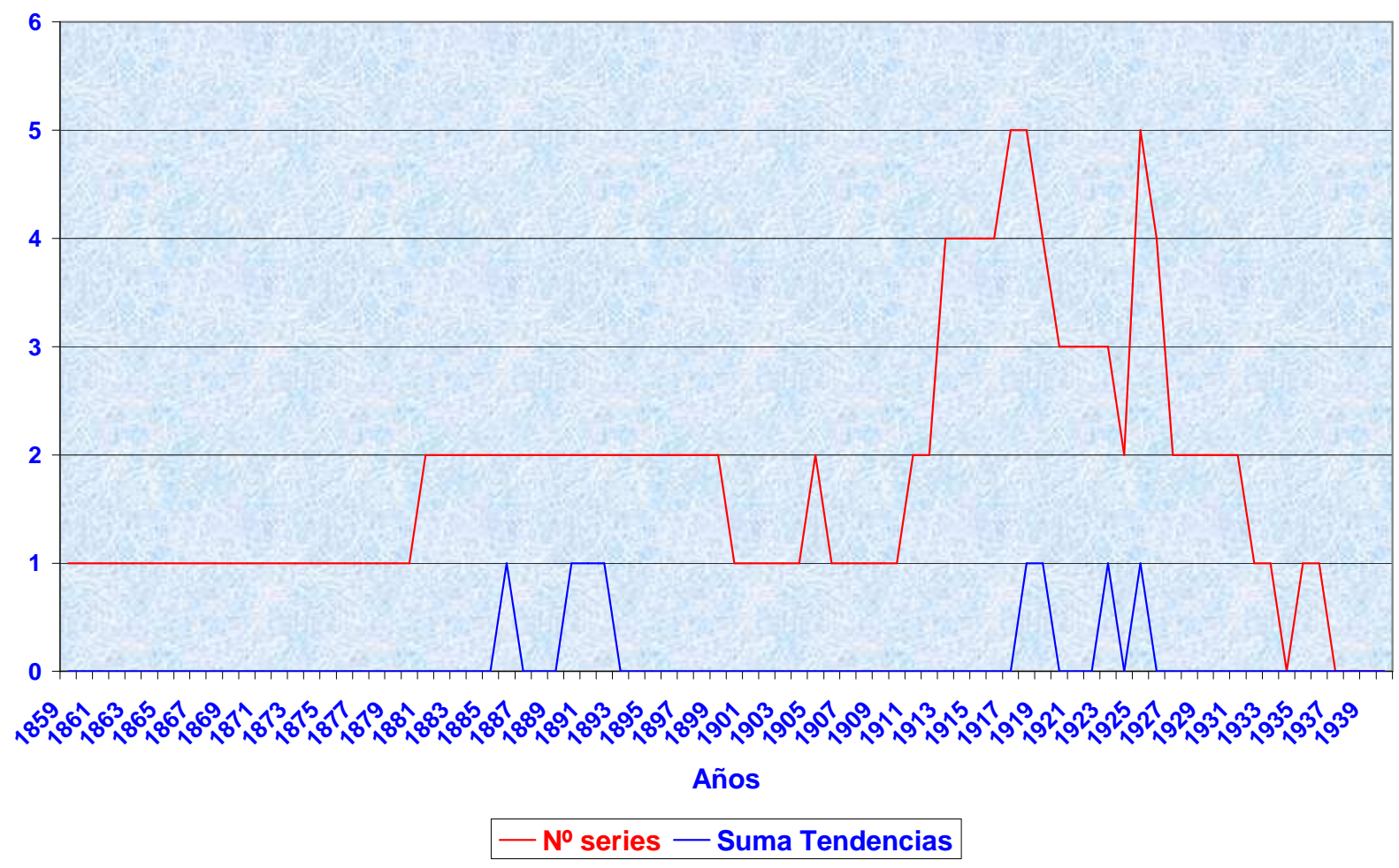

De la gráfica 40 se advierte que:

1) El número de tendencias precedentes a 1940 es 6, barrunte de la muy buena homogeneidad de las medidas pluviométricas anteriores a 1940.

2) La totalidad de las tendencias detectadas es positiva. 
La gráfica 41 representa la evolución temporal de las tendencias descubiertas por el test de Mann - Kendall en la precipitación media MAM de 1941 a 2013 de Vizcaya y de la vertiente cantábrica de Álava.

Gráfica 41: Evolución temporal de las tendencias del análisis del test de Mann - Kendall de las series de precipitación media MAM de 1941 a 2013:

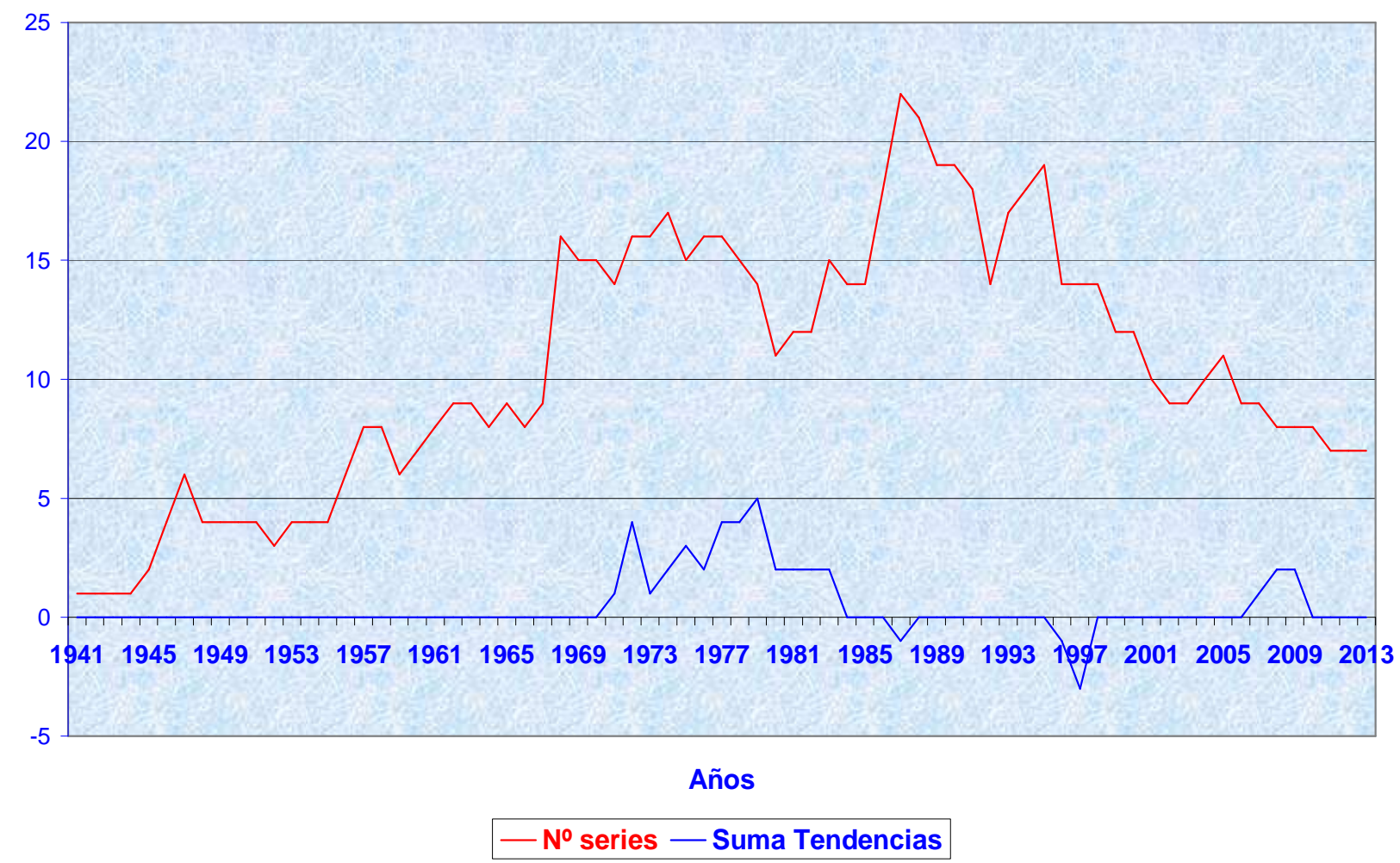

De la gráfica 41 se colige:

1) Los máximos de tendencias positivas acontecen en 1972 y de 1974 a 1979.

2) La tendencia negativa máxima sucede en 1997.

3) La totalidad de tendencias positivas sobrepasa a la cuantía de las tendencias negativas.

La tabla 85 compila las inhomogeneidades y tendencias reveladas por el test de Mann - Kendall en la precipitación media MAM de Vizcaya y de la vertiente cantábrica de Álava. 
Tabla 85: Inhomogeneidades y tendencias detectadas aplicando el test de Mann - Kendall a la precipitación media MAM de 1859 a 2013:

\begin{tabular}{|c|c|c|c|c|}
\hline Años inhomogeneidad & Indicativos & Tendencia & $\begin{array}{l}\text { Inhomogeneidad } \\
\text { "climatológica" }\end{array}$ & $\begin{array}{l}\% \text { series } \\
\text { sobre total }\end{array}$ \\
\hline 1886 y $1890-1892$ & 1059L & + & Sí & $50(2)$ \\
\hline $1918-1919$ & 1055 & + & No & \multirow{2}{*}{$20-33(3-5)$} \\
\hline $1923,1925,1926$ & 1055 & + & No & \\
\hline 1926 & 1059 & - & Sí & $25(4)$ \\
\hline 1971 & 1093 & + & Sí & \multirow{4}{*}{$6-25$} \\
\hline 1972 & $1054,1082,1093,9076 \mathrm{I}$ & + & 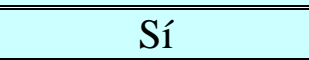 & \\
\hline 1973 & 1093 & + & Sí & \\
\hline 1974 & 1054,1093 & + & Sí & \\
\hline 1975 & 1060A, 1082, 1093 & + & Sí & \multirow{6}{*}{$13-36$} \\
\hline 1976 & 1082,1093 & + & Sí & \\
\hline \multirow{2}{*}{$1977-1978$} & 1060A, 1082, 1093 & + & Sí & \\
\hline & 1083 & + & No & \\
\hline \multirow{2}{*}{1979} & 1060A, 1075E, 1082, 1093 & + & Sí & \\
\hline & 1083 & + & $\mathrm{No}$ & \\
\hline $1980-1983$ & 1082,1093 & + & Sí & $13-18$ \\
\hline 1987 & $1079 \mathrm{I}$ & 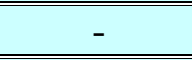 & Sí & 5 \\
\hline 1996 & 1053 & 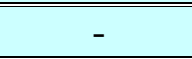 & $\overline{\text { Sí }}$ & 7 \\
\hline 1997 & $1059,1078 \mathrm{E}, 1083$ & 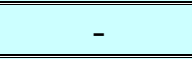 & Sí & 21 \\
\hline 2007 & 1082 & + & $\overline{\text { Sí }}$ & \multirow{2}{*}{$11-25(8-9)$} \\
\hline $2008-2009$ & $1081 \mathrm{U}, 1082$ & + & Sí & \\
\hline
\end{tabular}

Los descubrimientos de la tabla 85 se contraponen con los revelamientos del examen del test de Mann - Kendall de las series de precipitación media MAM de Guipúzcoa debido a:

a) La parca densidad espacial y temporal de las series de precipitación MAM conteniendo al menos 10 años en Vizcaya y en la vertiente cantábrica de Álava.

b) Las similares características del clima de Vizcaya, la vertiente cantábrica de Álava y Guipúzcoa.

Los datos de Vizcaya y de la vertiente cantábrica de Álava se contrastan con las mediciones de 1013 I $\vee$ Irún Viteri, 1024B $\vee$ Igueldo Faro, 1024D $\vee$ San Sebastián Instituto, 1024F II $\vee$ San Sebastián y 1050 II $\vee$ Eibar.

La tabla 86, proveniente de la Nota Técnica No 13 de AEMET, reproduce los resultados del estudio de las series de precipitación MAM de Guipúzcoa de 1941 a 2012 con el test de Mann - Kendall. 
Tabla 86: Inhomogeneidades y tendencias detectadas aplicando el test de Mann - Kendall a la precipitación media MAM en Guipúzcoa de 1941 a 2012:

\begin{tabular}{|c|c|c|c|c|}
\hline $\begin{array}{c}\text { Años } \\
\text { inhomogeneidad. }\end{array}$ & Indicativos & Tendencia & $\begin{array}{l}\text { Inhomogeneidad } \\
\text { "climatológica" }\end{array}$ & $\begin{array}{c}\% \text { series } \\
\text { sobre total }\end{array}$ \\
\hline 1951 & 1022A, 9268, 1037 & + & Sí & 19 \\
\hline 1955 & 1026 & - & Sí & 5 \\
\hline 1969 & 1044 & + & Sí & 9 \\
\hline 1970 & 1018,1026 & + & Sí & 9 \\
\hline 1971 & $1018,1026,1044,1044 \mathrm{~A}$ & + & Sí & 17 \\
\hline 1972 & $1018,1026,1036,1044 \mathrm{~A}$ & + & 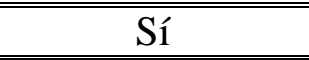 & 17 \\
\hline 1974 & 1026 & + & Sí & 4 \\
\hline 1975 & $\begin{array}{c}1016,1018 \mathrm{~A}, 1024,1026,1032 \mathrm{~A}, 1036 \\
1044 \mathrm{~A}\end{array}$ & + & Sí & 32 \\
\hline 1976 & $1016,1024,1026,1036$ & + & Sí & 19 \\
\hline 1977 & $1016,1022,1026,1036$ & + & Sí & 17 \\
\hline 1978 & $1016,1022,1024,1026,1036$ & + & Sí & 22 \\
\hline 1979 & $\begin{array}{c}1016,1021 \mathrm{O}, 1022,1023,1024,1024 \mathrm{E} \\
1026,1031,1036,1044 \mathrm{~A}\end{array}$ & + & Sí & 45 \\
\hline 1980 & $\begin{array}{c}1016,1022,1023,1024,1024 \mathrm{E}, 1026,1035, \\
1036\end{array}$ & + & Sí & 35 \\
\hline 1981 & (1016, 1022, 1023, 1024, 1024E, 1026, 1036 & + & Sí & 32 \\
\hline 1982 & $1016,1024 \mathrm{E}, 1026,1036$ & + & Sí & 18 \\
\hline 1982 & $1025 \mathrm{E}, 1037 \mathrm{O}$ & - & Sí & 99 \\
\hline 1983 & 1016, 1024, 1024E, 1026 & + & Sí & 15 \\
\hline 1984 & $1016,1024,1026$ & + & 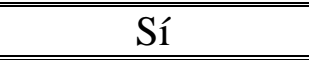 & 12 \\
\hline 1985 & $1024,1024 \mathrm{E}, 1026$ & + & Sí & 17 \\
\hline 1986 & 1024E, 1026, 1035, 1036 & + & Sí & 16 \\
\hline 1987 & $1024 \mathrm{E}, 1026$ & + & Sí & 8 \\
\hline $\begin{array}{c}1988-1990 y \\
1993-1995\end{array}$ & $1024 \mathrm{E}$ & + & Sí & 3 \\
\hline $1991-1992$ & $1024 \mathrm{E}, 1035$ & + & "Sí & 7 \\
\hline 1992 & $1013 \mathrm{I}$ & - & Sí & 4 \\
\hline 1993 & $1013 \mathrm{I}, 1019 \mathrm{~A}$ & 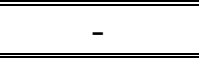 & 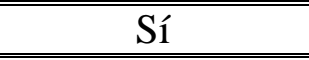 & 7 \\
\hline 1995 & 1013I & 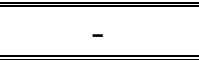 & 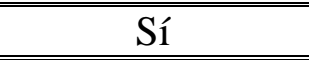 & 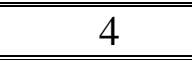 \\
\hline 1996 & 1013I, 1025N, 1033U, 1038 & 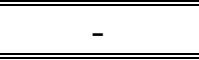 & Sí & 14 \\
\hline 1997 & "1013I, 1019A, 1031, 1033U, 1038, 1048 & 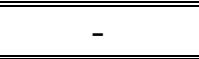 & Sí & 25 \\
\hline 1998 & 1013I, 1019A, 1038 & 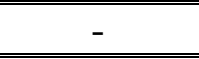 & Sí & 12 \\
\hline 1999 & $1026 \mathrm{~A}$ & - & Sí & 4 \\
\hline 2000 & $1026 \mathrm{~A}, 1036 \mathrm{O}$ & 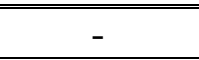 & Sí & 9 \\
\hline 2001 & 1026A, 1031, 1036O, 1048, 1049O & - & Sí & 23 \\
\hline 2002 & 1026A, 1036O, 1048, 1049O, 1049U & 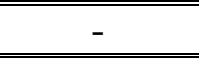 & Sí & 26 \\
\hline 2003 & 1026A, 1031, 1036O, 1048, 1049O, 1049U & 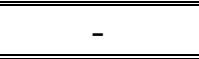 & Sí & 30 \\
\hline 2004 & 1026A, 1036O, 1048, 1049O, 1049U & 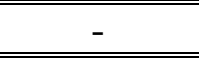 & Sí & 25 \\
\hline $2005-2006$ & $1014,1026 \mathrm{~A}, 1036 \mathrm{O}$ & 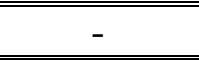 & Sí & $17-18$ \\
\hline $\begin{array}{l}2007-2008 \text { y } \\
2010-2012\end{array}$ & 1014 & - & Sí & 6 \\
\hline
\end{tabular}




\section{1.- Tendencia positiva en 1886 y de 1890 a 1892 en 1059L:}

1.- Los únicos lugares con mediciones pluviométricas en Guipúzcoa, Vizcaya y Álava simultáneos a 1059L I $\vee$ Orduña son 1077C \& Bilbao Histórica y 1024D P San Sebastián Instituto.

La tabla 87 expone la fecha de inicio y los años incompletos de los intervalos sin rupturas de 1059L I $\nabla, 1077 \mathrm{C} \vee$ y 1024D $\nabla$.

Tabla 87: Fecha inicio y años incompletos de 1059L I $\vee, 1077 \mathrm{C} \vee$ y 1024D $\vee$ :

$\begin{array}{rccc}\text { Indicativo } & \text { Nombre } & \text { Comienzo } & \text { Años incompletos } \\ \text { 1059L I } ~ & \text { Orduña } & 01-02-1881 & \\ \text { 1077C } & \text { Bilbao Histórica } & 01-01-1859 & 1862-1864,1874 \\ \text { 1024D } \supsetneq & \text { San Sebastián Instituto } & 01-01-1878 & \end{array}$

2.- Los valores de 1059L I $\nabla$ provienen de los Resúmenes de las Observaciones Meteorológicas efectuadas durante los años 1913 a 1923.

3.- La carencia de datos de Febrero, Marzo, Abril y Mayo de 1874 en $1077 \mathrm{C} P$ es sincrónica al asedio de Bilbao del 21 de Febrero al 2 de Mayo de 1874 durante la $3^{\text {a }}$ Guerra Carlista.

4.- Los jardines meteorológicos de 1077C $\vee$ y 1024D $\bigcirc$ se ubicaron en Institutos (1024D $\bigcirc$ en la terraza superior); el de 1059L I $\vee$ en el claustro anejo a un Colegio.

5.- El análisis del test de rachas de la precipitación MAM descubre una inhomogeneidad climatológica en $1077 \mathrm{C} \vee$ de 1877 a 1887 y de 1888 a 1898 (tabla 33, página 79) y en 1024D $\vee$ de 1891 a 1900 (Nota Técnica No 13 AEMET).

6.- No hay tendencias coetáneas detectadas por el test de Mann - Kendall en Guipúzcoa (Nota Técnica No 13 AEMET).

7.- Los años más pluviosos de 1059L I \ son 1890, 1892, 1888 y 1889 (tabla 37, página 84$)$.

8.- La gráfica 42 muestra la precipitación media MAM y la mediana de 1881 a 1899 de 1059L I $\vee, 1077 \mathrm{C} \vee$ y 1024D $P$.

La gráfica 42 denota con líneas de trazo continuo la precipitación media MAM y con líneas discontinuas, la mediana de la precipitación media MAM en el lapso temporal entre roturas de cada serie. 
Gráfica 42: Precipitación media MAM y mediana de la precipitación media MAM $\left(1 / \mathrm{m}^{2}\right)$ de 1059L I $\nabla, 1077 \mathrm{C} \vee$ y 1024D $\nabla$ :

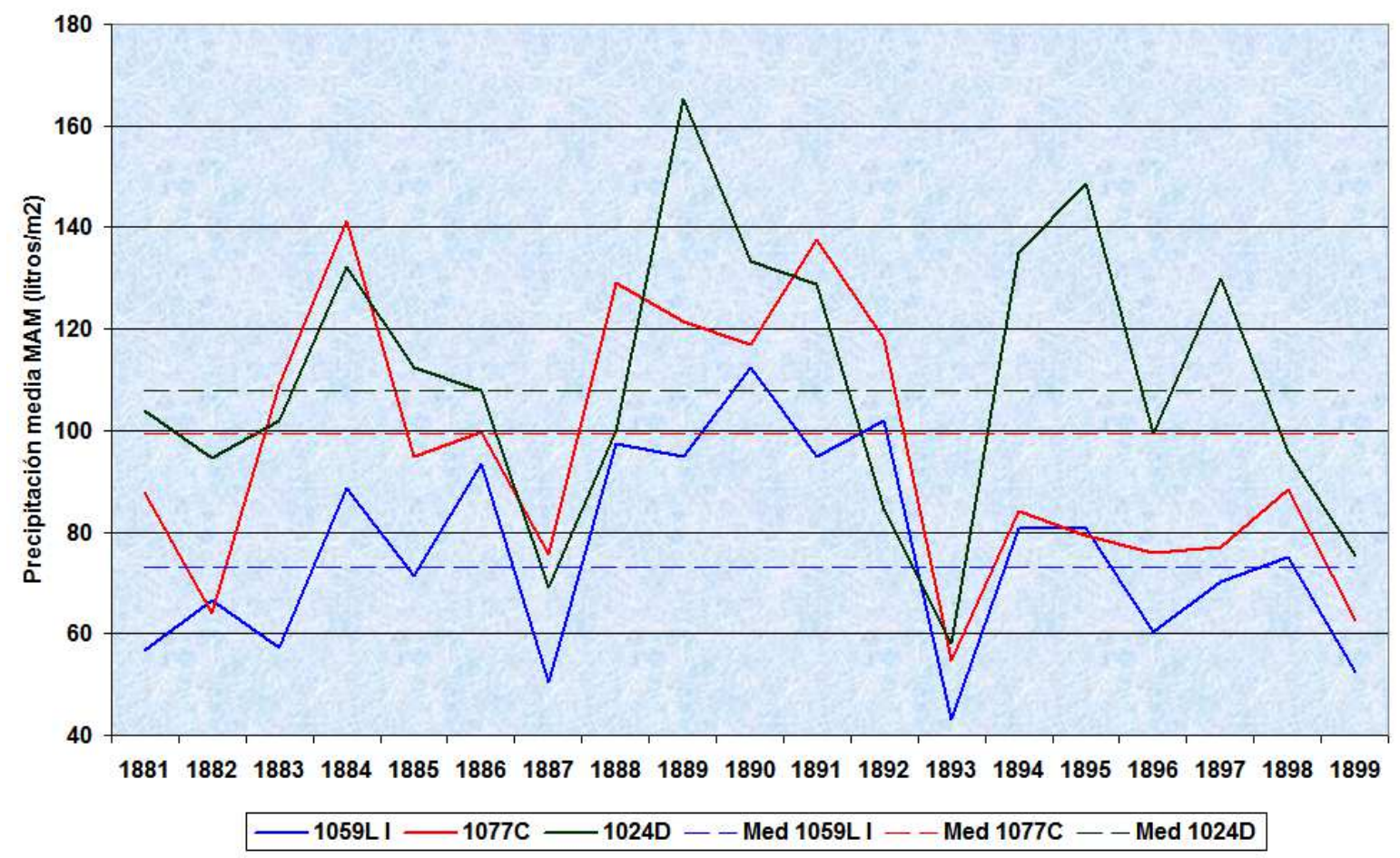

De la gráfica 42 se colige:

8.1.- Las precipitaciones en MAM aumentan de 1882 a 1884; 1885 y 1886 son años normales.

Al mínimo acusado de 1887 le suceden 1888 a 1892, de una elevada pluviosidad, con precipitaciones muy superiores a las respectivas medianas en las 3 localizaciones disponibles.

Al muy seco 1893 le sobrevienen 1894 y 1895 con una recuperación pluviométrica, más acusada en Vizcaya.

La tendencia positiva escrutada de 1886 y de 1890 a 1892 en 1059 L I $\varnothing$ es coherente con los citados años de abundantes precipitaciones.

8.2.- Los máximos pluviométricos coinciden en $1884,1888,1889,1891$ y 1894 , concordantes con los máximos expuestos en la tabla 49 (página 103).

8.3.- Las sequías concurren en $1881,1882,1887,1893$ y 1899, corroborando los resultados de la tabla 49 bis (página 104).

8.4.- Las precipitaciones acrecen de Oeste a Este y son más cuantiosas en el litoral que en Orduña. 
8.5.- El año de inicio es crítico en la elusión de conclusiones erróneas: positiva.

a) Si las 3 series se hubieran fundado en 1887, la tendencia de la precipitación sería

b) De principiar los testimonios en 1889 , la tendencia de la precipitación devendría negativa. Craso error sería entonces la conclusión de una disminución de la precipitación en MAM en Vizcaya y en la vertiente cantábrica de Álava.

9.- La gráfica 43 revela el cociente de la precipitación media MAM de 1059L I $\nabla$ Orduña referida a la precipitación media MAM de 1077C $\nabla$ y 1024D $\nabla$ de 1881 a 1899.

\section{Gráfica 43 Razón de las precipitaciones de 1059L I $\nabla$ respecto a 1077C $\vee$ y 1024D $\vee$ :}

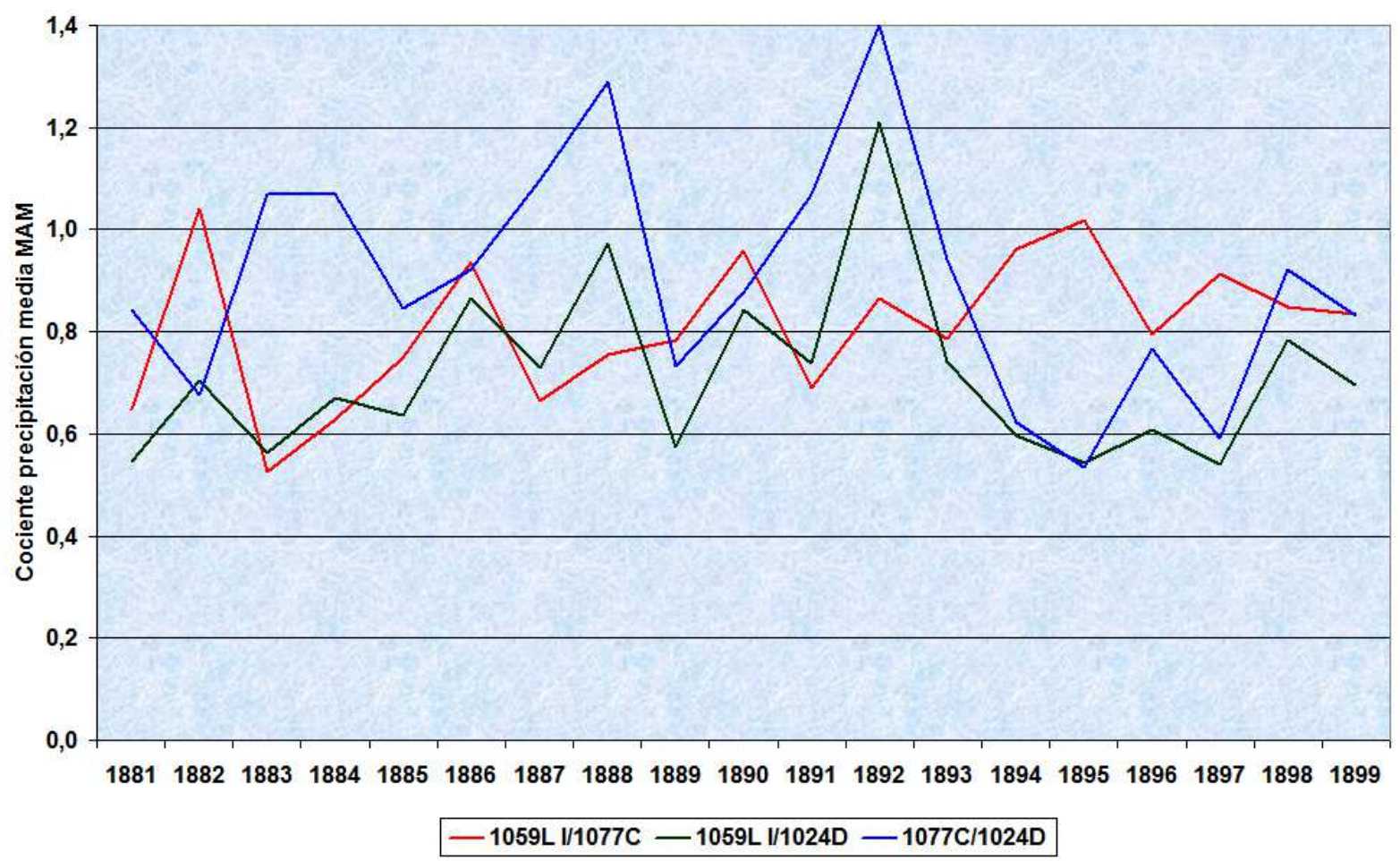

De la gráfica 43 se aprecia:

9.1.- El cociente de las precipitaciones de 1059L I $\nabla$ fluctúa entre unos valores máximos y mínimos constantes, con una cadencia de 10 años en los máximos (1882 y 1892; 1888 y 1898$)$ y cercana a los 10 en los mínimos (1883 y $1891 ; 1887$ y 1897$).$

9.2.- La relación de la pluviosidad de 1059L I $\nabla$ es mejor respecto a 1077C $\nabla$ (ambas sitas en Vizcaya) que referida a 1024D $P$.

Por tanto, se la cataloga de tendencia "climatológica". 
2.- Tendencia positiva de 1918 a 1919 , en 1923 y de 1925 a 1926 en 1055 y negativa en 1059 en 1926:

1.- Los registros pluviométricos de $1055 \nabla$ Lequeitio Faro y de 1059 I $\nabla$ Punta Galea Faro se contrastan con las mediciones de 1013 I $\vee$ Irún Viteri, 1024B $\vee$ Igueldo Faro y 1024F II $\vee$ San Sebastián.

Los valores de Lequeitio Faro 1055 P, Punta Galea Faro 1059 I $\nabla$ y de Machicaco Faro 1057C I $\vee$ y 1057C II $\vee$ proceden de los Resúmenes de las Observaciones Meteorológicas efectuadas durante los años 1911 a 1926.

La tabla 88 recoge el empiece y los años incompletos de los periodos sin roturas de 1055 P, 1059 I $\vee, 1057$ C I $\vee, 1057$ C II $\vee, 1013$ I $\vee, 1024$ B $\vee$ y 1024F II $\vee$ y tiene presente la rotura de 1057C $\vee$ Machicaco Faro en Noviembre del año 1921, descrita en la página 20.

Tabla 88: Fecha inicio y años incompletos de 1055 P, 1059 I $\vee, 1057 \mathrm{C}$ I $\vee, 1057 \mathrm{C}$ II $\vee$, 1013 I $P, 1024 \mathrm{~B} \vee$ y $1024 \mathrm{~F}$ II $\vee$ :

\begin{tabular}{|c|c|c|c|}
\hline Indicativo & Nombre & Comienzo & Años incompletos \\
\hline 1055 P & Lequeitio Faro & $01-05-1911$ & $1912,1920,1924$ \\
\hline 1059 I $P$ & Punta Galea Faro & $01-01-1911$ & 1921,1925 \\
\hline $1057 \mathrm{C} \mathrm{I} P$ & Machicaco Faro & $01-01-1913$ & \\
\hline $1057 \mathrm{C}$ II $\nabla$ & Machicaco Faro & $01-12-1921$ & 1930 \\
\hline 1013 I $P$ & Irún Fitosanitaria & $01-02-1914$ & \\
\hline 1024B 8 & Igueldo Faro & $01-01-1913$ & 1924 \\
\hline 1024F II $P$ & San Sebastián & Final Marzo 1918 & \\
\hline
\end{tabular}

2.- Una tendencia negativa se observa en Guipúzcoa en 1921 en 1024 F II $\nabla$ San Sebastián (Nota Técnica No 13 AEMET).

3.- El examen de la precipitación media MAM con el test de las rachas aflora una inhomogeneidad "climatológica" en 1057C II $\vee$ de 1922 a 1932 (tabla 33, página 79), en 1013 I $\vee$ de 1918 a 1927 y de 1920 a 1930 y en 1024 F II $\nabla$ de 1919 a 1932 (Nota Técnica $\mathrm{N}^{\mathrm{o}} 13$ AEMET).

4.- La gráfica 44 representa la precipitación media MAM y la mediana de 1055 , 1059 I $\nabla, 1057$ C I $\vee, 1057$ C II $\vee, 1013$ I $\vee, 1024 \mathrm{~B} \vee$ y 1024F II $\vee$ de los años 1913 a 1926.

La gráfica 44 expone la precipitación media MAM con líneas continuas; con líneas discontinuas, la mediana en los intervalos entre roturas de cada serie. 
Gráfica 44: Precipitación media MAM y mediana de la precipitación media MAM $\left(1 / \mathrm{m}^{2}\right)$ de

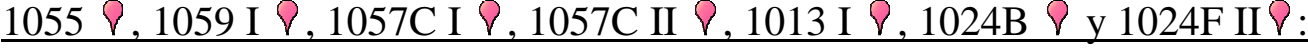

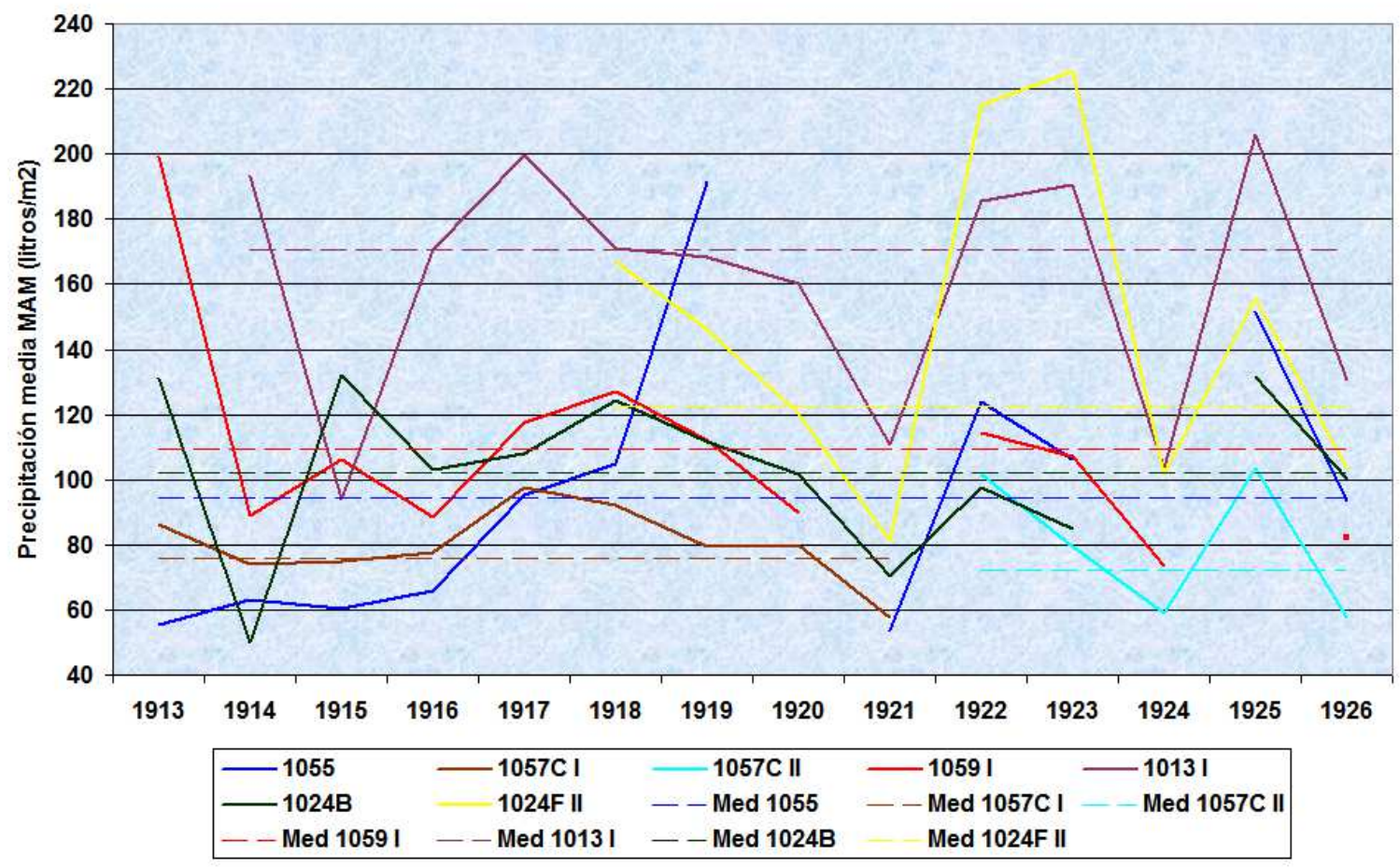

4.1.- Irún y San Sebastián son los lugares más lluviosos.

4.2.- 1055 Lequeitio Faro es el único con pluviosidad inferior a la mediana en 1913.

Las precipitaciones en 1055 \& se incrementan sin intermisión de 1915 a 1919; $1055 \vee$ muta de ser el emplazamiento más seco de 1913 a 1917 al más pluvioso en 1919, anotando la mayor precipitación en 1919 de Guipúzcoa, Vizcaya y Álava.

Tras 1920, las precipitaciones registradas en $1055 \nabla$ vuelven a mudar de la última posición (1921) a la segunda (1925).

4.3.- Los acrecentamientos y decrecimientos de los datos de precipitación de 1055 尺 son congruentes con las anotaciones en el resto de enclaves:

a) Los máximos acaecen simultáneamente en 1913 (muy pluvioso), 1918 (secundario), 1922 (en Guipúzcoa 1923 fue también muy lluvioso) y 1925.

b) Los mínimos acontecen sincrónicos en 1914, 1920, 1921 y 1924.

4.4.- El dato de 1914 en 1024B $\vee$ y los valores de 1024F II $\nabla$ de $1921-1923$ y de 1925 - 1926 son sospechosos. 
4.5.- Los resultados de la contraposición de 1055 en MAM con las restantes series disponibles son análogos a los de la comparativa anual (gráfica 15, página 134).

5.- La gráfica 45 ilustra el cociente de la precipitación media MAM de 1055 P Lequeitio Faro referida a la precipitación MAM en cada sucesivo año de 1057C I $\nabla$, 1057C II $\vee, 1059$ I $\vee, 1013$ I $\vee, 1024$ B $\vee$ y 1024F II $\vee$ de 1913 a 1926.

Gráfica 45: Razón de las precipitaciones de 1055 P respecto a 1057C I $\vee, 1057 \mathrm{C}$ II $\nabla$, 1013 I $\vee, 1024 \mathrm{~B} \vee$ y $1024 \mathrm{~F} \mathrm{II} \vee:$

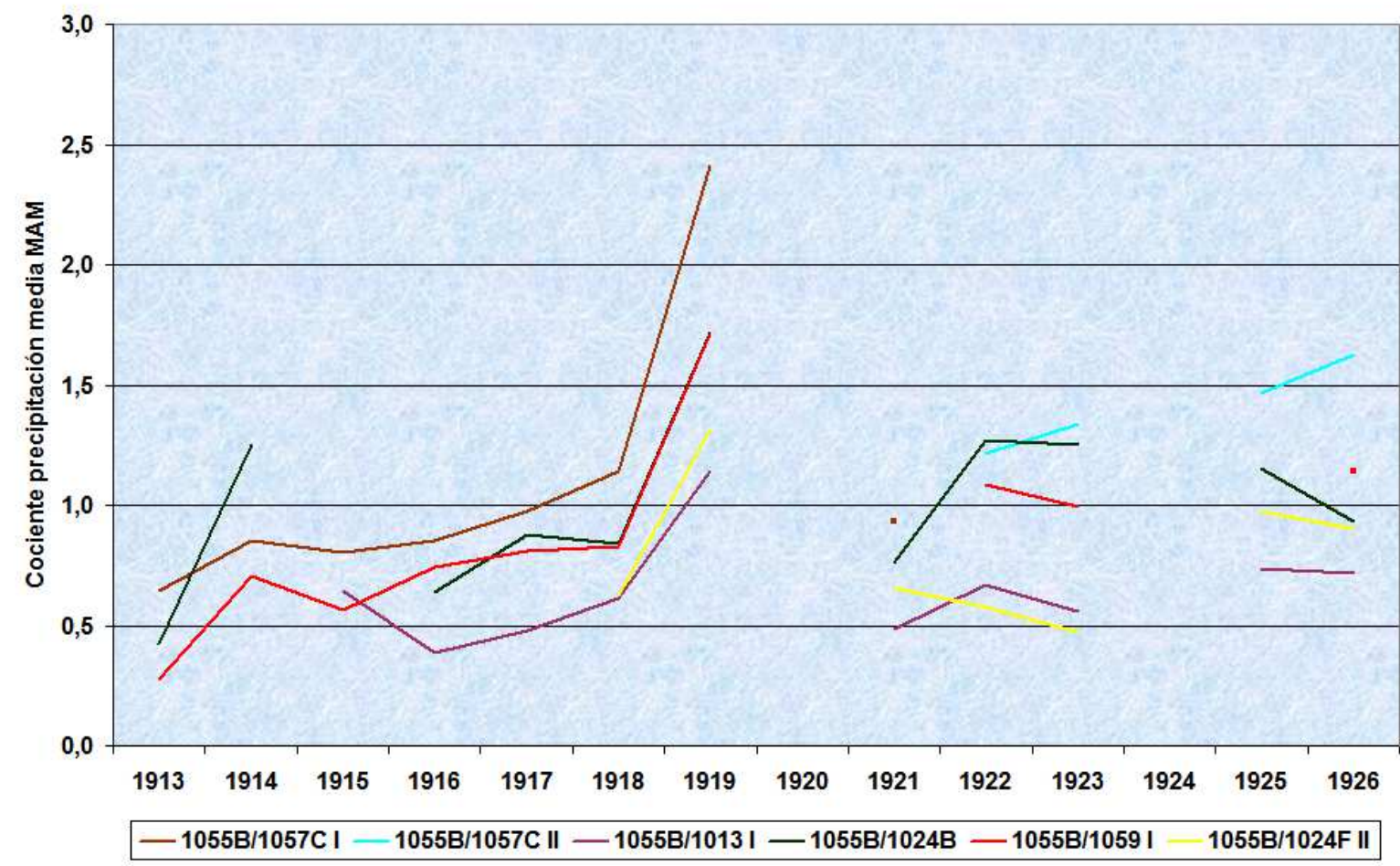

5.1.- La ausencia de registros de $1055 \nabla$ coadyuva la omisión de las razones en 1920 y 1924.

5.2.- El cociente de la precipitación media MAM recabada en $1055 \nabla$ respecto a la precipitación de las restantes ubicaciones acrece de 1913 a 1919 y de 1921 a 1926. Un incremento de la precipitación en un único lugar carece de sentido físico.

5.3.- Los hallazgos expuestos en la gráfica 45 del cociente de 1055 en MAM concuerdan con los descritos en el cotejo anual (gráfica 16, página 135): El acrecimiento de las cuantías de precipitaciones apuntadas en 1055 \& en la precipitación anual se advierte a $\underline{\text { su vez en MAM. }}$

5.4.- La recopilación de estos revelamientos corrobora la prevención de la calidad de las mediciones de pluviosidad anotadas en 1055 . 
6.- La gráfica 46 ostenta el cociente de la precipitación media MAM de 1059 I $\nabla$ Punta Galea Faro en relación a 1057C I $\nabla, 1057$ C II $\nabla, 1013$ I $\nabla, 1024$ B 8 y 1024F II 8 de 1913 a 1926 y el cociente de la precipitación media MAM de 1057C I $\nabla$ en relación a 1024B P.

Gráfica 46: Razón de las precipitaciones de 1059 I $\nabla$ respecto a 1057C I $\nabla, 1057 \mathrm{C}$ II $\nabla$, 1013 I $\vee, 1024 \mathrm{~B} \vee$ y $1024 \mathrm{~F}$ II $\vee$ y razón de las precipitaciones de $1057 \mathrm{C}$ I $\vee$ respecto a 1024B P:

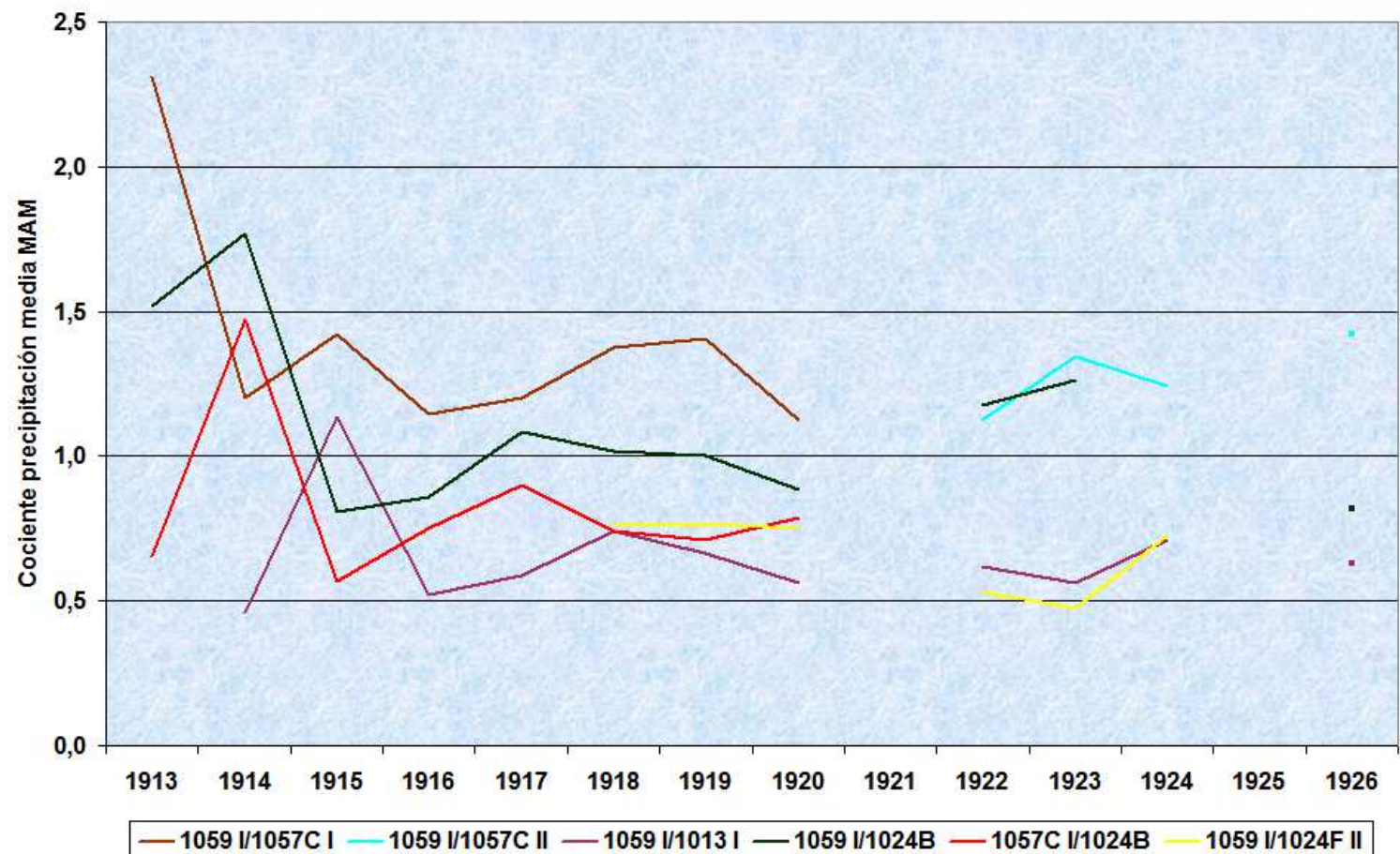

De la gráfica 46 se infiere: 1914.

6.1.- Una elevada variabilidad en MAM de las precipitaciones en los años 1913 y

6.2.- El cociente de las precipitaciones de 1059 I $\vee$ posterior a 1914 oscila en un rango constante.

6.3.- La razón 1057C I $\vee / 1024 \mathrm{~B} \vee$ reafirma la cautela referente al registro pluviométrico de 1024B $\vee$ en MAM en 1914.

Por consiguiente, la tendencia de 1055 de 1918 a 1919 , en 1923 y de 1925 a 1926 se cataloga de tendencia "no climatológica" y la tendencia de 1059 I $\nabla$ en 1926 se clasifica de "climatológica". 
3.- Tendencia positiva de 1971 a 1974 en 1093 , en 1972 en 1054,1082 y 9076 I y en 1974 en 1054:

1.- Los datos pluviométricos de 1093 I 8 Carranza, 1054 II $\nabla$ Marquina, 1082 I 8 Bilbao Aeropuerto y 9076I $\nabla$ Ceanuri Casa Forestal son contrapuestos a las observaciones de 1050 II $\vee$ Eibar, 1053 I $\vee$ Echevarría, 1068 II $\vee$ Basauri y 1070 P Abadiano.

La tabla 89 detalla la fecha de iniciación y los años con valores parciales de los intervalos sin roturas de 1054 II $\vee, 1082$ I $\vee, 1093$ I $\vee, 9076$ I $\vee, 1050$ II $\vee, 1053$ I $\vee$, 1068 II $\odot$ y $1070 \vee$.

Tabla 89: Fecha inicio y años incompletos de 1054 II $\nabla, 1082$ I $\vee, 1093$ I $\vee, 9076 I$, 1050 II $\vee, 1053$ I $\vee, 1068$ II $\vee$ y 1070 \&:

\begin{tabular}{|c|c|c|c|}
\hline Indicativo & Nombre & Comienzo & Años incompletos \\
\hline $1054 \mathrm{II} \vee$ & Marquina & $01-05-1956$ & 1959,1975 \\
\hline $1082 \mathrm{I} \curlyvee$ & Bilbao Aeropuerto & $01-03-1947$ & \\
\hline $1093 \mathrm{I} P$ & Carranza & $01-11-1956$ & \\
\hline $9076 \mathrm{I} P$ & Ceanuri C. Forestal & $24-04-1945$ & $1946,1948-1967,1973-1982$ \\
\hline $1050 \mathrm{II} \vee$ & Eibar & Final 1964 & \\
\hline $1053 \mathrm{I} \vee$ & Echevarría & $01-10-1961$ & \\
\hline 1068 II $\nabla$ & Basauri & Final 1954 & \\
\hline $1070 \curlyvee$ & Abadiano & $01-12-1967$ & \\
\hline
\end{tabular}

2.- Una tendencia positiva sincrónica de la precipitación media MAM aflora en Guipúzcoa en 1971 en 1044 P Escoriaza; de 1971 a 1972 en 1018 P Rentería, 1026 Beasain y 1044A $\vee$ Escoriaza Tesa; en 1972 en $1036 \vee$ Zarauz y en 1974 en $1026 \nabla$ Beasain (tabla 86, página 174).

3.- El test de rachas de Thom aplicado a la precipitación media MAM exterioriza una inhomogeneidad "climatológica" en 1060A P Amurrio Colegio de 1964 a 1975 y de 1967 a 1977, en 1054 II $\vee$ de 1965 a 1976, en 1093 I $\vee$ de 1967 a 1976, en 1060 II $\vee$ Amurrio Instituto de 1967 a 1977, en 1070 \& de 1968 a 1977 y en 1075 II $\vee$ Dima de 1968 a 1978 (tabla 33, página 79).

4.- La gráfica 47 representa la precipitación media MAM y la mediana de 1054 II $\nabla$, 1082 I $\nabla, 1093$ I $\vee, 9076$ I $\vee, 1050$ II $\vee, 1053$ I $\vee, 1068$ II $\vee$ y $1070 \vee$ de 1957 a 1974.

La gráfica 47 denota la precipitación media MAM con segmentos continuos; con segmentos discontinuos la mediana en los intersticios entre las roturas de cada serie. 
Gráfica 47: Precipitación media MAM y mediana de la precipitación media MAM $\left(1 / \mathrm{m}^{2}\right)$ de 1054 II $\vee, 1082$ I $\vee, 1093$ I $\vee, 9076$ I $\vee, 1050$ II $\vee, 1053$ I $\vee, 1068$ II $\vee$ y $1070 \vee:$

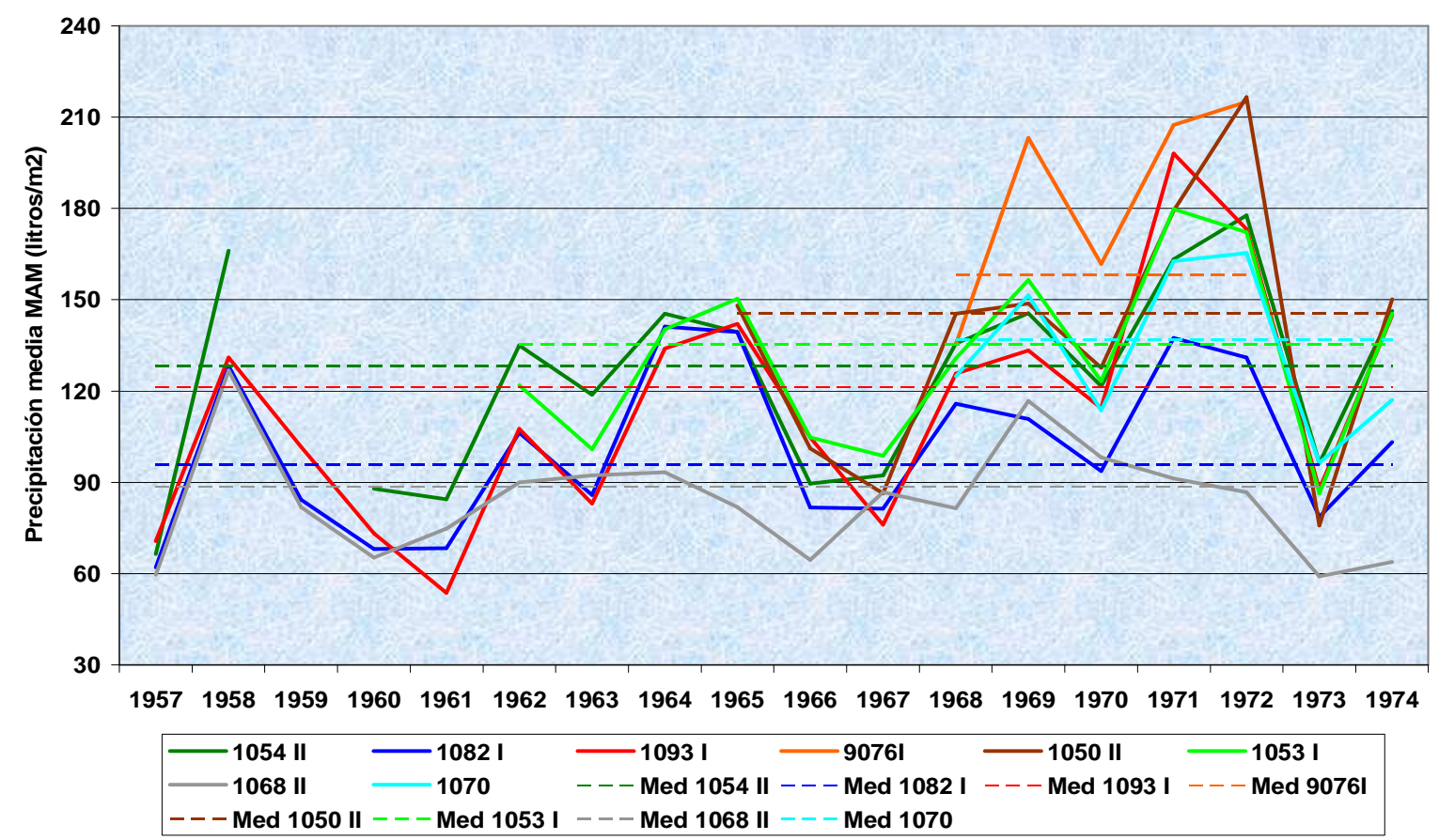

De la gráfica 47 se concluye:

4.1.- Las precipitaciones se acrecientan de 1957 a 1975 en todos los enclaves, con sucesivos máximos y mínimos crecientes y la salvedad de 1068 II $\nabla$. Las tendencias positivas de 1054 II $\nabla, 1082$ I $\nabla, 1093$ I $\nabla$ y 9076I $\nabla$ son concomitantes con el transcurso de la pluviosidad en MAM en las restantes ubicaciones.

4.2.- Los máximos simultáneos de 1958, 1964, 1965, 1969, 1971 y 1972 concuerdan con las tendencia positivas examinadas y con los resultados de la tabla 49 (página 103).

4.3.- Los mínimos coetáneos de 1957, 1960, 1961, 1966, 1967 y 1973 coinciden con los descritos en la tabla 49 bis (página 104).

4.3.- El devenir de la precipitación en 1082 I $\nabla$ en 1960 - 1961, 1964 - 1965, 1968 - 1969 y 1971 - 1972, contrapuesto al del resto de jardines meteorológicos, precede al discurrir pluviométrico del año ulterior.

4.4.- La pluviosidad registrada en 1068 II $P$ en MAM, de pareja magnitud en 1957 y en 1958 a las pluviometrías de 1082 I $\nabla$ y de 1093 I $\vee$, es la única que no aumenta de 1957 a 1974, resultado análogo al expuesto en la gráfica 24 (página 146), referente a la precipitación anual de 1068 II $\nabla$. 
5.- La gráfica 48 presenta el cociente de la precipitación media MAM de 1093 I $\nabla$ Carranza y de 1082 I $\vee$ Bilbao Aeropuerto referida a 1053 I $\vee$, 1054 II $\vee$ y $1070 \vee$ y el cociente de la precipitación media MAM de 1093 I $\vee$ con 1082 I $\vee$ de 1957 a 1974.

Gráfica 48: Razón de las precipitaciones de 1093 I $\$$ y 1082 I $\nabla$ respecto a 1053 I $\vee$, 1054 II $\vee$ y $1070 \vee$ y razón de las precipitaciones de 1093 I $\vee$ en relación a 1082 I $\vee$ :

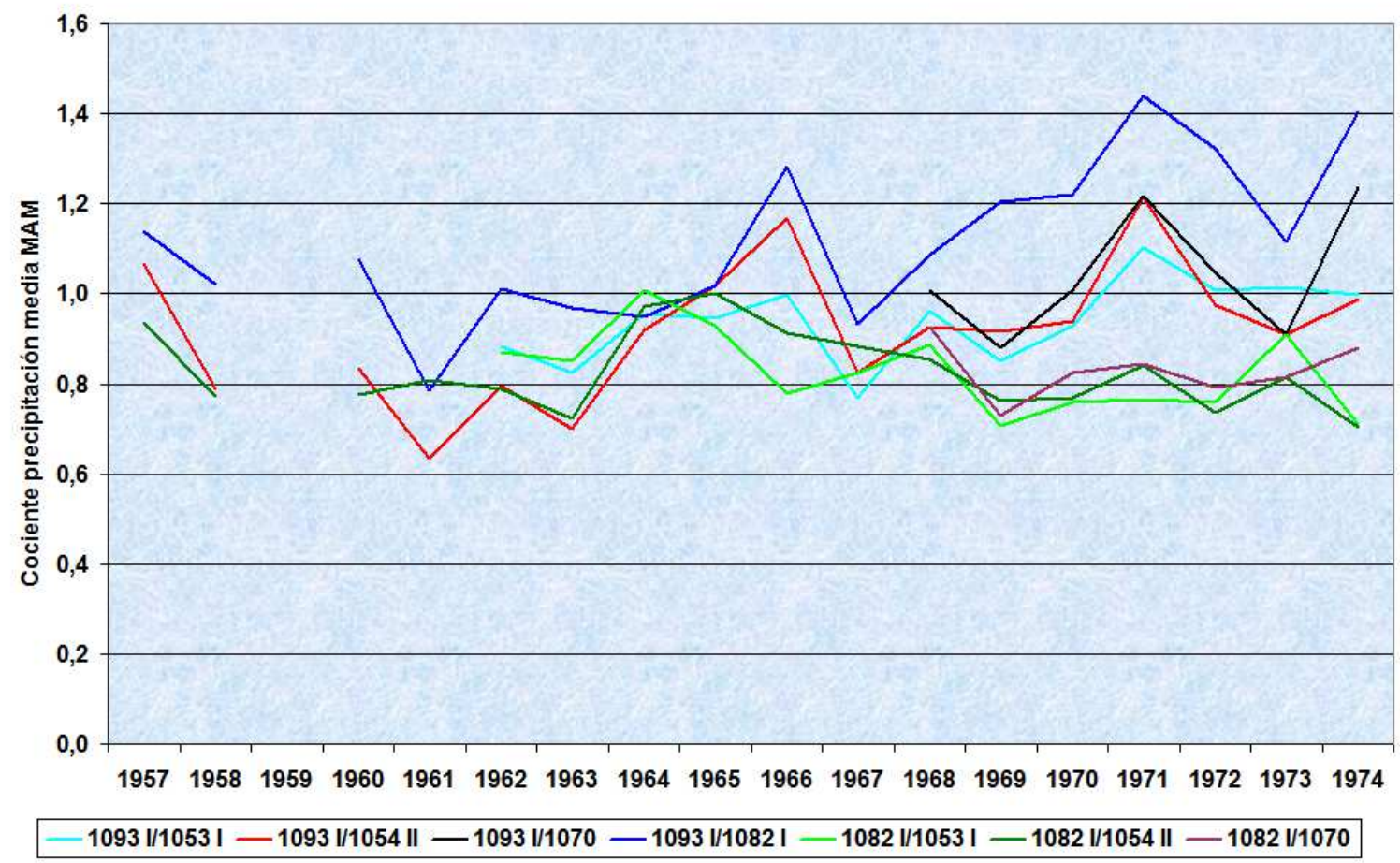

De la gráfica 48 se observa:

5.1.- El cociente de las precipitaciones es constante, con unos valores similares en 1957 y en 1974 y una regularidad en los máximos (1957 y 1966; 1960 y 1971) y en los mínimos (1961 y 1969) próxima a los 10 años.

5.2.- La trascendencia de una adecuada resolución espacial: El cociente 1093 I $\vee /$ 1054 II $\vee$ es conforme a lo largo del tiempo. Ídem ocurre con la razón de 1093 I $\varnothing$ versus 1053 I $\vee .1093$ I $\vee, 1053$ I $\vee$ y 1054 II $\vee$ se sitúan en los respectivos lindes W y E de Vizcaya.

La carencia de 1053 I $\nabla$ y de 1054 II $\vee$ conllevaría la errónea conclusión de un incremento "no climatológico" de la precipitación anotada en 1093 I $\vee$, por sus comparativas con 1082 I $\nabla$ y $1070 \bigcirc$.

5.3.- La relación de las mediciones de 1082 I $\nabla$ con las cuantías de $1070 \vee$ es óptima, indicio de una similitud pluviométrica entre Bilbao Aeropuerto y Abadiano en MAM, al menos de 1968 a 1974. 
6.- La gráfica 49 expone la razón de la precipitación media MAM de 1054 II $\vee$ Marquina y de 9076I $\vee$ Ceanuri respecto a 1053 I $\nabla, 1070 \vee, 1050$ II $\vee$ y la razón de la precipitación media MAM de 1054 II $\vee$ respecto a 9076I $\vee$ de 1962 a 1974.

Gráfica 49: Razón de las precipitaciones de 1054 II $\nabla$ y de 9076I $\nabla$ respecto a 1053 I $\nabla$, $1070 \vee, 1050$ II $\vee$ y razón de las precipitaciones de 1054 II $\vee$ respecto a 9076I $\vee$ :

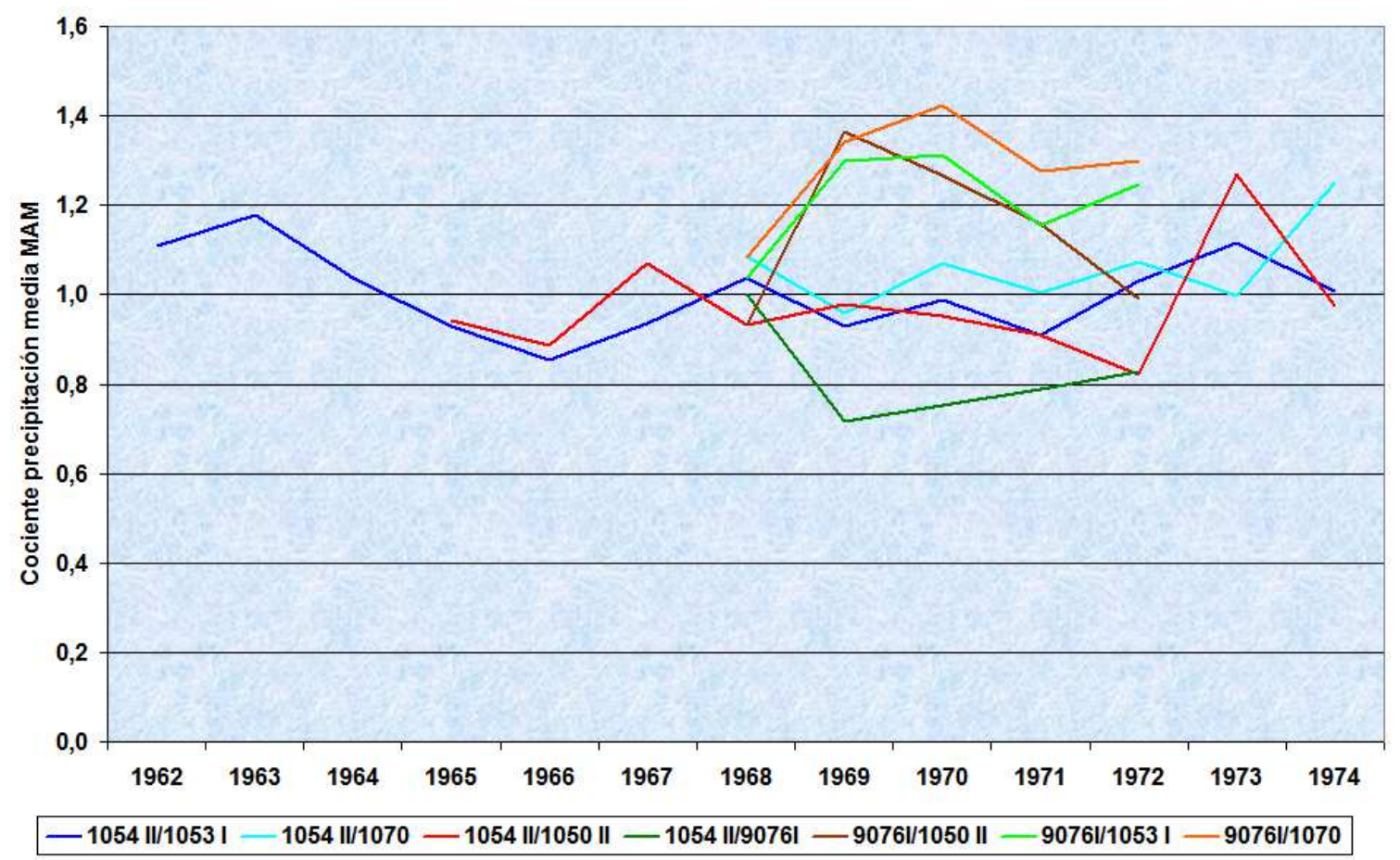

De la gráfica 49 se deduce:

6.1.- El cociente de las precipitaciones de 1054 II $\nabla$ fluctúa entre unos máximos y mínimos constantes de 1962 a 1974.

6.2.- Los máximos del cociente 1054 II $\vee / 1053$ I $\vee$ (1963 y 1973) distan 10 años.

6.3.- La excelsa correlación entre las vecinas sincrónicas 1054 II $\nabla$ Marquina y 1053 I $\nabla$ Echevarría (1054 II $\nabla$ a 4,8 Km. al Norte de 1053 I $\nabla$ ) y la muy buena relación de 1054 II $\nabla$ respecto a 1050 II $\nabla$ Eibar, a $7,5 \mathrm{Km}$. al Sur de 1053 I $\nabla$ y no tan óptima respecto a las restantes series.

6.4.- Las precipitaciones recogidas en 1054 II $\nabla, 1053$ I $\nabla$ y 1050 II $\nabla$ de 1962 a 1974 son de una montante semejante, con unas fluctuaciones inferiores al $20 \%$.

6.5.- La razón 9076I $\vee / 1050$ II $\vee$ en 1968 no difiere del cociente de la relación 9076I $\vee / 1050$ II $\vee$ en 1972 lo cuál disipa cautelas acerca de la pluviometría MAM en 1968 de $9076 \mathrm{I} P$. 
7.- La gráfica 50 recoge el cociente de la precipitación media MAM de 1068 II $\nabla$ Basauri tocante a 1093 I $\vee, 1082$ I $\vee, 1054$ II $\vee, 1070 \vee, 1053$ I $\vee$ y 1050 II $\vee$ de 1957 a 1974.

Gráfica 50: Razón de las precipitaciones de 1068 II $\nabla$ respecto a 1093 I $\nabla, 1082$ I $\nabla$, 1054 II $\vee, 1070 \vee, 1053$ I $\vee$ y 1050 II $P$.

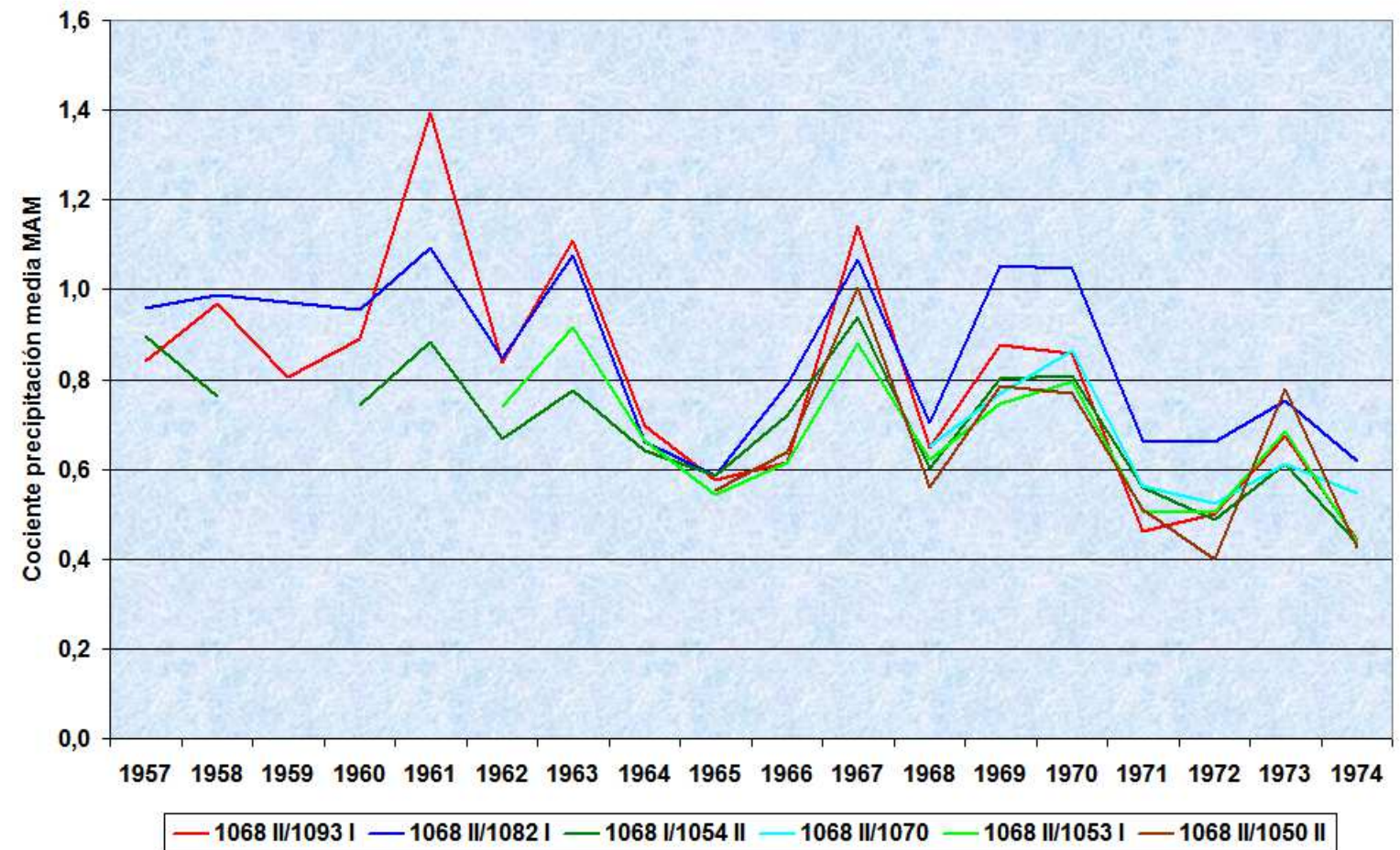

De la gráfica 50 se percata:

7.1.- Las precipitaciones anotadas en 1068 II $\nabla$ decrecen continuamente en su cotejo con las 6 series sincrónicas restantes, con unos sucesivos picos de sierra menguantes en los máximos y mínimos pluviométricos.

Los cocientes 1068 II $\nabla / 1082$ I $\nabla$ y 1068 II $\nabla / 1093$ I $\nabla$ merman de 1958 a 1974 en un $40 \%$ y en un $50 \%$ respectivamente.

7.2.- Este es el motivo por el cuál no se emplea 1068 II $\nabla$ en la comparativa, por el decremento en la precipitación anotada por 1068 II 8 .

El test de Mann - Kendall no indica tendencia en MAM en 1068 II $\nabla$, mas la confrontación con las precipitaciones de 1082 I $\nabla$ y 1093 I $\nabla$ corrobora la mediocre calidad de 1068 II $\vee$, ya detectada en la comparativa de la pluviosidad anual de 1068 II $\nabla$ (gráfica 25, página 147).

Por consiguiente, se trata de una tendencia "climatológica". 
4.- Tendencia positiva en 1975 en $1060 \mathrm{~A}$, de 1975 a 1983 en 1082 y en 1093 , de 1977 a 1979 en $1060 \mathrm{~A}$ y en 1083 y en 1979 en $1075 \mathrm{E}$ :

Los valores de 1060A $\nabla$ Amurrio Colegio, 1082 I $\nabla$ Bilbao Aeropuerto, 1093 I $\nabla$ Carranza y 1075E I $\vee$ Aránzazu se confrontan con los datos de 1060 II $\vee$ Amurrio, 1070 P Abadiano y 1083 I $\vee$ y 1083 II $\vee$ Arcentales.

La tabla 90 describe la fecha de empiece y los años no íntegros de los intervalos sin rupturas de 1060A $\nabla, 1075 \mathrm{E}$ I $\vee, 1082$ I $\vee, 1083$ I $\vee, 1093$ I $\vee, 1060$ II $\vee, 1070 \vee$ y 1083 II $P$.

Tabla 90: Fecha inicio y años incompletos de 1060A $\vee, 1075 \mathrm{E}$ I $\vee, 1082$ I $\vee, 1083$ I $\vee$, 1093 I $\vee, 1060$ II $\vee, 1070$ \& y 1083 II $\vee:$

\begin{tabular}{|c|c|c|c|}
\hline Indicativo & Nombre & Comienzo & Años incompletos \\
\hline $1060 \mathrm{~A} P$ & Amurrio Colegio & $01-10-1961$ & 1966 \\
\hline 1075E I 8 & Aránzazu & $01-12-1967$ & \\
\hline $1082 \mathrm{I} \nabla$ & Bilbao Aeropuerto & $01-03-1947$ & \\
\hline $1083 \mathrm{I} P$ & Arcentales & $01-08-1967$ & \\
\hline $1093 \mathrm{I} P$ & Carranza & $01-11-1956$ & \\
\hline $1060 \mathrm{II} \vee$ & Amurrio & Final 1966 & 1967 \\
\hline $1070 \varnothing$ & Abadiano & $01-12-1967$ & \\
\hline 1083 II $\vee$ & Arcentales & $01-02-1981$ & 1988,1990 \\
\hline
\end{tabular}

2.- 1082 I $\vee$ empieza en la sequía de 1947; 1060A $\vee$ en el seco en extremo 1961; 1075E I $\vee, 1083$ I $\vee$ y $1070 \vee$ en el seco 1967 (tabla 49 bis, página 104).

3.- Una tendencia positiva generalizada y simultánea de la precipitación MAM aflora en Guipúzcoa (tabla 86, página 174).

4.- El análisis del test de las rachas de la precipitación media MAM señala una inhomogeneidad "climatológica" en 1060A P Amurrio Colegio de 1964 a 1975 y de 1967 a 1977, en 1054 II $\nabla$ Marquina de 1965 a 1976, en 1060 II $\vee$ de 1967 a 1977, en 1093 I $\vee$ de 1967 a 1976, en 1070 \& de 1968 a 1977, en 1075 II $\vee$ Dima de 1968 a 1978 y de 1974 a 1984 en 1082 I $\vee$ (tabla 33, página 79).

5.- La gráfica 51 refiere la precipitación media MAM y la mediana de $1060 \mathrm{~A} \vee$,

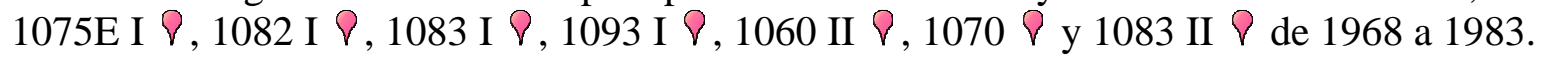

La gráfica 51 indica con líneas de trazo continuo la precipitación total anual y con líneas discontinuas, la mediana en el lapso temporal entre rupturas de cada serie pluviométrica. 
Gráfica 51: Precipitación media MAM y mediana de la precipitación media MAM $\left(1 / \mathrm{m}^{2}\right)$ de

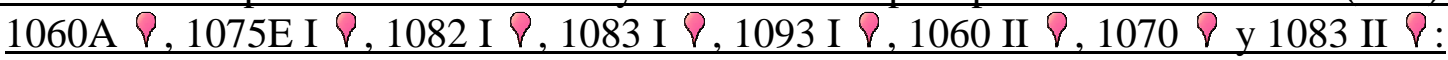

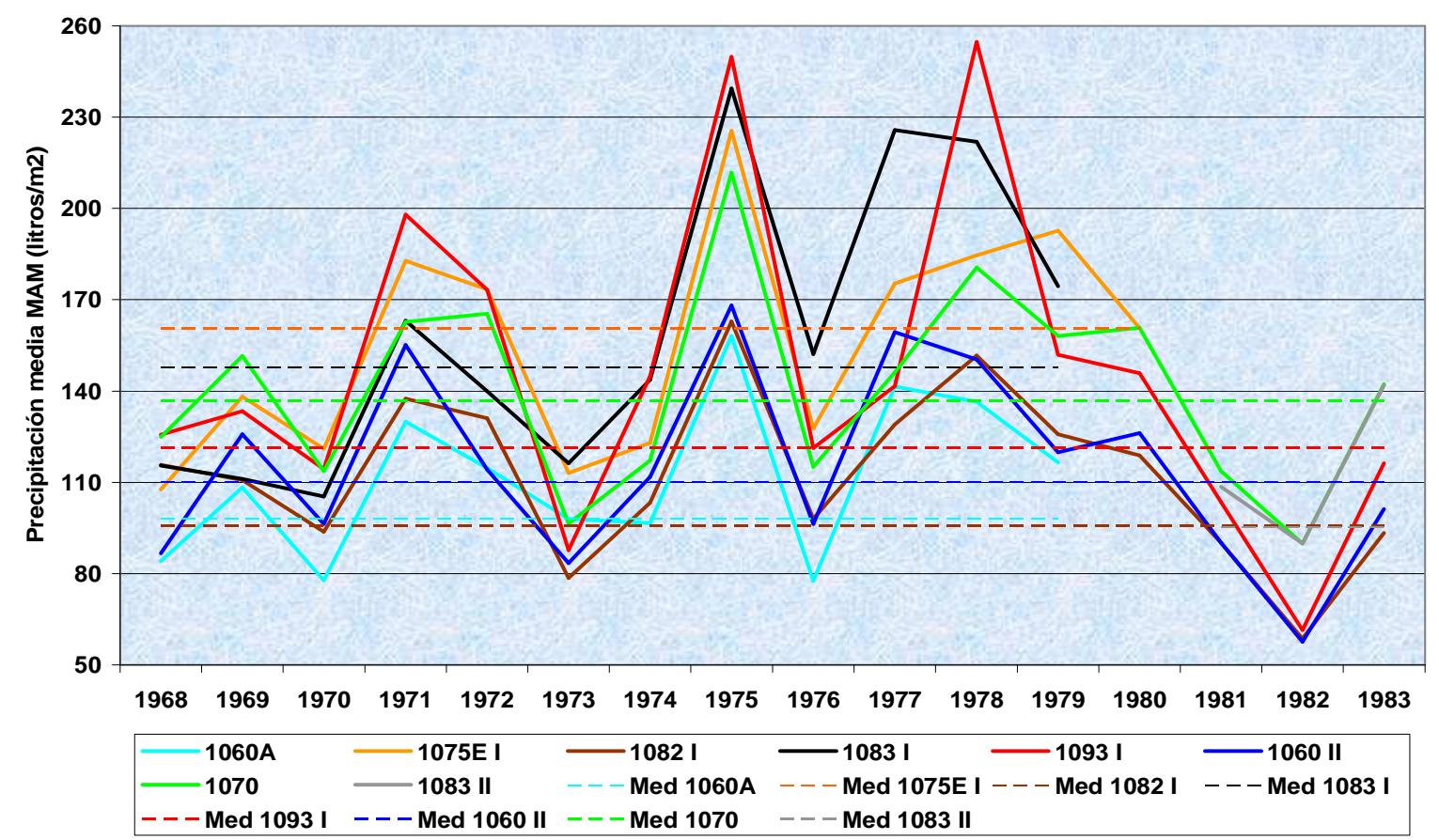

Las características de 1060 II $\nabla$ y $1060 \mathrm{~A} \vee$ se bosquejan en la tabla 25 bis y en la figura 13 (páginas 61 y 62).

De la gráfica 51 se advierte:

5.1.- A los normales MAM de 1968 y 1970 le suceden los pluviosos 1971 y 1972. Al seco 1973 le prosigue un impetuoso acrecimiento de las precipitaciones hasta 1975. Tras el normal 1976 acaece una acusada reversión de la precipitación en los muy lluviosos 1977 y 1978.

Ulteriores a 1979, sobrevienen el normal 1980 y un gradual descenso que toca fondo en 1982, más acusado en el Occidente de Vizcaya y en la vertiente cantábrica de Álava que en el Duranguesado, representado por $1070 \nabla$.

La década de los 70 es muy lluviosa, con efemérides de precipitación en 1050 II $\vee$, 1053 II $\vee, 1054$ II $\vee, 1060$ A $\vee, 1070$ \&, 1075 II $\vee$ y 1093 I $\vee$ (tabla 44, página 93).

La precipitación discurre pareja en 1082 I $\vee, 1060$ II $\nabla$ y 1060A $\nabla$.

5.2.- Los máximos sincrónicos de 1971, 1972, 1975, 1977, 1978 y 1979 en las 8 series (gráfica 51) son coherentes con los recopilados en la tabla 49 (página 103) y con la tendencia positiva estudiada.

5.3.- 1973 y 1982 son mínimos significativos y 1976 un mínimo secundario de precipitación concurrentes y congruentes con los resultados de la tabla 49 bis (página 104). 
6.- La gráfica 52 revela el cociente de la precipitación media MAM de 1060A $P$ Amurrio Colegio y de 1075E I $P$ Dima referida a 1060 II $\vee, 1070$ P, 1082 I $\vee$ y 1093 I $\vee$ y el cociente de la precipitación media MAM de 1060A $\vee$ referida a 1075E I $\vee$ de 1968 a 1979.

Gráfica 52: Razón de las precipitaciones de 1060A $\nabla$ y de 1075E I $\nabla$ respecto a 1060 II $\nabla$, $1070 \vee, 1082$ I $\nabla$ y 1093 I $\nabla$ y razón de las precipitaciones de 1060A $\nabla$ en relación a 1075E I $\vee$ :

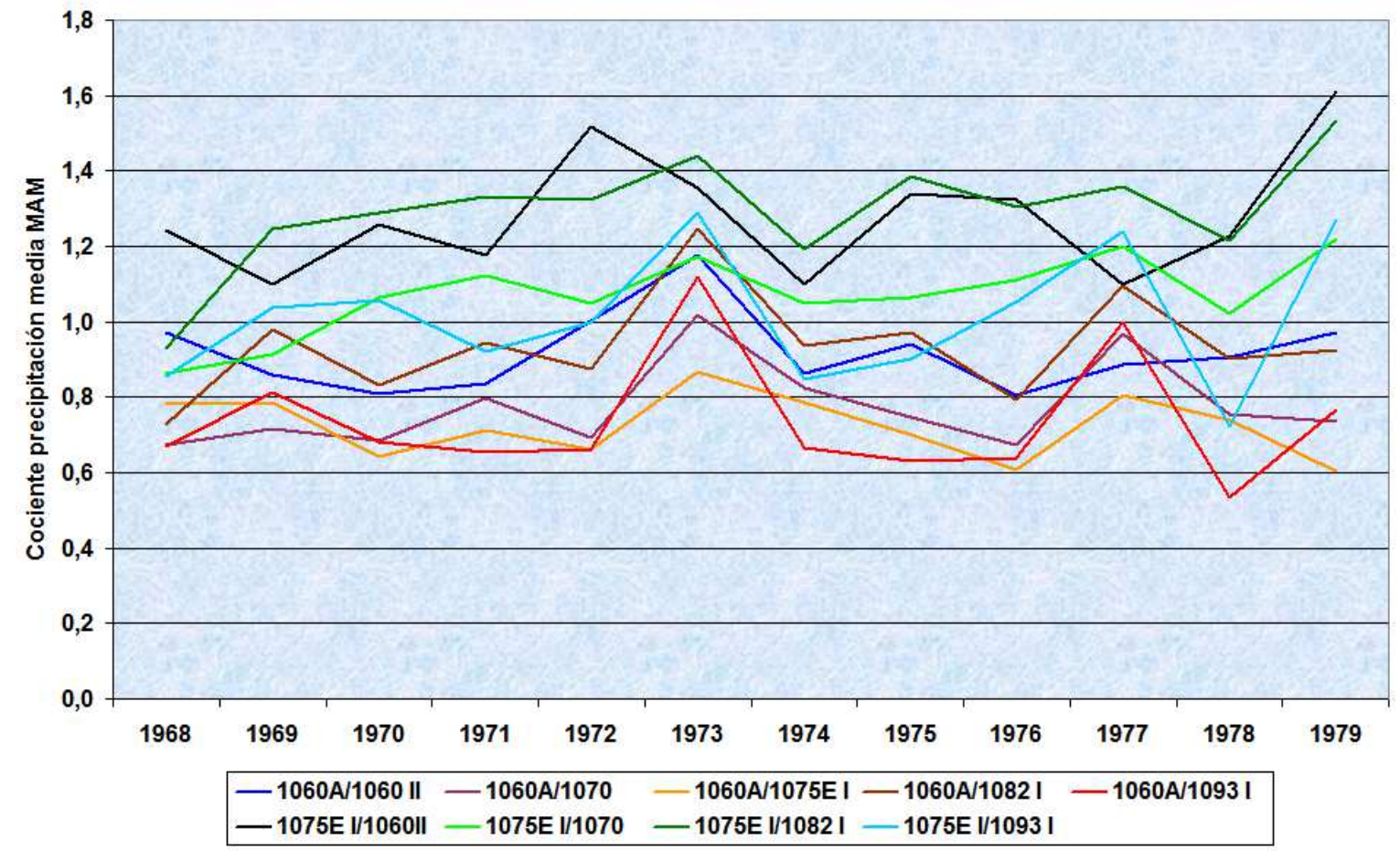

De la gráfica 52 se colige:

6.1.- La razón de las precipitaciones de 1060A $\nabla$ respecto al resto de enclaves es similar, alternando entre unos máximos (1973 y 1977) y mínimos (1968 y 1976) conformes.

Una óptima correlación emerge entre la pluviosidad MAM de 1060A $\nabla, 1060$ II $\nabla$ y 1075E I $\vee$, indicio de un comportamiento pluviométrico análogo, al menos de los años 1968 a 1979.

6.2.- El cociente de la pluviometría de $1075 \mathrm{E}$ I $\nabla$ respecto a los restantes emplazamientos oscila entre unos máximos (1973, 1977 y 1979) y mínimos (1968, 1974 y 1978) parejos.

La proporción entre las precipitaciones MAM de 1075E I $\vee$ y $1070 \vee$ de 1968 a 1979 es excelsa. 
7.- La gráfica 53 puntualiza la razón de la precipitación media MAM de 1082 I $\vee$ Bilbao Aeropuerto y de 1093 I $\vee$ Carranza respecto a 1060 II $\vee$ y $1070 \vee$ y la razón de la precipitación media MAM de 1082 I $\nabla$ tocante a 1093 I $\vee$ de 1968 a 1983.

Gráfica 53: Razón de las precipitaciones de 1082 I $\$$ y de 1093 I $\nabla$ respecto a 1060 II $\nabla$ y $1070 \vee$ y razón de las precipitaciones de 1082 I $\vee$ respecto a 1093 I $\vee$ :

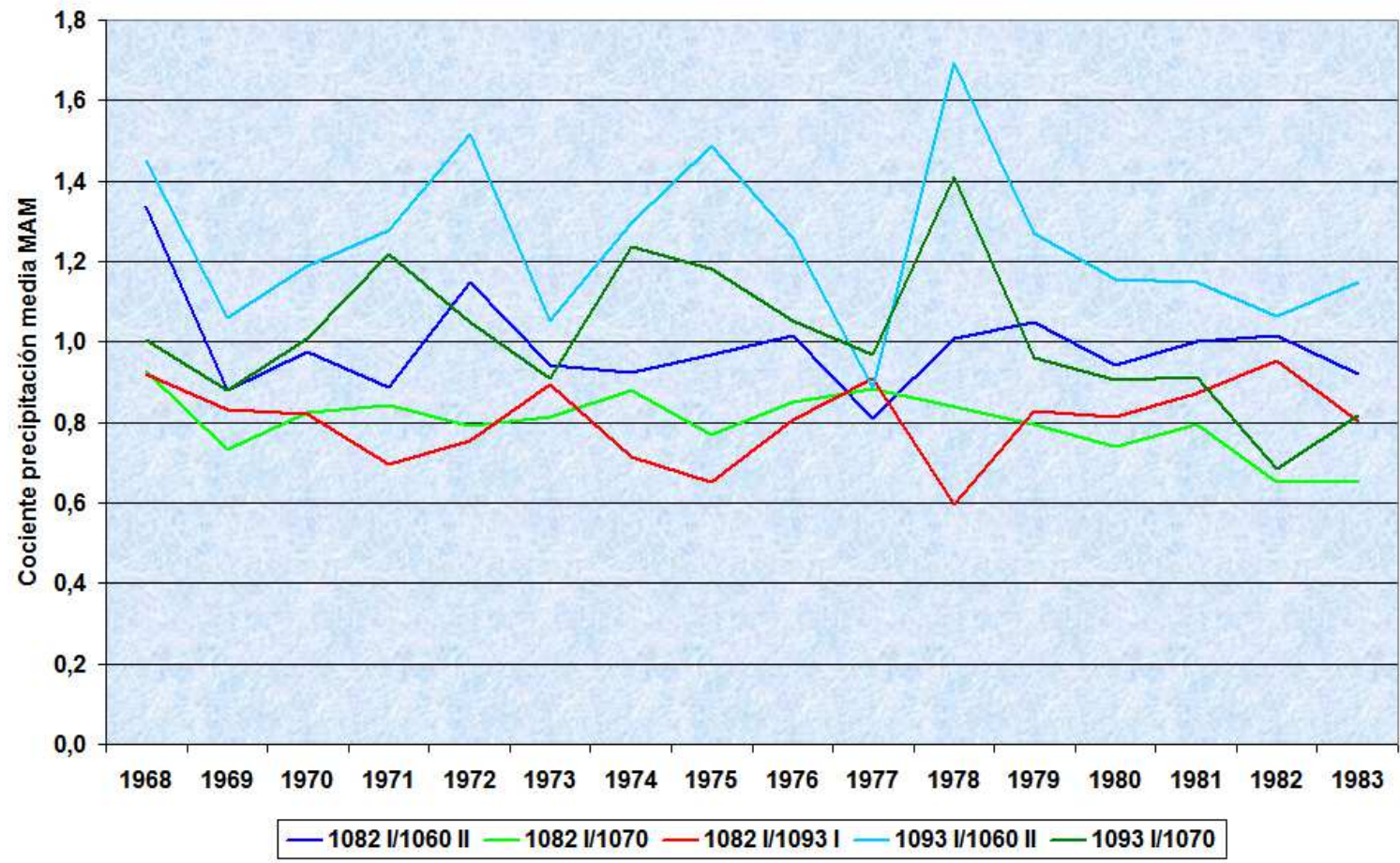

De la gráfica 53 se percibe:

7.1.- La razón de las precipitaciones MAM de 1082 I $\vee$ y 1093 I $\vee$ en relación a 1060 II $\nabla$ y $1070 \vee$ oscila entre límites semejantes:

a) Los máximos del cociente $(1971,1972,1974,1975$ y 1978) coinciden con los años lluviosos expuestos en la gráfica 51 y en la tabla 49 (página 103). Los años pluviosos de 1968 a 1983 acrece la precipitación en 1082 I $\vee$ y 1093 I $\vee$ comparada con las demás localizaciones expuestas en la gráfica 53.

b) Los mínimos del cociente (1969 y 1977; 1973 y 1982) insinúan una cadencia próxima a los 9 años.

c) El cociente 1082 I $\nabla / 1070$ oscila entre 0,65 y 0,88 y el cociente 1082 I $\nabla /$ 1093 I $\nabla$ entre 0,60 y 0,90, asomo de una semejanza pluviométrica entre Bilbao Aeropuerto y Abadiano en MAM, al menos de 1968 a 1983.

7.2.- El conocimiento de las menores amplitudes de las fluctuaciones del cociente de precipitaciones y de la euritmia del cociente se revela útil para un relleno de lagunas. 
8.- La gráfica 54 especifica el cociente de la precipitación media MAM de 1083 I $\nabla$ Arcentales en relación a 1060A $\nabla, 1060$ II $\nabla, 1070 \nabla, 1075$ E I $\nabla, 1082$ I $\vee$ y 1093 I $\nabla$ de 1968 a 1979.

Gráfica 54: Razón de las precipitaciones de 1083 I $\nabla$ respecto a 1060A $\nabla, 1060$ II $\nabla$,

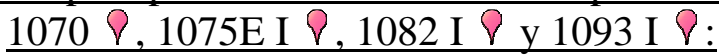

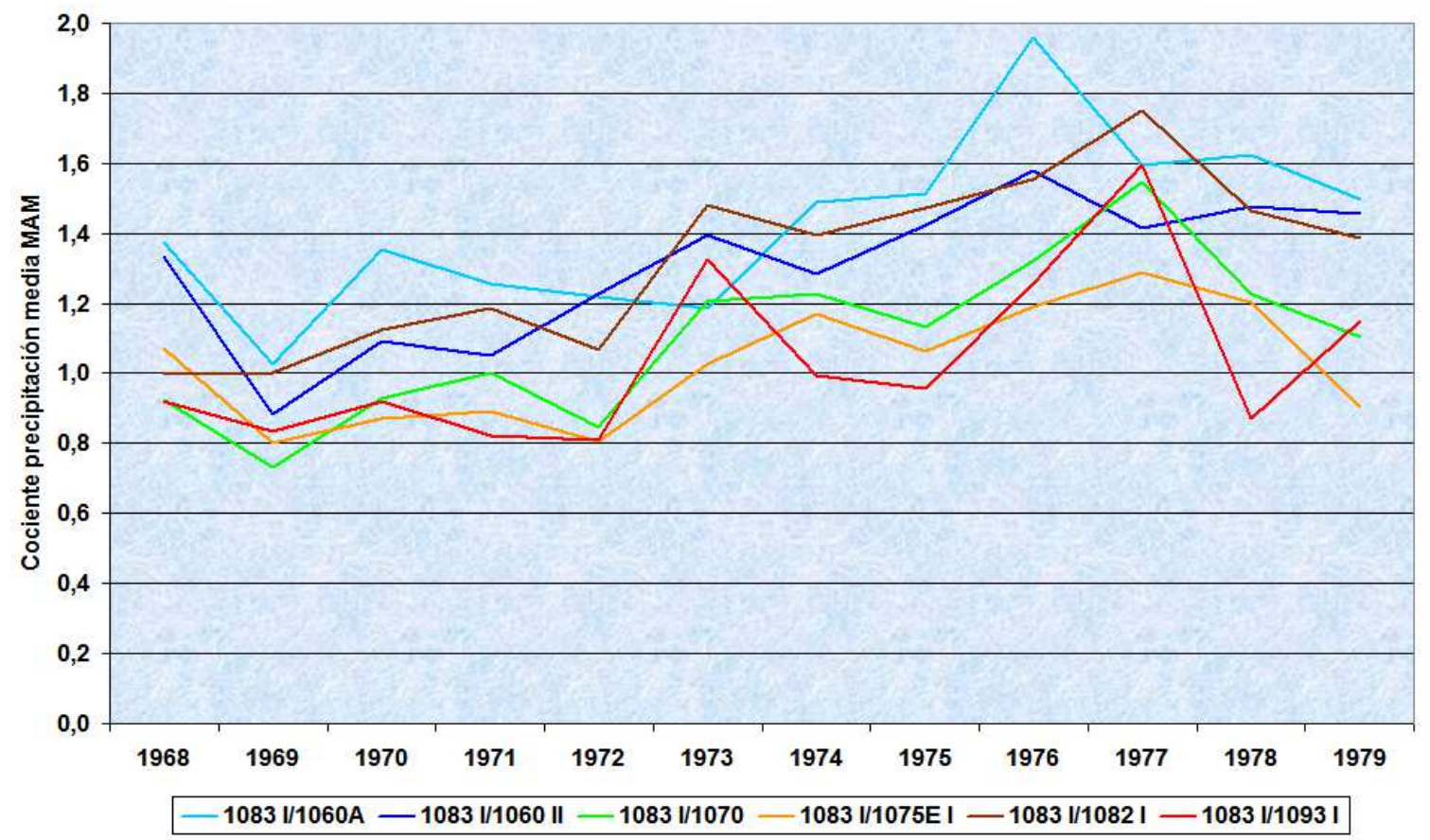

De la gráfica 54 se deduce:

8.1.- Las precipitaciones anotadas en $1083 \mathrm{I} \nabla$ aumentan respecto al resto de enclaves, en especial respecto a los 2 sitos en Amurrio (1060 II $\vee$ y 1060A 8 ) con un incremento entre el 75 y el $95 \%$. 53.

Este es el motivo de la exclusión de 1083 I $\vee$ en los contrastes de las gráficas 52 y

La tendencia positiva "no climatológica" de 1083 I $\vee$ es de arduo descubrimiento en un análisis superficial carente bien de la gráfica de evolución temporal de la precipitación MAM, bien de una contraposición mediante los cocientes de la precipitación, al hallarse embebida en el incremento generalizado de precipitación en Vizcaya y en la vertiente cantábrica de Álava de la década de los 70, culminante en los picos de 1975 y 1978.

Esta inhomogeneidad "no climatológica" de 1083 I 8 confirma los hallazgos "no climatológicos" de la pluviometría anual de 1083 I P de 1975 a 1979 (comentarios a las gráficas 22 y 29, páginas 144 y 152).

Por todo lo expuesto, la tendencia de 1975 en 1060A $P$, de 1975 a 1983 en 1082 I $\varnothing$ y en 1093 I $\nabla$, de 1977 a 1979 en $1060 \mathrm{~A} \vee$ y en 1979 en $1075 \mathrm{E}$ I $\nabla$ se trata de una tendencia "climatológica" y la tendencia de 1977 a 1979 en 1083 I $\vee$ se califica de "no climatológica". 
5.- Tendencia negativa en 1987 en 1079I, negativa en 1996 en 1053 y en 1997 en 1059, 1078E y 1083:

1.- Los registros pluviométricos de 1053 II $\vee$ Echevarría, 1059 III Punta Galea Golf, 1078E II $\vee$ Valmaseda, 1079I $\vee$ Gordejuela y 1083 II $\vee$ Arcentales se cotejan con las anotaciones de 1050 II $\nabla$ Eibar, 1060 II $\vee$ y 1060 III $\$$ Amurrio, 1078E I $\vee$ Valmaseda, 1082 II $\vee$ Bilbao Aeropuerto y 9077E II $\vee$ Ochandiano.

La tabla 91 expone la fecha de comienzo y los años sin la plenitud de valores de

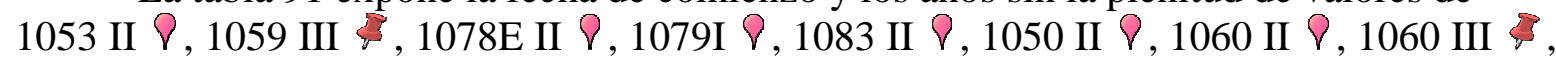
1078E I $\vee, 1082$ II $\vee$ y 9077 E II $\vee$.

Tabla 91: Fecha inicio y años incompletos de 1053 II $\vee, 1059$ III $\$, 1078 E$ II $\vee, 1079$ I $\vee$, 1083 II $\vee, 1050$ II $\vee, 1060$ II $\vee, 1060$ III $\$, 1078$ E I $\vee, 1082$ II $\vee$ y 9077E II $\vee:$

\begin{tabular}{|c|c|c|c|}
\hline Indicativo & Nombre & Comienzo & Años incompletos \\
\hline 1053 II $\vee$ & Echevarría & Final 1975 & \\
\hline 1059 III & Punta Galea Golf & $01-03-1994$ & \\
\hline $1078 \mathrm{E} \mathrm{II} 8$ & Valmaseda & $28-12-1991$ & \\
\hline 1079I 8 & Gordejuela & $01-06-1972$ & 1976 \\
\hline 1083 II $\nabla$ & Arcentales & $01-02-1981$ & 1988,1990 \\
\hline 1050 II $P$ & Eibar & Final 1964 & \\
\hline 1060 II $\vee$ & Amurrio & Final 1966 & 1967 \\
\hline 1060 III $\$$ & Amurrio & Final 1992 & \\
\hline $1078 \mathrm{E}$ I 8 & Valmaseda & $01-01-1972$ & \\
\hline 1082 II $\vee$ & Bilbao Aeropuerto & $27-11-1984$ & \\
\hline 9077E II $\vee$ & Ochandiano & $01-08-1973$ & 1992 \\
\hline
\end{tabular}

2.- El test de Mann - Kendall aprecia una tendencia negativa coetánea de la precipitación en 1997 en Guipúzcoa, detectándose en un 25\% de las series (tabla 86, página 174).

3.- El test de las rachas aplicado a la precipitación media MAM desvela una inhomogeneidad "climatológica" en 1053 II $\vee$ de 1980 a 1992, en 1082 II $\vee$ de 1986 a 1995, en 1070 \& Abadiano de 1988 a 2002 y en 1082 II $\vee$ de 1989 a 1998 (tabla 33, página 79).

4.- La gráfica 55 revela la precipitación media MAM y la mediana de 1053 II $\nabla$, 1059 III $\$, 1078$ E II $\vee, 1079$ I $\vee, 1083$ II $\vee, 1050$ II $\vee, 1060$ II $\vee, 1060$ III $\$, 1078$ E I $\vee$, 1082 II $\vee$ y 9077 E II $\vee$ de 1980 a 1998.

Un trazo continuo denota la precipitación media MAM en la gráfica 55; uno discontinuo, la mediana en el intervalo entre rupturas de cada serie. 
Gráfica 55: Precipitación media MAM y mediana de la precipitación media MAM $\left(1 / \mathrm{m}^{2}\right)$ de 1053 II $\vee, 1059$ III $₹, 1078$ E II $\vee, 1079$ I $\vee, 1083$ II $\vee, 1050$ II $\vee, 1060$ II $\vee, 1060$ III $\%$, 1078E I $\vee, 1082$ II $\vee$ y 9077 E II $\vee:$

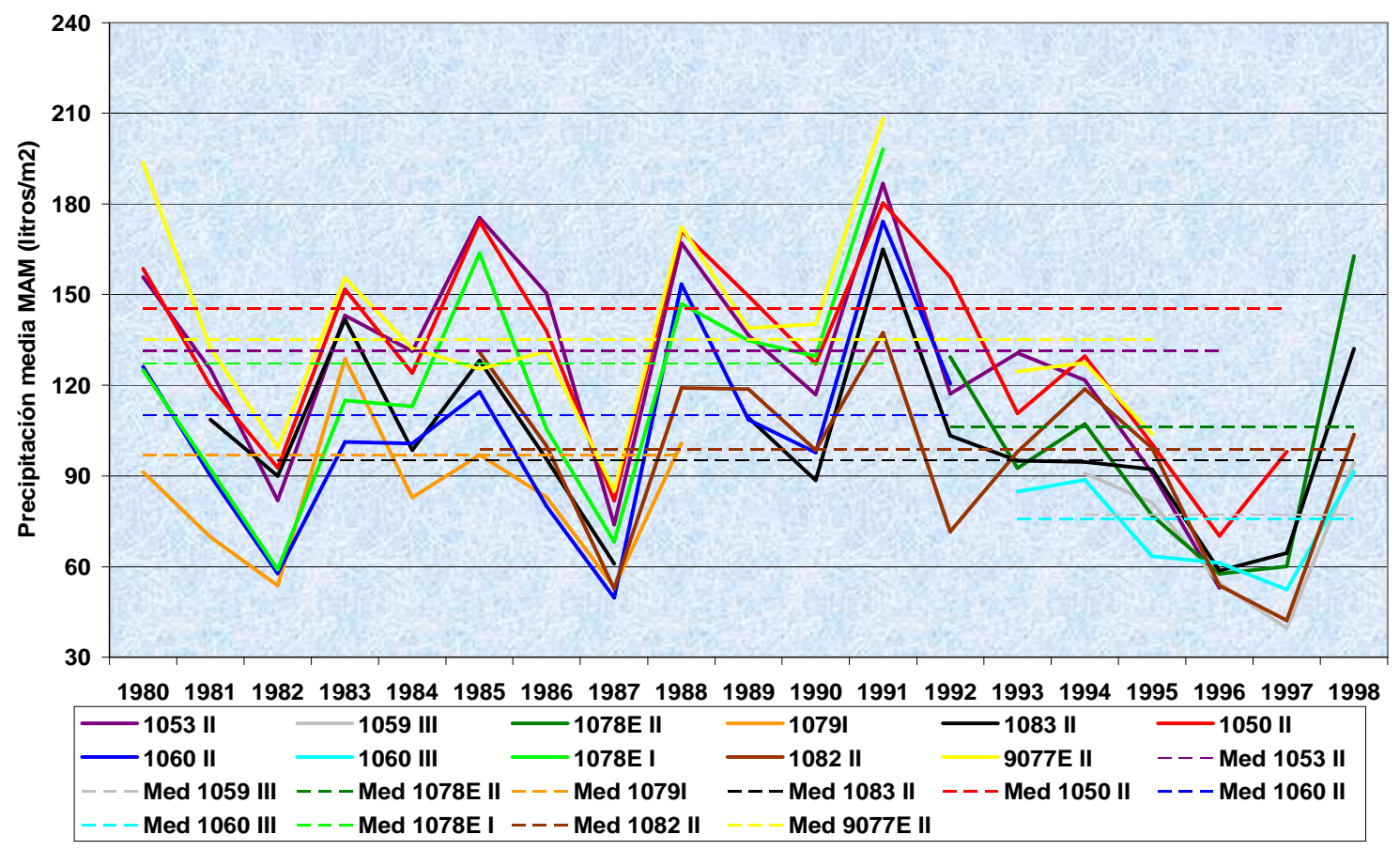

De la gráfica 55 se colige:

4.1.- Al muy pluvioso 1985 le sucede un impetuoso decremento pluviométrico, con un acusado mínimo en 1987 (entre el 45 y el 64 \% sobre la mediana), al cuál sobreviene una rápida reversión de las precipitaciones alcanzando un máximo en 1991.

A 1991 prosigue un descenso de la pluviosidad MAM hasta 1997, interrumpido brevemente por el normal 1993 y el húmedo 1994 (en precipitación anual fue muy seco 1989, gráfica 30 de la página 154).

4.2.- Las precipitaciones crecen de Oeste a Este (lugares más lluviosos 1053 II $\nabla$, 1050 II $\nabla$ y 9077E II $\vee$ ), ubicándose los más secos en las comarcas del Gran Bilbao (1059 III y 1082 II $\vee$ ) y de la Cantábrica Alavesa (1060 II $\vee$ y 1060 III $)$.

4.3.- El tránsito de los máximos y mínimos pluviométricos concurre en todos los lugares con los siguientes:

a) Máximos en 1985, 1988, 1991, 1994 (secundario) y 1998, concordantes con los valores de la tabla 49 (página 103).

b) Mínimos en 1982, 1987, 1996 y 1997 (significativos) y 1992 (secundario), congruentes con los datos de la tabla 49 bis (página 104). La tendencia negativa escrutada es acorde con la evolución de las precipitaciones en todas las ubicaciones analizadas. 
5.- La gráfica 56 exterioriza el cociente de la precipitación media MAM de 1079I $\nabla$ Gordejuela referida a 1050 II $\nabla, 1053$ II $\vee, 1060$ II $\vee, 1078$ E I $\nabla, 1082$ II $\vee, 1083$ II $\nabla$ y 9077E II $\vee$ de 1980 a 1988.

\section{Gráfica 56: Razón de las precipitaciones de 1079I $\nabla$ respecto a 1050 II $\varnothing, 1053$ II $\varnothing$,} 1060 II $\vee, 1078$ E I $\vee, 1082$ II $\vee, 1083$ II $\vee$ y 9077 E II $\vee:$

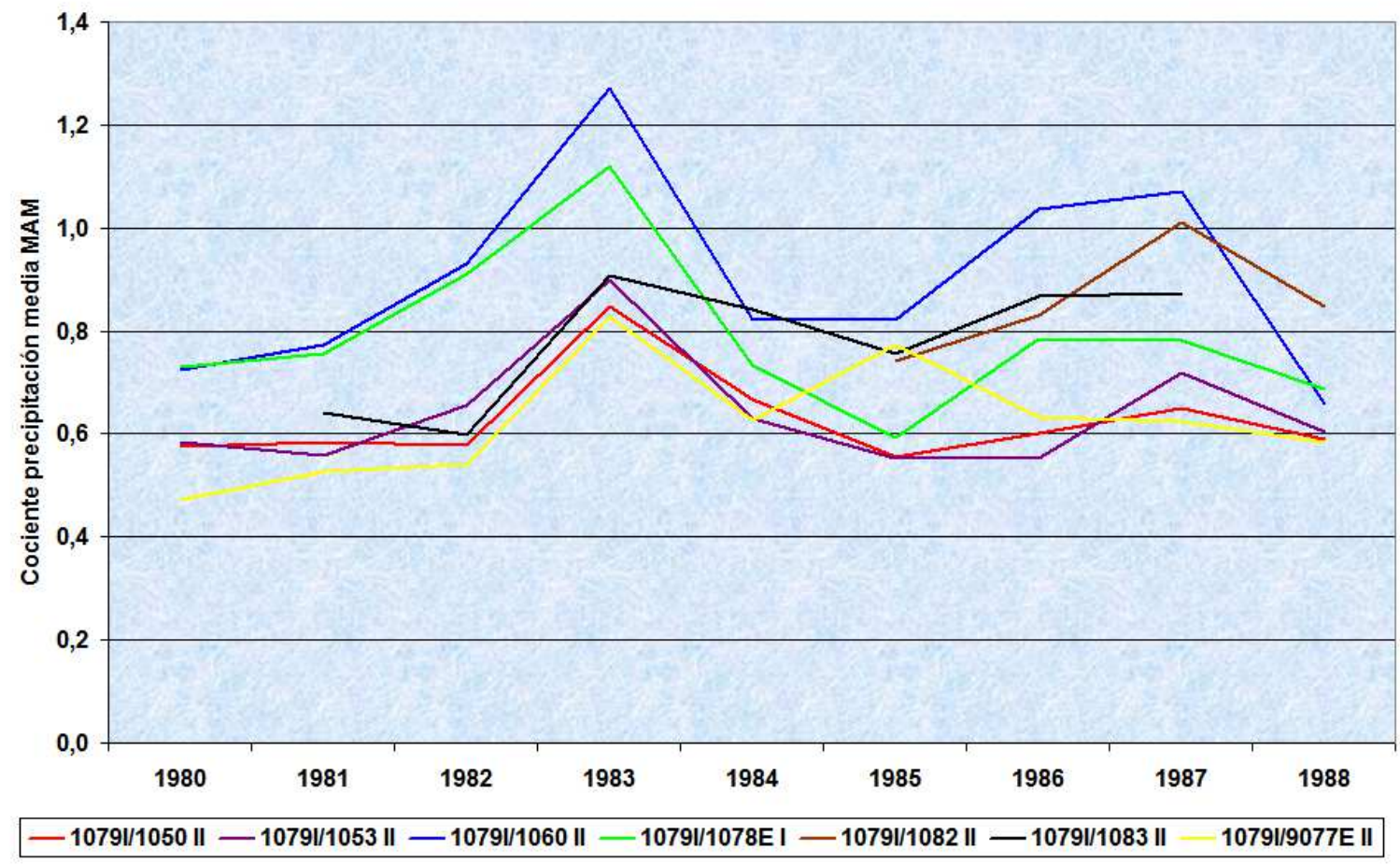

De la gráfica 56 se aprecia:

5.1.- Los valores del cociente de 1079I $\bigcirc$ presentan valores similares en 1980 y en 1988.

5.2.- 1079I $\vee$ Gordejuela, enclavada en el valle más oriental de las Encartaciones, presenta una mejor correlación respecto a 9077E II $\vee$ Ochandiano, 1053 II $\vee$ Echevarría y 1050 II $\nabla$ Eibar que en relación a las restantes series de las Encartaciones (1078E I $\vee$ Valmaseda y 1083 II $P$ Arcentales).

Este hecho realza la necesidad de una densa y luenga red de mediciones pluviométricas, dada la variabilidad espacial de la pluviometría en Vizcaya, originada por su abrupta orografía.

6.- La gráfica 57 representa la proporción de la precipitación media MAM de 1053 II $\nabla$ Echevarría en relación a 1050 II $\vee, 1078$ E II $\nabla, 1082$ II $\nabla, 1083$ II $\vee$ y 9077E II $\vee$ de 1980 a 1996. 
Gráfica 57: Razón de las precipitaciones de 1053 II $\vee$ respecto a 1050 II $\nabla, 1078 \mathrm{E}$ II $\vee$, 1082 II $\vee, 1083$ II $\vee$ y 9077 E II $\vee$ :

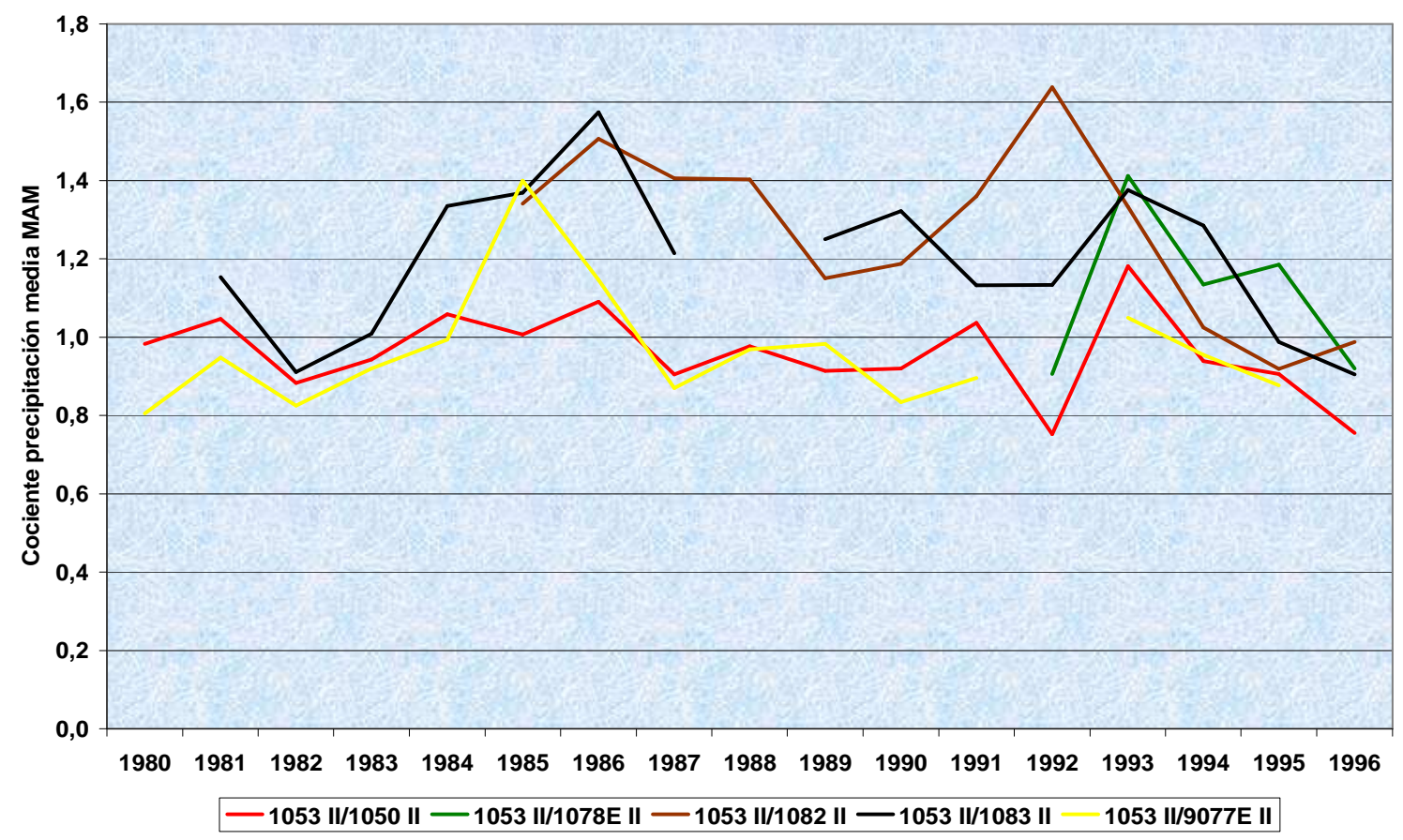

De la gráfica 57 se percibe:

6.1.- El cociente 1053 II $\vee / 1050$ II $\vee$ permanece constante de 1980 a 1996. Esto permite la inferencia de:

a) Un devenir parejo de las precipitaciones en 1053 II 8 Echevarría y en 1050 II 8 Eibar, lo cuál conlleva la consideración de "climatológica" la tendencia de 1053 II $\nabla$.

b) Unas afines características pluviométricas de 1053 II $\nabla$ y 1050 II $\nabla$ de 1980 a 1996, en línea con la similitud entre 1054 II $\vee, 1053$ II $\vee$ y 1050 II $\vee$ de 1962 a 1974 (gráfica 49, página 185).

\section{2.- La correlación de 1053 II $\vee$ con 9077E II $\vee$ es muy buena.}

6.3.- El vislumbre de un ciclo cercano a los 10 años en los extremos del cociente con máximos en 1981 y 1993; 1986 y mínimos en 1982 y 1992; 1987 y 1996 (coincidentes con los años secos de la tabla 49 bis, página 104).

\section{Echevarría.}

Los años secos de 1980 a 1996 se acusa más el descenso pluviométrico en

7.- La gráfica 58 muestra la razón de la precipitación media MAM de 1083 II $\nabla$ Arcentales y de 1059 III $\&$ Punta Galea Golf tocante a 1060 III $\$$, 1078E II $\nabla$ y 1082 II $\nabla$, la razón de la precipitación media MAM de 1083 II $\nabla$ respecto a 1050 II $\nabla$ y el cociente de la precipitación media MAM de 1078E II $\vee$ en relación a 1060 III \$ de 1981 a 1998. 
Gráfica 58: Razón de las precipitaciones de 1083 II $\nabla$ y de 1059 III $\$$ respecto a 1060 III $\$, 1078 \mathrm{E}$ II $\nabla$ y 1082 II $\vee$, la razón de las precipitaciones de 1083 II $\vee$ respecto a 1050 II $\vee$ y el cociente de las precipitaciones de $1078 \mathrm{E}$ II $\vee$ con 1060 III

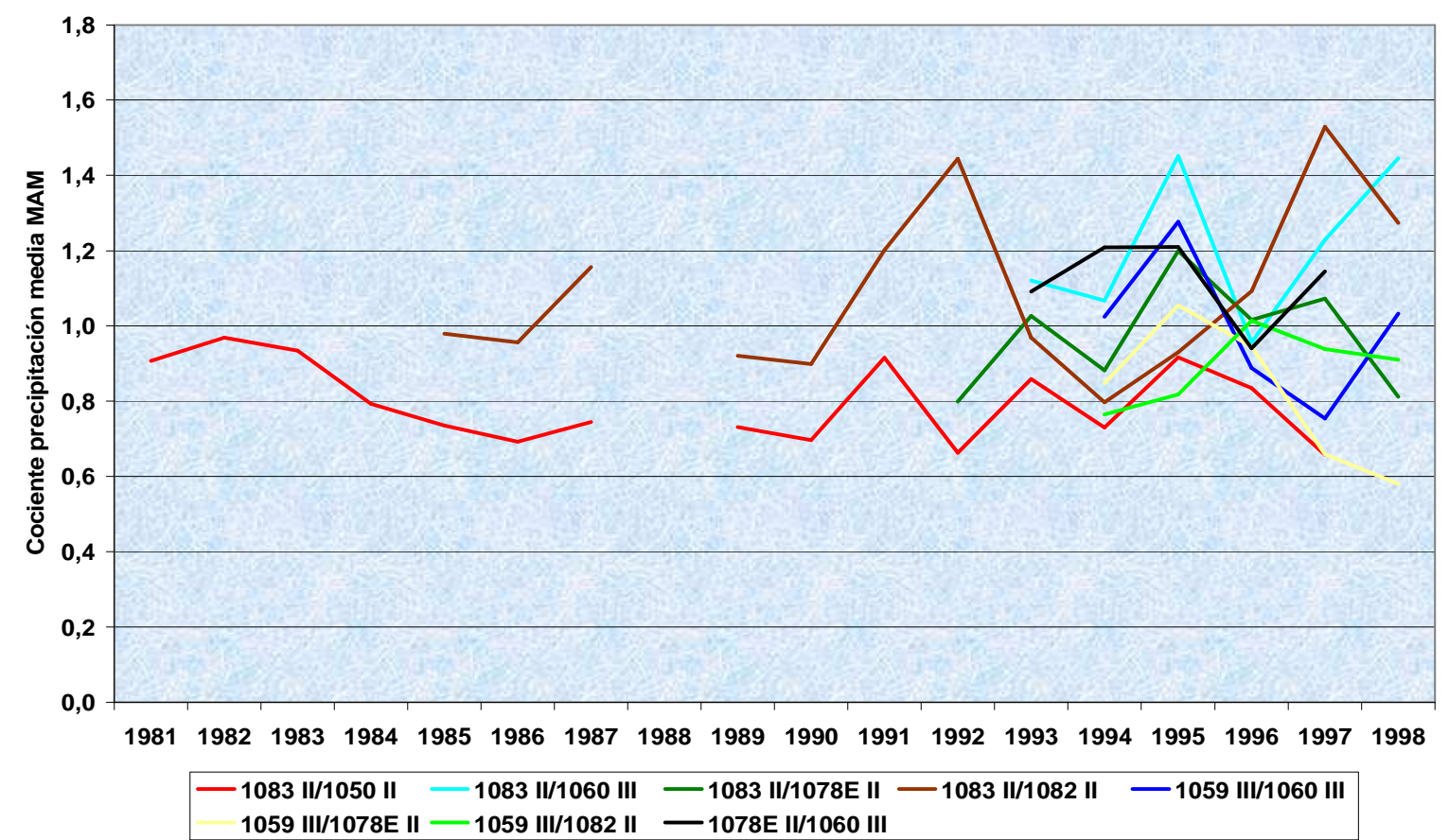

Los datos de la división en MAM de 1988 se omiten, por la falta de plenitud de datos de 1083 II $P$.

De la gráfica 58 se observa:

7.1.- El cociente es constante y fluctúa entre unos márgenes superior e inferior con una euritmia de 10 años: Un intervalo temporal inferior (verbi gratia, de 1981 a 1990) conduciría a la errónea deducción de un decremento de la precipitación de 1083 II $\vee$.

7.2.- La óptima evolución de la relación 1083 II $\nabla$ versus 1050 II $\nabla$.

La única comparación de 1083 II $\vee$ con 1082 II $\vee$ hubiera colegido la espuria conclusión de un incremento ficticio de las precipitaciones en 1083 II $\nabla$ de 1985 a 1998.

7.3.- Las observaciones de 1059 III $\$$ y 1078E II $\bigcirc$ oscilan un $+/-20 \%$ en torno a las mediciones de 1060 III $\$$.

7.4.- El dispar carácter de la pluviosidad de las comarcas de las Encartaciones, representada por 1078E II $\vee$ y 1083 II $\vee$ y del Gran Bilbao, simbolizada por 1059 III 1082 II $\vee$, de 1981 a 1998.

Por tanto, se la clasifica como tendencia "climatológica". 


\section{6.- Tendencia positiva de 2007 a 2009 en 1082 y de 2008 a 2009 en 1081 U:}

1.- Los valores de 1081U II $\vee$ Derio Neiker y 1082 III $\vee$ Bilbao Aeropuerto se contrastan con los datos de 1057E I $\nabla$ Baquio, 1059 III Punta Galea Golf, 1060 III Amurrio Instituto, 1078E II $\vee$ Valmaseda y 1082 II $\vee$ Bilbao Aeropuerto.

La tabla 92 transcribe la fecha de inicio y los años incompletos de los lapsos sin roturas de 1081U II $\nabla, 1082$ III $\vee, 1057 \mathrm{E}$ I $\nabla, 1059$ III $\%, 1060$ III $\$$, 1078E II $\nabla$ y 1082 II $\vee$ y considera la ruptura de $1082 \vee$ Bilbao Aeropuerto de Diciembre de 2000 a Enero de 2001 inclusive.

Tabla 92: Fecha inicio y años incompletos de 1081U II $\vee, 1082$ III $\nabla, 1057$ E I $\nabla$, 1059 III $\&, 1060$ III $\$, 1078$ E II $\vee$ y 1082 II $\vee:$

\begin{tabular}{|c|c|c|c|}
\hline Indicativo & Nombre & Comienzo & Años incompletos \\
\hline 1081U II $P$ & Derio Neiker & Final Marzo 1996 & \\
\hline 1082 III $P$ & Bilbao Aeropuerto & $01-02-2001$ & \\
\hline 1057E I $\vee$ & Baquio & $01-04-1986$ & 1992 \\
\hline 1059 III & Punta Galea Golf & $01-03-1994$ & \\
\hline 1060 III & Amurrio Instituto & Final 1992 & \\
\hline 1078E II 8 & Valmaseda & $28-12-1991$ & \\
\hline 1082 II $\nabla$ & Bilbao Aeropuerto & $27-11-1984$ & 2000 \\
\hline
\end{tabular}

2.- Esta tendencia únicamente emerge en el Gran Bilbao.

3.- La tabla 47 segunda (página 100) describe las características geográficas de 1081 U II $\vee$ y 1082 II $\vee$ y las de la cercana 1059 III $\$$.

La figura 20 (página 100) refleja las ubicaciones de 1081U II $\nabla, 1082$ III $\nabla$ y 1059 III $\$$. Las figuras 7 y 8 (páginas 30 y 31) ilustran las diversas radicaciones de 1081 U $\vee$ Derio Neiker y de 1082 \& Bilbao Aeropuerto.

4.- La gráfica 59 expone la precipitación media MAM y la mediana de 1081 U II $\vee$, 1082 III $\nabla, 1057$ E I $\nabla, 1059$ III $\$, 1060$ III $\$, 1078$ E II $\nabla$ y 1082 II $\nabla$ entre los años 1993 a 2009.

La gráfica 59 representa con líneas continuas la precipitación media MAM y mediante líneas discontinuas la precipitación media MAM en el intersticio temporal entre rupturas de cada serie. 
Gráfica 59: Precipitación media MAM y mediana de la precipitación media MAM $\left(1 / \mathrm{m}^{2}\right)$ de 1081U II $\vee, 1082$ III $\vee, 1057$ E I $\vee, 1059$ III $\$, 1060$ III $\&, 1078$ E II $\vee$ y 1082 II $\vee$ :

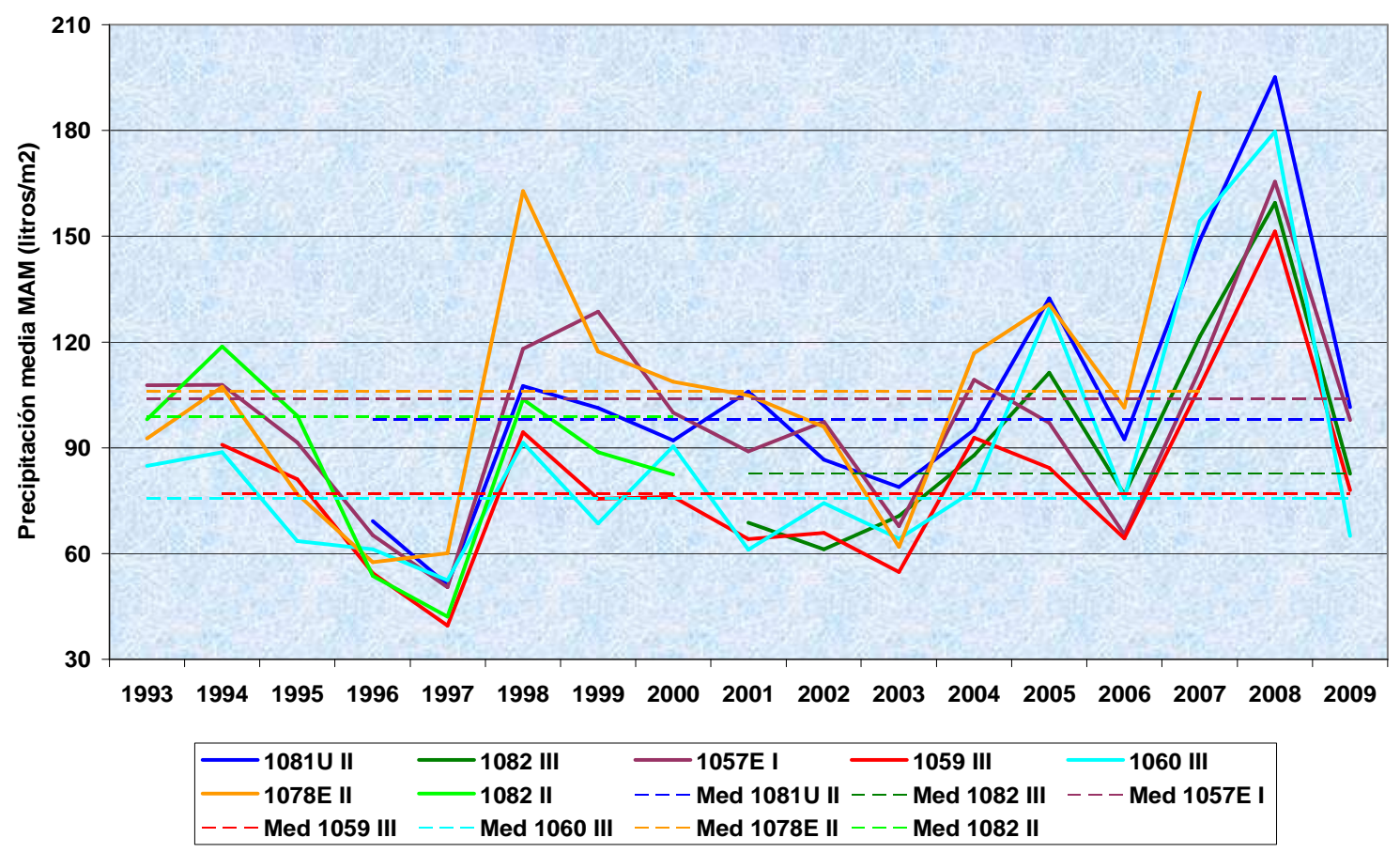

De la gráfica 59 se advierte:

4.1.- Al normal 1993 le deviene una paulatina merma de la precipitación hasta 1997, seguida por un brusco incremento en el pluvioso 1998, prosiguiendo un suave decrecimiento hasta el mínimo de 2003.

De 2004 a 2008 la pluviosidad MAM acrece, con el lapso del seco 2006. 2009 es un año normal de precipitaciones.

La tendencia positiva de 2007 a 2009 en 1082 III $\nabla$ y de 2008 a 2009 en 1081 U II $\nabla$ es coherente con el transcurso de la precipitación en las demás localizaciones de Vizcaya y de la vertiente cantábrica de Álava.

4.2.- Los máximos pluviométricos simultanean en 1994, 1998, 2005, 2007 y 2008 los 2 últimos muy copiosos - y concuerdan con los descubrimientos de la tabla 49 (página 103).

4.3.- Los mínimos de precipitación sincronizan en 1996, 1997, 2001, 2003 y 2006 (los 2 primeros muy secos) y concurren con los hallazgos de la tabla 49 bis (página 103).

4.4.- La mediana de 1081 U II $\varnothing$, prácticamente igual a la mediana de 1082 II $\varnothing$, supera a la mediana de 1082 III $\varnothing$, evidencia corroborante de la rotura de $1082 \varnothing$ Bilbao Aeropuerto de Noviembre de 2000 a Enero de 2001. 
4.5.- 1059 III $\$$ y $1057 \mathrm{E}$ I $\vee$ preludian en 2005 el decremento generalizado de precipitaciones de 2006.

5.- La gráfica 60 refleja el cociente de la precipitación media MAM de 1081 U II $\vee$ Derio Neiker y 1082 III $\nabla$ Bilbao Aeropuerto en relación a 1057E I $\nabla, 1059$ III $\$$, 1060 III $\$$ y 1078E II $\nabla$ y el cociente de la precipitación media MAM de 1082 II $\$$ y 1082 III $\vee$ respecto a 1081 U II $\vee$ de 1996 a 2009.

Gráfica 60: Razón de las precipitaciones de 1081U II $\nabla$ y 1082 III $\nabla$ respecto a 1057E I $\nabla$, 1059 III $\&, 1060$ III $\&$ y 1078 E II $\vee$ y de las precipitaciones de 1082 II $\vee$ y 1082 III $\vee$ referidas a $1081 \mathrm{U}$ II $\nabla$ :

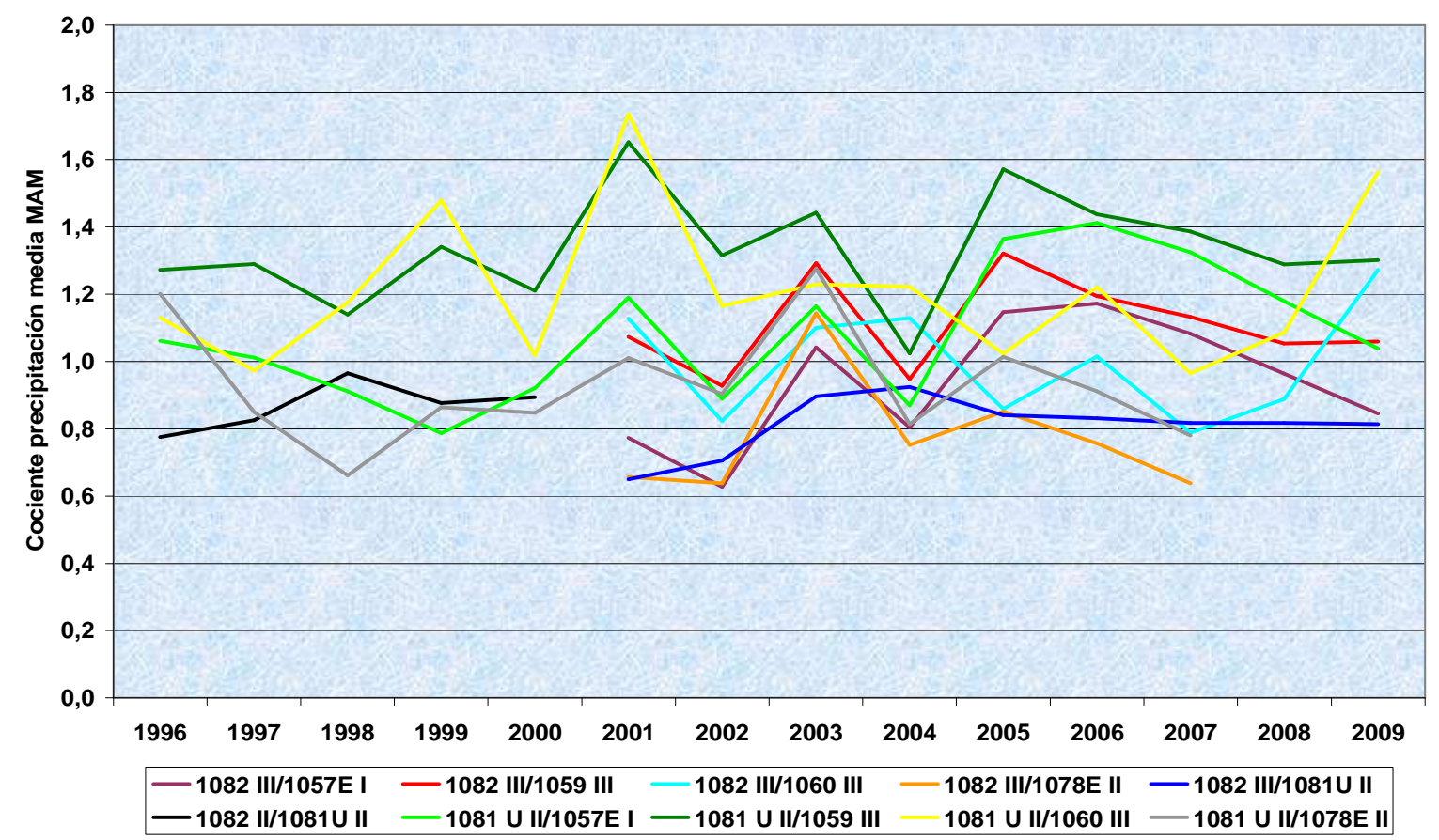

De la gráfica 60 se colige que el cociente de las precipitaciones de:

5.1.- 1081 U II $\nabla$ respecto a 1082 II $\nabla$ y a 1082 III $\nabla$ es constante, señal de una correlación excelsa y parejas cualidades pluviométricas de Derio Neiker y de las 2 situaciones del jardín meteorológico del Aeropuerto de Bilbao.

5.2.- 1082 II $\nabla$ y 1082 III $\nabla$ referido a 1081 U II $\vee$ corrobora el revelamiento de la ruptura de 1082 \& Bilbao Aeropuerto de Diciembre de 2000 a Enero de 2001.

5.3.- 1081 U II $\vee, 1082$ II $\vee$ y 1082 III $\vee$ en relación a las cuantías recabadas en los demás lugares oscila entre unos márgenes similares.

Por todo lo expuesto, se la cataloga como tendencia "climatológica". 
La recopilación del análisis con el test de Mann - Kendall de la precipitación media MAM (Marzo, Abril y Mayo) de Vizcaya y de la vertiente cantábrica de Álava:

\section{1.- Las tendencias se distinguen en "climatológicas" y "no climatológicas".}

Las tendencias "no climatológicas" se exteriorizan por la dispar evolución de la precipitación en contraposición a las series allegadas en 1055 \& Lequeitio Faro y 1083 I $\nabla$ Arcentales (de 1975 a 1979).

2.- El acrecimiento y el decrecimiento de la precipitación concurre en todos los enclaves, excepto en las tendencias "no climatológicas" de 1055 \&, en 1083 I $\vee$ de 1975 a 1979 y en la dispareja evolución de 1068 II $\nabla$.

La precipitación transcurre pareja en las localizaciones espulgadas, con una excelsa simultaneidad de los máximos y mínimos pluviométricos.

3.- Las tendencias "climatológicas" de Vizcaya y de la vertiente cantábrica de Álava son acordes con:

3.1.- El acaecimiento de la pluviosidad en los emplazamientos coetáneos próximos (gráficas 42 a 60).

3.2.- La retahíla de años pluviosos y secos de las ubicaciones (gráficas de precipitación media MAM 42, 44, 47, 51, 55 y 59), con las sequías rigurosas antecediendo a los años muy lluviosos, del mismo modo que en la pluviometría anual.

3.3.- Las tablas 93 y 94 compendian las glosas de las gráficas 42, 44, 47, 51,55 y 59 en una síntesis de los años de máximos y mínimos de pluviosidad revelados por la investigación del test de Mann - Kendall de la precipitación media MAM de Vizcaya y de la vertiente cantábrica de Álava.

La siguiente nomenclatura se maneja en las tablas 93 y 94 :

a) En azul oscuro, los máximos y mínimos pluviométricos simultáneos en Vizcaya, en la vertiente cantábrica de Álava y en Guipúzcoa.

b) En azul aguamarina, los máximos y mínimos de precipitación secundarios coetáneos en Vizcaya, en la vertiente cantábrica de Álava y en Guipúzcoa.

c) En rojo, los extremos pluviométricos de Vizcaya y de la vertiente cantábrica de Álava no sincrónicos con los registrados en Guipúzcoa y congruentes con el doble ciclo de 10 años de MAM pluviosos y de MAM áridos.

d) En rojo oscuro, los máximos y mínimos de precipitación secundarios de Vizcaya y de la vertiente cantábrica de Álava no coincidentes en Guipúzcoa y coherentes con el duplo ciclo decenal de MAM lluviosos y de MAM secos.

e) Se dejan en blanco los años sin máximos o mínimos pluviométricos MAM sea por la carencia de series de datos (1934 a 1943) o por concurrir con un intervalo carente de inhomogeneidades (de 1859 a 1884, tabla 85, página 173). 
f) En negrita, los años con máximos y mínimos de precipitación MAM prominentes, por el número de ubicaciones y por su índole de extremos. 1997.

g) Un guión - denota años de la tabla englobados: Por ejemplo 1996-97: 1996 y

h) Una coma , indica años no consecutivos. Verbi gratia 1972,5: 1972 y 1975.

Tabla 93: Años con máximos pluviométricos en precipitación MAM:

\begin{tabular}{|l|c|c||c|c||c|c|c||}
\hline Máximos & $\mathbf{1 8 8 4}$ & $1888-9, \mathbf{1}$ & 1894 & & & & $\mathbf{1 9 1 3}$ \\
\hline \hline Máximos & 1918 & $\mathbf{1 9 2 2}$ & $\mathbf{1 9 2 5}$ & & & & \\
\hline \hline Máximos & & & $\mathbf{1 9 5 8}$ & $1964-\mathbf{6 5}$ & 1969,71 & $1972, \mathbf{5}$ & $1977-8-9$ \\
\hline \hline Máximos & 1985 & 1988,91 & 1994 & 1998 & 2005 & $\mathbf{2 0 0 7 - 0 8}$ & \\
\hline \hline
\end{tabular}

Tabla 94: Años con mínimos pluviométricos en precipitación MAM:

\begin{tabular}{|l||c||c|c|c|c|c|c||}
\hline Mínimos & $1881-82$ & 1887 & $\mathbf{1 8 9 3}$ & $\mathbf{1 8 9 9}$ & & & \\
\hline \hline Mínimos & 1914 & $1920-21$ & 1924 & & & & \\
\hline \hline Mínimos & & & $\mathbf{1 9 5 7}$ & $\mathbf{1 9 6 0 - 6 1}$ & $1966-\mathbf{6 7}$ & $\mathbf{1 9 7 3}$ & 1976 \\
\hline Mínimos & $\mathbf{1 9 8 2}$ & $\mathbf{1 9 8 7}$ & 1992 & $\mathbf{1 9 9 6 - 9 7}$ & $2001, \mathbf{0 3}$ & 2006 & \\
\hline
\end{tabular}

3.4.- Los máximos y mínimos pluviométricos aflorados por el escrutinio de las inhomogeneidades del test de Thom de la precipitación MAM (tablas 49 y 49 bis, páginas 103 y 104), concuerdan con los desvelamientos exteriorizados en las tablas 93 y 94 , correspondientes al escrutinio del test de Mann - Kendall.

3.5.- Las tendencias "climatológicas” de la pluviosidad MAM de Guipúzcoa referidas en la tabla 86 de la página 174, escudriñadas en la Nota Técnica $\mathrm{N}^{\circ} 13$ AEMET.

3.6.- Los revelamientos de las tendencias "climatológicas" en la precipitación anual.

4.- Se destaca la trascendencia y la eficacia de la inspección de la precipitación con los tests de Thom y de Mann-Kendall.

5.- Los clímax de tendencias positivas acontecen en 1972, de 1974 a 1979 y de 2008 a 2009 (subsiguiente a las sequías de 1967 y 1973 y sucesiva al muy seco 2003) y preceden a los cúlmenes de Guipúzcoa entre 1979 y 1986 (Nota Técnica № 13 AEMET).

El culmen de tendencias negativas ocurre en 1997, congruente con el máximo de tendencias negativas de Guipúzcoa de 1996 a 1998 (Nota Técnica No 13 AEMET).

El cómputo de tendencias "climatológicas" positivas (38) rebasa al de negativas (7), expuesto en las gráficas 40 y 41 y en la tabla 85 (páginas 171 a 173). 
Ambos sucesos barruntan:

a) La mudanza un lapso de sequía a uno de pluviometría cuantiosa es más rápida que el cambio de un intervalo de abundantes precipitaciones a uno de sequía, fenómeno observado también en la precipitación anual.

Esta rauda mutación de años secos a pluviosos transcurre concorde a los descubrimientos de Guipúzcoa (Nota Técnica No 13 AEMET).

b) La cuantía de series de comienzo en años de MAM secos (15) excede al número de series de arranque en años de MAM lluviosos (8).

El primer MAM íntegro de las subsiguientes series sin tendencias "no climatológicas" es:

A) Seco: 1082 I $\nabla, 9076$ I $\nabla$ y 9077E I $\nabla$ (1947); 1054 II $\nabla$ y 1093 I $\vee(1957)$; 1060 II $\vee$ (1967); 1079I $\vee$ (1973); 1053 II $\vee$ (1976); 1055A I $\vee, 1057$ E I $\vee, 1077 \mathrm{H} \vee$ y 1079E I $\vee$ (1987); 1078E II $\vee$ (1992); 1081U II $\vee$ (1996) y 1082 III $\vee$ (2001) (tabla 49 bis, página 104).

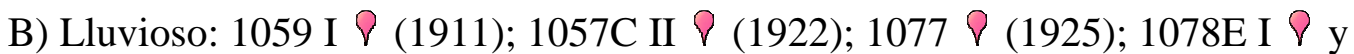
1093A $\vee$ (1972); 1082 II $\vee$ (1985); 1056M $\vee$ (1991) y 1059 III \& (1994) (tabla 49, página 103).

La serie de tendencia "no climatológica" 1068 II $\vee$ principia en el seco 1955.

El año de arranque de cada serie es crítico en el acaecimiento de un ulterior incremento o decremento pluviométrico: El examen de una serie (verbi gratia 1059 I $\nabla$ Punta Galea Faro), según empezara en un MAM pluvioso (1911) o seco (1912), conllevaría a un ulterior decremento o un acrecentamiento de la pluviosidad.

El conocimiento del carácter pluviométrico del MAM del primigenio año de las observaciones de la precipitación y de las concausas externas (cambios de emplazamiento, de entorno, instrumentación y/o observador) es crucial previo a la investigación del devenir de la pluviosidad MAM de una localización, de los acrecentamientos, descrecencias y ciclos pluviométricos.

La privación del mismo conduce a deducciones erróneas relativas a aumentos o disminuciones posteriores de la precipitación, impropios a variaciones climáticas y de origen, bien el peso del año inicial de registros, bien perturbaciones en las índoles de medida.

Es precisa la incorporación de las especificidades climatológicas del MAM del año inicial a las causas externas descritas en una etapa anterior al escudriñamiento de la evolución de la pluviosidad de una ubicación.

6.- La razón de la precipitación media MAM de las series de tendencia "climatológica" oscila entre unos extremos parejos, con una periodicidad en los máximos y mínimos próxima a los 10 años (gráficas 43, 45, 46, 48, 49, 50, 52, 53, 54, 56, 57, 58 y 60). 
Cara a una completitud de las ausencias de datos son convenientes la fijación de la disposición del MAM no íntegro en la cadencia del ciclo de cocientes y la cognición de las razones de precipitaciones con menores amplitudes, no siempre coincidentes con las series más cercanas (por ejemplo, el cociente 1082 I $\vee / 1070 \vee$ oscila entre 0,65 y 0,88 y el cociente 1082 I $\vee / 1093$ I $\vee$ entre 0,60 y 0,9 ).

7.- El cociente de precipitaciones permite:

7.1.- La afloración de roturas inadvertidas por el examen de los tests de Thom y de Mann - Kendall (verbi gratia, 1083 \& Arcentales en Octubre de 1973).

7.2.- La confirmación de las rupturas reveladas por los tests de Thom y de Mann Kendall (verbi gratia, $1082 \vee$ Bilbao Aeropuerto de Noviembre de 2000 a Enero de 2001).

8.- La importancia de:

8.1.- La resolución temporal en la distinción de una tendencia "climatológica" o "no climatológica" (verbi gratia, considerar 11 ó 18 años en 1083 II $\vee$ Arcentales, gráfica 58).

8.2.- La resolución espacial en el discernimiento de las tendencias "climatológicas" de las "no climatológicas" (por ejemplo, 1093 I $\vee$ Carranza de 1971 a 1974).

Un único cotejo de 1093 I $\nabla$ con 1082 I $\nabla$ Bilbao Aeropuerto y $1070 \nabla$ Abadiano, sin una comparativa con 1053 I $\vee$ Echevarría y 1054 II $\vee$ Marquina, hubiera conllevado a la calificación de "dudosa" de la precipitación MAM de 1093 I $\nabla$ de 1971 a 1974.

La escasez de valores puede inferir en la catalogación de valores exactos como sospechosos.

8.3.- La trascendencia y la precisión de una dilatada y compacta malla de jardines meteorológicos, de una representatividad a escala comarcal e incluso superior con un hincapié en la subsistencia de series pluviométricas luengas.

8.4.- Una densidad de gradación excedente a la provincia:

A) La tabla 95 refiere la distribución comarcal de las tendencias "climatológicas" del test de Mann - Kendall de la precipitación media MAM.

Tabla 95: Distribución comarcal de las tendencias "climatológicas" del test de Mann - Kendall de la precipitación media MAM:

Comarca

Arratia - Nervión

Duranguesado

Encartaciones

Gran Bilbao

Guernica - Bermeo

Marquina - Ondarroa

Plencia - Munguía

Cantábrica Alavesa
$\mathrm{N}^{\mathrm{o}}$ series analizadas

5

5

5

7

2

4

1

3
Inhomogeneidad media

1

0

3,2

2,6

0

0,75

0

1,3 
Las tendencias "no climatológicas" de 1055 \ y 1083 I $\vee$ de 1978 a 1979 son descartadas en la recopilación de la tabla 95.

El apogeo de inhomogeneidades aflora en el Gran Bilbao y en las Encartaciones.

La repartición de inhomogeneidades no es homogénea, difiriendo según la comarca.

B) Analogía de las tendencias "climatológicas" reveladas en enclaves cercanos:

B1) Las tendencias "climatológicas" de 1980 a 1983 únicamente se exteriorizan en el Gran Bilbao y en las Encartaciones (tabla 85, página 173).

B2) Las tendencias "climatológicas" de 1987 a 1997 exclusivamente emergen en el Gran Bilbao, en las Encartaciones y en Marquina - Ondarroa (tabla 85).

B3) La tendencia “climatológicas” de 2007 a 2009 aflora sólo en el Gran Bilbao.

Estas propiedades comunes robustecen y arrecian la exigencia de una investigación a una resolución, al menos de escala comarcal.

C) Similitud entre series no siempre allegadas, indicio de un acorde comportamiento pluviométrico en MAM en los siguientes intervalos:

C1) 1093 I $\vee$ Carranza y 1054 II $\vee$ Marquina de 1957 a 1974; 1093 I $\nabla$ y 1053 I $\vee$ Echevarría de 1962 a 1974; 1053 I $\vee$ y 1054 II $\vee$ de 1962 a 1974; 1054 II $\vee$ y 1050 II $\vee$ Eibar de 1965 a 1974. a 1979.

C2) 1060A $\vee$ Amurrio Colegio, 1060 II $\vee$ Amurrio y 1075E I $\vee$ Aránzazu de 1968

C3) 1082 I $\vee$ Bilbao Aeropuerto y 1070 \& Abadiano de 1968 a 1983.

C4) 1079I $\vee$ Gordejuela 9077E II $\vee, 1053$ II $\vee$ y 1050 II $\vee$ de 1980 a 1988.

D) El dispar carácter de la pluviosidad de las comarcas de las Encartaciones, representada por 1078E II $\vee$ y 1083 II $\vee$ y del Gran Bilbao, encarnada por 1059 III $\$$ y 1082 II $P$.

9.- La índole anticipativa de la precipitación MAM de 1082 I $\nabla$ Bilbao Aeropuerto en 1960 - 1961, 1964 - 1965, 1968 - 1969 y 1971 - 1972, preludio de la evolución en el año posterior en las restantes ubicaciones, rol asumido por 1059 III $\$$ Punta Galea Golf y 1057E I 8 Baquio de 2004 a 2005.

10.- La precelente homogeneidad de las longas $1060 \bigcirc$ Amurrio (57 años con 2 roturas), 1077C $\vee$ Bilbao Histórica (55 años), $1070 \bigcirc$ Abadiano (37 años) y 9077E II $\vee$ Ochandiano (44 años y 1 una ruptura).

11.- Lo crucial de una apropiada densidad espacial y temporal de series de pluviosidad sin lagunas con el fin de la consecución de una adecuada cognición del clima en Vizcaya y en la vertiente cantábrica de Álava, de una abrupta orografía. 


\subsubsection{3.- Evolución temporal de inhomogeneidades test de Mann-Kendall aplicado a la precipitación media AMJ:}

El extenso intersticio temporal escudriñado (de 1859 a 2013) y el parvo número de series precedentes a 1940 (inferior a 6 coetáneas) constriñe la ilustración gráfica en 2 intervalos: De 1859 a 1940 y de 1941 a 2013.

La gráfica 61 ilustra la evolución temporal de las tendencias descubiertas por el test de Mann - Kendall en la precipitación media AMJ de 1859 a 1940 de Vizcaya y de la vertiente cantábrica de Álava.

Gráfica 61: Evolución temporal de las tendencias del análisis del test de Mann - Kendall de las series de precipitación media AMJ de 1859 a 1940:

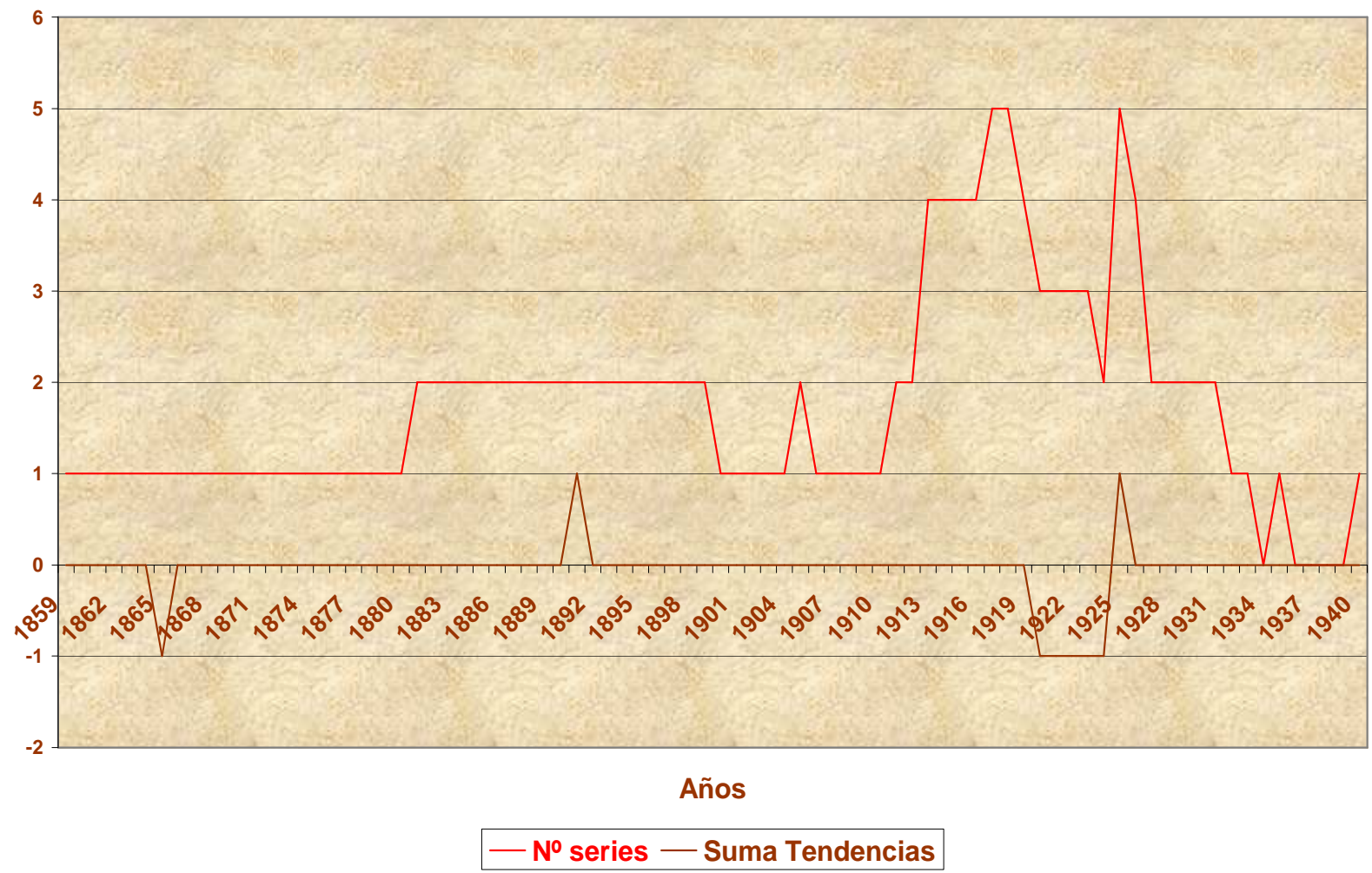

De la gráfica 61 se observa:

1) El número de tendencias previas a 1940 es 8 , indicio de la muy buena homogeneidad de los registros pluviométricos anteriores a 1940.

2) La ausencia de tendencias de 1866 a 1890 y de 1892 a 1919. 
La gráfica 62 ostenta la evolución temporal de las tendencias descubiertas por el test de Mann - Kendall en la precipitación media AMJ de 1941 a 2013 de Vizcaya y de la vertiente cantábrica de Álava.

Gráfica 62: Evolución temporal de las tendencias del análisis del test de Mann - Kendall de las series de precipitación media AMJ de 1941 a 2013:

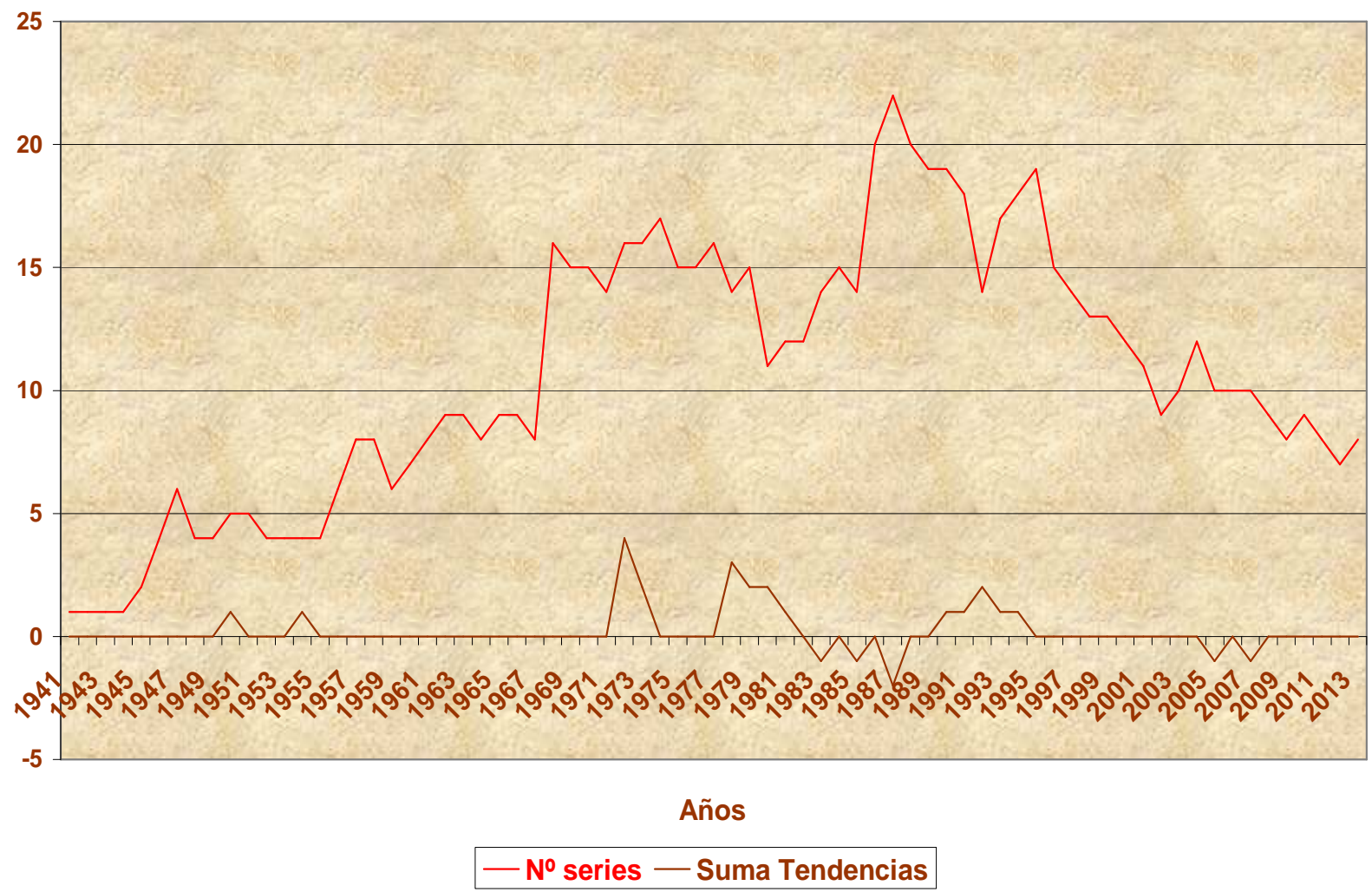

De la gráfica 62 se advierte:

1) Los cúlmenes de tendencias positivas devienen de 1972 a 1973 y de 1978 a 1980.

2) El clímax de tendencias negativas sucede en 1987.

3) El cómputo de tendencias positivas rebasa al sumatorio de tendencias negativas.

La tabla 96 allega las inhomogeneidades y tendencias afloradas por el test de Mann - Kendall en la precipitación media AMJ de Vizcaya y de la vertiente cantábrica de Álava. 
Tabla 96: Inhomogeneidades y tendencias detectadas aplicando el test de Mann - Kendall a la precipitación media AMJ de 1859 a 2013:

\begin{tabular}{|c|c|c|c|c|}
\hline Años inhomogeneidad & Indicativos & Tendencia & $\begin{array}{l}\text { Inhomogeneidad } \\
\text { "climatológica" }\end{array}$ & $\begin{array}{c}\% \text { series } \\
\text { sobre total }\end{array}$ \\
\hline 1865 & $1077 \mathrm{C}$ & - & Sí & $100(1)$ \\
\hline 1891 & $1077 \mathrm{C}$ & + & Sí & $50(2)$ \\
\hline $1920-1924$ у 1926 & 1059 & - & S Sí & $25-50(2-4)$ \\
\hline $1925-1926$ & 1055 & + & No & $20-25(4-5)$ \\
\hline 1950,1954 & $9077 \mathrm{E}$ & + & Sí & $20-25(4-5)$ \\
\hline 1972 & $1054,1060 \mathrm{~A}, 1093,9076 \mathrm{I}$ & + & Sí & \multirow{2}{*}{$13-25$} \\
\hline 1973 & 1060A, 1093 & + & Sí & \\
\hline \multirow{2}{*}{1978} & 1060A, 1093 & + & Sí & \multirow{5}{*}{$8-21$} \\
\hline & 1083 & + & No & \\
\hline 1979 & 1060A, 1093 & + & Sí & \\
\hline 1980 & 1082,1093 & + & Sí & \\
\hline 1981 & 1093 & + & SSí & \\
\hline 1983,1985 & $9077 \mathrm{E}$ & - & Sí & \multirow{2}{*}{$7-9$} \\
\hline 1987 & 99077E, 1079I & 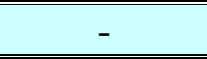 & Sí & \\
\hline 1990 & 1082 & + & Sí & \multirow{5}{*}{$5-14$} \\
\hline 1991 & $1069 \mathrm{E}$ & + & Sí & \\
\hline 1992 & $1064 \mathrm{P}$ & + & Sí & \\
\hline 1992 & $1075 \mathrm{E}$ & + & No & \\
\hline $1993-1994$ & $1075 \mathrm{E}$ & + & No & \\
\hline 2005 & $1055 \mathrm{~A}$ & - & Sí & \multirow{2}{*}{10} \\
\hline 2007 & $1057 \mathrm{E}$ & 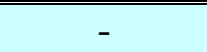 & Sí & \\
\hline
\end{tabular}

Los desvelamientos de la tabla 96 se contrastan con los resultados del espulgo del test de Mann - Kendall de las series de precipitación media AMJ de Guipúzcoa debido a:

a) La exigua densidad espacial y temporal de las series de una duración igual o superior a 10 años en Vizcaya y en la vertiente cantábrica de Álava.

b) La semejanza pluviométrica del clima de Vizcaya, la vertiente cantábrica de Álava y Guipúzcoa.

Las medidas de precipitación de Vizcaya y de la vertiente cantábrica de Álava se confrontan con 1013 I $\vee$ Irún Viteri, 1024B P Igueldo Faro, 1024D P San Sebastián Instituto, 1024F II $\vee$ San Sebastián, 1037 I $\vee$ Legazpia, 1041 Zumaya, 1046 III $\vee$ Aránzazu, $\vee$ Real Seminario de Nobles de Vergara, 1050 I $\vee$ Eibar, 1050 II $\vee$ Eibar y 9268 I $\vee$ Otzaurte.

La tabla 97 dimana de la Nota Técnica No 13 de AEMET y refiere los hallazgos del espulgo de las series de precipitación AMJ de Guipúzcoa de 1941 a 2012 con el test de Mann - Kendall. 
Tabla 97: Inhomogeneidades y tendencias detectadas aplicando el test de Mann - Kendall a la precipitación media AMJ en Guipúzcoa de 1941 a 2012:

\begin{tabular}{|c|c|c|c|c|}
\hline Años inhomogeneidad & Indicativos & Tendencia & $\begin{array}{l}\text { Inhomogeneidad } \\
\text { "climatológica" }\end{array}$ & $\begin{array}{l}\% \text { series } \\
\text { sobre total }\end{array}$ \\
\hline $1948-1949$ & 1013 & - & Sí & 13 \\
\hline $1950-1954$ & $1032 \mathrm{~A}$ & + & Sí & $5-6$ \\
\hline 1957 & 1016 & + & Sí & 5 \\
\hline 1958 & 1016,1031 & + & Sí & 10 \\
\hline $1960-1961$ & $1032 \mathrm{~A}$ & + & Sí & 5 \\
\hline 1964 & 9268 & - & No & 4 \\
\hline 1970 & 1026 & + & Sí & 5 \\
\hline 1971 & $1026,1044 \mathrm{~A}$ & + & Sí & 9 \\
\hline 1972 & $1018,1026,1044 \mathrm{~A}$ & + & Sí & 14 \\
\hline $1974-1977$ & 1026 & + & Sí & $4-5$ \\
\hline $\begin{array}{l}1976 \\
\end{array}$ & 1037 & - & Sí & $\begin{array}{c}5 \\
\end{array}$ \\
\hline $1975-1977$ & 1017 & 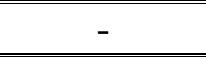 & No & $4-5$ \\
\hline $1978-1979$ & 1022,1026 & + & Sí & 9 \\
\hline 1980 & $1016,1022,1023,1026$ & + & Sí & 17 \\
\hline 1981 & 1022,1026 & + & Sí & 9 \\
\hline $1981-1982,1985$ & $1025 \mathrm{E}$ & - & Sí & 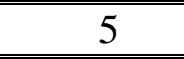 \\
\hline 1982 & 1026 & + & Sí & 5 \\
\hline 1983 & 1025E, 1037O, 1048 & 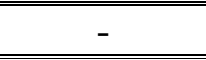 & Sí & 13 \\
\hline 1984 & $1025 \mathrm{E}, 1037 \mathrm{O}$ & 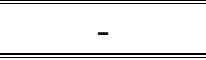 & Sí & 8 \\
\hline 1987 & 1025E, 1044D & - & Sí & 8 \\
\hline 1990 & $1019 \mathrm{~A}$ & + & Sí & 4 \\
\hline 1991 & $1037,1037 \mathrm{Q}$ & + & Sí & 7 \\
\hline 1992 & $1036 \mathrm{O}, 1037,1044 \mathrm{U}, 1049 \mathrm{U}$ & + & Sí & 14 \\
\hline 1993 & $\begin{array}{c}\text { 1026A, 1036O, 1037, 1037Q, } \\
\text { 1044U, 1049, 1049U }\end{array}$ & + & Sí & 25 \\
\hline 1994 & $\begin{array}{c}1026 \mathrm{~B}, 1036 \mathrm{O}, 1037,1037 \mathrm{Q} \\
1044 \mathrm{U}, 1049,1049 \mathrm{U}\end{array}$ & + & Sí & 25 \\
\hline 1995 & $\begin{array}{c}1037,1049 \mathrm{U} \\
\end{array}$ & + & Sí & 8 \\
\hline 1998 & 1044D & + & ¿Sí? & 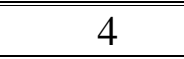 \\
\hline $1999-2000$ & 1046 & 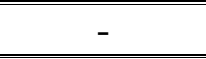 & Sí & 5 \\
\hline 2001 & 1026A, 1046, 1048 & 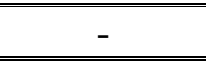 & Sí & 14 \\
\hline $2002-2003,2005$ & 1026A, 1048 & - & Sí & 10 \\
\hline 2004 & 1026A, 1031, 1048 & 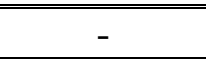 & Sí & 14 \\
\hline 2006 & 1026A, 1031, 1036O, 1048 & - & Sí & 24 \\
\hline 2007 & 1026A, 1031, 1048 & 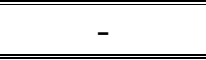 & Sí & 18 \\
\hline
\end{tabular}




\section{1.- Tendencia negativa en 1865 y positiva en 1891 en 1077C:}

1.- El único pluviómetro en 1865 en Vizcaya, Guipúzcoa y Vizcaya se ubicaba en la terraza del Instituto de Segunda Enseñanza de Bilbao 1077C P.

Las anotaciones de 1077C $\vee$ se cotejan con los registros de 1024D $\vee$ San Sebastián Instituto, del $\vee$ Real Seminario de Nobles de Vergara y de 1059L I $\vee$ Orduña.

Los valores del Real Seminario de Nobles de Vergara provienen de los Resúmenes de las Observaciones Meteorológicas efectuadas en la Península desde el $1^{\circ}$ de diciembre de 1867 al 30 de noviembre de 1874.

2.- La tabla 98 revela la fecha de inicio y los años incompletos de $1077 \mathrm{C} \nabla$, 1024D $\vee, \curlyvee$ Real Seminario de Nobles de Vergara $\vee$ y 1059L I $P$.

Tabla 98: Fecha inicio y años incompletos de 1077C $९, 1024 \mathrm{D} \vee, \nabla$ Vergara y 1059L I $\vee$ :

$\begin{array}{rccc}\text { Indicativo } & \text { Nombre } & \text { Comienzo } & \text { Años incompletos } \\ \text { 1077C } \varnothing & \text { Bilbao Histórica } & 01-01-1859 & 1862-1864,1874 \\ \text { 1024D } \varnothing & \text { San Sebastián Instituto } & 01-01-1878 & \\ & \text { Vergara } & 01-12-1866 & \\ \text { 1059L I } \varnothing & \text { Orduña } & 01-02-1881 & \end{array}$

2.- El test de las rachas empleado en la pluviosidad AMJ no detecta inhomogeneidades en los 58 años de duración de 1077C $\nabla$ (tabla 50, página 108) ni aflora ninguna inhomogeneidad coetánea a las 2 tendencias de 1077C 8 .

3.- El test de tendencia de Mann-Kendall aplicado a la precipitación media en AMJ no revela tendencias coetáneas en Guipúzcoa (Nota Técnica Nº 13 AEMET).

4.- El espulgo del test de Mann-Kendall de la precipitación media anual y de la precipitación media MAM no detecta tendencia (tablas 71 y 85, páginas 131 y 173) en 1077C P.

5.-La gráfica 63 desvela la precipitación media AMJ y la mediana de $1077 \mathrm{C} \vee$, de 1024D $\vee$, del $\vee$ Real Seminario de Nobles de Vergara y de 1059L I $\vee$ de los años 1859 a 1891.

La gráfica 63 indica con líneas de trazo continuo la precipitación media AMJ y con líneas discontinuas, la mediana de la precipitación media AMJ en el lapso temporal entre roturas de cada serie. 
Gráfica 63: Precipitación media AMJ y mediana de la precipitación media AMJ $\left(1 / \mathrm{m}^{2}\right)$ de 1077C $\vee, 1024 \mathrm{D} \vee$, Vergara y 1059L I $\vee$ :

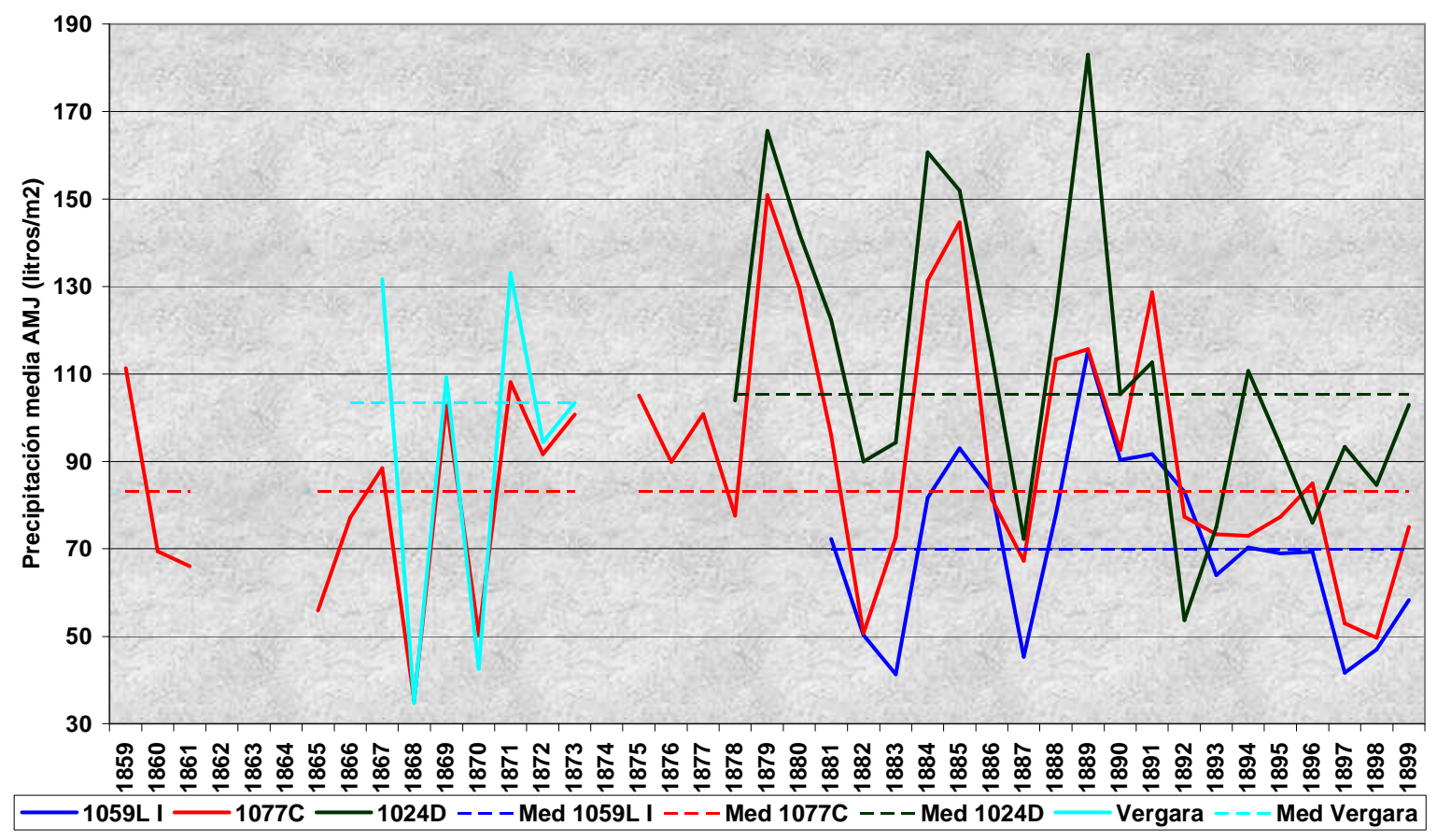

De la gráfica 63 se aprecia:

6.1.- Al pluvioso 1859 le sobrevienen los secos 1861 y 1865 ( $7^{\circ}$ y $6^{\circ}$ años más áridos de 1077C $\bigcirc$ en AMJ de 1859 a 1899).

De 1868 a 1873 la sincronía con $\vee$ Vergara es óptima. Al normal 1867 le suceden el seco 1868, el pluvioso 1869, el seco 1870, el lluvioso 1871 y el normal 1872.

Del húmedo 1875 al normal 1878 las precipitaciones recabadas descienden ligeramente, proseguidas por un abrupto acrecentamiento en 1879. La pluviosidad ulterior al copioso 1880 descrece en el normal 1881 y en el seco 1882, precediendo a los cuantiosos 1884 y 1885 .

El normal 1886 y el seco 1887 anteceden a los abundantes 1888,1889 y 1891 , de pluviometría rebosando las atañederas medianas.

La tendencia negativa de 1865 y la tendencia positiva de 1891 en $1077 \mathrm{C} \nabla$ son congruentes con el transcurso de las precipitaciones en los 4 lugares disponibles.

6.2.- La excelente sincronía de los máximos y mínimos pluviométricos de 1077C $\mathrm{P}$, $\checkmark$ Vergara, 1024D $\nabla$ y 1059L I $\nabla$ aseverada por:

a) Los años de máximos pluviométricos coinciden en 1859, 1869, 1871, 1875, 1879 , 1880, 1884, 1885, 1888, 1889 y 1891. 
b) Los años de pluviosidades mínimas sincronizan en 1861, 1865, 1868, 1870, 1882 y 1887.

6.3.- La pluviosidad acrece de Oeste a Este.

7.- La gráfica 64 ilustra la razón de la precipitación media AMJ de 1077C $\vee$ Bilbao Instituto en relación a 1024D $\vee$, P Vergara y 1059L I $\vee$ de 1867 a 1891.

Gráfica 64: Razón de las precipitaciones de 1077C $\nabla$ respecto a 1024D $\nabla, \nabla$ Vergara y 1059L I $8:$

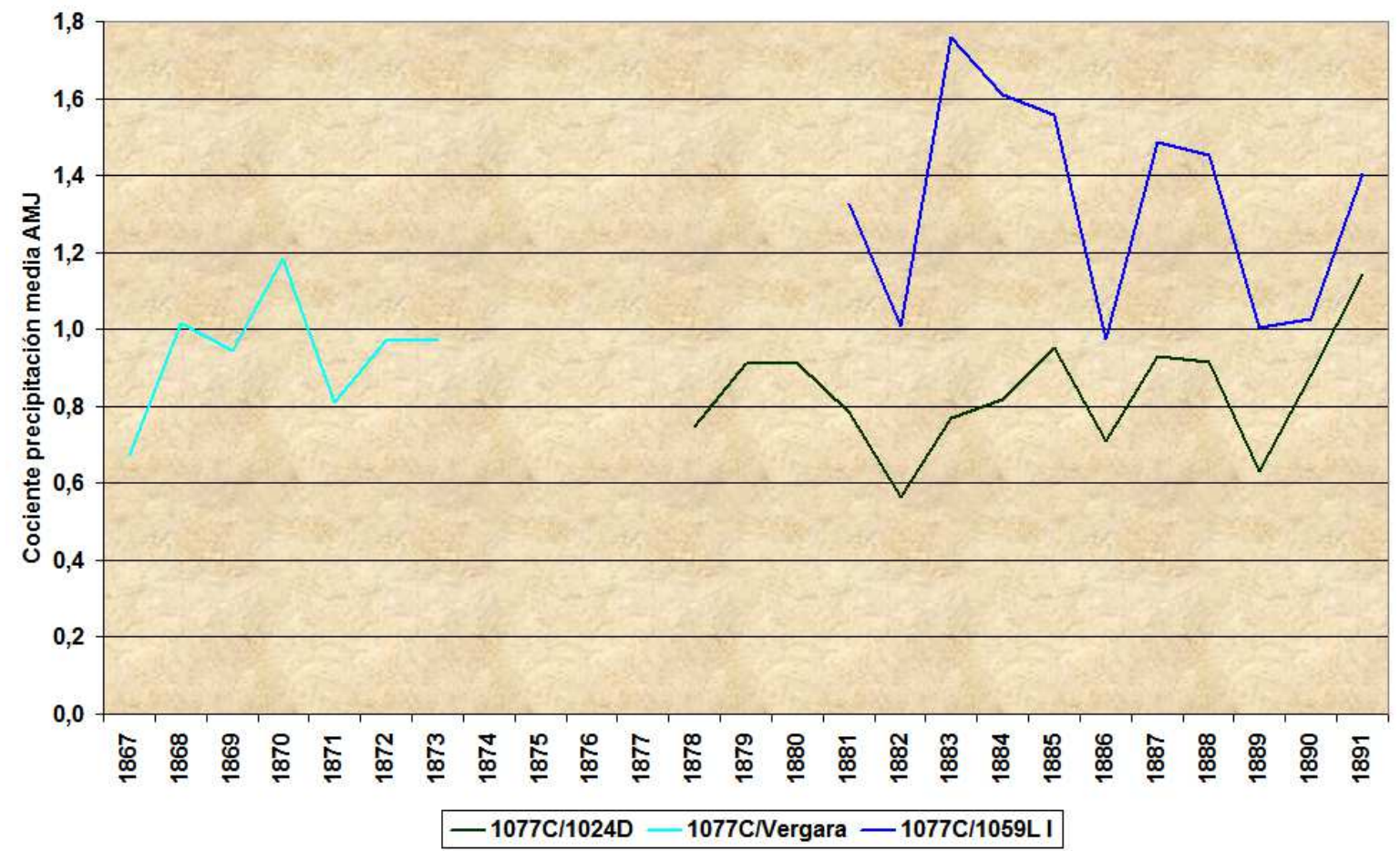

De la gráfica 64 se colige:

7.1.- El cociente de las precipitaciones de 1077C $\nabla$ fluctúa entre unos valores máximos y mínimos cuasi constantes, con una cadencia cercana a los 9 años en los máximos $(1870,1879$ - 1880 y 1887 - 1888) y próxima a los 8 en los mínimos $(1871,1878$ y 1886; 1882 y 1889).

7.2.- La razón de la pluviosidad de $1077 \mathrm{C} \vee$ Bilbao es más regular tocante a 1024D $>$ San Sebastián (ambas ubicadas en la costa) que referida al $\nabla$ Real Seminario de Nobles de Vergara y a 1059L I $\vee$ Orduña.

Por consiguiente y dadas las excelsas características pluviométricas de $1077 \mathrm{C} \vee$ y su pareja evolución respecto a los restantes enclaves, se califican ambas tendencias de "climatológicas". 
2.- Tendencia negativa de 1920 a 1924 y en 1926 en 1059 y positiva de 1925 a 1926 en

1055:

1.- Los datos de $1055 \bigcirc$ Lequeitio Faro y 1059 I $\vee$ Punta Galea Faro se confrontan con las cuantías medidas en los pluviómetros de 1057C I $\nabla$ y 1057C II $\nabla$ Machicaco Faro, 1013 I $\vee$ Irún Viteri, 1024B $\vee$ Igueldo Faro y 1024F II $\vee$ San Sebastián Instituto.

Los registros de Lequeitio Faro 1055 P, Punta Galea Faro 1059 I 8 y Machicaco Faro 1057C I $\vee$ y 1057C II $\vee$ provienen de los Resúmenes de las Observaciones Meteorológicas efectuadas durante los años 1911 a 1926.

La tabla 99 recopila la fecha de arranque y los años incompletos de $1055 \nabla$, 1059 I $\nabla, 1057$ C I $\nabla, 1057$ C II $\vee, 1013$ I $\nabla, 1024$ B $\vee$ y 1024F II $\nabla$.

Tabla 99: Fecha inicio y años incompletos de 1055 P, 1059 I $\nabla, 1057 \mathrm{C}$ I $\nabla, 1057 \mathrm{C}$ II $\nabla$, 1013 I $P, 1024 \mathrm{~B} \vee$ y $1024 \mathrm{~F}$ II $\vee:$

\begin{tabular}{|c|c|c|c|}
\hline Indicativo & Nombre & Comienzo & Años incompletos \\
\hline 10558 & Lequeitio Faro & $01-05-1911$ & $1912,1920,1924$ \\
\hline $1059 \mathrm{I} P$ & Punta Galea Faro & $01-01-1911$ & 1921, 1925 \\
\hline $1057 \mathrm{C} \mathrm{I} P$ & Machicaco Faro & $01-01-1913$ & \\
\hline $1057 \mathrm{C} \mathrm{II} P$ & Machicaco Faro & $01-12-1921$ & 1930 \\
\hline 1013 I $\vee$ & Irún Fitosanitaria & $01-02-1914$ & 1914 \\
\hline 1024B P & Igueldo Faro & $01-01-1913$ & 1924 \\
\hline $1024 \mathrm{~F}$ II $P$ & San Sebastián & Final Marzo 1918 & \\
\hline
\end{tabular}

2.- El estudio de la precipitación media $\mathrm{AMJ}$ con el test de las rachas exterioriza una inhomogeneidad "climatológica" en 1059 I $\vee$ de 1912 a 1923 y en $1055 \nabla$ de 1913 a 1926 (tabla 50, página 108).

3.- El test de Mann - Kendall no detecta tendencias pluviométricas coetáneas de la pluviometría AMJ en Guipúzcoa (Nota Técnica No 13 AEMET).

4.- La gráfica 65 expone la pluviosidad media AMJ y la mediana de 1055 , 1059 I $\nabla, 1057$ C I $\vee, 1057$ C II $\vee, 1013$ I $\vee, 1024$ B $\vee$ y 1024F II $\vee$ de 1913 a 1926.

La precipitación media AMJ se dibuja mediante segmentos continuos en la gráfica 65 y con segmentos discontinuos la mediana en el lapso temporal entre rupturas de cada serie pluviométrica. 
Gráfica 65: Precipitación media AMJ y mediana de la precipitación media AMJ $\left(1 / \mathrm{m}^{2}\right)$ de

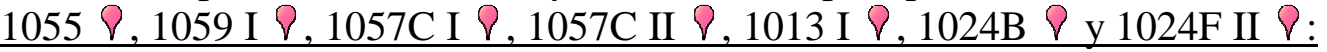

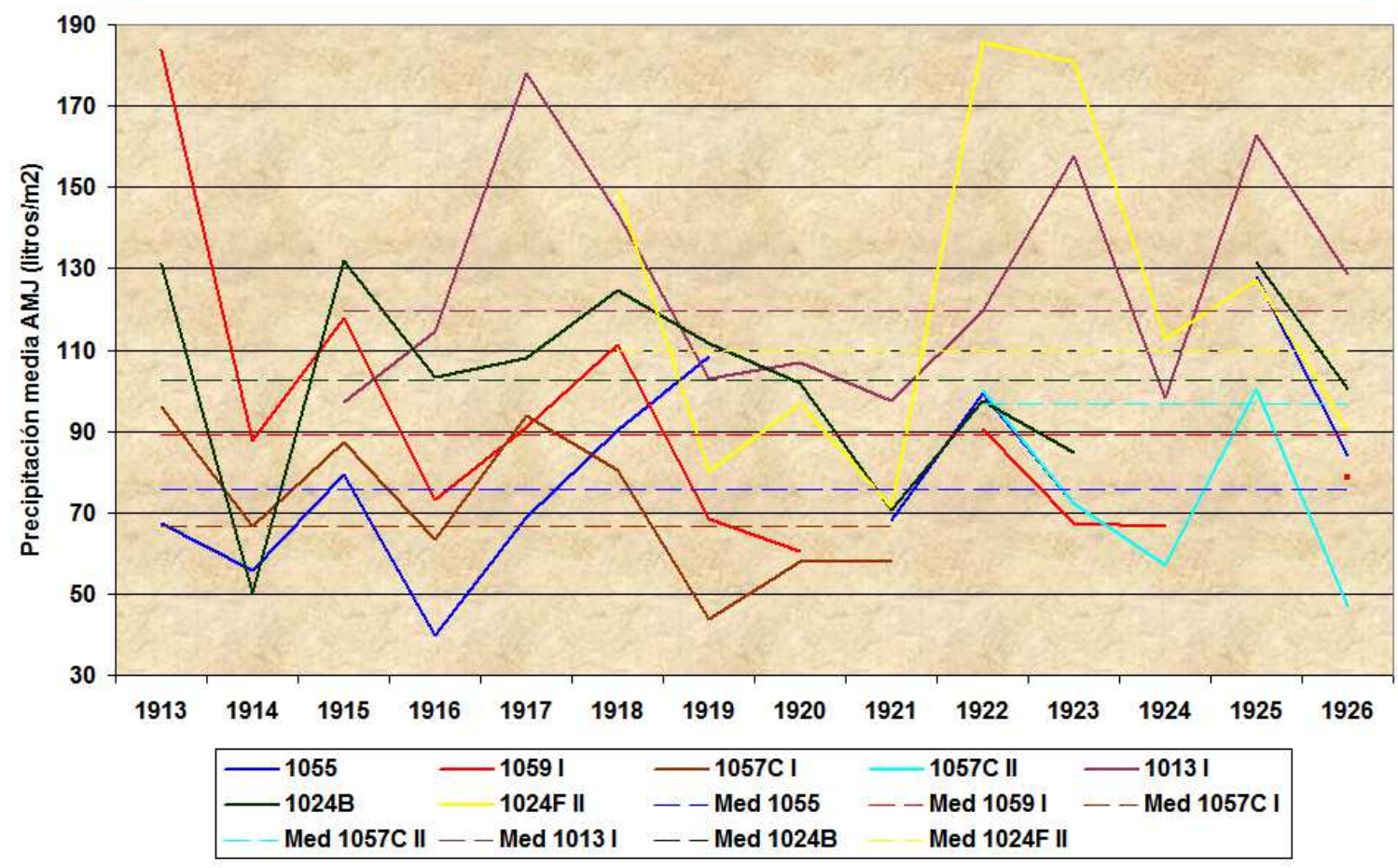

De la gráfica 65 se infiere:

4.1.- Las precipitaciones apuntadas en $1055 \nabla$ acrecen dispar y exclusivamente: De 1913 a 1916 es el enclave más seco; de 1916 a 1919 aumentan únicamente en 1055 \&, siendo el $2^{\circ}$ más pluvioso en 1919. $1055 \nabla$ retorna al lugar más árido en 1921 y 1922 y muta en 1925 al $3^{\circ}$ más lluvioso.

Similares revelamientos del carácter de las anotaciones de la pluviosidad de $1055 \nabla$ se describen en el escrutinio de la precipitación MAM de $1055 \nabla$ (páginas 179 a 181).

4.2.- Los acrecimientos y decrecimientos de los valores pluviométricos de 1055 尺 son congruos con los apuntes de los colaboradores de los demás enclaves:

a) Los máximos de 1913, 1915, 1917, 1918, 1922 y 1925 convienen con los resultados de la tabla 70 (página 127).

b) Los mínimos de 1916, 1919, 1920 y 1924 son coherentes con los hallazgos de la tabla 70 bis (página 127). 1926 es un año árido simultáneo en todos los emplazamientos.

4.3.- $L a$ tendencia negativa de 1059 I $\nabla$ de 1920 a 1926 (sin datos en 1925) concuerda con el devenir de la pluviosidad en las restantes ubicaciones, con la salvedad antepuesta de 1055 P. 
5.- La gráfica 66 muestra el cociente de la precipitación media AMJ de 1055 จ Lequeitio Faro respecto a 1057C I $\nabla, 1057 \mathrm{C}$ II $\nabla, 1059$ I $\vee, 1013$ I $\nabla, 1024 \mathrm{~B} \vee$ y 1024F II $\vee$ de 1913 a 1926.

Gráfica 66: Razón de las precipitaciones de $1055 \bigcirc$ respecto a 1057C I $\nabla, 1057 \mathrm{C}$ II $\nabla$, 1059 I $\vee, 1013$ I $\vee, 1024 \mathrm{~B} \vee$ y $1024 \mathrm{~F}$ II $\vee:$

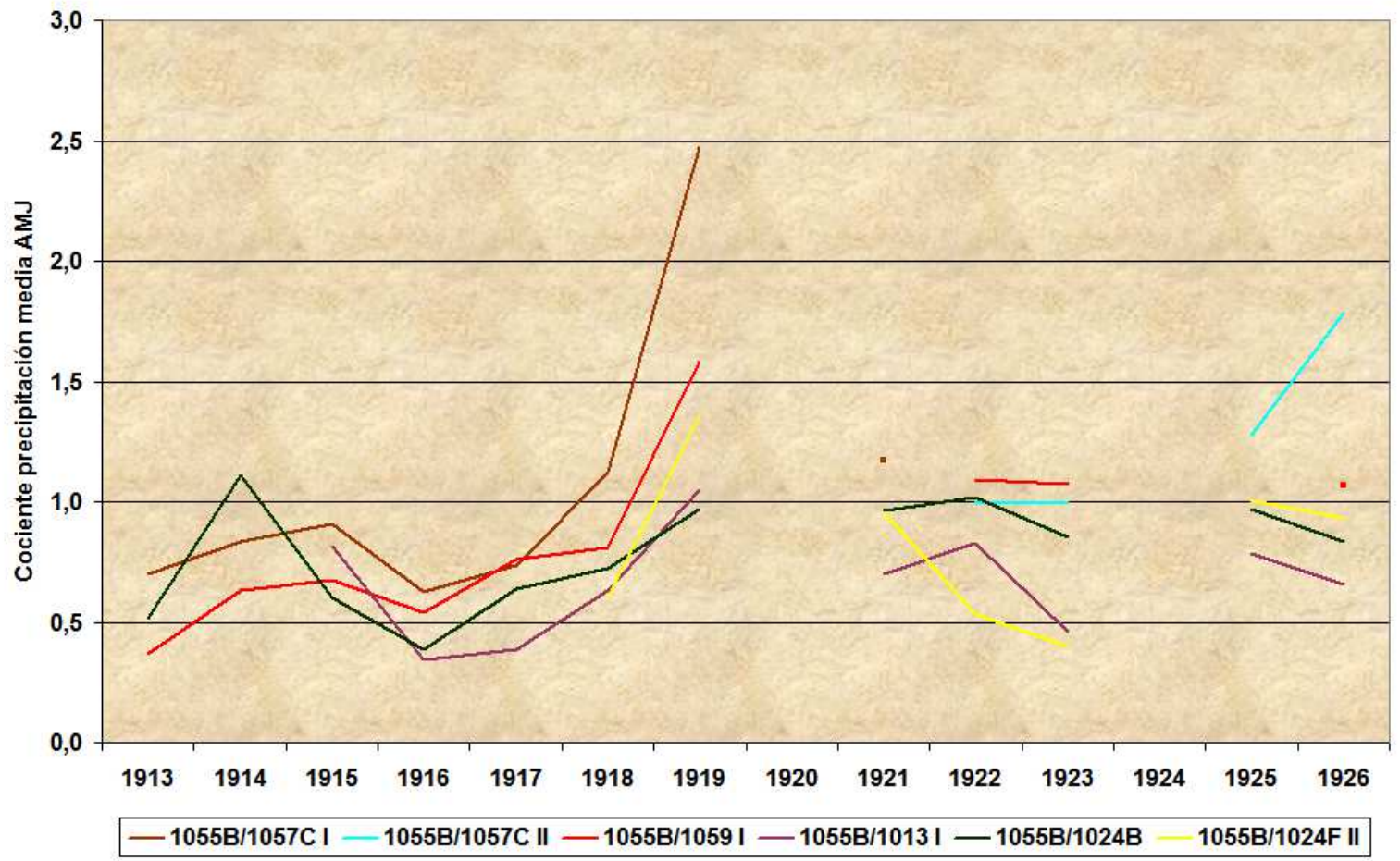

La gráfica 66 advierte de:

5.1.- La trascendencia de un acervo de series de datos pluviométricos sin lagunas.

5.2.- El desmedido aumento del cociente de la precipitación media AMJ recopilada en $1055 \bigcirc$ referida a la precipitación media de las otras localizaciones.

5.3.- Los descubrimientos de la gráfica 66 conforman con los descritos en los cotejos del análisis de Mann - Kendall MAM (gráfica 45, página 180), anual (gráfica 16, página 135) y del test de Thom AMJ (discrepancias de los extremos de 1055 , página 110).

El incremento de las magnitudes de precipitación registradas en $1055 \nabla$ se detecta en el escrutinio de la precipitación anual y MAM.

5.4.- La recapitulación de estos desvelamientos refuerza la caución de la calidad de $\underline{\text { los testimonios de precipitación asentados en } 1055 \text { P }}$. 
6.- La gráfica 67 presenta la división de la precipitación media AMJ de 1059 I $\curlyvee$ Punta Galea Faro en relación a 1057C I $\nabla, 1057 \mathrm{C}$ II $\vee, 1013$ I $\vee, 1024 \mathrm{~B} \vee$ y 1024F II $\nabla$ y la división de la precipitación media AMJ de 1057C I $\nabla$ respecto a 1024B $\vee$ de 1913 a 1926.

Gráfica 67: Razón de las precipitaciones de 1059 I $\nabla$ respecto a 1057C I $\nabla, 1057 \mathrm{C}$ II $\nabla$, 1013 I $\vee, 1024 \mathrm{~B} \vee$ y $1024 \mathrm{~F}$ II $\vee$ y de las precipitaciones de 1057C I $\vee$ en relación a 1024B $\nabla$ :

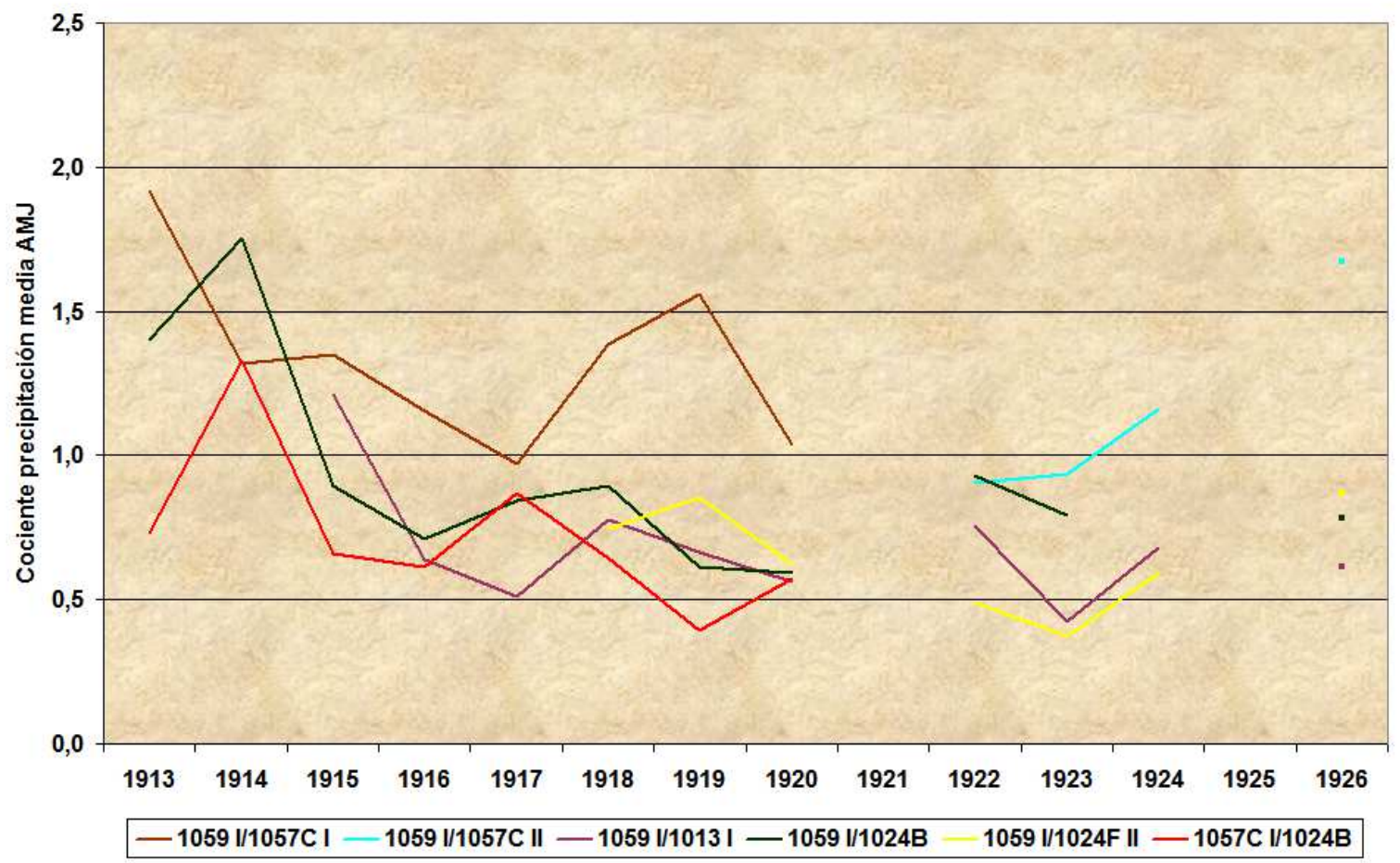

De la gráfica 67 se concluye:

6.1.- Una gran desemejanza en AMJ de las precipitaciones de los años 1913 y 1914, pareja a la disparidad de la precipitación en MAM (gráfica 46, página 180).

6.2.- El cociente de la pluviosidad AMJ de 1059 I $\nabla$ ulterior a 1913 alterna en un rango constante.

6.3.- La división 1057C I $\vee / 1024 \mathrm{~B} \vee$ asevera la prevención de los datos de precitación de 1024B $\vee$ en 1914.

Por consiguiente, la tendencia de $1055 \bigcirc$ de 1925 a 1926 se cataloga de tendencia "no climatológica" y la tendencia de 1059 I $\vee$ de 1920 a 1924 y en 1926 se clasifica de "climatológica". 


\section{3.- Tendencia positiva en 1950 y en 1954 en 9077E:}

1.- La parquedad de medidas pluviométricas en Vizcaya y en la vertiente cantábrica de Álava (4 en 1954) precisa de su acrecentamiento para cotejo; se opta por la contraposición de los registros de 9077E I $\nabla$ Ochandiano con las mediciones de las guipuzcoanas 1037 I $\vee$ Legazpia, 1046 III $\vee$ Aránzazu, 1050 I $\vee$ Eibar, 1082 I $\vee$ Bilbao Aeropuerto y 9268 I $\vee$ Otzaurte.

La tabla 100 expone la fecha de arranque y los años no íntegros de precipitación de los intervalos sin rupturas de las retahílas de 9077E I $\nabla, 1037$ I $\nabla, 1046$ III $\nabla, 1050$ I $\varnothing$, 1082 I $\nabla$ y 9268 I $\nabla$.

Tabla 100: Fecha inicio y años incompletos de 9077E I $\nabla, 1037$ I $\vee, 1046$ III $\vee, 1050$ I $\nabla$, 1082 I $P$ y 9268 I $\vee$ :

$\begin{array}{rccc}\text { Indicativo } & \text { Nombre } & \text { Comienzo } & \text { Años incompletos } \\ \text { 9077E I } \varnothing & \text { Ochandiano } & 01-01-1947 & \\ 1037 \text { I } \varnothing & \text { Legazpia } & 01-01-1946 & \\ \text { 1046 III } 8 & \text { Aránzazu } & 01-12-1945 & 1947,1948,1952 \\ 1050 \text { I } \nabla & \text { Eibar } & 01-07-1945 & 1949,1956 \\ 1082 \text { I } \varnothing & \text { Bilbao Aeropuerto } & 01-03-1947 & \\ 9268 \text { I } \varnothing & \text { Otzaurte } & 01-12-1945 & 1959,1960,1961\end{array}$

2.- La totalidad de las series principia entre 1945 y 1947.

3.- Una tendencia positiva concurrente es detectada de 1950 a 1954 en 1032 A $\nabla$ Villabona (tabla 97, página 208).

4.- El examen del test de las rachas de la precipitación media AMJ señala una inhomogeneidad "climatológica" en la vizcaína 1059 II P Punta Galea Faro de 1954 a 1965 (tabla 50, página 108) y en Guipúzcoa en 9268 I $\nabla$ de 1944 a 1955 y en 1037 I $\vee$ de 1950 a 1962 (Nota Técnica Nº 13 AEMET).

5.- La gráfica 68 ilustra la precipitación media AMJ y la mediana de 9077E I 8 , 1037 I $\vee, 1046$ III $\vee, 1050$ I $\vee, 1082$ I $\vee$ y 9268 I $\vee$ de 1947 a 1970.

La gráfica 68 describe la precipitación media AMJ en segmentos continuos; en segmentos discontinuos, la mediana en los intersticios entre roturas de cada serie. 
Gráfica 68: Precipitación media AMJ y mediana de la precipitación AMJ $\left(1 / \mathrm{m}^{2}\right)$ de 9077E I $\vee, 1037$ I $\vee, 1046$ III $\vee, 1050$ I $\vee, 1082$ I $\vee$ y 9268 I $\vee$ :

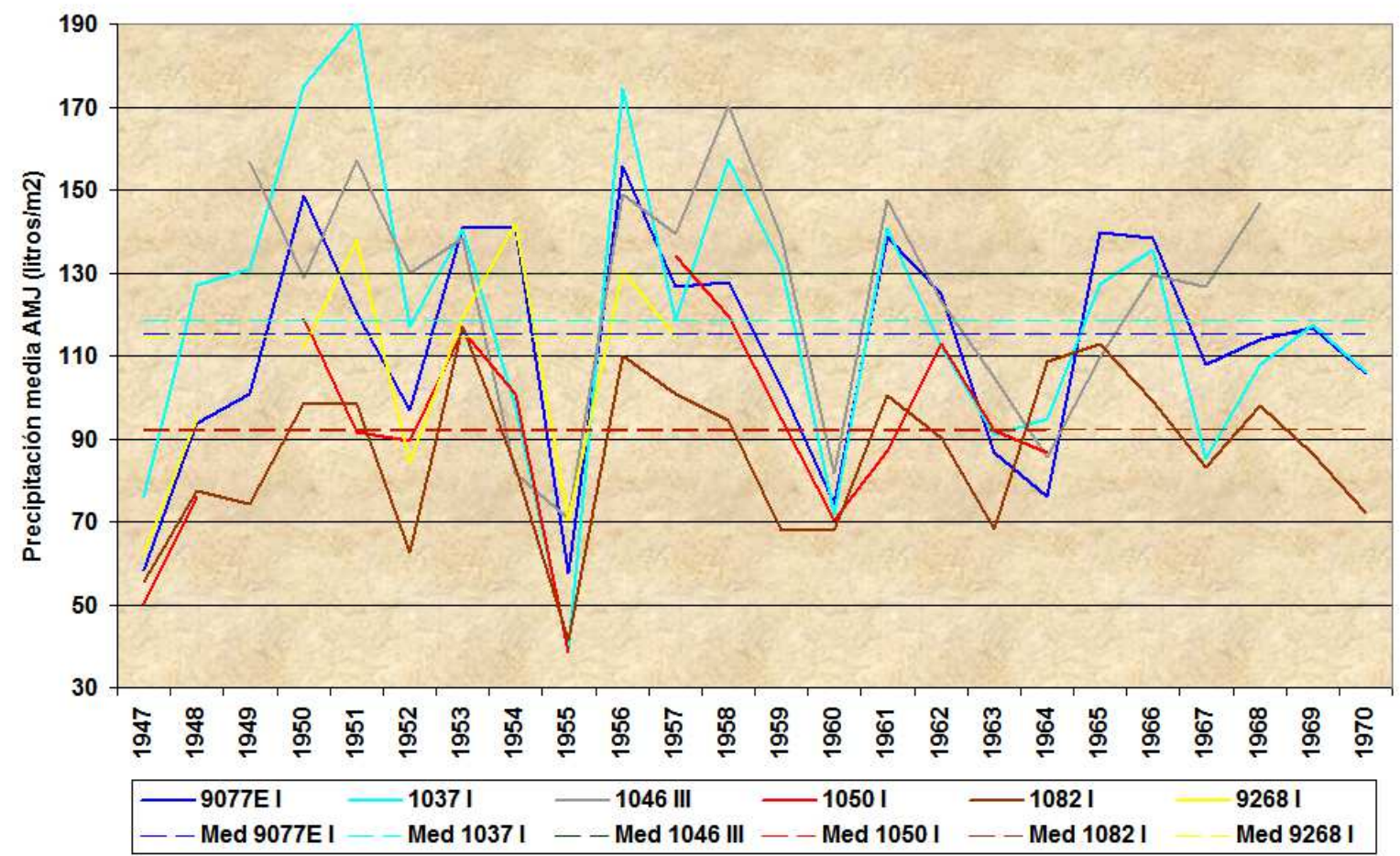

5.1.- Las medianas de 1037 I $\vee, 9077$ E I $\vee$ y 9268 I $\vee$ son parejas; las de 1050 I $\vee$ y 1082 I $\vee$ cuasi idénticas $\left(91,9\right.$ y $92,31 / \mathrm{m}^{2}$ respectivamente).

5.2.- Las precipitaciones acrecen de 1947 a 1951 en la totalidad de ubicaciones. Al seco 1952 le sucede el pluvioso 1953, copiosa pluviosidad persistente en 1954 en 9077E I 8 y en 9268 I 8 (ambos en la vertiente mediterránea y próximos a la divisoria de aguas).

La tendencia positiva espulgada de 9077E I $\bigcirc$ es concomitante con el tránsito de la pluviometría en AMJ en el resto de jardines meteorológicos.

5.3.- Ascensos bruscos de la precipitación AMJ de 1947 a 1950, 1952 a 1953, 1955 a 1956 y de 1960 a 1961: Al igual que en Guipúzcoa (Nota Técnica No 13 AEMET), a una rauda transición de AMJ secos a muy lluviosos, le siguen unos AMJ en que las precipitaciones decrecen gradualmente hasta alcanzar un mínimo y el ciclo se reanuda.

5.4.- Los máximos coetáneos de 1956, 1961, 1966 y 1969 acuerdan con las tendencias positivas de $9077 \mathrm{E}$ I $\vee$, con los hallazgos recopilados en la tabla 70 (página 127) y con los de Guipúzcoa (tabla 69, página 127). 1950 y 1953 son máximos comunes a la plenitud de emplazamientos.

5.5.- Los mínimos simultáneos de 1955, 1959, 1960, 1963 y 1967 concuerdan con los revelamientos de la tabla 70 bis (página 127) y con los registrados en Guipúzcoa (tabla 69 bis, página 127). 1947 y 1952 años muy áridos en todos los lugares.

5.6.- El transcurso de la precipitación en 1082 I $\supsetneq$ en 1950 - 1951, 1957 - 1958, 1959 - 1960, 1963 - 1964, 1965 - 1966 y 1968 - 1969, confrontado a los demás enclaves, antecede al discurso pluviométrico del año posterior. 
5.7.- La criticidad del año de iniciación en la prevención de conclusiones espurias:

a) Si las series escrutadas hubieran comenzado en 1955, la tendencia de la precipitación hubiera sido positiva.

b) Si se hubieran fundado en 1956, la tendencia de la precipitación devendría negativa. Un craso yerro sería la inferencia de incrementos o decrementos de la precipitación en primavera en Vizcaya y en la vertiente cantábrica de Álava, supliendo el carácter cíclico de la precipitación.

6.- La gráfica 69 refleja la razón de la precipitación media AMJ de 9077E I $\vee$ Ochandiano tocante a 1037 I $\vee, 1046$ III $\vee, 1050$ I $\vee, 1082$ I $\vee$ y 9268 I $\vee$ de 1947 a 1970.

Gráfica 69: Razón de las precipitaciones de 9077E I $\nabla$ respecto a 1037 I $\vee, 1046$ III $\vee$, 1050 I $\vee, 1082$ I $\vee$ y 9268 I $\vee$ :

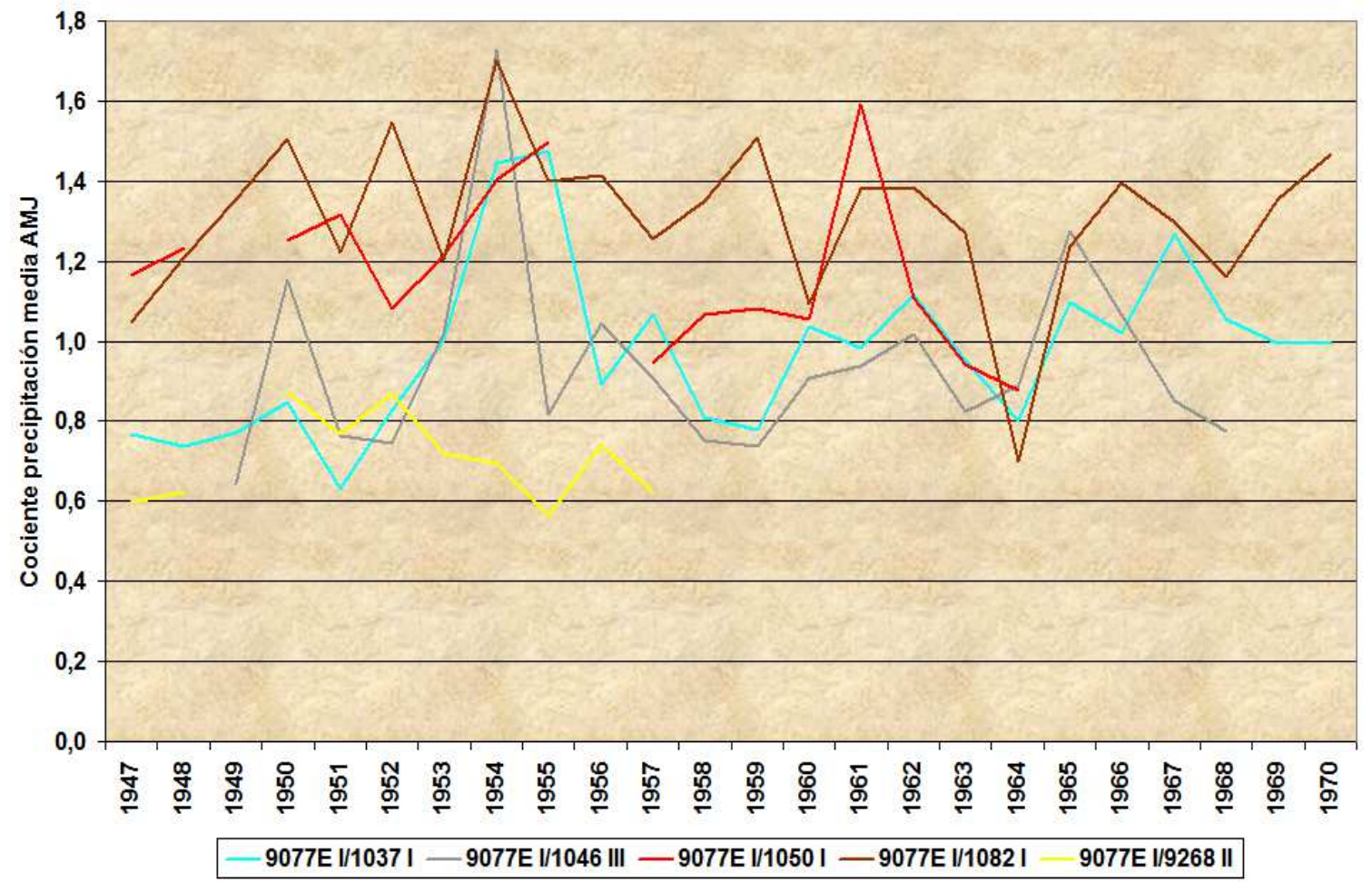

De la gráfica 69 se percata:

6.1.- El cociente de las precipitaciones es constante y revela una euritmia en:

a) Los máximos (1950 y 1961; 1954 y 1966) ligeramente superior a los 10 años, los cuáles coinciden cuasi plenamente con los años pluviosos de la tabla 70.

b) Los mínimos (1947, 1955 y 1963 - 1964; 1952, 1960 y 1968) de 8 años. Los mínimos coinciden prácticamente en su totalidad con los años áridos de la tabla 70 bis.

Por tanto, se la cataloga de tendencia "climatológica". 
4.- Tendencia positiva en 1972 en 1054 y $9076 \mathrm{I}$ y de 1972 a 1973 en 1060 A y 1093 :

1.- Las anotaciones pluviométricas de 1054 II $P$ Marquina, 1060A $P$ Amurrio Colegio, 1093 I $\vee$ Carranza y 9076I $\vee$ Ceanuri se contrastan con las mediciones de 1050 II $\vee$ Eibar, 1053 I $\vee$ Echevarría, 1060 I $\vee$ y 1060 II $\vee$ Amurrio, 1068 II $\vee$ Basauri, $1070 \vee$ Abadiano y 1082 I $\&$ Bilbao Aeropuerto.

La tabla 101 recoge la fecha de inicio y los años sin plenitud de datos de los intersticios sin roturas de 1054 II $\nabla, 1060 \mathrm{~A} \nabla, 1093$ I $\nabla, 9076 \mathrm{I} \nabla, 1050$ II $\nabla, 1053$ I $\nabla$, 1060 I $\nabla, 1060$ II $\nabla, 1068$ II $\nabla, 1070 \nabla$ y 1082 I $\nabla$.

Tabla 101: Fecha inicio y años incompletos de 1054 II $\nabla, 1060 \mathrm{~A} \nabla, 1093$ I $\nabla, 9076$ I $\nabla$,

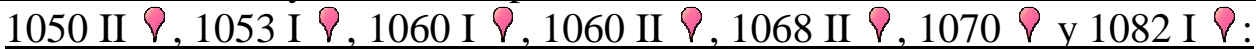

\begin{tabular}{|c|c|c|c|}
\hline Indicativo & Nombre & Comienzo & Años incompletos \\
\hline $1054 \mathrm{II} P$ & Marquina & $01-05-1956$ & 1959,1975 \\
\hline $1060 \mathrm{~A} P$ & Amurrio Colegio & $01-10-1961$ & \\
\hline $1093 \mathrm{I} P$ & Carranza & $01-11-1956$ & 1959 \\
\hline $9076 \mathrm{I} P$ & Ceanuri & $24-04-1945$ & $1945,1946,1948-1967,1973-1982$ \\
\hline $1050 \mathrm{II} P$ & Eibar & Final 1964 & 1987 \\
\hline 1053 I $\vee$ & Echevarría & $01-10-1961$ & \\
\hline $1060 \mathrm{I} P$ & Amurrio & $01-05-1955$ & 1964 \\
\hline 1060 II $P$ & Amurrio & Final 1966 & 1967 \\
\hline 1068 II 8 & Basauri & Final 1954 & \\
\hline 1070 P & Abadiano & $01-12-1967$ & \\
\hline $1082 \mathrm{I} \nabla$ & Bilbao Aeropuerto & $01-03-1947$ & \\
\hline
\end{tabular}

2.- Una tendencia positiva coetánea aflora en Guipúzcoa en 1972 en 1018 I $\nabla$ Rentería, en 1026 จ Beasain y en 1044A $\vee$ Escoriaza - Tesa (tabla 97, página 208).

3.- El análisis de la precipitación media AMJ con el test de las rachas (tabla 50, página 108) revela una inhomogeneidad "climatológica" en 1060A $P$ de 1965 a 1977, en 1053 I $\nabla$ de 1966 a 1975, en 1082 I $\vee$ de 1966 a 1976, en 1093 I $\vee$ Carranza de 1966 a 1977 y en $1070 \bigcirc$ de 1968 a 1983.

4.- La gráfica 70 exterioriza la precipitación media AMJ y la mediana de 1054 II $\nabla$,

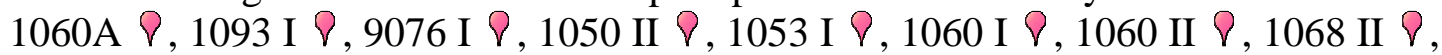
$1070 \vee$ y 1082 I $\vee$ de 1957 a 1974.

La gráfica 70 representa con un trazo continuo la precipitación media AMJ y mediante trazo discontinuo la mediana en el intersticio temporal entre rupturas de cada serie. 
Gráfica 70: Precipitación media AMJ y mediana de la precipitación AMJ $\left(1 / \mathrm{m}^{2}\right) \mathrm{de}$

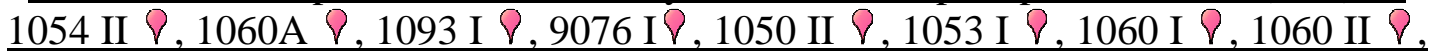
1068 II $P, 1070 \vee$ y 1082 I $\vee:$

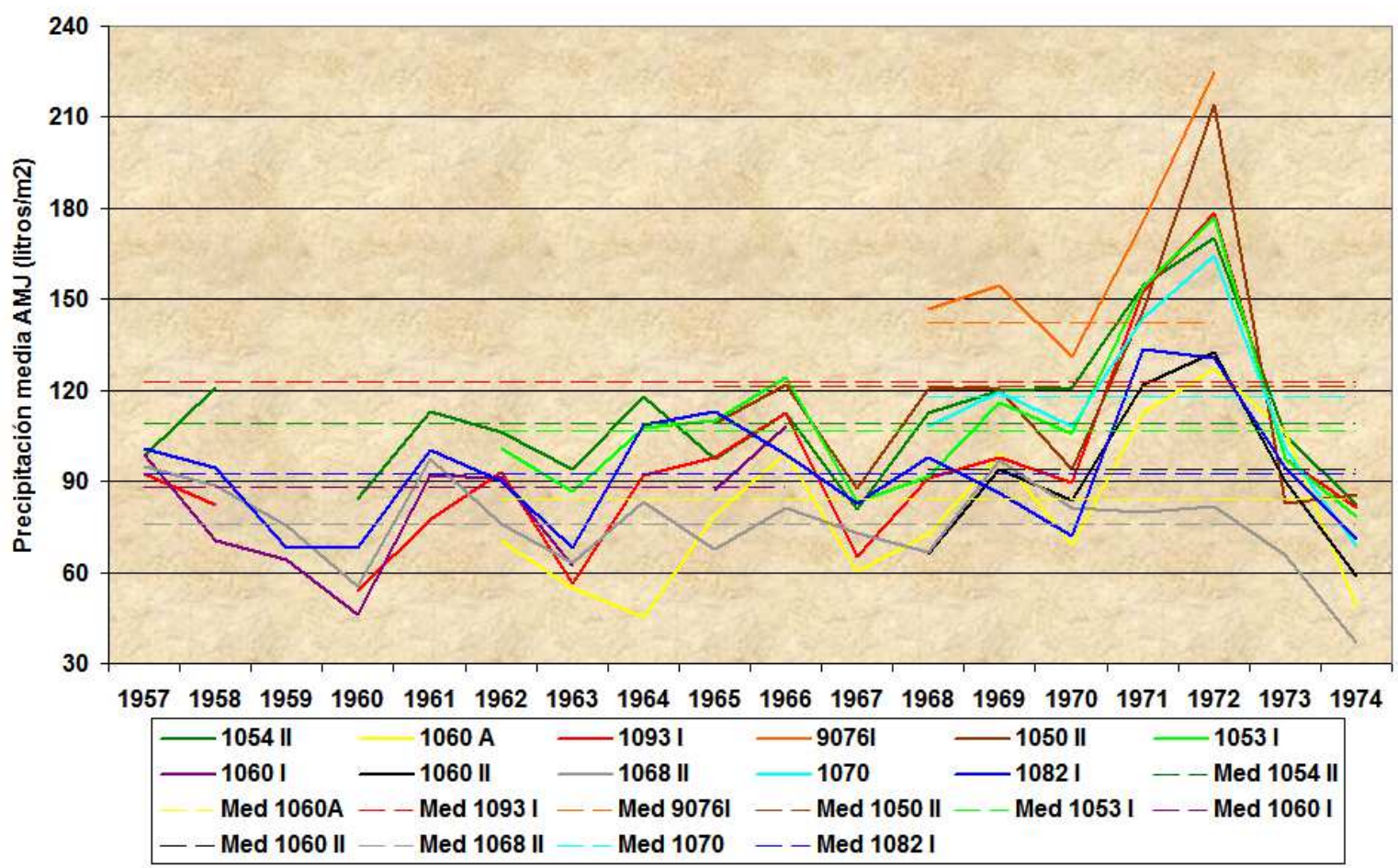

De la gráfica 70 se aprecia:

4.1.- Las precipitaciones, al igual que en MAM (gráfica 47, página 182), aumentan en todos los lugares, con una retahíla de máximos y mínimos ascendentes. Las tendencias positivas de 1054 II $\vee, 1060 \mathrm{~A} \vee, 1093$ I $\nabla$ y $9076 \mathrm{I} \vee$ son acordes con el progreso de la pluviosidad en los restantes emplazamientos.

4.2.- Los máximos pluviométricos sincrónicos de 1956, 1961, 1966, 1969, 1971 y 1972 son coherentes con los compendiados en la tabla 70 (página 127), con los extremos de Guipúzcoa sintetizados en al tabla 69 (página 127) y con las tendencias positivas escrutadas.

4.3.- Los mínimos de precipitación concurrentes de 1959, 1960, 1963, 1967 y 1974 se corresponden con el compendio de la tabla 70 bis (página 127) y con los años áridos de Guipúzcoa, recogidos en la tabla 69 bis (página 127).

4.4.- La evolución de la pluviosidad de 1082 I $\vee$ en los años 1959 - 1960, 1963 - 1964, 1965 - 1966, 1968 - 1969 y 1971 - 1972, opuesta al del resto de localizaciones, anticipa el incremento/decremento pluviométrico en el año ulterior.

5.- La gráfica 71 recoge el cociente de la precipitación media AMJ de 1093 I $\nabla$ Carranza y de 1060A $\nabla$ Amurrio Colegio respecto a 1053 I $\vee, 1054$ II $\vee, 1060$ I $\vee$, 1060 II $\vee, 1082$ I $\vee$ y la razón de la precipitación media AMJ de 1060A $\vee$ respecto a 1093 I $\bigcirc$ de 1957 a 1974. 
Gráfica 71: Razón de las precipitaciones de 1093 I $\nabla$ y de 1060A $\nabla$ respecto a 1053 I $\nabla$, 1054 II $\vee, 1060$ I $\vee, 1060$ II $\vee$ y 1082 I $\nabla$ y razón de las precipitaciones de 1060A $\vee$ respecto a 1093 I $\nabla$ :

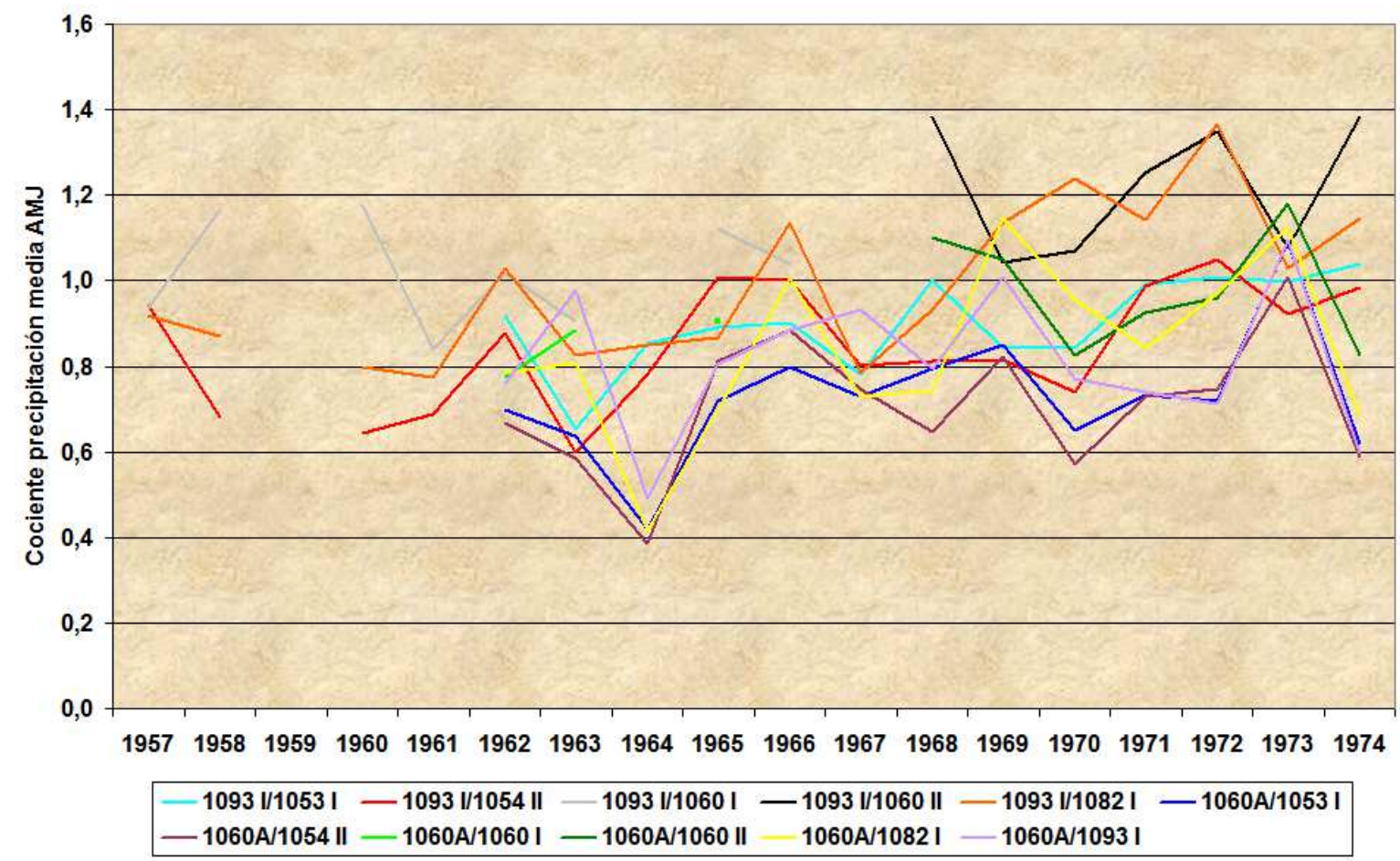

De la gráfica 71 se infiere:

5.1.- La razón de las precipitaciones de 1093 I $\nabla$ y de 1060A $\nabla$ en relación al resto de sitios es constante, fluctuando entre unos similares:

a) Máximos en los años 1962, 1966, 1972 y 1973, asomo de una euritmia próxima al decenio (1962 y $1972-1973)$.

b) Mínimos comunes en los años (1964 y 1974; 1961 y 1970) de una cadencia de 9 10 años.

5.2- La ruptura de 1060 I $\nabla$ y 1060 II $\nabla$ es exteriorizada por el salto de los cocientes de 1093 I $\nabla / 1060$ I $\nabla$ respecto a 1093 I $\nabla / 1060$ II $\nabla$ y de $1060 \mathrm{~A} \nabla / 1060$ I $\nabla$ en relación a 1060A $\vee / 1060$ II $\vee$ tras 1966.

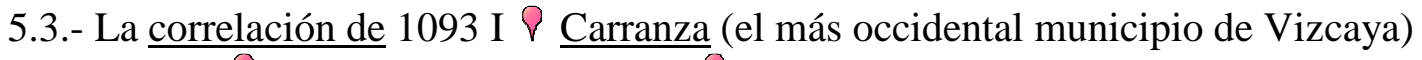

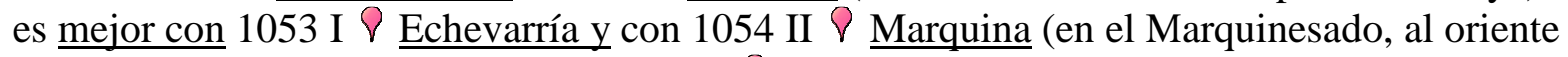
de Vizcaya) que con la más cercana 1082 I $\nabla$ Bilbao Aeropuerto, analogía apercibida en menor medida en 1060A $P$ Amurrio. 
6.- La gráfica 72 ostenta la división de la precipitación media AMJ de 1054 II $\curlyvee$ Marquina y 9076 I $\vee$ Ceanuri referida a 1050 II $\vee, 1053$ I $\vee$ y $1070 \vee$ y la división de la precipitación media AMJ de 1054 II $\vee$ en referencia a 9076I $\vee$ de 1962 a 1974.

Gráfica 72: Razón de las precipitaciones de 1054 II $\nabla$ y 9076I $\nabla$ respecto a 1050 II $\nabla$. 1053 I $\vee$ y 1070 \& y razón de las precipitaciones de 1054 II $\vee$ respecto a 9076I $\vee$ :

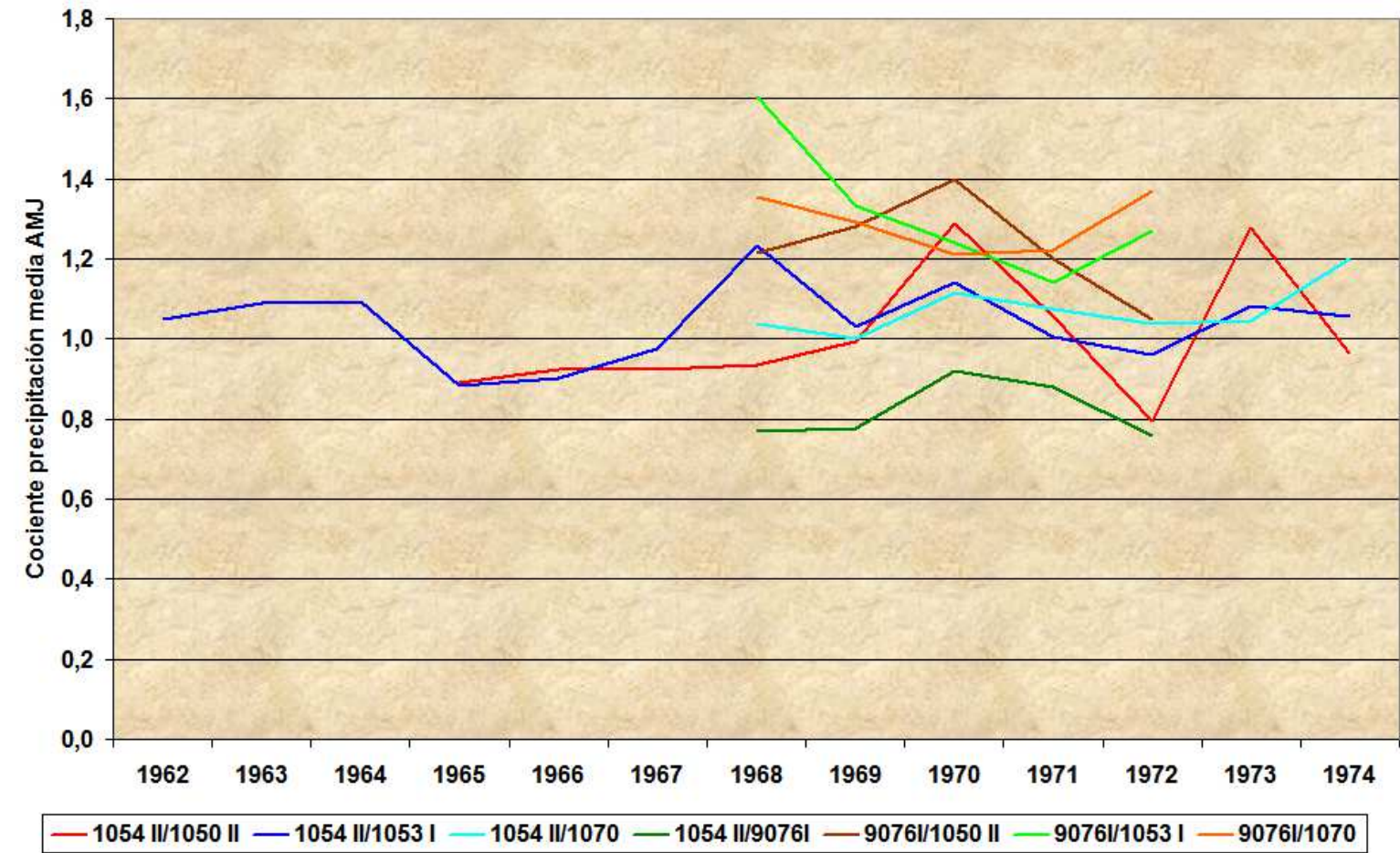

De la gráfica 72 se concluye:

6.1.- La razón de las precipitaciones de 1054 II $\bigcirc$ oscila entre unos máximos y mínimos parejos.

6.2.- Los máximos del cociente de precipitaciones 1054 II $\vee / 1053$ I $\nabla$ de 1964 y 1973 distan 9 años.

6.3.- La óptima correlación entre las allegadas 1054 II $\vee$ Marquina y 1053 I $P$ Echevarría y la muy buena correlación respecto a 1050 II $\vee$ Eibar, resultados similares a MAM (página 185).

6.4.- La breve 9076I $\nabla$ Ceanuri tiene una excelsa correlación con 1054 II $\bigcirc$ Marquina en el lapso de años comunes de 1968 a 1972. 
7.- La gráfica 73 puntualiza la razón de la precipitación media AMJ de 1068 II $\bigcirc$ en relación a 1093 I $\vee, 1082$ I $\vee, 1050$ II $\vee, 1053$ I $\vee, 1054$ II $\vee$ y $1070 \vee$ de 1957 a 1974.

Gráfica 73: Razón de las precipitaciones de 1068 II $\nabla$ respecto a 1093 I $\nabla, 1082$ I $\nabla$, 1050 II $\odot, 1053$ I $\vee, 1054$ II $९$ y 1070 尺:

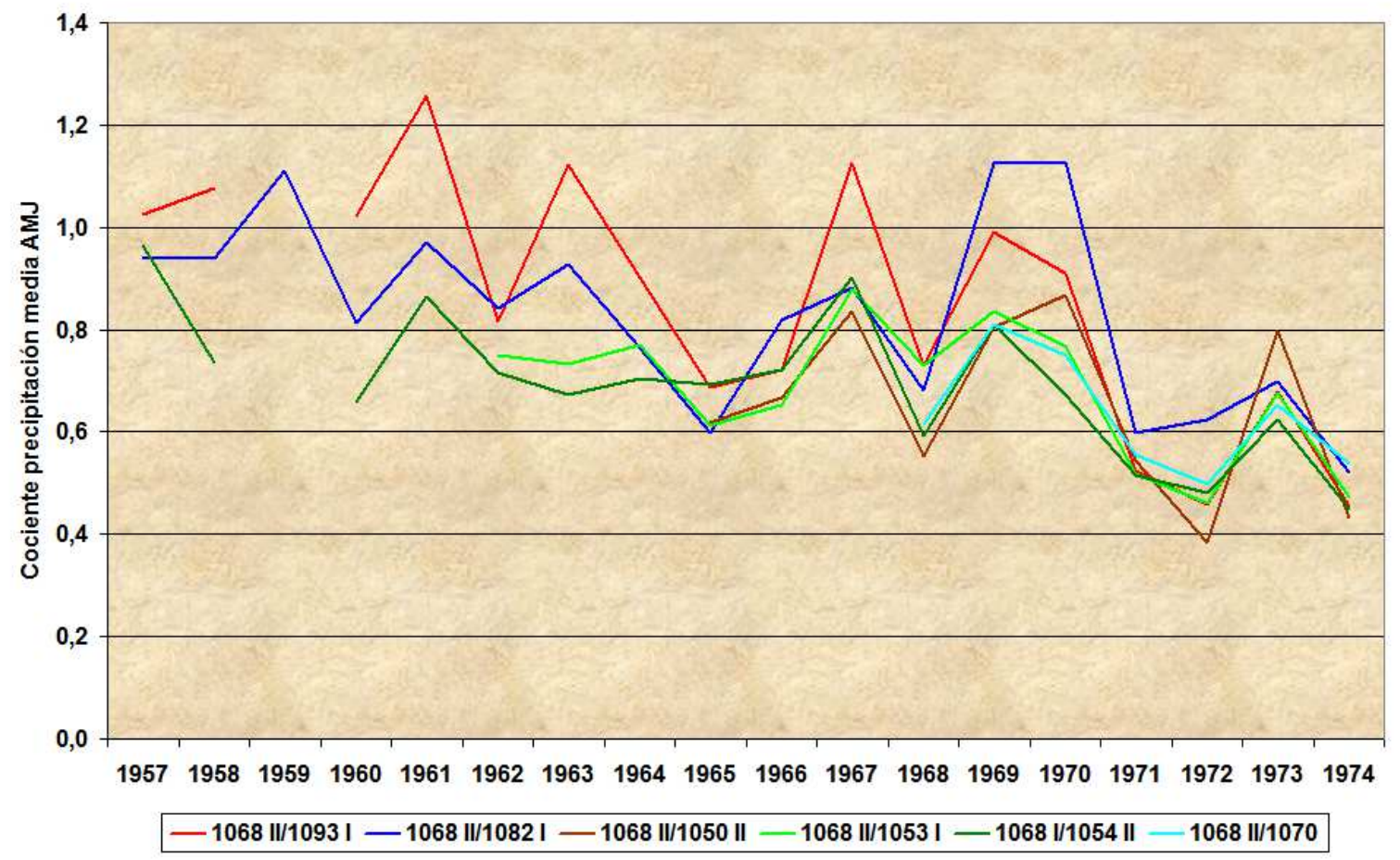

De la gráfica 73 se percibe:

7.1.- El cociente de las precipitaciones apuntadas en 1068 II $\nabla$ descrece desde su inicio en 1957, con una retahíla de dientes de sierra menguantes de los máximos y mínimos de la pluviosidad.

Los cocientes 1068 II $\nabla / 1093$ I $\vee$ y 1068 II / 1082 I $\vee$ aminoran en unos respectivos 60 y $45 \%$ de 1958 a 1974.

7.2.- Esta disparidad de la precipitación AMJ de 1068 II $\nabla$ da pábulo a la exclusión de 1068 II $\vee$ de las gráficas de cotejo 71 y 72.

7.3.- Los máximos y mínimos son acordes con los extremos pluviométricos del resto de lugares (al unísono con los resultados de la gráfica 70).

7.4.- Esta disminución de la precipitación registrada en AMJ 1068 II $\nabla$ concuerda con las razones de las precipitaciones media MAM y anual de 1068 II $P$, descritas respectivamente en los comentarios a las gráficas 26 (página 148) y 50 (página 186).

Por tanto, la tendencia positiva en 1972 en 1054 II $\nabla$ y 9076 I $\nabla$ y de 1972 a 1973 en 1060A $\nabla$ y 1093 I $\nabla$ es “climatológica". 
5.- Tendencia positiva en 1978 en 1083 , de 1978 a 1979 en $1060 \mathrm{~A}$, de 1978 a 1981 en 1093 $\mathrm{y}$ en 1980 en 1082:

1.- Los valores de la pluviosidad de 1060A $\nabla$ Amurrio Colegio, 1082 I $\vee$ Bilbao Aeropuerto, 1083 I $\vee$ Arcentales y 1093 I $\$ Carranza son comparados con los registros de 1060 II $\vee$ Amurrio, $1070 \vee$ Abadiano, 1075E I $\vee$ Aránzazu, 1083 II $\vee$ Arcentales y 1093A $\curlyvee$ Carranza.

La tabla 102 muestra el empiece y los años incompletos de los intersticios sin roturas de los pluviómetros de 1060A $\nabla, 1082$ I $\nabla, 1083$ I $\nabla, 1093$ I $\nabla, 1060$ II $\vee, 1070 \vee$, 1075E I $\vee, 1083$ II $\vee$ y 1093A $\vee$.

Tabla 102: Fecha inicio y años incompletos de 1060A $P, 1082$ I $\vee, 1083$ I $\vee, 1093$ I $P$, 1060 II $P, 1070$ P, 1075E I, 1083 II $P$ y 1093A $\vee:$

\begin{tabular}{|c|c|c|c|}
\hline Indicativo & Nombre & Comienzo & Años incompletos \\
\hline $1060 \mathrm{~A} \nabla$ & Amurrio Colegio & $01-10-1961$ & \\
\hline $1082 \mathrm{I} P$ & Bilbao Aeropuerto & $01-03-1947$ & \\
\hline $1083 \mathrm{I} \vee$ & Arcentales & $01-08-1967$ & \\
\hline 1093 I P & Carranza & $01-11-1956$ & 1959 \\
\hline 1060 II $P$ & Amurrio & Final 1966 & 1967 \\
\hline $1070 \vee$ & Abadiano & $01-12-1967$ & \\
\hline $1075 \mathrm{E} I 8$ & Aránzazu & $01-12-1967$ & \\
\hline 1083 II $\vee$ & Arcentales & $01-02-1981$ & 1988,1990 \\
\hline $1093 \mathrm{~A} P$ & Carranza & $01-01-1972$ & \\
\hline
\end{tabular}

$1070 \vee$ y 1075E I $\vee$ comienzan el mismo día; 1083 I $\vee$ en el mismo año.

2.- Una tendencia positiva sincrónica de la precipitación se observa en Guipúzcoa de 1978 a 1981 en 1022 Pernani y 1026 Peasain (tabla 97, página 208) y en 1980 en $1016 \bigcirc$ Oyarzun Arditurri y $1023 \bigcirc$ Astigarraga.

3.- El examen del test de las rachas de la precipitación media AMJ (tabla 50, página 108) aflora una inhomogeneidad "climatológica" en 1060 II $\nabla$ y en 1070 \& de 1970 a 1981 y de 1974 a 1983.

4.- La gráfica 74 refiere la precipitación media AMJ y la mediana de $1060 \mathrm{~A} \vee$, 1082 I $\nabla, 1083$ I $\nabla, 1093$ I $\nabla, 1060$ II $\nabla, 1070 \nabla, 1075$ E I $\nabla, 1083$ II $\vee$ y 1093A $\nabla$ de 1968 a 1983.

La gráfica 74 denota la precipitación media AMJ con segmentos continuos y con segmentos discontinuos la mediana en los intervalos entre las rupturas de cada serie. 
Gráfica 74: Precipitación media AMJ y mediana de la precipitación AMJ $\left(1 / \mathrm{m}^{2}\right)$ de

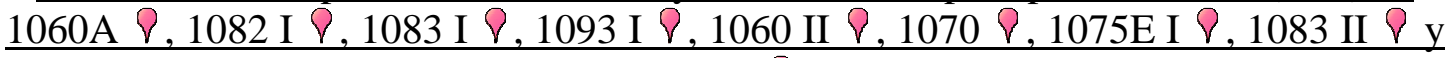
1093A P:

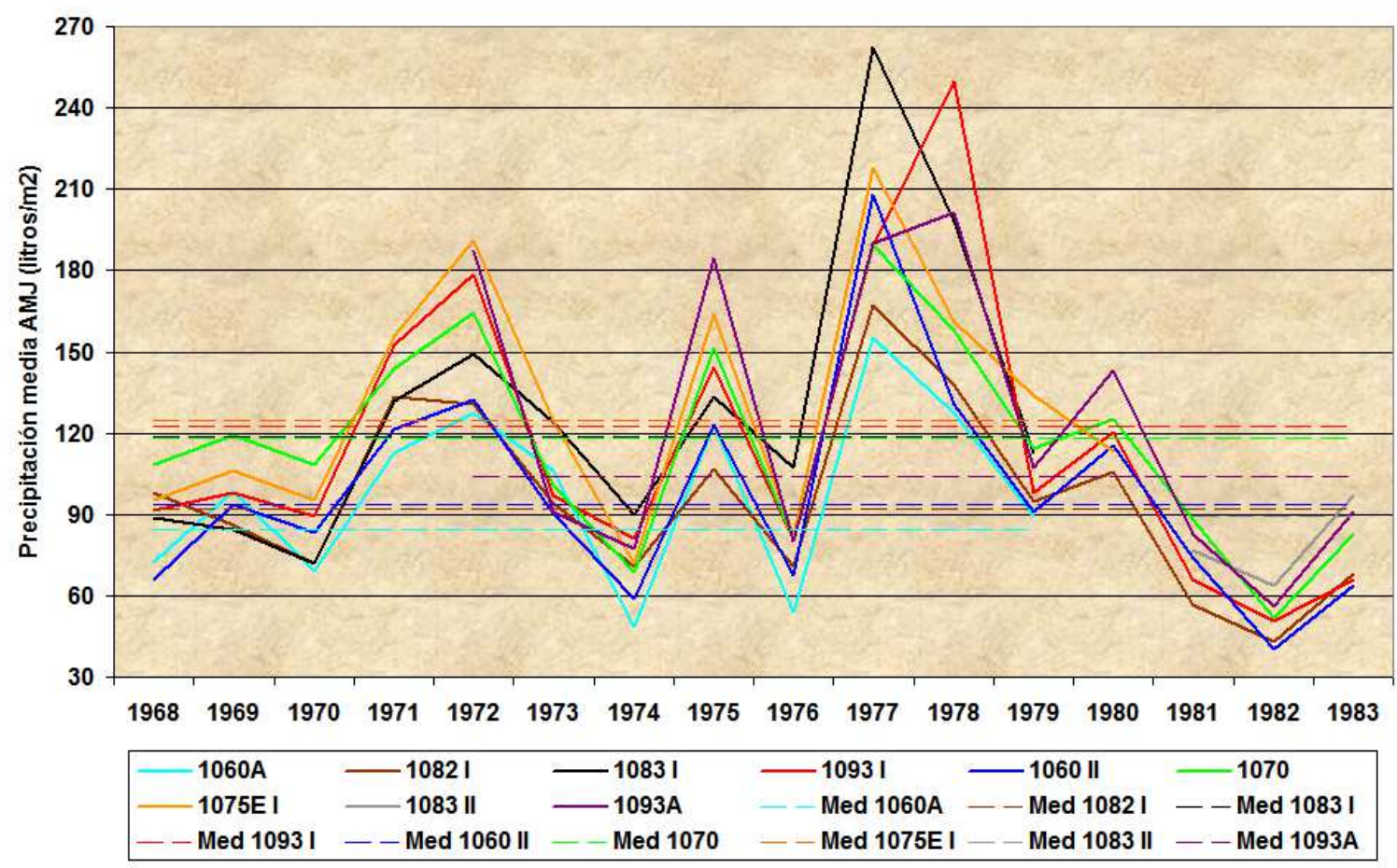

De la gráfica 74 se colige:

4.1.- Al normal 1968 le prosiguen los lluviosos 1969, 1971 y 1972. Posterior al normal 1973 se alcanza un mínimo en el muy seco 1974, antecesor del pluvioso 1975. Al árido 1976 le sobreviene una violenta acrecencia de la pluviosidad en 1977, subsistente en 1978.

Efemérides de precipitación acaecen en 1979 en 1060A $\vee, 1070$ ४, 1071 , 1075E I $\vee, 1060$ II $\vee$ y 9077E I $\vee$ (tablas 55 y 58, páginas 113 y 116).

El normal 1979 es subseguido por un descenso pluviométrico hasta los muy secos 1981, 1982 (mínimo de 1968 a 1983) y 1983.

4.2.- La tendencia positiva conviene con la evolución de la precipitación AMJ en los diversos lugares.

4.3.- Los máximos simultáneos de 1969, 1971, 1972, 1975, 1977, 1978 son conformes con los allegados en la tabla 70 (página 127).

4.4.- Los mínimos coetáneos de 1974, 1976, 1981, 1982 y 1983 coinciden con los recopilados en la tabla 70 bis (página 127). 
4.5.- La progresión de la precipitación de 1082 I $\vee$ en 1968 - 1969 y 1971 - 1972, dispar al resto de ubicaciones, preludia la descrecencia del siguiente año (1970 y 1973).

5.- La gráfica 75 especifica el cociente de la precipitación media AMJ de 1060A $\nabla$ Amurrio Colegio referido a 1060 II $\vee, 1070$ P, 1075E I $\vee, 1082$ I $\vee$ y 1093 I $\vee$ de 1968 a 1979.

Gráfica 75: Razón de las precipitaciones de 1060A $\nabla$ respecto a 1060 II $\nabla, 1070 \varnothing$, 1075E I $\vee, 1082$ I $\vee$ y 1093 I $\vee$ :

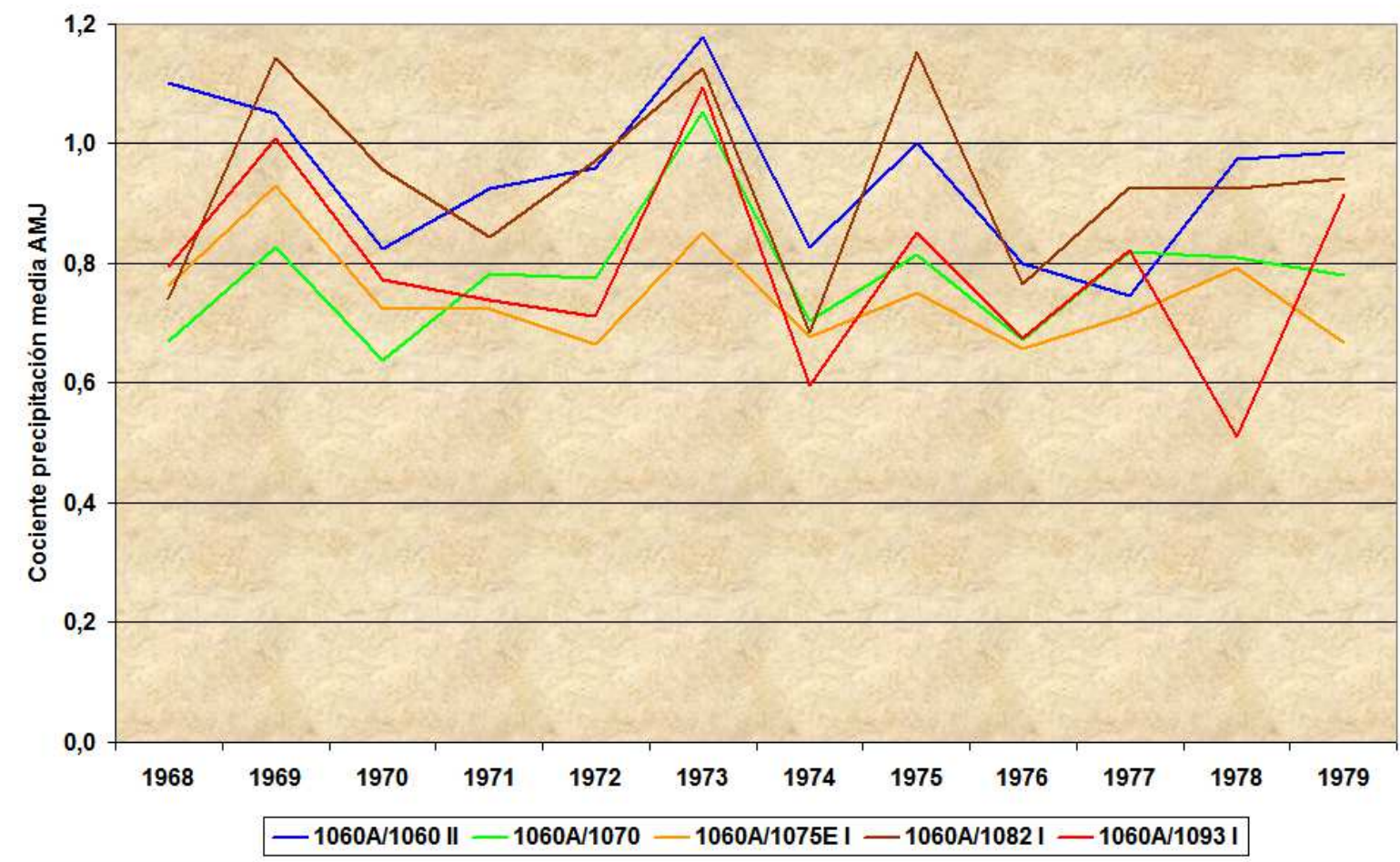

De la gráfica 75 se percibe:

5.1.- El cociente de las precipitaciones de 1060A $\nabla$ referido a las demás ubicaciones oscila entre unos parejos máximos (1969 y 1978; 1973) y mínimos pluviométricos (1970 y 1974) en el lapso escrutado de 1968 a 1979.

5.2.- La cuantía de las precipitaciones recabadas en $1060 \mathrm{~A} \vee$ y 1082 I $\vee$ fluctúa en torno al $20 \%$ respecto a 1060 II $\vee$.

5.3.- La notable correlación de 1060A $\nabla$ con 1060 II $\nabla, 1070 \nabla, 1075 \mathrm{E}$ I $\nabla$ y 1082 I $\nabla$, acorde con los resultados de MAM de la gráfica 52 (página 189), sugiere una pluviometría semejante en primavera en dichas radicaciones, al menos de los años 1968 a 1979.

La figura 14 (página 64) muestra la situación de 1060A $\nabla, 1060$ II $\nabla, 1070 \vee$ y $1075 \mathrm{E}$ I $\nabla$; la figura 21 derecha (página 114) indica los enclaves de 1060A $\vee, 1082$ I $\vee$ y 1093 I $P$. 
6.- La gráfica 76 exterioriza la razón de la precipitación media AMJ de 1082 I $\nabla$ Bilbao Aeropuerto y 1093 I $\vee$ Carranza tocante a 1060 II $\vee, 1070$ \&, 1075E I $\vee$ y 1093A $\nabla$ y la razón de la precipitación media AMJ de 1082 I $\nabla$ referente a 1093 I $\vee$ de 1968 a 1983.

Gráfica 76: Razón de las precipitaciones de 1082 I $\nabla$ y 1093 I $\nabla$ respecto a 1060 II $\nabla$, $1070 \vee, 1075 \mathrm{E}$ I $\nabla$ y 1093A $\vee$ y razón de 1082 I $\nabla$ respecto a 1093 I $\vee$ :

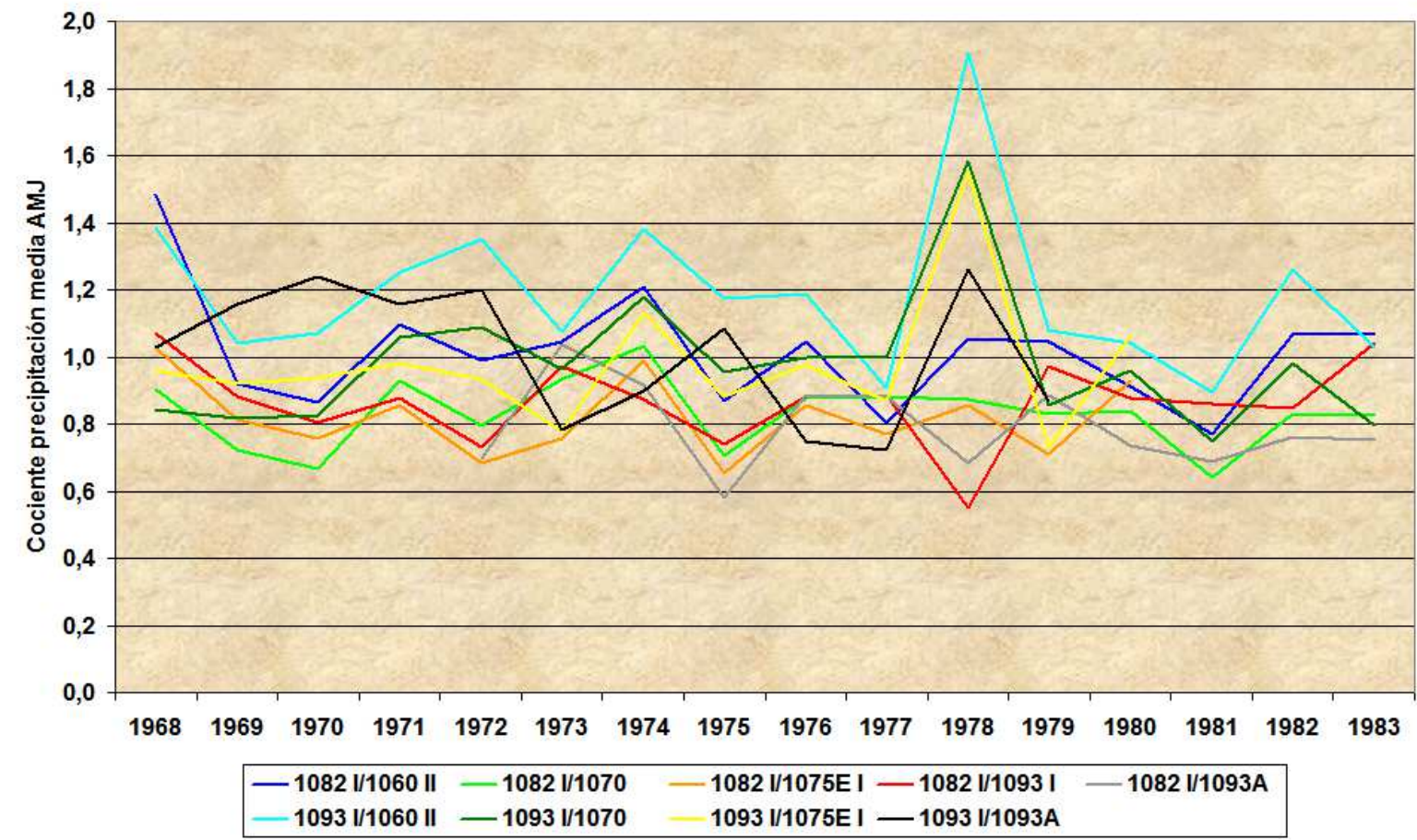

De la gráfica 76 se aprecia:

6.1.- El cociente de 1082 I 8 referido a las restantes localizaciones alterna entre unos máximos y mínimos constantes.

6.2.- La óptima correlación de 1082 I $\nabla$ con 1070 P, 1075E I $\nabla$ y 1060 II $\nabla$, resultado análogo a la precipitación en MAM (gráfica 53, página 190), siendo excelsa la correlación con 1075E I P.

6.3.- La muy buena correlación de 1093 I $\vee$ con $1070 \vee$, 1075E I $\nabla$ y 1060 II $\nabla$, salvo en el copioso AMJ de 1978 y la muy buena correlación de 1093 I $\nabla$ con $1093 \mathrm{~A} \vee$ de 1968 a 1983.

6.4.- La carencia de 1093A $\nabla$ hubiera colegido en la espuria conclusión de la catalogación de erróneo el dato de AMJ de 1093 I 8 . Nótese como en 2 ubicaciones en la misma localidad, la precipitación recogida puede variar del 80 al 120\%. 
7.- La gráfica 77 denota la proporción de la precipitación media AMJ de 1083 I $\nabla$ Arcentales relativa a 1060A $\nabla, 1060$ II $\vee, 1070$ P, 1075E I $\vee, 1082$ I $\vee$ y 1093 I $\vee$ de 1968 a 1979.

Gráfica 77: Razón de las precipitaciones de 1083 I $\vee$ respecto a 1060A $\vee, 1060$ II $\vee$, $1070 \vee, 1075 \mathrm{E}$ I $\vee, 1082$ I $\&$ y 1093 I $\vee$ :

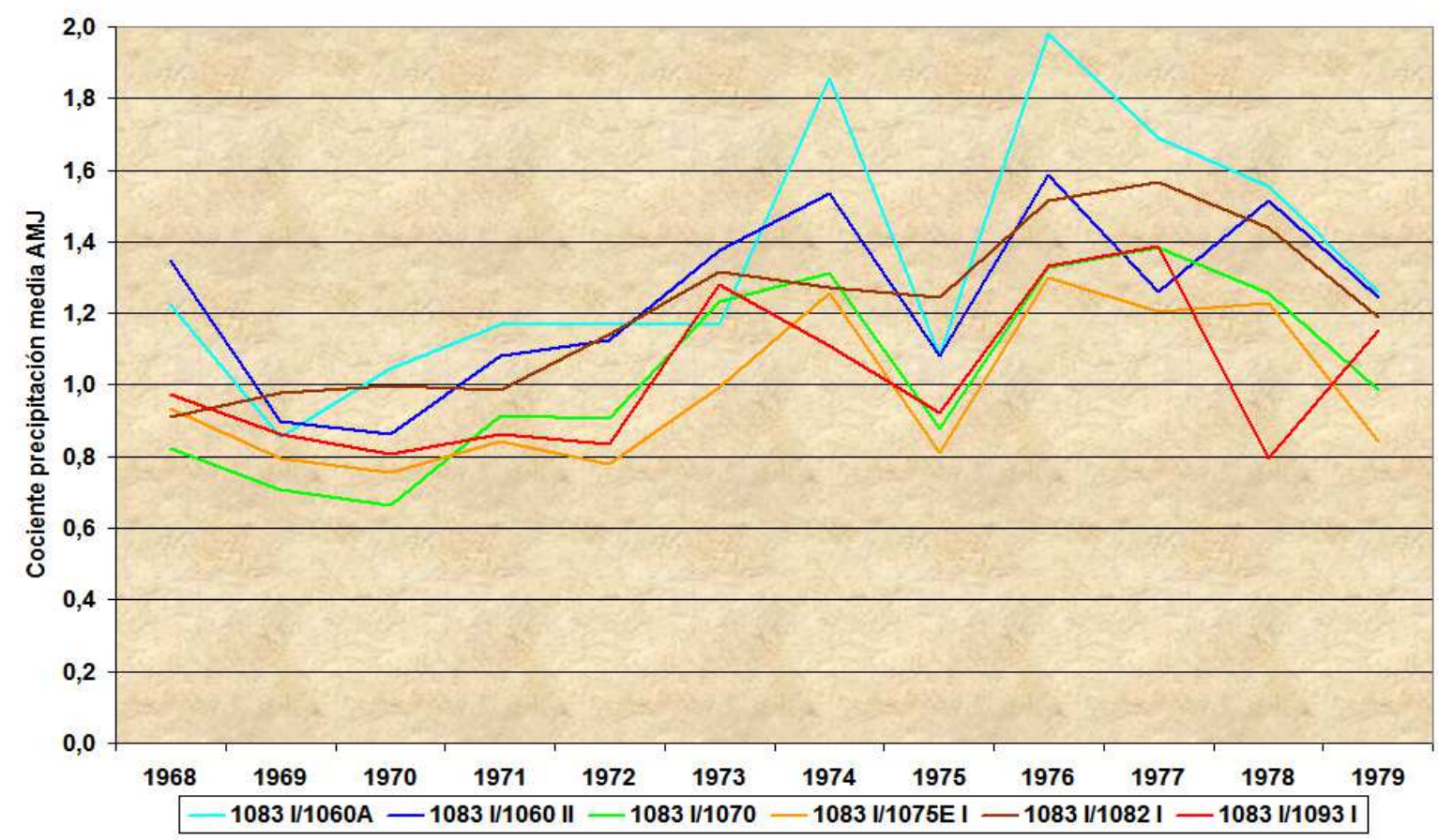

De la gráfica 77 se observa:

7.1.- Las precipitaciones registradas en 1083 I $\nabla$ acrecen en comparación al resto de emplazamientos, en especial respecto a los 2 situados en Amurrio (1060 II $\nabla$ y 1060A $\nabla$ ) con un incremento del 84 al $116 \%$ y respecto a 1082 I $\nabla$ Bilbao Aeropuerto, con un acrecimiento del $71 \%$.

Esta es la causa de la exclusión de 1083 I $\vee$ en los contrastes de las gráficas 75 y 76.

7.2.- La tendencia positiva "no climatológica" de 1083 I $\vee$ es de difícil revelamiento en un estudio somero falto, bien de la gráfica de evolución temporal de la precipitación AMJ, bien de una confrontación de los cocientes de la precipitación AMJ, al encontrarse dicha tendencia encubierta en el aumento global de precipitación en Vizcaya y en la vertiente cantábrica de Álava de la década de los 70, de apogeo en los clímax de 1977 y 1978 (gráfica 74, página 225).

7.3.- Esta inhomogeneidad "no climatológica" de 1083 I $\nabla$ corrobora los resultados "no climatológicos" de la precipitación anual y MAM de 1083 I $\vee$ de 1975 a 1979 (comentarios a las gráficas 22, 29 y 54, páginas 144, 152 y 191).

Por todo lo expuesto, la tendencia positiva de 1978 a 1979 en 1060A $\vee$, de 1978 a 1981 en 1093 I $\vee$ y en 1980 en 1082 I $\vee$ se trata de una tendencia "climatológica" y la tendencia positiva de 1978 en 1083 I $\nabla$ se califica de "no climatológica". 
Los valores pluviométricos de 1079I $\vee$ Gordejuela y 9077E II $\nabla$ Ochandiano se contrastan con los datos de pluviosidad de 1053 II $\vee$ Echevarría, 1060 II $\vee$ Amurrio, 1070 P Abadiano, 1078E I $\vee$ Valmaseda, 1082 II $\vee$ Bilbao Aeropuerto, 1083 II $\vee$ Arcentales y 1093A $\vee$ Carranza.

La tabla 103 detalla el inicio y los años incompletos de los lapsos sin rupturas de 1079I $\vee$, 9077E II $\nabla, 1053$ II $\nabla, 1060$ II $\vee, 1070 \vee, 1078$ E I $\vee, 1082$ II $\vee, 1083$ II $\vee$ y 1093A $P$.

Tabla 103: Fecha inicio y años incompletos de 1079I $\nabla, 9077 \mathrm{E}$ II $\varnothing, 1053$ II $\nabla, 1060$ II $\varnothing$, 1070 P, 1078E I $\vee, 1082$ II $\vee, 1083$ II $\vee$ y 1093A $\vee:$

\begin{tabular}{|c|c|c|c|}
\hline Indicativo & Nombre & Comienzo & Años incompletos \\
\hline 1079I $\vee$ & Gordejuela & $01-06-1972$ & 1976 \\
\hline 9077E II $\vee$ & Ochandiano & $01-08-1973$ & 1992 \\
\hline 1053 II $P$ & Echevarría & Final 1975 & \\
\hline 1060 II $P$ & Amurrio & Final 1966 & 1967 \\
\hline 10708 & Abadiano & $01-12-1967$ & \\
\hline $1078 \mathrm{E}$ I 8 & Valmaseda & $01-01-1972$ & \\
\hline 1082 II $\vee$ & Bilbao Aeropuerto & $27-11-1984$ & \\
\hline 1083 II $P$ & Arcentales & $01-02-1981$ & 1988,1990 \\
\hline 1093A 8 & Carranza & $01-01-1972$ & \\
\hline
\end{tabular}

2.- Una tendencia negativa simultánea de la precipitación acontece en Guipúzcoa en 1983 en 1025E $\vee$ Mutiloa, 10370 \& Azcoitia y 1048 I $\vee$ Arechavaleta; en 1985 en 1025E $\bigcirc$ Mutiloa y 1044D $\vee$ Aramayona (tabla 97, página 208).

3.- El test de las rachas aplicado a la precipitación media AMJ detecta una inhomogeneidad "climatológica" en 1060 II $\vee$ de 1975 a 1984 (tabla 50, página 108).

4.- La gráfica 78 representa la precipitación media AMJ y la mediana de 1079I $\nabla$, 9077E II $\nabla, 1053$ II $\nabla, 1060$ II $\nabla, 1070 \vee, 1078$ E I $\nabla, 1082$ II $\nabla, 1083$ II $\varnothing$ y $1093 \mathrm{~A} \vee$ de 1980 a 1998.

En la gráfica 78 se representa la precipitación media AMJ con líneas continuas y con líneas discontinuas la mediana de la precipitación media AMJ en el intersticio temporal entre rupturas de cada serie. 
Gráfica 78: Precipitación media AMJ y mediana de la precipitación AMJ $\left(1 / \mathrm{m}^{2}\right)$ de 1079I $\vee$,

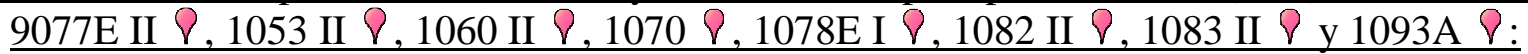

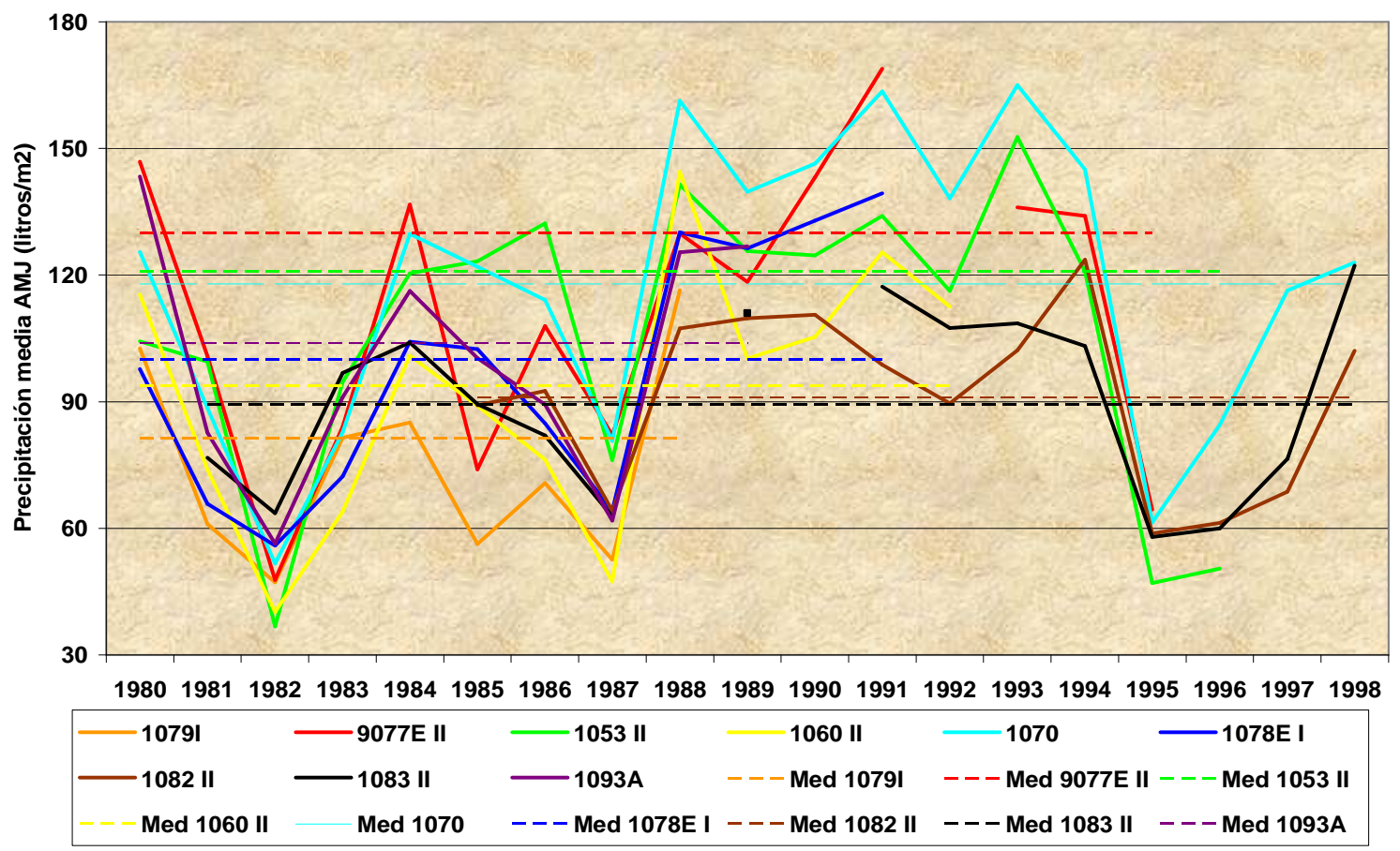

De la gráfica 78 se repara:

4.1.- El descenso desde 1980 hasta los áridos AMJ de 1981, 1982 y 1983 (1982 el más seco de 1980 a 1998). A los normales 1984 y 1985 les sucede el lluvioso 1986, seguido por el muy seco 1987.

1988 supone un abrupto acrecentamiento de la precipitación; le prosiguen el normal 1989 y los copiosos 1990 a 1994, interrumpidos por el normal 1992.

4.2.- La mudanza de los máximos y mínimos de precipitación coincide en todos los sitios con los siguientes:

a) Máximos simultáneos en 1993, 1994 y 1998, congruentes con el epítome de la tabla 70 (página 127). 1986, 1988, 1990, 1991 son años de AMJ pluviosos simultáneos en las localizaciones escrutadas.

b) Mínimos sincrónicos en 1981, 1982, 1983, 1995 y 1996, acordes con los revelamientos de la tabla 70 bis (página 127). 1987 es un año de AMJ seco en exceso y común a todos los jardines meteorológicos. La tendencia negativa espulgada es congrua con el progreso de las precipitaciones en todas las ubicaciones estudiadas.

4.3.- Las medianas 1082 II $\nabla$ y 1083 II $\nabla$ difieren en un $2 \%$; la diferencia de las medianas de 1053 II $\vee$ y $1070 \vee$ es inferior al 3\%. 
4.4.- La índole precursora de 1082 II $\vee$ en 1988 - 1989 y 1990 - 1991, disidente de los demás jardines meteorológicas, anticipa el incremento de la precipitación de 1989 a 1990 y el decremento pluviométrico de 1991 a 1992 en Vizcaya y en la vertiente cantábrica de Álava.

5.- La gráfica 79 representa la división de la precipitación media AMJ de 1079I $\curlyvee$ Gordejuela en relación a 1053 II $\vee, 1060$ II $\vee, 1070$ ९, 1078E I $\vee, 1082$ II $\vee, 1083$ II $\vee$, 1093A $\nabla$ y 9077E II $\vee$ de 1980 a 1988.

Gráfica 79: Razón de las precipitaciones de 1079I $\nabla$ respecto a 1053 II $\vee, 1060$ II $\varnothing$, 1070 P, 1078E I $\vee, 1082$ II $\vee, 1083$ II $\vee, 1093 \mathrm{~A} \vee$ y 9077E II $\vee:$

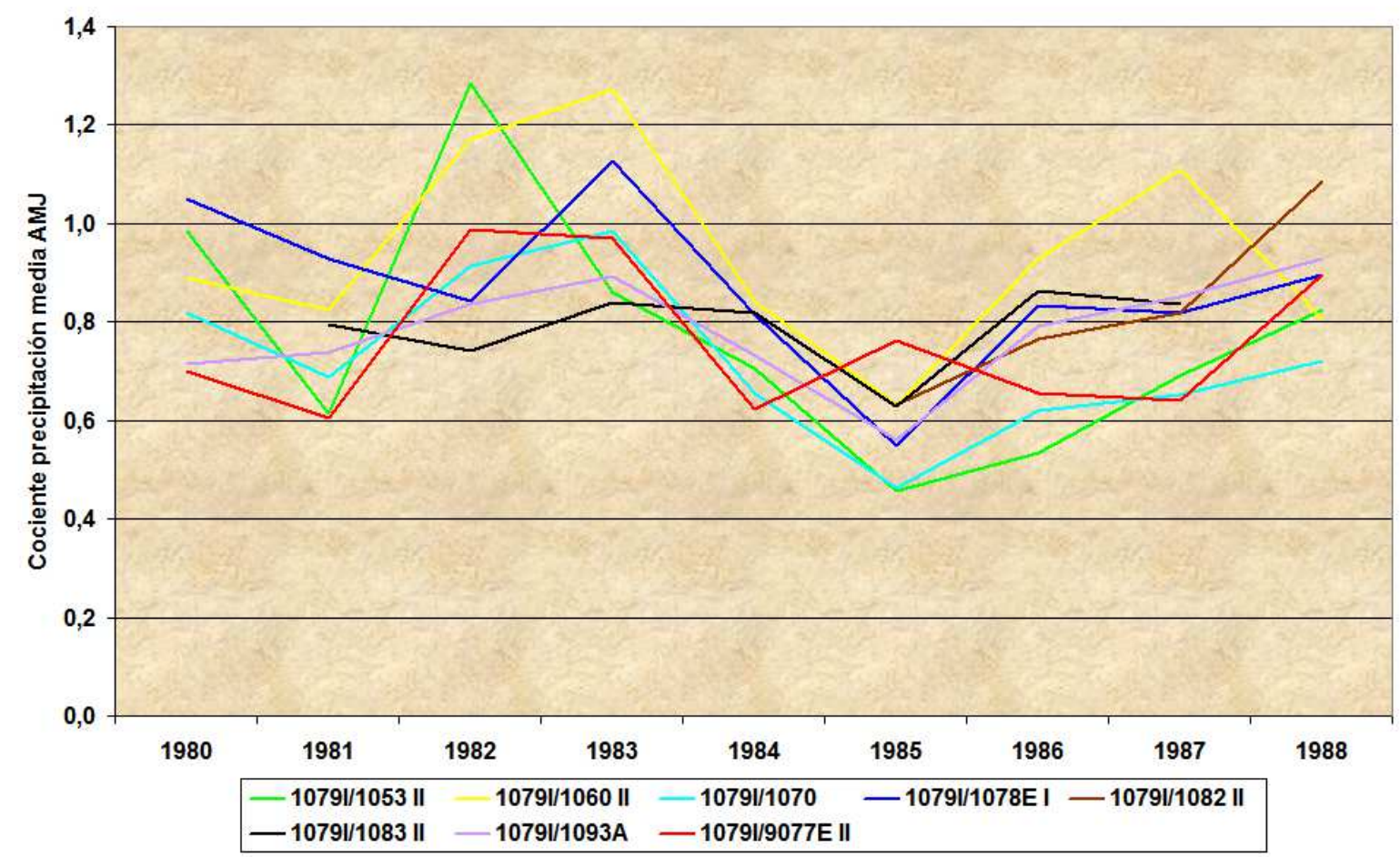

De la gráfica 79 se advierte:

5.1.- El cociente de las precipitaciones de 1079I $\nabla$ Gordejuela oscila entre unos extremos similares.

5.2.- La importancia de un adecuado conocimiento de la orografía y de las especificidades de cada enclave. La correlación de 1079I $\nabla$ respecto a:

a) $1093 \mathrm{~A} \vee$ Carranza, ambas en las Encartaciones, es excelente.

b) $9077 \mathrm{E}$ II $\vee$ Ochandiano es mejor que tocante a la allegada 1078E I $\vee$ Valmaseda. 
6.- La gráfica 80 refleja el cociente de la precipitación media AMJ de 9077E II $\nabla$ Ochandiano respecto a 1053 II $\vee, 1060$ II $\nabla, 1070 \vee, 1078$ E I $\nabla, 1082$ II $\nabla, 1083$ II $\nabla$ y 1093A $\vee$ de 1980 a 1995.

Gráfica 80: Razón de las precipitaciones de 9077E II $\nabla$ respecto a 1053 II $\nabla, 1060$ II $\nabla$. 1070 P, 1078E I $\vee, 1082$ II $\vee, 1083$ II $\vee$ y 1093A $\vee:$

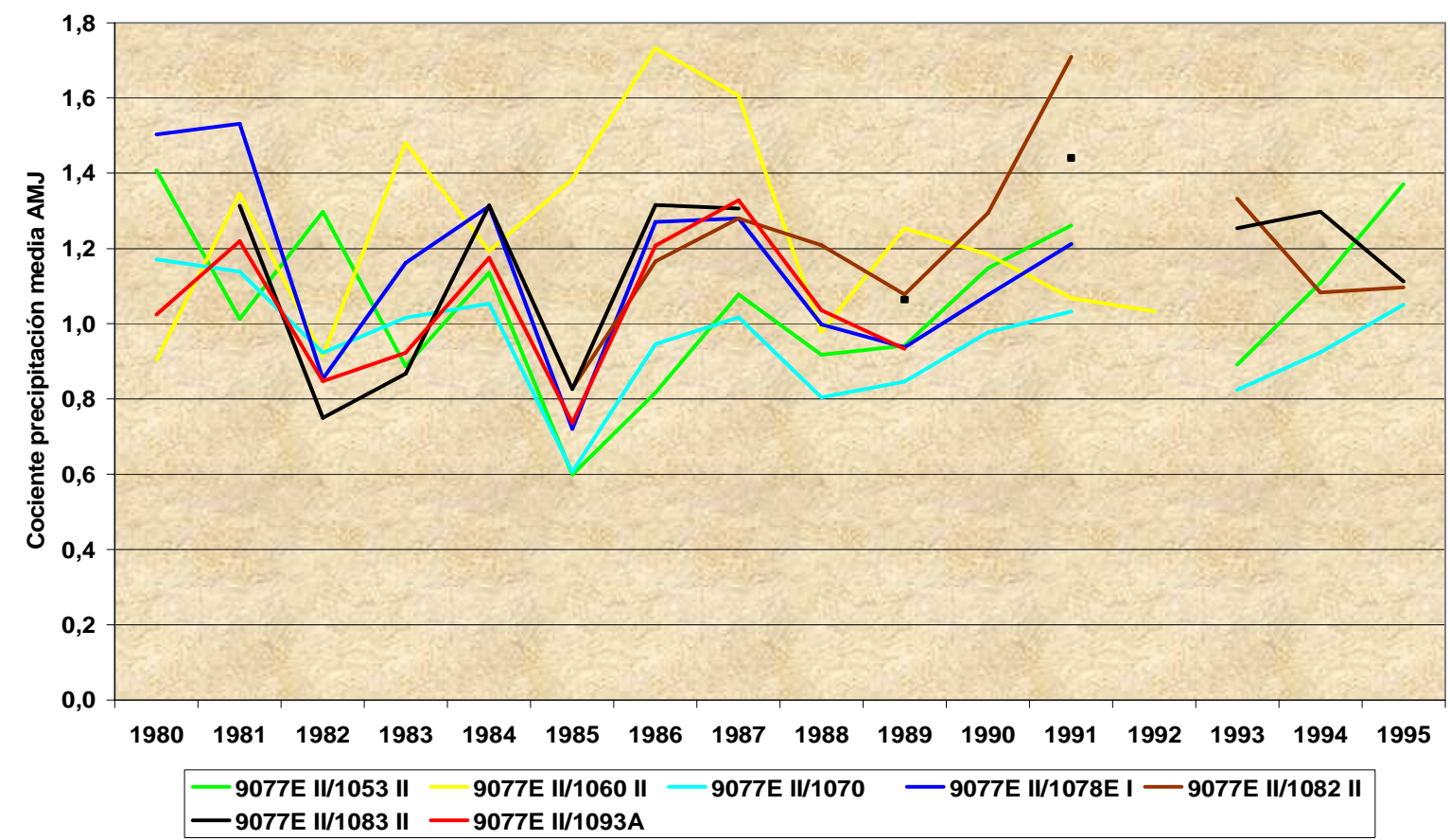

De la gráfica 80 se colige:

6.1.- La razón de las precipitaciones de 9077E II $\bigcirc$ fluctúa entre unos máximos y mínimos constantes.

6.2.- La correlación de 9077E II $\nabla$ en relación a 1083 II $\vee$ Arcentales es mejor que referida a la más cercana $1070 \varnothing$ Durango.

La discordancia expuesta en las gráficas 79 y 80 entre correlación pluviométrica y distancia entre lugares vigoriza la necesidad de una densa y larga red de medidas de la precipitación, dada la variabilidad espacial pluviométrica en Vizcaya, originada por su escarpada orografía.

Por todo lo expuesto, se la considera una tendencia "climatológica". 
7.- Tendencia positiva en 1990 en 1082, en 1991 en 1069E, en 1992 en $1064 \mathrm{P}$ y de 1992 a 1994 en 1075E:

Los registros de 1064P $\vee$ Orozco, 1069E $\vee$ Urquiola, 1075E II $\vee$ Aránzazu y 1082 II $\nabla$ Bilbao Aeropuerto se confrontan a los valores de 1050 II $\vee$ Eibar, $1070 \vee$ Abadiano, 1083 II $\vee$ Arcentales y 9077E II $\vee$ Ochandiano.

La tabla 104 describe la data de empiece y los años no íntegros de precipitación de los lapsos sin roturas de 1064P $\nabla, 1069 \mathrm{E} \nabla, 1075 \mathrm{E}$ II $\nabla, 1082$ II $\nabla, 1050$ II $\nabla, 1070 \varnothing$, 1083 II $\vee$ y 9077E II $\vee$, especificados en el apartado 4.1. "Rupturas detectadas en las series de precipitación”.

Tabla 104: Fecha inicio y años incompletos de 1064P $\nabla, 1069 \mathrm{E} P, 1075 \mathrm{E}$ II $\nabla, 1082$ II $\nabla$, 1050 II $\odot, 1070$ P, 1083 II $\vee$ y 9077 E II $\vee:$

\begin{tabular}{|c|c|c|c|}
\hline Indicativo & Nombre & Comienzo & Años incompletos \\
\hline $1064 \mathrm{P} P$ & Orozco & $01-07-1982$ & \\
\hline $1069 \mathrm{E} \gamma$ & Urquiola & $01-10-1985$ & $1992,1996-2004$ \\
\hline 1075E II P & Aránzazu & Final 1981 & 2005 \\
\hline 1082 II $P$ & Bilbao Aeropuerto & $27-11-1984$ & \\
\hline 1050 II $\vee$ & Eibar & Final 1964 & 1987 \\
\hline 10708 & Abadiano & $01-12-1967$ & 1976 \\
\hline 1083 II $\nabla$ & Arcentales & $01-02-1981$ & 1988,1990 \\
\hline 9077E II $\vee$ & Ochandiano & $01-08-1973$ & 1992 \\
\hline
\end{tabular}

2.- Una tendencia positiva de la precipitación media AMJ acontece en Guipúzcoa (tabla 97, página 208).

3.- El análisis del test de las rachas de la precipitación media AMJ señala una inhomogeneidad “climatológica” en 1078E II $\vee$ de 1993 a 2005 (tabla 50, página 108).

4.- 1993 y 1994 son años pluviosos en 1082 II $\vee$, 1057E I $\vee$ Baquio, 1078E II $\vee$ Valmaseda y en 1083 II $\nabla$ (tabla 62, página 119).

5.- La gráfica 81 refiere la precipitación media AMJ y la mediana de 1064P $\vee$, 1069E $\nabla, 1075$ E II $\nabla, 1082$ II $\nabla, 1050$ II $\vee, 1070 \vee, 1083$ II $\nabla$ y 9077E II $\nabla$ de 1982 a 1998.

La gráfica 81 indica con líneas de trazo continuo la precipitación media AMJ y con líneas discontinuas, la mediana en el intervalo temporal entre rupturas de cada serie. 
Gráfica 81: Precipitación media AMJ y mediana de la precipitación AMJ $\left(1 / \mathrm{m}^{2}\right)$ de 1064P $\nabla$,

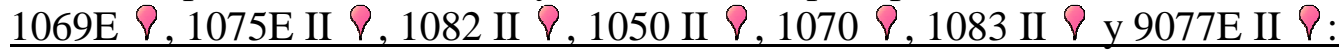

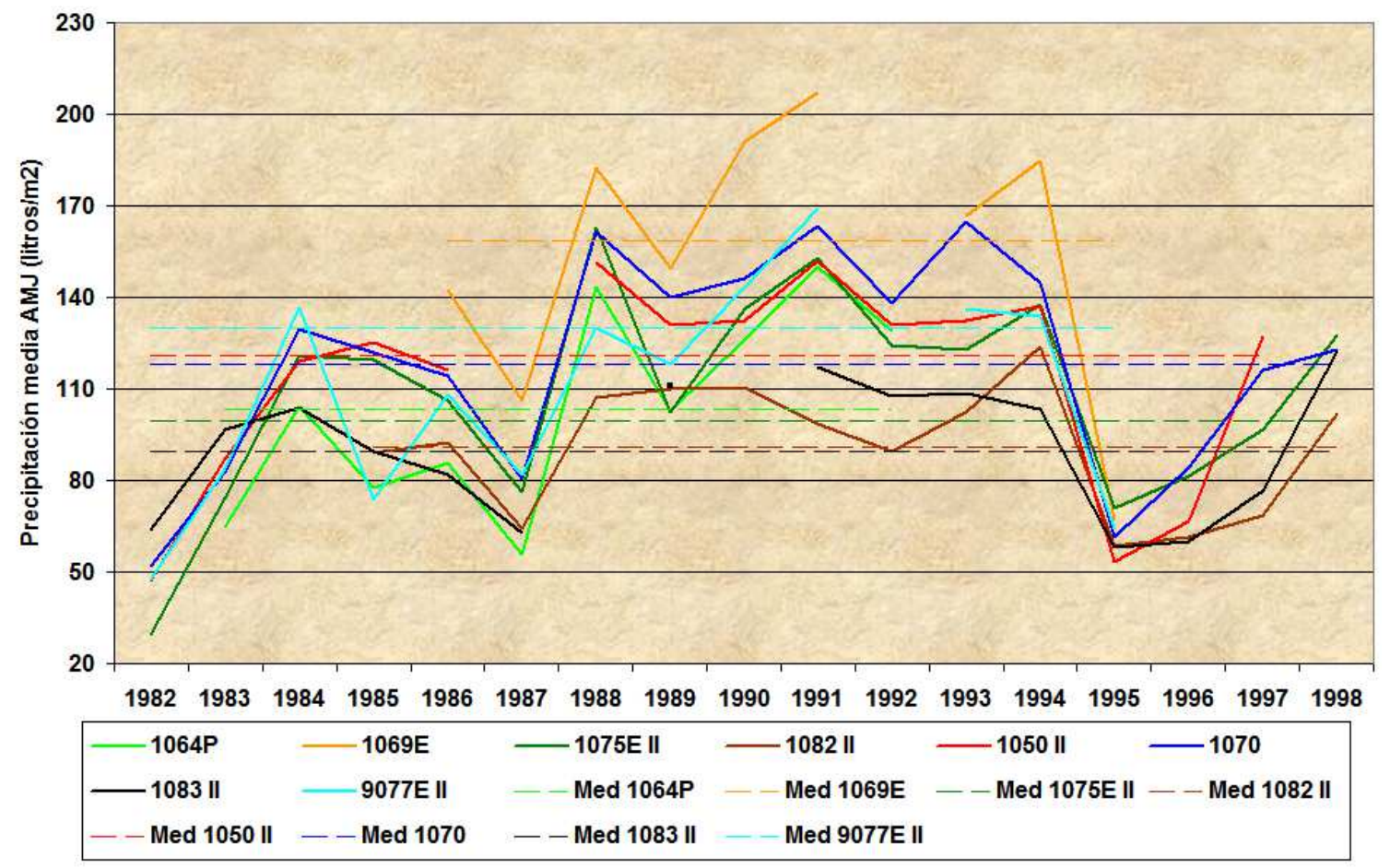

De la gráfica 81 se percata:

5.1.- Al muy árido 1982 (el más seco en AMJ de 1982 a 1998) le deviene un ascenso pluviométrico a lo largo del seco 1983 y del normal 1984. El normal 1985 y el húmedo 1986 anteceden al árido 1987.

Una abrupta acrecencia pluviométrica acontece en 1988 (del $70 \%$ en 1069E $\nabla$ y 1082 II $\vee$ y superior al 100\% en 1064P $\vee$ y en 1075E II $\vee$ ). De 1988 a 1994 acaecen años de abundantes precipitaciones en AMJ, los más copiosos de 1982 a 1998, con los normales 1989 y 1992 intercalados.

La tendencia positiva escrutada es coherente con la evolución de la pluviosidad en AMJ en las demás radicaciones de Vizcaya y de la vertiente cantábrica de Álava expuestas en la gráfica 81 .

5.2.- Los máximos pluviométricos de 1993, 1994 y 1998 sincronizan con los hallazgos de la tabla 70 (página 127). 1986, 1988, 1990 y 1991 son años concomitantes de copiosa pluviosidad.

5.3.- Los mínimos de 1982, 1983, 1995 y 1996 confirman los hallazgos de la tabla 70 bis (página 127). 1987 es un año muy árido en la plenitud de ubicaciones.

5.4.- 1082 II $\vee$ preludia en 1988 - 1989 y 1990 - 1991 las generales acrecencias de 1989 a 1990 y la descrecencia de 1991 a 1992 en Vizcaya y en la vertiente cantábrica de Álava, análogo al reflejo de la gráfica 78 (página 230). 
5.5.- A la vista de la gráfica 81 , un análisis superficial coadyuvaría la errónea conclusión de un incremento de la precipitación AMJ en Vizcaya y en la vertiente cantábrica de Álava.

5.6.- El colaborador de 1075E II $\nabla$ anota $01 / \mathrm{m}^{2}$ en Abril de 1982, siendo el único de Vizcaya y de Guipúzcoa que no registra precipitaciones. El valor de $01 / \mathrm{m}^{2}$ de la tarjeta de Abril de 1982 es, pues, catalogado de erróneo. En puridad, Abril de 1982 en 1075E II P debiera considerarse como "mes sin datos". Este hecho concuerda con el periodo homogéneo de $1075 \mathrm{E}$ II $\vee$ de 1983 a 2004 (tabla 16, página 46).

6.- La gráfica 82 ostenta la razón de la precipitación media AMJ de 1082 II $\nabla$ Bilbao Aeropuerto y 1075E II $\nabla$ Aránzazu referida a 1050 II $\nabla, 1070$ y 1083 II $\vee$ (situadas respectivamente al E, S y W) y el cociente de la precipitación media AMJ de 1082 II $\nabla$ respecto a $1075 \mathrm{E}$ II $\nabla$ de 1982 a 1998.

Gráfica 82: Razón de las precipitaciones de 1082 II $\nabla$ y 1075E II $\nabla$ respecto a 1050 II $\nabla$, $1070 \vee$ y 1083 II $\vee$ y razón de las precipitaciones de 1082 II $\vee$ respecto a 1075E II $\vee$ :

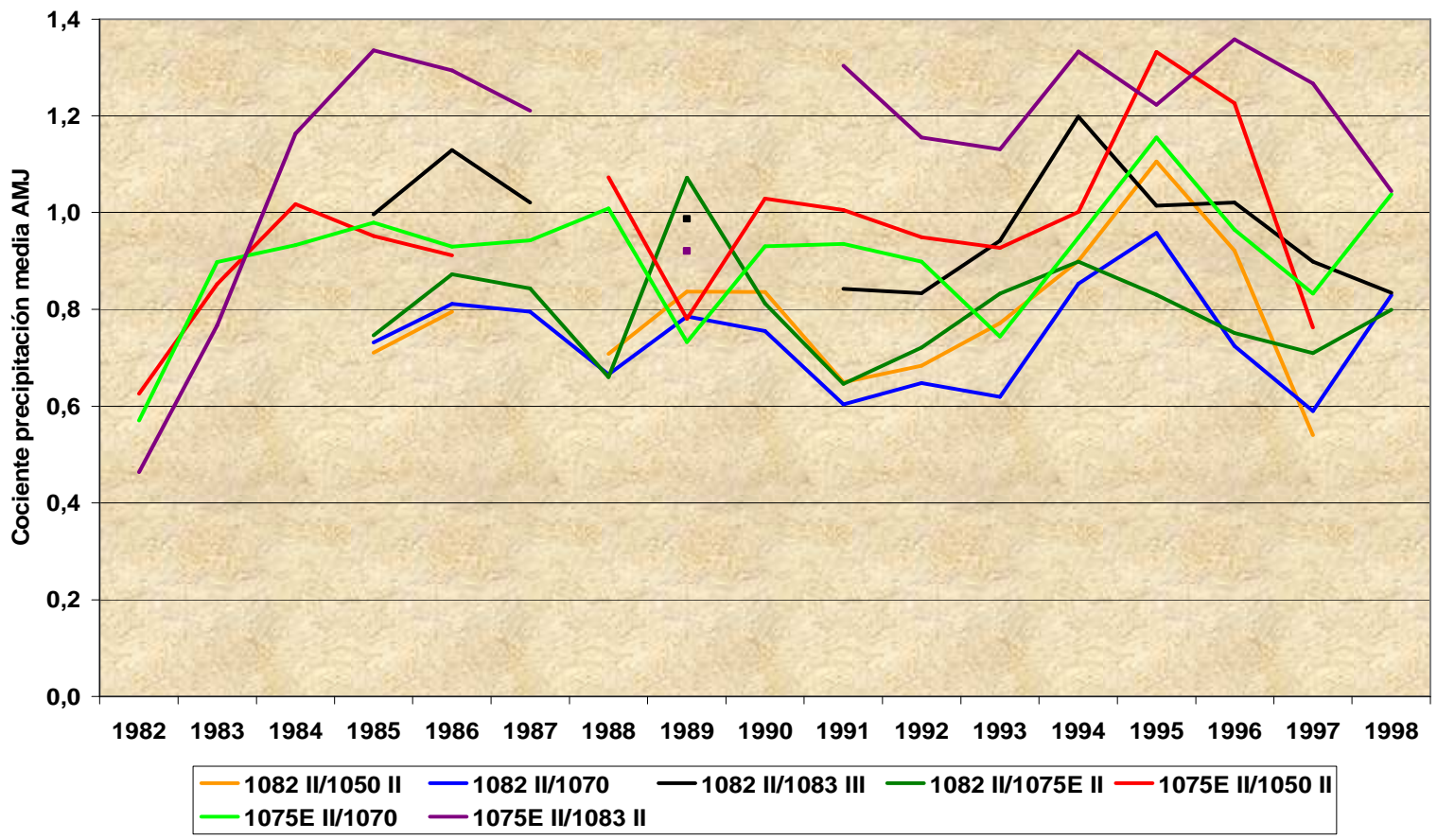

De la gráfica 82 se desprende:

6.1.- Los cocientes de 1082 II $\vee$ y 1075 E II $\vee$ (éste con la salvedad descrita de 1982) oscilan entre unos máximos (1985 - 1986 y 1994 - 1995) y mínimos (1988 - 1997) constantes, amago de una euritmia rayana los 9 años.

6.2.- La corroboración de las dudas acerca de la sospechosa observación pluviométrica de 1075E II $\vee$ en Abril de 1982. Este prolijo método de investigación permite un hilado fino, identificando valores de incierta calidad. 
7.- La gráfica 83 expone la proporción de la precipitación media AMJ de 1064P $\bigcirc$ Orozco y 1069E $\vee$ Urquiola en relación a 1050 II $\vee, 1070$ 8 y 9077E II $\nabla$ y el cociente de la precipitación media AMJ de 1064P $\vee$ en relación a 1069E $\vee$ de 1983 a 1995.

Gráfica 83: Razón de las precipitaciones de 1064P $\nabla$ y 1069E $\nabla$ respecto a 1050 II $\nabla$, $1070 \vee$ y 9077E II $\vee$ y razón de las precipitaciones de 1064P $\odot$ respecto a 1069E $\vee$ :

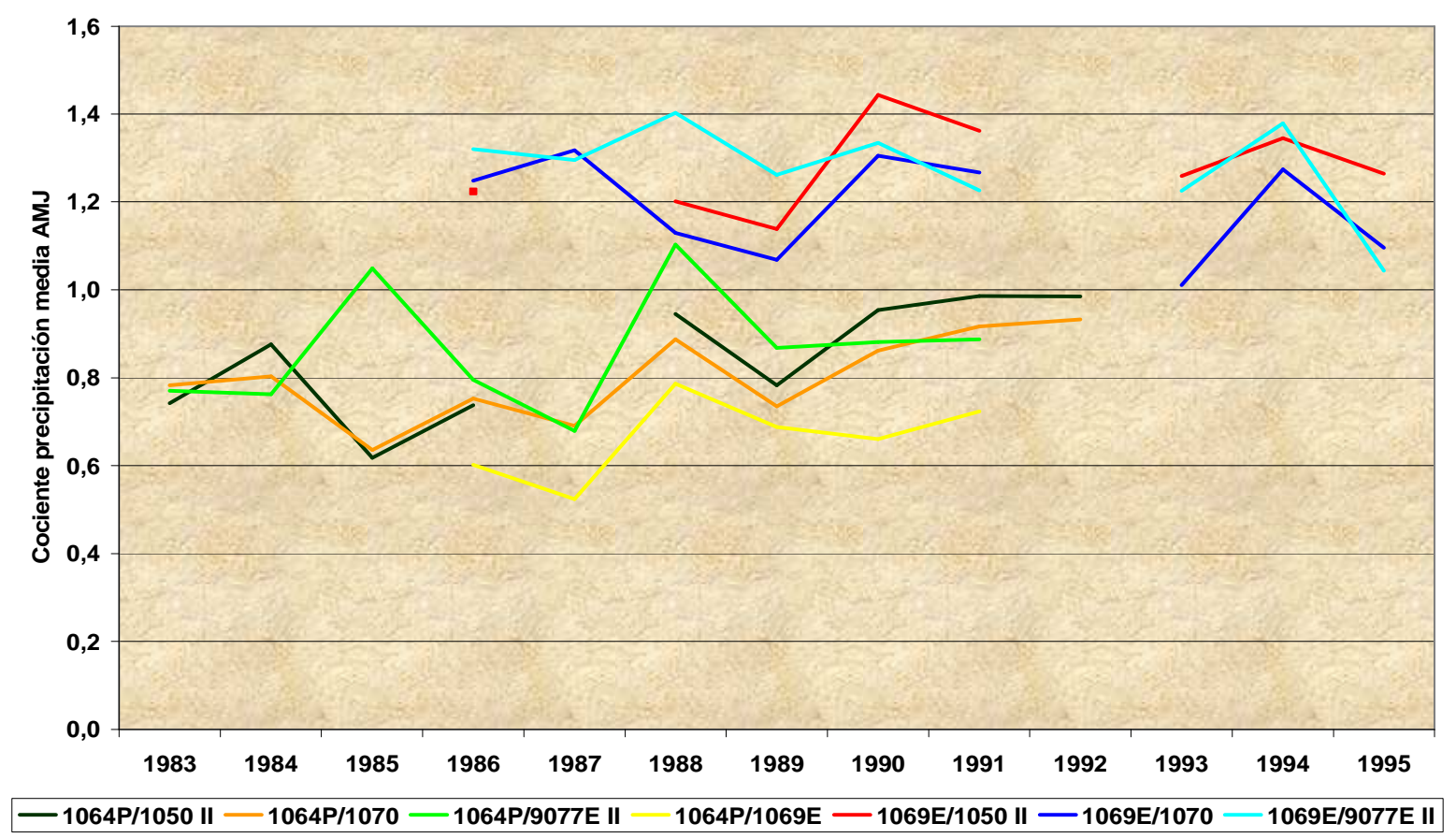

De la gráfica 83 se observa:

7.1.- El cociente de 1064P $\vee$ referida a los demás lugares alterna entre unos extremos parejos.

7.2.- La división de 1069E $\nabla$ respecto a las diferentes localizaciones oscila entre unos máximos y mínimos constantes.

7.3.- La reiterada importancia de la resolución espacio - temporal de datos pluviométricos sin lagunas. La carencia de 1050 II $\nabla$ en 1995 inferiría la catalogación del dato de 1995 de 1069E $P$ de dudoso.

Por tanto, la tendencia positiva de 1990 en 1082 II $\nabla$, de 1991 en 1069E $\nabla$ y de 1992 en 1064P $\vee$ se clasifica de tendencia "climatológica" y la tendencia positiva de 1075E II $\nabla$ se califica de "no climatológica". 
1.- Los registros de 1055A I $\nabla$ Lequeitio Agustinas y de 1057E I $\nabla$ Baquio se cotejan con los valores pluviométricos de 1041 Zumaya Carmelitas, 1075E II $\nabla$ Aránzazu y 1081 U II $\vee$ Derio Neiker.

La tabla 105 detalla la fecha de comienzo y los años sin la plenitud de datos anuales de precipitación de 1055A I $\nabla, 1057$ E I $\nabla, 1041 \nabla$, 1075E II $\nabla$ y 1081 U II $\nabla$.

Tabla 105: Fecha inicio y años incompletos de de 1055A I $\nabla, 1057 \mathrm{E}$ I $\nabla, 1041 \nabla$, 1075E II $\vee$ y 1081 U II $\vee$ :

\begin{tabular}{|c|c|c|c|}
\hline Indicativo & Nombre & Comienzo & Años incompletos \\
\hline $1055 \mathrm{~A} \mathrm{I} P$ & Lequeitio Agustinas & $01-04-1986$ & $1991,1992,2002$ \\
\hline 1057E I $\vee$ & Baquio & $01-04-1986$ & 1992 \\
\hline 10418 & Zumaya Carmelitas & $01-01-1987$ & 1991 \\
\hline 1075E II $P$ & Aránzazu & Final 1981 & 2005 \\
\hline 1081U II $\vee$ & Derio Neiker & Final Marzo 1996 & 2001 \\
\hline
\end{tabular}

1055A I $\vee$ y 1057E I $\vee$ principian en un mismo día.

La figura 17 y sus comentarios anejos (páginas 70 y 71) refieren someramente las características geográficas de los emplazamientos de 1041 ○ y 1055A I $\nabla$.

2.- Esta tendencia negativa aflora singularmente en las 2 ubicaciones costeras.

3.- El test de Mann - Kendall aprecia una tendencia negativa coetánea de la precipitación en 2007 en las guipuzcoanas 1026A $>$ Ordizia, 1031 III \& Elduayen y 1048 II Frechavaleta (tabla 97, página 208).

4.- El test de las rachas aplicado a la precipitación media AMJ revela una inhomogeneidad "climatológica" en 1078E II P Valmaseda de 1993 a 2007, en 1059 III Punta Galea Golf de 1994 a 2006 y de 1998 a 2013, en 1060 III \& Amurrio Instituto de 1997 a 2006 y de 2000 a 2013, en 1081U II $\nabla$ de 1998 a 2008 y en 1082 III $P$ Bilbao Aeropuerto de 2001 a 2013 (tabla 50, página 108).

5.- La gráfica 84 expone la precipitación media AMJ y la mediana de 1055A I $\nabla$, 1057E I $\vee, 1041 \vee, 1075$ E II $\vee$ y 1081 U II $\vee$ de 1986 a 2007

La gráfica 84 presenta la precipitación media AMJ con líneas continuas; con líneas discontinuas, la mediana de la precipitación media AMJ en el intersticio temporal entre rupturas de cada serie. 
Gráfica 84: Precipitación media AMJ y mediana de la precipitación AMJ $\left(1 / \mathrm{m}^{2}\right) \mathrm{de}$

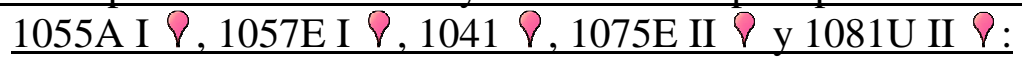

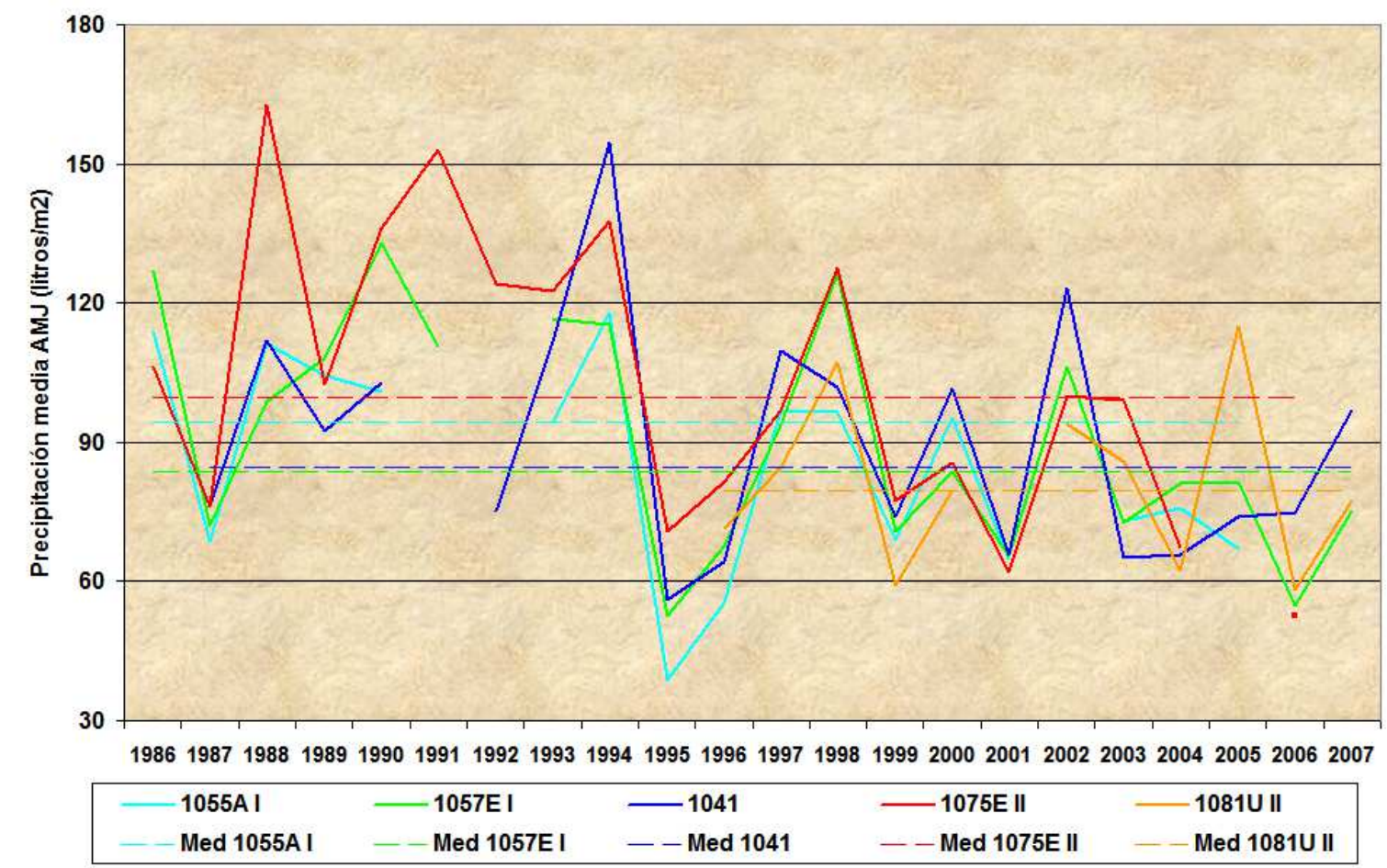

De la gráfica 84 se colige:

5.1.- Un descenso generalizado de las precipitaciones con posterioridad al muy pluvioso 1988.

5.2.- La tendencia negativa escrutada en 2005 en 1055A I $\nabla$ es congruente con la evolución de las precipitaciones en las restantes localizaciones.

5.3.- Los máximos de 1993, 1994, 1998 y 2005 concuerdan con los desvelamientos del test de Thom (tabla 70, página 127). 1988, 1990 y 1991 son años de máximos comunes.

5.4.- Los mínimos de 1995, 1996, 1999, 2001 y 2006 son coetáneos con los resultados del test de Thom expuestos en la tabla 70 bis (página 127). 1987 es un año árido concomitante en las localizaciones examinadas.

5.5.- El carácter precursor de 1057E I $\vee$ en 1988 - 1989, 1993 - 1994 y en 2003 - 2004, preludia el devenir pluviométrico en el año subsiguiente.

5.6.- Craso error sería la consideración, a la vista de la gráfica 84, una disminución de la precipitación AMJ en Vizcaya y en la vertiente cantábrica de Álava. 
6.- La gráfica 85 ilustra la razón de la precipitación media AMJ de 1055A I $\nabla$ Lequeitio Agustinas y de 1057E I $\nabla$ Baquio respecto a $1041 \nabla, 1075 \mathrm{E}$ II $\nabla$ y 1081 U II $\nabla$ y la razón de la precipitación media AMJ de 1057E I $\nabla$ respecto a 1055A I $\vee$ de 1986 a 2007.

Gráfica 85: Razón de las precipitaciones de 1057E I $\nabla$ y 1055A I $\nabla$ respecto a $1041 \nabla$. 1075E II $\vee$ y 1081U II $\vee$ y razón de las precipitaciones de 1057E I $\vee$ respecto a $1055 \mathrm{~A}$ I $\nabla$ :

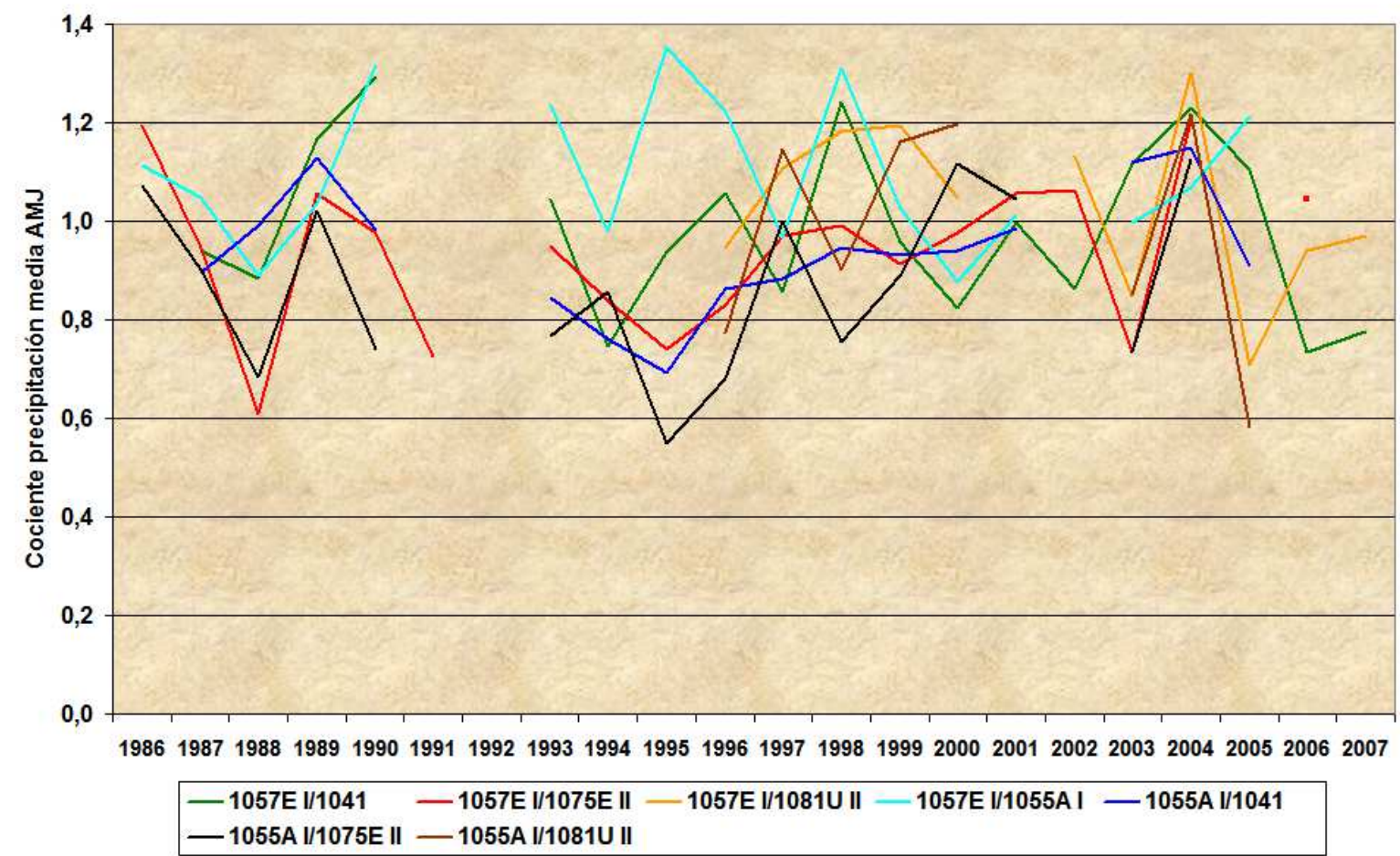

De la gráfica 85 se concluye:

6.1.- El cociente de las precipitaciones de 1057E I $\bigcirc$ alterna entre unos máximos (1989 y 1998; 1993 y 2002; 1996 y 2004) constantes de una cadencia propincua a los 9 años y mínimos de 1988 y 20001991 y 20031995 y 2005 de una regularidad rayana los $10-12$ años.

6.2.- La proporción de las precipitaciones de 1055A I $\nabla$ acontece constante con una euritmia en los máximos y mínimos.

Por todo lo expuesto, se la cataloga como tendencia "no climatológica". 
El compendio del examen con el test de Mann - Kendall de la precipitación media AMJ (Abril, Mayo y Junio) de Vizcaya y de la vertiente cantábrica de Álava:

1.- Las tendencias se clasifican en "climatológicas" y "no climatológicas".

Las tendencias "no climatológicas" se revelan por:

1.1.- La dispareja evolución de la precipitación referida a las series vecinas en 1055 \&equeitio Faro y 1083 I $\nabla$ Arcentales (ésta de 1975 a 1979).

1.2.- La existencia de datos primigenios de dudosa calidad: $1075 \mathrm{E}$ II $\vee$.

2.- La acrecencia y la descrecencia de la precipitación coincide en todas las ubicaciones, a excepción de las tendencias "no climatológicas" de 1055 P y 1083 I $P$ (1975 a 1979) y en el diferente transcurso de 1068 II $P$.

El discurso de la precipitación es análogo en las localizaciones estudiadas, con una óptima concurrencia de los máximos y mínimos de pluviosidad.

3.- Las tendencias "climatológicas" de Vizcaya y de la vertiente cantábrica de Álava $\underline{\text { son coherentes con: }}$

3.1.- El acontecimiento de las precipitaciones en las radicaciones simultáneas cercanas (gráficas 63 a 85).

3.2.- La prosecución de años lluviosos y secos de las localizaciones (gráficas de precipitación media AMJ 63, 65, 68, 70, 74, 78, 81 y 84), con las sequías extremas anticipando los años muy pluviosos, similar a la precipitación anual y MAM.

3.3.- Las tablas 106 y 107 sintetizan las exégesis de las gráficas $63,65,68,70,74$, 78,81 y 84 en un compendio de los años lluviosos y áridos aflorados por el escrutinio del test de Mann - Kendall de la precipitación media AMJ de Vizcaya y de la vertiente cantábrica de Álava.

La siguiente nomenclatura se emplea en las tablas 106 y 107:

a) En azul oscuro, los máximos y mínimos pluviométricos simultáneos en Vizcaya, en la vertiente cantábrica de Álava y en Guipúzcoa.

b) En azul aguamarina, los máximos y mínimos de precipitación secundarios simultáneos en Vizcaya, en la vertiente cantábrica de Álava y en Guipúzcoa.

c) En rojo, los extremos pluviométricos de Vizcaya y de la vertiente cantábrica de Álava no concurrentes en Guipúzcoa y congruos con el duplo ciclo decenal de AMJ pluviosos y áridos.

c) Se dejan en blanco los años sin máximos o mínimos pluviométricos AMJ sea por la exigüidad de series de datos (1934 a 1943) o por su coincidencia con un lapso sin inhomogeneidades: De 1866 a 1890, de 1927 a 1949 y ulterior a 2008 (tabla 92, página 205). 
e) En negrita, los años con máximos y mínimos pluviométricos AMJ relevantes, por el número de jardines meteorológicos y por la notabilidad de sus extremos.

f) Un guión - señala años de la tabla conjuntos: Por ejemplo 1919-20: 1919 y 1920.

g) Una coma , denota años no consecutivos. Verbi gratia 1953,56: 1953 y 1956.

Tabla 106: Años con máximos pluviométricos en precipitación AMJ:

\begin{tabular}{||c|c|c|c|c|c||c|c||}
\hline Máximos & $\mathbf{1 8 5 9}$ & & 1869,71 & 1875 & $\mathbf{1 8 7 9 - 8 0}$ & $\mathbf{1 8 8 4 - 8 5}$ & $\mathbf{1 8 8 8 - 9 , 1}$ \\
\hline \hline Máximos & & & & & $\mathbf{1 9 1 3}$ & $\mathbf{1 9 1 5 , 7 - 8}$ & $\mathbf{1 9 2 2}$ \\
\hline \hline Máximos & $\mathbf{1 9 2 5}$ & & & & & 1950 & $\mathbf{1 9 5 3 , 5 6}$ \\
\hline Máximos & 1961 & 1966 & $1969, \mathbf{7 1}$ & $\mathbf{1 9 7 2 , 7 5}$ & $\mathbf{1 9 7 7 - 7 8}$ & & $\mathbf{1 9 8 8 , 0 - 1}$ \\
\hline \hline Máximos & $1993-94$ & $\mathbf{1 9 9 8}$ & $\mathbf{2 0 0 5}$ & & & & \\
\hline \hline
\end{tabular}

Tabla 107: Años con mínimos pluviométricos en precipitación AMJ:

\begin{tabular}{|c||c||c|c||c|c|c|c||}
\hline Mínimos & 1861 & $1865, \mathbf{6 8}$ & $\mathbf{1 8 7 0}$ & & $\mathbf{1 8 8 2}$ & $\mathbf{1 8 8 7}$ & \\
\hline Mínimos & & & & & 1916 & $\mathbf{1 9 1 9 - 2 0}$ & 1924 \\
\hline Mínimos & & & & & $\mathbf{1 9 4 7}$ & $1952, \mathbf{5 5}$ & $1959, \mathbf{6 0}$ \\
\hline Mínimos & 1963 & 1967 & $\mathbf{1 9 7 4}$ & 1976 & $\mathbf{1 9 8 1 - 2}-3$ & $\mathbf{1 9 8 7}$ & \\
\hline \hline Mínimo & $\mathbf{1 9 9 5 - 9 6}$ & $1999, \mathbf{0 1}$ & $\mathbf{2 0 0 6}$ & & & & \\
\hline \hline
\end{tabular}

3.4.- Los máximos y mínimos de pluviosidad emergentes del espulgo de las inhomogeneidades del test de Thom de la precipitación AMJ (tablas 70 y 70 bis, página 127).

3.5.- Las tendencias "climatológicas" de la pluviometría AMJ de Guipúzcoa expuestas en la tabla 97 de la página 208 (desentrañadas en la Nota Técnica No 13 AEMET).

3.6.- Los descubrimientos de las tendencias "climatológicas" en la precipitación anual y MAM.

4.- Se realza la significación y la capacidad de la investigación de la precipitación por medio de los tests de Thom y de Mann - Kendall.

5.- Los apogeos de tendencias positivas ocurren de 1972 a 1973 y de 1978 a 1980, concordantes con los máximos secundarios de tendencia positiva de Guipúzcoa de 1971 a 1972 y de 1978 a 1980 (Nota Técnica No 13 AEMET).

Los máximos de tendencias negativas devienen en 1983, 1985, 1987, 2003 y 2005, concomitantes con los máximos de tendencia negativa de Guipúzcoa entre 1983 y 1984 y entre 2001 y 2007 (Nota Técnica No 13 AEMET). 
La totalidad de tendencias "climatológicas" positivas (19) sobrepasa a la de negativas (13), ilustrado en las gráficas 61 y en la tabla 96 (páginas 205 a 207).

Ambos son síntoma de que el tránsito de un intersticio de sequía a uno de precipitaciones elevadas es más veloz, suceso común a la precipitación anual y MAM.

Esta presta transición de años secos a lluviosos deviene conforme a los desvelamientos de Guipúzcoa (Nota Técnica No 13 AEMET).

No obstante, el sumatorio de series de empiece en años de AMJ lluviosos (14) supera a la cuantía de las series de inicio de sequía (11).

El inicial AMJ pleno de las siguientes series sin tendencias "no climatológicas" es:

A) Árido: 1082 I $\vee$, 9076I $\vee$ y 9077E I $\vee$ (1947); 1053 II $\vee$ y 9077E II $\vee(1976)$;

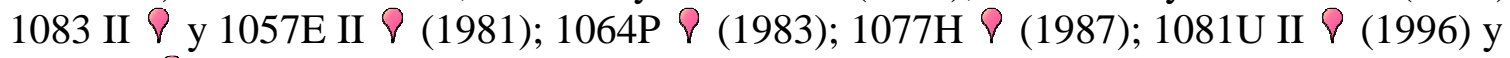
1082 III $\vee$ (2001) (tabla 70 bis, página 127).

B) Pluvioso: 1077C $\vee$ (1859); 1057C II $\vee$ (1922); 1077 ४ (1925); 1060 I $\vee(1956)$;

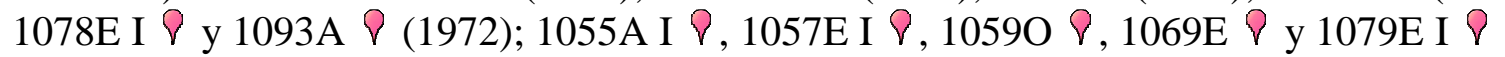
(1986); 1056M $\vee$ (1991); 1060 III $\vee$ (1993); 1059 III $\vee$ (1994) (tabla 70, página 127).

La serie de tendencia "no climatológica" 1068 II $\vee$ arranca en el seco 1955.

El año de empiece es trascendental en el acontecimiento de un posterior acrecentamiento o descrecimiento de la pluviosidad. El análisis de una serie (por ejemplo, 1057E I Aránzazu P), conforme principiara en un AMJ seco (1987) o lluvioso (1986), colegiría una fementida aumento o disminución pluviométrica.

La aprehensión de la especificidad pluviométrica del AMJ del primer año de registros y el discernimiento de los elementos exógenos (cambios de emplazamiento, de entorno, instrumentación y/o observador) resulta decisiva previa al escudriñamiento del acaecimiento de la pluviosidad AMJ de cada enclave, de las acrecencias, mermas y ciclos de las cantidades de precipitación anotadas.

La ausencia del mismo acarrea inferencias desacertadas acerca de incrementos o decrementos subsiguientes de la precipitación, ajenos a mudanzas climáticas y debidas al influjo del año originario de mediciones o a cambios en las condiciones de medida.

Es necesario añadir las particularidades climáticas del AMJ del año primigenio a los factores de origen externo precisados en una fase precedente a la investigación de la pluviosidad de un enclave.

6.- El cociente de la precipitación media AMJ en las series de tendencia "climatológica" alterna entre unos máximos y mínimos conformes, con una euritmia en los máximos y en los mínimos allegada a los 9 a 10 años (gráficas 64, 66, 67, 69, 71,72, 73, 75, $76,77,79,80,82,83$ y 85$)$.

La compleción de las lagunas de los registros pluviométricos precisa la cognición del lugar del AMJ incompleto en la consonancia del ciclo de razones. 
7.- La razón de precipitaciones facilita:

7.1.- La visualización de rupturas inapreciadas en el escrutinio de los tests de Thom y de Mann - Kendall (verbi gratia, 1083 I $\vee$ Arcentales en Octubre de 1973).

7.2.- La ratificación de las roturas detectadas por los tests de Thom y de Mann Kendall (por ejemplo, $1060 \vee$ Amurrio a finales de 1966).

\section{8.- La repercusión de:}

8.1.- La resolución temporal en el desentrañamiento de una tendencia "climatológica" o "no climatológica" (verbi gratia, la exclusión o inclusión de 1982 en el escrutinio de 1075E II $\vee$ Aránzazu, gráfica 82, página 233).

8.2.- La resolución espacial en la percatación de las de las tendencias “climatológicas" de las "no climatológicas" (por ejemplo, 1069E P Urquiola en 1995, gráfica 83 , página 236 ).

La única confrontación de 1069E $P$ con sus más allegadas $1070 \vee$ Abadiano y 9077E II 8 Ochandiano hubiera inferido la clasificación de "dudosa" a la precipitación AMJ de 1069E $\nabla$ en 1995. La parvedad de registros puede colegir en la ilación de sospechosos de registros fidedignos.

8.3.- La conveniencia y la constricción de un largo y tupido conjunto de lugares de observación meteorológica, de una densidad a nivel de comarca e inclusive mayor, con una relevancia en la persistencia de series pluviométricas estables.

\section{4.- Una resolución espacial de escala sobresaliente a la provincial:}

A) La tabla 108 compila la distribución comarcal de las tendencias "climatológicas" del test de Mann - Kendall de la precipitación media AMJ.

Tabla 108: Distribución comarcal de las tendencias "climatológicas" del test de Mann - Kendall de la precipitación media AMJ:

\begin{tabular}{|c|c|c|c|}
\hline Comarca & $\mathrm{N}^{\mathrm{o}}$ series analizadas & $\mathrm{N}^{\mathrm{o}}$ inhomogeneidades & $\begin{array}{c}\text { Inhomogeneidad } \\
\text { media }\end{array}$ \\
\hline Arratia - Nervión & 5 & 1 & 0,2 \\
\hline Duranguesado & 5 & 7 & 1,4 \\
\hline Encartaciones & 5 & 7 & 1,4 \\
\hline Gran Bilbao & 7 & 10 & 1,4 \\
\hline Guernica - Bermeo & 3 & 0 & 0 \\
\hline Marquina - Ondarroa & 4 & 2 & 0,5 \\
\hline Plencia - Munguía & 1 & 1 & 1 \\
\hline Cantábrica Alavesa & 3 & 4 & 1,3 \\
\hline
\end{tabular}

Las tendencias "no climatológicas" de 1055 P, 1083 I $\vee$ y 1057E II $\vee$ se descartan en la tabla 108. 
El culmen de de inhomogeneidades aflora en el Gran Bilbao, las Encartaciones y el Duranguesado. comarca.

El repartimiento de las inhomogeneidades no es homogéneo, variando según la

B) Semblanza de las tendencias "climatológicas" desveladas en ubicaciones allegadas:

B1) La tendencia "climatológica" de 1973 a 1981 se centra en las Encartaciones y en la Cantábrica Alavesa (tabla 96, página 207).

B2) La tendencia "climatológica" de 1990 a 1994 únicamente se exterioriza en el Gran Bilbao, el Duranguesado y en Arratia - Nervión (tabla 96, página 207).

B3) La tendencia "climatológica" de 2005 a 2007 emerge exclusivamente en las comarcas de Marquina - Ondarroa y de Plencia - Munguía (tabla 96, página 207).

Estas cualidades generales robustecen y alientan la precisión de un prolijo escrutinio, por lo menos a una escala comarcal.

C) Analogía de los valores de las series no siempre más próximas, barrunte de unas parejas características de la precipitación AMJ en los siguientes intersticios:

C1) 1093 I $\vee$ Carranza y 1054 II $\nabla$ Marquina de 1957 a 1974; 1093 I $\vee$ y 1053 I $\vee$ Echevarría de 1962 a 1974; 1053 I $\vee$ y 1054 II $\nabla$ de 1962 a 1974; 1054 II $\&$ y 1050 II $\nabla$ Eibar de 1965 a 1974.

C2) 1060A $\nabla$ Amurrio Colegio, 1054 II $\vee$ y 1053 I $\vee$ de 1962 a 1974; $1060 \mathrm{~A} \vee$ Amurrio Colegio, 1060 II $\vee$ Amurrio Instituto, $1070 \vee$ Abadiano, 1075E I $\vee$ Aránzazu de. 1968 a 1979.

Los hallazgos expuestos en C1) y C2) concuerdan con los resultados desvelados en MAM (página 204).

C3) 9077E II $\vee$ Ochandiano y 1079I $\vee$ Gordejuela de 1980 a 1988; 9077 E II $\nabla$ y 1083 II $\nabla$ Arcentales de 1980 a 1995.

9.- La especificidad previsora de la precipitación AMJ de 1082 I $\nabla$ Bilbao Aeropuerto en 1950 - 1951, 1957 - 1958, 1959 - 1960, 1963 - 1964, 1965 - 1966, 1968 1969 y 1971 - 1972 y de la pluviometría de 1082 II $\vee$ Bilbao Aeropuerto en 1988 - 1989 y 1990 - 1991, precursora del progreso de la pluviosidad en el año ulterior en las demás localizaciones.

10.- La óptima homogeneidad de las vastas 1060 Amurrio (56 años con 2 roturas), $1070 \bigcirc$ Abadiano (37 años) y 1035 \& Echevarría (35 años y una ruptura).

11.- La trascendencia de una conveniente densidad espacial y temporal de series de precipitación sin lagunas con el propósito de la obtención de una apropiada comprensión del clima en Vizcaya y en la vertiente cantábrica de Álava, de un relieve escabroso. 


\section{Conclusiones de Vizcaya y de la vertiente cantábrica de Álava:}

1.- La encomiada importancia, trascendencia y potencia de la investigación conjunta mediante los tests de las rachas de Thom y de tendencia de Mann - Kendall de las rupturas de las series pluviométricas de Vizcaya y de la vertiente cantábrica de Álava en los 3 intervalos (anual, MAM y AMJ).

La inclusión del escrutinio de los periodos MAM y AMJ en el análisis estacional acrece la resolución temporal y conlleva un incremento del cómputo de las roturas detectadas en las series, desapercibidas en el escudriñamiento de la pluviosidad anual, ya que la totalidad de las rupturas no es descubierta al unísono por ambos tests en la plenitud de lapsos analizados.

1.1.- La cuantía de las rupturas desveladas respecto a la integridad de las series de pluviosidad disponibles en Vizcaya y en la vertiente cantábrica de Álava es mayor que el montante de Guipúzcoa, primer atisbo de la calidad de las series de precipitación de Vizcaya y de la vertiente cantábrica de Álava versus la calidad de las series pluviométricas de Guipúzcoa.

1.2.- Las inspecciones de los tests de las rachas de Thom y de tendencia de Mann $\underline{\text { Kendall de las series de datos en los } 3 \text { lapsos (anual, MAM y AMJ) concurren en la fijación }}$ de la fecha de cada ruptura de las series de pluviosidad.

1.3.- Todas las roturas evidenciadas (con registros de mudanzas de ubicación, entorno, colaborador y/o instrumental) son reveladas y el $79 \%$ de las rupturas afloradas en esta nota técnica está documentado. Este resultado patentiza la validez y la eficacia del procedimiento de espulgo aplicado en la detección de rupturas.

Las medianas de las medidas de la precipitación varían, en ocasiones relevantemente, en cada intersticio de las series pluviométricas con ruptura(s).

La localización precisa de los enclaves conocidos actuales y antiguos de las series con rupturas es ilustrada con mapas.

Una vez deslindada(s) la(s) ruptura(s) de cada serie de observaciones de pluviosidad, se delimitan y se exponen para cada serie y para cada periodo (anual, MAM y AMJ), los intervalos homogéneos (series con rupturas) o el intervalo homogéneo de la serie global (series sin rupturas).

El test de las rachas de Thom es más eficaz que el test de tendencia de Mann Kendall en el descubrimiento de las roturas de Vizcaya y de la vertiente cantábrica de Álava, conclusión concorde a los hallazgos de Guipúzcoa. 
2.- Las inhomogeneidades se catalogan en "climatológicas" (debidas a fluctuaciones privativas de la naturaleza, verbi gratia, sequías o lapsos lluviosos) y "no climatológicas" (de origen exógeno al clima).

2.1.- El test de las rachas de Thom detecta una cuantía de inhomogeneidades “climatológicas" en la precipitación primaveral superior a las halladas en la pluviosidad anual.

2.2.- El test de Mann Kendall es más efectivo en la clasificación de las inhomogeneidades en "climatológicas" y "no climatológicas".

2.3.- Las características pluviométricas de los primigenios años de cada serie de valores de precipitación repercuten en el montante de las ulteriores tendencias mostradas por el test de Mann - Kendall.

2.4.- La superposición de años secos y lluviosos en el periodo mínimo de 10 años de examen del test de las rachas acarrea una imprecisión mayor en las inhomogeneidades educidas del test de las rachas en relación con las inhomogeneidades inferidas del test de Mann - Kendall.

2.5.- La persistencia de las tendencias "climatológicas" en la precipitación MAM supera a la duración de las tendencias de la pluviometría anual, resultado semejante a Guipúzcoa.

2.6.- La precelente homogeneidad de las anotaciones pluviométricas de Vizcaya y de la vertiente cantábrica de Álava: El acaecimiento de inhomogeneidades "no climatológicas" es raro, constatación de la eximia homogeneidad de las mediciones de la precipitación del $\mathrm{SMN}^{1}-\mathrm{INM}^{2}$ - AEMET en Vizcaya y en la vertiente cantábrica de Álava, desvelamiento análogo a Guipúzcoa.

Por ejemplo, en los 55 años de registros de precipitación anual de 1077C \& Bilbao Histórica, el test de las rachas de Thom exterioriza 3 inhomogeneidades "climatológicas" y el test de Mann - Kendall no refleja ninguna tendencia.

2.7.- La totalidad de las inhomogeneidades señaladas por el test de Thom en los lapsos anual, MAM y AMJ es "climatológica".

2.8.- La distinción de las tendencias emanadas del test de Mann - Kendall en "climatológicas", causadas por variaciones y/o fluctuaciones del clima, generales a múltiples ubicaciones y "no climatológicas", originadas por alteraciones de la calidad de la medida (cambio de emplazamiento, alteración del entorno, reemplazo del colaborador y/o instrumental...) requiere del conocimiento de las rupturas afectadoras a la precipitación y se realiza por medio del cotejo meticuloso con las restantes series coetáneas de parejas calidad y altitud, preferentemente de la misma comarca o de las comarcas adyacentes. 
Esta crucial comparativa de la pluviosidad de las series con tendencias detectadas frente a las series pluviométricas próximas en activo y antiguas posibilita el esclarecimiento de cada inhomogeneidad en "climatológica" o no "climatológica" e inhibe la exclusión de inhomogeneidades y/o tendencias "climatológicas" de la precipitación, acaecidas simultáneamente en diversos emplazamientos.

2.9- Las tendencias "no climatológicas" se distinguen por:

a) La dispar índole de la pluviosidad tocante a las series propincuas en $1055 \nabla$ Lequeitio Faro, 1068 II $\vee$ Basauri y 1083 I $\vee$ Arcentales (de 1975 a 1979).

b) La ausencia de datos pluviométricos en 1057E I $\nabla$ Baquio o una anotación de incierta calidad en Abril de 1982 en 1075E II $\vee$ Aránzazu, únicas tendencias en las cuáles la precipitación prosigue consonante a la de las demás localizaciones.

La exigüidad de observaciones puede acarrear la desacertada ilación de la calificación de valores correctos como dudosos o erróneos.

El declive de lugares de medidas de la precipitación de subsistencia superior al decenio, principiado en 1988, sobrepasa límites alarmantes en los albores del siglo XXI.

En el desarrollo de esta Nota Técnica, se han recuperado registros de 1059L I $\nabla$ Orduña de Febrero de 1881 a Octubre de 1899 y de 1905; de $1055 \nabla$ Lequeitio Faro, de 1059 I $\vee$ Punta Galea Faro de 1911 a 1926 y de 1057C I $\nabla$ Machicaco Faro de 1913 a 1915 y de 1057C II $\vee$ de 1929 a 1933.

2.10.- La repercusión y el requisito de una luenga y densa red de emplazamientos de observación pluviométrica de una resolución a escala comarcal e incluso superior, haciendo hincapié en la pervivencia de las series largas de pluviosidad.

3.- Los máximos y los mínimos pluviométricos resultantes del escudriñamiento de las inhomogeneidades del test de las rachas de Thom concuerdan plenamente con los extremos de la pluviosidad colegidos del escrutinio del test de Mann - Kendall en los disertados lapsos anual, MAM y AMJ.

La pluviosidad evoluciona conformemente en las radicaciones investigadas, con una sublime sincronía de los máximos y de los mínimos de la precipitación.

3.1.- Las tendencias "climatológicas" desveladas en Vizcaya y en la vertiente cantábrica de Álava por el test de Mann - Kendall en la precipitación anual, MAM y AMJ son congruas con el progreso de la pluviosidad en las localizaciones coetáneas allegadas (con las sequías severas antecediendo a los intersticios muy pluviosos) y con los extremos pluviométricos obtenidos del examen de las inhomogeneidades del test de las rachas de Thom.

Las tendencias "climatológicas" descubiertas por el test de Mann - Kendall en Vizcaya y en la vertiente cantábrica de Álava son congruentes con las tendencias "climatológicas" de Guipúzcoa. 
3.2.- El acrecentamiento y la descrecencia de la precipitación son sincrónicos en la plenitud de lugares, salvo las tendencias "no climatológicas" de 1055 P, 1068 II $\vee$ y de 1975 a 1979 en 1083 I $\nabla$.

Son "no climatológicas" las cualidades de series que bien muestran una tendencia negativa en, por ejemplo, la década de los 70 del siglo XX, mientras que en el entorno la precipitación acrece (1068 II $\nabla$ ) o bien una tendencia positiva, embebida en el acrecimiento generalizado de la precipitación anual de la década de los 70 del siglo pasado (1083 I 8 muta de ser el 5ºn 1970 al enclave más lluvioso de 1974 a 1977).

3.3.- Los jardines meteorológicos contemporáneos de 1059 III Punta Galea Golf, 1060 III $\$$ Amurrio Instituto y 1082 III $\vee$ Bilbao Aeropuerto registran pluviosidades mermadas respecto a sus índoles prístinas; en 1068 II $\nabla$ la pluviometría recabada decrece al cotejarla con las series coetáneas del entorno.

Un somero estudio de la precipitación de Vizcaya y de la vertiente cantábrica de Álava circunscrito a las series vigentes más longevas (1059 Punta Galea 59 años, Amurrio 56 años y Bilbao Aeropuerto 64 años) soslayando la cognición de las alteraciones del entorno, cambios de radicación, de colaborador y/o instrumentación educiría la espuria conclusión de un decrecimiento de la pluviosidad en Vizcaya y en la vertiente cantábrica de Álava.

La estabilidad de las condiciones de medida, de la situación y del contorno de cada una de las series pluviométricas es sumamente relevante.

3.4.- El montante de series cuya primigenia medición es seca en anual y en MAM excede al cómputo de series de primer valor lluvioso.

El dato inicial de cada serie es crucial en el acaecimiento de un ulterior aumento o disminución de la precipitación: La investigación de una serie (por ejemplo 1082 I $\vee$ Bilbao Aeropuerto), según comience en un año seco (1955) o pluvioso (1954), infiere una acrecencia o una descrecencia de la pluviosidad.

El número de tendencias positivas del test de Mann - Kendall en los intervalos anual, MAM y AMJ sobrepasa al de negativas, barrunte de una transición más rauda de un intersticio de sequías a uno pluvioso que la mutación opuesta y de un primer registro de las $\underline{\text { series árido o muy árido. Este súbito transito es acorde a los descubrimientos de las series de }}$ Guipúzcoa.

La cognición de las especificidades pluviométricas del primer año de las anotaciones y el pleno conocimiento de los factores exógenos alteradores de la calidad de las medidas (modificaciones de emplazamiento, de entorno, instrumentación y/o observador) es una precisión perentoria previa al reconocimiento de la evolución de la pluviosidad (anual, MAM y AMJ), de los incrementos, decrementos y cadencias de la cuantía de la precipitación acopiada en cada ubicación. 
La carencia del mismo infiere deducciones desacertadas tocantes a acrecimientos o decrecimientos posteriores de la pluviosidad, extraños a variaciones del clima y engendrados, bien por la influencia del prístino valor de los apuntes pluviométricos, bien por alteraciones en las condiciones de observación (verbi gratia, decrecimientos en 1059 Punta Galea, en 1060 Amurrio Instituto y en 1082 Bilbao Aeropuerto, acrecentamiento en 1059L $\vee$ Orduña).

La agregación de las condiciones pluviométricas del año primigenio a las concausas de origen externo antedichas es un requisito que ha de anteponerse al escudriñamiento de la sucesión de las precipitaciones recogidas en una localización.

4.- La similar índole de la pluviosidad de las series a escala provincial (con propiedades peculiares de un territorio de clima oceánico) y a nivel de la misma comarca y/o de comarcas limítrofes.

Esta cualidad se exterioriza en la excelsa sincronía de los máximos y mínimos pluviométricos y en la prominente correlación de la pluviosidad de las diversas radicaciones y facilita la investigación de la precipitación a una resolución comarcal.

La semejanza de los registros de las series pluviométricas no siempre alcanza su valor más elevado en la confrontación con las series más cercanas.

Estas características dan pie a departir de "microclimas" en Vizcaya y en la vertiente cantábrica de Álava, de modo parejo a lo acaecido en Guipúzcoa. Vizcaya y Guipúzcoa son las 2 provincias de menor extensión y comparten un abrupto relieve.

4.1.- La notable afinidad de las cualidades de las series rayanas de precipitación anual, MAM y AMJ de Vizcaya y de la vertiente cantábrica de Álava posibilita la disertación no sólo de inhomogeneidades y de tendencias "climatológicas" a escala provincial, sino en el seno de una misma comarca o de comarcas colindantes.

La distribución de las inhomogeneidades y de las tendencias "climatológicas" desveladas por los test de rachas de Thom y de tendencia de Mann - Kendall difiere espacial (la homogeneidad de la pluviosidad muda de comarca a comarca) y temporalmente (el número de inhomogeneidades varía en los lapsos anual, MAM y AMJ).

4.2.- Esta detección de inhomogeneidades y tendencias "climatológicas" simultáneamente a nivel comarcal y/o en comarcas adyacentes coadyuva la necesidad de una resolución excedente a la provincial para espulgar las inhomogeneidades y tendencias en "climatológicas" y "no climatológicas".

No se pueden fijar las pautas pluviométricas de un territorio vasto sin la cognición $\underline{\text { minuciosa de la climatología en un ámbito comarcal. }}$ 
5.- La singular índole precursora de la pluviosidad de 1082 I $\nabla$ Bilbao Aeropuerto (anual, MAM, AMJ), 1082 II $\vee$ (AMJ) y 1059 III \& Punta Galea (MAM), sitas en el Gran Bilbao.

6.- El cociente de precipitaciones refrenda las roturas detectadas por los tests de rachas de Thom y de tendencia de Mann-Kendall y aflora rupturas inadvertidas por el escrutinio de ambos tests (verbi gratia, 1083 I $\nabla$ Arcentales en 1975).

6.1.- La razón de la pluviometría de las series escudriñadas en Vizcaya y en la vertiente cantábrica de Álava es prácticamente constante, con unos reducidos intervalos de variación de los cocientes de las precipitaciones y con una amplitud mayor de los cocientes los años secos o áridos in extremo versus a los lluviosos o muy pluviosos en los intersticios anual, MAM y AMJ.

6.2.- El cociente de la pluviosidad anual, MAM y AMJ en las series con tendencias “climatológicas" en Vizcaya y en la vertiente cantábrica de Álava oscila entre unos extremos concordes, con una cadencia en los máximos y en los mínimos de la pluviosidad allegada a $\underline{\operatorname{los} 9 \text { a } 10 \text { años. }}$

6.3.- El cotejo de la división de las precipitaciones máximas y mínimas redunda beneficioso para una compleción de las intermisiones.

La compleción de las lagunas de los registros pluviométricos precisa del conocimiento de la disposición del año incompleto en la consonancia de la euritmia de cocientes y de la cognición de las razones de las pluviosidades de menores dispersiones, no siempre coincidentes con las series más próximas.

7.- Afloran dobles cadencias en los máximos y mínimos de la precipitación anual, MAM y AMJ propincuas a los 10,20 y 30 años en las series de pluviosidad de Vizcaya y la vertiente cantábrica de Álava con una notoria y relevante congruencia respecto a los ciclos hallados en Guipúzcoa.

Los años pluviosos y áridos no devienen fortuitamente, sino según esta euritmia, sucediéndose correlativos y rayanos en los lapsos anual, MAM y AMJ en Vizcaya y en la vertiente cantábrica de Álava.

La criticidad de una adecuada densidad espacial y temporal de series de registros pluviométricos sin lagunas con la finalidad de la obtención de un idóneo conocimiento del clima en Vizcaya y en la vertiente cantábrica de Álava, de un escabroso relieve. 


\section{6.- Agradecimientos}

- A la Delegada Territorial de AEMET en el País Vasco, por el férreo afán de conservación, preservación y ampliación de la red de observaciones termopluviométricas en el País Vasco

- Al jubilado Supervisor de Sistemas Básicos de la Delegación Territorial de AEMET en el País Vasco, por su colaboración en la búsqueda de las evidencias de cambios de emplazamiento, de colaborador y/o de instrumental y por su documentación y registro de las incidencias afectadoras a las mediciones de los colaboradores.

- A los técnicos de Sistemas Básicos de la Delegación Territorial de AEMET en el País Vasco, por su cooperación en la recuperación de las localizaciones de las antiguas ubicaciones de medida.

- Al resto del personal de Sistemas Básicos de la Delegación Territorial de AEMET en el País Vasco, por sus detalladas y pacientes respuestas y aclaraciones.

- A los colaboradores de AEMET de Vizcaya y de la vertiente cantábrica de Álava, por su encomiable labor de recogida diaria de datos de precipitación.

\section{7.- Referencias:}

Almarza, C; López-Díaz; J.A. y Flores C. (1996) "Homogeneidad y variabilidad de los registros históricos de precipitación de España.” Monografía Técnica A-143 Instituto Nacional de Meteorología, Ministerio de Medio Ambiente, ISBN 8449802210

Servicio de Aplicaciones Climatológicas del Instituto Nacional de Meteorología "Las precipitaciones máximas en 24 horas y sus periodos de retorno en España. Volumen 0 Introducción y Metodología" Publicación D50.0 Instituto Nacional de Meteorología, Ministerio de Medio Ambiente, ISBN 8483200430

Servicio de Aplicaciones Climatológicas del Instituto Nacional de Meteorología "Las precipitaciones máximas en 24 horas y sus periodos de retorno en España. Volumen 3 País Vasco" Publicación D50.3 Instituto Nacional de Meteorología, Ministerio de Medio Ambiente, ISBN 8483200465.

M. Yolanda Luna “¿Está cambiando el clima?: Análisis de los cambios observados en España a luz del $5^{\circ}$ informe del IPCC” ACAM XX Jornades de Meteorología Eduard Fontserè Agencia Estatal de Meteorología

Sneyers, R. (1975) "Sobre el análisis estadístico de las series de observaciones" Nota Técnica No 143 Organización Meteorológica Mundial 
Caballero, I. "Análisis de la homogeneidad de las series de precipitación de Guipúzcoa" Nota Técnica No 13 de la Agencia Estatal de Meteorología, Misterio de Agricultura, Alimentación y Medio Ambiente, NIPO 281-13-010-3

Nuñez Corchero M; Sosa Cardo J.A. (2001) “Climatología de Extremadura” Publicación A153 Instituto Nacional de Meteorología

Martínez Molina I (1986): "Estadística aplicada a la Hidrometeorología” Publicación D-47 Instituto Nacional de Meteorología.

Font I (2000) “Climatología de España y Portugal, 2nd edn.” Ediciones Universidad de Salamanca

Font I (1988) "Historia del clima en España Cambios climáticos y sus causas", Instituto Nacional de Meteorología, Serie A-123, ISBN 84-505-1778-2.

García de Pedraza L; Reija Garrido A (1994): “Tiempo y Clima en España. Meteorología de las Autonomías” Ed. Dossat 2000 ISBN 8423708063

Peterson Thomas C., Aguilar, E. Auer I, Brunet M, Wieringa J. "Guidelines on climate metadata and homogeneization” WCDMP No. 53 - WMO/TD No 1186

Uriarte Cantolla A: "Régimen de precipitaciones en la costa NW y N de la Península Ibérica” Caja de Ahorros Provincial de Guipúzcoa 1983, ISBN 8472319296

Doporto M. "Cincuenta y cinco años de observaciones pluviométricas en San Sebastián (1878-1932)” Imprenta de la Diputación de Guipúzcoa 1933.

Doporto M. "Resumen de las observaciones efectuadas en la red termopluviométrica durante el año 1934." Imprenta de la Diputación de Guipúzcoa 1934

Álvarez Usabiaga J.I. "Variaciones observadas en el Observatorio de Igueldo en 60 años" XX jornadas de la Asociación Meteorológica Española San Sebastián Mayo 1989

Publicación Fundación Cultural Caja de Guipúzcoa, ISBN 8450595053

Aguilar Antonio (1867) "Resumen de las Observaciones Meteorológicas efectuadas en la Península desde el día $1^{\circ}$ de Diciembre de 1866 al 30 de Noviembre de 1867”.

Aguilar Antonio (1870) "Resumen de las Observaciones Meteorológicas efectuadas en la Península desde el día $1^{\circ}$ de Diciembre de 1867 al 30 de Noviembre de 1868”.

Aguilar Antonio (1871) "Resumen de las Observaciones Meteorológicas efectuadas en la Península desde el día $1^{\circ}$ de Diciembre de 1868 al 30 de Noviembre de 1869”.

Merino Miguel (1872) "Resumen de las Observaciones Meteorológicas efectuadas en la Península desde el día $1^{\circ}$ de Diciembre de 1869 al 30 de Noviembre de 1870”.

Merino Miguel (1872) "Resumen de las Observaciones Meteorológicas efectuadas en la Península desde el día $1^{\circ}$ de Diciembre de 1870 al 30 de Noviembre de 1871”. 
Merino Miguel (1873) "Resumen de las Observaciones Meteorológicas efectuadas en la Península desde el día $1^{\circ}$ de Diciembre de 1871 al 30 de Noviembre de 1872”.

Merino Miguel (1874) "Resumen de las Observaciones Meteorológicas efectuadas en la Península desde el día $1^{\circ}$ de Diciembre de 1872 al 30 de Noviembre de 1873”.

Observatorio de Madrid (1885) "Resumen de las Observaciones Meteorológicas efectuadas en la Península y algunas de sus islas adyacentes durante el año de 1881”.

Observatorio de Madrid (1883) "Resumen de las Observaciones Meteorológicas efectuadas en la Península y algunas de sus islas adyacentes durante el año de 1882”.

Observatorio de Madrid (1888) "Resumen de las Observaciones Meteorológicas efectuadas en la Península y algunas de sus islas adyacentes durante el año de 1883".

Observatorio de Madrid (1889) "Resumen de las Observaciones Meteorológicas efectuadas en la Península y algunas de sus islas adyacentes durante el año de 1884".

Observatorio de Madrid (1889) "Resumen de las Observaciones Meteorológicas efectuadas en la Península y algunas de sus islas adyacentes durante el año de 1885 ”.

Observatorio de Madrid (1890) "Resumen de las Observaciones Meteorológicas efectuadas en la Península y algunas de sus islas adyacentes durante el año de 1886 ”.

Observatorio de Madrid (1890) "Resumen de las Observaciones Meteorológicas efectuadas en la Península y algunas de sus islas adyacentes durante el año de 1887”.

Observatorio de Madrid (1891) "Resumen de las Observaciones Meteorológicas efectuadas en la Península y algunas de sus islas adyacentes durante el año de 1888”.

Observatorio de Madrid (1891) "Resumen de las Observaciones Meteorológicas efectuadas en la Península y algunas de sus islas adyacentes durante el año de 1889”.

Observatorio de Madrid (1892) "Resumen de las Observaciones Meteorológicas efectuadas en la Península y algunas de sus islas adyacentes durante el año de 1890”.

Observatorio de Madrid (1895) "Resumen de las Observaciones Meteorológicas efectuadas en la Península y algunas de sus islas adyacentes durante los años 1891 y 1892”.

Observatorio de Madrid (1896) "Resumen de las Observaciones Meteorológicas efectuadas en la Península y algunas de sus islas adyacentes durante los años 1893 y 1894”.

Observatorio de Madrid (1899) "Resumen de las Observaciones Meteorológicas efectuadas en la Península y algunas de sus islas adyacentes durante los años 1895 y 1896".

Observatorio de Madrid (1902) "Resumen de las Observaciones Meteorológicas efectuadas en la Península y algunas de sus islas adyacentes durante los años 1897 y 1898 ".

Observatorio de Madrid (1906) "Resumen de las Observaciones Meteorológicas efectuadas en la Península y algunas de sus islas adyacentes durante los años 1899 y 1900”. 
Ob. C. M. ${ }^{3}$ (1916) "Resumen de las observaciones efectuadas durante los años 1904 y 1905 "

Ob. C. M. (1914) "Resumen de las observaciones efectuadas durante los años 1911 y 1912 "

Ob. C. M. (1915) "Resumen de las observaciones efectuadas durante el año 1913"

Ob. C. M. (1916) "Resumen de las observaciones efectuadas durante el año 1914"

Ob. C. M. (1917) "Resumen de las observaciones efectuadas durante el año 1915"

Ob. C. M. (1918) "Resumen de las observaciones efectuadas durante el año 1916"

Ob. C. M. (1919) "Resumen de las observaciones efectuadas durante el año 1917"

Ob. C. M. (1922) "Resumen de las observaciones efectuadas durante el año 1918"

O. C. M. ${ }^{4}$ (1924) "Resumen de las observaciones efectuadas durante el año 1919"

O. C. M. (1924) "Resumen de las observaciones efectuadas durante el año 1920"

O. C. M. (1924) "Resumen de las observaciones efectuadas durante el año 1921"

O. C. M. (1925) "Resumen de las observaciones efectuadas durante el año 1922”

O. C. M. (1925) "Resumen de las observaciones efectuadas durante el año 1923"

O. C. M. (1927) "Resumen de las observaciones efectuadas durante el año 1924”

O. C. M. (1929) "Resumen de las observaciones efectuadas durante el año 1925”

O. C. M. (1932) "Resumen de las observaciones efectuadas durante el año 1926"

S. M. E. (1932) "Resumen de las observaciones efectuadas durante el año 1927"

S. M. E. (1933) "Resumen de las observaciones efectuadas durante el año 1928"

S. M. E. (1935) "Resumen de las observaciones efectuadas durante el año 1929"

S. M. N. ${ }^{6}$ (1939) "Resumen de observaciones meteorológicas de 1930"

S. M. N. (1940) "Resumen de observaciones meteorológicas de 1931"

S. M. N. (1942) "Resumen de observaciones meteorológicas de 1932"

S. M. N. (1942) "Resumen de observaciones meteorológicas de 1933"

\footnotetext{
${ }^{3}$ Ob. C.M.: Observatorio Central Meteorológico

${ }^{4}$ O.C.M.: Oficina Central Meteorológica

${ }^{5}$ S.M.E.: Servicio Meteorológico Español

${ }^{6}$ S.M.N: Servicio Meteorológico Nacional
} 
S. M. N. (1942) "Resumen de observaciones meteorológicas de 1934"

S. M. N. (1948) "Resumen de observaciones meteorológicas de 1935"

S. M. N. (1950) "Resumen de observaciones meteorológicas de 1936 y 1937”

S. M. N. (1952) “Resumen de observaciones meteorológicas de 1938-39”

S. M. N. (1942) "Resumen de observaciones meteorológicas de 1940"

S. M. N. (1944) "Resumen de observaciones meteorológicas de 1941"

S. M. N. (1946) "Resumen de observaciones meteorológicas de 1942"

S. M. N. (1948) "Resumen de observaciones meteorológicas de 1943"

S. M. N. (1949) "Resumen de observaciones meteorológicas de 1944"

S. M. N. (1952) "Resumen de observaciones meteorológicas de 1945"

S. M. N. (1954) "Resumen de observaciones meteorológicas de 1946"

Asociación Etnográfica de Amurrio “Amurrio 1900 - 1950 Un paseo por el pueblo de nuestros abuelos a través de las fotografías" 


\section{8.- Anexo}

Tabla 109: Nomenclátor (Indicativo climatológico, nombre, fecha inicial y localización) de las series antiguas superiores a 10 años, detallando las rupturas) y de las series actuales de 1053 I $\vee$ Echevarría a 10590 Lendoño

\begin{tabular}{|c|c|c|c|c|c|}
\hline Indicativo & Nombre estación & Fecha inicio & Longitud & Latitud & Altitud (m) \\
\hline 1053 I 8 & Echevarría & $01-10-1961$ & $2^{\circ} 28^{\prime} 34,14^{\prime \prime} \mathrm{W}$ & $43^{\circ} 15^{\prime} 15,50^{\prime \prime} \mathrm{N}$ & 107 \\
\hline 1053 II $\bigcirc$ & Echevarría & Final 1975 & $2^{\circ} 28^{\prime} 34,14^{\prime \prime} \mathrm{W}$ & $43^{\circ} 15^{\prime} 15,50^{\prime \prime} \mathrm{N}$ & 107 \\
\hline $1054 \mathrm{I} P$ & Marquina Plazakola & $01-01-1946$ & $2^{\circ} 28^{\prime} 30^{\prime \prime} \mathrm{W}$ & $43^{\circ} 17^{\prime} 52^{\prime \prime} \mathrm{N}$ & 33 \\
\hline 1054 II $\vee$ & Marquina Plazakola & $01-05-1956$ & $2^{\circ} 28^{\prime} 30^{\prime \prime} \mathrm{W}$ & $43^{\circ} 17^{\prime} 52^{\prime \prime} \mathrm{N}$ & 33 \\
\hline $1054 \mathrm{~A} \xi$ & Marquina Barroeta & $04-11-2013$ & $2^{\circ} 29^{\prime} 38,10^{\prime \prime} \mathrm{W}$ & $43^{\circ} 16^{\prime} 24,70^{\prime \prime} \mathrm{N}$ & 94 \\
\hline $1054 \mathrm{E} \&$ & Zenarruza Monast. & $01-11-2013$ & $2^{\circ} 33^{\prime} 46,45^{\prime \prime} \mathrm{W}$ & $43^{\circ} 14^{\prime} 51,81^{\prime \prime} \mathrm{N}$ & 303 \\
\hline $1055 \mathrm{~A} \mathrm{I} P$ & Lequeitio Agust. & $01-04-1986$ & $2^{\circ} 30^{\prime} 23,22^{\prime \prime} \mathrm{W}$ & $43^{\circ} 21^{\prime} 54,88^{\prime \prime} \mathrm{N}$ & 32 \\
\hline 1055A II & Lequeitio Agust. & $01-06-2006$ & $2^{\circ} 30^{\prime} 23,18^{\prime \prime} \mathrm{W}$ & $43^{\circ} 21^{\prime} 54,86^{\prime \prime} \mathrm{N}$ & 32 \\
\hline $1055 \nabla$ & Lequeitio Faro & $01-05-1911$ & $2^{\circ} 30^{\prime} 36^{\prime \prime} \mathrm{W}$ & $43^{\circ} 22^{\prime} 37^{\prime \prime} \mathrm{N}$ & 15 \\
\hline $1055 \mathrm{~B}$ & Lequeitio Faro & $01-04-1997$ & $2^{\circ} 30^{\prime} 37,18^{\prime \prime} \mathrm{W}$ & $43^{\circ} 22^{\prime} 36,44^{\prime \prime} \mathrm{N}$ & 27 \\
\hline $1056 \mathrm{~K}$ & Forua Gaitoka & $05-03-2009$ & $2^{\circ} 40^{\prime} 16,32^{\prime \prime} \mathrm{W}$ & $43^{\circ} 20^{\prime} 32,61^{\prime \prime} \mathrm{N}$ & 47 \\
\hline $1056 \mathrm{M} \vee$ & Arteaga & $01-02-1991$ & $2^{\circ} 38^{\prime} 16^{\prime \prime} \mathrm{W}$ & $43^{\circ} 21^{\prime} 49^{\prime \prime} \mathrm{N}$ & 142 \\
\hline $1057 \mathrm{~B}$ & Machicaco Faro & $01-04-1997$ & $2^{\circ} 45^{\prime} 09,86^{\prime \prime} \mathrm{W}$ & $43^{\circ} 27^{\prime} 13,82^{\prime \prime} \mathrm{N}$ & 103 \\
\hline $1057 \mathrm{C} \mathrm{I} 8$ & Machicaco Faro & $01-01-1913$ & $2^{\circ} 45^{\prime} 11^{\prime \prime} \mathrm{W}$ & $43^{\circ} 27^{\prime} 19^{\prime \prime} \mathrm{N}$ & 60 \\
\hline $1057 \mathrm{C}$ II 8 & Machicaco Faro & $01-12-1921$ & $2^{\circ} 45^{\prime} 11^{\prime \prime} \mathrm{W}$ & $43^{\circ} 27^{\prime} 19^{\prime \prime} \mathrm{N}$ & 60 \\
\hline $1057 \mathrm{E}$ I $\varnothing$ & Baquio & $01-04-1986$ & $2^{\circ} 49^{\prime} 02,08^{\prime \prime} \mathrm{W}$ & $43^{\circ} 25^{\prime} 16,24^{\prime \prime} \mathrm{N}$ & 17 \\
\hline $1057 \mathrm{E}$ II $\$$ & Baquio & $21-05-2009$ & $2^{\circ} 49^{\prime} 02,67^{\prime \prime} \mathrm{W}$ & $43^{\circ} 25^{\prime} 16,71^{\prime \prime} \mathrm{N}$ & 17 \\
\hline 10588 & Maruri & $01-12-1967$ & $2^{\circ} 51^{\prime} 49^{\prime \prime} \mathrm{W}$ & $43^{\circ} 23^{\prime} 08^{\prime \prime} \mathrm{N}$ & 60 \\
\hline $1059 \mathrm{I} P$ & Punta Galea Faro & $01-01-1911$ & $3^{\circ} 02^{\prime} 11^{\prime \prime} \mathrm{W}$ & $43^{\circ} 22^{\prime} 24^{\prime \prime} \mathrm{N}$ & 27 \\
\hline 1059 II $P$ & Punta Galea Faro & $01-01-1946$ & $3^{\circ} 02^{\prime} 07,7^{\prime \prime} \mathrm{W}$ & $43^{\circ} 22^{\prime} 18,1^{\prime \prime} \mathrm{N}$ & 52 \\
\hline 1059 III & Punta Galea Golf & $01-03-1994$ & $3^{\circ} 01^{\prime} 17,59^{\prime \prime} \mathrm{W}$ & $43^{\circ} 22^{\prime} 30,21^{\prime \prime} \mathrm{N}$ & 77 \\
\hline $1059 \mathrm{X} \&$ & Punta Galea Golf & $03-03-2005$ & $3^{\circ} 01^{\prime} 17,39^{\prime \prime} \mathrm{W}$ & $43^{\circ} 22^{\prime} 30,11^{\prime \prime} \mathrm{N}$ & 77 \\
\hline 1059B & El Abra (Getxo) & $01-05-2013$ & $3^{\circ} 01^{\prime} 00,38^{\prime \prime} \mathrm{W}$ & $43^{\circ} 19^{\prime} 41,00^{\prime \prime} \mathrm{N}$ & 3 \\
\hline 1059L I 8 & Orduña Jesuitas & $01-02-1881$ & $3^{\circ} 00^{\prime} 32^{\prime \prime} \mathrm{W}$ & $42^{\circ} 59^{\prime} 37,7^{\prime \prime} \mathrm{N}$ & 290 \\
\hline 1059L II 8 & Orduña Carmelitas & $01-10-1985$ & $3^{\circ} 01^{\prime} 19^{\prime \prime} \mathrm{W}$ & $42^{\circ} 59^{\prime} 35^{\prime \prime} \mathrm{N}$ & 323 \\
\hline 105908 & Lendoño & $01-10-1985$ & $3^{\circ} 03^{\prime} \mathrm{W}$ & $43^{\circ} 01^{\prime} \mathrm{N}$ & 440 \\
\hline
\end{tabular}


Tabla 110: Nomenclátor (Indicativo climatológico, nombre, fecha inicial y localización) de las series antiguas superiores a 10 años, detallando las rupturas) y de las series actuales de 1060 I $\vee$ Amurrio Instituto a 1079I $\vee$ Gordejuela (Molinar):

\begin{tabular}{|c|c|c|c|c|c|}
\hline Indicativo & Nombre estación & Fecha inicio & Longitud & Latitud & Altitud (m) \\
\hline 1060 I $P$ & Amurrio Instituto & $01-05-1955$ & $3^{\circ} 00^{\prime} 19,60^{\prime \prime} \mathrm{W}$ & $43^{\circ} 03^{\prime} 00,82^{\prime \prime} \mathrm{N}$ & 232 \\
\hline 1060 II $P$ & Amurrio Instituto & Final 1966 & $3^{\circ} 00^{\prime} 19,60^{\prime \prime} \mathrm{W}$ & $43^{\circ} 03^{\prime} 00,82^{\prime \prime} \mathrm{N}$ & 232 \\
\hline 1060 III & Amurrio Instituto & Final 1992 & $3^{\circ} 00^{\prime} 19,60^{\prime \prime} \mathrm{W}$ & $43^{\circ} 03^{\prime} 00,82^{\prime \prime} \mathrm{N}$ & 232 \\
\hline $1060 X$ & Amurrio Instituto & $01-08-2003$ & $3^{\circ} 00^{\prime} 19,54^{\prime \prime} \mathrm{W}$ & $43^{\circ} 03^{\prime} 00,89^{\prime \prime} \mathrm{N}$ & 232 \\
\hline 1060A $P$ & Amurrio Colegio & $01-10-1961$ & $2^{\circ} 59^{\prime} 47^{\prime \prime} \mathrm{W}$ & $43^{\circ} 04^{\prime} 08^{\prime \prime} \mathrm{N}$ & 190 \\
\hline 1064L \& & Orozco (Ibarra) & $01-10-2009$ & $2^{\circ} 51^{\prime} 36,83^{\prime \prime} \mathrm{W}$ & $43^{\circ} 05^{\prime} 44,22^{\prime \prime} \mathrm{N}$ & 264 \\
\hline $1064 \mathrm{P} P$ & Orozco (Beraza) & $01-07-1982$ & $2^{\circ} 54^{\prime} 09,59^{\prime \prime} \mathrm{W}$ & $43^{\circ} 06^{\prime} 08,07^{\prime \prime} \mathrm{N}$ & 177 \\
\hline $1068 \mathrm{I} 8$ & Basauri (Finaga) & $01-09-1944$ & $2^{\circ} 53^{\prime} 4^{\prime \prime} \mathrm{W}$ & $43^{\circ} 13^{\prime} 1^{\prime \prime} \mathrm{N}$ & 195 \\
\hline 1068 II $\nabla$ & Basauri (Finaga) & Final 1954 & $2^{\circ} 53^{\prime} 4^{\prime \prime} \mathrm{W}$ & $43^{\circ} 13^{\prime} 1^{\prime \prime} \mathrm{N}$ & 195 \\
\hline $1069 \mathrm{E} \nabla$ & Urquiola Santuario & $01-10-1985$ & $2^{\circ} 38^{\prime} 38,88^{\prime \prime} \mathrm{W}$ & $43^{\circ} 05^{\prime} 57,10^{\prime \prime} \mathrm{N}$ & 733 \\
\hline $1069 Y$ & Urquiola Santuario & $08-04-2006$ & $2^{\circ} 38^{\prime} 38,85^{\prime \prime} \mathrm{W}$ & $43^{\circ} 05^{\prime} 57,07^{\prime \prime} \mathrm{N}$ & 733 \\
\hline 1070 I 8 & Abadiano & $01-01-1935$ & $?$ & $?$ & $?$ \\
\hline 1070 II $\vee$ & Abadiano (Mend.) & $01-12-1967$ & $2^{\circ} 36^{\prime} 50,14^{\prime \prime} \mathrm{W}$ & $43^{\circ} 08^{\prime} 27,48^{\prime \prime} \mathrm{N}$ & 177 \\
\hline 1070 III & Abadiano (Mend.) & $01-10-2013$ & $2^{\circ} 37^{\prime} 05,83^{\prime \prime} \mathrm{W}$ & $43^{\circ} 08^{\prime} 22,19^{\prime \prime} \mathrm{N}$ & 187 \\
\hline 10718 & Durango (Dolomet) & $01-07-1967$ & $2^{\circ} 39^{\prime} 08^{\prime \prime} \mathrm{W}$ & $43^{\circ} 09^{\prime} 26^{\prime \prime} \mathrm{N}$ & 276 \\
\hline $1074 \mathrm{C} \&$ & Amorebieta & $28-02-2009$ & $2^{\circ} 42^{\prime} 21,98^{\prime \prime} \mathrm{W}$ & $43^{\circ} 12^{\prime} 10,17^{\prime \prime} \mathrm{N}$ & 103 \\
\hline $1075 \mathrm{I} P$ & Dima (Zamacola) & $01-01-1925$ & $2^{\circ} 43^{\prime} 4^{\prime \prime} \mathrm{W}$ & $43^{\circ} 07^{\prime} 0^{\prime \prime} \mathrm{N}$ & 277 \\
\hline 1075 II P & Dima (Lapur Errek) & $01-11-1967$ & $2^{\circ} 40^{\prime} 35^{\prime \prime} \mathrm{W}$ & $43^{\circ} 04^{\prime} 0^{\prime \prime} \mathrm{N}$ & 574 \\
\hline $1075 \mathrm{E}$ I 8 & Aránzazu (Olarra) & $01-12-1967$ & $2^{\circ} 47^{\prime} 27,6^{\prime \prime} \mathrm{W}$ & $43^{\circ} 08^{\prime} 52,2^{\prime \prime} \mathrm{N}$ & 112 \\
\hline $1075 \mathrm{E}$ II $\nabla$ & Aránzazu (Olarra) & Final 1981 & $2^{\circ} 47^{\prime} 27,57^{\prime \prime} \mathrm{W}$ & $43^{\circ} 08^{\prime} 52,22^{\prime \prime} \mathrm{N}$ & 112 \\
\hline $1077 \varnothing$ & Larrasquitu (Aguas) & $01-03-1925$ & $2^{\circ} 56^{\prime} 0^{\prime \prime} \mathrm{W}$ & $43^{\circ} 14^{\prime} 4^{\prime \prime} \mathrm{N}$ & 116 \\
\hline $1077 \mathrm{C} \mathrm{P}$ & Bilbao Instituto & $01-01-1859$ & $2^{\circ} 55^{\prime} 17,0^{\prime \prime} \mathrm{W}$ & $43^{\circ} 15^{\prime} 32,0^{\prime \prime} \mathrm{N}$ & 52 \\
\hline $1077 \mathrm{H} P$ & Bilbao Labein & $01-09-1986$ & $2^{\circ} 57^{\prime} 2^{\prime \prime} \mathrm{W}$ & $43^{\circ} 15^{\prime} 49^{\prime \prime} \mathrm{N}$ & 20 \\
\hline $1078 \mathrm{C}$ & Valmaseda Salin & $11-02-2009$ & $3^{\circ} 12^{\prime} 34,66^{\prime \prime} \mathrm{W}$ & $43^{\circ} 10^{\prime} 50,59^{\prime \prime} \mathrm{N}$ & 205 \\
\hline 1078E I 8 & Valmaseda (V. Sol) & $01-01-1972$ & $3^{\circ} 11^{\prime} 10,01^{\prime \prime} \mathrm{W}$ & $43^{\circ} 12^{\prime} 00,90^{\prime \prime} \mathrm{N}$ & 159 \\
\hline $1078 \mathrm{E}$ II $\vee$ & Valmaseda (V. Sol) & $28-12-1991$ & $3^{\circ} 11^{\prime} 10,01^{\prime \prime} \mathrm{W}$ & $43^{\circ} 12^{\prime} 00,90^{\prime \prime} \mathrm{N}$ & 159 \\
\hline $1078 I$ & Güeñes & $01-04-1997$ & $3^{\circ} 06^{\prime} 17,01^{\prime \prime} \mathrm{W}$ & $43^{\circ} 12^{\prime} 11,98^{\prime \prime} \mathrm{N}$ & 197 \\
\hline $1079 \mathrm{E}$ I $\vee$ & Arceniega Agust. & $01-04-1986$ & $3^{\circ} 07^{\prime} 41,67^{\prime \prime} \mathrm{W}$ & $43^{\circ} 07^{\prime} 14,35^{\prime \prime} \mathrm{N}$ & 207 \\
\hline 1079E II 8 & Arceniega Agust. & $25-03-2004$ & $3^{\circ} 07^{\prime} 41,67^{\prime \prime} \mathrm{W}$ & $43^{\circ} 07^{\prime} 14,35^{\prime \prime} \mathrm{N}$ & 207 \\
\hline 1079I $P$ & Gordejuela (Molin.) & $01-06-1972$ & $3^{\circ} 03^{\prime} 51^{\prime \prime} \mathrm{W}$ & $43^{\circ} 10^{\prime} 57^{\prime \prime} \mathrm{N}$ & 72 \\
\hline
\end{tabular}


Tabla 111: Nomenclátor (Indicativo climatológico, nombre, fecha inicial y localización) de las series antiguas superiores a 10 años, detallando las rupturas) y de las series actuales de

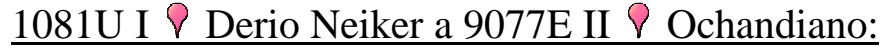

\begin{tabular}{|c|c|c|c|c|c|}
\hline Indicativo & Nombre estación & Fecha inicio & Longitud & Latitud & Altitud (m) \\
\hline $1081 \mathrm{U}$ I $P$ & Derio Neiker & $01-05-1986$ & $2^{\circ} 52^{\prime} 01,7^{\prime \prime} \mathrm{W}$ & $43^{\circ} 18^{\prime} 03,1^{\prime \prime} \mathrm{N}$ & 67 \\
\hline 1081U II $\nabla$ & Derio Neiker & Final 03 - 1996 & $2^{\circ} 52^{\prime} 24,24^{\prime \prime} \mathrm{W}$ & $43^{\circ} 17^{\prime} 28,11^{\prime \prime} \mathrm{N}$ & 30 \\
\hline 1081U III & Derio Neiker & $23-06-2009$ & $2^{\circ} 52^{\prime} 23,85^{\prime \prime} \mathrm{W}$ & $43^{\circ} 17^{\prime} 26,04^{\prime \prime} \mathrm{N}$ & 29 \\
\hline $1082 \mathrm{I} P$ & Bilbao Aeropuerto & $01-03-1947$ & $2^{\circ} 55^{\prime} 46,1^{\prime \prime} \mathrm{W}$ & $43^{\circ} 18^{\prime} 07,8^{\prime \prime} \mathrm{N}$ & 33 \\
\hline 1082 II $\nabla$ & Bilbao Aeropuerto & $27-11-1984$ & $2^{\circ} 55^{\prime} 42,57^{\prime \prime} \mathrm{W}$ & $43^{\circ} 18^{\prime} 05,87^{\prime}, \mathrm{N}$ & 32 \\
\hline 1082 III $\vee$ & Bilbao Aeropuerto & $01-02-2001$ & $2^{\circ} 54^{\prime} 21,11^{\prime \prime} \mathrm{W}$ & $43^{\circ} 17^{\prime} 53,14^{\prime \prime} \mathrm{N}$ & 32 \\
\hline $1082 \mathrm{IV} \&$ & Bilbao Aeropuerto & $23-11-2013$ & $2^{\circ} 54^{\prime} 21,77^{\prime \prime} \mathrm{W}$ & $43^{\circ} 17^{\prime} 52,20^{\prime \prime} \mathrm{N}$ & 30 \\
\hline $1083 \mathrm{I} P$ & Arcentales (Garmo) & $01-08-1967$ & $3^{\circ} 12^{\prime} 53^{\prime \prime} \mathrm{W}$ & $43^{\circ} 13^{\prime} 29^{\prime \prime} \mathrm{N}$ & 427 \\
\hline 1083 II $\nabla$ & Arcentales (Garmo) & $01-02-1981$ & $3^{\circ} 12^{\prime} 53^{\prime \prime} \mathrm{W}$ & $43^{\circ} 13^{\prime} 29^{\prime \prime} \mathrm{N}$ & 427 \\
\hline 1083 III $\nabla$ & Arcentales (Tlviña) & $01-12-1999$ & $3^{\circ} 13^{\prime} 05,74^{\prime \prime} \mathrm{W}$ & $43^{\circ} 14^{\prime} 24,41^{\prime \prime} \mathrm{N}$ & 215 \\
\hline $1083 B$ & Sopuerta (Jarralta) & $01-03-2015$ & $3^{\circ} 10^{\prime} 06,85^{\prime \prime} \mathrm{W}$ & $43^{\circ} 16^{\prime} 47,21^{\prime \prime} \mathrm{N}$ & 171 \\
\hline 1093 I $P$ & Carranza Instituto & $01-11-1956$ & $3^{\circ} 21^{\prime} 27^{\prime \prime} \mathrm{W}$ & $43^{\circ} 13^{\prime} 21^{\prime \prime} \mathrm{N}$ & 168 \\
\hline 1093 II $\vee$ & Carranza Instituto & $01-11-1983$ & $3^{\circ} 21^{\prime} 27^{\prime \prime} \mathrm{W}$ & $43^{\circ} 13^{\prime} 21^{\prime \prime} \mathrm{N}$ & 168 \\
\hline 1093 III $P$ & Carranza & $01-03-1989$ & $3^{\circ} 21^{\prime} 2^{\prime \prime} \mathrm{W}$ & $43^{\circ} 13^{\prime} 2^{\prime \prime} \mathrm{N}$ & 170 \\
\hline 1093 IV $\nabla$ & Carranza & $01-01-1990$ & $3^{\circ} 21^{\prime} 2^{\prime \prime} \mathrm{W}$ & $43^{\circ} 13^{\prime} 2^{\prime \prime} \mathrm{N}$ & 170 \\
\hline $1093 \mathrm{~V} \vee$ & Carranza & De 1990 a 94 & $3^{\circ} 21^{\prime} 2^{\prime \prime} \mathrm{W}$ & $43^{\circ} 13^{\prime} 2^{\prime \prime} \mathrm{N}$ & 170 \\
\hline $1093 \mathrm{VI} P$ & Carranza (C.I.T.) & $01-01-98$ & $3^{\circ} 19^{\prime} 02^{\prime \prime} \mathrm{W}$ & $43^{\circ} 14^{\prime} 17^{\prime \prime} \mathrm{N}$ & 300 \\
\hline $1093 \mathrm{~A} P$ & Carranza (Ambas.) & $01-01-1972$ & $3^{\circ} 21^{\prime} 17^{\prime \prime} \mathrm{W}$ & $43^{\circ} 14^{\prime} 10^{\prime \prime} \mathrm{N}$ & 143 \\
\hline $9076 \mathrm{I} P$ & Ceanuri C. Forestal & $24-04-1945$ & $2^{\circ} 41^{\prime} 44^{\prime \prime} \mathrm{W}$ & $43^{\circ} 03^{\prime} 00^{\prime \prime} \mathrm{N}$ & 602 \\
\hline 9077E I 8 & Ochandiano & $01-07-1947$ & $2^{\circ} 39^{\prime} 22^{\prime \prime} \mathrm{W}$ & $43^{\circ} 02^{\prime} 26^{\prime \prime} \mathrm{N}$ & 558 \\
\hline 9077E II $\vee$ & Ochandiano & $01-08-1973$ & $2^{\circ} 39^{\prime} 19,01^{\prime \prime} \mathrm{W}$ & $43^{\circ} 02^{\prime} 23,64^{\prime \prime} \mathrm{N}$ & 558 \\
\hline
\end{tabular}

La precisión en las coordenadas geográficas denota la exactitud del grado de conocimiento de la ubicación del pluviómetro; las décimas de segundo indican la máxima precisión, visualizada por el autor y/ o por el jubilado supervisor de SS.BB. de la Delegación Territorial).

1077C P Bilbao Instituto situada en el Instituto de Enseñanza de Bilbao, a $21 \mathrm{~m}$ sobre el suelo, el cuál tiene en esa zona de Bilbao una altitud de $31 \mathrm{~m}$.

Los interrogantes de latitud, longitud y altitud denotan la ignota ubicación de 1070 I $\nabla$ Abadiano 
Leyenda:

Colaboradores TP (Termo pluviométricos) actuales.

Colaboradores P (Pluviométricos) actuales.

Estaciones automáticas.

Colaboradores antiguos.

Aeropuerto.

Tabla 112: Distribución de series investigadas por comarcas:

\begin{tabular}{|c|c|}
\hline Comarca & Indicativos \\
\hline Arratia - Nervión & 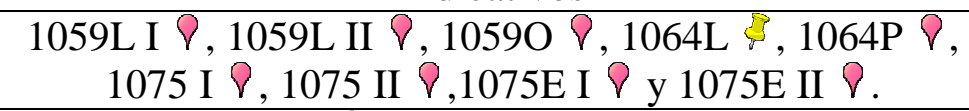 \\
\hline Duranguesado & 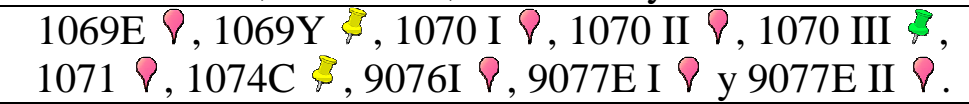 \\
\hline Encartaciones & 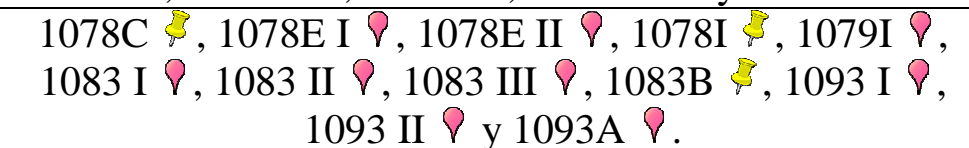 \\
\hline Gran Bilbao & 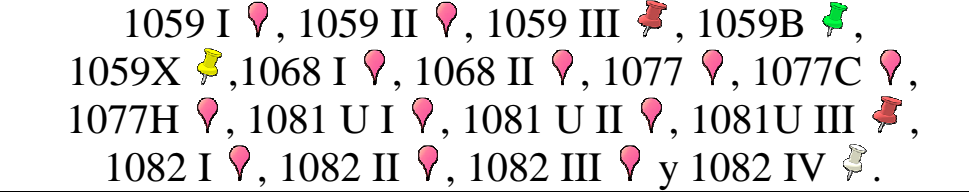 \\
\hline Guernica - Bermeo & $1056 \mathrm{M} \vee, 1056 \mathrm{~K} \xi, 1057 \mathrm{~B} \xi, 1057 \mathrm{C}$ I $\vee$ y $1057 \mathrm{C}$ II $\vee$ \\
\hline Marquina - Ondarroa & 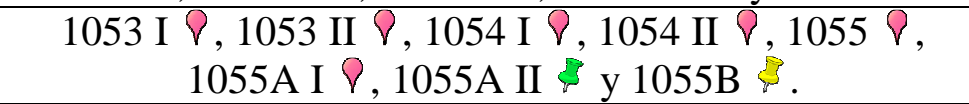 \\
\hline Plencia-Munguía & 1057E I $\vee, 1057 \mathrm{E}$ II $\&$ y $1058 \curlyvee$. \\
\hline Cantábrica Alavesa & 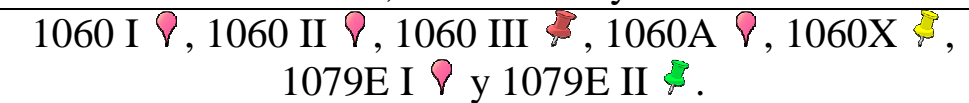 \\
\hline
\end{tabular}

